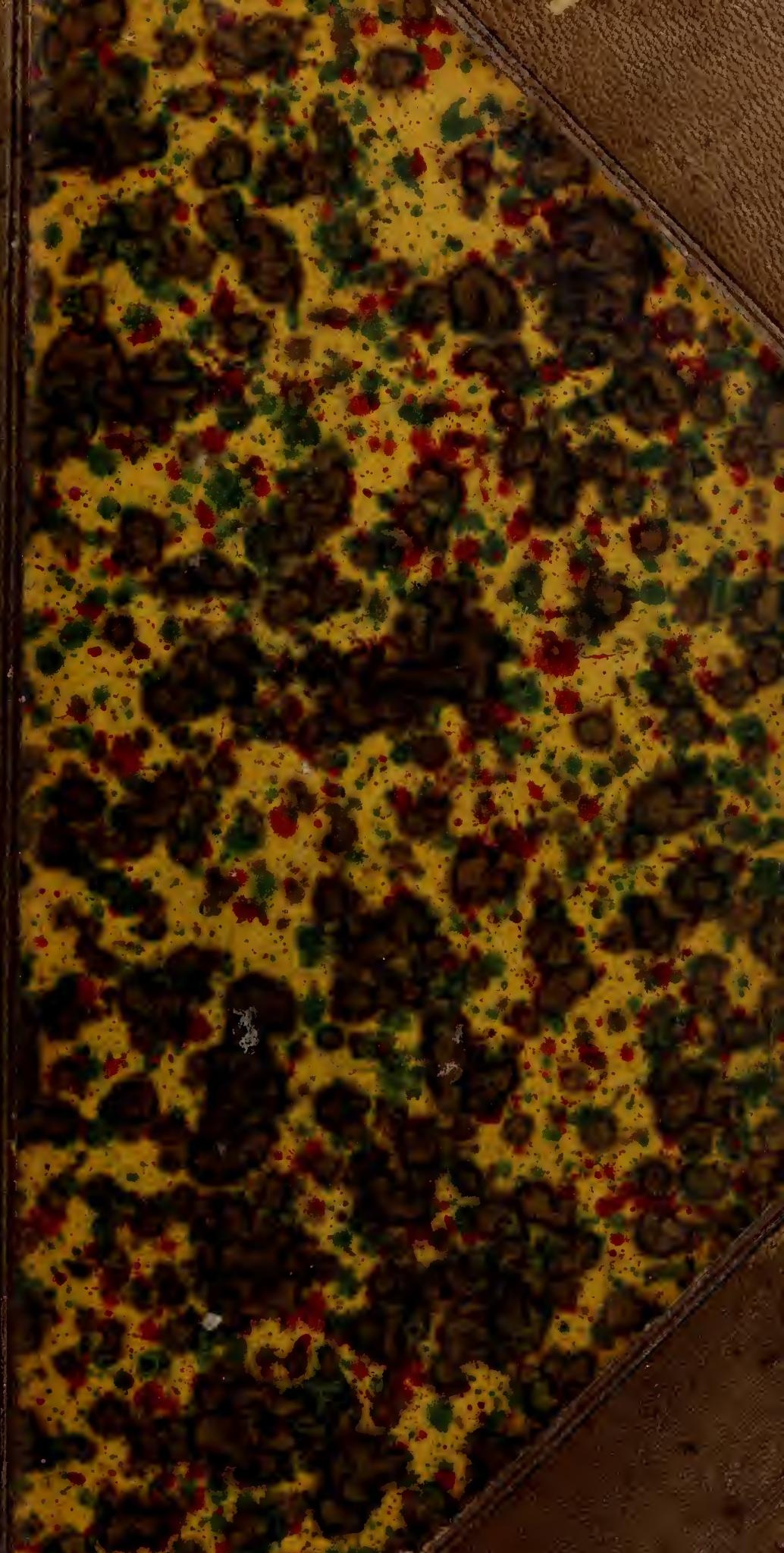




\title{
GIVEN TO THE
}

California Academy of Sciences BY

The Academy of Natural Sciences

\author{
OF \\ PHILADELPHIA
}

After the Earthquake and Fire of April, 1906 


Digitized by the Internet Archive in 2012 with funding from

California Academy of Sciences Library 



\section{PRINCIPES}

DE

\section{PHYSIOLOGIE COMPARÉE.}




\section{OUVRAGES DU MEME AUTEUR}

QUI SE TROUVENT CHEŻ LES MÊMES LIBRAIRES.

De l'influence de la Pesanteur sur les phénomènes de la vie; Paris, 1822, in-8. $75 \mathrm{c}$.

Recherches sur le mécanisme de la Respiration et sur la Circulation du sang, etc. Paris. 1820, in 8. $2 \mathrm{fr}$.

Mémoires que l'Institut a honorés d'un accessit au premier concours pour les prix Montyon.

Principes de Physiologie médicale; Paris, 1828. 2 vol. in-8. 12 fr. 


\section{PRINGIPES}

DE

\section{PHYSIOLOGIE COMPAREE}

o 8

HISTOIRE DES PHÉNOMÈNES DE LA VIE DANS TOUS LES ÊTRES QUI EN SONT DOUÉS, DEPUIS LES PLANTES JUSQU'AUX

ANIMAUX LES PLUS COMPLEXES;

par ISID. BOURdON,

DE L'ACADÉMIB BOXALE DE MÉDECINE.

Histoire générale des Corps vivans, - de leur Génération ou de leur Reproduction, - de lear Accroissement, - de lear Nutrition.

\section{PARIS.}

GABON, - J.-B. BAILLIERE,

Libraires, rue de l'École de Médecine;

montpellier, librairie médigale de GABON;

LONDRES, J.-B. BAILLIERE, 3 BEDFORD STREET, BEDFORD SQUARE;

BRUXELLEs, AU DÉPÔt DE LA LIERAIRIE MÉdicale FRANÇAISE.

\section{0.}




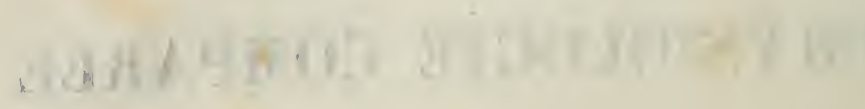

$.411 . \cdot \pi=14$ 


\section{$\mathcal{A}$ monsteur}

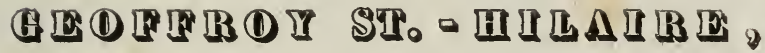

MEMBRE DE L'INSTITUT.

AU MAITRE HABILE A ENCOURAGER, AU SAVANT TOUJOURS ACCESSIBLE,

A L'AMI CONSTANT DONT JE M'HONORE,

HOMMAGE VRAI, HOMMAGE DU COEUR.

ISID. BOURDON. 



\section{PREFACE.}

Chaque science a son époque de gloire, son temps de progrès et de maturité; chacune devient successivement populaire. Tout siècle a sa science préférée, et la Physiologie est celle de nos jours.

Nous possédons déjà beaucoup de livres sur cette branche importante de nos connaissances ; par malheur la plupart de ces traités n'envisagent que l'espèce humaine. Il en est quelques-uns consacrés aussi à l'histoire des fonctions des plantes; mais aucun d'eux n'embrasse l'ensemble des corps vivans. A la vérité c'est un sujet d'une extrême difficulté, et d'une étendue immense.

M. Cuvier, avant lui Perrault, Monro, Hunter, Blumenbach et Vicq-d'Azir, et après lui, MM. Everard Home, Geoffroy St.-Hilaire, Blainville, Duméril et Meckel, sont les principaux savans qui se soient occupés un peu généralement de l'anatomie des animaux. Mais ces auteurs si estimables se sont presque toujours bornés à décrire les instrumens, les organes : ils ont exposé, avec une exactitude tantôt philosophique et tantôt minutieuse, la composition, la structire des machines vivantes, sans presque jamais en dire le mécanisme, sans en montrer l'admirable jeu, l'harmonie.

Si l'étude dont nous traitons a été jusqu'alors si génẻralement négligée, c'est qu'elle exige, ou d'heu- 
reux et longs loisirs, ou un désintéressement qui devient de plus en plus rare; c'est qu'outre cela, il faut des musées, de riches collections, où l'on puisse consulter sans cesse des matériaux indispensables à quiconque veut éviter l'erreur. Aussi ne doit-on pas s'étonuer si l'on est obligé de remonter jusqu'à Aristote pour trouver une esquisse un peu supportable de la physiologie comparée : encore faut-il attribuer la généralité philosophique de l'ouvrage d'Aristote, à l'enfance, à l'imperfection de la science, alors qu'Aristote s'en occupait.

Un pareil livre, convenons-en sans dissimulation et sans flatterie, gagnerait beaucoup à être fait par M. Cuvier. Mais cet homme illustre, sérieusement occupé maintenant de la réimpression et de l'achèvement des ouvrages de sa jeunesse, ne fera jamais pour la physiologie, nous avons de trop grands motifs de le craindre, ce qu'il a exécuté avec tant de bonheur et de succès pour l'anatomie. C'est ici d'ailleurs un de ces ouvrages qu'il ne convient d'entreprendre que dans la deuxième partie de la vie, à cet âge d'illusions et d'espoir, où l'existence a tant de plénitude, que c'est à peine si l'on songe à en prévoir le terme, à en régler l'emploi et ménager le cours : sans compter que l'esprit même le plus vaste a ses limites, ou plus restreintes, ou moins bornées, mais prescrites à tous et toujours infranchissables.

Si du moins M. Cuvier pouvait encorc abandonner, comme jadis, sans repentir, sans imprudence, à la foule de ceux qu'il instruit el qui l'admirent, les précieux matériaux que ses collec- 
tions renferment! s'il maintenait toujours accessibles, sans restriction, sans réserve, les documens dont plusieurs ont besoin! Mais la générosité et la complaisance ont aussi leurs bornes; et s'il est une chose qui doive profondément attrister, c'est que ce soit l'ingratitude des hommes, l'injustice de ses contemporains, qui ait ainsi forcé $M$. Cuvier à se réserver pour lui seul des trésors où, de son noble consentement, le monde entier puisait à loisir et sans limites il y a peu d'années.

Heureusement nous avions consulté autrefois tout ce que le Musée du Jardin du Roi, tout ce que les cabinets de M. Cuvier offrent de plus important. Ces matériaux nous sont d'un grand secours àujourd'hui. Nommé de l'école des naturalistes du gouvernement, fondée en I 8 I 9 par M. Decazes, à l'instigation de M. de Mirbel et des professeurs du Musée d'histoire naturelle de Paris, j'eus le bonheur alors d'être attaché à M. Cuvier en qualité de disciple particulier, d'être personnellement choisi par lui après concours.

Ce fut alors que j'étudiai et l'histoire naturelle, et l'anatomie comparée, sous les maîtres les plus habiles et dans les circonstances les plus propices qui se puissent jamais rencontrer. Mais il faut bien le dire aussi : ce n'était point là que je pouvais apprendre la physiologie comparée; la vie ne peut être étudiée que sur des corps vivans, et tout est mort, tout est inanimé dans les musées d'histoire naturelle. Je dus donc recourir à l'étude des corps réellement vivans. J'observai les animaux et les plantes, je lus les observateurs, je fis des expé- 
riences; et comme j'avais avant tout, et plus attentivement que tout autre être, étudié l'homme luimême, mes premiers travaux et mémoires, et mon premier ouvrage, eurent l'homme pour unique objet.

Sans donc perdre de vue mon projet de tracer l'histoire de la vie dans tous les êtres, je publiai d'abord une physiologie de l'homme, cette Physiologie médicale, à l'occasion de laquelle les médecins les plus distingués de Paris ont déjà publié, dans le seul but de la critiquer, plus de pages que ce livre luimême n'en contient; cet ouvrage qui a soulevé tant de passions, et qu'on a traité, pour tout dire en un mot, comme on traite ordinairement une découverte. Je veux dire qu'on a commencé par soutenir avec vivacité qu'il contient des erreurs, quelques contradictions, quelques paradoxes (ce qui peut bien être v̀rai), et l'on a fini par assurer qu'il n'était pas nouveau, dernier reproche assurément beaucoup plus endurable que les autres, la lumière du jour et l'impartialité du siècle étant là pour me défendre, et devant suffire pour m'en justifier.

Toutefois ce livre si vivement critiqué, contient tous les grands principes de la physiologie, la science de l'homme, mes opinions et mes croyances personnelles, et par anticipation aussi, les corollaires du livre que je publie aujourd'hui. Je me hâte d'ajouter qu’à son tour, la Physiologie comparée renferme la plupart des faits particuliers que l'on espérait peut-être rencontrer dans le premier ouvrage. Je souhaite qu'on veuille se donner la peine de 
lire entièrement cette première partie, avant d'exprimer aucune opinion au sujet de ce nouvel ouvrage. Mais je crains bien que l'on ne le feuillette d'abord, encore animé de cette vive colère que la Physiologie médicale a excitée. A la vérité, j’en suis sûr, et cela du moins me tranquillise, on finira par y mettre plus de calme, et aussi plus d'impartialité; je n'ose encore compter sur beaucoup d'indulgence, et pourtant j'en aurais besoin.

Je ne publie maintenant que la première partie de la Physiologie comparée : quatre livres composent ce volume. Le premier traite de la Vie, de ses lois générales, de ses diverses manifestations, et des corps qui en sont doués. Le deuxième Livre contient l'histoire de la Génération ou de la Reproduction dans les animaux des différentes classes et dans les plantes. Le troisième renferme tout ce qui concerne les progrès et les lois de l'Accroissement des corps vivans, ainsi que beaucoup de chapitres qui, bien qu'imprimés depuis long-temps, ont trait à la grande question des analogues qui a été tout récemment débattue entre deux célèbres naturalistes, devant l'Académie des sciences de Paris. Le quatrième Livre traite de la Nutrition des corps vivans.

Dans la deuxième partie, qui suivra d'assez près celle-ci, il me restera à faire l'histoire de la respiration des corps vivans, de leur chaleur propre, et des causes productives de cette chaleur; des fluides, humeurs et émanations des corps vivans, de leur sécrétion, de leurs sources, et de la circulation de plusieurs; des sensations des animaux, de leurs divers instincts, de leurs mouvemens, dispersions et 
voyages, et aussi de leurs langages; enfin des causes qui, modifiant leur nature, produisent leurs nombreuses variétés, et des principales influences qui en déterminent la multiplication et la distribution sur le globe.

Je termine en appelant de tous mes voeux la critique et les avis de mes émules : qu'ils soient vrais, qu'ils soient impartiaux et judicieux, et ils verront combien je serai docile et reconnaissant !

\section{ERRATA.}

Page 28 , ligne $2^{\mathrm{e}}$ du chapitre $I X$, - composent, lisez : couvrent.

$4825,-$ mais on ne voil d'œufs, ajoutez: vérirables.

Go I2, - Goudyles, lisez Gongyles.

I1 6, - plus léger que l'air, lisez : plus léger que l'albumen. I28, au bas de la page, corrigez plusieurs singuliers mal à propos melés à des pluriels.

r5r, ligne $17,-$ effacez: presque.

2 i9 3o, - effacez: l'est.

$3_{9 \mathrm{I}} \quad 20$, mettez : plumule, au lieu de: radicule.

42017, - lisez: ne se transforment jamais l'une en l'autre.

$42623,-$ ne se fondent, lisez: ne se soudent.

$427 \quad$ I $5,-$ meme changement.

48 4 , - nécessaires, lisez : naturels,

$5054,-$ attẻrer, lisez : altérer.

$55623,-$ maniêre, lisez : matière. 


\section{PRINCIPES}

\section{DE}

\section{PHYSIOLOGIE}

\section{COMPARÉE.}

\section{LIVPE PREMIER.}

\section{Des Corps Vivans en général.}

\section{CHAPITRE PREMIER.}

Idée des Corps Vivans et des rapports quills ont avec toutes choses.

Quand on porte les yeux sur la terre, on la voit partout couverte de corps vivans. A l'exception des pôles, d'où le froid et l'obscurité les éloignent, les plantes et les animaux habitent toutes les parties du globe. On en retrouve d'anciens vestiges jusqu'aux profondeurs des terrains charriés par des fleuves, déposés par les mers déplacées, ou tourmentés par diverses révolutions. La couche superficielle de la terre, formée des débris des générations détruites, sert à l'accroissement des plantes actuelles, et, par ces plantes, de nourriture aux animaux. Autour de la I. 
terre, ainsi peuplée, tout est arrangé pour la vie : la lumière et la chaleur vivifient les corps organisés; l'air lui-même, qui forme à la terre une enveloppe de plusieurs lieues d'épaisseur, entre dans la composition de ces corps par des échanges continuels et toujours compensés. Enfin l'eau, qui pénètre le sol ou qui se vaporise dans l'atmosphère, l'eau, qui passe incessamment de la mer aux nuages et des nuages à la mer, est un autre élément nécessaire à la vie.

Tous les êtres vivans, quelque diversifiés qu'ils soient, ont des caractères communs : tous naissent de corps semblables à eux, et s'accroissent aux dépens de molécules étrangères qu'ils-assimilent à leur propre substance; tous sont formés de diverses parties qu'on nomme organes, ce qui les fait eux-mêmes nommer corps organisés; ces organes réunis forment pour chaque être vivant un tout ensemble, un tout concordant et d'une parfaite unité pour les formes, pour les phénomènes et pour la durée; et comme un seul de ces organes ne saurait être distrait des autres sans nuire à l'ensemble de l'être, à cause de cela chaque corps vivant s'appelle individu. Tous ont unc chaleur propre, différerte, et jusqu'à un certain degré indépendante des corps environnans; tous résistent aux lois d'affinité des corps bruts, et les composés qu'ils forment sont dus à d'autres lois que celles par qui s'opèrent les mixtes de la chimie; tous absorbent quelque chose du dehors et le transforment, et tous exhalent quelques principes nés de la vie; tous se reproduisent par des actes semblables aux actes qui les ont eux-mêmes produits; tous durent un temps variable pour chaque ĉtre, mais à-peu-près le même 
pour tous les êtres de la même espèce restés à l'état sauvage ou de nature : après cette durée active et individuelle tous cessent d'exister, et enfin leurs corps se dissipent en leurs plus simples élémens, selon les lois de la chimie universelle.

Ainsi chaque être vivant forme un petit monde par son ensemble, par son unité; mais ce petit monde ne peut subsister isolé du grand. Il y a toujours pour la vie liaison et mutuelle dépendance d'organes, loujours concours et concordance d'actions; il y a pour chaque être vivant, commerce de chaque partie avec le tout, et du tout avec l'univers.

Si donc on veut distinguer un corps actuellement vivant d'avec un autre corps organisé, mais sans ${ }^{*}$; on n'a qu'à s'assurer s'il a commerce aver yuil l'entoure, ou si, au contraire, il no. ...serve plus aucun rapport avec l'univers. $S$; ' wa veut distinguer un corps. organisé qui a ce-cue vivre, d'avec un corps brut et inorganisé -1 n'a qu'à voir si les différentes parties. do corps sont unies autrement que par l'attraction. moléculaire, et si la libre action des élémens finit. bientôt par le putréfier ou le consumer.

\section{CHAPITRE II.}

Deux Classes d'Êtres organisés : animaux et végétaux.

Quant à l'universalité des corps vivans, leur séparation en deux grandes classes, ou, comme on dit, en deux régnes, est tracée par la nature. Les uns, plus complexes, pourvus d'une cavité intérieure qui recoit leurs alimens, doués de sentiment et de mou- 
vemens spontanés, mus par instinct vers ce qui leur

- convient, s'éloignant également de ce qui peut leur nuire, sont nommés animaux. Les autres, implantés dans la terre par une racine, privés de la faculté de sentir et de se mouvoir, entourés naturellement des choses nécessaires à leur existence, les absorbent directement sans instinct, sans déplacement, sans préparalifs, sans travail compliqué. Les animaux, pourvus d'organes sexuels, tantôt unis dans le même être, plus souvent séparés dans deux êtres de la même espèce, conservent ces organes aussi long-temps que la vie : presque tous les végétaux ont les organes des deux sexes réunis dans le même être, et ces organes, animauxdent et les renouvellent chaque année. Les animaux su. "urtout compliqués à l'intérieur; c'est là que se passent tè a -incipaux phénomènes de leur existence : les végétaux, au nntraire, ont les principaux organes placés à leur surfac. leurs fonctions sont plus extérieures. Dès en naissant, _...imal (si l'on excepte quelques cas de métamorphoses) a si différentes parties de son corps déjà ébauchées; parfait dès son origine, ses organes n'ont plus qu'à se développer, qu’à s'agrandir. Le végétal, né d'une graine, développe successivement ses organes : une racine, une tige, des feuilles, des fleurs, etc.; et après que ces fleurs sont épanouies, bientôt le reste des organes dépérit, et bientôt tout meurt, ou seulement la tige, ou quelquefois seuleınent les feuilles : chaque année ou chaque floraison le détruit ou le renouvelle, ou parliellement, ou tout entier. Ainsi les deux classes d'êtres ont en commun la faculté de se nourrir et la faculté de se reproduire; l'animal a, 
CHAP. III. ÊtRES AMBIGUS.

de plus que les végétaux, le pouvoir de sentir el de se mouvoir spontanément; il a seul des nerfs, seul des muscles, du sang et une espèce d'estomac, et toujours visiblement au moins l'une de ces choses: et comme les nerfs et les muscles sont intermittens dans leur action, il naît de là une nouvelle différence pour l'animal; je veux parler du sommeil périodique auquel il est assujetti.

\section{CHAPITRE III.}

Êtres ambigus : cause d'erreur et de confusion. Existe-t-il des ctres intermédiaires aux animaux et aux plantes?

Celui qui ne connaît la vic que pour l'avoir étudiée dans l'homme et dans les gros animaux les plus rapprochés de l'homme, lit avec dédain ces ennuyeuses. discussions dont le but est de distinguer sans erreur un animal d'avec une plante : il regarde comme impossible toute confusion entre des êtres si différens à ses yeux prévenus; tant de recherches lui semblent de vaines subtilités.

S’il n'existait sur la terre que des animaux aussi bien caractérisés. que le sont les oiseaux, les poissons et les quadrupèdes, sans doute il ne serait pas besoin d'enseigner à les séparer d'avec les végétaux : la barrière mise entre eux par la nature devrait suffire. Leurs sens si manifestes, leurs mouvemens spontanés, la symétrie et la complesité de leur structure, et plus que tout cela, l'instinct qui dirige leurs actions, pré serveraient sûrement de toute erreur. Alors on pourrait se contenter de dire avec Linné, Vegetabilia eres- 
LIV. I. DES CORPS VIVANS EN GÉNÉRAL.

cunt et vivunt; Animalia crescunt, vivunt et sentiunt : et tout incomplète qu'elle est, cette courte et jolie définition serait suffisante. Il ne serait pas besoin non plus de distinguer, d'avec les végétaux, les insectes, les crustacés, les coquillages symétriques, espèces de vertébrés retournés et en miniature, Mais il faut remarquer que les animaux n'ont pas tous cette perfection apparente : tous ne sont pas aussi compliqués, ni tous aussi visiblement mobiles. La preuve en est que Tournefort, homme d'un bon esprit et grand naturaliste, forma neuf des genres de sa dix-septième famille des plantes avec les polypiers connus de lui et des savans ses contemporains. Depuis Tournefort, Trembley consacra un temps fort long à s'assurer si l'Hydre d'eau était un animal ou une plante, et les expériences auxquelles il se livra pour éclairer ses incertitudes, le conduisirent à une découverte que les écrivains d'alors ont vivement célébrée. Les tâtonnemens de 'Trembley sont d'autant plus remarquables, que déjà avant lui Peyssonnel avait observé que de petits animaux habitaient les différens compartimens des coraux. Cette découverte, Ellis et Solander l'avaient étendue à ioutes les sortes de polypiers; et Donati, Réaumur et B. de Jussieu la consacraient déjà ou dans leurs leçons ou dans leurs ouvrages. Cependant il resta long-temps des doutes dans. les esprits et de l'obscurité sur la matière.

Les grands naturalistes du dix-huitième siècle furent tous frappés de ces difficultés; lillustre Buffon surtout sut les apprécier : il proposa, en conséquence, d'établir une classe d'êtres intermédiaires aux deux règnes, Linné, à qui celte idée parut juste, qquoi-a 
qu'elle fût de Buffon, la réalisa par le nom de Zoophytes (animaux-plantes), qu'il donna à ces êtres óquivoques si nuisibles aux généralités dont sans eux les deux règnes seraient susceptibles. Le célèbre Pallas imita Linné en cette occasion comme en tant d'autres; M. Cuvier lui-même admit le mot et la dislinction qu'il consacrait; mais 4 . de Lamarck a depuis rejeté le mot et la chose.

Tant d'bésitations et de doutes de la part d'homimes aussi éclairés ne teraient pas seulement à l'obscurité du sujet; ils avaient leur source essentielle dans une première et fausse direction de vues et d'études : concentrés dans lears cabinets, les naturalistes étaient trop loin de la nat ure. On avait trouvé des corps solides, des coraux, des éponges, des alcyons, des polypiers de mille formes, tantôt nus, tantôt recouverts de corps mous et mobiles. On confondit toutes ces choses; on ne distingua pas l'habitant d'avec sa demeure, le polype d'avec son polypier. Loin de regarder le corps mou conme le fabricateur de la masse solide, on crut que ce dernier corps produisait l'autre; et comme on voyait ces polypiers s'aceroître et comme végéter, on les prit sans cérémonie pour des. plantes, et les polypes furent regardés comme les. fleurs de ces planies singulières. Il est juste de dire qu'à l'époque où ces êtres se reproduisent, leur corps est couvert de petits gemmes ou bourgeons qui ne sont pas sans quelque analogie avec de certaines fleurs: d'une structure peu distincte. Mais quand on vit que ces prétendues fleurs étaient mobiles, quand on vit qu'elles paraissaient sensibles, on fut alors dans un. grand embarras; et c'est pour en sortir qu'on les. 
nomma Zoanthes; c'est-à-dire animaux-fleurs ou fleurs animées.

La vérité est (et cela est bien certain aujourd'hui) que les polypes composent eux-mêmes ces espèces de végétations solides qui leur servent de demeures, à-peu-près comme les mollusques forment leurs coquilles, le taret son fourreau, l'écrevisse son test, les tortues leurs carapaces, les poissons leurs écailles, les insectes leurs élytres, les oiseaux leur plumage, les tatous leur toiture, les baleines leurs fanons, les quadrupèdes leurs poils et leurs défenses, et l'homme ses cheveux, ses ongles et son épiderme. Il y a dans tous les êtres vivans certaines parties qui végètent; et si l'on jugeait de chaque animal d'après ces parties. végétantes de son corps, il faudrait les ranger tous parmi les zoophytes de Linné et de Pallas.

Voici toutefois à quels signes on peut reconnaître si un corps vivant, si un corps organisé, se nourrissant et s'accroissant par lui-même, si un être doué d'une température propre et se reproduisant, est un végétal ou un animal.

S'il se meut chaque fois qu'on l'irrite en le tonchant, si d'ailleurs il se meut spontanément pour vaquer à ses besoins, sỉl est plutôt adhérent au sol qu'enraciné dans la terre, si son corps est pourvu d'une cavité centrale, si Jorsqu'on l'a tué il se putréfie, si les parties séparées de son corps et jetées. au feu brûlent avec une sorte d'effervescence et en répandant une odeur de corne ou d'ammoniaque, si en le décomposant par les procédés chimiques il donne plus d'azote que.de carbone; alors on peut ètre assuré qu'un pareil être est un animal. Mais si 
GHAP. III. Êtres AMBIGUS.

le corps vivant, d'une nature équivoque, ne jouit d'aucun mouvement à-la-fois durable et spontané, s'il est dépourvu d'une cavité intérieure, s'il tient dans le sol et que, détaché de ses adhérences, il ne tarde pas à se faner et à mourir, si une fois mort il se dessèche ou fermente sans putréfaction, s’il brûle sans odeur de plume ou de corne torréfiées, et si son résidu, très-considérable, est charbonneux; alors il s'agit là d'un végétal.

Ces caractères sont suffisans et la plupart faciles à apprécier. Je n'ai point fait mention de la sensibilité dans cette distinction positive des êtres vivans, car pour les animaux inférieurs surtout (les seuls dont il soit quelquefois difficile d'apprécier la nature), ce n'est qu'à l'aide de mouvemens excités qu'on peut juger s'ils sont sensibles. Je n'ai point parlé non plus des phénomènes de la reproduction : il est évident qu'il n'y a d'ambiguité embarrassante que pour des êtres dont les fonctions sont d'une grande obscurité ou tout-à-fait inconnues. Ce n'est point, comme on pourrait le penser, les plus parfaits, je veux dire les plus complexes des végétaux, qu'on est exposé à confondre avec les animaux les plus simples. Un peu de réflexion fait voir qu'il serait impossible de ne pas toujours discerner une plante feuillée et fleurie d'avec n'importe quel animal. Mais on a souvent confondu les êtres les moins caractérisés des deux règnes: l'ensemble des animaux et l'ensemble des plantes forment donc comme deux pyramides qui se toucheraient par leurs bases.

Voyez combien il est difficile de caractériser par une formule courte, mais positive, ce qui constitue 
et différencie l'animal! Aussi M. Cuvier, qui employa vingt années de sa vie à scruter l'organisation des êtres inimés, depuis le simple polype jusqu'à l'homme, s'est-il sagement abstenu d'une définition générale. Plus on a vu d'animaux, plus on a de peine à les définir. Ia difficulté n'est pas de savoir ce qui est propre aux seuls animaux, mais ce qui leur est commun à tous, parmi ces chose 3 qu'eux seuls possèdent. On sait bien qu'ils ont seuls un cerveau, des nerfs, des muscles, un cœur, des poumons, un estomac, un squelette; on sait qu'eux seuls se meuvent, digèrent, respirent, qu'eux seuls ont du sang et semblent sentir : mais. que leur reste-t-il de tous ces caraclères, quand on redescend la longue chaîne qu'ils forment, depuis le dernier anneau jusqu'au premier? presque rien. On voit successivement disparaître les poumons, les glandes, le cerveau, le squelette, le cœur, les branchies, le sang, les nerfs, les muscles et enfin les vaisseaux; à peine est-on sûr si tous ont une cavité digrestive ou un estomac. Cependant, comme on reIrouve ce dernier organe dans la presqu'universalité des animaux, et comme on le retrouve manifestement dans ceux même qui ne conservent plus aucun autre organe visible, on est porté à croire qu'il existe dans tous; et si nos recherches sont vaines pour le découvrir dans plusieurs, il faut croire que c'est faute d'assez d'adresse, faute de sens assez délicats, et probablement aussi à cause de l'exiguité des êtres où nous le cherchons sans le trouver. On admet, en conséquence, que tous les animaux ont un estomac it quils digèrent : on suppose en outre que tous sont sensibles; mais ce qui est sûr, c'est que tous, et eux 
seuls, ont des mouvemens spontanés et durables. Ce dernier caractère est le plus évidemment universel.

Résumé. S’il me fallait donner une définition générale des animaux, je dirais : Estomacs servis par des organes. L'estomac est, en effet, la grande pièce essentielle de tout être animé, comme le grand ressort est la pièce indispensable d'une pendule. Je sais bien que les nerfs et les muscles, organes du sentiment et du mouvement, paraisśent d'une nature plus relevée que l'estomac; mais sans lui que seraient-ils? On dirait un ressort d'acier faisant mouvoir des aiguilles d'or, lesquelles sans lui resteraient immobiles.

\section{CHAPITRE IV.}

Conditions de la vie. Organes indispensables. Unité dans l'action.

Concordance et perfection dans la structure.

Nous ignorons ce que c'est que la vie, son essence nous est cachée; mais nous voyons comment sont faits les corps vivans, comment se succèdent et s'enchaînent les phénomènes de la vie. Nous sommes forcés de borner là notre étude.

Tous les corps vivans sont organisés; ce qui veut dire qu'ils sont formés de différentes parties agissant chacune à sa manière, et reınplissant diverses fonctions : ce sont là comme les instrumens de la vie. L'ensemble de ces organes forme un tout parfait pour chaque être, et l'ensemble des actions que ces organes exercent compose la vie en ce qu'il nous est permis d'en connaître. La vie ne saurait exister sans le bon 
état de tous les organes; mais ces organes existent encore après que la vie a cessé d'ètre. Ce qui confond notre faible intelligence, c'est que nous ne voyons aucune différence entre les organes d'un corps vivant et les organes d'un corps qui vient de mourir. Nous voyons une machine à qui rien ne paraît manquer : d'où vient donc que son jeu a cessé? tous les rouages en sont parfaits, il n'y manque que la main agissante de l'ouvrier. Nous en étudions les ressorts évidens après en avoir admiré lé sublime mécanisme, mais le principe moteur nous échappe toujours.

Tous ces organes solides sont baignés par des fluides: qui séjournent ou circulent dans des espèces de canaux ; et canaux comme organes, en quelques êtres qu'on les observe, sont toujours formés d'un tissu celluleux à mailles plus ou moins serrées. Ce tissu à cellules, les vaisseaux qu'il compose, les fluides qui remplissent ces vaisseaux, voilà ce qu'ont de commun tous les organes en tous les corps vivans. Le reste dela structure differe en chacun.

La plupart des êtres vivans ont des organes nombreux et des fonctions compliquées : plus les fonctions sont variées, plus la structure est complexe. Mais il existe une hiérarchie entre les fonctions comme entre les organes. Tous les corps vivans se nourrissent et se reproduisent, tous les animaux se meuvent spontanément au moins par quelques-unes de leurs parties, beaucoup respirent visiblement, l'homme pense : mais il est évident que le preuier degré de loutes ces fonctions est la nutrition; les autres phénomènes supposent toujours celui-là. Cherchons donc les organes de la nutrition; et si nous parvenons à les 
CUAP. IV. CONDITIONS DE LA VIE.

trouver, nous serons sûrs de tenir en nos mains le premier chainon de la vie.

La plupart des plantes ont une racine fixée dans la terre, une tige qui s'élance dans l'air et se dirige vers la lumière; cette tige porte des feuilles, des rameaux, des fleurs; ces fleurs, plus ou moins compliquées, donnent des fruits ou des graines destinées à une postérité d'êtres analogues à l'être qui les a produites. Mais parmi ces organes quel est le plus essentiel? Otez les fleurs et leurs graines, le reste de la plante n'en subsiste pas moins; la tige peut perdre ses feuilles sans en soufrir; et la tige coupée, la racine continue d'absorber et de vivre à sa manière; souvent même elle reproduit des parties semblables à celles qu'on en a séparées. Cette racine est donc la partie la plus importante du végétal, c'est donc par elle principalement que toute la plante se nourrissait. Voyons maintenant les animaux.

Beaiucoup d'entr'eux ont une structure très-complexe: un squelette ossetix, des nerfs, des sens, un cerveau, des muscles pour se mouvoir, un cœur pour répartir le sang, des espèces de poumons pour l'imprégner d'air, un estomac dans lequel la nourriture séjourne et se prépare, des glandes pour composer des humeurs, des organes pour perpétuer l'espèce, une enveloppe générale pour protéger cet ensemble, et des membres pour le déplacer: tous ces organes et beaucoup d'autres composent leur substance. Dans des êtres aussi compliqués il serait impossible d'assigner précisément à chaque partie son degré d'importance; car on n'en peut soustraire aucune sans 
mettre le trouble dans l'ensemble, et l'on ne.peut même toucher à plusieurs d'entr'elles sans détruire l'édifice commun. Mais cette dissociation d'organes que nous ne pouvons opérer, la nature l'a réalisée d'ellemême dans la longue chaîne des animaux. En descendant des quadrupèdes vivipares aux oiseaux, des oiseaux aux reptiles et aux poissons, et des oiseaux et des poissons, par les insectes et les mollusques, jusqu'aux vers et aux polypes, nous voyons peu-à-peu se simplifier les machines vivantes, à ce point, que nous ne trouvons plus dans les derniers degrés que le premier principe, le principe indispensable à l'animalité. Le corps du polype ne forme en effet qu'un vaste estomac sans autre organe appréciable; et c'en est assez pour la nutrilion et l'existence d'un être si simple. Nous pouvons conclurè de là, que le premier élément du végétal est la racine, et que l'estomac est le fondement de toute organisation animale. La nature ellemême confirme ce principe par ses œuvres: elle a créé des végétaux qui n'ont qu'une racine pouir tout organe, comme elle a créé des animaux composés uniquement d'un estomac. Il est vrai que toutes les fonctions sont d'une extrême simplicité dans des corps aussi homogènes. Pour qu'un végétal puisse se suffire à lui-même avec une racine pour tout organe, il faut que les substances propres à la nourrir environnent cette racine: il faut qu'elle tienne à un sol formé d'humus et imbibé d'eau : alors c'en est assez pour la vie individuelle. Quant à la reproduction, la chose est également simple : ce qui ne peut être produit par desfleurs, il faut que des caicux, des bou:geons, des divisions naturelles ou artificielles de la 
CHAP. IV. CONDITIONS DE LA VIE.

racine l'opèrent. C'est en se divisant que de pareils corps se multiplient. Mais comment peut vivre un animal, ver ou polype, dont un simple estomac compose tout l'être? Comme cette poche nourricière est à l'intérieur, il est clair que les alimens y doivent être portés ; il est clair, par conséquent , qu'il faut que cet être se meuve vers ses alimens ou qu'il attire par des mouvemens partiels sa nourriture à lui; il faut pour la chercher qu'il la sente, qu'il l'apprécie ; il lui faut même une espèce d'instinct poux proportionner de pareils mouvemens à ses besoins. Voyez combien cet être si simple, mais parfait, nous paraît déjà compliqué!

Je dis que cet être est infiniment simple, car il n'a pour tout organe qu'un estomac. Encore qu'il se meuve et qu'il doive sentir, on ne lui voit ni muscles, ni cerveau, ni nerfs : il a des actions dont les instrumens restent cachés. Je dis aussi que malgré cette simplicité le polype forme un être parfait, car il possède en lui tout ce qui le fait exister : il est donc aussi parfait qu'un oiseau, qu'un mammifère. Il n'a ni cœur, ni poumons, ni vaisseaux intermédiaires, ni glandes, cela est vrai ; mais il n'en a pas besoin. Lorsque l'estomac occupe tout le corps d'un animal, et que ce corps est parfaitement simple et partout homogène, il est évident qu'il n'est besoin pour une pareille structure, ni de poumons, ni d'un cœur, ni de vaisseaux diversifiés; une telle économie d'organes peut se passer de circulation et d'une respiration circonscrite. Chaque partie de l'animal peut isolément puiser dans le canal commun la portion d'alimens dont elle a besoin; elle peut la respirer, l'éla- 
borer à sa manière. Mais dès que le tout animé n'a plus cette homogénéité parfaite en tous ses points, il lui faut dès-lors un estomac pour préparer la nourriture commune, il lui faut un cour pour la distribuer, elle et le sang, entre les organes; et comme ce sang revient au cœur privé de ses principes, comme il y revient fort différent selon les organes qu'il a pénétrés et nourris, il faut bien qu'une espèce de poumon le purifie par son mélange à l'air et à de nouveau chyle, ot qu'il le rende identique et homogène avant que le cœur ne le fasse de nouveau circuler par tout le corps. L'unité est le premier principe de la vie : or, dans ces organisations compliquées, c'est le cœur et le poumon qui produisent cette unité pour la nutrition, comme le cerveau la produit pour les sensations.

Il résulte de ce que nous venons de dire, que le corps vivant de lapparence la plus simple et la plus chétive ne laisse pas de former un tout aussi parfait que l'être le plus complexe, puisqu'il possède en lui tout ce qui est nécessaire à son existence.

\section{CIIAPITRE V.}

Dépendance mutuelle des organes, variable selon les étres.

Comme les corps vivans sont assujettis à la mort, l'organisation peut exister sans la vie; mais qui dit vie, dit organisation. Buffon faisait donc un pléonasme lorsqu'il écrivait dans ses pages sublimes que les animaux sont des corps vivans et organisés. 
CHAP. V. DÉPENDANCE MUTULLLE DES ORGANES. I7

Cette organisation des corps vivans est soumise à de certaines règles qui par leur constance et lcurgénéralité ont mérité le nom de lois. Nous venons d'exposer deux de ces lois, je veux dire la perfection et. l'unité de tout corps vivant. Quant à l'unité, cependant, ce principe n'est pas absolu. L'individualité n'existe véritablement que pour les animaux d'une? structure déjà fort complexe : elle n'est parfaite ni pour les plantes, ni pour les animaux les plus inférieurs : je m'explique. Il est bien vrai que, tant que les divers organes de ces êtres restent intacts, ils vivent d'une vie commune, et ne font qu'un tout parfait et concordant; mais il n'est pas impossible d'en distraire ou d'en élaguer quelques parties sans interrompre la vic dans le reste de l'être ainsi mutilé. On sait qu'on peut couper d'une plante ses fleurs, ses feuilles, ses branches, sans pour cela la faire mourir: ne restât-il qu'une racine elle-même divisée avec une tige tronquée, ce débris n'en jouit pas moins de la vie. Je dis plus, c'est que plusieurs des parties détachées du tout ont souvent reproduit l'être complet, lorsqu'on les plaçait dans des circonstances favcrables: il suffit quelquefois d'un rameau ou d'une feuille pour reproduire un végétal semblable à celui dont ces parties proviennent. C'est sur de pareils faits que repose la théorie des marcottes et des boutures. Il en est de même de quelques animaux : un polype nu, coupé en plusieurs parties, forme autant de nouveaux polypes parfaits qui continuent de vivre à la manière de leur souche commune : certains vers se comportent de la sorte. On a pu aussi détacher plusicurs rayons complels d'une astérie sans, la I. 
faire périr. Des limaces survivent sans affaiblissement notable à leur détroncation : Voltaire, à l'exemplè de plusieurs naturalistes de son temps, s'est souvent amusé à de pareilles expériences. Mais ce qu’il y a de plus étonnant, c'est que les animaux vertébrés eux-mêmes ont souvent souffert des mutilations analogues sans perdre subitement la vie : des tortues, des sálamandres, à qui la tête avait été enlevée, ont néanmoins continué de vivre un temps notable. L'empereur Commode se plaisait à couper la tête à des autruches courant dans le cirque de Rome; et cette cruelle opération, assure-t-on, n'interrompait point subitement leur course. Enfin il n'y a pas jusqu'aux mammifères nouveau-nés qui nè puissent survivre quelques instans, fort courts à la vérité, à de pareilles blessures. Mais nous devons nous hâter dè dire que toute soustraction d'organes importans n'est pas pour long-temps compatible avec la vie des mammifères, des oiseaux, et même d'animaux moins corn= plexes et moins élevés que ceux-là. La mort suit de près ordinairement de semblables opérations : il n'y a que l'extirpation d'un membre, d'un appendice, d'une. glande, d'un organe d'une importance secondaire, des organes génitaux, d'une partie superficielle enfin, qui puisse être supportée sans préjudice notable pour ces animaux. C'est qu'il existe chez tous les vertébrés une solidarité parfaite entre les organes : un de ces organes ôté, bientôt le reste du corps cesse de vivre; et si l'un d'eux est malade ou blessé, la souffrance en rejaillit sur tous les autres. Mais il est cinq organes dont l'intégrité est indispensable à l'existence des êtres vivans qui en sont naturellement pourvus : 
CHAP. v. DÉPENDANGE MUTULLLE des ORgANES. je veux parler du cœur, du cerveau, des organes de la respiration, de la moelle épinière et de l'estomac (1). Ce sont là des parties inséparables lorsqu'une fois elles se sont associées pour former un être vivant : toute division notable au tronc d'un animal pourvu de ces cinq organes est promplement mortelle.

Si les diverses parties d'une plante sont de moins près enchaînées et plus indépendantes les unes des autres, si l'on peut en détruire plusieurs sans porter dommage au tout, c'est qu'il y a presque homogénéité entre ces parties : ce qu'il en reste est suffisamment pourvu de tout ce que possédait l'ensemble de l'être. J'en dis autant de ces animaux simples, formés presque entièrement d'un estomac s'étendant à fout leur corps; ces êtres ne possédant aucun organe spécial et circonscrit, chacun de leurs segmens divisés a la complexité de l'ensemble. Mais il est clair que les résultats doivent différer là où des organes spéciaux vaquent isolément à des fonclions nécessaires à l'ensemble de l'animal. On voit bien que dans ces derniers êtres l'individu résulte de l'exacte réciprocité des pièces variées dont le corps est formé. Règle générale : plus les animaux sont élevés, c'est-à-dire plus leur structure est complexe, et plus les organes essentiels à la vie sort concentrés et étroitement unis. Le monarchisme (qu'on nous pardonne ce terme) est pour les grands états; le polyarchisme pour les petits. La multiplicité dans les rouages exige plus d'unité dans les ressorts.

(1) Voyez la Physiologie médicale. 


\section{CHAPITRE VI.}

\section{Symétrie des Corps vivans.}

11 est remarquable combien sont symétriques la plupart des corps vivans. Je ne parle ni des racines des plantes, ni de l'ensemble des rameaux des grands arbres; car le sol étont fort irrégulier pour sa composition, les racines se portent toujours de préférence du côté où la terre est la plus meuble et la plus grasse; et quant aux branches, elles sont principalement attirées vers la lumière la plus intense. Aussi voit-on les arbres les plus vivaces, je veux dire les arbres résineux et verts, ceux sur qui toutes les influences ont moins d'action, conserver une symétrie plus parfaite.

Cel arrangement régulier n'est dans aucune autre famille de plantes plus parfait que dans les labićes : je ne parle point de leurs fleurs, qui ont moins de symétrie que dans beaucoup d'autres; mais leur tige carrée, leurs feuilles opposées, leurs rameaux, leurs pédoncules, lout y est dans un ordre admirable. Également chaque feuille prise séparément dans la généralité des plantes, est disposée avec symétrie : il y a de chaque côté du pétiole, si nul accident n'est survenu, à-peu-près la même largeur de lymbe. L'arrangement définitif du contour est ensuite subordonné à la distribution des vaisseaux par qui les feuilles paraissent veinées. Selon que ces vaisseaux se ter- 
minent seulement aux bords, ou selon qu'ils s'anastomosent avant d'y arriver, les feuilles sont dentelées ou arrondies. Mais tout cela n'approche pas de la double symétrie des feuilles ailées des acacias, des feuilles de la sensitive ou du sapin.

Il en faut dire autant des fleurs, au moins dans le plus grand nombre des plantes: il y a presque toujours la plus exacte mesure entre chaque division du calice et de la corolle, entre chaque étamine, chaque pistil, "chaque compartiment de l'ovaire et du fruit. A l'exception de certaines fleurs analogues à celles de l'acacia, à celles des labiées, des orchis, etc., les irrégularités que plusieurs d'entre elles présentent sont dues à des avortemens d'organes, à des adhérences ou à des transformations.

Passant des plantes aux animạux, nous voyons ces derniers êtres déjà symétriques à partir des polypes pourvus de cils, munis de tentacules ou de petits bras: ces appendices sont arrangés avec régularité autour de leur bouche. Il n'y a pas jusqu'aux corps calcaires et arborisés qu'ils, forment insensiblement et qu'ils habitent,' qui n'observent une semblable disposition. Nous retrouvons surlout cette symétrie dans les compartimens étoilés des euryales et des oursins. Pour les insectes, elle est parfaite : on la retrouve aussi dans beaucoup de mollusques, au moins dans leurs coquilles; mais principalement dans les crustacés du genre des crabes ou des écrevisses.

Mais c'est dans les animaux vertébrés que celte symétrie est portée à sa.plus grande perfection : leurs os, leurs nerfs, leurs sens, leur cerveau, lcurs muscles el leurs glandes, leurs ouies ou leurs 
poumons, tout y est par paires latérales, ou bien en nombre impair, et placé au milieu du corps. Il faut convenir, cependant, que tous les organes intérieurs n'ont pas la même régularité : on ne la voit ni pour les intestins, ni pour le foie, ni pour le cœur, etc. II faut dire aussi que quelques animaux font une exception manifeste à cette grande loi de symétrie : la plupart des mollusques ont les orifices digestifs et sexuels placés d'un côté du corps, ordinairement à droite; les poissons plats, nageant sur le côté, ont les deux yeux placés sur celle de leurs faces qui est tournée vers le ciel, et c'est encore presque toujours le côté droit. Enfin, chez les animaux le plus symétriquement organisés, il est avéré que l'un des côtés prédomine ordinairement sur l'autre côté, et cette moitié du corps la plus forte est presque toujours la droite. On le voit chez les crustacés, notamment chez les pagures ermites; on le voit même chez les gros oiseaux, dont les plumes du côté droit sont toujours les plus fortes et de la meilleure qualité. La même inégalité se retrouve chez les mammifères, et peutêtre chez aucun autre plus manifestement que chez l'homme, le moins ambidextre de tous les animaux.

\section{CHAPITRE VII.}

Il y a moins d'analogie entre les organes des corps vivans quientre les fonctions de ces organes.

Dans les quatre premières grandes lois que nous venons d'exposer, nous n'avons vu que des analogies 
CHAP. VII. ANALOGIE DES ETTLS VIVANS.

assez parfaites entre tous les corps vivans des deux règnes. Nous avons vu chez tous Unité et Perfection dans l'ensemble, Dépendance mutuelle de parties, et Symétrie dans les formes. Nous voyons aussi la plus grande Analogie dans les fonctions essentielles de ces êtres : analogie pour la reproduction, analogie pour la nutrition, pour la température propre à chacun, pour la nécessité que chacun d'eux éprouve d'être en contact immédiat avec un air renouvele, elc. Les résultats sont les mêmes pour tous; il n'y a que les moyens qui diffèrent. Ainsi tous ont besoin d'alimens pour se nourrir; mais les animaux sont les seuls qui reçoivent ces alimens dans. une cavité, et seuls ils les digèrent. Tous ígalement ont besoin d'air, tous l'absorbent et le respirent; mais rien n'est:plus. variable que les instrumens de la respiration dans tous les êtres. L'homme, les mammifères, les oiseaux et les reptiles respirent par des poumons; les poissons, les crustacés et les mollusques par des ouies ou branchies; les insectes par des trachées ou pertuis dont. leur surface est perforée; plusieurs vers et les polypes paraissent n'absorber l'air que par la peau dont est formée leur enveloppe. Les végétaux le respirent parleurs.feuilles, et mème plusieurs plantes étant privées de ces feuilles, il ne reste plus que leur écorce par qui la respiration de l'air puisse. avoir lieu.

J'en dirais autant de la reproduction, qui a le même terme chez tous, mais qui suit des voies extrêmement variées pour y tendre. Quelles différences ne voyonsnous pas entre les mammifères, dont les petits naissent viṿans et déjà parfaits, et la classe nombreuso. 
des ovipares! Quelles différences, enfin, entre tous ces animaux à sexe visible, et les polypes, qui n'ont ni sexes, ni véritables germes, et qui se reproduisent par des bourgeons; et les plantes, qui se reproduisent par des fleurs à sexes distincts, fleurs dont plusieurs même sont privées!

Nous retrouvons pour toutes les fonctions celte analogie dans le but, cette diversité dans les instrumens. Nous le voyons bien plus manifestement encore pour les fonctions particulières aux animaux. Tous paraissent sentir, et cependant plusieurs sont réduits à la peau seule pour unique organe du sentiment; le cerveau manque chez un très-grand nombre, et plusieurs n'offrent pas le moindre vestige de nerfs. Tous se meuvent spontanément, cela est notoire; et beaucoup n'ont aucun muscle visible. Nous ne finirions jamais si nous voulions montrer toutes les disparités que présentent les corps vivans entre leurs organes et leurs phénomènes.

Il vaut mieux nous attacher à montrer l'extrême analogie de certains êtres. Or cette analogie n'est nulle part aussi manifeste que dans les animaux qu'on nomme avec raison vertébrés. Tous ont une colonne osseuse, composée de vertèbres empilées. Cette colonne solide loge dans son canal une moelle épinière, et elle supporte, chez tous, une boîte osseuse qui renferme un cerveau. On trouve dans tous ces êtres un cœuì , du sang rouge, des poumons ou des ouies; dans tous, les organes plus ou moins parfaits des cinq sens, des nerfs, des muscles, un canal digestif plus ou moins compliqué, toujours un foic et un pancréas, toujours des orrganes génitaux manifestes. $\boldsymbol{A}$ la seule exception 
CIIAP. VII. ANALOGIE Des Etres vivans.

d'une espèce peut-ĉtre, tous ont la bouche dirigée horizontalement ; et lorsqu'ils ont des membres, ils n'en ont jamais plus de quatre. Ils ont la plus grande analogie pour la charpente et pour les fonctions. II est bien vrai que leurs surfaces varient prodigieusement selon leurs diverses destinations : leurs organes du mouvement diffèrent beaucoup selon qu'ils sont destinés à nager, à voler, à seulement marcher, etc. Les organes de la respiration ne'sont pas non plus les mêmes dans ceux qui vivent dans l'eau et dans ceux qui vivent dans l'air. Mais cela n'empêche pas la plus exacte ressemblance de régner dans l'ensemble : il n'y a que leur extérieur qui diffère. Si nous voulions comparer un quadrupède avec un poisson, le premier coup-d'œil n'embrassant que les surfaces de ces animaux, ne nous laisserait voir entre eux que des différences. Mais si nous prenions cháque organe un à un, nous verrions d'exacts équivalens dans les deux êtres; l'analogie serait constamment pour les choses essentielles, Ja différence pour les détails eî les accessoires. Le poisson, à la première vue, paraît n'avoir ni cou ni poitrine; mais en y regardant de plus près et plus profondément, on voit qu'il possède toutes les séries de vertèbres, et que les différentes pièces de sa poitrine sont venues se concentrer lout près du crâne, avec lequel elles se confondent. M. Geoffroy a fait de ce point curieux d'organisation une étude vraiment philosophique. Mais une différence bien essentielle qui sépare les animaux vertébrés - aériens d'avec les vertébrés - aquatiques, c'est que ces derniers ne respirant point d'air pur, sont privés et de la voix et des organes qui servent à la produire. 
L'analogie des animaux vertébrés est si exacte, que l'étude assidue qu'on en a faite a dans tous les temps porté préjudice à la connaissance complète du règne animal. On est presque toujours parti de ce qu'on voyait manifestement chez les vertétorés pour l'admettre dans tous les animaux. Toujours plein de l'idée de leur structure et de leurs fonctions, on n'a dès lors pu concevoir rien de vivant sans circulation, sans cœur, ni sang, ni vaisseaux; on a supposé des nerfs dans tout ce qu'on voyait sensible, des muscles partout où l'on voyait des mouvemens; Tournefort allait même jusqu’à admettre des muscles dans les plantes, et, qui plus est, jusqu’à les décrire. Mais de nos jours de pareilles erreurs ne sont plus à craindre. Encore que nous voyions la plus grande analogie dans les fonctions de tous les animaux, nous ne les regardons plus comme identiques pour la structure.

\section{CHAPITRE VIII.}

Divers degrés d'organisation. Complication graduelle des êtres.

Nous ne pouvons, dans ces prolégomènes, qu'esquisser rapidement les premiers principes de la science des êtres organisés; avant de sonder les profondeurs d'une pareille matière, il nous faut en explorer les surfaces. Il serait imprudent de marcher droit au cœur d'un pays inconnu, sans en avoir constaté la position, étudié les limites, évalué l'étendue. Nous nous attachons done d'abord à ces élémens. 
CHan. VIII. DIVERS DEgrés d'ORganisation

En parcourant la longue chaîne des corps organisés, nous les voyons se compliquer par degrés presque insensibles el sans disparates subits. Ies premiers. de ces êtres n'ont uniquement qu'une racine : les plus complexes ont un cerveau d'une organisation luimême fort compliquée. Si nous allons d'un extrême à l'autre, nous trouvons des plantes imparfaites, je veux dire d'une grande simplicité, qui ne sont composées, les unes, que d'une tige à parasol ajoutée à la racine, organe essentiel de tout végétal; les autres n'ont que des feuilles pour parties apparentes; d'autres que des fleurs pédiculées sans feuilles. Enfin nous trouvons des plantes composées à-la-fois d'une racine, de feuilles, d'une tige, de fleurs; et ces fleurs elles-mêmes présentent, ou seulement un ovaire, des étamines et des pistils, organes essentiels de la reproduction; ou, avec ces pistils, ces étamines et ces ovaires, des pétales et un calice plus ou moins compliqués.

Dans le règne animal, la complication des organes a des degrés beaucoup plus, nombreux : à l'estomac., que nous savons composer à lui seul les plus simples des animaux, nous voyons s'ajouter successivement des appendices, des tentacules mobiles, puis quelques vestiges de vaisseaux remplis. d'un fluide blanc, quelques.filets nerveux épars, quelques fibres musculeuses incolores, et dès-lors le canal digestif se complique; au lieu d'une ouverture, on lui en voit deux; l'intestin se contourne et s'allonge : ensuite on trouve des espèces de poumons, des trachées, des branchies, des muscles compliqués, occupés à mouvoir des pièces de plus en plus neltement séparées; 
LIV. I. DES CORTS VIVANS RN GÉNÉRAL.

puis un ou plusieurs cœurs imparfaits, des sens évidens, des organes de la génération compliqués, des nerfs noucux, une moelle renflée à son extrémité; et enfin un squelette vertébré, des sens parfaits, du sang rouge, un cœur unique, une moelle épinière renfermée dans un étui osseux, un crâne, un cerveau. Du réste, cette chaîne progressive est fort difficile à suivre dans les animaux inférieurs, depuis les vers jusqu'aux vertébrés, pour la raison que les organes de la nutrition et les organes du sentiment ont des progrès de complication qui discordent en plusieurs endroits de la chaîne. Les organes des sens et ceux des mouvemens sont déjà arrivés à une grande complication chez des êtres qui n'ont encore ni cour, ni circulation évidente, ni respiration notable. Ou bien, chez d'autres êtres, le cœur est déjà manifeste, les vaisseatx déjà évidens, les organes respiratoires déjà compliqués, sans 'qu'on voie les organes des sens et du mouvement faire parallilement des progrès. Ceci même est une grande objection à opposer aux faiseurs de chaînes universelles.

\section{CHAPITRE IX.}

Chaîne universelle des êtres.

Si nous voulions établir une chaîne universelle des êlres qui composeni le globe que nous habitons, nous n'aurions qu'à douer, par la penséc, la roche des montagues ou le métal des filons de la facullé de 
se nourrir et de s'accroitre : nous aurions alors un être semblable au végétal, lequel possède deux ordres de fonclions, les unes essentielles à la conservalion de l'individu, les autres indispensables à la perpétuité de l'espèce. A ces deux ordres subordonnés, et néanmoins bien distincts, ajoutons la propriété de se mouvoir spontanément et la propriété de sentir, ajoutons aussi une cavité centrale qui dirige les alimens; et nous verrons naître un animal des plus simples qu'on puisse observer. A cette masse mobile, sensible et digérante, joignons des nerfs nombreux et de toutes parts enchaînés, des sens spéciaux d'une structure complexe, un cerveau central, servant d'instrument à la perception et au vouloir; ajoutons-y des muscles pour obëir, un squelette que l'action de ces muscles puisse déplacer, et nous verrons paraître les animaux de l'ordre le plus élevé, de la structure la plus compliquée. Au sommet de cette série d'êtres supérieurs, on trouve l'homme, être remarquable par la situation verticale de son corps, par le volume de son cerveau, par l'accord parfait de ses sens, par sa prudence, sa curiosité et sa sagesse, par la puissance de sa volonté, par les lumières de sa raison et la sublimité de son génie.

Plusieurs philosophes, mais surtout Donati et Ch. Bonnet, avaient eu l'ingénieuse pensée de subordonner les corps de la nature les uns aux autres, d'après l'analogie progressive qu'ils offriraient à l'observateur. Ils voulaient que l'on passât par degrés d'une production à une autre production voisine, àpeu-près comme dans le spectre solaire on passe presque insensiblement de nuance en nuance, du 
violet au bleu, du bleu à l'indigo, de celui-ci au vert, au jaune, à l'orangé, et enfin au rouge, et du rouge, par un nouveau cercle, au violet, etc. Les savans que je viens de nommer pensaient donc que tous les corps de la nature forment une longue chaîne sans interruption; et voici comment Bonnet concevait cette chaîne naturelle.

Il croyait voir dans les talcs, dans les ardoises, dans les schistes, mais surtout dans l'amyanthe, un passage assez direct des minéraux vers les végétaux. La sensitive ensuite, ainsi que plusieurs algues et plusieurs fucus, forment (toujours d'après l'illustre Charles Bonnet) un lien fort naturel entre les plantes et les animaux les plus simples. Après cela mille différentes nuances spécifiques s'observent dans le règne animal et ses nombreux embranchemens : si quelques espèces de simples polypes forment le moyen d'union des deux règnes de corps organisés, elles servent en même temps d'intermédiaires entre les animaux infusoires, les orties de mer et les méduses; puis ces derniers animaux conduisent aux vers et aux mollusques d'un côté, aux insectes, aux arachnides et aux crustacés d'un autre côté et pour d'autres motifs. Ensuite, les vers aquatiques s'unissent aux mollusques par les sangsues, et les mollusques aux reptiles par les limaces. Les reptiles, à leur tour, tiennent aux poissons par les tétards des grenouilles, comme lés insectes, par une autre division, liennent successivement aux vers, aux mollusques et aux reptiles par leurs larves et leurs chenilles. Les serpens d'eau ressemblent beaucoup aux anguilles; les poissons s'unissent à la classe des oiseaux par les poissons volans, 
CIIAP. 1X. CHAINE UNIVERSELLE DES ÊTRES.

les trygles et les exocœts; les oiseaux tiennent aux mammifères par-les ornithorynques dans un sens, et par les chauve-souris et les écureuils volans dans un autre sens.

Bonnet admet encore beaucoup d'autres analogies : ainsi les oiseaux palmipèdes, selon lui, conduisent aux poissons, comme les manchots et les autruches conduisent aux mammifères. On va des mammifères aux poissons par les loutres et les baleines; des mammifères aux reptiles par les phoques, aux oiseaux par les chauve-souris et les échidnés, à l'homme par les singes, et à la divinité par l'homme. Toutefois le sage Bonnet ajoute avec son éloquence ordinaire : a Un - seul être est placé hors de la chaîne, et c'est celuí "qui l'a créée."

Je me serais bien gardé d'insister ainsi sur une idée toute systématique, si je n'étois persuadé que ces analogies et ces comparaisons même grossières, sont d'une grânde utilité pour donner une première idée des êtres vivans aux personnes qui ignorent la zoologie. Rien n'attache comme les rapprochemens. Mais nous devons dire que cette chaine universelle des êtres est loin d'être aussi parfaite que Bonnet et ses partisans ont paru le penser. Dans plusieurs endroits cette chaîne semble se ramifier et perdre ainsi de son unité. Elle présente, en outre, des lacunes trop évidentes pour rester inaperçues. Il existe un vide immense entre les mollusques, les insectes et les poissons: si l'on place les mollusques avant les insectes, il n'y a pas moyen de passer brusquement d'une mouche à une anguille; et si l'on place les mollusques après les insectes, voyez quel choquant disparate il y aura entre 
une huître, par exemple, et une carpe ou tout autre poisson. Nous devons donc absolument renoncer à cette chaine de Bonnet comme moyen de classer les êtres vivans, et nous borner, afin de soulager la mémoire, à diviser ces êtres par groupes ou familles d'espèces analogues; mais une pareille classification a des règles que nous devons dire.

\section{CHAPITRE X.}

Loi de subordination et de coexistence. Comment on pent juger dc tout un être organisé par nne de ses parties.

Dans tout corps organisé une fonction suppose unc autre fonction, comme certains organes supposent d'autres organes. Toul être qui se meut sous l'impression d'un irritant doit être sensible; le mouvement suppose donc du sentiment. La vie est temporaire de sa nature; par conséquent, elle suppose la reproduction des individus ou l'extinction des espèces. Également, la circulation suppose une sorte de respiration; il $\mathrm{y}$ a donc des espèces de poumons partout où l'on voil un cœur, comme il y a des nerfs où l'on voit des muscles. Enfin, la vie apparente n'est qu'un enchaînement de phénomènes produits par des organes entre eux coordonnés. La chose importante serait de saisir la coexistence et la hiérarchie des instrumens de la vie dans leurs combinaisons diverses. L'étude réfléchie des fonctions donne une partie de ces connaissances; mais il est des rapports qu'il eût 
CHAP. $x$. LOI DE SUBORDINAT. ET DE COLXIST. 33 été impossible de prévoir avant de les avoir une première fois constatés. Voici, par exemple, des coexistences que la réflexion seule n'aurait pu nous faire deviner.

On a vu que toutes les plantes dont l'embryon est pourvu d'un ou de plusieurs cotylédons, ou espèces de fenilles séminales, étaient composées de tissu cellulaire et de vaisseaux; tandis que les plantes dont l'embryon n'a pas de cotylédons sont composées seulement de tissu cellulaire sans vaisseaux appréciables. On s'est en outre assuré (et ceci est une des plus jolies découvertes modernes ) que les végétaux dont l'embryon a plusieurs cotylédons opposés l'un à l'autre ont les vaisseaux disposés par couches excentriques, et que les plus jeunes et les plus molles de ces couches sont placées à l'extérieur. On a ensuite examiné celles des plantes dont l'embryon est pourvu ou d'un seul cotylédon, ou de plusicurs cotylédons alternes et non pas opposés, et l'on a vu que leur organisation était absolument inverse de ce qu'on voit dans les autres; je veux dire que leurs vaisseaux, au lieu d'être disposés par couches, le sont par faisceaux, et que les derniers formés de ces faisceaux sont dirigés vers le centre de la plante, au lieu de l'être vers sa surface, comme dans les précédentes. Or, comme ces rapports sont d'une grande constance et qu'ils ont Irait à des parties essentieiles, on concoit qu'il suffit de connaître un seul des caractères dont nous venons de parler pour deviner ceux qui lui sont toujours co-existans. Voilà même pourquoi la présence et l'arrangement des cotylédons sont devenus la base d'une classification des plantes quon s'est efforeć de rendre natuI. 
relle en l'établissant d'après la considération des organes les plus importans, et toujours selon les lois des coexistences organiques. On a fondé les divisions secondaires d'après la disposition des fleurs, et l'on s'est appliqué à mesurer l'importance comparée des organes qui les constituent, leur constance ou leurs variations, et leurs rapports entre elles ou avec d'autres parties des végétaux qui les produisent. On s'est d'abord assuré que certaines plantes sont Cryptogames, c'est-à-dire sans fructification connue, et la plupart de ces plantes sans fleurs visibles sont celles dont nous avons vu l'embryon manquer de cotylédons : de sorte que cryptogames et acotylédones sont deux mots presque synonymes. On a ensuite découvert que le nombre des étamines répondait presque toujours aux divisions du calice ou de la corolle; qu'il était en général, ou exactement semblable, ou multiple de l'autre; et que le nombre des divisions des stygmates était semblable aux compartimens de l'ovaire, etc. On a aussi découvert des rapports entre la forme de la fleur et la configuration d'autres parties des plantes : on a vu, par exemple, que des fleurs configurées en papillon répondaient à des fruits en gousses; que des fleurs labiées étaient supportées par des tiges ordinairement quadrangulaires et dont les feuilles étaient opposées; que la plupart des fleurs en rose avaient des fruits charnus; que les fleurs en épis écailleux avaient des tiges noueuses et engaînées, etc.

Parmi les animaux, on a constaté que les uns avaient des vertèbres, et que d'autres en étaient dépourvus; voilà un premier fait. On a vu ensuite que ceux qui sont Vertóbrés ont tous une moelle épinière et un 
CHAD. X. IOI DE SUBORDINAT. ET DE COEXIST.

cerveau compliqué ; tous, quatre organes des sens plus ou moins parfaits à la tête, et des mâchoires horizontales; jamais plus de quatre membres, quand ils en ont, et toujours du sang rouge. On a examiné par comparaison les Animaux sans Vertèbres, et l'on s'est assuré qu'aucun n'a ni un cerveau, ni une moelle épinière, ni des sens aussi manifestes; qu'aucun n'a de sang d'un rouge aussi vif; et que tous ont plus de quatre membres quand ils en ont.

En examinant comment les vertébrés se reproduisent, on a vu que la plupart d'entre eux sont ovipares, tandis que d'autres font des petits vivans. On s'est ensuite assuré que ces derniers ont seuls des mamelles pour allaiter leurs petits, et on les a nommés Mammifères. On a aussi observé que les organes génitaux des mammifères ont un orifice séparé de l'issue des intestins, tandis que les ovipares ont un cloaque, ou issue commune pour l'intestin et pour les organes génitaux.

On concoit comment ces premières coexistences ont fourni les bases d'une classification des animaux. Il a suffi de voir un animal pourvu d'une colonne de vertèbres osseuses, pour être assuré que cet animal appartenait ou aux Mammifères, ou à l'une des trois classes d'Ovipares; et voilà ensuite comment on a distingué les trois classes d'ovipares entre elles : on a nommé Oiseau, tout animal vertébré et ovipare ayant des plumes et des poumons; Reptile, tout vertébré ovipare pourvu de poumons, mais sans plumes; et Poisson, tout vertébré ovipare pourvu de branchies, sans véritables poumons. Et comme en scrulant plus avant dans la structure, on a trouvé d'autrés diffé- 
rences constamment coexistantes avec les différences essentielles, il en est résulté qu'on a pu assigner précisément le rang d'un animal d'après la plus simple parcelle de quelques-uns de ses organes; on a même été jusqu’à découvrir des rapports entre ces diversités de structure des animaux et leurs principales habitudes ou leurs instincts. On a vu que les animaux carnassiers, par exemple, avaient le canal digestif plus simple, plus court, moins puissant, et conséquemment le corps plus grêle; qu'au contraire, ils avaient les mâchoires, ou les parties analogues aux mâchoires, plus fortes, mieux armées, mues par des muscles plus énergiques. Les oiseaux de proie ont les ongles des pattes plus déchirans, le bec plus fort et plus crochu. Les lions et tous les chats ont pareillement des griffes redoutables et rétractiles, des dents tranchantes et alternatives, une mâchoirc solidement articulée et nue par des muscles puissans. Ces premiers changemens rejaillissent ensuite sur toute la structure; de sorte qu'on peut, d'après la saillie d'une dent de mammifère carnassier, ou d'après le condyle de sa mâchoire, décrire tout le reste de sa charpente et faire l'histoire de ses habitudes. Pareillement, on peut juger de la force du vol d'un oiseau par la configuration du sternum, auquel se fixent les muscles de ses aîles. On peut affirmer que l'animal au bassin duquel on trouve deux petits os dits marsupiaux, on peut assurer, dis-je, que cet animal a une matrice dépourvue de col, que sa glotte est imparfaite, que ses petits avortent, qu'une poche placée sous le ventre de la femelle les reçoit et les protège. Enfin on sait que les animaux ruminans ont 
CIIAP. X. LOI DE SUBORDINAT. ET DE COEXIST.

tous le pied fourchu, que tous ont quatre estomacs, qu'ils n'ont pas de dents incisives à la mâchoire supévieure, et que ceux d'entr'eux qui portent des bois ou. des cornes au front n'ont pas de dents canines à la mâchoire d'en haut. L'histoire des corps organisés offre beaucoup d'autres faits analogues qui trouveront place dans d'autres endroits de cet ouvrage.

Mais il faut remarquer que tous les organes concordent dans. chaque être vivant : jamais la nature ne réunit dans une espèce les parties contrastantes de plusieurs ( 1 ); On ne voit jamais: s'associer des dents et des mâchoires de carnassiers avee des pieds d'herbivores. Yoilà ce qu'ont ignoré les peintres, poètes et statuaires qui dans des temps antérieurs ont voulu représenter des êtres singuliers dont: leur imagination ou leurs croyances. leur suggéraient les trompeuses images. Tantôt ce sont des âles immenses qu'àucun muscle ne saurait mouvoir ; tantôt les têtes unies de plusieurs animaux d'espèces différentes, associées à un corps et à des membres qui conviennent au plus à l'une d'elles. Or la nature n'offre en aucune créature les traits discordans des anges ou du cerbère de nos arlistes et de nos poètes. Aucune pièce dans ses admirables machines n'est en désaccord avec l'ensemble:l'harmonie est le caractère de toutes ses œuvres.

Malbeureusement l'importance et la subordination. des organes n'est pas aussi bien connue pour les animaux inférieurs que pour les vertébrés; aussi. les divisions qu'on en a faites ne sont-elles ni très naturelles ni parfaitement stables. Sur quelque principe

(1) Voyez G. Cuvier : Ossemens fossiles. 
qu'on se fonde, les quatre divisions des vertébrés sont les mêmes pour tous les savans; mais la division des invertébrés diffère pour chaque zoologiste.

\section{CHAPITRE XI.}

Quels sont les plus importans des organes? Premières bases de classification des êtres vivans.

Lorsqu'on envisage l'ensemble du règne animal, et qu'on voit dans beaucoup d'êtres l'estomac isolé de tout autre organe, sans nerfs visibles, sans muscles, sans vaisseaux, sans cœur, sans cerveau ni sens, on est porté à le considérer comme la partie la plus essentielle. Si les organes les plus variables sont réputés les moins importans, il faut bien regarder les nerfs et les muscles, le cœur, les poumons et le cerveau comme des parties subalternes. Il est impossible, en effet, que l'inconstance d'un organe aille plus loin qu'être ou n'être pas.

Mais dans un animal complexe, pourvu de tous les organes que nous venons d'énumérer, l'étude de ses développemens successifs enseigne que le cœur est, sinon le premier formé des organes, du moins le premier visible et celui dont l'action est d'abord évidente. Lorsqu'on étudie des êtres monstrueux, on voit le cceur se passer des autres organes beaucoup mieux que les autres organes ne peuvent se passer de lui. Lorsqu'enfin l'on envisage l'aniunal venu au jour et déjà accru, on voit des organes, le cerveau et 
CHAP. XI. PRÉEMINEACE DES ORGANES.

la plupart des muscles, suspendre périodiquement leurs fonctions; on voit les poumons eux-mêmes momentanément cesser d'agir, tandis que le cœur ne discontinue jamais de palpiter tanı que la vie subsiste: pour tous ces motifs, le cœur paraitrait donc le plus important des organes dans les animaux les plus complexes.

Il faut avouer que dans un animal vertébré, sain, accru, d'une structure parfaite et dont chaque organe remplit exactement ses fonctions, il faut convenir que, dans un pareil être, il est difficile de préciser lequel des cinq organes principaux est le plus essentiel. Il est en effet avéré que si l'en`emble des organes suppose l'action de l'estomac, qui les nourrit; que si les poumons et les branchies ont besoin du cerveau, le cerveau à son tour á besoin de l'action du cœur, comme ce cœur lui-même ne peut se passer ni de l'action des poumons que le cerveau gouverne, ni de l'accession de la moelle épinière. C'est une chaîne de toutes parts adhérente. Il est vrai que si nous examinons un des organes subalternes en particulier, cet organe nous semble avoir besoin de sang plus que de nerfs, et pouvoir se passer plus long-temps de l'action du cerveau que de celle du cœur. Mais pour les rouages essenticls à la vie, l'enchaînement est réciproque et plusieurs fois compliqué. Si pourtant nous remarquons que le cœur a commencé d'agir avant l'estomac et les poumons; qu'il continue de battre en l'absence ou après la cessation de la respiration; que de profondes altérations du cerveau ne produisent pas toujour's une mort instantanée, tandis que la destruction de la moelle épinière fait promptement cesser 
et l'action du cour et la vie; nous aurons d'assez puissans motifs pour penser que la circulation du sang est la première condition de l'existence d'un animal complexe; nous regarderons le cœur, en conséquence, comme la pièce essentielle d'une pareille organisation; et puisque c'est la moelle épinière qui paraît fournir au cœur le principe de ses mouvemens, nous la regarderons comme l'organe le plus essentiel du corps; et comme nous verrons que la base de tout squelette osseux est une colonne de vertèbres destinée à envelopper cette moelle épinière, la considération de ces vertèbres sera pour nous le point de départ de toute bonne classification des animaux.

Voici donc quelles sont les bases de notre classification, établie d'après l’importance comparée des organes, d'après leur constance et d'après les lois de leur subordination.

Une Racine représente à nos yeux tout le Règne Végétal, comme un Estomac tout le Règne Animal. Mais comme ces parties peuvent exister isolées de tout autre organe, nous devons avoir recours à d'autres parties pour établir les divisions secondaires des deux règnes.

Pour les végétaux, nous prenons d'abord la graine, qui suppose des fleurs; puis les cotylédons, dont le nombre, la position ou l'absence entraine avec soi de notables différences dans l'organisation de la tige; ensuite nous examinons la fleur, ses étamines, ses pistils, son ovaire, etc.

Pour les animaux, nous avons à examiner s'ils sont vertébrés, et, dans ce cas, s'ils sont vivipares ou ovipares, c'est-à-dire s'ils ont des mamelles ou s'ils en 
CHAP. Xi. PRÉlimence des orfanes.

manquent; s'ils sont aériens ou aquatiques, je veux dire sils respirent par des poumons ou par des branchies; enfin s'ils sont ou non carnivores, s'ils volent, s'i!s marchent, s'ils nagent ou s'ils rampent, etc. Cela nous conduit de degrés en degrés des premières grandes divisions jusqu'aux groupes plus circonscrits de genres et d'espèces. Si, au contraire, ils sont sans vertèbres, nous examinons quelle est la forme de leur corps, quels sont leurs mouvemens, s’ils respirent par des branchies, par des trachées, ou seulement par la peau; s'ils ont un ou plusieurs cœurs, ou s'ils en manquent; s'ils sont pourvus d'aîles, de pattes, d'antennes, de tentacules, recouverts de tesis, de coquilles ou d'élytres; s'ils ont des nerfs et une espèce de moelle noueuse, un cerveau imparfait, des intestins plus ou moins compliqués, des métamorphoses, etc.

Nous aurons de cette sorte trois divisions principales pour les plantes :

I. Les Acotylédones.

II. Les Monocotylédones.

III. Les Dicotylédonés.

et six grandes divisions pour les animaux :

I. Les Infusoires ou Microscopiques?

II. Les Polypes.

III. Les Vers et les Radinires.

IV. Les Mollusques.

V. Les Articulés (comprenant les crustacés, les insectes et les arachnides).

VI. Les Vertébrés (mammiféres, oiseaux, reptiles et poissons).

Cespremières divisions des corps vivans doivent nous 
suffire pour le moment. Nous verrons dans la suite de cet ouvrage le détail de leurs caractères et les bases de lcurs subdivisions, à propos des organes et des fonctions qui fournissent ces caractères.

Nous faisons reposer les divisions secondaires des plantes sur la considération de leurs fleurs, sur le nombre, la position respective, l'isolement ou les adhérences de leurs étarnines et de leurs pistils, sur la réunion de ces organes sexuels dans les mêmes fleurs ou les mêmes plantes, ou leur séparation sur plusieurs, etc., etc. Quant aux subdivisions des animaux, elles sont fondées tantôt sur la forme des mâchoires et des membres, tantôt sur la forme du corps, la nature de ses tégumens, et sur mille détails de strúcture qui ne peuvent être ni sagement exposés, ni suffisamment compris au point où nous suusmes de cet ouvrage. Toute bonne division des objets supposant la parfaite connaissance de leur nature, la classificatioil des êtres vivans sera mieux placée dans nos corollaires que dans cette introduction préliminaire.

Une remarque à faire au sujet des nomenclatures naturelles, c’est la nécessité où se sont trouvés les savans de différencier par des détails excessivement minutieux une infinité d'êtres souvent très-analogues. entre eux par l'ensemble (1). A la vérité, il est résulté de là une parfaite connaissance de la structure de chaque être : les différences les moins appréciables ont été remarquées avec un soin extrême; mais les analogies, les équivalens, les coexistences d'organi-

(1) Voyez Ch. Bonnet et Geeffroy.Saint-Hilaire. 
CIAP. XI. PRĹÉMINENCE DES ORGANes.

sation sont restées inconnucs. Tandis que l'anatomie faisait de grands progrès, la physiologie comparée est demeurée telle à-peu-près que nous la trouvons dans les immortels ouvrages d'Aristote, sans accroissement, sans lumières nouvelles. A force de distinguer toutes choses jusqu'à des degrés presque infinis, les généralités qui font les sciences ont été presque entièrement négligées. Excepté trois ou quatre naturalistes dont les ouvrages font la gloire des sciences modernes, la plupart de ceux qui se sont occupés de l'histoire de la nature en ont fait une science remplie de puérilités. Encore que les médecins aient presque toujours borné leurs études à l'homme; encore que ces études aient été de leur part souvent trop peu réfléchies, par trop de causes interrompues, et souvent détournées d'un but sage par de vulgaires intérêts; il faut pourtant convenir que c'est presque exclusivement dans leurs ouvrages qu'on trouve le germe ou les développeinens du petit nombre de grandes vérités que la science de la vie possède. Pourquoi faut-il qu'elles s'y trouvent mêlées à tant de systèmes et à tant d'erreurs ! 


\section{LIVRE SEGOND.}

\section{De la Reproduction des Êtres Vivans.}

\section{CHAPITRE PREMIER.}

Données incertaines sur la première origine des Animaux el des Planles.

La première origine des êtres vivans est un objet de croyance bien plus que de démonstration. On a fait beaucoup de systèmes sur cette matière sans la rendre plus claire et plus compréhensible. La version. la plus probable, à ne la considérer même que par des motifs humains, est encore celle de Moise. Si l'on prend les six jours de la Genèse pour des siècles, les récits de l'historien sacré paraissent d'une grande vraisemblance : les recherches des savans modernes. en vérifient chaque jour l'exactitude. En fouillant dans les entrailles de la terre, on trouve des débris d'êtres. organisés d'autant plus simples qu'on pénètre plus profondément : lesincrustations de fougères et d'animaux radiaires se trouvent dans les terrains les plus anciens; après cela viennenit des plantes plus élevées, des animaux plus complexes, des coquilles, des crustacés, des poissons et des reptiles; enfin, les ossemens fossiles de quadrupèdes et d'oiseaux ne se retrouvent que dans des couches récentes, et plus on approche de la surface, plus les êtres dont on voit 
CHAP. II. DE LA REPRODUCTION DES ÊtRES VIVANS. 45 les dépouilles pétrifiées sont semblables aux animaux et aux plantes qui existent encore sous nos yeux.

De ces faits bien avérés sont nés des systèmes bizarres. On a dit que toute la terre étant primitivement à l'état fluide, les élémens des roches cristallines se précipitèrent et s'agglomérèrent d'abord pour former le noyau du globe; qu'ensuite, dans le fluide baignant toujours sa surface, se développèrent des animalcules, des polypes, des mollusques, des poissons, etc., et que les dépouilles de ces différens êtres, nés les uns des autres, donnèrent lieu aux terrains calcaires. On a ajouté que sur les premiers rochers mis à découvert, se développèrent les premières mousses, les plus simples végétaux, et que de leurs débris vinrent les couches d'argile et de silex dont le globe terrestre est en partie forıné. Demaillet et M. de Lamarck ont surtout insisté sur cette proposition, que tous les êtres sont nés des liquides dont notre planète fut primitivement composée ou seulement recouverte, et qu'ensuite les différens corps vivans sont venus les uns des autres en se compliquant par degrés. Avec de pareilles idées, tout s'explique, la création successive des êtres aussi bien que la possibilité d'un déluge universel. Admettez, en eflet, que la surface de la terre, déjà habitée, vienne à se recouvrir d'eau dans tous ses points, la difficulté n'a plus rien d'insurmontable, puisqu'il reste encore la plus grande partie des êtres vivans. Outre les graines des plantes et les germes de beaucoup d'animaux que l'eau ne peut détruire, tous les animaux aquatiques, les infusoires, les coraux, les radiaires, les vers et les mollusques, les crustacés, les poissons et les oi- 
seaux nageurs, beaucoup de reptiles et les cétacés, continuent de vivre pendant ce cataclysme général; les animaux aériens et terrestres sont les seuls dont la destruction soit inévitable; mạis comme, suivant nos auteurs, les animaux se reproduisent les uns des autres, vous voyez qu'il n'existe aucun embarras pour la reproduction des êtres détruits, puisque l'homme même, selon ces hypothèses, aurait commencé par être poisson.

Nous l'avons dit, tout absurdes qu'ils paraissent, ces systèmes reposent sur des faits certains, mais non probans (1) : il est sûr que les corps pétriliés les plus simples occupent les terrains de la plus ancienne formation; les quadrupèdes et les oiseaux ne se trouvent que dans les couches les plus modernes, et l'on n'a encore trouvé en aucun lieu de débris fossiles de l'homme. Cela permet de penser qu'il fut le dernier formé des êtres, et cela même confirme les traditions de la Genèse et rend vraisemblables les systèmes dont nous venons d'esquisser les principales idées.

Mais c'est assez d'étudier comment se reproduisent les êtres actucllement existans, sans nous violenter en vain l'esprit pour dévoiler leur création première. Nous rechercherons plus loin par combien de causes physiques encore subsistantes les premiers êtres vivans ont pu être modifiés, et si les espèces connues aujourd'hui sont les mêmes, sont les seules qui vécurent autrefois et dont on retrouve en beaucoup de lieux les débris fossiles.

(1) Voyez Telliamed (anagramme de Demaillet), Werner, G. Cuvicr, d'Aubuisson de Voisins, Brongniart, et le I'cntateuque. 


\section{CHAPITRE II.}

Idée de la Reproduction des Êtres vivans.

Il serait imprudent, il serait difficile de donner des règles générales sur une fonction qui offre presque autant de différences qu'il y a au monde d'espèces d'êtres vivans; qui varie dans chacune pour les instrumens qu'elle emploie, pour les voies qu'elle suit, pour le mode et la durée de ses phénomènes, et qui enfin n'a rien de général, si ce n'est son but, lequel consiste à perpétuer les espèces et à réparer sans relâche les continuelles destructions dues à la mort. Le caractère le plus universel de cette fonction est d'appartenir à tout ce qui existe; tout être vivant se régénère. La vie étant de sa nature temporaire, la rénovation perpétuelle des espèces était indispensable. Aussi Dieu, lorsqu'il eut achevé le monde, commandat-il à toutes les créatures sorties de ses mains de crôttre et de multiplier. Il ne dit pas : sentez et agissez, car il voulait une obéissance universelle.

Ainsi la vie semble n'être que pour se communiquer : elle n'est jamais plus active qu'à l'époque de l'amour et de la reproduction, qui est son but comme son principe. Elle commence à s'affaiblir aussitôt que le grand acte de la rénovation des individus est achevé : on voit des animaux qui vieillissent et meurent dès le momeat où ils viennent de se reproduire, comne on voit des fleurs se faner et se fétrir bientôt 


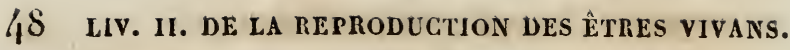

après la cérémonie nuptiale (1). Le mouvement perpétuel n'existe donc nulle part hors des grands corps planétaires; pas plus dans les machines vivantes que dansles mécaniques ingénieuses que l'homme a savamment combinées; même plus le mouvement est rapide, plus vite il est communiqué, et plus tôt il se perd. C'est ainsi que l'ordre général est constamment maintenu dans la nature : l'énergie de la vie conduit à la transmettre, et la reproduction est un acheminement vers la mort. Voilà comme la destruction est une conséquence de la perpétuité qúelle rend nécessaire.

Nous comprenons bien le but de la génération sous quelque aspect qu'elle se présente, mais nous répétons qu'on ne peut énoncer rien d'absolu, rien de général sur les procédés selon lesquels se font ses opérations. Nous ne pouvons pas dire que cette fonction exige toujours le concours des sexes, car, outre les plantes cryptogames et quelques vers intestinaux, où ce concours est fort douteux, et dans lesquels même l'existence des organes sexuels est loin d'être prouvée, nous savons que les polypes se reproduisent sans ces organes et sans ce concours. La plupart des corps organisés naissent d'une espèce d'œuf qui éclot en-dehors ou au-dedans de l'être d'où il provient; mais on ne voit d'œuf's ni pour les cryptogames ni pour certains vers, et l'on est sûr que les polypes n'ont, aa lieu d'œufs, que des bourgeons et des espèces de gremmes. Presque tous les corps vivans ont un fluide pour élément; mais encore ici la chose n'est pas gé-

(1) Expression de Linné. Voyez sa dissertation intitulée : Sponsalia plantarum, dans les Amenitates academice. 
CHAP. III. GÉNÉRATION SPONTANÉE.

nérale : il est des animaux qui se reproduisent par des fragmens solides détachés ou déchirés du corps principal. Enfin il est bien vrai que la plupart des êtres vivans proviennent d'êtres semblables à eux ; mais cette parenté n'est pas incontestable pour tous; et cela même nous conduit à examiner s'il y a des êtres dont la production soit spontanée.

\section{CHAPITRE III.}

Existe-t-il des êtres organisés dont la production soit spontanée?

Parmi les savans qui ont soutenu la génération spontanée des êtres vivans, les uns l'ont fait par système, et ceux-là se sont beaucoup moins occupés des preuves avérées de leur opinion que de ses conséquences finales; les autres, adoptant cette doctrine sans arrière-pensée , sans parti pris d'avance, sans calcul délibéré, ont minutieusement examiné les faits les plus propres à l'établir. Or voici de quelles données ils se sont autorisés.

D'abord il est des plantes cryptogames dont le développement est si subit, qu'on ne peut assister à ses progrès, et dont les organes sexuels et les moyens de reproduction sont si cachés, qu'on ne saurait les découvrir dans un grand nombre : c'est donc spontanément qu'elles naissenı! Mais voici une réponse à de pareils argumens. Peu-à-peu on découvre des organes sexuels dans des végétaux qu'on en avait crus absolument privés : si beaucoup d'entre cux semblent encore I. 
50 LIV. II. DE LA REPRODUCTION DES EtTRES VIVANS. dépourvus de cet ordre d'organes, au moins trouve-t-on des espèces de graines dans la plupart (1). D'ailleurs, comme il naît en divers lieux et chaque année de ces végétaux analogues entre eux, et pareils à ceux qui les ont précédés, cet air de ressemblance et de famille suppose une succession d'espèces; ces espèces démontrent une origine commune par des germes identiques: or, que ces germes proviennent d'associations d'organes sexuels ou qu'ils naissent sans cela, assurément les générations d'êtres analogues que ces germes perpétuent ne sauraient être réputées spontanées.

Autre fait. On a vu naître d'innombrables animalcules microscopiques dans les infusions des corps organisés; on les a vus remuer à la manière des animaux; on les a ensuite étudiés sous tous les aspects et dans les circonstances les plus variées : et, comme on les trouvait tous à-peu-près de la même grosseur et qu'avant de les découvrir dans les infusions on n'avait pu voir dans les corps employés à ces expériences ni œufs, ni germes, ni aucun vestige d'animaux pareils, on en a conclu qu'ils s'y étaient formés de toute pièce et d'une manière apparemment spontanée. Or, a-t-on dit, ce que font ces animaux informes, pourquoi des êtres plus élcvés ne le feraientils pas également? On a alors cherché dans les liqueurs séminales des grands animaux; on a eu soin de se servir du microscope comme on l'avait fait pour étudier les infusoires, et l'on a découvert dans ces fluides des animalcules d'un autre genre, mais pourtant analogues aux 'précédens. Alors les imaginations se

(1) Voyez le bel ouvrage d'Hedwig : Historia muscorum. 
CIIAP. III. GÉNÉRATION SPONTANÉv.

sont échauflées : on n'a plus dès-lors mis en doule ni la formation spontanée de ces petits corps réputés vivans, ni la propriété qu'ils ont de s'accroître, de se transformer, et de composer de plus grands animaux. L'observateur anglais dont Buffon se servit dans ses recherches microscopiques, le subtil Needham, était convaincu que tout provenait de ces animalcules; qu'ils produisaient tantôt des plantes et tantôt des animaux : il alla même jusqu'à assurer qu'on avait vu des plantes se changer en animaux et des animaux redevenir plantes; et par cette puissance qu'il nommait végétative, il expliquait comment les premiers animalcules, en se transformant, avaient pu former le premier homme, et comment ensuite Eve, la première femme, avait pu provenir d'une des parties d'Adam. Et pourquoi tous ces systèmes? parce que beaucoup de liquides semblent donner naissance à des animalcules, et que certains organes sćparés de certains êtres les reproduisent ensuite dans leur totalité. Mais laissons-là ces chimères, et raisonnons.

Est-il vrai que les petits corps infusoires soient des animaux? (1) Est-il vrai qu'ils se meuvent, et le mouvement de corpuscules aussi ténus les doit-il faire supposer doués de la vie? Enfin, en admeltant que ces êtres soient animés, leur production est-elle réellement spontanée?

On a dit que les infusoires étaient des animaux, et pour quelle raison? parce qu'on les voit se mouvoir au microscope. Mais voici ce qu'il faut remarquer :

(1) Voyez les ouvrages de Leeuwenhocck, de Needham, de Hartsocker, de Spallanzani, de O. F. Müller, de M. Bory Saint-Vincent, de M. Vaucher, etc. 
52 IIP. II. DE TA REPRODECTION DES ETRES VIVANS.

$1^{\circ}$. ces corps sonl si potits quau dire de Leeuwenhoeck; le premier qui les ait observés, il en faudrait plus de cinquante milliers pour égaler le grain de sable le plus. fin. $2^{\circ}$. Ces petits corps se rencontrent surtout dans les infusions des corps organisés; or, les liquides où l'on a fait macérer des débris de plantes ou d'animaux se chargent nécessairement de leurs molécules; et comme elles sont très-divisées, très-légères, elles y restent suspendues. $3^{\circ}$. On trouve aussi ces animalcules dans les liqueurs animales; mais songez à la nature, à la source de ces humeurs : le sang vient du chyle, le chyle des alimens, et toutes les humeurs, c'est ensuite le sang qui les fournit. Outre ce que le sang doit aux alimens, il est encore composé des débris peu à peu détachés et bientôt remplacés des organes : est-il donc étonnant d'après cela, qu'on voie des corpuscules dans la liqueur séminale, dans les urines et dans d'autres humeurs? $4^{\circ}$. Mais, dit-on, ces corpuscules se meuvent! Qui vous l'a dit? le microscope. Mais ce moyen d'exploration est-il toujours sans mensonge? comment pouvez-vous être certain des actions précises d'un corps qui n'a pas la cent millième partie du plus petit corps que vous pourriez apercevoir sans lentille? S’il était possible de voir un être à l'extrémité la plus éloignée de la terre, serait-il raisonnable d'espérer le décrire aussi exactement que l'animal qu'on voit marcher tout près de soi? D'ailleurs ne voit-on pas les observateurs inicroscopiques se contredire sans cesse sur les objets selon eux les plus importans : leurs récits varient selon leur âge, selon l'habitude qu'ils ont acquise, selon l'instrument dont ils se scrvent. Enfin, sans parler de leurs 
dissidences et de leurs disputes, nous savons à combien de faux systèmes leurs observations ont domé liec. On ne cesse de s'extasier sur le nouveau monde qu'a fait découvrir le microscope, mais prenez gardè que ce monde ne se peuple de chimères!

Ces corpuscules se meuvent donc. Mais sait-on la nature de ce mouvement, sait-on ce qui l'excite et s'il indique sûrement la vie? ne peut-il pas dépendre de l'imprégnation de ces petits corps, de l'attraction, de l'électricité, etc. ? A coup sûr, du moins, on voit des mouvemens analogues dans tous les corps dont on a projeté quelques molécules, quelque poussière dans des liquides. A ce compte, ce seraient donc des animalcules qui composeraient tous les corps? $5^{\circ}$. Leur voit-on du moins exécuter quelques fonctions? Müller a cru voir sortir du corps de plusieurs d'entre eux, d'autres corps mobiles comme eux, et il en a conclu qu'ils se mangeaient les uns les autres. Mais n'est-il pas possible qu'on ait pris pour des animalcules se dévorant les uns les autres, des molécules inertes qui se divisaient de plus en plus par l'effet de l'imbibition? On a cru voir aussi qu'ils se reproduisaient en se séparant par la moitié de leur corps, de sorte que chacune des divisions offrait le même aspect, les mêmes signes de vie que le corps entier : mais la confusion dont je parlais à l'instant, il serait encore possible qu'on l'eût commise ici. $6^{\circ}$. Sont-ils influencés par des substances irritantes? Spallanzani l'a cru, et comme il s'agit du plus sage, du plus ingénieux des expérimentateurs, cette opinion est d'un grand poids. II a donc vu que le vinaigre et d'autres substances mêlées à l'eau dans larguelle les infusoires élaient suspendus, en dimi- 
54 LIV. II. DE LA REPRODCCTION DES ÊTRES VIVANS.

uuaient le nombre ou même les faisaient disparaître. Mais en supposant que ce fussent des molécules purement inertes, n'est-il pas évident qu'il arriverait un changement pareil? Un liquide qui se mêle à l'eau n'al-il pas pour effet d'en changer la nature ou du moins la densité et l'affinité? Une fois unie à cette nouvelle liqueur, elle laisse échapper les corps qu'elle tenait suspendus ou dissous : ces choses se passent chaque jour sous nos yeux. $7^{\circ}$. Sont-ils influencés par les choses extérieures? Spallanzani a fait beaucoup d'expériences à ce sujet. Il a vu que la chaleur de l'eau bouillante (lorsque les vases restaient ouverts) et un froid de six à sept degrés ne parvenaient point à les faire disparaître. Or, pense-t-on que des corps aussi frêles puissent résister à de semblables influences s'ils étaient vivans? ils seraient donc les plus réfrac1 aires des animaux, eux dont la structure est si fragile. $8^{\circ}$. On dit qu'on les a vus ressusciter après plusieurs années d'immobilité et de dessiccation : le même Spallanzani a fait à ce sujet sur le Rotifère qui porte son nom, des expériences devenues célèbres. II desséchait ce petit corps imperceptible, il le tenait renfermé durant un temps très-long loin de l'air et de l'humidité, et lorsqu'il venait à le plonger de nouveau dans un fluide, il lui voyait reprendre ses mouvemens. 11 obtint de pareils résultats d'un autre petit corps qu'on a appelé Tardigrade; et toutes les expériences qu'il fit sur ces êtres, il les consigna dans un très-long mémoire, où l'on voit du moins une chose admirable, c'est l'extrême sagacité et la bonne foi de l'expérimentateur. Mais, malgré tous les systèmes et les singulières espérances que ce fait curieux a fait naître, peut-on 
concevoir sans miracle la résurrection d'un animal mort depuis des années? Je vais plus loin, ce fait seul n'encourage-t-il pas à douter si ces corpuscules mobiles jouissent de la vie? $9^{\circ}$. On conçoit d'ailleurs que des êtres assez petits, assez multipliés pour qu'une seule goutte d'eau en offre des millions, on conçoit que les espèces de ces êtres infinis pour le nombre et la petitesse devraient offrir des différences d'autant plus nombreuses que leur production serait spontanée: car là où la parenté disparaît, la ressemblance constante des individus n'est plus possible. Eh bien! le conseiller d'état 0 . Fr. Müller, qui a décrit et figuré ces êtres, n'en a pu former qu'une quinzaine de groupes analogues. Peut-être pourrait-on arguer de ce fait que la reproduction de ces êtres n'est pas spontanée; mais j'aime mieux en conclure qu'ils sont inanimés, car si peu de différences dans les formes semble indiquer qu'il s'agit là des molécules très-divisées de corps inertes.

J'avoue que ces difficultés m'ont paru assez fortes pour douter que les êtres infusoires ou microscopiques soient animés : d'ailleurs on ne leur voit d'organes d'aucune espèce; comment donc vivraient-ils? et quels rapports aurait une semblable existence avec celle dont nous voyons jouir les autres êtres vivans? Ce n'est pas que je n'admette de vie possible que dans des corps assez grands pour être aperçus par nos sens grossiers; mais qu'il est difficile de constater et d'étudier la vie dans des c̀tres microscopiques!

Il est clair qu'un moyen décisif de trancher la question de savoir si la production de ces etres est 
LIV. II. DE LA REPRODUCTION DES E'TRES VIVANS.

spontanée, serait de révoquer formellement leur existence en tant que corps animés. Mais en admettant même qu'ils vivent, rien ne prouve sans réplique qu'ils se produisent spontanément. Spallanzani, qui croyait à leur existence comme à la sienne, pensait que leur reproduction n'avait rien de particulier. Ses expériences lui prouvaient que les uns s'engendraient en se divisant, par scission. II croyait que la plupart étaient en outre ovipares, et même il était persuadé. que !'on prenait pour des animalcules très-petits des. œufs ou des larves d'animalcules réels et plus gros; il allait même jusqu'à croire que plusieurs d'entre eux étaient vivipares à la manière des pucerons et de quelques poissons ou reptiles. Concluons donc de tous ces faits obscurs, qu'il serait peu raisonnable d'arguer. de l'histoire des animalcules infusoires que certains. êtres vivans soient engendrés spontanément.

Il est un fait qu'on pourrait alléguer à l'appui des productions spontanées des corps crganisés, je veux parler des Vers parasites ou intestinaux (1). Ce ne sont pas cependant ceux de ces animaux qu'on trouve dans le conduit digestif dont l'origine cause de. l'embarras; car on conçoit que leurs germes peuvent y être importés du dehors par les alimens, par les. fruits, par les boissons, etc. : on sait d'ailleurs que ces êtres, une fois établis dans les intestins, s'y reproduisent comme d'autres vers par des œufs ou par. la division de leur propre corps. Toutefois, ces animaux n'ayant pas tous des analogues dans les vers qui

(1) Voyez les onvrages de Bluch, Rudolphi, Golz, Bréra, B:emser, Drugaiere, D. de Buinrille, Laënnc, elc. 
habitent ou la terre ou dans les eaux, il est naturel de penser qu'ils ont leur origine dans les corps vivans où on les trouve, et que les germes s'en transmettent par la génération : et ce qui confirme encore celte pensée, c'est que ces animaux parasites ne causent en aucun temps de la vie plus de ravages que durant l'enfance : ils sont donc contemporains des organes. Mais d'où proviennent ces vers et comment s'en transmeltent les germes?

Il aurait toujours fallu aborder cette difficulté de la transmission des vers des pères aux enfans, puisqu'on en trouve dans le corps même des fotus, ft que d'ailleurs plusieurs espèces de ces parasites occupent des viscères solides qui n'offrent aucun accès aux choses du dehors. Cette question est fort embarrassante. Il est sûr que si l'on ne trouvait dans le corps des animaux que des espèces de vers analogues à ceux qu'on voit sur la terre, on pourrait penser sans invraisemblance que ces êtres passent de la mère au fœlus par la même voie qui transmet une partie des alimens d'elle à luị, c'est-à-dire avec le sang. par les vaisseaux; et puisque ce sang de la mère pénètre également tous les organes du jeune animal, il n'est pas plus difficile d'expliquer la transmission ét la présence de ces vers dans la substance des organes inaccessibles que dans les conduits digestifs ou autres. Mais puisque la plupart des espèces de vers parasites. sont particulières aux animaux óu même à certains de leurs organes, les vers trouvés dans les enfans supposent de semblables parasites dans leurs auteurs, ou plutôt seulement dans leur mère; car pourle père. 
58 LIV. II. DE LA REPRODUCTION DES ÊTRES VIVAXS.

on ne voit guère comment les germes pourraient provenir de lui par la semence. Il est des personnes qui expliquent toutes les choses embarrassantes de ce genre par des prédispositions obscures qu'ils nomment spécifiques; mais outre que de pareilles raisons ne peuvent porter aucune lumière sur ces questions difficiles, cela conduirait droit à l'admission forcée des reproductions spontanées; et il faut avouer qu'un seul fait obscur ne doit jamais faire admettre un principe dont tant d'autres raisons certaines démontrent l'invraisemblance. Les savans dont je parle ont dit : la preúve que les animaux parasites se développent sponlanément comme le cancer ou les tubercules, c'est que rien ne favorise leur production aussi bien que l'état maladif ou d'extrême faiblesse. Ces auteurs avaient oublié que les prétendus animalcules de la semence et d'autres humeurs (qu'ils regardent comme animés et dont la production est aussi, selon eux, apparemment spontanée) ne se trouvent que dans des hommes doués de force et de santé, et qu'ils n'existent ni durant les maladies et les grands chagrins, ni dans l'enfance et la vieillesse ! Rien ne cache la vérité aux yeux même les plus éclairés comme la préoccupation d'un système.

- Enfin on a prétendu que des animaux, même des animaux d'une structure très-complexe, avaient été trouvés daus des troncs d'arbres intacts, daus des pierres solides et sans nulle issue, n'offrant nulles traces de brisures anciennes. Ces êtres vivaient et se nourrissaient là sans alimens, y respiraient sans air, s'y ćtaient formés sans germes, sans auteurs! Assurément 
CHAP. IV. SANS ORGANES SEXEELS.

si la superstition reprenait dans de pareilles histoires le merveilleux qu'elles lui doivent, nous n'aurions plus besoin ou de les combattre ou de les révoquer.

\section{CHAPITRE IV.}

Reproduction sans le concours d'organes scxuels.

Tout le monde sait avec quelle facilité les plantes vasculaires ou pourvues de cotylédons se reproduisent à l'aide de boutures, de drageons, de jets, de caieux, de coulans, etc. Je dis les plantes vasculaires, car celles qui ne sont composées que de tissu cellulaire sans vaisseaux, autrement les acotylédones, ne sont pas susceptibles de celte espèce de reproduction. Pour favoriser la végétation des boutures, on a souvent recours à des ligatureś ou à des incisions, afin de faire gonfler l'écorce en forme de bourrelet; car c'est de ce dernier point que naissent les nouvelles racines. Quelquefois aussi on place une semence de graminée dans une fente pratiquée à l'extrémité de ces boutures; comme cette graine ne tarde pas à se gonfler et à germer, elle appelle vers le nouveau végétal l'humidité dont elle a besoin, outre que la chaleur développée dans la semence qui germe, favorise la végétation de la tige nouvelle.

Nous devons dire que les végétaux provenant de boutures perdent à la longue la faculté de produire des graines. Mais il est remarquable que ce soient précisément les plantes pourvues de fleurs ou d'or- 
ganes sexuels qui jouissent de la propriété de se reproduire par des fragmens détachés. Elles ont ainsi un double moyen de multiplication.

Les plantes acotylédones ou vasculaires ne se reproduisent ni par boutures, avons-nous dit, ni ordinairement par le concours d'organes sexuels: elles n'ont ni fleurs, ni étamines, ni pistils appréciables. Mais ces espèces de végétaux se perpétuent par des germes ou rudimens dont la forme varie pour chacun, et auxquels on a donné les différens noms de propitgines (dans les mousses), de conides (dans les lichens), de grondyles (dans les algues), de bulbes ou bulbiles, etc. Beaucoup de botanistes regardent ces rudimens comme de véritables graines : mais l'absence d'organes sexuels dans les végétaux d'où ils provienuent ne permet guère de partager celle opinion. Cies petits corps occupent.ordinairement des espèces de cavités ou urnes d'une forme remarquable: leur stratification perpendiculaire dans les champignons mérite toute l'attention des observateurs: l'ouvrage d'Hedwig en offre de merveilleuses images. Ces espèces de grcrnes, ces bulbes ressemblent plutôt quelquefois à des plantes en miniature qu'à des graines comme en produisent les fleurs. C'est à ce point, qu'on a regardé ceux des végétaux qui les produisent comme une sorte de vivipares : on voyait il y a quelques années au Jardin du Roi, un Agavé qui s'éleva à la hauteur de vingt-sept pieds dans l'espace de six semaines; on s'attendait qu'il finirait par donner des fleurs, mais point : it en sortit des espèces de bulbes qui, tombés à terre, au lieu d'y germer à la manière des graines, y prirent aussitôt racines. Si cette manière de se re. 
produire ne ressemble pas à ce qu'on voit dans les animaux vivipares, assurément du moins elle a plus d'analogie avec les gemmes des polypes qu'avec les graines des végétaux à fleurs.

$\mathrm{Au}$ reste, ce genre de reproduction n'est pas particulier aux plantes; on le voit aussi chez plusieurs animaux, dont les uns ont des sexes et dont les autres n'ont d'organes sexuels d'aucune espèce. Par exemple, les polypes dont je parlais à l'instant, se reproduisent, sans sexes, de deux manières différentes : d'abord ils ont des gemmes, espèces de germes qui, développés dans l'épaisseur de leurs membranes, font saillie au-dehors et au-dedans de leur corps; et lorsque ces gemmes sont parvenus à une certaine grosseur, i!s se détachent de l'animal pour former autant de nouveaux polypes. L'autre manière dont ces êtres se reproduisent, c'est par boutures, par divisions spontanées ou artificicllement opérées. II pousse de la surface de leur corps des espèces de bourgeons, qui quelquefois s'en détachent pour donner lieu à de nouveaux animaux semblables au polype principal; et il suffit de quelques jours ou même de quelques heures dans les mers équatoriales, pour que des jeunes polypes détachés de la souche commune proviennent successivement plusieurs générations nouvelles. Même chose arrive lorsqu'on les coupe par fragmens petits ou gros; chaque tronçon devient un animal entier, et bientôt il naît de nouveaux animaux de chacun des bourgeons, de chacune des cloches dont il se recouvre. Il faut remarquer que le polype n'a point d'individualité, précisément parce quil est partout homogène : chaque troisçon 
contient un estomac pour exister et des gemmes pour se reproduire : c'est-à-dire tout ce qui est nécessaire à l'être et à l'espèce. Il en est de même chez toutes les espèces de polypes, mais ces phénomènes de régénération artificielle ou spontanée ne sont dans aucun autre plus curieux et plus variés que dans l'Hydre d'eau, sujet célèbre des belles expériences de Trembley. Non-seulement chaque fragment détaché de cet être devient un nouvel animal, mais ces fragmens se greffent les uns sur les autres à la manière des arbres d'espèces analogues; la tête de l'un peut être substituée à celle de l'autre et s'attacher aussitôt et durablement au corps mutilé. On multiplie de cette sorte, par sections ou par greffes, les queues et les têtes du même polype; il se forme des bouches nouvelles, des bras nouveaux : et après avoir assisté à de semblables expériences, l'histoire d'un des travaux d'Hercule, en perdant tout son merveilleux, acquiert ainsi plus de vraisemblance.

Ces phénomènes de reproductions non sexuelles ne se bornent pas à la seule et vaste famille des polypes: on les retrouve en d'autres êtres, en ceux même qui ont des sexes et qui portent des œufs. II est plusieurs vers, plusieurs radiaires qu'on multiplic ou qui engendrent ainsi d'eux-mêmes, par division. Beaucoup de vers peuvent être divisés par fragmens, chacun desquels redevient un vers parfait, parce qu'il jouit de la faculté de réintégrer toutes les parties de l'animal dont on l'a séparé. Ch. Bonnet a vu des vers aquatiques dont seulement la vingt-sixiène partie suffisait pour reproduire un animal parfait ayant au bout de quelques mois plusieurs pouces de lon- 
CHAP. Y. GÉNÉration des Plantes.

gueur. Toutefois chaque tronçon ne jouit pas également de la propriété de régénérer tout l'être : dans les vers un peu complexes, la tête et la queue ne repoussent aucune des autres parties; mais ceux des tronçons du centre qui renferment des viscères, reproduisent bientôt tout l'animal.

L'abbé Dicquemare a constaté de semblables singularités en d'autres animaux. Il a vu des Actinies, ou anémones de mer, dont les ligamens membraneux se divisaient d'eux-mêmes par lambeaux, et chacun d'eux, après être resté quelque temps collé à la souche comınne, devenait une actinie complète. Il a essayé d'imiter la nature par des divisions artificielles; et soit qu'il divisât ces corps gélatineux et animés par la moitié ou par fragmens plus ténus, les résultats étaient tous semblables et toujours certains.

\section{CHAPITRE V.}

Reproduction sexuelle des plantes.

Il résulte du chapitre précédent que tout être vivant ne provient pas d'un œuf, comme l'ont avancé des esprits systématiques qui ne tenaient compte que des faits favorables à leurs idées favorites : nous avons également vu qu'il est des reproductions possibles sans le concours d'organes sexuels. Mais dans la multitude d'êtres dont il nous reste à parler, nous verrons partout des espèces d'œufs où sont contenus leurs premiers linéamens, leurs embryons, el partout l'in- 
G/ LIV. II. DE LA REPRODUCTION DES ÊTRES VIVANS.

tervention d'organes sexuels. C'est par les plantes que nous commençons l'histoire de cette génération véritable (1).

A l'exception des Cryptogames, lesquels, comme le nom l'indique, ont des mariages cachés ou des sexes invisibles, tous les végétaux sont évidemment pourvus d'organes sexuels. Les Pistils, les Stygmates, les Ovaires, sont les organes du sexe Femelle; les Etamines, les Anthères, les organes du sexe Mâle. Les ovaires sont occupés par les rudimens des graines, par les Embryons; les anthères sont remplies d'une matière fécondante, c'est le Pollen; ensuite des organes accessoires, les Pétales de la Corolle, les divisions $\mathrm{du}$ Calice entourent, protègent ou décorent ces organes essentiels dont la durée n'est pas égale. II faut remarquer qu'il existe une assez parfaite analogie entre les organes sexuels des plantes et les mêmes organes des animaux : les anthères sont l'équivalent des testicules; le stygmate et l'ovaire représentent et la vulve, et la matrice, et l'ovaire des animaux femelles; s'il existe un conduit entre le stygmate et l'ovaire, il fait l'office et est l'analogue du vagin, ou plutôt des Irompes : ensuite le Pollen est une espèce de sperme, et l'embryon des graines est l'image de l'ovule des animaux. Mais comme Jes plantes n'ont ni instinct ni locomotion, il était essentiel que le principe fécondant fût à l'extérieur, contigu avec l'organe femelle qui l'absorbe et en est fécondé, ou accessible aux

(1) Voyez Malpighi $(16-5)$; Camerarius, de Sexu plantarum (1694); Linné (176n); Ch. Bonnet; Spallanzani (1777); Adanson: Kœlreuter; Gœrlner : Volta; Mirbel (1810-11) ; Turpin; Decandole; A. Saint-Hilaire; Nutrochet; Amici; liob. Prown $\left(18_{2} 6\right)$; Ad. Brongniart $(1827)$. 
vents qui le lui transportent; aussi est-ce là ce qu'on observe. Par la même raison la matière fécondante des anthères ne devait pas être liquide comme celle des testicules; aussi est-elle pulvérulente et renfermée dans de petites outres qui se rompent pour la transmettre au stygmate, au lieu d'être à nu comme le sperme des animaux.

Dans le plus grand nombre des plantes les organes des deux sexes sont réunis dans la même fleur, et non séparés sur deux êtres différens, comme dans la plupart des animaux : au lieu d'être unisexuelles, elles sont donc presque toutes hermaphrodites. C'est encore une conséquence de leur immobilité et de leur apathie : il est clair que pour des êtres qui ne peuvent ni se pressentir ni se chercher, le contact des organes par qui s'opèrent la génération et la perpétuité de l'espèce était une condition nécessaire. Toutefois les plantes ne sont pas à beaucoup près toutes hermaphrodites : il en est dont les organes mâles et les organes femelles sont placés en des fleurs isolées sur la même tige; d'autres, dont les sexes sont séparés sur des tiges différentes. Il y a même des combinaisons de sexes encore plus compliquées. Chaque fois donc que nous dirons Hermaphrodites, cela indi-quera des fleurs renfermant les organes réunis des deux sexes; nous nommerons Monoïques, les plantes où les sexes sont isolés en des fleurs supportées sur la même tige; et Dioiques, celles dont chaque tige ne contient que les organes isolés d'un sexe.

Ainsi les plantes sont pourvues d'organes sexuels comme les animaux. C'est une chose qui fut ignorée des anciens et qui n'a même été bien démontrée, I. 
bien avérée et connue que dans des temps assez rapprochés de nous. L’illustre Tournefort lui-même, lui cependant qui fit des fleurs une étude si profonde, paraît n'avoir eu sur ce fait important de physique que des idées fort confuses. Il lui arrive de nommer femelles, avec le vulgaire, des plantes supportant des fleurs mâles : il va même jusqu'à prétendre assigner pour usage aux anthères de purger les fleurs de tous les principes nuisibles.

Millington, à ce que dit Grew, mais surtout Camerarius, ont émis les premières idées justes sur cetle matière : mais il est impossible de douter que l'existence du sexe des plantes ne fût une tradition routinière des peuples avant de devenir une découverte scientifique. En 1759 ,'Linné adressa à l'Académie de Pétersbourg une dissertation fort instructive sur ce sujet; et malgré les expériences aussi équivoques qu'ingénieuses dont l'abbé Spallanzani embarrassa quelques années après ce beau fait de physiologie, trop d'expériences aujourd'hui le confirment, trop de témoignages l'attestent, pour qu'il ne s'empare pas des croyances de tous les hommes éclairés.

Voici donc ce qu'on observe au moment de la fécondation des plantes : les anthères, qui sont divisées en deux espèces de bourses à la manière des testicules, ordinairement ne paraissent contenir de pollen fécondant qu'à l'époque de l'épanouissement des fleurs. 'Toutefois cette règle n'est pas sans quelques exceptions : ainsi les fleurs de l'ordre des œillets (les Caryophyllées ) et celles de l'ordre des Solanées sont déjà à demi-fécondées quand la fleur vient à s'ouvrir. A l'instant de cette fécondation, les anthères sont 
CHAP. v. Génération des PLANTEs.

couvertes d'une poussière ordinairement jaunâtre, qui s'en échappe; le stygmate, presque toujours placé dans l'atmosphère de cette poussière, est enduit d'une espèce. de mucus glutineux où elle se fixe ; il est en outre hérissé de poils à sa surface, ce qui retient mieux les petits globales, et il paraît percé de pertuis très-fins par où s'introduiraient, sinon ces globules entiers, du moins les principes plus subtils qui en émanent. Nous verrons dans la suite de ce chapitre ce qu'il faut penser de cette apparence. Il est remarquable que le stygmate est toujours placé le plus favorablement possible pour se trouver en contact avec le pollen des. étamines : il est d'ordinaire moins élevé que les anthères; s'il est plus haut qu'elles, il se recourbe pour redescendre à leur niveau, ou même au-dessous; et, dans les plantes monoïques, les fleurs femelles (où se tróuve ce stygmate) sont presque toujours placées dans le bás de la plante, audessous des fleurs mâles. On a aussi observé (Linné) que les fleurs dont le pistil est plus long que les étamines sont ordinairement tombantes, ayant leur ouverture vers 'la terre; tandis que; si les étamines sont plus courtes, alors les fleurs restent presque tonjours droites.

Ces premiers faits que nous venons de relater wontrent déjà les grands rapports existant entre les anthères et les stygmales, et ils auraient suffi pour mettre sur la voie de la génération sexuelle des plantes; mais les preuves positives quil'établissent sont rombreuses. Lorsqu'on coupe les anthères d'une fleur un peu avant qu'elles soient devenues pulvérulentes, alors cette fleur reste stérile, ses graines avortent. Si l'on ob- 
serve une plante monoïque, on voit d'un côté que les fleurs qui ne portent que des étamines n'ont jamais de graines, tandis que les fleurs à pistils en sont pourvues. S'agit-il d'une plante dioïque? si on la tient isolée de toute autre plante d'espèce analogue, elle reste inféconde. On a fait cette expérience pour le chanvre, pour les épinards, les palmiers, la mercuriale et d'autres. Les paysans agissent en conséquence de ce fait lorsqu'ils ont le soin de n'arracher le chanvre mâle. (qu'ils nomment femelle par inattention, par routine) qu'au moment où les graines déjà fécondées du chanvre femelle (le mâle selon eux) dénotent qu'ils le pcuvent faire sans danger. Disons cependant que les expériences de Spallanzani ne s'accordent pas avec tous ces faits. Il assure, dans un style toujours persuasif, qu'il a vu du chanvre femelle prendre graines, quoiqu'il en eût séparé bien avant la floraison tous les pieds de chanvre mâle. Même Spallanzani ne se horne pas à cette moitié d'expérience; il l'achève avec sa sagacité accoútumée : il a un fait à opposer à chaque objection prévue. En vain dirait-on. que ces graines ne sont pas fécondes : il lès a semées et la plupart ont produit de nouveau chanvre. C'est le vent, pourrait-on dire, ce sont des insectes qui ont voituré le pollen d'un chanvre éloigné sur le vôtre : non, car Spallanzani avait ensemencé d'assez bonne heure pour avoir du chanvre en fleurs à une époque où celui des campagnes voisines de son château est encore en herbe et loin de fleurir. Enfin Spallanzani a prévu qu'on pouvait objecter que peut-être des fleurs mâles se trouvaient réunies sur le même pied avec dês fleurs femelles: il avoue que la chose est possible, qu'il l'a 
CHAP. V. GENTRATION DES PGINTES.

quelquefois observée; mais que toujours il a eu soin d'examiner chaque fleur une à une, et d'enlever les fleurs rarement trouvées pourvues d'étamines. Cependant, et quoique cet observateur assure avoir obtenu des résultats semblables d'autres expériences tentées sur des végétaux différens, les botanistes n'en persistent pas moins à penser qu'il s'agit là d'une erreur. Il faut se souvenir que Spallanzani était en correspondance suivie avec $\mathrm{Ch}$. Bonnet, son ami; qu'aussi bien que Bonnet, il croyait à la préexistence du germe dans l'ovule des femelles et au rôle très-secondaire du mâle : on se rappellëra ensuite combien la préoccupation d'un système exerce d'ascendant sur les hommes nıême les plus capables d'y résister.

Toutefois, Spallanzani convient que pour la plupart des plantes l'interrention des étamines est nécessaire à la fécondation: il avoue avec tous les botanistes', que, sans pollen, sans étamines, presque toujours les graines avortent ou se dessèchent avant la maturité, ou mûrissent imparfaitement sans pouvoir reproduire de plantes nouvelles. A ce sujet, les voix sont unanimes : Spallanzani est le seul qui admette des exceptions à une règle universellement regardée comme absolue. Cet habile expérimentateur était porté à penser qu'outre le chanvre, les épinards et la courge à écu pouvaient, comme les pucerons, engendrer sans l'intervention des organes mâles. Il avait encore un autre pressentiment à ce sujet : il ne regardait pas comme impossible que ces plantes pussent engendrer sans anthères; et voici pourquoi : il avait vu à l'extrémité des stygmates une poussière de même couleur que le pollen, mais étrangère à la dissémination de ce dernier ; ct 
il n'était pas éloigné de croire que celle malière ne provînt des stygmates eux-mêmes, et qu'elle n'eût la même efficacité que celle des anthères. Mais les expériences que le célèbre Volta a tentées depuis Spallanzani sur le même sujet, ont prouvé que celui-ci était dans l'erreur, et que, s'il avait obtenu des graines fécondes des: fleurs femelles isolées de plusieurs plantes, cela venait de ce qu'il n'en avait point séparé avec assez de soin les étamines qui s'y trouvent jointes. La généralité de la règle ne souffre donc plus aujourd'hui d'exceptions. Tout le monde connaît l'exemple des palmiers femelles, lesquels restent toujours stériles lorsque aucun palmier mâle ou à fleurs pourvues d'étamines n'est dans leur voisinage. On cite ce palmier femelle de Berlin, ne produisant jamais rien, restant infécond parce qu'il était isolé : on fit venir de Leipsick, par la poste, du pollen d'un palmier mâle situé dans cette ville; ce pollen, on le répandit sur les fleurs du palmier femelle jusques-là stérile, et pour la première fois on le vit produire. L'intermédiaire des vents. fut remplacé dans cette circonstance par l'entremise. industrieuse des hommes.

Nous disons done que sans pollen il n'est pas de fécondation possible, pas de fruit, pas de graines, pas de reproduction. Lorsqu'on a coupé toutes les étamines chargées de pollen d'une plante hermaphrodite, elle n'est cependant pas toujours stérile pour cela : du pollen peut parvenir aux stygmates de ses fleurs châtrées, par des fleurs analogues du voisinage. Plusieurs fois des expériences ont été tentées à ce sujet, et tonjours avec succès. 11 suffit pour qu'elles réussissent, que ic pllen dont on saupoudre les styg- 
CHAP. V. GÉNÉRATION DES PEANTES.

mates étrangers provienne de fleurs analogues aux leurs; il faut, pour que la fécondation soit parfaile, que les graines des unes et des autres emploient le même temps à se développer, à mùrir. Par ce moyen, on remplace les étamines excisées par le pollen pris sur d'autres étamines; et les plantes qui proviennent de ces unions adultérines sont hybrides, c'est-à-dire qu'elles réunissent les caractères de l'une et de l'autre.

11 est facile de pressentir par ce qui précède, de combien de causes peut provenir la stérilité des plantes, des plantes même qui ont des fleurs. $1^{\circ}$. L'excision des étamines est l'une des plus sûres. Mais il faut que cette opération précède la dissémination du pollen : il faut que de nouveau pollen ne puisse être transporté sur les stygmates isolés, ni par les vents, ni par des insectes, ni par l'homme. Il faut que cette castration soit opérée de bonne heure ; car il est des fleurs dont la fécondation est déjà commencée avant l'épanouissement de la corolle.

$2^{\circ}$. Les pluies abondantes, qui enlèvent subitement le pollen, peuvent amener l'avortement des graines. et la stérilité. C'est ainsi que les temps pluvieux, à l'époque de la floraison des graminées, du pomnier ou de la vigne, próduisent souvent une diselte de blés, de cidre ou de vins; c'est pour la mêuse raison, et par la prévoyance de la nature, que les fleurs des plantes aquatiques s'élèvent au-dessus des eaux au moment de la floraison pour s'y replonger lorsque la fécondation est opérée (1). Toutefois il est des fleurs qui s'ouvrent dans l'eau et qui s'y fé-

(1) Voyez Théophraste, liv. iv, chap. x. 
72 LIV. II. DE LA REPRODUCTION DES ÊTRES VIVANS.

condent sans en sortir; mais voici par quelle voic admirable se propage le pollen : il se développe une. bulle d'air au milieu de la fleur épanouie et submergée, et par ce moyen le pollen se dissémine ( 1 ).

Les gelées et les coups de soleil brûlans ont quelquefois l'effet des pluies; mais ils agissent différemment, je veúx dire, en mortifiant ou desséchant le stygmate: des fleurs à-demi épanouies. Toute atteinte profonde. aux pistils ou aux ovaires a des effets analogues à la destruction des étamines ou à la disparition du pollen.

$3^{\circ}$. L'isolement des pistils ou l'isolement des étamines produit toujours la stérilité. Il est en conséquence indispensable qu'une plante dioique ait dans son voisinage une plante de son espèce et d'un sexe. différent du sien : et s'il existe de grandes distances entre les deux êtres, il faut la main de l'homme ou. l'intervention des vents pour les rapprocher.

$4^{\circ}$. Ce n'est pas assez qu'une plante ait des fleurs. mâles et des fleurs femelles, qu'une même fleur ait des étamines et des pistils, ou que les deux sexes des. plantes dioïques soient voisins l'un de l'autre; il faut, de plus, que les étamiries et les pistils, les fleurs mâles et les fleurs femelles croissent au même degré, et soient pour ainsi dire du même âge, arrivant en même temps à la maturité : mais celte concordance, ordinaire pour la plupart des plantes, n'est pas toujours assez parfaite. Si, par exemple, les fleurs femelles sont plus hâtives que les mâles, si déjà elles sont flétries quand les fleurs mâles sont disposées à donner leur pollen, alors la fécondation est impos-

(1) Voycz Ra:mont, Bastard, A. Saint-Hilaire. 
CHAP. V. GÉNÉRATION DES PLANTES.

sible. Linné cite des cas de ce genre. Lorsque ce sont les flecirs mâles qui s'épanouissent d'abord, la chose n'est pas aussi embarrassante; car le pollen pouvant se conserver plusieurs jours et même des semaines entières sans dommage, on le recueille d'avance, et on a soin ensuite de le projeter sur les premières fleurs femelles qui viennent à s'ouvrir. Le même et illustre Linné a fait de ces expériences sur le jatropa.

$5^{\circ}$. Il est bien vrai qu'on n'a jamais vu d'espèce de plante qui eût exclusivement des fleurs femelles ou exclusivement des fleurs mâles. Mais les deux sexes. ne se développent pas toujours également; et cela produit encore la stérilité. Linné avait dans son jardin d'Upsal du Chanvre de Crète qu'il était forcé de multiplier par racines, par la raison que cette plante n'ayant jamais en que des fleurs femelles, il n'en pouvait obtenir aucune graine : désespérant d'en récolter chez lui, il en fit venir de Paris, et les sema; mais les plantes qu'elles lui donnèrent portaient toutes des fleurs femelles comme celles d'Upsal. Enfin, de nouvelles graines lui fournirent d'autres plantes, et parmi elles il se trouva un mâle. Comme celui-ci était éloigné des femelles, Linné prit le soin d'en recueillir le pollen, de le répandre sur une ou deux plantes portant des fleurs femelles à pistils, et pour la première fois celles-là, et elles seules, furent fécondes et donnèrent des graines.

Les plantes monoïques et dioïques, ayant une fécondation plus incertaine, à raison de l'isolement des organes sexuels sur des fleurs ou sur des pieds différens, c'est probablement à cause de cela que leur pollen est extrêmement abondant et que la terre environnante 
74 LIV. I1. DE LA REPRODUCTION DES ÈTRES VIVANS.

en est quelquefois jonchée. C'est comme les œufs des. poissons, dont le nombre est prodigieux. Toujours. attentive d la conservation des êtres vivans, la nature semble avoir multiplié les moyens propices à la propagation des espèces, à mesure que celte propagation rencontrait plus d'obstacles et courait plus de dangers.

On ne peut douter, d'après ces différens faits, que le pollen des anthères ne joue un rôle fort important à l'égard de la fécondation du fruit et des graines; on ne peut douter non plus que le pistil ne serve d'intermédiaire entre le pollen et les graines rudimentaires que l'ovaire renferme. Mais comment toutes ces choses se font-elles, et quelle est la part d'influence de l'organe mâle et de l'organe de l'autre sexe?

D'abord, si l'on examine une fleur encore en bouton, et par conséquent non 'encore fécondée, on trouve dans l'ovaire, au-dessous des étamines et des pétales recoquillés, les rudimens très-petits et imparfaits des graines futures. Si l'on ouvre avec soin ces graines rndimentaires, on les trouve entièrement composées d'une humeur pulpeuse et homogène qui disparaît toujours avant la maturité (1), et qui ressemble à une gelée un peu consistante. Ces petits grains se trouvent dans beaucoup de fleurs plus de vingt jours avant qu'elles soient ouvertes, long-temps donc avant que le pollen ait pu les féconder. Ces graines naissantes sont massives ; leur centre n'offre aucune cavité, ni rien qu'on puisse prendre pour le germe ou l'embryon de la nouvelle plante qui en aurait dù naître.

(1) Voyez Malpighi, Grew, Spällanzani, Nirbel. 
CHAP. v. GÉNERITION dES PLANTES.

Mais les choses prennent bientôt un auire aspect lorsque la fécondation est opérée, c'est-ì-dire après que le pollen, devenu pulvérulent, a élé mis en contact avec le slygmate correspondant aux jeunes graines. Alors ces graines se creusent vers lẹur centre; ces cavités sont remplies par une humeur vitrée que Malpighi a nommée amnios, par analogie à ce qu'on observe dans l'ovule de quelques animaux : et l'on croit que ce liquide sert de nourriture à l'embryon, lequel paraît bientôt suspendu au milieu du fluide. Cet embryon, qui n'existe que dans les graines fécondes, n'offre pas d'abord de caractères bien distincts; mais bientôt on y aperçoit toutes les parties d'une plante en miniature : il est composé d'une radicule, d'une plumule (rudiment de la tige future), et d'un corps de cotylédons, qui sont les premières feuilles que cette graine aurait produites.

Nous voyons donc l'embryon paraître après que la fécondation des ovules ou jeunes graines a été opérée par la poussière des anthères, mais sans pouvoir assurer qu'il ne préexistât point à cette fécondation. Puisqu'on ne peut l'apercevoir que quelque temps après cette fécondation, et que l'ébullition nous le fait voir dans des graines où il paraissait invisible ì froid, nous ne pouvons pas savoir de quelle époque date précisément sa première existence. Mais voici ce qu'on sait être sûr, malgré les dénégalions du judicieux Spallanzani : c'est que, soit que l'embryon résulte de la fécondation ou qu'il lui préexiste, certainement du móins il ne se développe et ne devient productif qu'alors que la fécondation de l'ovule a eu lieu. Nous verrons cette question si délicate se reproduire à l'occasion des animaux. 
Une chose porterait à penser que l'embryon, l'embryon inerte, préexiste invisible à la fécondation; ce sont les liens, ce sont les rapports qu'on lui voit dès sa première apparition dans l'ovule. Nous avons déjà dit qu'il nage dans un liquide qui lui est contemporain; mais, outre cela, on le voit presque toujours lié par deux de ses points, souvent opposés l'un à l'autre, à l'ensemble de la graine. L'amnios, qui le baigne, est entourée ordinairement d'une membrane; souvent audelà de celle-ci est un autre liquide bientôt épaissi et qu'on nomme albumen, tant qu'il est à l'état fluide, et périsperme, lorsqu'il est solidifié autour de l'embryon. Autour de cet ensemble est une nouvelle membrane protectrice.Or, les deux ligamens de l'embryon correspondent aux deux endroits de l'amande où ces membranes sont ou adhérentes ou perforées, savoir : à l'ombilic et au sommet de la graine. Celui de ces ligamens qui est tourné vers l'ombilic ne va pas ostensiblement jusqu'à lui; il s'attache en dedans de l'amnios à un point qui correspond à la chalaze, et qui fait l'office comme d'un placenta interne; ensuite, ce placenta, cette chalaze reçoit des vaisseaux de l'ombilic; et c'est par l'ombilic que la graine adhère à l'ovaire et reçoit des vaisseaux de la plante-mère, vaisseaux qui pour cette raison sont appelés ombilicaux. De cette manière l'embryon tient à la graine comme cette graine tient à la plante, et par les mêmes vaisseaux.

Je dis que ces adhérences de l'embryon avec son ovule, au moyen des ligamens dont nous venons de parler, semblent indiquer une coincidence dans l'origine de ces deux corps. En effet, comment le principe fécondant du pollen pourrait-il exercer efficacement son action au milieu d'un fluide sans conduits inter- 
médiaires? Je vais plus loin : en supposant la formation spontanée de l'embryon au milieu du fluide, comment se trouverait-il subitement en commerce de vaisseaux avec l'ovule, et par celui-ci avec la plante entière? Ne semble-t-il pas plus raisonnable, je le demande, de regarder toutes les parties de la fleur. et l'embryon lui-même comme étant d'une origine simultanée et contemporaine? Mais il faut convenir que les expériences qu'on a tentées pour découvrir l'existence de l'embryon dans des ovules non fécondés ont toujours été vaines. Ce n'est même que plusieurs jours après la fécondation qu'on parvient à le trouver : encore même n'est-ce qu'à l'aide de la chaleur ou de l'esprit-de-vin, lesquels le coagulent.

Ainsi donc, il est certain que l'embryon n'apparaît et ne se développe que du moment où se fait l'émission du pollen. Mais comment cette poussière est-elle transmise de l'anthère jusqu'à l'ovaire? quelle voie suit-elle pour y parvenir? quelle est sa structure, et est-ce par le stygmate qu'elle s'introduit?

On a beaucoup examiné le Pollen dans ces derniers temps : on a donné la plus grande attention à sâ forme, à son volume, à l'arrangement des pelits grains qui le forment (1). On a vu que les corpuscules dont il est composé étaient contenus dans l'intérieur des anthères, disposés par compartimens, par cellules, et renfermés dans autant de membranes particulières. Lorsque les fleurs s'épanouissent et que le pollen arrive à l'état de maturité, les anthères éclatent tout-à-coup, et les

(1) Voyez de Gleichen, Amici, Rob. Brown, Guillemin, Ad. Bronguiart, Raspail. 
grains de pollen en sortent avec vélocité , à-peu-près comme des grains de poudre enflammés sortent par la lumière d'une fusée. Après cela, si ces grains de pollen sont exposés à l'bumidité, on les voit éclater de nouveau; alors on s'aperçoit qu'il est sorti de leur intérieur un nombre infini de corpuscules excessivement déliés, formant une sorte de traînée; et de plus, on en voit tout-à-coup saillir un long tuyau membraneux qui semble n'être qu'un débris de l'enveloppe interne de ces petits corps. Lorsque les grains du pollen tombent sur le stygmate des fleurs, l'humidité qu'ils y rencontrent Jes fait éclater comme nous venons de le dire; et l'on croit que l'espèce de canal qui s'échappe de leur intérieur avec les grains de poussière, s'introduit dans la substance même du stygmate. Il suit de là que les petits grains de pollen sont directement projetés dans le pistil, et que le stygmate n'a pas besoin de les absorber. Aussi bien ne convenait-on pas que le pistil eût des ouvertures et des vaisseaux conducteurs; et cela causait beaucoup d'incertitudes et sollicitait sans cesse de nouvelles hypothèses, la plupart vraisemblables, il est vrai, mais peu dignes de confiance comme imaginaires. En supposant donc l'introduction immédiate des grains de pollen au moyen des tuyaux membraneux dont il s'agit, il reste toujours de grandes difficultés pour expliquer comment ces corpuscules vont du pistil jusqu'à l'ovule. S'il ne s'agissait que d'hypothèses à faire, voici ce qu'on pourrait supposer $: 1^{\circ}$. le pistil est composé de petits globules unis et séparés par du tissu cellulaire; le pollen ne peut-il pas pénétrer jusqu'à l'ovule par ces intervalles celluleux? Comme le stygmate ordinairement paraît avoir aułant 
de compartimens, autant de divisions que l'ovaire a de cellules, on avait cru que le pistil était percé d'autant de petits conduits : mais ces conduits, leur existence est mise en doute. Linné, qui les admettait comme certains, croyait que la fécondation d'un stygmate n'avait d'effet que pour l'ovule correspondant; mais on sait aujourd'hui qu'il suffit d'un seul stygmate pour féconder tout un ovaire. $2^{\circ}$. Toutes les parties de la plante absorbent apparemment par des vaisseaux exprès; pourquoi donc le pistil, qui a sans doute les mêmes vaisseaux, n'exercerait-il pas la même absorption? $3^{\circ}$. A l'instant de la fécondation, le stygmate et le pistil sont enduits et imprégnés de sucs; mais dès que le pollen est disséminé, toutes les parties de la fleur se dessèchent et se flétrissent : or, n'est-il pas probable qu'une partie de l'humidité dont le stygmate était inondé se trouve attirée vers l'ovaire, lequel s'humecte à son tour et se dilate de plus en plus? $4^{\circ}$. A l'instant de la fécondation, il se développe beaucoup de chaleur dans les organes sexuels de la plante; or cela dilate les sucs dont ces organes sont imprégnés; et comme le reste de la plante se trouve à une température plus basse, et que le calorique tend toujours à se mettre en équilibre, cela même n'est-il pas une des causes qui font afluer les liquides du stygmate vers l'ovule, et avéc ces liquides les émanations du pollen?

Quel que soit le mode d'introduction du pollen dans l'ovule, toujours est-il qu'il communique jusqu'à lui, et l'on croit que cetie communication a lieu par les vaisseaux déliés et presqu'imperceptibles qu'on trouve vers le mamelon ou le sommet de l'amande : c'est aussi vers ce point de la graine que s'attache l'un 
des ligamens de l'embryon dont il a élé question plus haut; c'est en ce lieu pareillement que les tuniques de l'amande sont perforées, ainsi que l'a prouvé M. R. Brown. Mais on ignore si ce sont les globules du pollen lui-même ou des fluides subtils émanés de lui qui s'introduisent dans l'ovule pour former ou animer l'embryon. Koelreuter, Adanson, Ad. Brongniart et d'autres ont émis différentes opinions à ce sujet.

Comme on a cru voir remuer les globules du pollen, on a pensé que ce pouvaient être des animalcules, et que peut-être il s'en introduisait dans la jeune graine pour former l'embryon. Mais il est évident que toutes ces choses sont hypothétiques, et que c'en serait fait de la physiologie si on lui donnait de pareilles bases.

Toujours est-il que l'embryon n'apparaît que plusieurs jours après la dissémination du pollen, et lorsque déjà les différentes parties de la fleur sont fanées. C'est qu'en effet il est évident que n'importe comment les granules des anthères pénètrent jusqu'à l'ovaire, leur passage ne saurait être instantané ni leur action aussitôt manifeste. Le moment où le pollen s'introduit dans le stygmate est toujours marqué par la flétrissure de la fleur entière: on a remarqué que les fleurs châtrées et les fleurs femelles et veuves des plantes dioïques conservaient plus long-temps leur fraîcheur que les fleurs hermaphrodites dont les anthères sont restées intactes. Il en est de même des fleurs doubles et stériles, et pour la même raison (1).

En récapitulant toutes les parties de la fleur.servant à la génération sexuelle des plantes, nous trou-

(1) Voyez Linné et Mirbel. 
vons : les divisions vertes ou colorées du Calice ou de la Corolle, lesquelles entourent et protègent les vrais organes sexuels; les Etamines, ou organes mâles, terminées par des anthères; celles-ci, recélant dans leurs cellules de petits sacs formés de la matière séminale nommée Pollen; le Pistil, ou organe femelle, dont l'évasement terminal prend le nom de Stygmate, et le support, le nom de Style; les vaisseaux très-fins et très-délicats du sommet de l'amande, que l'on croit être le conduit de la matière fécondante émanée du pollen; l'Ovaire ou fruit, réunion des semences et de leurs enveloppes; la Graine, qui est formée de l'embryon et du périsperme; l'Embryon lui-même, lequel date ostensiblement de l'époque de la fécondation, est entouré d'un fluide nommé amnios, et communique par des vaisseaux, d'un côté avec le pistil, et par lui avec le pollen des anthères, et d'un autre côté avec l'ombilic du fruit, et par lui avec le reste de la plante; enfin la Plantule, ou l'embryon grandi, of-. frant les différentes parties d'une plante nouvelle : la Radicule, la Plumule ou jẹne tige, le Collet, ou partie intermédiaire, et les Cotylédons ou feuilles sé.minales.

Les organes de la fructification varient rarement pour les plantes de la même famille, ou plutôt c'est surtout d'après l'examen de ces organes qu'on juge de l'uffinité ou de l'éloignement des espèces et des genres. Les végétaux qui se ressemblent par la disposition des fleurs et du fruit diffèrent rarement pour le reste de la structure : aussi les principaux bolanistes ont-ils pris les organes de la leur ou les différentes parties du fruit pour bases de leurs systèmes I. 
S2 LiV. II. DE LA REPRODUCTION DES ÊTRES VIVANS. de classification (1). Tournefort, envisageant avant tout l'apparence extérieure des fleurs, distinguait les plantes en campaniformes, infundibuliformes, cruciformes, rosacées, personnées, flosculeuses, radiées, anomales, etc. B. et A. de Jussieu ont fondé leur méthode, surnommée naturelle malgré ses grandes difficultés, sur l'existence ou l'absence, sur le nombre et la disposition des cotylédons de la plantule renfernéc dans la grain. Il est sûr, en effet, que les plantes qui se ressemblent en ce premier point sont analogues sle toute manière. linné, qui ne se dissimulait point la paresse des hommes, s'efforça de créer un système d'une étude plus expéditive, d'une conception plus facile : il aima mieux, en conséquence, londer ses distributions sur le nombre, sur l'arrangement visible des organes sexuels, mâles et femelles, étamines et pistils. Nous croyons devoir donner ici une idée de sa classification.

D’abord, Linné considérait si les organes sexuels étaient visibles, s'ils étaient réunis dans la mêure fleur, libres ei non adhérens entr'eux; et, lorsque les étamines étaient, égales entr'elles, il les comptait, de manière à ce que ses dix premières classes reposassent uniquement sur ce nombre des étamines", variant d'une à dix ; puis, unissant le nom de nombre gree avec un autre mot grec signifiant mari, il désignait ces dix premières classes par les noms suivans : Monandrie, Diandrie, Triandrie, Tétrandrie, Pentandrie, Sexandrie, Heplandrie, Octandrie, Ennćan-

(1) Voycz les ouvrages de Tournefort, Linné, Adanson, Jussieu, Lamarck et Decandole. 
drie, Décandrie; et il rangeait dans la Dodécandrie les plantes dont les fleurs ont moins de vingt étamines, mais plus de dix.

Quant aux plantes ayant au moins vingt étamines, elles étaient de l'Icosandrie lorsque les étamines adhéraient au calice, et de la Polyandrie quand elles tenaient à l'ovaire ou réceptacle. Si de quatre étamines renfermées dans la même fleur deux se trouvaient plus longues, c'était la Didynamie; si sur six étamines il y en avait deux courtes et quatre longues, alors c'était la Tétrad́ynamie.

A l'égard des plantes dont les étamines adhéraient entr'elles par leurs filets, il les rangeait dans la Monadelphie, la Diadelphie eu la Polyadelphie, selon qu'elles formaient un, deux ou plusieurs faisceaux; et lorsque cette adhérence des étamines se faisait par les anthères, il en faisait une dix - neuvième classe sous le nom de Syngénésie. Était-ce avec le pistil que les étamines adhéraient, ou se trouvaient-elles posées sur lui, alors c'était la Gynandrie.

A près cela venaient les fleurs ne renfermant chacune qu'une partie des organes sexuels : dans ce cas, lorsque les fleurs mâles et les fleurs femelles naissaient sur la même tige, la plante était classée dans la Mo. nœcie; dans la Diœcie, au coniraire, lorsque les fleurs mâles étaient toutes sur un pied et toutes les fleurs femelles sur un autre; enfin la Polyganie renfermait les plantes ayant des fleurs mâles, des fleurs femelles et des hermaphrodites, isolées les unes des autres, mais réunies sur la même tige, ou bien séparées sur deux ou sur trois individus différens. Linné formait sa vingt- 
S4 LIV. II. DE LA REPRODUCTION DES ÊTRES VIVANS. quatrième et dernière classe avec des plantes n'ayant point de fleurs visibles : c'était la Cryptogamie.

Si cette méthode de classification des plantes n'est ni la plus profonde ni la plus philosophique, il faut avouer du moins qu'elle est la plus facile et la plus générale : il n'existe aucune plante qui n'y ait sa place marquée. Elle est d'ailleurs la plus utile à connaître, puisque la plupart des grands ouvrages de botanique sont distribués d'après les principes de Linné, d'après le Système sexuel.

\section{CHAPITRE VI.}

Reproduction sexuelle des Vers et des Animaux Radiaires (1).

Il y a peu de ressemblance entre les Vers pour les organes du sexe : les uns sont unisexuels, d'autres hermaphrodites, et d'autres androgynes.

Les lombrics, ou vers de terre, sont de ce dernier genre : ils réunissent dans un seul être les organes des deux sexes et ils ont besoin d'un accouplement réciproque. Leurs organes génitaux sont placés vers l'extrémité antérieure de l'animal, près de la tête: ils consistent dans une espèce de corps glanduleux, apparemment le testicule, lequel communique avec une sorte de poche; et ces différens organes ont deux issues à l'extérieur. C'est probablement par ces ori-

(1) Voyez Ellis, Cavolini, Bruguières, Rudolphi, R. Grant. 


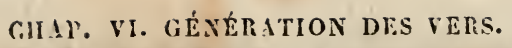

fices que se fait leur accouplement; accouplement non douteux, quoiqu'on ne connaisse point les orgaries destinés à l'opérer. On a aussi trouvé dans ces vers plusieurs paires de paquets d'œufs, rangés à la file les uns des autres comme des grains de chapelet. Il y a des vers dans le corps desquels on trouve un tas d'œufs éparpillés de toutes parts et sans aucun ordre.

A l'égard des vers intestinaux, il en est plusieurs espèces qui ont les sexes séparés. Le mâle du grand ver lombric des intestins a une verge manifeste, sortant par la queue, et, près de ce lieu, une vésicule séminale qui s'étend au tiers environ de la longucur du corps. Une humeur laiteuse la remplit : c'est probablement un testicule que l'espèce de corps pelotonné que l'on voit près de lá. La femelle présente pour organes génitaux une suite de vaisseaux où l'on voit beaucoup d'œufs très-petils, nageant dans une liqueur laiteuse. Les ténias portent aussi des œufs destinés à la reproduction.

La sangsue est androgyne comme le ver de terrc. Ses vésicules séminales sont si considérables, qu'on a vu des personnes les prendre pour un cerveau. Elle a aussi deux testicules glandulcux rubanés, et deux conduits déférens qui versent le sperme dans les vésicules séminales, lesquelles à leur tour le font couler jusqu’à la base de la verge, qui est très-manifeste et très-flexible. M. Cuvier dit que cette verge peut se replier en arrière comme celle du limaçon. L'orifice par où cct organe sort de la sangsue cst voisin d'une espèce de vulve, et ces deux ouvertires sont situćes vers l'extrémité antérieure de l'animal, et sur 
le côté droit du cou. Les sangsues s'accouplent doublement, et leurs oufs éclosent dans leur corps : elles font des petits vivans.

Les radiaires, les étoiles de mer, les oursins, tout cela est hermaphrodite, se reproduit par des œufs et sans accouplement préalable : chaque individu réunit les organes des deux sexes, ou du moins des œufs et le fluide propre à les féconder. Les ovaires forment ici des paquets énormes qui composent toute la partie mangeable de ces animaux. On a remarqué que les œufs de beaucoup de radiaires offraient des mouvemens manifestes à la manière des animaux parfaits. Il sont aussi garnis d'une sorte de cils ou de poils qui les disposent à flotter à la surface des eaux. Il paraîtrait d'après cela qu'ils ont besoin d'éprouver le contact de l'air.

\section{CHAPITRE VII.}

Reproduction sexuelle des Arachnides el des Crustacés (1).

Les Araignées ont des sexes isolés et une espèce d'accouplement : les organes de la génération sont placés à la base de l'abdomen chez le mâle comme chez la femelle. Cependant les mâles des aranéides ou araignées fileuses ont ces organes placés dans des espèces de mains qu'on a nommées palpes. L'accouplement de ces animaux est assez singulier : comme

(1) Foy, Kéaunur, Swammerdam, Latreille, Walckenaër, Leach, etc, 
CHAP. VII. GÉNÉRATION DES MRICHNIDES, ete. ST plusieurs d'entr'eux s'entre-dévorent, ce n'est pas sans d'extrêmes précautions que le mâle se risque à aborder la femelle. Poussé par un besoin devenu irrésistible, il approche de celle-ci; mais avant de la toucher, de la caresser ( car il y a de l'amour et une sorte de caresses partout où la reproduction des espèces exige des accouplemens); avant donc d'aborder la femelle renfermée dans sa toile, le mâle suspend un peu plus haut un fil assez fort pour le supporier et lui servir de retraite en cas de surprise et de danger. Après tous ces préparatifs de prudence qu'il faudrait croire intelligens s'ils n'étaient pas les mêmes chez tous et dans tous les temps sans nulle variation; après ces précaulions machinales, l'animal approche de sa femelle, la touche, et aussitôt se retire, comme pour observer à quelle réception il doit s'attendre. Si la femelle paraît le souffrir ou le désirer, alors il s'expose à en approcher de plus près, et c'est alors que se fait l'accouplement, lequel paraît résulter de l'introduction, dans les organes génitaux de la femelle, d'une petite antenne, sorte de bouton qui est une dépendance des palpes renférmant les organes reproducteurs. Ensuile les femelles pondent des masses d'œufs dans des cocons, variables pour la couleur et la forme : plusieurs même portent paticmment ces oufs dans leurs paltes, et les petits venant à éclore sent quelquefois placés sur le dos de leurs nères. Il est singulier que des animaux si voraces à l'égard des mâles aient quasi la tendresse des didelphes pour leurs pelils.

Les crustacés sont misexucls : les uales ont deux verges siluées vers la cinquième paire de palles, et 
SS LIV. II. DE LA REPRODECTION DES ÊTRES VIVANS.

la femelle a deux vulves répondantà la troisième paire; et ce qui est assez singulier, c'est que, quoique les organes de l'accouplement soient doubles, les organes intérieurs, les testicules des mâles et les ovaires des femelles sont presque toujours uniques pour chaque animal. Lorsque les œufs sont pondus, bientôt les femelles les collent et les fixent aux membranes dont le dessous de leur queue est garni : et c'est là qu'ils éclosent. Cette particularité fait que les sexes sont faciles à reconnaître dans cette sorte d'animaux : la queue des femelles est plus large.

\section{CHAPITRE VIII.}

Comment se Reproduisent les Mollusques.

Nous sommes loin de connaître la génération des Mollusques aussi bien que celle des animaux vertébrés; il est difficile d'étudier des êtres vivant presque toujours dans les eaux, souvent entourés de tests ou de coquilles épaisses, et dont l'histoire toute entière a d'ailleurs si peu d'années d'existence (1).

Beaucoup de ces animaux réunissent sur un seul individu les organes sexuels mâles et femelles; et parmi eux, les uns ont besoin d'un accouplement réciproque pour se reproduire; les organes des deux sexes qu'ils possèdent n'ont d'action que par le concours des mêmes organes d'un animal de la même

(1) royez Bruguières, Denis de Montfort, G.Cuvier, Poli, Lamarck, Ilainville, Savigny, Péron, Quoy, Gaymard, Chamisso, cic. 
CHAP. VIII. REPRODVCTION DES MOLLUSQৃUES.

espèce : ce sont par conséquent de véritables andro. gynes. D'autres s'engendrent d'eux-mêmes sans union double ou simple, sans accouplement : ce sont en d'antres mots de véritables hermaphrodites. Enfin, il est des mollusques ayant des sexes séparés, et qui ne se fécondent qu'en s'accouplant à la manière de la plupart des animaux. Pareillement leurs œufs different : tantôt ils sont couverts d'une croûte calcaire comme ceux des oiseaux, tantôt mous comme ceux de beaucoup de poissons : ensuite les uns éclosent après leur sortie, et les autres dans le corps même de l'animal, ce qui fait paraître ces derniers vivipares. On ne pense pas qu'il y ait de véritable copulation dans aucun de ces animaux, quoique plusieurs d'entre eux afent une espèce de pénis et même une prostate; mais on croit que la fécondation des œufs se fait par une sorte d'arrosement séminal comme dans beaucoup de poissons; et la ponte des œufs est ordinairement précédée, comme on le voit pour les grenouilles et les crapauds, par de longs embrassemens qui paraissent exciter les contractions de l'oviducte.

Les œufs des Sèches sont gros, et enchaînés ensemble en forme de grappe, ce qui les fait nommer raisins de mer. Les limaçons et les mollusques des coquilles univalves, ou pour mieux dire les gastéropodes, ont, presque tous, les organes de la génération placés sur le côté droit du corps, et souvent près de la tête. Leurs organes sont nombreux et compliqués : ils ont un ovaire, un oviducte, une matrice, et de plus, un testicule, un conduit déférent, une verge, une boursc commune des organes de la génération. Cela est encore plus compliqué dans les colimaçons: 
ceux-ci ont des espèces de vésicules séminales; leur verge ressemble à un long fouet, et elle est percée en dessous : il faut même qu'elle se replie pour darder la semence. Chaque colimaçon a de plus une bourse à dard, laquelle peut se renverser sur elle-même à la manière de la bourse de la génération. Du fond de la première sort une espèce d'éminence tranchante à quatre pans, et à l'aide de laquelle ces animaux semblent chercher à se piquer réciproquement, au moment de la double copulation. "Ce n'est quaprés ces " cérémonies préliminaires, dit M. Cuvier, que le " véritable accouplement a lieu par l'insertion réci" proque des verges. Mais ce dard, à quoi sert-il? " est-ce pour réveiller un peu par sa piqûre l'énergie "de ces animaux apathiques? mais alors pourruoi " manquerait-il à la limace et à tant d'autres mo!" lusques qui n’ont guère plus de vivacité (1)?"

Il y a une espèce de paludine surnommée vivipare, qui, en effet, produit des pelits vivans : même Spallanzani a prétendu qu'il en était de cet animal comme des pucerons observés par Bonnet, c'est-à-dire qu'élevés séparément, quoiqu'assurêment unisexuels, ils produisent plusieurs générations sans accouplement. Cela est d'autant plus surprenant, ainsi que l'observe M. Cuvier, qu'on trouve parmi ces animaux autant de mâles que de femelles, et même des mâles dont le pénis est assez évident pour que l'examen le plus superficiel puisse toujours le faire distinguer de la femelle.

Les mollusques acéphales, dont les différentes.

(1) Cuvier : Mémoires pour servir ì l'Histoirc des Mollusques. 
CHAP. VIII REPRODUCTION DES MOLLUSQUES.

espèces d'huîtes font partie, sont tous hermaphrodites: ils se fecondent sans accouplement, et même ils nont d'évidens que les organes du sexe femelle. Un seul individu suffirait probablement pour perpétuel l'espèce entière. Les conduits des œufs communiquent avec une espèce de vésicules glanduleuses qu' peut-être sécrètent une humeur séminale par laquelle ces œufs sont fécondés. Tous ces mollusques acéphales font des petits vivans : ce ne sont pas des œu's, ce sont de petits animaux réunis dans leurs cocuilles qui sortent de leurs corps. Voici, au reste, cequ'on raconte de la production des huîtres proproment dites : "Les œufs sont rejetés sous la forme " de frai ou d'une sorte de fluide blanc assez sem" blable à une goutte de suif : c'est au milieu de cette , liqueur qu'on aperçoit au microscope une quantité " innombrable de petites huîtres. Cette malière, dans " laquelle elles nagent, sert sans doute à les agglu„ tiner aux corps sous-marins et plus souvent aux " individus de la même espèce. Alors les jeunes huî"tres, en se développant, étouffent pour ainsi dire „ les anciennes, car elles empêchent l'eau d'arriver „ jusqu'à elles et entraventt même l'ouverture de leurs „ coquilles. C'est ainsi que se forment ces énormes " bancs d'huîtres qui garnissent nos côtes, et qui " malgré l'immense consommation que l'on fait de n ces animaux depuis plusieurs siècles, semblent ne " devoir jamais s'épuiser. "On dit qu'il en est de même de plusieurs sortes de bivalves, dans les branchies desquels on trouve de petits mollusques vivans et pourvus de leurs coquilles. Mais il est des savans qui ont prétendu qu'il s'agissait là d'animaux parasites 
92 LIV. II. DE LA REPROdUCTION DES ÈrES VIVANs. et non de fotus sortant des ovaires par les branchies de leurs mères : MM. Rathke, Jacobson, Blainvile, E. Home et Bauër, discutent maintenant sur cet objet à Londres, à Copenhague et à Paris.

Pour prouver combien de choses restent à éclarcir relativement à la génération des mollusques, il sıffit. de citer ce qu'on rapporte de la reproduction les Biphores. On dit que non-seulement leurs œufs s.nt adhérens, mais que les petits qui sortent de ces œufs restent enchaînés entr'eux et nagent ainsi par aĝ̣lomérations constantes et régulières jusqu'au parait accroissement de chaque individu. On ajoute que es petits ne ressemblent nullement à leurs parens, at que ce n'est qu'au bout de deux générations qu'apres s'être transformés, cette ressemblance a lieu.

\section{CHAPITRE IX.}

Idée générale de la Génération chez les Poissons (1).

Les Poissons sont ovipares et unisexuels. On a prétendu cependant que plusieurs étaient hermaphrodites : on avait surtout insisté sur les lamproies, parmi lesquelles, disait-on, ne se rencontraient jamais d'individus mâles : mais des hommes dignes de foi se sont assurés du contraire dans ces derniers temps. Les poissons sont donc unisexucls; mais la plupart engendrent sans accouplement. La femelle incommodée par une

(1) Voyez Aristole, Artédi el Linné, Gouan, Daudin, Lacépède, Jacobi, Ed. Ilome, ctc. 
cHAP. IX. GÉNhation CHEz LES POISSONS. 93 masse d'œuls souven énorme (on en a compté jusqu'à neuf millions dar une seule morue), les dépose tantôt près des rivagedes eaux, tantôt dans la vase : le mâle, attiré là so par l'attachement désintéressé d'un sexe pour l'atre, soit par l'instinct de société, soit enfin par qu ques émanations échappées de ces œufs vers lui, rénd l'humeur séminale provenant de la laite, c'est-dire des testicules, sur le frai des femelles, et pari les œufs sont fécondés, et des petits en naissent $d_{15}$ l'espace d'environ huit à neuf jours.

Le premier jour, ces petı œufs paraissent simplement composés de jaune sa albumen, et entourés d'amnios; le deuxième jour, paraît déjà comme un point animé et opaque au cen? du petit œuf; le troisième jour, on peut apercevole cœur et ses battemens; l'embryon paraît teniùu jaune et ne faire qu'un avec lui; ce jaune, cobnu dans un double sac séreux, communique avec l'testin du jeune poisson, comme nous le verrons poule poulet : la queue

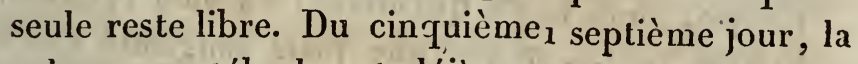
colonne vertébrale est déjà appente; le huitième jour, on voit deux points noirs àl tête, ce sont les yeux : les nageoires pectorales sontralement visibles; la queue est repliée; l'embryon s'ite en tous sens. Le neuvième jour enfin, la queue be les membranes de l'œuf, et le poisson sort de ses erloppes, emportant avec lui la portion du jaune i adhère à son ventre et dont il se nourrissait. Ceisidu du jaune sert à le nourrir encore les premieriours. II croît ensuite le premier jour plus qu'il ne cîtra les vingt jours suivans. Ordinairement il acqut finalement 
94 LIV. II. DE LA REPRODUCTIOTDES ETRES VIVANS. une étendue cent fois plus condérable qu'elle n’était à sa naissance.

Ainsi beaucoup de poisson pondent leurs œufs, et c'est après la sortie de ces œuf̣ue le mâle les féconde: mais il n'en est pas ainsi d tous les êtres de cetle famille. Il est d'autres poissis (les raies, les squales, les requins) qui font des atits vivans; je veux dire que leurs œufs restés danl'abdomen y ont éprouvé une sorte d'incubation mernelle, après laquelle ils ont éclos avant d'être retés dans les eaux. Par conséquent ces derniers antaux s'accouplent; car il est clair que des œufs écloiu dedans du corps n'ont pu être fécondés sans l'inomission du fluide séminal.

Mais quel que soit lieu où ils éclosent, les œufs des poissons ne sont $s$ toujours assez nous ou assez petits pour être expsés du corps sans difficuités et par les voies naturels : ces œufs ont quelquefois une conformalion si sirulière, leurs enveloppes sont si coriaces et leur mie offre un volume si grand, que, pour lear livrer psage, il faut que l'abdomen se rompe; alors voice qui arrive : ou bien l'abdomen s'ouvre tout-à-ç par une plaie sanglante que les inégalités des $œ^{j}$ ont produite; ou bien, par suite de la pression gexercent les œufs, les tissus peu-àpeu ramollis sechirent insensiblement et sans trop de douleurs. 


\section{CHAPITRE $\mathrm{X}$.}

De la Gínération chez les Reptiles (1).

Les Reptiles ont les sexes séparés; tous s'accouplent, mais plusieurs sans intromission. Les mâles ont toujours et des testicules et des canaux déférens ouverts dans le cloaque; les femelles ont des ovaires et des oviductes : ce sont là les organes essentiels de la génération. Chez les deux sexes, les organes reproducteurs ont la même issue que le conduit intestinal et les organes urinaires. Beaucoup de mâles n'ont pas de vésicules séminales; ct cela, joint à la lenteur naturelle à ces animaux, rend leur accouplement sourent fort long. J'ai dit que plusieurs s'accouplent sans intromission; ces derniers n'ont point de pénis.

Les Serpens s'accouplent en s'entrelaçant ; le pénis dont les mâles sont pourvus rend leur conjonction parfaite. Leurs œufs sont encroûtés; et la chaleur du soleil, chez le plus grand nombre des espèces, suffit pour les faire éclore sans iricubation. Cependant toutes les espèces ne pondent pas ainsi leurs œufs au grand air : les vipères, par exemple, les conservent dans leurs entraillez jusqu'à ce que les petits soient éclos. Ce sont donc de véritables vivipares, à cette différence près, que les petits n'ont aucune communication avec les organes et le sang de la mère,

(1) Voyez Swammcrdam. Valisnieri, Roesel, Demours, Daudin . Prevost et Dumas, Dutrochet, mais surtont le juclicicux Spallanzani. 
96 LIV. II. DE LA REPRODUCTION DES ÊTRES VIVANS.

comme cela a lieu chez les animaux à mamelles : ils sont isolés dans leur coquille comme ils le seraient posés sur la terre, quoi qu'ait pu dire de contraire M. Dutrochet; seulement, ils sont échauffés par la chaleur vitale des organes qui les tiennent renfermés.

Les Tortues s'accouplent aussi avec intromission : e!les ont une verge, des testicules, des ovaires, etc. Mais cet accouplement des tortues est lent comme toutes leurs actions : on le voit durer souvent de quinze à trente jours. Les œufs de la femelle ne sont que glaireux et mous en sortant de l'ovaire; mais ils se couvrent d'une croûte calcaire en parcourant l'oviducte. Ils éclosent sans incubation au bout d'un temps variable.

Les Lézards ont tous les organes de la reproduction, excepté des vésicules séminales chez le mâle et un clitoris chez la femelle : la plupart même ont deux pénis hérissés d'épines. Mais le crocodile n'en a qu'un. L'accouplement se fait à distance et sans intromission dans les Salamandres : les mâles de ces espèces n'ont point de pénis. Cependant ils embrassent leurs femelles, ils les stimulent en leur prodiguant des caresses. Mais la semence du mâle n'arrive dans le cloaque de la femelle que par l'intermédiaire de l'eau; de manière que l'éınission séminale ne féconde que les œufs déjà sortis et ceux qui sont au moment de sortir. Ici, l'accouplement et ses préludes d'amour sont beaucoup plus courts que dans les tortues et les grenouilles. L'œuf de la salamandre une fois pondu et fécondé par le mâle, il en sort un têlard au bout d'à-peu-près sept jours : et quelque temps après, ce petit animal se dépouille de ses organes de poisson, 
GHAP. X. GÉNÉRATION CHEZ LES REPTILES.

et il devient un vrai reptile par ses membres, par ses poumons et toute sa structure. Seulement, il conserve long-temps ses nageoires.

Dans les grenouilles et les crapauds, les cítreintes des mâles sont vives et durent long-temps. Les bras des mâles sont appliqués sur les flancs de la femelle, et lui forment comme une ceinture fortement serrée, ce qui ne laisse pas que de favoriser ses efforts pour l'expulsion des œufs. Ces animaux (je parle des mâlès) sont alors insensibles à la doúleur comme à la faim et à tout autre sentiment que l'amour: On a beau les blesser, les amputer, Ies brûler avec cruauté jusqu'aux os, ils ne quittent leurs femelles qu'aux approches de la mort : on en a mêmé décapité qui né cessaient pàs aussitôt pour cela leurs étreintes. Ils' semblent conserver l'ardeur de la procréation aussi' long-temps que la vie. C'est pendant ces embrassemens singuliers que lés œufs de la femelle sortent de son corps ; et le mâle ne cesse de les arroser de son: fluide prolifique à mesure qu'ìls paraissent ani-dehors. Ces vives étreintes du mâle, ont une durée variable comme la température du pays ou de la saison; mais elles peuvent, continuer jusqu'à dix jours, et même par-delà. Il paraît cependant que Roesel est parvenu à séparer ces animaux si ardens en coupant aux mâles les petits tubercules de leurs pattes de devant : et c'est probablement d'un fait semblable qu'est venue' l'opinion singulière que les grenouilles mâles et les crapauds fécondent leurs femelles par le pouce gonflé de leurs nembres antérieurs ! C'est pendant l'accouplement que se fait l'expulsion des oufs, et c'est un véritable accouchement pour les difficultés et la lenI. 
$9 S$ LIV. II. DE LA REPRODUCTION DES ÊTRES VIVANS.

teur des résultats. Le mâle, outre la fécondation qu'il opère, est un aide indispensable à l'expulsion des œufs. Si on sépare la femelle du mâle avant que les œufs soient tombés dans le cloaque, alors tout accouchement est impossible. C'est encore ici une prévoyance de la nature, d'avoir uni et associé dans le même acte et dans le même individu la puissance qui fait sortir le frai et celle qui le féconde.

Linné avait prétendu que dans aucun corps de la nature la fécondation ou l'imprégnation des germes ou des œufs n'avait lieu hors du sein de la mère : les reptiles dont nous parlons maintenant offrent la preuve du contraire. Les œufs de grenouilles et de crapauds nie sont féconds qu'alors qu'ils sont sortis, et sortis pendant l'accouplement. Ceux qu'on arrache ou qu'on fait forcément sortir de l'intérieur du corps sont toujours stériles si l'on ne fait pas intervenir le fluide séminal du mâle. L'abbé Spallanzani, de judicieuse mémoire, a fait des expériences sans réplique pour prouver ce fait. Toutes les fois que cet habile physiologiste a tiré des œufs de grenouilles soit des ovaires, soit des oviductês, il a eu beau les placer dans les circonstances les plus favorables, ces œufs n'ont jamais rien produit; mais ceux qui étaient sortis pendant l'accouplement étaient toujours féconds : au temps dit, des têtards en éclosaient. Il fit plus : pour s'assurer de l'intervention du mâle, il en cuirassa plusieurs au moment de l'accouplement; il leur mit des caleçons de tafetas ciré (s'inquiétant peu des railleries que ce genre d'expériences ne pouvait manquer d'attirer à un pieux abbé), et il vit qu'alors les œufs de ces reptiles restaient stériles. Il essaya 
CHAP. $X$. GÉNÉration GHEZ LES REPTILES.

d'arroser quelques portions de frai du fluide dont il trouvait ces petits caleçons mouillés, et il vit qu'il s'y développait alors des têtards. En transportant ces reptiles dans l'eau limpide d'un bocal, ou bien en les tenant accouplés dans sa main, il assista à cette aspersion des œufs de la femelle par le fluide prolifique du mâle, et constamment alors le frai était productif. Voilà même pourquoi l'accouplement de ces animaux est si long, le mâle ayant à féconder les œufs à mesure qu'ils sortent de la femelle. Spallanzani a trouvé en effet quaranle-trois pieds de long à un chapelet d'œufs sortis d'une seule grenouille, et cette masse de frai, composée de plus de douze cents œufs, avait été arrosée par le mâle successivement et de distance en distance. Cette sorte d'accouchement et de copulation, ce mélange de douleurs et de jouissances pour l'un des sexes, dure souvent l'espace de huit à quatorze jours. Cela est d'autant plus lent que les animaux frayent dans une saison ou dans un pays plus froid, plus long chez le crapaud que chez la grenouille, plus long en Allemágne qu'en Italie. Il y a eu, à l'égard de ces reptiles, les mêmes différences entre les résultats de Roesel et ceux de Spallanzani, qu'entré les expériences de Malpighi et celles du baron de Haller concernant la formation du poulet. Rien ne hâte ces choses comme la chaleur du climat.

Les embrassemens du mâle sont si violens dans celte sorte d'animaux, que la mort des femelles en est quelquefois le résultat : souvent du moins les oviductes se déchirent et les œufs passent dans le ventre ou dans la poitrine; mais comme le mâle n'a pu les féconder au milieu des organes, il est impossible 
100 LIV. II. DE LA REPRODUGTION DES ETTRES VIVANS. qu'il s'y développe jamais de têtards, impossible également que ces animaux fassent jamais de petits vivans.

Chez la plupart de ces reptiles le mâle reste accouplé et vivement uni à la femelle pendant la ponte de celle-ci, et s'il concourt à l'expulsion des oufs hors de leurs réservoirs, cela ne peut être que par les fortes pressions qu'il exerce sur les flanes de la femelle. Toutefois il est une espèce de crapaud, je veux parler du Pipa, qui emploie ses pattes antérieures à tirer les oufs du corps de sa femelle et à les pelotonner avec adresse tout en les arrosant de l'humeur fécondante. Cet animal, que ce genre d'inslinct a fait surnommer le crapaud accoucheur, finit par placer ces œufs sur le dos de sa femelle, qui les porte dans autant de cellules creusées dans sa peau jusqu'à leur entière maturité, à-peu-près comme la sarigue et le kanguroo conservent leurs petits dans l'espèce de poche qui protège leurs mamelles. Ce crapaud est pour ainsi dire le didelphe des reptiles.

\section{CHAPITRE XI.}

Idèe de la Feproduction des Oiseaux.

Les oiseaux, conme on sait, sont ovipares. Les femelles n'ont qu'un seul ovaire (le gauche), où sont renfermés tous les oeufs qu'elles doivent pondre en plusieurs années. Cles oufs sont de différentes grosseurs : ceux qui sont le plus près de sortir sont beau- 
coup plus gros et déjà jaunâtres; ils ne contiennent point encore d'albumen. Les autres sont successivement plus petits et incolores. Les premiers sont les seuls susceptibles d'être actuellement fécondés par le màle. Presque tonjours cetté fécondation s'opère quelque temps avant la sortie des oufs; cependant l'approche du mâle et le contact de la semence ne sont pour rien dans leur expulsion ni même dans leur accroissement. Ainsi donc, fécondés ou non, le pavillon dilaté de l'oviducte s'applique sur les ceufs les plus gros, les plus mûrs, et les détache de l'ovaire. Nous avons dit qu'ils étaient exclusivement composés de jaune sans albumen; mais pendant leur: trajet et leur séjour dans l'oviducte, le jaune s'entoure des glaires albumineuses qui lubréfient ce canal; et ces grlaires auxquelles le jaune s'unit, composent ensuite le blanc de l'œuf. Jusque-là l'ovule ćtait mou et sans enveloppe résistante; mais arrivé à l'extrémité de l'oviducte et dans le cloaque, il se trouve bientôt enveloppé par la matière calcaire que la surface de ces conduits sécrète. Ensuite l'expulsion de l'ouf est apérée par la contraction musculaire du cloaque et des parois du ventre, et c'est par l'incubation que le jeune animal se développe.

A l'égard de la fécondation de l'œuf, elle est l'ouvrage de la liqueur séminale du mâle, avec-accouplement, mais d'ordinaire sans intromission. La plupart des oiseaux n'ont, en effet, aucun organe visible pour une copulation véritable : à l'exception de l'autruche et de quelques oiseaux de l'ordre des canards, ces animaux nont point de verge; seulement on apercoit près de 
102 LIV. II. DE LA REPRODUCTION DES ÊTRES VIVANS.

l'orifice du cloaque un petit tubercule imperforé qui est l'équivalent très-imparfait du pénis des autres animaux, de sorte que l'accouplement du plus grand nombre des oiseaux n'a lieu que par un simple contact de l'anus des deux sexes. Ces animaux sont páreillement dépourvus de vésicules séminales servant de réservoir au sperme; et leurs testicules, qui restent collés à la partie postérieuré de l'abdomen dans le voisinage des reins, ne sortent jamais à l'extérieur et sont privés de toutes ces enveloppes qui composent les bourses des mammifères. Du reste, ils sont composés d'un tissu blanchâtre et délicat comme chez ces derniers; et l'immensité des petits vaisseaux dont ils sont formés aboutissent finalement à un conduit unique pour chaque testicule : ce sont les canaux déférens, lesquels ont leur terminaison finale dans le cloaque:

Une chose paraît étonnante dans cette structure des organes génitaux des oiseaux : je veux parler de la puissance de fécondation attachée à la liqueur séminale de ce genre d'animaux. Nous avons dit, en effet, que le sperme passe sans impulsion visible, sans copulation véritable, du cloaque du mâle dans celui de la femelle; et cependant ce fluide parvient constamment à travers la filière étroite des oviductes jusqu'aux ovaires, où il féconde plusieurs œufs à-lafois. Une autre chose surprenante ici, comme chez les autres animaux, c'est que le pavillon libre de l'oviducte aille précisément s'appliquer, pour l'en détacher, sur celui des ovules qui est le plus gros et le plus près de la maturité. Ne serait-on pas tenté d'attribuer à ce tube contractile et sans conscience une 
espèce d'instinct au moins égal à l'instinct qu'on voit en des animaux entiers plus imparfaits?

Parni les oiseaux, les uns vivent en polygames : je veux dire que le même mâle féconde plusieurs femelles, non sans choix, mais toujours sans constance. D'autres s'accouplent et vivent unis, du moins durant l'époque des amours, partageant en commun les soins de la famille. Ce sont les oiseaux de ce dernier ordre qui apportent à la construction de leurs nids l'industrie la plus admirable; ce sont cux également qui, après l'éclosion de leurs petits, leur prodiguent le plus assidûment tous les soins attentifs que réclame leur faiblesse. Ce n'est pas que l'incubation des œufs soit toujours plus prolongée chez les oiseaux polygames; mais les petits de ceux-ci sont ordinairement plus forts au moment de leur naissance, et plus capables, aussitôt après leur éclosion, de se mouvoir et de subsister sans le secours, sans la protection de leurs parens. Nous retrouvons partout la même prévoyance de la nature pour le parfait achèvement de ses ouvres: elle a donné plus de force aux jeunes animaux dont la conservation n'était point garantie par l'union et la tendresse mutuelles de leurs auteurs.

\section{CHAPITRE XII.}

De la Composition et de la Structure de l'œuf avant et durant l'in. cubation.

Pour ne pas compliquer ce sujet déjà assez difficile par lúi-même, nous nous bornerons dans ce chapitre 
104 LIV. II. DE LA REPRODUCTION DES ETRES VIVANS. uniquement à ce qui concerne l'œuf des oiseaux (1). Cette espèce d'ceuf est revêtu d'une enveloppe calcaire, poreuse, et dont la couleur varie suivant le genre d'oiseaux; mais la forme en est si invariable, qu'on la cite pour modèle. Cette coque calcaire est doublée d'une épaisse membrane ; c'est la membrane commune de l'ouf. Au-dedans d'elle est l'Albumen ou Je blanc d'œuf, au centre duquel se trouve le vitellus ou le jaune. Co dernier a , comme dit l'illustre Haller, la forme de la terre ; c'est un globe aplati vers ses pôles, lequel est de toutes parts entouré par l'albumen. Outre cela, toute la masse fluide de l'œuf est attachée aux deux bouts de la coque par des espèces de ligamens blanohâtres qu'on a nommés Chalazes. Le vitellus est la partie la plus légère de l'œuf, de sorte qu'il tend toujours à se rapprocher de la surface; mais la structure des deux chalazes est telle, qu'elle rend ce déplacement impossible tant quẻ l'œuf reste plein. Nous devons ajouter que le vitellus est entóuré d'une membrane fine qui lui est particulière; c'est elle qui empêche la diffusion du jaune. Une chose singulière, c'est que la cicatricule de ce jaune est constamment tournée vers le gros bout de la coquille : nous verrons avec quelles autres conditions cette première disposition coïncide, et combien Ja nature se montre conséquente dans le plan de ses desseins.

Le premier effet de l'incubațion est d'élerer la température de l'œuf et d'en évaporer l'humidité à tra-

(1) Voyez Aristote, Fabrice d'Aquapendente, G. Harvey, N. 8ténon, A. Maître-Jean, Malpighi, Lancisi, A. Haller, Needham, Vicq-d'Azyr, Dutrochet, G. Curier, Prévost et Dumas. 
vers les porosités de la coque calcaire. Il rúsulte de cela que l'intérieur de l'œuf diminue à-peu-près comme diminuerait un liquide qu'on ferait chauffer dans un vase inerte. Alors il se forme un vide dans l'œuf, et la membrane de la coquille se sépare en deux feuillets vers le gros bout. Le feuillet extérieur reste adhérent à celte coquille; l'interne suit la chalaze qui le tiraille, et s'applique sur les parties fluides de l'œuf. Ensuite la chalaze affaiblie de ce feuillet de membrane s'en détache, et e'est alors que tout l'albumen gagne le petit bout de l'œuf et que le jaune se rapproche du bout opposé, de manière à exposer la cicatricule, où se trouve renfermé le germe du nouvel ètre, en contact aveo l'air qui remplit le vide. Cela fait que la même chaleur qui détermine le développement du germe, lui procure en même temps les moyens de respirer dès les premiers instans de son accroissement.

Toutefois nous devons dire qu'il y a dans ce premỉer phénomène autre chose qu'un pur effet physique. D'ahord rien n'explique la rupture d'une chalaze plutôt que la rupture de l'autre, si elles n'avaient été organisées en conséquence. Ensuite, ce n'est pas une chose physique que la tendance du jaune à se porter vers le gros bout de l'œuf; car nous avons dit que ce jaune est plus léger que le.blanc, et l'on voit bien que le gros bout de la coquille, comme le plus pesant, doit tendre à devenir le plus déclive : il y a donc ici quelque chose de vital.

Voilà,les premiers préparatifs pour la formalion du nouvel être. Cependant on voit paraître des vaisseaux dans l'ouf aux environs de la cicatricule. Ces vaisseaux, qui forment bientôt une belle figure veineuse 
en auréole, sont le premier indice de la vie du nouvel être; mais est-ce de lui qu'ils proviennent? On ne voit encore de vaisseaux nulle part ailleurs : ni dans l'épiderme du vitellus, ni dans la membrane par qui la coque de l'œuf est revêtue; et à l'égard de la membrane moyenne et du cborion, nous verrons qu'elles proviennent du nouvel être, et que conséquemment elles ne précèdent point l’incubation. Lorsqu'on examine un œuf couvé seulement depuis trois jours, on s'assure, en dépouillant le vitellus de son épiderme, qu'il n'y a de vaisseaux que dans ce vitellus, c'est-àdire autour du germe qui s'accroît.

Mais bientòt l'organisation de l'œuf éprouve d'autres changemens. Au lieu de perdre de son volume, le jaune ou vitellus prend de l'accroissement, au point de roinpre sa membrane propre : en même temps il devient plus fluide, moins consistant. Et comme il n'a de rapports qu'avec l'albumen, et avec l'air par qui le vide de l'(euf est occupé, on conçoit que ce n'est qu'aux dépens de ces deux fluides qu'il peut s'accroître, car le nouvel animal dont il contient le germe ne peut rien lui fournir. L'épiderme du vitellus se rompt spontanément vers le quatriéme jour de l'incubation, mais il est aussitôt remplacé par une autre membrane dont on aurait.jusques-là vainement cherché les traces, tant le tissu en est délicat. Le jeune animal est renfermé sous cette fine enveloppe du.jaune, il est de plus entouré d'une autre membråne qu'on nomme amnios, laquelle adhère à la tunique du vitellus vers le dos de l'embryon.

Ainsi le vitellus a sa membrane comme le jeune foetus ala sienne: voilà presque tout ce qu'on peut 
voir vers le quatrième jour de l'incubation. Mais alors les choses se compliquent.L'amnios, dont nous avons vu le fotus entouré, ne lui forme pas une poche parfaite qui ne permettrait aucun accès. La disposition de l'amnios n'est point telle. Cette membrane adosse ses feuillets de manière à laisser, juste vis-à-vis de l'ombilic du foetus, un espace tubuleux qui sert de passage au cordon ombilical, très-compliqué dans ce genre d'animaux. C'est par cet intervalle laissé par l'amnios que le vitellus communique avec le jeune animal, et celui-ci avec tout l'œuf. Étudions maintenant comment se font ces communications réciproques de l'œuf et du fœtus.

Jusqu'au quatrième jour nous n'avions trouvé que la meubrane commune de la coque et l'épiderme du jaune; mais bientôt le déploiement successif de l'allantoide va former deux nouvelles membranes. Voici comment a lieu ce déploiement d'abord obscurément indiqué par le grand Haller, et démontré depuis avec tous les caractères d'une véritable découverte par Dutrochet, lequel d'ailleurs ignorait absolument ce qu'avait énoncé Haller à cet égard. L'Allantoìde est une dépendance de la vessie : elle tient à celle-ci jusqu'à l'heure de l'éclosion par un canal nommé Ouraque; ct, comıne la vessie, elle est remplie, à ce qu'on croit, par de l'urine. Ce sac urinaire sort de l'abdomen de l'embryon vers le quatrième jour de l'incubation; elle traverse l'ouverture ombilicale entre les feuillets adossés de l'amnios, et, cornme nous l'avons dit, en dehors de la cavité de cette dernière membrane. Ainsi c'est de l'intérieur même du fotus que provient l'allantoide, à laquelle nous verrons bientôt prendre un 
grand accroissement. En même temps, dès la mênie. heure, et pareillement à l'ouverture de l'ombilic, on. aperçoit très-distinctement le pédicule aminci du vitellus qui va aboutir finalement dans l'intestin de l'embryon, de sorte que le jaune de l'œuf communique avec la cavité in testinale. Mais ce n'est pas tout: ce vitellus et son pédicule est entouré de deux membranes. Nous avons dit comment la première de ces tuniques so rupture à l'époque où le jaune se dilate; nous avons dit qu'uno nouvelle tunique apparaissait au-dessous de l'autre après sa rupture g eh bien ! ces deux membranes accompagnent lo vitellus vers l'ombilic de l'embryon. La plas extérieure se joint avec le péritoine costal du foetus; la seconde, la plus interne, continue d'envelopper le vitellus jusqu'à l'intestin, et elle s'unit là avec cette partie du péritoine qui revêt. extérieurement le canal digestif. De cette manière le péritoine et les enveloppes du vitellus ne font qu'un; et si la tunique la plus superficielle du vitellus n'avait pas d'abord été déchirée, le péritoine serait encore imperforé dans tous ses points. Il est impossible d'assigner l'origine de ces connexions du jaune avec l'intestin du jeune animal, et du péritoine de l'un avec les tuniques de l'autre : on ne sait si cette parfaite union résulte de la fécondation de l'œuf ou seulement de lincubation; mais cette connexion, tout mystérieux qu'en soient et la cause et le principe, n'en est pas moins du plus haut intérêt : c'est-là même vraisemblablement qu'est le secret caché de la génération.

Il suit de ee que nous venons de dire que le vitellus communique avec l'intestin du jeune animal, et les 
char. xil. strecture de ínete.

enveloppes de ce vitellus avec le péritoine; de même que la vessie du foetus communique par l'ouraque avec l'allantoïde. Or, nous avons laissé ces deux parties, je veux dire le vitellus et l'allantoïde, renfermées dans la tunique du vitellus; par conséquent, ces deux poches se croisent et s'enclavent l'une dans l'autre vers l'ouverture ombilicale. Cependant, vers le cinquième et le sixième jour de l'incubation, l'allantoide prend un plus grand volume : bientôt, dilatée de plus en plus par le liquide urinaire qu'elle renferme, elle finit par rompre la tunique interne du jaune, par se juxtaposer à la membrane commune de la coque et par lui adhérer. Après cela, elle se plisse en mésentère pour entourer les vaisseaux qu'ellc rencontre sur sa route, et, continuant toujours à sé dilater, elle parvient vers la fin du neuvième ou dixième jour à entourer l'œuf dans toutes lès directions, à-peuprès comme une goutte d'huile répandue sur une petite sphère s'étend de proche en proche jusqu'à en enduire bientôt tout le contour. L'endroit de l'œuf où les ex-, trémités de l'allantoïde se rencontrent est le pelit bout; c'est en effet là qu'elle éprouve le plus de difficultés à s'étendre, à cause de la chalaze inférieure, qui jusqu'alors était restée persévéramment adhérente. Ce déploiement de l'allantoide autour de l'œuf produit deux membranes nouvelles: la plus antérieure est collée à la membrane de la coque; on la nomme Chorion (Harvey), ou membrane ombilicale (Haller) : c'est la plus vasculaire des deux, et l'on dit qu'elle remplit à l'égard du jeune être l'usage à quoi serviront plus tard les poumons : c'est elle, dit-on, qui rougit le sang et qui l’imprègne d'oxygène; elle opère une 
110 LIV. II. DE LA REPRODUCTION DES ETTRES VIVANS.

sorte de respiration. L'autre feuillet de l'allantoïde est plus interne; il enveloppe à-la-fois le vitellus et l'embryon, et ce qui reste de l'albumen : on lui donne le nom de Membrane moyenne : celle-ci est plus mince et un peu moins vasculaire que l'autre. Le canal compris entre les deux feuillets de l'allantoïde est rempli par un fluide urinaire dont la source est probablement aux reins du jeune embryon. Ce qui avait mis obstacle à la découverte des deux membranes nées du déploie. ment de l'allantoïde, c'est qu'on avait confondu ce liquide urinaire avec l'albumen de l'œuf; et justement' ce dernier diminue jusqu'à disparaître complètement à mesure que le liquide de l'allantoïde s'accroît. Ceci même est une harmonie remarquable. Puisque le liquide des reins augmente sans cesse, il fallait bien un espace où il pût s'accumuler sans inconvénient pour l'existence de l'embryon. Or, les deux feuillets de l'allantoïde s'écartent de plus en plus pour le contenir; ces feuillets vont même jusqu'à se séparer toutà-fait l'ún de l'autre. En même temps, par un accord parfait, l'albumen est absorbé par le vitellus qu'il délaye et qu'il liquéfie, et le vitellus lui-même se dégorge dans l'intestin du fœtus; ce qui même est apparemment la principale source où ce dernier puise sa nourriture. Quant au jaune, il conserve toujours à-peu-près le même poids et le même volume jusqu'à la fin de l'incubation : il augmente plutôt qu'il ne diminue. Haller pesa le jaune d'un œuf qui n'avait que sept heures d'incubation, il pesait trois gros; il en pesa un autre qui avait éprouvé une incubation de cinquante-quatre heures, son poids était de quatre gros. Mais si le jaune augmente d'abord, si même il ne 
diminue guère avant l'éclosion, et si, rentré dans le ventre du jeune oiseau, on en retrouve encore des traces trente ou quarante jours après la naissance, il n'en est pas de même de l'albumen, qui diminue d'abord beaucoup et qui finit par disparaître en totalité dès le quinzième jour de l'incubation. Ainsi, le fluide qu'on trouve à l'ouverture d'un œuf déjà avancé n'est point le blanc ou l'albumen; mais c'est le fluide urinaire de l'allantoïde. Cependant, vers la fin de l'incubation, ce dernier fluide diminue pour faire place au fotus plus accru; et vers les derniers jours de l'incubation, on ne trouve plus entre les deux feuillets de l'allantoïde qu'un enduit visqueux, mêlé à des flocons calcaires. Nous examinerons plus tard comment il peut se faire que l'urine du poulet soit si abondante avant même que les reins soient visibles, tandis que ce fluide semble se tarir à une époque où les glandes qu'on en croit la source sont très-développées. Maintenant, nous devons parler des vaisseaux qui se distribuent dans la membrane de l'œuf.

Ces vaisseaux sont de deux sortes, veineux et artériels ; et ces artères ont deux sources différentes. Les vaisseaux du chorion et de la membrane moyenne sont les ombilicaux : ils naissent par trois troncs comme chez les mammiferes. Il y a deux artères qui proviennent des iliaques primitives du fotus, et une veine qui va traverser le foie pour se rendre au cœur : enfin, je le répète, c'est comme pour les mammifères. Mais les vaisseaux du vitellus et de ses tuniques ont une autre source, ils proviennent des vaisseaux mésentériques; l'ouverture s'en fait 
112 LIV. II. DE LA REPRODUCTION DES ÊTRES VIVANS. près du pancréas, et ils se rendent au vitellus en suivant le pédicule que ce dernier envoie à l'intestin du foetus. Ceci offre la plus grande analogie avec ce que nous verrons en étudiant la vésicule ombilicale des ınammifères. Il suit delà que les vaisseaux mésentériques sont les premiers visibles sur les membranes de l'œuf, puisqu'ils ne se'distribuent qu'au vitellus et à ses tuniques: ce sont eux qui composent cette figure veineuse que Malpighi a vue dans l'œuf dès la doużième heure, et que Haller, Harvey et Sténon n'ont aperçue que plusicurs heures plus tard. Mais les vaisseaux ombilicaux ne laissent voir leurs admirables réseaux qu'après plusieurs jours d'incubation; et ce qui précède èn fait deviner la cause : effectivement, puisque ces derniers vaisscaux ne se distribuent qu'aux membranes chorion et moyenne, autrement les deux feuillets de l'allantoide, on voit bién que leurs réseaux ne peuvent être aperçus qu'après le déploiement de ce sac urinaire. Cela explique un fait bien naturel qui causait l'étonnement de l'illustre Haller : c'est que la figure veineuse est déjà bien dessinée au bout de quaranle à cinquante heures, tandis que ce qu'il nomme le beau cercle veineux, c'est-à-dire ce vaste réseau de vaisseaux qui entoure l'œuf en totalité, ne se voit bien que du septième au neuvième jour.

Si maintenant nous récapitulons les différentes parties dont nous venons de faire l'histoire, nous aurons le tableau suivant :

La coquille, dont la forme est ovale et la substance poreuse : elle est de nature calcaire et perméable à l'air et aux fluides aqueux réduits en vapeurs par l'incubation. 
Membrane commune : qui revêt la coque ct est dépourvue de vaisseaux.

L'action de l'air et de la chalcur la sépare en deux feuillets vers la grosse extrémité de l'œuf; alors il se forme un vide que l'air extérieur vient remplir.

Vitellus ou jaune : globe sphérique déprimé vers ses pôles ; plus léger que l'air, il surnage et se met en contact avec l'air intérieur. Il porte à sa surface une tache on cicatricule blan-

(Embryon.) châtre où le germe est renfermé : Malpighi a aperçu les premiers linéamens du poulet dans cette cicatricule au bout de six heures d'incubation, et même avant lincubation.

Albumen ou blanc : entourant d'abord le vitellus dans toutes les direc. tions, rejetẻ ensuite vers la petite extrémité de l'œuf après la rupture de la chalaze supérieure; disparait entièrement après le quinzième jour d'incubation.

Chalazes : ligamens blanchâtres par qui le vitellus était attaché aux deux bouts de l'œuf. L'évaporation détache c'abord celui d'en haut, et vers le neuvième jour le déploiement de l'allantoïde rompt celui d'en bas.

Tuniques séreuses du jaune : Au nombre de deux, la plus superficielle est bientôt rompue par l'augmentation du vitellus ; l'autrẹ l'est ensuite par le passage de l'allantoïde. C'est alors qu'on trouve le jaune de toutes parts diffluent lorsqu'on vient à ouvrir l'œuf incubé.

Pédicule du vitellus : Il communique avec l'intestin de l'embryon, et est entouré jusqu'à l'ombilic d'un double canal formé par les deux tuniques du vitellus : la plus superficielle s'unit au péritoine costal ; et linterne, au péritoine dè l'intestin.

Amnios : Membrane propre et immédiate de l'embryon. Celui-ci est entouré par elle jusquà l'ombilic, qu'elle laisse libre en se réfléchissant sur le cordon ombilical. Cette membrane existe dès la première origine du foetus : il y a entre elle et lui un fluide aqueux formant une sorte d'atmosphère.

Allantoïde: Prolongement de l'ouraque el de la vessie. Composée de deux feuillets ; un fluide cru urineux en remplit l'intervalle. Elle franchit lombilic vers le quatrième jour de l'incubation, et au bout de cinq autres jours elle entoure la (Chorion.) totalité del'œu de ses deux membranes vasculaires ainsi que 
I i/f LIV. II. DE LA MLPRODUCTION DES ÈTRES VIVANS.

de la cavilé qui les sépa re et du liquide que celte cavitérenferme; elle tráverse le vitellus, rompt la chalaze infé-

(M. moy.) ricure, adhère à la membrane commune, el communique d'abord avec la vessie du fotus, ensuite avec le cloarue. Son adbérence avec les tuniques du vilellus empêclse celui-ci d'entrer tout entier dans l'abdomen à l'époque de l'éclosion.

Vaisseaux blancs : ceux qui, selon Haller, introduisent l'albumen dans le vitellus.

Vaisseaux rouges : De deux sortes : les ombilicaux, veines et artères, lesquels se distribuent dans les deux feuillets de l'allantoïde ; et les mésentériques, qui se bornent au vitellus et à ses tuniques. Cenx-ci sont beaucoup plus précoces que les autres, parce que les tuniques du vitellus sont bien antérieures au déploiement de l'allantoïde.

Figure veineuse : Péseau formé par les vaisseanx mésentériçues darrs les tuniques du jaune. Visible dès la douzième heure.

Cercle veineux : Réseau né des divisions des vaisseaux ombilicaux dans les deux feuillets de l'allantoïde, c'est-à-dire le chorion ct la membrane moyenne.

Cordon ombilical : héunion des vaisseaux mésentériques el ombilicaux, de l'ouraque, du pédicule du vilellus et des luniques séreuses de ce dernier. L'amnios se réfléchit súr ces diverses parties, d'où résulte leur union.

Nous verrons au livre suivant dans quel ordre apparaissent et selon quels progrès se développent les divers organes du jeune animal. Il nous suffit de remarquer dès à présent que le fotus a près de lui et uni à ses propres organes tout ce dont il a besoin pour commencer d'exister : le vitellus charrié dans ses intestins peut le nourrir; les vaisseaux ramifiés dans les membranes superficielles de l'œuf peuvent exercer une sorte de respiration; lui-même peut respirer véritablement au moyen de l'air que l'œuf tient en réserve; son urine peut fuer vers l'allantoide; 
CHAP. XIII. COMPARALSON DES OCUFS.

enfin, indépendamment de lincubation, il a autant de sources de chaleur qu'il exerce déjà de fonctions différentes.

\section{CHAPITRE XIII.}

Comparaison des OEufs de Reptiles et de Poissons avec les prícédens.

Il paraît que les OẺufs de vipère et ceux de tous les Reptiles qui ne subissent point de métamorphoses sont semblables aux œufs des Oiseaux : la seule différence est qu'ils sont dépourvus d'albumen. Mais on y trouve, comme dans ceux des oiseaux, un vitellus logeant le petit embryon; on y trouve le pédicule de ce même vitellus allant communiquer avec l'intestin du fœtus. On y voit en outre la membrane commune de la coque, les deux feuillets de l'allantoide, la cavité de cette dernière communiquant avec l'ouraque et la vessie, et s'étendant par degrés, comme chez les oiseaux. Il y a de même un amnios entourant l'embryon, et deux sortes de vaisseaux : les mésentériques, destinés au vitellus, et les ombilicaux, se distribuant dans les feuillets de l'allantoïde. Enfin les phénomènes sont"analogues comme la structure: on voit le vitellus rentrer dans l'abdomen des petits serpens qui sont près d'éclore, comme cela a lieu dans les ois?aux. On a parlé d'une autre analogie qui rapprocherait les vipères des véritables vivipares : on a dit que lorsque les œufs de ces animaux éclosaient dans leurs oviductes, le jeune embryon, entouré de ses mem- 
branes, finissait par contracter des adhérences et par avoir un vrai placenta comme les mammifères; mais il est bien probable qu'il 's'agit là d'une apparence trompeuse admise comme réalité sans assez d'examen.

Ce que nous avons dit des œufs de serpens est également vrai des œufs de lézards et de tortues, à ce qu'on assure; c'est-à-dire que tous les animaux qui ont des poumons dès leur première origine naissent d'un œuf pourvu d'une allantoïde. Au contraire, ceux des reptiles qui subissent des métamorphoses, ceux qui avant d'avoir des poumons n'ont d'abord que des branchies tant qu'ils sont à l'état de têtards, les grenouilles, les crapauds, les salamandres, ces animaux ont des œufs d'une grande simplicité et dépourvus d'allantoide, tout comme les oufs des poissons. Ces derniers reptiles, alors qu'ils sont à l'état d'embryon', n'ont pour toute enveloppe que là membrane amnios. Leur œuf ne contient ni d'allantoide, ni par conséquent de membranes chorion et moyenne : on voit dans cet œuf l'ébauche d'un têtard de couleur noire; ce têtard a un vitellus renfermé sous la peau et continu à ses intestins : il n'envoie au reste de l'œuf ni vaisseaux ombilicaux ni vaisseaux mésentériques; enfin il vit absolument isolé de sa coque. Voilà ce qu'a observé M. Dutrochet. M. Cuvier assure que la structure de l'œuf des poissons est en tout semblable: dépourvu des mêmes parties, il a la même simplicité, et l'cmbryon qu'il recèle est dans le même isolement.

Voici maintenant les conséquences physiologiques qu'on peut tirer de tous ces faits (i).

(1) Voyez Blumenbach, Hochstetter et Emmert, Viborg, Dutrochet, G. Cuvier. 
Puisque les Têtards des grenouilles et des salamandres, puisque les Poissons ont des branchies, il leur est possible, dit-on, de respirer dans un liquide dès leur première origine : ils n'ont donc besoin ni d'un autre liquide que l'amnios dont ils sont baignés, ni d'autres organes que leurs branchies. Ils doivent respirer dans l'ouf comme ils respireront dans les eaux, car ils y trouvent un fluide analogue et ils y ont les mêmes organes. Mais la chose est différente pour les reptiles sans métamorphose et pour les oiseaux : ces animaux, n'ayant jamais que des poumons, ne peuvent assurément respirer dans l'œuf, car il faut de l'air à des poumons : cependant il faut bien que le sang soit respiré ; ce n'est qu'à cetle condition qu'il sert à la vie. Lorsque ce fluide n'est pas aéré et rougi par la mère, comme dans les mammifères, il faut qu'il le soit par le foetus, comme cela a lieu pour les poissons et les têtards; et s'il n'est respiré ni par la mère ni par l'embryon, il faut qu'une partie de l'œuf lui-même subvienne jusqu'à l'éclosion du jeune animal à cette fonction nécessaire. Et d'abord on a prouvé qu'il se fait une espèce de respiration dans l'œuf : on a vu que le sang rapporté au fotus du lézard et de l'oiseau par la veine ombilicale est plus rouge que celui qui va du foetus à l'œuf par les artères ombilicales. L'académie de Copenhague a cherché à faire éclore des œufs dans des g̊az irrespirables, et elle n'a pu y parvenir : l'incubation n'a rien produit. D'ailleurs, il y a dans la structure même de l'œuf plusieurs particularités qui semblent indiquer qu'il s'y opère. une espèce de respiration : la coque est poreuse, tout près d'elle sont des tuniques très-yasculaires et bai- 
118 LIV. II. DE I.A REPRODUCTION DES L̂TRES VIVANS. gnées d'un sang abondant; et même lincubation de l'œuf des oiseaux a pour premier effet d'y déterminer un vide, et ce vide devient un réservoir d'air hon à respirer.

Il se fait donc une espèce de respiration dans l'œuf des animaux privés de branchies; mais quel est l'organe de celte respiration? Il est clair qu'il le faut chercher parmi les choses particulières à l'œuf des aiseaux et à l'ueuf des reptiles privés de branchies à toutes les époques de leur existence. Or ce n'est ni l'amnios, ni le vitellus, ni la coque et sa membrane, puisque ces différentes parties sont communes à l'œuf des poissons et à l'œuf de tous les reptiles comme à celui des oiseaux. C'est donc l'allantoïde et ses membraṇes, c'est-à-dire la tunique moyenne et le chorion. Je dis que c'est l'allantoïde, car cette poche et ses tuniques n'existent que dans les œufs des animaux à poumons, dans les oiseaux, les serpens, elc. Cette membrane reçoit un grand nombre de vaisseaux, et l'air y a facilement accès à travers la coque criblée de pores. A la vérité cette poche n étant pas de première formation, on peut demander par quelle autre partie elle est d'abord remplacée. On répond que jusqu'à l'apparition de l'allantoïde, c'est le vitellus qui est en contact avec les parois de la coque; et comme les enveloppes de ce vitellus reçoivent beaucoup de vaisseaux des mésentériqués, il est probable qu'il a pour usage, à cette première époque, de remplacer l'allantoïde. Ainsi ce serait donc l'allantoïde qui ferait l'office d'organe respiratoire dans les ceufs des fœtus ¿ poumons. Cependant on pent faire quelques objections a cette théorie remarquable : on peut d'abord 
demander s’il est sûr que les œufs respirent. A ce sujet un physicien de Berlin a fait des expériences contradictoires avec celles que nous avons rapportées: il a mis incuber des œufs dans toutes sortes de gaz, et cela n'a eu, à ce qu'on assure, aucun inconvénient pour les jeunes embryons : chaque œuf est venu à. bien. Mais on peut élever des doutes sur cette expérience : comment est-il possible d'isoler des œufs d'avec l'air de l'atmosphère? Ne faut-il pas, s'il s'agit d'œufs d'oiseaux, que la couveuse respire? or, comment vivrait-elle dans un air sans oxygène? D'ailleurs; ne faut-il pas qu'elle mange, qu'elle bouge, qu'elle se promène? Veut-on parler d'œufs incubés artificiellement par la chaleur, ou seulement d'œufs de serpens et de lézards, qui éclosent sans incubation? alors on peut encore répondre victorieusement à cette nouvelle objection, car nous avons dit quill se forme dans l'œuf, près du germe, une cavité que l'air vient remplir; et on aura beau placer l'œuf dans un air irrespirable, il faudra toujours qu'il reste pourvu de ce petit réservoir que nous avons vu s'y førmer.

Mais il est une autre difficulté beaucoup plus forte: je veux parler de l'allantoïde, que nous verrons exister dans les mammifères comme elle existe dans les oiseaux. Cependant les mamnifères reçoivent de leur mère un sang tout prêt respiré; d'ailleurs comment l'allantoïde pourrait-elle servir chez eux à la respiration? elle n'est entourée d'aucun fluide aérien, et les organes qui l'environnent sont tous solides et sans communication avec l'extérieur. On pourrait dire que son objet est peut-être d'extraire des liquides qu'elle zenferme le peu d'air qui s'y trouve mêlé, el qu'ellẹ 
sert ainsi d'organe supplémentaire aux poumons de la mère; mais alors pourquoi son volume est-il si variable dans les animaux quadrupèdes, et pourquoi n'existe-t-elle nullement chez l'homme? il y a donc encore quelque obscurité relativement à l'allantoïde, surtout dans les mammifères; mais il paraît certain qu'elle opère une véritable respiration dans les œufs qui en sont pourvus.

En nous résumant nous devons dire, que les œufs des poissons et ceux des reptiles originairement pourvus de branchies n'ont point d'allantoïde; qu'ils n'ont par conséquent ni de chorion ni de membrane moyenne. Une autre différence importante, c'est que les embryons renfermés dans ces œufs sont pareillement privés de vaisseaux ombilicaux et d'un véritable cordon ombilical. A la vérité lès poissons ont une espèce d'ombilic, car c'est par cetle ouverture que le vitellus de l'œuf s'introduit dans l'abdomen et communique avec l'intestin ; c'est aussi par-là que sortent les petits vaisseaux mésentériques qui vont se répandre dans ce vitellus; mais le cordon ombilical est fort imparfait, fort simple, puisqu'il ne contient ni d'ouraque ni de vaisseaux oinbilicaux, partie essentielle à ce cordon. Au contraire, tous les animaux dont l'ovule est pourvu ou d'une allantoide ou d'un placenta, ont en même temps un cordon ombilical, renfermant une grosse veine qui va traverser le foie pour se rendre au cœur, et deux grosses artères qui naissent des iliaques primitives. Cette disposition est manifeste et incontestable dans les oiseaux, dans les serpens et dans les mammifìres. Il n'y a donc que les embryons pourvus de branchies qui manquent d'un cordon om- 
bilical; ce cordon est donc l'intermédiaire entre l'embryon et la partie de l'œuf qui reçoit ou qui fabrique un sang nouveau, un sang rouge, aéré, artériel. On en pourrait conclure que l'allantoïde est l'organe par qui l'œuf exerce une espèce de respiration; mais comme ce serait une pétition de principe, il faut se borner à émettre celte proposition incontestable, savoir : que les vaisseaux ombilicaux d'un embryon sont le signe assuré que le sang dont sont imprégnés ses organes est aéré et respiré au-dehors de lui; par conséquent il y a dans l'œuf des oiseaux et dans l'œuf des serpens un organe chargé d'exercer celte respiration; et comme c'est dans les feuillets de l'allantoïde que se distribuent les vaisseaux ombilicaux, il est fort probable que c'est par elle que cette respiration s'effectue.

Il résulte de ce que nous venons de dire que les vaisseaux ombilicaux n'existent point chez les fotus pourvus de branchies, et que toujours ils annoncent des poumons. On peut conséquemment juger de l'un par l'autre : les zoologistes sentiront l'importance de ce principe.

Autrefois on pensait que les foetus des vrais vivipares ctaient seuls pourvus d'un cordon ombilical; alors on regardait ce cordon comme indiquant toujours et certainement des mamelles : un de ces organes faisait supposer l'autre. On sait aujourd'hni que cette règle prétendue est une erreur. Un cordon ombilical indique certainement des poumons dans l'embryon qui le porte; il indique de plus un placenta ou une allantoïde dans l'œuf d'où provient cet embryon, ou à-la-fois une allantoide et un placenta : il 
122 LIV. IJ. DE LA REPRODUCTION DES ETHES VIVANS.

est le signe certain que le fotus n'a point de branchies, et que le sang de ce fœtus est aéré par sa mère ou par ses propres enveloppes, lui-même ne pouvant res: pirer. J'ose espérer que les principes exposés dans ce chapitre obtiendront l'assentiment des physiologistes.

\section{CHAPITRE XIV.}

Des Finveloppes fotales des Mammifères, et de leur analogie avec liOEuf. des Oiseaux.

Nous n'avous pas le dessein d'éludier dans ce chapitre l'origine et les progrès de l'OEuf et de l'embryon des Mammifères; nous ne voulons pour le moment que décrire la composition de cet ouf et l'arrangement des membranes, des humeurs et des vaisseaux. dont il est formé. En conséquence, nous le supposons arrivé à sa plus grande perfection.

Nous devons d'abord parler de ce qui différencie essentiellement les ovules des mammifères et les œufs des oiseaux. Le fotus de ces derniers est toutà-fait isolé de l'animal qui l'a produit; l'œuf qui le. renferme a tout son volume dès le premier moment, et doit suffirc à tous ses besoins; l'embryon doit y trouver de quoi se nourrir, avec quoi respirer : jusqu'à la naissance, c'est là tout son univers. Chaque

(1) Voyez C. Galien, Vésale, R. Columbus, Fallope, Eustache, I: d'Aquapendente; G. Harvey, N. Sténon, G. Needham, A. H.ller, G. Ilunter, Blumenbach, Baudelocque, Sœmmerring, Trevern, Oken, Hochstetter et Emmert, F. Meckel, Dutrochit, G. Curier, Velpeau. 
partie de cet œuf lui est d'une aussi grande importance que les organes mêmes qui composent la trame de son propre corps ; l'allantoïle, s'il est sans branchies, lui sert de poumons, et le vitellus verse dans ses intestins les matériaux de son accroissement.

Mais les choses ne sont plus entièrement les mêmes dans les mammifères : l'embryon de ces animaux a bien à-peu-près les mêmes enveloppes; on le trouve entouré, dans la plupart de ces animaux, d'un chorion, d'une allantoide, d'un amnios et d'une vésicule oubilicale; ce qui forme en tout quatre membranes et trois bumeurs. Ces parties équivalentes à ce qu'on voit dans l'œuf des oiseaux, n'ont plus ici ni la même importance, ni les mêmes fonctions: aussi les voit-on varier d'un quadrupède à l'autre; il y a même de ces membranes qui manquent absolument dans certains genres. Mais ce qui carätérise essentiellement les ovules des quadrupèdes et de tous les animaux mammifères, c'est le placenta simple ou multiple dont l'extérieur du chorion est nanti. Cette masse sanguine et charnue retient le nom de placenta, lorsqu'elle est unique' et concentrée comme dans l'homme; et on l'appelle cotylédon, lorsqu'elle est multiple et par petits fragmens isolés les uns des autres, comme dans le cochon et la brebis. C'est dans ce placenta que viennent finalement se ramifier les vaisseaux ombilicaux; il sert d'intermédiaire entre les vaisseaux de l'embryon et ceux de la mère: sa surface est hérissée de petites éminences qui sont reçues dans des sinus correspondans de la matrice, et c'est par ces points de contact intime que les vaisseaux des deux êtres s'abouchent ensemble, 
124 LIV. II. DE LA REPHODCCTION DES ETRES VIVANS.

Ce n'est point assurément par le placenta que le sang du foctus est aéré et renouvelé; mais cette espèce d'organe est le moyen de transition du sang d'un de ces êtres à l'autre. Nous avons dit que les vaisseaux ombilicaux indiquent des poumons et une respiration empruntée dans l'embryon pourvu de ces vaisseaux; nous disons maintenant qu'un placenta est l'indice que l'embryon ne respire ni par lui-même, conme les fotus des poissons et des grenouilles, ni par ses enveloppes, comme les fœtus des oiseaux. II forme par conséque nt un des traits distinctifs des vrais vivipares : lui et les glandes mammaires s'entre-supposent toujours. Voici, au reste, quelle est la disposition de l'ovule des mammifères :

Il est composé, avons-nous dit, de quatre membranes dans la plupart des animaux de cette classe. $1^{\circ}$. Le chorion est la plus extérieure de ces membranes : un placenta, simple ou multiple, l'unit au tissu de la matrice. Ia partie externe de cette première enveloppe est ordinairement recouverte d'une pellicule que G. Hunter a nommée membrane caduque: c'est un enduit apparemment inorganique, et qui, à cause de cela, finit par s'exfolier à mesure que le produit de la conception prend de l'accroissement. Le chorion est en quelque sorte l'équivalent de la membrane commune de l'œuf des oiseaux, dont la caduque représente aśsez bien la coquille.

$2^{\circ}$. L'amnios enveloppe immédiatement le fotus juisqu'à l'ombilic; mais, en ce lieu, elle se réfléchit sur le cordon ombilical : c'èst la mêue membrane que nous avons indiquée dans les œufs des autres animaux comme entourant toujours les foitus. 
$3^{\circ}$. L'illantoide est un prolongement de la vessie, et elle s'unit à cette vessie jusqu'à la dernière heure de la gestation par l'ouraque. Elle forme ordinairement une double voûte entre le chorion et l'amnios; et son union avec ces membranes est formée par un lacis de vaisseaux dont quelques personnes voudraient faire une membrane à part, sous le nom d'arachnoide fatale. Cette membrane allantoide est l'analogue de celle des oiseaux portant le même nom; mais elle en diffère en ce que son développement est en tout semblable à celui des autres enveioppes de l'œuf : à l'inverse de celle des oiseaux, son étendue relative diminue plutôt que d'augmenter à mesure que l'embryon s'accroît; et elle a, dès les premiers momens, les connexions qu'elle conserve durant la gestation; d'ailleurs, elle ne paraît point servir à la respiration comme dans ces derniers. Enfin, l'homme est le seul des mammifères qui n'ait point d'allantoìde, encore qu'il ait un ouraque.

$4^{\circ}$. La vésicule ombilicale est la quatrième membrane de l'ovule des mammifères; elle tient ordinairemeni au chorion par des ligamens ou chalazes, et ne communique avec l'embryon que par les vaisseaux qu'elle reçoit des mésentériques à la hauteur du pancréas. Toutefois, on l'a vue adhérer par un mince pédicule avec l'intestin grêle; mais cette disposition est rare. Cette poche est l'équivalent du vitellus des oiseaux, avec cette différence qu'elle ne paraît pas communiquer avec la cavité intestinale du fotus, qu'elle diminue beaucoup aux approches de la naissance du nouvel être, qu'elle. ne rentre jamais, comme le vitellus, dans l'abdomen de l'embryon, 
126 LIV. II. DE LA REPRODLCTIOY DES EATRES VIVANS.

et que, si elle sert à sa nourriture, cela ne peut avoir lieu que par une absorption opérée par les seuls vaisseaux mésentériques.

De ces quatre membranes, le chorion ne fournit aucun fluide; mais les trois autres 'en contiennent un, dont la nature diffère pour chacune. Ces diverses enveloppes, mais surtout l'allantoïde et la vésicule ombilicale, varient beaucoup dans les différentes classes de quadrupèdes. Ainsi la vésicule ombilicale, si petite et si vite disparue dans le fotus de l'homme et dans ceux des animaux, a au contraire un grand volume dans les carnassiers et dans les rongeurs. Elle l'emporte même de beaucoup sur l'allantoïde, dans ces derniers animaux. Il y a dans ce genre d'êtres une véritable inversion entre ces deux membranes, inversion pour la situation et pour le volume; ce qui a causé et qui cause encore, au moment où nous écrivons ces lignes, beancoup de démêlés et de contestations. Toutefois il faut vouloir l'erreur pour confondre ensemble la vésicule ombilicale et l'allantoïde : on reconnaîtra toujours celle-ci à l'aide de sa communication avec l'ouraque, et à l'aide des vaisseaux ombilicaux qu'elle reçoit sans mélange d'autres vaisseaux; tandis qu'on peut toujours distinguer la vésicule ombilicale, en ce qu'elle recoit uniquement les vaissèux omphalo-mésentériques, qu'elle les reçoit tous à elle seule, et qu'elle n'a pas d'autres moyens de communication avec le fotus. Le liquide des deux membranes est de même dissemblable; mais il varie tellement d'une classe à l'autre, qu'il serait peu sûr de fonder la distinction de ces membranes d'après les caractères de ce liquide. 
CIIAP. XIV OELFS DES MAMUIFÉRS.

Nous voyons donc que l'allantoüde des rongcurs est entièrement réduite, mais elle a de très-grandes dimensions dans les chiens et les autres carnassiers; cette membrane diffère autant, dans ces deux classes de quadrupèdes, qu'elle diffère dans deux œufs d'oiseau, dont l'un a quatre jours d'incubation et l'autre neuf. Elle est aussi très-petite et en forme de boyau dans les ruminans; et comme ce fut dans un de ces animaux que Galien l'étudia, elle doit le nom que cet illustre médecin lui a denné à sa disposition dans ces derniers êtres.

A l'égard des vaisseaux de l'œuf des mammifères, ils ont deux sources, comme dans l'œuf des oiseaux; je veux dire qu'ils se composent des ombilicaux et des mésentériques, veines et artères. Les premiers vont seuls, et vont tous se répandre dans la vésicule ombilicale, à-peu-près comme nous les avons vus se distribuer au vitellus de l'œuf des ovipares; mais les vaisseaux ombilicaux ne se bornent pas à l'allantoïde, comme ils s'y bornent dans l'œuf : après avoir formé de magnifiques réseaux sur celte membrane, ils la transpercent, elle et le chorion, toujours en se divisant et se ramifiant; et finalement ils aboutissent à la matrice après avoir traversé le placenta ou les cotylédons, qui sont pour ainsi dire leur ouvrage. Il résulte de là de grandes différences entre l'embryon du mammifère et celui de l'oiseau : ce dernier se nourrit principalement aux dépens du vitellus; l'autre tire peu de secours de la vésicule ombilicale et de la liqueur de celte vésicule : sa nourriture lui vient toute préparée et presque en totalité du sang de sa mère; cnsuite, c'est exclusivement par l'allantoide que l'oi- 
128 LIV. II. DE LA REPRODUCTION DES ÊTRES VIVANS.

scau respire avant de naître, tandis que le jeune mammifère recoit par la matrice et le placenta un sang tout prêt chargé d'air comme de chyle: les poumons et l'estomac de sa mère agissent à-la-fois pour deux êtres. Une autre différence importante entre les vivipares et les ovipares, est celle-ci : coume le jeune ovipare emporte avec lui dans son abdomen le résidu du vitellus qui l'a jusqu'alors nourri, il en résulte qu’il peut presque toujours se suffire à lui-même dès le premier moment de sa naissance; il porte au-dedans de lui un réservoir de nourriture. Mais le mammifère n'a rien de semblable : il naît seul et dépouillé de toutes ses enveloppes, sans forces pour agir, et sans réservoir pour subvenir à ses besoins sans action. II naît d'ailleurs sans habitude de l'isolement; et, à l'exception de son cœur, aucun de ses organes n'a encore agi. Aussi voit-on la plupart des oripares se nourrir seuls, ou au moins de la même nourriture que ses parens, soit qu'il la cherche seul ou qu'il la reçoive d'eux; tandis qu'il faut à tout vivipare nouveau-né un fluide nourricier que lui donne sa mère aussitôt qu'elle a cessé de lui donner du sang. Voilà pourquoi tout vivipare est mammifère, pourquoi toute femelle à placenta a des mamelles : tout fœlus qui a d'abord vécu d'un sang étranger, a besoin de lait pour première nourriture. 


\section{CHAPITRE XV.}

Organes génitaux des femelles. Origine de l'œnf et de l'embryon des Mammifereg.

Pour aller plus directement au but de ce chapitre, nous faisons abstraction pour le moment de la structure génitale du mâle, des propriétés de la semence et de son émission pendant le coît : nous reviendrons plus tard sur ces différentes choses. Nots ne devons parler maintenant que des organes génitaux de la femelle, et des changemens qui s'y font remarquer à la suite d'un coît fécondant (1).

Les organes génitaux des femelles de mammifères se composent de deux Ovaires, de deux Trompes, canaux de communication entre les ovaires et la matrice; de cette Matrice elle-même, laquelle est ordinairement bifurquée dans les animaux portant à-lafois plusieurs petits, et simple au contraire dans ceux n'engendrant d'habitude qu'ún fœtus à-la-fois. Après la matrice vient le Vagin, dont l'ouverture extérieure, garnie de Nymphes, d'un Clitoris et d'un Méat urinaire, porte le nom de Vulve.

Comme la matrice ne communique au-dehors par le vagin qu'à l'aide d'une ouverture étroite et toujours fermée, qu'on nomme Orifice du col utérin, il est certain que rien ne saurait s'en échapper hors de

(1) Voy. les ouvrages d'Aristote, d'Harvey, $165_{1}$; de Coiler (Volcher) ${ }_{1} 575$; de R. de Graaf, 1671 ; de Malpighi, de N. Sténon, de A. Nuck, de Vallisneri, de J. G. Duverney, de G. Hunter, de Buffon, de Haller, etc. 
50 I:V. II. DE LA REPRODUCTION DES ETTES VIVANS.

liaccouchement, et que par conséquent on doit y relrouver, dès qu'il existe, le produit visible de la conreption.

Dans l'état ordinaire, on trouve le col de la matrice fermé, les parois solides de cette matrice accolées sans intervalle appréciable, et son intérieur n'offrant aux yeux que quelques inucosités filantes et les orifices plus ou moins apparens de quelques vaisseaux. Les trompes, qui s'altachent à ses côtés, ont une cavité excessivement étroite, ne contenant rien non plus : elles ont une petite ouverture souvent invisible mais réelle dans la matrice; et leur extrémité opposée, libre et flottante dans le ventre, s'épanouit en une espèce de pavillon, et se trouve placée dans le voisinage des ovaires. Ceux-ci n'ont pas d'autre voie de communication avec le dehors que le canal des trompes et la cavité de la matrice; le prétendu conduit cxcréteur qu'on a cru y voir est lout-à-fait chimérique, chimérique aussi est la seinence qu'on a dit s'y former. Enfin, si tant d'écrivains distingués ont cru voir dans les ovaires des femelles l'équivalent des testicules des mâles, si même ils sont allés jusqu'à leur donner ce nom de testicules, cela n'a pu provenir que d'un examen trop superficiel de ces organes, et peut-ĉtre aussi de ce qu'on s'était laissé prévenir par quelque hypothèse attrayante qui nécessitait des testicules et du sperme dans les femelles comme dans les mâles. C'est en particulier dans ce cas que nous semble s'être trouvé l'illustre Buffon.

Cependant ce nom d'ovaires que portent aujourd'hui ces organes nous est une preuve que tout lc 
CHAP. XV. ORGANES GÉNITAUX DES FEHELLES. 1 monde n'a pas partagé l'idée que ce fussent des teslicules et qu'il s'y formât de la semence, car il faut remarquer que le nom de chaque objet exprime souvent beaucoup moins sa vraie nature que l'opinion de celui qui l'a dénommé. Or ce fut Sténon qui leur donna ce nom d'ovaires, fondé sur ce qu'on y trouvait des espèces d'œufs dans les femelles de tous ples animaux alors connus : c'est du reste à l'époque où Sténon vivait que l'étude plus cultivée de l'anatomie, et surtout les beaux travaux d'Harvey, faisaient naître l'idée que tout corps vivant provient d'un œuf; et ce fut une raison puissante pour mieux étudier ces organes. On les examina donc dans diverses circonstances et aux différens âges de la vie : chez le fœtus, dans l'adulte, après le coït, pendant la gestation. On vit qu'il ne paraissait aucun œuf, aucune vésicule dans les premiers temps de la jeunesse; mais qu'ensuite il s'en développait à mesure que l'animal approchait de la puberté. Ces espèces d'œufs, ces petites vésicules ne sont pas toutes de la mêıne grosseur : il y en a de plus apparentes, il y en a de plus cachées. Ce volume varie selon l'âge, selon l'espèce de mammifère, sclon la santé de l'individu; il augmente surtout par le coït et la fécondation; mais il n'est pas toujours en proportion avec la grosseur de l'animal : l'éléphant, par exemple, a ces vésicules fort petites.

11 n'y a rien de constant pour leur nombre : Haller, il est vrai, n'en a jamais compié plus de quinze dans un ovaire de femme; mais d'autres auteurs y en ont trouvé jusqu'à cinquante. D'autres fois il n'y en a que six, ou même que deux. La même inconstance existe pour le reste des mammifères. On remarque que le 
152 LIV. II. DE LA REPLODUCTION DES İTRES VIVANS.

nombre de ces petits corps diminue souvent dans les femelles qui ont fait des petits, non-seulement parce que plusicurs de ces œufs ont été employés aux fécondations précédentes, mais aussi parce que les autres se rapetissent et s'effacent même jusqu'à disparaître entièrement. Il paraît certain qu'il ne se forme jamais de nouvelles vésicules dans les animaux dont nous parlons. Lorsqu'on examine les ovaires des vieilles femelles, on n'y trouve plus que des grains miliaires solides, sans fluide intérieur, souvent même tout-àfait endurcis et comme cartilagineux.

Jamais ces pelits œufs n'ont de pédicule; le péritoine leur forme à tous une enveloppe commune; mais en-dessous de cette membrane séreuse sans vaisseaux visibles, chaque vésicule a sa membrane particulière, et cette tunique propre a des vaisseaux. Le fluide renfermé dans ces petits corps est homogène; il n'est pas composé de deux parties comme les oufs des oiseaux. Celle humeur est ordinairement transparente, souvent jaunâtre; le feu et l'alcool la coagulent. Il paraîtrait que ce liquide est analogue au blanc d'œuf. Vésale, Fallope, Albert le Grand, Riolan, et tous les anatomistes jusqu'à Sténon, avons-nous dit, donnèrent à ces petits corps le simple nom de Vésicules; Harvey lui-même fit taire sa propre conviction pour céder à l'ascendant des vieilles traditions et de la routine; mais Sténon, restant plus conséquent et avec la théorie de ce grand homme et avec les faits eux-mêmes, fut le premier qui osa donner le nom d'OEufs à ces granulations des ovaires.

On prétendit ensuite non-seulement que ce n'étaient point de véritables œufs, mạis que l'existence 


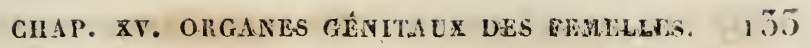

de ces corps n'était pas naturelle et résultait d'un état maladif; qu'enfin ce n'étaient là que des Hydatides. Il est bien vrai qu'il se forme quelquefois des hydatides à la surface des ovaires; mais leur groupement n'est pas semblable, leur situation est toujours limitée, et ordinairement ces espèces de kystes sont pédiculés et deviennent très-gros. D'ailleurs, l'existence des hydatides est assez rare, tandis que celle des petits oufs est constante dans les ovaires de tout mammifère femelle encore jeune. Il se forme encore d'autres espèces de kystes ou de loupes dans les ovaires, mais toujours fort différens des oufs doni nous faisons. l'histoire.

Nous voyons donc que la matrice communique avec le vagin par un col saillant, dont l'ouverture étroite est toujours fermée hors le temps du coit, hors le. temps des règles et de l'accouchement; nous savons que cette matrice est percée vers les côtés de son sommet par les deux conduits très-étroits des trompes de Fallope; que ces trompes, composées d'un tissu dilatable et contractile comme la matrice, se terminent en s'épanouissant par une sorte de pavillon au-delà mais tout près des ovaires; et que ces derniers sont composés de petites vésicules ou d'oufs, n'ayant ni conduits excréteurs ni aucune voié de communication avec la matrice autres que les trompes de Fallope. Maintenant il s'agit d'examiner quels changemens surviennent dans ces différentes parties à la suite du coït et lorsque la conception est opérée : nous devons surtout nous attacher à montrer l'œuf et l'embryon des mammifères dans ses premiers commencemens.

Si l'on examine la matrice et les trompes peu apris 
154 LIV. II. DE LA REPRODLCTION DES ÊTRES VIVANS.

la conception, on trouve ces organes plus colorés, plus imprégnés de liquides; les trompes contiennent même quelquefois des mucosités sanguinolentes. Il paraît certain également que les trompes s'érigent, et que leur extrémilé évasée se recourbe vers les ovaires en s'adaptant à l'une de leurs vésicules : Haller ayant ouvert une lapine six jours après l'approche du mâle, trouva la trompe collée à l'ovaire par son pavillon, ainsi que nous venons de le dire; il vit aussi qu'un des œufs s'était séparé de l'ovaire, et il trouva cet œuf dans le canal déjà un peu élargi de la trompe. Nuck, avant Haller, avait cité une observation encore plus décisive : cet anatomiste lia vers le milieu de sa longueur la trompe d'une chienne trois jours après l'approche du mâle; au bout de quatre autres jours il trouva deux fotus entre l'orifice libre de la trompe et la ligature qui en étreignait le canal. Santorini, Riolan, Duverney ont vu des foetus dans les trompes. Les dénégations les plus formelles des auteurs ne sauraient infirmer un fait positivement articulé par un homme comme Haller, surtout lorsque tant d'autres observateurs l'attestent; aussi regardons-nous ce fait comme avéré. D'ailleurs, que trouve-t-on de douteux ou d'incroyable dans cette observation? est-ce la route suivie par l'ovule? Mais ne sait-on pas que la trompe a son ouverture libre près de l'ovaire, et qu'elle est percée d'un canal ayant issue dans la Inatrice? n'a-t-on pas vu des fœtus s'accroître plus ou moins complètement dans les trompes? Ces canaux sont à la vérité fort étroits; mais les parois n'en sont. alles pas dilatables? On ne comprend pas comment la trampe peut détacher l'ouf; mais est-ce une raison 
CHAP. XV. ORGANES, GENITAUX DES FEMELLES. 155 pour nier la chose? On ne voit pas de rapport entre cet ouf et l'embryon; mais en voit-on davantage enIre l'œuf de la poule et le poulet? On ne conçoit pas enfin de conception possible sans le concours du sperme ( en cela on a raison), et l'on derrande comment le sperme lancé dans le vảgin peut pàrvenir jusqu'à l'ovaire. Mais sait - on mieux la voie du sperme dans les ovipares, où l'espace, sans être aussi torlueux, est au moins aussi long? D'ailleurs, trouve-t-on le sperme quelque part, une fols qu'il a été in troduit dans les parties génitales; et si l'on ne peut le trouver, même dans la matrice, comment espère-t-on suivre ses traces ou s'assurer de soh absence dans les trompes? Mais, ajoute-t-on, l'ouf s'introduisît-il dans les trompes pour alle'v jusqu'à la matrice, il est sûr au moins qu'il est trop petit pour être visible dans le canal où l'on dit l'aveir trouvé peu de jours après le coit; plusieurs bons observateurs l'y ont vainement cherché : Haller et de Graaf, conclut-on, se sont mépris.

Il faut avouer que celte dernière objection n'est pas sans quelque force; car effectivement les oeús de l'ovaire sont fort petits, et beaucoup d'anatomistes n'ont pu les trouver dans les trompes, nonobstant l'attention extrême qu'ils ont apportée dans leurs recherches. Mais voici d'autres faits qui viennent à l'appui de l'observation que nous avons citée. On a. ouvert des brebis et d'autres animaix, moins d'une heure après l'accouplement et l'émission séminale : alors on a presque toujours trouvé une ou plusieurs vésicules de l'ovaire gonflées, quelquefois tachées de sang, et souvent si élevées au-dessus des autres 
136 LV. U. DG E.A REPRODUCTION DES ẼTRES VIVAN=.

œufs, qu'elles semblaient tout près de se rompre. Ė les examinant plus soigneusement, une heure ou deux après le coit, on s'est assuré qu'il y avait des vaisseaux sanguins \& leur intérieur, et qu'ordinairement elles paraissaient fendues par le milieu. On a vu que ces. vésicules se vident au bout de quatre à cinq heures, qu'après cela les membranes s'en épaississent, que des vaisseaux s'y développent : vers la vingt-deuxième heure, la vésicule rompue est remplie d'un corps. jaune que Haller a rendu célèbre. Ce corps ensuite s'accroît beaucoup, est entouré d'un lacis de vaisseaux, et ressemble finalement, dit Haller, au mamelon rosé d'une jeune fille. Au bout de quelques jours la fente médiane n'est plus visible. Quel que soit l'usage du corps jaune, et quoi qu'ait pu dire Buffon pour en nier l'importance, assurant, par exemple, qu'on le trouvait dans les animaux vierges comme dans les autres, le témoignage et les recherches de de Graaf, de Morgagni et de Haller établissent comme un fait très-certain qu'il n'existe que dans des femelles qui ont déjà conçu ou qui viennent de concevoir. Ce corps jaune finit par prendre l'aspect d'une petite glande; il commence, après quelques jours de fécondation, par occuper une grande partie de l'ovaire; il diminue ensuite à mesure que la gestation avance vers son terme; mais il en reste presque toujours des traces, mếme après l'accouchement. Il persévère long-temps, principalement chez les femmes; longtemps aussi on y remarque les indices de la fente primitive de la vésicule rompue. On a cru remarquer que les ovaires contenaient autant de corps jaunes qu'il y avait eu de foetus : Haller n'en a trouvé qu'un 
CIIAP. Xv. ORGANES GENITAUX DES FLHELLE. 157 après le premier accouchement de la femme, et dixhuit dans les ovaires d'une truie qui arait mis bas dixhuit petits d'une première gésine. Il faut d'ailleurs remarquer que dans les femelles où l'on trouve des corps jaunes, la matrice offre en même temps les empreintes plus ou moins conservées des cotylédons ou placentas. On trouve, en outre, dans plusieurs femelles, une cicatrice au col utérin, des éraillures à la peau du ventre, et sensiblement plus de volume aux mamelons. Ce sont là autant de signes de la maternité, ces derniers principalement chez la femme. Buffon assure que le corps jaune est tout formé dans l'ovaire au moment de la conception; mais c'est une conjecture que détruit l'observation impartiale des faits.

Si nous réfléchissons un peu sur les détails précédens, nous verrons que cette vésicule trouvée distendue après la conception, que la fente ou cicatrice de son sommet, que le corps jaune qui lui succède et qui persévère souvent toute la vie; tous ces faits, dis-je, porteront à penser qu'il s'échappe quelque chose de l'ovaire au moment de la fécondation.

Outre ces premic̀res preuves, tirées d'une vésicule qui se gonfle après le coit, et des trompes, dont l'extrémité dilatée s'applique à l'ovaire, et d'une cicatrice qui succède à la fécondation, il y a d'autres observations qui démontrent que le principe du nouvel être provient de l'ovaire.

$1^{\circ}$. On voit quelquefois le foelus se développer dans le ventre des femelles fécondées par leurs mâles, et dans ce cas encore on trouve une des vésicules de l'ovaire ouverte, déchirée êt désemplie: c'est qu'a- 
13 LIV. II. DE LA REPRODUCTION DES ÈTRES VIVANS.

lors probablement les trompes ont mal fait leur office ; elles sont obstruées ou malades.

$2^{\circ}$. On a plusieurs fois trouvé dans un ovaire des débris de fotus, chez des femelles qui avaient reçu les approches du mâle sans engendrer : ces especes de kystes contiennent ordinairement des os, des cheveux, des dents, en un mot toutes les parties les moins destructibles d'un corps organisé. D'où toutes ces choses viendraient-elles, si ce n'est d'un embryon développé dans son premier berceau?

$5^{\circ}$. On peut châtrer une femelle aussi bien qu'un mâle, l'extirpation des ovaires, comme celle des testicules, produit toujours la stérilité: la chose est avérée pour les mammifères comme pour les animaux ovipares. Les ovaires servent donc à la génération: or, comment y concourent-ils, sinon par ces petils œufs, par ces vésicules qui le composent; comment ensuite $\mathbf{y}$ serviraient-ils efficacement si les trompes ne les conduisaient pas dans la matrice. D'ailleurs, ces petits œufs ont été trouvés dans les trompes peu de temps après la copulation : de Graaf, il y a plus d'un siècle, et de nos jours MM. Cruikshanks, Prévost et Dumas ont observé ces petits corps dans le canal même des trompes. Ils s'y trouvaient libres d'adhérences, étaient d'une extrême petitesse, et composés d'une sorte de petite sphère de liquide transparent, revêtue d'une tunique excessivement ténue : c'est du moins ainsi que ces auteurs en parlent dans leurs ouvrages. Il faut ajouter que ces petits ovules ne sauraient être confondus avec des hydatides, puisque ces dernières sont constamment adliérentes aux parois des 
CHAP. XV. ORGANES GÉNITACX DES FEMLLLES.

trompes, lorsque c'est dans leur cavité qu'on les trouve. On a même cru découvrir à leur surface, examinée au microscope, de petits prolongemens cotonneux analogues à ceux que présente plus tard et dans de grandes proportions la membrane caduque dont le chorion du fotus est extérieurement revêtu : on a dit aussi qu'on apercevait à l'un de leurs pôles un point blanchâtre qu'on croyait être la cicatricule résultant apparemment de l'action du fluide séminal. On ajoute encore que ces ovules augmentent en grosseur â mesure qu'ils approchent de la mairice, c'està-dire de l'orifice interne des trompes, et qu'on a pu y découvrir les premières traces d'un foetus dès le douzième jour de la conception.

Voilà sans doute assez de détails sur les oufs des mammifères; peut-être même est-ce parler avec trop de précision de corps auxquels ceux qui assurent les avoir observés n'accordent pas une demi-ligne de diamètre. Mais quand mềne on admettrait que de pareilles observations ont peu de certitude et méritent peu de confiance, ce que nous avons dit des changemens visibles de l'ovaire et des trompes, ce que nous savons de l'organisation de ces parties, plusieurs phénomènes dont nous avons parlé, et surtout les grossesses extra-utérines sans rupture de la matrice, tous ces faits ne permettent pas de douter si c'est réellement de l'ovaire que proviennent les linéamens de l'embryon et de ses enveloppes.

On a dû remarquer, dans le cours de ce chapitre, à combien de conditions difficiles la génération des animaux vivipares est assujettie : la petitesse de leurs œufs, l'étroit canal qu'ils ont à traverser, la distance 
1 fo LIV. II. DE LA REPRODUCTION DES ÊTRES VIVANS.

où ils sont des approches possibles des organes génitaux du mâle, et surtout la circonstance que des corps si fragiles puissent parcourir, sans se briser mille fois, des conduits aussi solides que le sont les trompes; j'avoue que tant d'obstacles à surmonter pour l'achèvement d'un seul acte, me semblent ajouter à ce qu'il a de merveilleux. Ne nous étonnons donc plus si. la fécondité est beaucoup moins grande qu'ailleurs dans les gros animaux qu'on nomme mammifères! Outre que ces animaux ont un bien moins grand nombre d'œufs que les vrais ovipares, nous voyons de hombreuses occasions de stérilité dans les détails de leur structure; mais nous n'en voyons dans aucune espèce autant que chez l'homme, d̀ cause de sa longue enfance et de l'immensité de ses besoins; à cause de l'excès de ses passions et des innombrables maladies. qu'engendrent ses vices.

\section{CHAPITRE XVI.}

Les Etres organisés engendrent-ils ious par une sorte d'œufs?

Si l'on se rappelle ce que nous avons dit dans les. chapitres précédens, on verra que nous avons d'abord récusé comme improbables les générations spontanées des corps vivans; qu'ensuite, pour les êtres dont la génération est connue, nous avons vu les plantes à fleurs se reproduire par des graines, et les champignous et d'autres cryptogames, et même les polypes, par des espèces de gemmes ou de bulbes : nous n'avons ensuite trouvé dans la longue chaine des animaux que des 
ovipares el des vivipares; c'est une distinclion qui date du temps d'Aristote, et qu'on voit élablie dans les ouvrages de ce grand homme. La question, maintenant, est de savoir quelle idée on doit attacher à ce qu'on nomme cuf (1). Assurément, si nous prenions l'œuf des oiseaux pour type, il serait difficile d'en trouver. l'équivalent dans la plupart des autres êtres: il faudrait commencer par refuser cette dénomination d'œuf aux gemmes des polypes et aux bulbes des plantes cryptogames; car ces sortes de germes, composés d'une substance homogène, n'offrent ni enveloppes, ni compartimens, ni le principe essentiel et séparé d'un embryon; c'est la totalité de ces petits corps qui reproduit les êtres entiers dont ils sont les premiers rudimens. Ne pouvant donc les assimiler aux oufs, nous ne verrions plus en eux qu'une sorte de bourgeons, ainsi que nous l'avons dit au commencement de ce II Livre. Mais si nous appelons ouf tout corps duquel peut provenir un être semblable à l'être dont lui-même provient, les germes dont nous parlions à l'instant seront eux-mêmes des œufs, aussi bien que les graines plus compliquées des plantes à fleurs; et il ne restera plus à examiner que les animaux distingués entr'eux par les noms d'ovipares et de vivipares.

Quant aux ovipares, leur nom, tiré de leur genre de reproduction, ne permet pas de mettre en doute que ce soit par des œufs qu'ils naissent et se perpétuent : la chose ne serait donc incertaine qu'à l'égard des vrais vivipares ou mammifères. Mais

(1) Voyez Aristote, lib. I; et Harvey, Exercit. Lxir. 
142 LIV. II. DE LA REPRODUCTION DES ETTRES VIVANS.

comme nous avons vu ces derniers n'avoir euxmềmes pour origine que des espèces d'œufs ou de petites vésicules; comme ces vésicules ont certainement leur source dans les ovaires, et qu'elles se manifestent, soit dans les trompes, soit dans la matrice, plusieurs jours avant que l'embryon n'y devienne visible, il en résulte que les vivipares, nonobstant leur nom, naissent d'un œuf comme les oiseaux, comme les poissons et les reptiles; qu'enfin c'était avec justesse et vérité qu'Harvey disait : Omne ex ovo.

\section{CHAPITRE XVII.}

Génération équiroque de l’Ornithorhynque.

L'Ornithorhynque de Blumenbach est un animal fort singulier à beaucoup d'égards ( 1 ); les détails de sa structure en font l'être le plus équivoque qu'il y ait au monde. Quelques auteurs disent que, bien qu'il n'ait point d'ailes et qu'il ait des dents molaires, cependant il faut le ranger parmi les oiseaux à cause de son bec aplati, de ses pieds à ergots et de son cloaque. On dispute d'un bout de l'Europe à l'autre pour savoir si cet animal est ovipare ou vivipare : les uns tirent de son cloaque et de ses oviductes la preuve qu'il pond des œufs; les autres soutiennent

(1) Voyez Shaw, Blumenbach, Everard Home, Geoffroy-SaintHilaire, Lamarck, Gurier, Blainville, Tiedemann, Quoy, F. Meckel, Garnot et Lesson, Knox, Rudolphi, Van-Der-Hoeven et Isid. Geoffroy. 
CUAP. XVII. GÉNĹRATION DE L'ORNITHORHYNQUE。 14 禾 qu'il a des mamelles; M. Fr. Meckel a même décrit et figuré ces organes, et cela est un argument puissant en faveur de ceux qui affirment qu'il s'agit d'un vivipare. Néanmoins on réplique qu'on a vu les œufs assez gros de cet animal; on ajoute que l'on prend pour des mamelles des organes étrangers à l'allaitement; on va mème jusqu'à faire entendre, assurément contre. les bons principes de physiologie, qu'un animal peut porter des mamelles sans être vivipare! Toutefois la disposition de ses trompes utérines, la structure de son bassin, les poils dont son corps est couvert (1), la similitude de ses quatre membres, et la longueur de son urèthre, toutes ces choses portent à penser que l'ornithorhynque est un véritable vivipare ou mammifère. Il est étonnant qu'après tant de voyages à la Nouvelle-Hollande, la difficulté dont nous parlons n'ait pas été résolue. Espérons que nos compatriotes MM. Quoy et Gaymard seront plus heureux ou plus habiles que leurs célèbres devanciers! On recoit à l'instant même (sept. 1828) de ces voyageurs infatigables, des lettres où l'on semble annoncer de grandes découvertes concernant la génération encore si conjecturale des ornithorhynques et des kanguroos.

Observons toutefois que l'ignorance où l'on est touchant la reproduction de ces animaux ne saurait détruire la conséquence du chapitre précédent: que ces êtres engendrent à la manière des oiseaux ou des mammifères, ils auront toujours une sorte d'œuf pour première originc.

(1) Voyez Aristote, de Animalibus : "Les animaux velus sont vivipares. "Lib. I, cap. 5. 
1/4 LIV. II. DE LA REPRODUCTION DES ETRES VIVANS.

\section{CHAPITRE XVIII.}

De la Liqueur Séminale des mâles et de la Fécondation des femelles.

Tout être vivant, avons-nous dit, naît d'un œuf; mais less œufs ne deviennent féconds que par l'intervention du fluide séminal : toute femelle séparée des mâles de son espèce demeurerait stérile. A l'exception des hermaphrodites, qui ont les organes des deux sexes réunis dans chaque individu, les animaux isolés ne sauraient se reproduire. La génération nécessitait donc l'association des êtres par couples ou par des rassemblemens plus nombreux ; or c'est par l'attrait du plaisir que la nature a formé partout des familles: l'origine des sociétés, c'est'l'amour.

Nous àvons montré en quoi les animaux femelles concourent à la génération, indiqué par quels organes, et d'après quel ordre, quelle succession : nous avons vu des vésicules de différentes grosseurs se former ou du moins s'accroître dans les ovaires, parcourir ensuite de longs conduits qui aboutissent, tantôt dans un cloaque où ils ne peuvent long-temps séjourner, tantôt dans une matrice extensible aux parois de laquelle ils adhèrent tout le temps nécessaire au développement de l'embryon, dont ils recèlent les rudimens; et cclte matrice, nous avons dit qu'elle communique au-dehors par un vagin que termine une vulve garnic de nymphes charnues et d'un clitoris. 
Mais, jusquà présent, nous ne nous sommes occupé ni des organes génitaux des mâles, ni du fluide que ces organes ont pour objet ou de produire ou de projeter loin de sa source. Cela même va former la matic̀re de ce chapitre ; mais nous éviterons tout détail étranger au but présent, qui est l'examen du mode selon lequel les œufs de la femelle sont fécondés par la semence du mâle.

Les organes génitaux des mâles sont presque aussi compliqués que ceux des femelles. D’ordinaire, voici de quoi ils se composent : $1^{\circ}$. de deux Testicules par qui le sperme est sécrété; tantôt ces organes restent fixés dans l'abdomen sans jamais en sortir, comme dans les oiseaux et les reptiles; tantôt ils sortent audelà du ventre, et s'y revêtent de plusieurs enveloppes nommées Bourses, comme dans la plupart des mammifères; d'autres fois, ils séjournent habituellemênt dans le corps, et ils n'en sortent qu'à l'époque du rut ou de l'amour, comme cela a lieu dans les rats : mais toutes ces choses ne changent nullement les fonclions de ces organes. $2^{\circ}$. Les testicules sont composés de petits vaisseaux très-déliés, et dont la réunion donne lieu à deux Conduits excréteurs ou déférens. $5^{\circ}$. Ces conduits déférens se rendent quelquefois dans leurs réservoirs, nommés Vésicules séminales, et d'autres fois directement dans la cavité du cloaque ( chez les ovipares), ou dans le canal de l'urèthre (chez les mammifères ). $4^{\circ}$. Lorsque c'est dans le canal de l'urèthre qu'aboutissent finalement les conduits spermatiques, alors cet urèthre est garni et forlifié par des Corps caverneux très-vasculaires, trèsextensibles, et susceptibles d'érection : ce lissu érectile 
146 LIV. II. DE LA REPRODUCTION DES ÉTRES VIVANS.

a pour effet de tendre le canal, d'en augmenter Ix longueur et en même temps de le rétrécir par des courbures, toutes circonstances propres à donner plus de rapidité aux jets de la semence chassée de ses réservoirs : l'urèthre, ainsi compliqué, porte le nom de Verge ou de Pénis. La forme en est trèsvariće selon l'espèce d'animal : il est tantôt simple et effilé, tantôt surmonté par une espèce de gland ou par des renflemens en forme de bourrelets, quelquefois même il est en partie osseux. Mais la verge est surtout fort différente chez les animaux ovipares, dans lesquels elle est séparée de tout urèthre et rarement perforée ; presque toujours alors elle offre simplement à sa surface des sillons plus ou moins profonds, destinés à recevoir la semence et à la répandre. Le pénis a pour principal usage de projeter le fluide séminal dans les organes de la femelle, ou seulement sur les ouís qu'elle rend, le plus loin et le plus rapidement possible : le contact réitéré de ce corps est d'ailleurs un moyen de titillation et un élément de jouissances.

La Seinence provient done des testicules. Ce fluide est blanchâtre dans tous les animaux; il est composé de deux parties , dont l'une est plus pesante que l'eau, tandis que l'autre, dit Haller, reste attachée à la surface du liquide sous la figure de toiles d'araignées. Celte liqueur porte une odeur sịgulière extrêntement pénétrante; les chairs et les humeurs des animaux s'en imprègnent désagréablement à l'époque dn rut. Le pollen de beaucoup de végétaux a une odeur en tout semblable, et ceci est d'autant plus digne d'attention, que le pollen est pour les plantes ce 
qu'est la semence pour les animaux. II serait curieux de comparer chimiquement ces deux liquides, mais ce n'est point notre objet.

La sécrétion de la semence ñe date que de l'époque. de la puberté, et d'ordinaire elle tarit dans la vieillesse; mais la durée du fluide prolifique.est bien difficile à fixer chez l'homme, à cause de ses passious, qui devancent quelquefois les besoins réels et souvent leur survivent. Pour les animaux, ils n'ont guère de semence au-delà de l'époque de leurs amours: leurs testicules se rapelissent et semblent s'atrophier le reste de l'année. Il en est ûême qui n'ont de semence qưune fois dans leur vie, ęt qui meurent après l'avoir répandue; à-peu-près comme on voit les étamines se flétrir après la dissémination du pollen : je veux parler des insectes, lesquels périssent après qu'ils ont engendré. La chaleur du climat, l'abondance de la nourriture, le bon état de la santé, le repos, un sommeil tranquille et prolongé, toutes ces choses ont beaucoup d'action sur la semence pour' en accroître la puissance et la quantité : les animaux à qui l'homme fait partager les commodités de la vie donestique et les précieuses acquisitions dues à son industrie et à sa prévoyance, sont plus enclins à l'amour, sinon plus aptes à la propagation, que les. animaux des mêmes espèces vivant à l'état sauvage. Rien n'agit sur le sperme autant que les longues privations, les maladies et surlout les chagrins; ce fluide alors perd sa consistance et son odeur en même temps que la quantité en est moindre; pour être propre à féconder, le fluide séminal des grands animaux doịt être consistant et comme granuleux. 
$1 / 8$ LE. II. DE LA REARODUCTIONDES HTRES VIVANG.

Mais d'où provient et en quoi consiste la propriété fécondante du sperme? voilà ce qu'il nous importe d'examiner. Il est vrai de dire qu'on voit s'accroître les œufs de beaucoup d'animaux ovipares sans que la semence $y$ soit intervenue; mais on ne voil jamais d'embryon se développer sans cette intervention du fluide séminal. Les œufs même de grenouilles et de salamandres, dans lesquels on croit voir des embryons ébauchés avant toute approche des sexes, ces œufs ne produisent jamais ricn s'ils ne reçoivent le contact de quelques particules de sperme : Spallanzani en a fait plusieurs fois l'essai. L'action intime de ce fluide sur les œufs n'est pas connue, mais elle se manifeste à tous les yeux par des phénomènes qu'on ne saurait récuser. Lorsqu'il s'est répandu sur dés cufs de vers à soie un peu de la semence du mâle de cette espèce, de jaunes qu'ils étaient ces œufs deviennent violets; ceux des poissons se troublent légèrement par un pareil contact; ceux des grenouilles, des crapauds et des salamandres, déjà à moitié noirs dès qu'ils sortent, noircissent bien davantage aussitôt qu'on les a arrosés da fluide séminal; en même temps on remarque qu'ils se sillonnent de rides nombreuses, 'se creusant de plus en plus. L'œuf d'oiseau a déjà une cicatricule à l'un des pôles de son vitellus avant l'imprégnation spermatique; mais après l'imprégnation celte cicatricule devient plus large et plus épaisse, de manière qu'il est impossible qu'une personne habituée à ce genre de recherches confonde jamais un œuf coché avec celui qui ne.l'a pas été; mais l'effet du contact de la semence est encore plus marqué sur l'ovule des vivipares. Les œufs des autres animaux peuvent du 
noins s'accroître et sortir avant d'avoir éprouvé ce contact, tandis que chez les mammilères ces pelites vésicules ne rompent leur membrane, ne parcourent les trompes et ne parviennent dans la matrice pour s'y accroître qu'après l'émission séminale du mâle. On croit même que le sperme en obscurcit un peu la transparence, et macule légèrement l'une des extrémités; mais comme ces corps sont excessivement petits, il faut se tenir sur ses gardes quant aux observations dont ils sont le sujet.

I.a semence du mâle, en quelque animal qu'on l'observe, a done pour usage de fécónder par son contact les œufs contenus dans la femelle ou déjà expulsés de son corps; mais cet arrosement spermatique se fait très-diversement selon les espèces d'auimaux : dans les hermaphrodites, par exemple, il y a communication directe entre les conduits séminifères el les réservoirs des œufs, de sorte que la fécondation est opérée sans accouplement et par łes organes unis lu même animal; c'est ce qui arrive chez les huîtres et la plupart des mollusques. Cette fécondation est aussi simple que celles des fleurs réunissant dans la même corolle des étamines et des pistils. D'autres animaux portent aussi dans le même individu les organes des deux sexes, mais trop séparés, trop éloignés pour se suffire. Les animaux ainsi conformés sọnt obligés à un double accouplement avec d'autres êtres de la même espèce, ayant à-la-fois des organes mâles et femelles : cela se voit pour les limaces, les sangsues, pour plusieurs vers et plusieurs mollusques; ce sout ces êtres-là que nous avons nommés androgyues. 
150 LIV. II. DE LA REPRODLCTION DES ETRES VIVANS.

On ne trouve rien d'analogue dans les plantes. Ensuite, depuis les insectes jusqu'à l'homme, tous les. animaux sont à sexe simple, et la plupart s'accouplent. Il y a bien dans quelques espèces des êtres neutres ou Mulets n'ayant les organes d'aucun sexe, comme on le voit pour les abeilles et les fourmis; mais il existe toujours parmi ees animaux assez d'individus à sexes distincts pour perpétuer la famille.

L'accouplement des sexes n'est pas toujours visible ni même constant pour tous les animaux unisexuels: on doute, par exemple, que beaucoup de poissors s'accuuplent jamais; et comme on ne sait par quelle iníluence le mâle peut être attiré vers les oufs frayés par la femelle, on a douté qu'il les fécondat : on a vu des poissons femelles avaler la laite répandue des mâles, des mâles manger les oufs des femelles, et l'on a prêtó à cela un but et des motifs fort bizarres. Si Linné (1) avait tenu compte de la voracité des poissons, s'il avait remarqué que les individus des deux sexes mangent également des oufs, souvent même dès qu'ils les ont frayés, et surtout s'il avait fait attention que les intestins où ces œufs s"introduisent n'ont guère de communication avec les organes formateurs du sperme; alors sans doute Linné aurait moins vite partagé un préjugé antérieur à Aristote. Toutefois, comme beaucoup de ces animaux ont un, cloaque, c'est-à-dire une cavité terminale servant d'aboutissant commun aux intestins, à la vessie ct aux organes génitaux, peut-être ne serait-il pas im!

(1) Voyç louvrage d'Artédi, publié par Linné , son ami. 
CHAP. XVHI. SLERME ET FÉCONDATION.

possible que des œufs avalés par quelques espèces éprouvassent en cet endroit l'impression du fluide séminal.

Quant à beaucoup de reptiles, nous savons qu'ils se fécondent sans coït et sans intromission véritable; les grenouilles et les salamandres mâles projettent immédiatement leur semence sur les œufs expulsés des femelles. On dit même chose des abeilles et de plusieurs autres insectes. Mais il y a émission intérieure de sperme dans les femelles des olseaux, daus les serpens, les tortues, la plupart des insectes, et dans les mammifères. Cependant, et quoique les pénis des mâles soient en général proportionnés aux organes des femelles, on n'est pás certain que le sperme soit projeté jusqu'à l'extrémité des trompes ou des oviductes: il y a plus, Harvey et Haller ne l'ont presque jamais trouvé dans la matrice des mammifères. Voilà ce qui a porté quelques personnes à conjecturer que peut-être la seule vapeur de la semence suffisait à la fécondation des œufs des femelles, car conçoit-on que ce fluide puisse êlre lancé par le pénis jusqu'aux ovaires, au delà des conduits si déliés qui séparent ces ovaires d'avec-la matrice! On a donc pensé qu'il s'élevait du sperme éjaculé dans la matrice, une vapeur, un esprit essentiel, un aura, comme on dit. Mais les expériences de Spallanzani sont venues détruire ces pressentimens. Cet illustre observateur a plusieurs fois exposé les œufs de divers animaux à cette vapeur de semence encore récente, et jamais il n'a pu réussir à les féconder : au lieu que le sperme en substance, le sperme pur ou mitigé, déterminait toujours le développement des embryons. 
152 LIV. II. DH LA REPRODECTION DES ETRES YYANS.

Plus l'action de la semence paraissait surpretrante, ct plus on mettait d'attention, plus on mettait de zèle à l'étudier. Le microscope une fois trouvé, on en fit bientôt usage pour examiner le sperme de plusieurs animaux; ce fut alors qu'on découvrit dans ce fluide d'innombrables petits corps mobiles, ayant une queue, portant une grosse tête, et présentant mille phénomènes singuliers (1). Cette découverte fut faite par un écolier nommé Louis Hamme; lequel s'empressa de la communiquer à Leeuwenhoek à qui finalement l'honneur en est resté; tant il est rare qu'une invention illustre le nom de son premier auteur. Toutefois Harlsoeker publia presque aussitôt que Leeuwenhoek des ouvrages sur les Animalcules spermatiques; il lui disputa même la gloire de l'antériorité, et s'il en faut croire Fontenelle, ce fut à d'assez justes titres. Les observations se multipliant toujours nonobstant les discussions de l'amour-propre, on grossit peu-à-peu l'histoire de ces corpuscules des détails les plus merveilleux. Comme on les voyait se mouvoir, on dit que c'élait par une volonté délibérée : on ajouta qu'ils avaient des sexes, qu'ils s'accouplaient, qu'à leur tour ils répandaient une sorte de sperme, apparemment aussi peuplé d'animalcules proportionnés à leur grosseur; qu'enfin ils concevaient, engendraient, subissaient des métamorphoses; et tout cela dansl'espace de quelques heures qu'on assignait à leur durée!

On mesura leur volume, et l'on vit avec étonnement qu'il variait peu dans le sperme des différens

(1) Voyez Leeuweuhoek $(1675)$, Hartsoeker, Lieberkuhn, Ledermuller, Neelham, de Gleichen, Vallisneri, Verheyen, Buffon, Bory, Prévost et Dumas, Spallanzahi, Maupertuis, elc. 


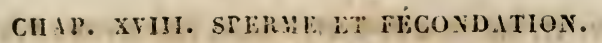

animaux : car il faut dire qu'on trouva des animalcules dans la semence de toutes les espèces. Il fallait aussi éludier les circonstances propices à leur développement; et l'on assura qu'il y avait peu ou point d'animalcules dans le sperme des animaux ou tout jeunes, ou très-vieux, malades ou éjennés. On n'en vit point non plus dans la liqueur imparfaite des mulets, peu ou point dans les autres humeurs; et l'on a assuré tout récemment que le fluide séminal des oiseaux, à l'exception du coq et du pigeon, n'a d'animalcules qu'à l'époque des amours, une ou deux fois l'année.

Dans l'origine de cette découverte on mêla beaucoup de faits incroyables à ce que laissait voir de réel le foyer grossissant du microscope, et plusieurs accréditèrent ces erreurs; les uns par une crédulité excessive, d'autres dans le but de rendre ridicules des faits. qu'ils regardaient tous comme fabuleux, d'autres enfin, dans l'intérêt de quelque système déjà émis ou projeté ; caril est des personnes qui trouvent toujours les faits assez avérés, s'il doit en résulter un système. On prétendit donc qu'on avait vu des animalcules à longues oreilles dans la semence de l'âne, et un petit poulet déjà bien conformé dans le fluide séminal du coq; bien plus, on assura qu'un animalcule spermatique de l'homme s'étant par hasard dépouillé de son enveloppe, avait laissé voir une figure humaine, bien petite à la vérité, mais pourtant reconnaissable (1). Et ce qui mérite une sérieuse attention au milieu de

(1) C'est Haller qui raconte ces faits : voyez Elem. Physiologice. 
154 LIV. II. DE LA REPRODUCTION DES İTRES VIVANS.

fables aussi ridicules, ce sont les conséquences quion crut pouvoir en déduire: on éinit ce principe, par cxemple, que toute femelle (sans excepter la fème; ayant reçu les approches du mâle, peut féconder. une autre femelle, une femelle vierge, au moyen des petits animalcules se transportant de l'une à l'autre.

Il est facile de pressentir quel rôle on a fait jouer aux animalcules spermatiques dans les phénomènes de la génération. Nous entrerons dans quelques détails à ce sujet, lorsque nous examinerons les principales hypothèses dont cette belle fonction a été le motif. Nous avons déjà exposé, au chapitre des $G \dot{e}-$ nćrations spontanées, les raisons quí nous font douter que ces prétendus animalcules soient des êtres animés. Il est certain, cependant, que tout est vivant dans un corps jouissant de la vie, le sang, la semence et toutes les humeurs, aussi bien que les organes euxmêmes : il serait donc possible que ce mouvement de. molécules, observé dạns le fluide séminal, fût une manifestation de cette vitalité dans une des parties qui se la partagent. Mais il ne faut point oublier qu'il s'agit là de véritables atômes, dont le microscope a fait des géans; et comme nous ne devons donner à chaque chose qu'une importance méritée, il est sage. de ne tenir compte de ces corpuscules qu'à raison de la réalité, et non d'après une apparence mensongère. Retournons donc à l'observation.

On accordait beaucoup aux animalcules au temps où Spallanzani faisait ses expériences, et il tenta plusicurs essais pour s'assurer du fait : il avait observé que lorsqu'on proje!te du vinaigre sur la semence dé- 
GIIAP. XIX. PÍ́cONDITIOYS ARTIFICLRLES.

layée des reptiles, cela faị disparaître du fluide tous les corpuscules mobiles. Il fit son expérience, et elle eut un plein succès : quoique sans animalcules, la semence fut toujours fécondante.

Quelqu'un ayant prétendu que peut-être la semence agissait à la manière de l'électricité, Spallanzani en fit l'essai. Il vit bientôt qu'un courant électrique laisse inféconds des œufs non spermatisés, mais que cela influe sur le développement de l'embryon en des œufs fécondés; que ce développement devient. par là plus précoce et plus rapide. Il fit de semblables tentatives avec d'autres substances, et il n'on trouva aucune par quoi le sperme pût être remplacé.

Cette puissance de la semence une fois bien établie, nulle fécondation n'ayant lieu sans son contact avec les ovules des femelles, Spallanzani voulut en connaître le degré d'énergịe.

\section{CHAPITRE XIX.}

Fécondations artificielles.

Spallanzani réfléchissant sur la manière dont beaucoup de poissons et de reptiles fécondent les ceuls de leurs femelles, il lui vint à la pensée d'opérer artificiellement de ces fécondations. Il commença par faire des essais sur les œufs des salamandres: or, tant qu'il n'employa que la semence pure des mâles pour en arroser les oufs des femelles, il n'obtint aucụn résultat; les oufs ainsi imprégnés furent stériles 
156 LIV. IF. DE LA REPLOUECHON DES ETRES VIVANS.

Nais le sperme délayé dans l'eau les fécondait con tamment. Il répéta cette expérience sur des ouf̣s de grenouilles et de crapauds; ce furent toujours mêmes résultats. Il mêla la semence avec différens liquides, avec du vinaigre, de l'urine, du sang, de la bile ou d'autres humeurs; et la fécondation continua de même. Le sperme conserve encore cette propriété fécondante plusieurs heures après la mort de l'animal qui le fournit, mais surtout dans un temps froid. Egalement les œufs de la femelle (je parle des reptiles de l'ordre des grenouilles) sont susceptibles d'être fecondés dix à douze heures après la mort de l'animal. Mais ils demeurent stériles sils sont restés plongés dans l'eau plus de douze minutes avant d'avoir reçu le contact du fluide séminal.

Spallanzani a voulu s'assurer jusqu'où pouvait aller la puissance fécondante du sperme des reptiles: il a délayé trois grains de sperme dans douze onces d'eau ordinaire, et ce mélange spermatique a suffi pour féconder et amener à bien les œufs réunis de cinquante grenouilles. Peu importait même que ces cufs n'cussent été plongés que peu de temps ou un moment, qu'ils en fussent partaut imprégnés ou touchés seulement par un point de leur surface. Il suffit, par exemple, qu'une pointe d'aiguille trempée dans le fluide séminal soit appliquée sur un œuf pour féconder celui-ci, et même la fécondation s'étendra à un deuxième œuf collé au premier et non touché par l'aiguille. On a calculé dans quelles proportions étaient la semence et la masse d'œufs fécondés par elle, et l'on est arrivé à des résultats étonnans. Il a souvent suffi qu'un instrument eût approché des testicules pour transmeltre 
une vertu fécondante à tout ce qu'il touchait ensuite. Spallanzani en cite un exemple : il avait plongé dans du sang des œufs non encore fécondés de crapauds; il s'attendait à les voir rester stériles, mais il fut trompé; bientôt il vit paraître des têtards vivans et bien formés. Surpris de ce résultat, il finit par se rappeler que les œufs avaient été tirés de l'oviducte de la femelle avec des pinces qui avaient servi à disséquer les testicules d'un mâle de la même espèce. Ne dirait-on pas que nous faisons l'histoire de phénomènes ẻlectriques ou magnétiques!

On a varié ces opérations à l’infini; on a vu que l'eau spermatisée conserve plus long-temps sa vertu fécondante que le sperme pur; que la chaleur lui communique d'abord plus d'énergie, mais qu'ensuite elle la lui fait perdre par l'effet de la vaporisation; que lorsqu'on la filtre, elle perd sa vertu, tandis que le dépôt resté sur le filtre la conserve en entier; que l'agitation à l'air lui est également nuisible; qu'enfin elle cesse bientôt d'êtr'e fécondante quand on l'expose à un froid glacial ou à une chaleur de plus de trente-cing degrés, aussi bien que lorsqu'on la mêle à de l'alcool ou à du sel marin. Ce dernier fail prouve, pour le dire en passant, que les poissons de mer ne peuvent féconder les œufs de leurs femelles qu'en répandant leur semence immédiatement sur eux. Mais les reptiles et les poissons d'eau douce peavent opérer cette fécondation à distance; l'eau sert de véhicule à leur semence, à-peu-près comme l'air sert d'intermédiaire au pollen des plantes dioïques. I.es expériences de Spallanzani en sont la preuve. Ce judicieux et illustre physiologiste a été plus loin : il a mis des masses 
I5S LIV. II. DE LA REPR̈ODUCTION DES ĖTRES VIVANS. d'oufs de grenouilles non fécondés dans une eau quí - contenait d'autres œufs fécondés, et tous ont été productifs, ils ont tous donné le jour à des têtards. Il suit de là que l'émission séminale d'une seule grenouille suffirait pour féconder tous les œufs de mème espèce contenus dans la même pièce d'eau. Admirable providence!

Le même expérimentateur a voulu voir si les testicules avaient la même propriété que le sperme dont ils sont la source, et voici ce qu'il est résulté de ses essais : lorsque les testicules sont demeurés entiers, jetés dans de l'eau avec des oufs non fécondés, ils né leur font rien produire; mais ils les fécondent toujours quand on a eu soin de les couper par morceaux.

Ces expériences de Spallanzani sur des grenouilles et des salamandres ont été répétées pour les poissons, et elles ont donné les mêmes résultats. On peut repeupler les étangs et les viviers en y jetant les oeufs artificiellement fécondés des poissons qu'on détruit. On s'est autorisé de ces faits remarquables pour conclure que même les mammifères peuvent se féconder à distance, leur semence ayant un liquide pour véhicule et pour interinédiaire : on a été jusqu’à assurer qu'une fille avait conçu (à la manière de quelques poissons et reptiles) pour avoir pris le bain spermatisé de son amant! Cependant les faits que l'abbé Spallanzani raconte sont assez merveilleux sans y joindre des fables aussi ridicules : il est vrai quils ont le tort d'êlre d'une extrềne exactitude, et que l'auteur en fait l'histoire dans un style simple comme la vérité. Spallanzani ne borna pas ses expériences sur les fé- 
GHAP. XIX. FÉCONDATIONS ARTIFIGIELLE.

condations artificielles, aux seuls reptiles. Malpighi avait essayé sans succès de féconder les oufs du papillon du ver-à-soie avec la semence du mâle ; Spallanzani échoua aussi dans ses premières tentatives, mais il réussit à une seconde épreuve.

Des insectes el des reptiles, Spallanzani passa aux mammifères; car, pourquoi des êtres si analogues à tant d'égards vivraient-ils sous des lois diflérentes? Comment n'engendreraient-ils pas de la même manière? II injecta donc dans l'utérus d'une chienne en chaleur environ vingt grains de sperme pur éjaculé spontanément par un chien de sa race; ce fluide iut maintenu avec soin à la température de $50^{\circ} \mathrm{h}$., naturelle à l'animal : au bout de soixante-deux jours, durant lesquels on la séquestra absolument de la société de ses pareils, la chienne mit bas trois petits, qui ressemblaient au père encore plus qu'à la mère. Cette expérience fit du bruit; on la répéta, et chaque fois elle eut de semblables résultatś (1).

II restait à savoir si la semence d'une espèce pourrait léconder les oufs d'une espèce différente. Iinné avait fait des expériences à ce sujet pour le pollen des végétaux; Koelreuter et Gœrtner en ont depuis tenté de nouvelles : ce fut Spallanzani qui résolut la question pour les animaux. Il répandit du sperme de crapaud sur des wufs de grenouilles; il injecta aussi de la semence de son même chien barbet dans l'utérus d'une chatte en chaleur, et jamais il n'y eut de fécondation par de semblables moyens.

(1) Un physiologiste de nos jours a proposé de féconder des fumelles eu iujectant du sperme dans leurs veines. 
1 Co hiv. II. DE La hipronuction des êtres vivars.

Spallanzani s'assura également que la semence d'une espèce de grenouilles ne saurait servir à féconder les œufs d'une autre espèce ; mais que le mélange des deux sortes de sperme jouit de la propriété de féconder les deux sortes d'œufs. D'oú vient celle inaction du fluide séminal passant d'une race à l'autre? Est-ce l'effet du volume ou de l'arrangement des molécules? Est-ce l'effet des élémens chimiques ou d'une aflinité cachée? Nous ne savons rien sur ces choses; mais nous en voyons les conséquences, et elles nous semblent dignes d'admiration.

Dans un univers rempli d'êtres aussi variés, ayant chacun sa destination, son but, son lieu, ses besoins, ses usages, il fallait bien que la confusion ne pùt s'introduire parmi tant de créatures diverses; car leur donner les moyens d'assimiler leur nature c'eût élé changer leurs rapports, compromettre leur existence et détruire le grand système dont ils font partie: L'harmonie de l'ensemble, dans un monde comme le nôtre, résulte de la diversité constante des élémens; l'identité de deux rouages originairement différens eût entravé le sublime jeu de la machine. Je dis donc qu'il était nécessaire que tant d'êtres divers, de toutes parts unis comme individus, demeurassent éternellement séparés comme espèces : il fallait qu'ils pụssent vivre ensemble, s'entre-aider, s'entre-détruire, sans pouvoir jamais s'engendrer les uns les autres en confondant leurs grandes familles : il fallait assigner pour loujours des limites à chaque espèce, et nous venons de voir que la nature a posé ces limites à la source wême des générations. 


\section{CHAPITRE XX.}

Remarques d'Aristote sur les Sexes et l'Accouplement des aninaur.

L'histoire des sexes et de l'accouplement des animaux est une des choses que les naturalistes de l'antiquité ont le mieux connues : c'est effectivement un sujet plein d'intérêt et d'une observation facile; il ne demande ni recherches pénibles, ni longues expériences, ni dissections. Aussi Aristote s'y est-il particulièrement complu. Son immortel ouvrage sur les animaux renferme un grand numbre de détails intéressans sur cetle matière; et quoiqu'il s'y mêle souvent quelques préjugés des vieux âges, nous croyons faire une chose utile en empruntant quelques passages à cet ouvrage, sans modèle à sa naissance, sans pareil encore aujourd'hui; toujours original après tant de copies, toujours jeune après deux mille ans; simple et fécond comme la nature, sublime et vrai comme le génie. Si nous citons ce grand homme, c'est pour la vérité, non pour sa gloire, car cette gloire esț telle, qu'un suffrage de plus ne saurait l'accroître. On a raison d'admirer Aristote sur parole; mais que l'on gagne à le méditer!

".... La plupart des animaux ont des sexes, mais tous n'en ont point; et ce n'est que par métaphore qu'on dit de ces animaux qu'ils portent des petits et qu'ils les mettent bas. Chez ceux qui restent attachés à une place fixe, il n'y a point de mâle et de femelle. 
162 Liv. II. DE LA RePRoduction des Etres vivans.

Mais celle différence de sexe a lieu chez les animaux qui se meuvent avec des pieds, bipèdes comme quadrupèdes, et génćralement chez tous ceux dont l'accouplement est suivi de la production d'un animal, d'un œuf ou d'un ver. En général, à l'égard des animaux qui ne sont ni poissons ni insectes, on peut nier ou affirmer d'eux l'existence du sexe d'une manière absolue. Par exemple, dans tous les quadrupèdes, chaque individu est mâle ou femelle; dans les testaoés, au contraire, il n'y a ni mâle ni femelle (hermaphrodites); ils ressemblent aux plantes, dort les unes sont fécondes et les autres stériles (Aristote ignorait, comme on voit, que les plantes eussent des sexes). On ne saurait avancer rien de général pour les sexes des insectes et des poissons : il y a des espèces où la distinction des scxes n'a aucunement lieu; par exemple, il n'y a ni femelle ni mâle parmi les anguilles : l'anguille ne produit rien de soi. On prétend, il est vrai, avoir vu des espèces de vers adhérens à l'anguille; mais les conséquences qu'on veut tirer de cette obscrvation ne soni pas rigoureuses, faute d'avoir fait altention au lieu du corps où ces vers se trouvaient. Premièrement, aucun animal du genrc de l'anguille ne produit de petits vivans qu'après avoir eu des œufs, et jamais on n'a trouvé d'œufs dans l'anguille (cela est encore vrai aujourd'hui); d'autre part, les animaux vivipares portent leurs petits dans la matrice où ils sont altachés : ils ne les ont pas dans le ventre, car les petits seraient digérés tout comme les alimens. Quant à la différence qu'on dit être entre les anguilles mâles, qui ont, à ce qu'on prétend, la tête plus grosse et plus allongée, et les anguilles femelles, 
CHAP. XX. REMarǫues D'ARISTOTE.

qui l'ont plus aplatic, cette diversité de forme n'est pas relative à la différence de sexes; clle indique seulement différentes espèces d'anguilles.

- Il"y a de certains poissons qu'on nomme bréhans, qui n'ont ni œufs ni laite. Il s'en trouve de tels parmi les poissons des fleuves, parmi les cyprins et les $\beta_{a-}$ pivos. Quelques poissons ont des individus qui concoivent et produisent, comme les testacés et les plantes, sans avoir de males qui les fécondent : tels sont les plies, les rougets, les serrans. On ne trouve que des œufs dans les individus de ces espèces.

๖ Chez les animaux qui se meuvent avec des pieds et qui ont du sang, le plus ordinaire, quand ils ne sont point ovipares, est que le mâle est plus gros que la femelle, et qu'il vit plus long-temps. Il faut excepter le mulet, par rapport auquel on observe le contraire. A l'égard des animaux qui se reproduisent au moyen d'un œuf ou d'un ver, les poissons , par exemple, ct les insectes, la femelle est plus grande chez eux que le mâle. Voyez les serpens, les stellions, les batraciens (grenouilles), les sélaques, les poissons qui vivent par troupes, et tous ceux qu'on nomme saxatiles. La preuve que parmi les poissons la femelle vit plus long-temps que le mûle, e'est qu'on pêche des femelles plus vieilles qu'aucun mâle de même espèce.

„Voici une autre différence qui distingue les deux sexes dans quelque genre d'animaux que ce soit : less parties les plus grosses et les plus vigoureuses sont, dans le mâle, les parties antérieures et supérieures; dans la femelle, ce sont les parties postérieures t inférieures. La même observation est vrạe poc: 
16 4 LIV. II. DE LA REPRODUCTION DES ÂTRES VIVANS.

l'homme aussi bien que pour tous les animaux vivipares qui se meuvent avec des pieds. La femelle est moins nerveuse (musculeuse); ses traits sont moins prononcés; son poil, lorsqu'elle en a, ou ce qui répond au poil lorsqu'elle n'en a point, est plus fin; sa chair est plus humide, ses genoux sujets à craquer, ses jambes plus grêles, et si la nature de l'animal est d'avoir des pieds, ceux de la femelle sont micux faits. Parmi les animaux qui ont de la voix, celle de la femelle est plus claire et plus aiguë que celle du mâle : il n'y a d'exception que pour l'espèce du bœuf, où la voix de la femelle est plus grave. Dans certaines espèces, les armes que la nature a données à l'animal pour se défendre, telles que les dents, les crocs, les cornes, les ergots et autres parties semblables, manquent absolument à la femelle : le mâle les a seul. Ainsi la biche n'a point de bois, et dans le nombre des oiseaux à ergot, il y a des espèces où les femelles n'en ont point du tout. De même la femelle du sanglier n'a point de crocs saillans. Dans d'autres espèces le mâle et la femelle ont les mêmes armes; seulement celles du mâle sont plus fortes. Les cornes du taureau, par exemple, sont plus fortes que les cornes de la vache $(1)$.

- ...... L'accouplement a lieu dans les espèces qui out des individus de l'un et de l'autre sexe, mais it n'est pas partont le même; il ne se fait pas toujours de la même manière. Les mâles de tous les animaux qui sont vivipares et qui se meuvent sur la surface de la terre avec des pieds, ces animaux ont tous un or-

(1) Aristale, IIist. des Animeux, lix. ux. 
CHAP. XX. REMARQUES D'ARSTOTE.

gane destiné à l'œuvre de la génération; mais les approches des sexes ne sont pas pour cela semblables : ceux qui jettent leur urine en arrière, comme les lions, les lynx, les dasypodes, s'approchent à reculons et s'accouplent en arrière (e'est-à-dire que c'est dans cette position que le coit finit de s'accomplir, comme chez plusieurs autres quadrupèdes dépourvus de vésicules séminales). Entre les dasypodes, c'est souvent la femelle qui saute la premièrè sur le mâle : c'est l'inverse chez la plupart des autres animaux, chez les quadrupèdes, les oiseaux, les batraciens, etc. Quelquefois la femelle fléchit les pattes pour faciliter l'accouplement. Malgré l'élévation de ses jambes, la grue reste debout; le mâle saute sur elle, et l'accouplement est aussi prompt que chez le passereau.

"Pour revenir aux quadrupèdes, l'ourse se couche par terre, et elle reçoit le mâle tout comme les autres femelles, qui demeurent sur leurs pieds pendant cette action, c'est-à-dire que le dessous du corps du mâle est sur le dos de la femelle. Les hérissons se tiennent droits, le devant du corps de l'un contre le devant du corps de l'autre. Les femelles des animaux vivipares ayant une certaine grandeur, la biche, la vache, par exemple, ne souffrent le cerf et le taureau que rarement, à cause de la roideur de la verge. Elles ne reçoivent la liqueur prolifique qu'en cherchant à se soustraire aux efforts du mâle : on en a fait l'expérience sur des cerfs privés. Le loup s'accouple comme le chien. Les Chats ne s'accouplent pas à reculons, mais le mâle se dresse et la femelle se place sous lui. La chatte est naturellement ardente; elle excite le mâle à la satisfaire; elle crie pendant l'accouplement 
166 LIV. II. DE LA HBPRODLCTION DES FTRES VIVANS. (le pénis du mâle disposé en croissant et comme hérissé d'épines la blesse). Dans l'accouplement du Chameau, la femelle fléchit les jambes de derrière, le mâle la couvre, et les croupes ne sont pas opposées : la situation du mâle est telle que dans les autres quadrupèdes. Ils demeurent dans cet état des jours entiers, mais ils se retirent alors dans les lieux écartés où ils ne se laissent approcher que du pâtre. La verge du chameau est si nerveuse, qu'on en tire des cordes pour les arcs. Les Eléphans ne s'accouplent non plus que dans les lieux solitaires : ils choisissent le voisinäge des rivières et Jes lieux où ils ont coulume de se retirer. La femelle s'abaisse et écarte les jambes, tandis que le mâle monte sur elle. L'accouplement des Phoques est le même que celui des animaux dont le canal urinaire est en arrière; ils restent attachés long-temps croupe à sroupe comme les chiens.

"...... L'union des serpens est si intime durant l'accouplement, qu'ils semblent ne plus former qu'un corps et un seul serpent à deux têtes. Les Lézards aussi s'entrelacent. L'accouplement de tous les Poissons, si l'on excepte les Sélaques, dont le corps est large, consiste à se glisser le ventre l'un contre l'autre. Les sélaques larges et qui ont une queue, la raie, par exemple, et autres de ce genre, ne se glissent pas seulement ainsi l'un contre l'autre : le mâle applique son ventre sur le dos de la femelle, à moins que l'épaisseur de la queue n'y mette obstacle. Ceux qui ont la queue fort grosse, tels que la lime, ne font que se frotter le ventre l'un contre l'autre. On prétend avoir vu des sélaques liés l'un à l'autre comme des chiens. Dans toute la classe des sélaques, la femelle 
est plus grosse que le mâle : il en est assez généralement de même de tous les poissons. La dénomination de Sélaques comprend les chiens marins, la torpille, la raie, etc. Leur accouplement a été plus facile à ubserver : on a pu voir qu'il se faisait de la manière que je viens de décrire, parse quen général les animaux vivipares demeurent plus long-temps accouplés que les animaux ovipares. Le dauphin ét tous les Cétacés s'accouplent de même; le mâle se frolle contre la femclle. Ia durée de cet accouplement n'est ni fort longue ni fort courte. Il y a des sélaques chez lesquels on reconnaît le mâle à deux appendices qui lui pendent auprès de l'orifice par lequel sortent les excrémens, appendices que les femelles n'ont point. Il est aisé d'étudier ces appendices dans les chiens de mer, car tous les ont.

- .... Il est difficile de bien voir la manière dont s'accouplent les Poissons ovipares, et c'est ce qui a fait. croire à plusieurs personnes que les femelles des poissons se fécondaient en avalant la liqueur que jette le mâle. Il faut convenir d'un fait dont on est assez souvent témoin : lorsque le temps de l'accouplement est venu, la femelle suit le mâle, elle avale la liqueur qu'it jette, et en lui frappant sous le ventre avec la bouche elle rend la sortie de cetle liqueur plus prompte et plus abondante; mais après le frai, les mâles suivent les femelles a leur tour et avalent leurs oufs : les poissons ne naissenc. que de ce qui échappe à cette voracité. De là est venu, sur les côtes de Phénicie, l'idée de se servir réciproquement des mâles et des femelles de quelques poissons: pour les prendre les uns et les autres. On présente aux muges femelles des muges mâles; clles se rassemblen 
163 u.IV. II. DE LA REPRODLCTION BLS ÈTRES VIVANS.

autour d'eux et les pêcheurs les enferment. On fait de même pour les muges mâles à l'égard des muges femelles. Ces observations souvent répétées ont firit naître sur la fécondation des poissons le système que j’ai exposé; mais on aurait dû remarquer qu'il n'y a rien là de particulier aux poissons. Les quadrupèdes mâles et femelles distillent dans la saison de leurs amours quelque chose de liquide; ils se flairent l'un l'autre les parlies génitales; il y a plus, c'est assez pour rendre une perdrix féconde qu'elle se trouve sous le vent, plus bus que le mâle (comme les palmiers!); souvent même il a suffi qu'elle eût entendu le chant du mâle dans un temps où elle était disposée à concevoir, ou que le mấe ê̂t passé en volant au-dessus d'elle, et qu'clle cût respiré l'odeur qu'il cxhalait (vieille erreur). Ces oiseaux, mâles comme femelles, tiennent le bec ouvert et la langue hors du bec pendant l'accouplement. Dans l'exacte vérité, les poissons se séparent presque aussitôt qu'ils se sont approchés, et on les voit rarement réunis; mais j'ai rendu compte à cet ćgard des faits que l'on a vus.

"...... Les sèches et les calmars nagent unis ensemble pendant l'accouplement, bouche contre bouche, bras contre bras. Le mouvement commun se fait par rapport à chacun d'eux dans des sens opposés : la trompe de l'un est ajustée à celle de l'autre, et nageant ainsi accouplés, si l'un va en ovant, l'autre va en arrière.

"Les Crustacés, tels que les langoustes, les écrevisses, les squilles et autres semblables, s'accouplent comme ceux des quadrupèdes qui jettent leur urine en arrière : l'un des deụx relève sa queue et en pré- 
sente le dessous; l'autre y applique la sienne. La saison de cet accouplement est quand le printemps commence à paraître. On voit dès-lors ces différens animaux s'accoupler : quelcues-uns s'accouplent encore lorsque les figues commencent à mûrir. L'accouplement des écrevisses et des squilles n'a rien de différent; mais les cancres s'unissenț par leurs parties antéricures, en ajustant les unes sur les autres les tablcttes écailleuses qui les enveloppent. Le plus petit des deux (le mâle) monte le premier sur l'autre par derrière, et alors le plus grand se retourne sur le côté. On n'aperçoit ici d'autre différence entre les deux sexes, si ce n'est que la femelle a l'écaille plus grande, plus détachée du corps et plus velue à la partie où elle dépose ses oufs et par laquelle elle se décharge de ses excrémens. Leur accouplement n'est accompagné de l'intromission d'aucun membre.

" On vient de voir, poursuit Aristote, comment les animaux s'accouplent : il faut ajouter que leur accouplement a dans chaque espèce un âge et des saisons marquées. Le temps que la nature a indiqué à la plupart pour se reproduire est celui où l'hirer fait place à l'été, je reux dire le printemps. Dans celte saison, la plupart des animaux qui habitent l'air, la terre et les eaux, sont pressés du besoin de s'unir; cependant quelques espèces d'animaux âlés et d'animaux aquatiques s'accouplent et mettent bas en automne et en hiver. L'homme à cẹt égard est plus indépendant des saisons qu'aucun autre animal. Plusieurs des animaux qui, vivant avec lui, jouissent d'une température d'air plus chaude et d'une nonrriture plus abondante, en sont moins dépendaus aussi, 


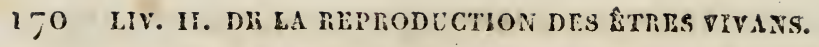

pourvu que d'aillemrs le teinps de leur gestation ne soit pas trop long. Ie porc, le chien, et les oiseaux dont la ponte se répète souvent en sont la preuve. Beaucoup d'animaux semblent songer d'avance aux besoins de leurs pelits, car ils s'accouplent précisément dans le temps le plus favorable pour qu'en naissant leurs petits trouvent leur nourriture. Dans l'espèce humaine, on remarque quel'homme a plus d'ardeur en hiver, la femme en été (1).

Voila ce que dil Aristole, et il faut convenir qu'il resle peu de choses à y ajouler. Nous avons eu soin de souligner quelques détails dont l'inexactitude est connue de nos jours. Chaque siècle a ses préjugés, ses erreurs, et il ne suffit pas toujours d'avoir dur génic pour savoir les apprécier et les comballre. Par exemple, celle idée émise par Aristole, que les lions s'accouplent à rebours, est un vieux préjugé qui s'est étendu à plusieurs animaux sauvages. Si l'espèce du chien ne nous était pas aussi familière, nous dirions même chose à son ćgard ; mais cette erreur était impossible au sujel d'un animal qui accompagne l'homme in tous licux. Il faut remarquer que l'accouplement des animaux est presque toujours plus long dans ceux qui manquent de vésicules séminales : le sperme n’ayant chez cux aucun réservoir, son émission est plus lente, el la nature a conformé la verge de manière à en rendre le relour difficile avant son entier relâchement. Voilà ce qui a licu pour le chien, qui a le pénis cerminé par un gros gland en bourrelet.

En général les deux sexes sont proporlionnés et à-

(1) Aristote, liv. $\mathrm{v}$. 
peu-près en même nombre chez lous les animaux. Si l'on a cru ne trouver que des femelles dans certaines espèces, cela vient de ce qu'il s'agissait d'hermaphrodites, dans lesquels effectivement les organes mâles sont d'ordinaire les moins apparens. II faut toutefois excepter les abeilles, parmi lesquelles il n'y a que quelques femelles pour plusicurs centaines de mâles et des milliers de neutres. Les sexes sont de même en proportion égale dans les plantes : à la vérité les plantes hermaphrodites ont plus d'étamines que de pistils; mais dans les végélaux monoĩques ct dioïques on ne remarque pas qu'il y ait de disproportion manifeste entre les fleurs mâles et les fleurs femelles. Il faut convenir qu'on observe quelquefois cette inégalité pour plusicurs animaux, soit seulement pour certains indivizus isolés, soit même pour certaines familles cantonnées dins quelques pays. Il y a des individus quine produisent que des mâles, d'autres qui engendrent presque uniquement des femelles : cela est vrai en particulier pour l'espèce liumaine. Ln gé́néral, le nombre des mâles prédomine chez lous les peuples, de sorte que les millions d'hommes massacrés par les armes ont peu d'effet sur les populations futures. On a cru qu'il y avait des pays ou l'aulre sexe était en majorité, et c'est la plus forle raison que Montesquicu ait alléguéc pour expliquer la polygamie de beaucoup de peuples d'Orient; mais la chose est loin d'être certaine : si vraiment le nombre des femmes prédominait dans un pays où l'homme les asservit par volupté, je regarderais cet excédent d'un sexe sur l'autre non comme la cause naturelle de la polyganic, mais comme l'effet de l'excès des jouissances 
1,2 LIV. II. DE LA REPRODECTION DES ÈTRES VIVANS.

énervant les hommes. On pense également que dans les capitales il y a plus d'enfans femelles que d'enfans mâles, et que toutes les circonstances favorables à la produclion des enfans naturels font prédominer le nombre des femmes. Il paraît du moins prouvé que les peuples actuels de l'Irlande comptent beaucoup plus de femmes que d'hommes, et cela même accroît la population de ce malheureux pays. Est-ce l'effet de l'oppression et de la misère? et serait-ce un signe de décadence?

Nous dirons dans l'un des chapitres suivans à quels signes on a prétendu connaître le sexe des fotus pendant la gestation même. On a fait plus, on a dit qu'on pouvait à volonté procréer un sexe plutôt que l'autre. Voici de quelle manière. On a supposé que les foetus mâles avaient leur source dans les ovaires droits des femelles, ou, selon d'autres systèmes, dans le testicule droit des mâles, ou à-la-fois dans les deux organes; les organes gauches ont été assignés à l'autre sexe. Or, il suffirait, dans une pareille hypothèse, que les organes d'un côté fussent extirpés, comprimés. ou sensiblement altérés, pour que la progéniture fût d'un mềme sexe; et l'on pourrait ainsi prévoir lequel. Otez, a-t-on dit, le testicule droit, ou comprimezen le cordon; ôtez pareillement l'ovaire droit de la femelle, ou comprimez, oblitérez la trompe droite, ou au moins que la femelle soit inclinée à gauche durant le coït et la conception, et toujours l'animal ainsi procréé sera du sexe femelle; du sexe mâle, au contraire, dans les circonstances opposées. Je répète, je répète avec insistance, que cela n'est qu'un système; mais ce système, tout bizarre gu'il est, lout inexacı. 


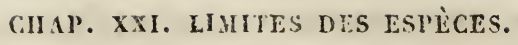

que le montre l'observation désintéressée des faits, on lui connaît encore des partisans, sinon des défenseurs. L'auteur de cette hypothèse aurait dû dire de quel sexe devrait être l'animal dont le père n'aurait que le testicule d'un côté, et la mère, le seul ovaire du côté opposé. D'ailleurs les oiseaux n'ont point d'ovaire droit.

On a cru aussi pouvoir pressenlir le sexe des oiseaux à la forme des oufs qui en renferment le premier germe : mais on s'est assuré que les mâles naissent, non pas des œufs les plus arrondis, comme on l'avait prétendu, mais des plus volumineux; ou plutôt voici quel résultat on a obtenu. On a pesé comparativement des œufs de différentes formes en nombre égal, mais d'une forme semblable, pour chaque lot, pour chaque couvéc; et l'on a vu qu'il naissait plus de mâles de ceux qui avaient été trouvés les plus gros et les plus pesans.

\section{CHAPITRE XXI.}

Linites des Espèces. Adultérisme. Bâtards. Métis. Mulets.

On reconnaît que deux êlres sont d'espicc différente en ce quils ne peuvent engendrer ensemble, encore qu'ils soient de sexes différens et féconds l'un et l'autre. Nous avons déjà dit la raison finale de cet isolement des espèces; nous allons maintenant en chercher les causes physiques. D'abord le pollen et le sperme d'une espèce ne jouit de la propriété fécondante que dans les limites de cette espèce : nous igrnorons la cause de cette particularité, mais nous avons cité les faits qui la constatent. Ensuite chaque 
1-4 Liv. II. DE LA REPRODECTION DES ItThes vivans.

plante a son temps de floraisou et de maturité, chaque animal son époque de rut et d'accouplement, sa durće d'incubation ou de gestation; et l'on concoit que deux êtres d'espèce dirférente ne pourraient engendrer ensemble qu'autant que toutes ces choses seraient dans une parfaitc concordance dans les deux espèces. Ajoutons à cela que les animaux n'ont de propension à s'accoupler qu'avec des êtres de leur sorte : jamais, dans l'étal de nature, on ne voit les animaux d'espèces différentes s'entrechercher ni s'unir; d'ailleurs les organes génitaux sont quelquefois trop discordans pour permellre ces conjonctions adultérines. S'il arrivait qu'on ne pût distinguer entr'elles deux espèces d'une apparence semblable en toutes choses, on n'aurait qu'à allendre l'époque de la reproduction, et l'on verrait l'amour élablir ces démarcations douteuses. C'est qu'en effet le mème instinct qui rassemble en famille les animaux analognes, sépare par la même raison les animaux diflérens.

Cependant on est parvenu à apparier des êtres qui nalurellement ne produisent jamais ensemble. On a fécondé les pistils d'une plante avec le pollen provenant d'une plante d'unc autre espèce, dans le cas toutefois où ces espèces n'étaient pas trop diflérentes: on est parvenu à faire accoupler ensemble la louve et le chien, le lapin et le lièvre, l'ânesse et le cheval, le bouc et la brebis, le faisan et la poule, le serin et le chardonneret, le moinęu et le bouvreuil, etc. Les animaux nés de ces unions adultérines ressenblaient aux deux parens également, ou quelquefois davantage à l'un des deux, mais ils étaient inféconds, cux ou leur progéniture. Si ces animaux wélis ou mulets s'accouplent, c'est d'ordinaire sans résultat: 
- its ne peuvent concevoir, ou, s’ils conçoivent, ils avortent. Quelquefois, cependant, des animaux mipartis ont produit de nouveaux êtres, mais ceux-ci étaient stériles. 11 en est de même des plantes : les graines provenant du croisement de deux espèces ou ne mûrissent point, ou sont improduclives. Il n'y a d'exception à celte loi que pour les métis de quelques oiseaux, lescucis paraissent conserver la faculté de se reproduire et de transmettre ainsi la bâtardise à plusieurs générations; mais, même pour les oiseaux, les métis n'ont pas une longue postérité : les descendans finissent bientôt par être stériles.

Ces unions hétéroclites ne sont point naturelles: on ne les obtient ordinairement que par la captivité d'animaux jeunes, forts et abondamment nourris; encore de pareilles tentatives échouent-elles souvent. Assurément du moins on ne voit jamais s'accoupler des animaux d'espèces très-différentes : ce qu'on a dit du commerce adultérin du taureau et de la jument, du lapin femclle et du chat, du canard et de la poule, d'un oiseau avec un quadrupède, etc., toutes ces choses me paraissent fabuleuses. Ce n'est pourtant pas l'accouplement ẹtre des êtres aussi dissemblables dont je nie la possibilité; je dis seulement que de pareilles conjorictions ne peuvent rien produire. A la vérité, plusieurs auteurs estimés paraissent croire à l'existence des jumars et d'autres productions aussi monstrueuses; mais nous ne voyons pas que de pareils phénomènes se soient offerts aux observateurs modernes. Les progrès des sciences diminuent le nombre des prodiges. 11 paraît prouvé que les animaux analogues pour la structure et pour les mours, 
176 LIY. H. DE IA REPRODCGTON DES ÊTHES vivANS.

pour l'époque de leurs amours et pour la durée de la gestation ou de l'incubation, peuvent bien engendrer ensemble dans quelques cas assez rares, et alors c'est l'espèce du mâle qui régit la durée de l'incubation ou de la gestation; mais toutes les fois que les deux êtres unis appartiennent à des espèces pour lesquelles la durée de la gestation difière beaucoup, comme le taurcau et la jument, la chatte et le lapin, alors toute conception adultérine est impossible. Il y a plus, le croisement entre des espèces roisines produit de grands changemens dans les organes génilaux femelles : par exemple, l'âne et le cheval sont analogues pour la structure; ils entrent en chaleur à la même époque ; la gestation a chez les deux la même durée; eh bien! cependant la matrice de la jument qui a d'abord produil un mulet, a éprouvé par-là de si grands changemeas, que les poulains qu'elle produit ensuite conservent quelque chose du mulet. La bâtardise semble s'étendre jusqu'aux produclions légitimes.

Les animaux métis liennent ordinairement de leurs deux parens, comme on le voit pour les mulâtres et les diférens mélanges de l'espèce humaine. Nous entrerons plus tard dans quelques détails sur le mélange des sangs, sur le croisement des races et les ressemblances hérédilaires. Nous devons dire dès à présent qu'il y a de certains caractères qui viennent du mâle et d'autres caractères qui viennent de la femelle. C'est même sur la constance de pareilles transmissions qu'on a fondé des règles pour le perfectionnement de certaincs races d'animaux, ou plutôt pour quelques-uns de leurs organes ou de leurs produits. 


\section{CHAPITRE XXII.}

Esquisse d'une Histoire critique et comparée de la Génération dé

l'Homme.

Nous n'avons encore parlé de la Reproduction de l'Homme qu'à l'occasion des mammifères; ce n'est pas assez. Outre sa prééminence morale sur les autres animaux, l'homme se distingue du plus grand nombre par plusieurs endroits de sa structure, mais en particulier par quelques détails de la fonction servant à le procréer. D'ailleurs il n'est pas d'animal dont l'histoire ait été aussi bien, autant de fois étudiée que la sienne : il y a dans le monde une classe entière d'observateurs qui consacrent à cette étude tous les instans d'une vie réfléchie. L'homme est donc le mieux connu de tous les êtres, et c'est pourquoi nous le choisirons toujours de préférence comme sujet de comparaison : non pour assimiler tout à sa nature, mais pour rendre plus sensibles les caractères distinctifs des autres espèces. Nous ne reviendrons pas sur les organes et les phénomènes que nous avons indiqués comme appartenant en commun à l'homme et à d'autres animaux : les remarques suivantes se rapportent presque entièrement à notre espèce.

L'homme est pubère vers sa quinzième année. Alors son pubis s'ombrage de poils, le fin duvet de son menton se colore et s'épaissit, l'accroissement des organes génitaux devient plus sensible, déjà un fluide séminal imparfait s'y prépare; Ies forces viennent, 
178 LIV. II. DE K. REDRODCCTION DES ÊTRES VIVANS.

la vie est plus active: inquiet, limide, incerlain, mais quelquefois audacieux, le caractère ne serait déjà plus celui de l'enfance, si la volonté avait moins d'inertie: ce n'est encore que l'adolescence, mais c'est l'époque de l'amour. Vers cet âge la voix change, devient rauque et voilée; sans être grave, elle n'est plus aiguë. Ce changement de la voix suit les premières jouissances et quelquefois les précède.

La même révolution s'annonce en même temps chez la jeune fille, mais elle a des phénomènes différens. Ici ce n'est pas la voix qui change; mais les mamelles se développent, les formes s'arrondissent, les organes génitaux, plus accrus, se pénètrent de sang, et finalement le flux menstruel s'établit et revient par périodes fixes : en outre des poils naissent au pubis, comine chez le jeune homme, et même un peu plus tôt.

- Le sang menstruel, dit Aristote, est lel que - celui qui sortirait d'une plaie récente. Ordinaire- ment ce flux périodique arrive quand les mamelles - s'élèvent déjà de deux doigts. Les jeunes filles ont - la voix plus aiguë que les garçons de leur âge, plus - aiguë aussi que les vieilles femmes : cela vient de - la glotte, dont l'ouverture est plus étroite. ”

C'est alors que le tempérarnent se forme et que la force du corps se prononce davantage. La révolution quis'opère, guérit souvent les maladies de l'enfance; d'autres fois elle prépare des soufirances pour toujours. La puberté est pour ainsi dire le nœud de la vie : à partir de cette époque, la fraîcheur et la santé des femmes/dépendent de la régularité du flıx menstruel. La tempérance dans l'union des sexes produit l'énergie du corps, la supériorité de lintelligence et la 
CIAP. XXII. GÉNÉRATION DE L'HOMME.

longévité : trop de précocité dans les jouissances de l'amour ćnerve l'homme et hâte sa fin après l'avoir abruti. Souvent les maux dont on accuse une continence excessive, c'est l'onanisme ou le libertinage qui les ont causés.

La puberté ne décide pas seulement du bien-être de la vie et de sa durée : elle produit aussi tous les vices, toutes les passions, ou l'habitude des vertus; car tout s'enchaîne dans les mœurs comme dans les . fonctions de l'homme, et c'est à l'âge où tant d'impressions rejaillissent sur l'âme qu'il faut se prémunir contre leur danger.

Ce n'est guères qu'à l'âge d'environ vingt ans que la semence de l'homme est prolifique. Les très-jeunes filles conçoivent aisément dès qu'elles sont réglées; mais à partir de la première grossesse leur crue se ralentit, outre que des accouchemens trop précoces sont toujours très-laborieux. La femme, toutefois, est plutôt nubile que l'hoınme : ses mamelles et son bassin ont déjà pris tout leur accroissement à un âge où l'autre sexe n'a pas encore de barbe; et ce sont là les indices les plus sûrs de la nubilité.

L'homme est celui des animaux qui, proportionnellement au volume de son corps, a le sperme le plus abondant. Ce fluide est toujours blanchâtre : Aristote réprimande Hérodote pour avoir prétendu. que les peuples de l'Éthiopie l'ont noir. L'épaisseur de la semence varie et fait varier la propriété fécondante : elle est inerte si elle est trop claire. Aristote ajoute qu'elle donne plutôt des enfans mâles lorsqu'elle est épaisse et grenue, "ou composée de glo" bu!es ressemblans à des grains de grêle; claire et 
1 So LIV. II. DE LA REPRODUCTION DES ÈTRES VIVANS.

" sans globules, elle ne produit rien, ajoute-t-il, ou "seulement des filles (1). On a beaucoup développé cette conjecture, surtout depuis quelques années : on a dit que les animaux trop jeunes et ceux qui sont affaiblis par des maladies ou par les années produisent surtout des femelles, et que deux animaux accouplés engendrent plus de femelles ou plus de mâles, selon celui des deux sexes qui a le plus d'ardeur et de puissance. D'après cette opinion, un mâle robuste, un mâle vigoureux et sain, ni trop jeune ni trop vieux, devrait surtout produire des mâles, si sa femelle est plus faible et plus délicate que lui. Il est bien vrai que l'homme est presque toujours plus fort et moins jeune que sa compagne; il est vrai aussi que pour notre espèce le nombre des mâles paraît l'emporter sur le nombre des femelles, et cela vient à l'appui de la conjecture. On dit de plus qu'on a vérifié ce principe pour quelques animaux, pour quelques oiseaux domestiques; mais comme les unions des animaux à l'état libre et de nature n'ont lieu qu'entre des individus de même âge et de même force, l'opinion ci-dessus fût-elle exacte, il n'en résulterait pour eux aucun désaccord, aucune inégalité dans la proportion des deux sexes. Toutefois il faudrait voir si les espèces où l'un des sexes prévaut sur l'autre par le volume et la force ont plus d'individus du sexe prépondérant.

L'écoulement des règles revient tous les mois, et voilà d'où vient le nom de menstrues. C'est un des caractères de l'espèce humaine, car hors le temps

(1) Aristote, de Animalibus, lib. vir, cap. 1. 
CHAl. XXII. 'GÉNÉRATION DE L'IIOMME.

du rut et de l'accouplement, ancun animal ne rend de sang par les parties génitales. La première érúption des règles est plus tardive ou plus précoce, suivant la chaleur du climat et les mœurs du pays : elle est plus hâtive au midi qu'au nord, dans les capitales que dans les provinces, chez les peuples faits que chez les sauvages. L'état de la santé aussi l'avance ou l'éloigne. Nous avons dit qu'elle indique la puberté. D'ordinaire les menstrues s'interrompent après la jeunesse, et la fécondité cesse avec elles. Les femmes non réglées sont rarement fécondes, et les femmes enceintes sont rarement réglées. La cessation des règles est un des signes de la coneeption, surtout dans les femmes jeunes et non malades. Aristote attribue à la nudité de l'homme l'abondance de la liqueur séminale chez le mâle et les menstrues chez la femmc : le surcroîl des humeurs employé dans les autres animaux à produire des poils, des plumes ou des écailles, afflue dans notre espèce vers les parties génitales. D'ailleurs, la nudité fait une nécessité des vêtemens, et la chaleur de ces derniers ajoute souvent à la vélocité du sang et à la réplétion des vaisseaux. Les menstraes et le sperme sont plus abondans dans des corps maigres et bruns, si d'ailleurs ils sont sains, que dans les circonstances opposées. Aristote assure que les personnes blondes sont plus sanguines et plus spermatiques : cela pouvait être chez les Grecs, mais c'est le contraire dans nos climals tempérés.

Les premiers signes de la conception sont fort obscurs : llippocrate dit que les femmes ont alors un claquement de dents; Aristote insiste particulièreınent sur ce que le ragin se sèche aussitôt après le 
1 $S_{2}$ LIV. II. DE LA REPRODEGTION DES L̀TRES VIVANS.

coit; d'autres disent qu'il y a des frissons, des convulsions vives et appréciables dans l'utérus, des sensations qui participent à-la-fois du plaisir et de la douleur, un certain trouble dans les entrailles, un sentiment pénible vers J'ombilic et un chatouillement vers l'ischion. On a aussi prétendu que le cou de la femme devient plus gros dès qu'elle a conçu : de-là beaucoup de pratiques aussi ridicules que chimériques. Les auteurs grecs étaient persuadés que la conception était d'autant plus certaine que le vagin avait plus d'inégalités, parce qu’ils pensaient qu’il fallait avant tout que la semence fủt retenue dans l'utérus. I.es vrais signes de la conception sont la suppression des règles sans maladie, un léger gonflement et quelques douleurs aux mamelles, le trouble des digestions, des nausées, des douleurs vagues, des frissons, des irrégularités de caractère, des goûts singuliers, des caprices changeant d'objet à chaque instant : quelquefois aussi il survient du gonflement et des pesanteurs dans les aines. Il paraît certain que toutes ces incommodités et ces malaises se manifestent principalement au temps où les menstrues avaient coutume de fluer. Plus tard la femme sent les mouvemens du fœtus. On a dit que les e̊ufans mâles rcmuaient dès le quarantième jour, et les filles seulement vers le quatre-vingt-dixième; mais il est difficile d'assurer quelque chose de précis à ce sujet. Aristote, qui rapporte celle opinion et qui semble y croire, y joint des détails propres à l'infirmer : il assure en effet qu'un embryon de quarante jours a le simple volume d'une grosse fourmi, encore bien que, selon lui, tous les organes soient déjà apparens: or, 
CHAP. XXII. GÉNÊRATION DE L'HOMME.

comment croire qu'un corps si petit ait des mouvemens assez marqués pour que la femme en ressente le choc?

Les anciens avaient la prétention de distinguer long-temps avant l'accouchement si la femme porte un enfant mâle ou femelle: selon eux, le foetus mâle remue plus tôt et davantage, est plus gros, occupe le côté droit, et fait sentir là ses mouvemens; la femme grosse d'un enfant mâle est plus colorée, et surtout à la joue droite; son pouls est plus fort, et principalement aux artères de ce même côté droit; sa mamelle droite est de même plus grosse; elle a moins d'envies, moins de malaises; enfin elle accouche plus tôt, mais avec plus de douleurs, et les eaux qui s'écoulent lors de l'accouchement sont plus claires. Nous avons montré dans notre Physiologie de l'homme l'origine et les causes probables de ces préjugés d'Hippocrate et d'Aristote, ou plutôt de leur siècle. Pour résumer nos raisonnemens à ce sujet, nous devons dire que les signes énumérés ci-dessus sont plus fréquens que les signes contraires, de même que le nombre des garçons l'emporte ordinairement sur celui des filles. Or, il est aisé de voir ce qu'il a dû arriver, c'est qu'on a regardé deux événemens d'une coïncidence accidentelle comme des choses ayant entre elles les relations constantes de cause et d'effet (I).

La durée de la grossesse est ordinairement de neuf mois. On est d'abord étonné de voir les anciens faire une règle de ce dont nos lois font prudemment une exception, en fixant à dix mois le terme ordinaire de

(i) Bourdon, Physiologie médicale. 
I 84 LIV. 11. DE LA REPRODUCTION DES ÊTRES VIVANS.

la grossesse; mais lorsqu'on se rappelle leur manière de diviser le temps par périodes lunaires, on trouve que leurs dix mois de vingt-sept jours ne donnent qu'un total de deux cent soixante-dix, juste comme. neuf de nos mois de trente jours. Il faut au reste remarquer que notre espèce n'est pas la seule où les naissances n'arrivent pas à jour fixe et d'une manière constante : le poulet n'éclot pas toujours précisément après 50 I heures d'incubation; le chien ne naît pas constamment au bout de 62 jours. Rien donc d'étonnant si la femme peut accoucher d'un foetus viable au bout de 240 jours, ou quel quefois seulement après 3 oo jours. Observez en outre que l'intempérance des sexes, à laquelle l'homme est si enclin, rend de pareils calculs fort difficiles à préciser, fort incertains.

Si l'on songe aussi à combien de mensonges honorables conduit le respect des mours et le besoin de l'estime d'autrui, on découvrira alors les vrais motifs de ces fixations de l'accouchement de sept à dix mois. par toutes les bonnes lois. Lesinstitutions des peuples n'ont-elles pas pour but de servir à leur bonheur en assurant leur tranquillité? Ainsi, c'est la pudeur des femmes, c'est l'honneur des farnilles, c'est une juste sollicitude pour les enfans, c'est le respect dủ au mariage, et l'incontinence naturelle à notre espèce, qui donnent à la naissance de l'homme une fausse apparence d'incertitude et d'inconstance. Chez les peuples sauvages, les fernmes accouchent toujours à neuf nois ou deux cent soixante-dix jours; et il n'y a guère de variations chez nous que pour les enfans posthumes ou les premiers-nés. Toutefois il faut ajouter que mille causes morales absolument étrangères aux ani- 
CHAP. XXII. GÉNÉRATION DE L'HOMHE.

maux rendent l'avortement naturel beaucoup plus fréquent dans notre espèce qu'en aucune autre.

Il paraît certain que l'enfant est moins viable, moins capable de vivre à huit mois qu'à sept. Sans doute cela peut provenir quelquefois de ce que l'enfant à qui l'on ne donne que sept mois en a réellement neuf; mais il est présumable aussi qu'il survient durant le huitième mois une inégalité dans les organes essentiels qui n'existait pas un mois plus tôt et qui disparaît le mois suivant. Nous reviendrons plus loin sur cet objet.

La femme ne conçoit ordinairement qu'un enfant à-la-fois : il en est de même de quelques gros animaux, tels que la jument et la vache. Il arrive que la femme enfante deux jumeaux; on en a même vu jusqu'à quatre; quelques auteurs disent cinq, jamais davantage. Aristote cite une femme qui avait eu vingt enfans en quatre couches. Ordinairement les enfans jumeaux sont du même sexe, et c'est un motif de plus poúr penser qu'il y a de certaines circonstances propices à la production d'un sexe plutôt que d'un autre. On assure qu'il est rare que les jumeaux survivent tous à l'accouchement lorsqu'ils sont de sexe différent.

On nie la superfétation dans l'espèce humaine, je ne sais pourquoi : elle doit être rare chez les animaux, car presque toutes les femelles repoussent le mâle aussitòt qu'elles ont conçu; mais il n'en est pas ainsi de la femme. On allègue contre la superfétation que le col de l'utérus se ferme hermétiquement dìs que la conception est consommće ; mais que peut-on assurer à ce sujet? On dit aussi que l'wuf humain une 
186 LIV. H. DE LA REPRODUCTION DES ETRES VIVAKS.

fois descendu dans la matrice en occupe la capacite entière, que l'orifice des trompes n'est plus dès-lors accessible, et que la matrice étant simple et sans bifurcation dans la femme, rien n'y saurait plus parvenir dès qu'un premier embryon en occupe la cavité; mais sait-on exactement comment le sperme s'insinue et selon quel mode il agit? Ensuite, dit-on, la matrice est simple, non bifurquéc. Presque tonjours, il est vrai ; mais cette règle a ses exceptions : on a cité des exemples de matrice double; jai vu il y a quelques années (et plusieurs médecins et naturalistes de Paris l'ont vue comme moi) une matrice bifurquée dont un jeune médecin de beaucoup d'instruclion a fait l'histoire. Il faut observer que tous les organes sont doubles ou divisés par moitié dans l'origine, et que la matrice partage cette disposition. $\mathrm{Or}$, il arrive quelquefois que cet état natif persiste toute la vie dans de certaines parties d'une importance secondaire. Toujours est-il qu'on cite quelques observations de matrices doubles. Enfin, ajoute-t-on, les trompes sont inaccessibles, l'vitérus déjà rempli en rend l'orifice impénétrable. Oui sans doute, mais cela est-il subit? le pelit œuf délaché de l'ovaire n'est-il pas plusieurs jours renfermé dans la trompe qu'il jarcourt? d'ailleurs il y a des preuves posilives de la superfélation. Sans parler d'Aristote, qui prend cette fois ses exemples dans la mythologie, en citant la double origine des jumeaux Itercule et Iphiclée; d'autres auteurs ont cité des faits plus décisifs. On sait l'histoire de cette femme adultère qui, recevant le même jour dans sa couche un nègre, son esclave aimé, et son mari, de race blanche comme elle, eut 
CIAP. XXII. GÉNÉRATION DL L'HOMME.

de ce double commerce, neuf mois après, deux enfans de deux couleurs, ressemblant l'un au mari, l'autre à l'esclave. Aristote lui-même, dans un second exemple plus grave que l'autre, rapporte qu'uine femme, "ayant fait infidélité à son mari, mit au monde - deux enfans, dont l'un ressemblait au mari, l'autre - à l'amant. : Le même auteur ajoute qu'ori a vu sortir de l'utérus (dans une fausse couche) jusqu'à douze embryons dus à la superfétation. Ajoutons que ces jumeaux d'origine différente ne peuvent venir à bien et ne sont même admissibles qu'auiant qu'ils seraient à-peu-près contemporains. Quelques personnes admettent aussi la superfétation pour la jument, et pour des raisons semblables.

Ordinairement, avons-nous dit, les femmes restent fécondes depuis la première apparition des menstrues jusqu’à leur entier tarissement; mais les termes de la fécondité ou de la puissance de reproduction sont moins précis, moins certains chez l'homme, surtout le terme final. Comme exemple de précocité on cite un prince qui, à seize ans, fut père de deux jumeaux (1). On connaît, en sens contrairc, des exemples de paternité non douteuse d'hommes âgés de cent ans et au-delà. Harvey assure que Thomas Parre, qui vécut un siècle et demi, se livra aux plaisirs de l'amour jusqu'à cent quarante ans : il est vrai qu'il s'était marié à cent vingt ans, qu'il était d'unc santé robuste, et que sa longue vie ne fut marquée ni par des infirinités ni par des excès. En général, l'homme de nos climats ne procréc guvèrc passé soixante ans. Les

(1) H:Iler, Elementa physiologia. 
188 LIV. II. DE LA REPRODUCTION DES ÈTRES VIVANS.

peuples du midi sont plus précoces que ceux du nord, mais aussi plus tôt impuissans. Au reste, il n'y a rien de fixe, rien de constant dans le règne de la fécondité; mille causes en font varier la durée : cela dépend de la force, de la santé, et surtout des mœurs : rien ne hâte la vieillesse et l'époque de l'impuissance autant que l'abus des forces et l'excès ou la précocité des jouissances. Il faut tenir compte aussi de l'amour qu'on ressent ou qu'on inspire : un vieillard aimé a plus de chances de paternité. L'extrême lenteur de l'acte vénérien dans un âge avancé en signale d'ailleurs l'inutilité autant que le danger.

Il existe pour notre espèce des causes nombreuses de stérilité. Sans parler de la difformité ou de l'absence entière des organes essentiels au commerce fécondant des sexes, sans parler de l'euneuchisme turc ou romain, l'impuissance peut provenir de l'oblitération des canaux déférens, de la fausse direction ou de la compression des conduits éjaculateurs, de la perforation maladive ou congénitale de l'urèthre au-dessous du gland, de l'engorgement de la prostate, des rétrécissemens de l'urèthre, etc. Chez la femme, la stérilité a d'autres causes fort nombreuses aussi : les trompes peuvent être oblitérées, les ovaires malades, la matrice pleine de corps étrangers, son col squirrheux et toujours fermé; le vagin peut être fort rétréci, ou manquer entièrement, ou s'ouvrir dans l'intestin. On cite une femme qui devint mère dans un cas de cette dernière espèce, mais l'exemple est unique.

II est un autre obstacle à la fécondation et au commerce des sexes; je veux parler de la persévérance 
CIIAP. XXII. GÉNÉRATION DE L'HOMME.

de la membrane hymen, dont l'orifice de la vulve est garni et comme fermé dans les très-jeunes filles. Les anciens autcurs ont beaucoup parlé de cette membrane : ils la regardaient comme l'indice certain de la virginité, et celte exagération a fait le tourment de beaucoup d'époux; mais l'bymen a perdu de son importance depuis qu'on s'est assuré qu'il manque quelquefois chez les plus jeunes enfans, et que d'autres fois il persiste dans sa presque intégrité jusqu’à l'accouchement. On a vu des femmes enceintes dont la membrane hymen était à peine perforée, et plusieurs accoucheurs ont été obligés de couper cette membrane pour faciliter la sortie de l'enfant. Les anatomistes modernes, habitant presque tous des villes capitales, conviennent presque unanimement que l'hymen est une chose assez rare; mais il est surtout très-rare qu'il naisse delà des obstacles réels à la copulation.

Souvent aussi, les organes étant parfaitement conformés, la stérilité est le simple effet d'un défaut de convenance ou de sympathie entre les époux. Voilà pourquoi l'ancienne épreuve du congrès était déraisonnable, indépendamment du ridicule et de l'indécence attachée à une coutume aussi indigne. Le marquis de Brinvilliers, juridiquement déclaré impuissant sur le témoignage de son infâme épouse et d'après l'épreuve si peu sûre du congrès, eut ensuite plusieurs enfans d'une autre femme. Même chose arriva à un marquis de Langey en 1677 , et ce fut même à cette occasion que le Parlement renonça pour toujours à des prátiques aussi honteuses que mensongères.

Les enfans retiennent ordinaircment quelque chose 
190 LIV. II. DELLA REPRODUCTION DES ĖTRES VIYANS.

de leurs deux parens : ils leur ressemblent pour la taille, la stature, pour les traits de la physionomic, pour l'organisation non moins que pour l'intelligence, les passions et lecaractère. Il n'y a pás jusqu'aux défautscorporels, jusqu'aux difformités et maladies, qui ne se transmettent d'une génération aux générations suivantes. On voit dans quelqúes familles plusieurs lignées de boiteux, de myopes, de bossus, de phthisiques, de calculeux, de rhumatisans, d'épilepliques, de goutteux, de maniaques, etc. Les taches, les signes naturels, les tics, les mouvemens désordonnés, se transmettent fréquemment aussi des pères aux enfans; mais, dans ces derniers exemples, l'influence de l'imitation s'unit à l'empire de la succession et de l'hérédité. On voit pendant des siècles les mêmes caractères moraux et physiques distinguer les mêmes familles, principalement parmi les classes élevées et puissantes, jouissant de l'oisiveté corporelle et d'une situation parfaitement stable; souvent même il en résulte pour elles des surnoms et des sobriquets caractéristiques que l'usage finit par consacrer durablement. Nous en voyons des exemples parmi nous, mais principalement chez les anciens Romains. Les Grecs attachaient beaucoup d'importance à ces caractères de famillc et d'hérédité: on en voit la preuve dans les écrits d'Homère, d'Hippocrate et d'Aristote. Hélène, dans l'Odyssée, reconnaît le fils d'Ulysse en Télémaque parcourant les mers et visitant la cour du roi Ménélas, uniquement à la couleur de ses yeux. ét à la forme de ses mains: - Vous êtes le fils d'Ulysse, lui dit Hélène? - Ma - mère, la vertueuse Pénélope l'atteste, répond le - jeune prince : c’est le témoin le plus sûr. "Alors la 
reine lui dit à quels caractères infaillibles elle l'a reconnu. Nous verrons combien cette vieille tradilion des peuples perpétuée par un grand poète est d'accord avec les observations des naturalistes modernes, et vers quelles conséquences cela conduit. Ajoutons cependant que les caractères de familles ne'se transmettent pas toujours exactement à chaque génération nouvelle : quelquefois les enfans ressemblent, non a leur père, mais à leur aieul. Aristote assure avec conviction " qu'une Sicilienne eut d'un noir une fille " qui se trouva blanche, mais que l'enfant de cette " fille fut noir comme son aieul. s. Cet auteur ne dit pas si l'union était légale; il n'élève même aucun doute sur la moralité des personnes. On croit avoir remarqué, nous l'avons dit, que les garçons ressemblent davantage à leur père et les filles à leur mère; mais la chose n'est pas sans quelques exceptions : tantòt c'est au père que ressemblent tous les enfans, -tantôt c'est à la mère. On a fait la même observation pour les animaux : la jument Dicœa, dit à ce sujet Aristote, faisait tous ses poulains ressemblans au mâle qui l'avait fécondée. Une remarque que chacun a faite, c'esı que les jumeaux se ressemblent toujours.

Toutefois les Anciens allaient plus loin que nous pour les idćes de ressemblance : ils prétendaient qu'un homme privé d'une partie du corps, d'un membre, d'un organe isolé, engendrait des êtres incompiets comme lui. La chose n'est pas exacte : l'observation la plus superficielle montre le contraire. Nous ne voyons pas qu'un borgne, un manchot, un ampuré, produise des enfans mutilés à son image. Cette opinion paraît née de l'ancienne thiorie du mélange des 
192 IIV. II. DE LA REPRODUCTION DES ÊTRES VIVANS.

liqueurs; et si elle était vraie, elle fortifierait beaucoup le systèmé plus moderne des molécules organiques (1); in ais nous avons dit qu'elle ne mérite aucune confiance.

Le fœtus humain communique avec la matrice ou plutôt avec la mère par le cordon ombilical et le placenta : c'est par cette voie que lui vient du sang nourrissant tout prêt respiré. Il est entouré de liquides comme les autres mammifères; il a les mêmes membranes qu'eux, à l'exception de l'allantoïde : sa vésicule ombilicale, ainsi que nous l'avons dit, est fort petite et bientôt oblitérée. Le corps du fotus est plié et fléchi sur lui-même; la tête repose ordinairement sur les genoux; elle est la partie la plus rapprochée du col de l'utérus, parce qu'elle est la plus pesante, et aussi vraisemblablement pour d'autres raisons peu connues, puisque cette disposition est la même dans tous les mammifères : c'est la tête qui sort la première. Ensuite viennent les autres parties du fœtus, et après elles le placenta et les débris des membranes rompues : c'est. là ce qu'on nomme le délivre. La femme a ensuite des lochies, après quoi vient la fièvre de lait. L'accouchement de la femme est plus lent et plus laborieux qu'en nul autre animal : il paraît certain qu'elle éprouve aussi plus de douleurs.

Le nouveau-né respire, crie aussitôt, rejette par le même effort le méconium, son premier excrément; bientôt un instinct de conservation le conduit vers les mamelles, et csest là qu'il se fixe comme à un autre utérus.

(1) Vyyez Buffon, IIistoire natırelle. 
CIIAP. XXIII. SYSTÉNES SUR LA GÉNÉPATION. 93

\section{CHAPITRE XXIII.}

Principaux Systèmes sur la Génération.

Après avoir exposé par quelle suite d'actions èt de phénomènes les êtres vivans se reproduisent, avoir prouvé qu'aucun n'est engendré spontanément, mais que beaucoup le sont sans organes sexuels, sans accouplement, sans anour, plusieurs même sans accouplement quoiqu'ils aient des sexes; après avoir exposé les différences de la génération dans les animaux et les végétaux, dans les animaux ovipares et. dans les vivipares; après avoir montré que ces dẹrniers êtres ne diffèrent entr'eux, quant à la reproduction, qu'en ce que le fœtus reste attaché à sa mère jusqu'à la naissance dans les uns, tandis qu'il en est isolé dès ses commencemens dans les autres; après nous être assuré que le mâle et la femelle sont également indispensables au grand acte de la procréation, que le sperme n'a d'action que sur l'ouf, et que l'œuf ne devient productif que par l'intervention du sperme, il nous reste à examiner comment a lieu ce concours, et à chercher pour quelle part chacun des sexes contribue à la première origine du fotus, ou si les premiers linéamens dé ce fotus proviennent plus particulièrement del'un des sexes.

Tout est dit à ce sujet, et cependant tout reste à savoir. On a épuisé la somme des vraisemblances et des probabilités dans les systèmes presque innomI. 
19/1 LIV. II. DT. LA REPRODUCTION DES ÈTRES VIVANS. brables dont la génération a été le sujet; mais la vérité est une, et elle reste à trouver. C'est comme une loterie mystérieuse dont on aurait pris tous les billets, tous les numéros jusqu'au dernier : certainement il n'y a qu'un bon numéro dans ce grand nombre, et ce billet fortuné, quelqu'un le possède, mais lequel est-ce? Pareillement on a peut-être dit ce qui a lieu en réalité dans la génération; mais comment s'en assurer parmi tant d'hypothèses composées au hasard et choisies sans motif? Nous ressemblons, dans ces parties obscures de la science (comme le disait le célèbre Huet, évêque d'Arranches), à des aveugles puisant dans un vaste sac rempli de jetons tous de cuivre, à l'exception d'un seul, qui est d'or; chacun prend le sien, et tous se persuadent tenir le jelon précieux.

\section{CHAPITRE XXIV.}

Système d'Hippocrate : Mélange des Semences.

Du temps d'Hippocrate, on faisait déjà des systèmes sur la génération; c'était même une époque favorable aux hypothèses, car la nature des choses Ćant peu connue, chacun devait s'évertuer à les deviner, à les interpréter à sa manière. Hippocrate céda donc à l'ascendant de la philosophie d'alors. Selon lui, la femelle a sa semence comme le mâle : la source de cette semence n'embarrasse point Hippocrate; il la fait provenir, dans les deux sexes, des veines et 
CIIA. XXIY. SYSTL̀ME D'HiPPOCRATE.

des nerfs distribués dans tout le corps, et voici quelles voies il lui assigne: répandue dans toutes les parties, elle se concentre principalement vers le cerveau et la moelle de l'épine; des lombes elle passe par les reins, des reins par les testicules des deux sexes, et enfin dans les autres parties génitales. Ensuite, lorsqu'une fois les deux semences se sont mêlées ensemble dans le coït, le froid, le chaud et les esprits vitaux interviennent, les parties similaires s'unissent et s'organisent, et le fotus se forme et s'anime. Comme Hippocrate ne doute nullement de ce mélange des semences, il ajoute que le fœtus ressemble ou plutôt au père ou plutôt à la mère selon que la semence de l'un des deux est en plus grande quantité. Mais comment se forment les sexes? Hippocrate l'explique également : chaque semence, celle du père et celle de la mère, est formée de deux parties, l'une forte, l'autre faible: si c'est la partie faible des deux semences qui s'unit, alors il se produit une femelle; au contraire, c'est un ınâle si les parties fortes des deux sexes se mêlent et se confondent seules. Voilà pourquoi, ajoute Hippocrate, certaines femmes n'ont que des garçons d'une première union, et au contraire des filles d'un nouveau mariage.

Il suffit d'une simple réflexion pour dẹtruire ce système : les femmes n'ont ni testicules ni véritable semence; d'ailleurs, nous ne savons pas à quels signes on pourrait reconnaître la semence forte d'avec la semence faible. Il résulterait ensuite de l'hypothèse d'Hippocrate que le fotus provenant de la semence forte du mâlè et de la semence faible de la mère ou serait hermaphrodite ou ne serait d'aucun sexe. 


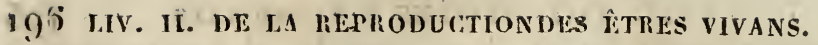

Notre juste respect pour Hippocrate ne doit pas aller jusqu'à nous faire partager les erreurs de sa philosophie.

\section{CHAPITRE XXV.}

Systeme d'Aristote : Forme et Matière.

Près d'un siecle s'écoula entre Hippocrate et Aristote. D'ailleurs celui-ci était meilleur anatomiste qu'on ne l'avait été jusqu'alors : les idées vagues et sublimement chimériques de son maître, le divin Platon, le tenaient dans une sage défiance contre les vues de l'esprit pur et lé portaient vers l'observation dés choses : plus il sentait la puissance de sa raison, plus il se'défiait de ses lumières. Les erreurs d'Aristote sont un tribut à la faiblesse humaine : elles ont plus de grandeur, plus d'enchaînement et plus de danger que celles d'Hippocrate.

Aristote admet d'abord une sorte de génération spontanée par pourriture des corps ayant joui de la vie, ou simplement par l'agglomération du limon du fond des mers. Nous avons déjà montré le peu de fondement de cesidées. Après cela, le reste des animaux, selon lui, s'engendrent tous avec ou sans copulation, les uns ayant des sexes séparés, les autres les réunissant dans le même individu. Or, voici comment ce grand homme conçoit le rôle de chacun des sexes. La fernelle fournit le principe matériel de la génération : cette matière n'est point une sennence, 
CHAP. XXV. SYSTÈME D'ARISTOTE.

ear la femelle n'en a point; mais ce que fournit la femelle, c'est le sang dont ses organes génitaux sont imprégnés; et la preuve que la chose est ainsi, selon Aristote, c'est que les femelles qui ont des menstrues ne compencent à en avoir qu'à l'époque de la fécondité, n'en ont plus dès qu'elles ont conçu ou dès qu'elles cessent d'être fécondes. Aristole ajoute que le foetus est formé par ce sang de la matrice, et qu'ensuite c'est par son entremise qu'il s'accroît el se nourrit. Quant au mâle, il ne fournit rien de uiatériet au nouvel être; la semence qui vient de lúi ne fait que donner la forme à la matičre provenant de l'autre sexe; ce qui émane du sperme est une sorte d'esprit aussi peu matériel que la lumière des étoilés, et c'est cet éther qui donne la vie et le mouvement à ta trame du foetus : c'est comme le feu de Prométhée qui vient animer une machine formée pour la vie, mais ne vivant que par lui. Enfin, selon Aristote, la femelle fournit le bloc de marbre ou la toile, le mâle fait l'office de sculpteur ou de peintre, et le foetus est la statue ou le tableau provenant de ce concours des. sexes.

Pour résumer ce système d'Aristote, nous dirons que le sang génital ou menstruel contient l'ensemble des matériaux du foetus; que l'esprit prolifique du mâle assemble, coordonne et anime tous ces linéamens disséminés et jusqu'alors inertes : la vie commence par le cœur, et c'est ensuite par lui que les. autres organes recoivent la vie et le mouveunent par l'entremise du sang.

Il est facile de voir, je ne dis pas les inconséquences, mais les erreurs d'un pareil systène. II faudrait, pour 
198 LIV. H. DE LA REPROdCCTION DES ÊTRES VIVANS. qu'il fùt vraisemblable, que tous les animaux eussent du sang et un cœur : or il en est beaucoúp qui n'ont ni l'un ni l'autre; ce système exigerait donc que tous les animaux fussent organisés comme l'homme, et nous savons combien peu la chose est exacte. Cela posé, il est inutile de combattre lès idées de ce grand philosophe. Il est d'ailleurs une manière d'interpréter favorablement sa théorié, c'est qu'il est certain qu'il ne se produit absolument rien sans l'entremise du sang dans les corps où du sang circule : le sperme du mâle en provient, aussi bien que les vésicules des ovaires de la femelle, et les organes du fœetus.

Aristote n'a erré au sujet de la génération que pour avoir été trop conséquent avec les grands principes de sa philosophie.

\section{CHAPITRE XXVI.}

Système d'Harvey : Contagion séminale.

Pendant environ deux mille ans les systèmes d'Hippocrate et d'Aristote au sujet de la génération ont régné sans opposition dans les écoles: les médecins conservant les idées du premier, les philosophes donnèrent la préférence à Aristote. Au lieu de rechercher comment agit la nature, on se bornait à faire prévaloir les opinions d'un de ces deux grands hommes. Enfin les temps d'examen succédèrent aux siècles de l'autorité des mâ̂tres; et, du jour où l'on 
scruta les faits, les systèmes de l'antiquité perdirent de leur crédit. Harvey fut un des premiers à suivre les voies de la raison en étudiant la nature : il cita souvent Aristote, mais presque toujours pour le contredire.

Cet homme illustre fut favorisé par la fortune presqu'autant que par la nature, et, ce qui est bien rare, il fit tourner lant d'avantages au profit de la vérité. Élevé à l'école d'un des grands anatomistes du temps, je veux parler de F. d'Aquapendente (lequel florissait vers la fin du seizic̀me siècle), il puisa dans les savantes leçons de son maître les germes de son immortelle découverte de la circulation du sang. Tant de gloire due à son application et à son génie attirèrent sur lui les regards de l'Europe savante et les faveurs de son roi, l'infortuné Charles $I^{\text {er }}$. 11 faut avouer que sa découverte de la circulation du sang lui fit perdre beaucoup d'années par les attaques qu'elle lui suscita de la part de l'ignorance ou de l'envie, ardentes à se venger du génie en le privant de la paix et lui refusant juslice; mais, malgré tous ces tourmens, Harvey, jeune encore, Harvey communiquant avec les hommes éclairés de tous les pays, Harvey médecin d'un roi qu'il rivalisait en gloire, ne pouvait passer sa vie en stériles discussions ou en cures vulgaires: les découvertes appellent d'autres découvertes, comme de premières vicloires entraînent d'autres combals. L'Europe décida donc autant qu'Harvey luimême, qu'il s'occuperait désormais du grand problème de la génération des animaux. Précisément F. d'Aquap̉endente lui avait beaucoup appris à ce sujet, en l'initiant à ses recherches sur la formation de l'embryon 
200 LIV. II. DR LA RIPRODUCTION DES ETRES VIVANS.

des oiseaux. Alors Harvey résolut de tirer parti de sa belle position : il demanda au roi les moyens de faire en grand les expériences que nécessitait son entreprise, et Charles I ter lui abandonna son parc de cerfs avec une munificence toute royale, sans condition et sans aucune réserve; sacrifice aisé pour un roi que les dissensions de ses sujets et les dangers de sa couronne détournaient de la dissipation des cours et des. plaisirs de la chasse. J'avais donc raison de dire qu'Harvey fut favorisé de toutes les manières et par. toutes choses, puisque les malheurs même de son pays et de son auguste prolecleur tournèrent à son, avantage. Ses expériences faites, il eut, à la vérité, le. malheur de perdre ses papiers dans la tourmente politique qui le priva de son roi et mit Cromwel sur le. trône d'Angleterre; mais forcé bientôt de s'éloigner de. Londres, la solitude et l'oisiveté dont il jouit dans son exil servirent encore ses travaux, car ce fut alors qu'it. mit de l'ordre dans ses découvertes et quil en écrivit, l'histoire sans notes et sans presque aucun livre, sice. n'est un Aristote. Il faut dire pourtant quil dut à la perte de ses journaux de commettre quelques erreurs; mais son ouvrage, tel que nous l'avons, n'en mérite. pas moins toute notre estime, et il est impossible de. ne pas gémir de la sévérité avec laquelle Buffon l'a jugé dans le but de mettre en crédit son propre sys-: tème des molécules organiques, système dont chaque: page du livre d'Harvey contient la critique anticipée. Au reste, nous ne parlons point isi des découvertes d'Harvey, nous ne faisons qu'exposer son système. . J'ai dit précédemment qu'Harvey était dans l'opinioui que tout être vivant provient d'un ouf, les animaux. 
vivipares aussi bien que les ovipares. Cependant Harvey, il faut bien l'avouer, ignorait la source de l'œuf et la vraie nature des ovaires dans les mammifères, bien que V. Coiter eût déjà démontré ce fait de physiologie. Seulement Harvey avait remarqué que l'embryon des vivipares a, dès sa première origine, une assez grande analogie avec l'œuf des ovipares, que les deux principales enveloppes surtout sont fort ressemblantes pour l'embryon des deux classes d'êtres; mais comme il n'avait remarqué aucun changement dans les ovaires des biches et des daines qu'il ouvrait ì différentes époques de la conception, il ne prévoyait yas que l'œuf des mammifères fût déjà ébauché dans l'ovaire de ces animaux, et qu'il préexistât à l'accouplement des sexes, et cela du moins établissait à ses yeux une notable différence entre la génération des vivipares et celle des ovipares.

Harvey avait bien observé des espèces de caronçules et comme des toiles d'araignées dans les cornes (le la matrice des biches éventrées plusieurs semaines après le coit; mais je répète que les ovaires lui paraissant intacts et leurs vésicules sans mécompte, il attribuait ces premiers linéamens de l'œuf ou de. l'embryon des mammifères, à la seule action de la matrice. Comme il n'avait jamais trouvé de semence dans cette matrice après l'accouplement, Harvey pensait que le sperme lui-même était étranger comme matière à la formalion de cet œuf; il niait même que cette liqueur eût aucun contact avec l'œuf déjà à demi-formé des oiseaux. Parisanus avait avancé que la cicatricule de cet œuf était due à la semence du mâle, mais Harvey prouva le contraire en montrant 
20:3 LIV. H. DE LA REPRODUGTION DLS ÉTHES VIVANS.

que cette tache blanche ou cicatricule existe dans. les œufs infécondés des oiseaux vierges tout comme. dans les œufs fécondés: c'est même là une des découvertes dues à Harvey. Quant aux mammifères, Harvey pensait que leur embryon et ses enveloppes se formaient par la seule action de la matrice et que cet organe en était la source exclusive. D'abord il n'avait observé aucun changement, ainsi que nous l'avons dit, dans les ovaires; outre cela, c'était vainement qu'il avait cherché les traces du sperme dans la matrice: jamais il n'en avait trouvé. Harvey concluait: de toutes ces choses, que l'œuf des mammifères n'est formé exclusivement ni par le mâle ni par la femelle, puisqu'il ne provient immédiatement ni de la semence ni des ovaires (qu'Harvey nommait testicules); mais it admettait que la formation de l'œuf des vivipares résulte de l'action spontanée de la matrice, fécondée, ainsi que tout le corps de la femelle, par le sperme du mâle. Harvey admettait donc une espèce de contagion séminale; il allait jusqu'à employer ce mot de contagion, et voici comme il concevait la chose.

Il supposait que le sperme du mâle, instillé dans. le vagin de la femelle, laissait exhaler quelque principe subtil qui fécondait instantanément et universellement celte dernière. Harvey n'admetlait pas que cette semence produise une action locale et matérielle sur l'utérus, mais seulement une contagion générale en fécondant tout le corps à-Ja-fois, à-peu-près comme l'aimant communique la vertu magnétique à l'acier qu'il a touché; ou encore, comme un alôme de. fluide variolique inoculé au bras d'un enfant commu. nique la variole à la personne entière. A près cette con- 
tagion générale du corps, après cette fécondation de tous les organes, il admet que la seule matrice reçoit la faculté de concevoir un nouvel être; et Harvey compare cette propriété de la matrice à la faculté qu'a le cerveau, et qu'il a seul, de concevoir des pensées par l'advention des sens, lesquels cependant ne lui fournissent que des images. Il ajoute que le fotus ressemble au mâle qui a fécondé la mère, comme les pensées ressemblent aux sensations qui les produisent, et de la même manière.

Il est évident que ces idées sont d'une bizarrerie et d'une complication extrèmes: mais ce qui détruit ce système de fond en comble, c'est l'observation tant de fois répétée que l'œuf des mammifères vient des ovaires, comme chez les ovipares eux-mêmes.

Ainsi nous admettons comme Harvey que tout ètre vivant provient d'un œuf, que tout œuf provient de la femelle dans les êtres ayant des sexes, et qu'il n'est pas de fécondation sans le. mâle; mais nous différons avec Harvey touchant la manière dont toutes ces choses arrivent.

\section{CHAPITRE XXVII.}

Système des OEufs L'Embryon proviınt de la Mère. Swammerdan, Spallanzani, etc.

Je donnerai peu de détails sur le Système des OEufs, par la raison que l'ensemble de ce deuxième licre en renferme les divers élémens et en montre la 
20 LIV. II. DE LA REPRODUCTION DES THTHS VIVANS. réalité ( voy. le chap. xv̧ı et ceux qui le précèdent). Je rappellerai seulement les recherches d'Aristole, de Parisanus, de Fabrice d'Aquapendente, sur la formation de l'embryon des oiseaux; les beaux travaux d'Harvey, lequel a démontré que la cicatricule de l'ouf en est la partie essentielle, et que c'est de là que l'embryon tire son origine; je citerai l'ouvrage. si remarquable où Malpighi a prouvé que le poulet provient de cette cicatricule et qu'il préexiste même à l'incubation, puisqu'ill'a pu découvrir dạs des.œufs récemment pondus: enfin je cite encore les expériences de Swammerdam, de Roesel, de Spallanzani, sur les œufs de reptiles, et celles de Jacobi, dé Réaumur et de Needham, sur les oufs despoissons, ceux. de quelques mollusques et des insectes.

Tous ces travaux sont parfaitement d'accord: pour montrer que la plupart des animaux ont un œuf pour première origine; mais ce n'est pas tout: outre les analogies que nous avons vu exister entre les œufs des animaux et les graines des plantes; avec ces mêmes œufs et les bourgeons des polypes, comme. entre ces graines des plartes à fleurs et les bulbes visibles de quelques végétaux réputés cryptogames, nous devons ajouter que toutes ces choses ont fait: penser que les manmifères eux-mêmes ont un œuf pour premier berceau ou pour première origine. De Graaf, Nuck, Sténon, Vallisneri, Haller et plusicurs autres anatomistes ont découvert cet œuf des quadrupèdes; ils en ont montré-la route et décrit les développemens. Buffon ayant douté de ces observalions, d'autres phyysiologistes les ont répétées et rendues irrécusables : nous avons rapporté ces différens faits, 
et nous en avons tiré la conséquence que tout être vivant provient d'une sorte d'œuf.

Mais tout en s'accordant sur ce point, que tout animal vient d'un œuf, la plupart des physiologistes modernes sont loin d'être unanimes relativement à l'opinion qu'ils se forment de la première origine des êtres vivans. Les uns pensent que l'embryon préexiste à la fécondation, l'œuf lui-même et lui seul en renferment les premiers rudimens; d'autres attribuent les premiers élémens du fœetus à la liqueur prolifique du mâle par qui l'œuf a été féconde; enfin il est des physiologistes qui pensent que le nouvel être résulte du juste et soudain concours de l'œuf de la femelle et de la semence du mâle, à-peu-près comme un courant voltaique compose de l'eau avec deux gaz invisibles, ou un cristal salin avec deux élémens différens mis en contact.

Nous ne devons pas nous dissimuler que la plupart des prenves qu'on a alléguées à l'appui de cette opinion que l'embryon préexiste dans l'ovaire des femelles, ne méritent pas toutes une égale confiance. Par exemple, on a dit avoir découvert les premières traces du poulet dans des œufs non cochés, mais ce fait ne paraît pas croyable: Malpighi a bien vu ces premiers rudimens du poulet dans des œufs qui n'avaient pas été couvés (fait que Haller a cru sans pouvoir s'assurer par lui-même de sa réalité); mais aucun ob'servateur digne de confiance n'a pu voir ces vestiges de l'embryon du poulet dans des œufs non féconicés. II est bien viai qu'on trouve de petits ovules dans le réceptacle de quelques fleurs non encore épanouies et non fécondlées par le pollen, et même Spallanzani 
206 LIV. H. DE LA REPRODUCTION DES ÊTRES VIVANS.

affirme que ces graines ébauchées se développent sans le concours du pollen, dans des fleurs châtrées, il a été jusqu'à prétendre que ces graines peuvent mûrir et germer, mais nous avons dit dans le chapitre $V$ ce qu'il faut penser de ces expériences de Spallanzani. Il est des animaux qui engendrent sans accouplement, la chose est vraie; mais il faut remarquer que ces êtres sont hermaphrodites, je veux dire qu'ils réunissent des organes mâles et des organes femelles dans le même individu. L'exemple Je plus probant et le plas difficile à récuser est celui des pucerons : on a dit que ces animaux engendrent plusieurs fois sans accouplement; que les femelles vierges, nées d'un premier accouplement, produisent à leur tour des femelles fécondes sans l'intervention d'aucun mâle : on a beau isoler chaque petite femelle aussitôt qu'elle est née, elle n'en produit pas moins des petits pucerons, lesquels produisent comme elle sans accouplement, et cela pendant huit ou neuf générations successives; mais est-on sûr que ces femelles réputées vierges n'aient pas été fécondées dans le ventre de leur mère par les mâles de la même ponte? est-on sîr qu'aucun de ces petits aninaux ne soit hermaphrodite? ne pourrait-on pas s'être mépris à l'égard des pucerons comme Spallanzani s'est mépris pour le chanvre? je veux dire qu'on pourrait avoir pris pour des femelles, des animaux réunissant les organes des deux sexes." Plus j'ai confiance dans la logique de Bonnet, et plus je me crois obligé de me défier de ses observations. Enfin, sans parler de Littre, qui assuire avoir observé les preniers linéamens très-réconnaissables de l'embryon dans la vésicule d'un ovaire 
Tle mammifère (observation évidemment controuvée, la chose n'étant supposable que pour une grossesse extrà-utérine), il ne reste plus que les observations de Needham et de Spallanzani sur des œufs de poissons et de reptiles, qui puissent faire admettre que l'embryon est visible dans l'œuf des femelles avant le contact de la liqueur spermatique du mâle.

Je commence par avouer que ces dernières observations, celles de Spallanzani principalement, ont un grand poids; à elles seules elles établiraient la preuve que l'embryon préexiste dans l'œuf non fécondé : en effet, ces œufs présentent aussitôt qu'ils sont sortis, et mêtne alors qu'ils sont dans le corps de la femelle, des embryons déjà noirs et discernables, et cependant le mâle ne les arrose de sa semence qu'après qu'ils sont pondus. Voyons cependant s'il ne reste pas quelque moyen de nier la chose. D'abord on pourrait dire que les points noirs des petits œufs de grenouilles et de salamandres, etc., ne sont pas de vrais fuetus; mais il est évident que les tétards proviennent de ces points noirs progressivement accrus, et qu'on peut aisément reconnaître les vestiges d'un être animé dans les enveloppes dont ce point noir est en partie formé. Une autre difficulté qu'on pourrait faire naître à l'égard de ces embryons préexistans, est celle - ci : il est bien vrai, pourrait-on dire, que ces oufs sont arrosés de la semence du mâle après qu'ils sont sortis du corps de la femelle; mais qui peut assurer qu'ils n'ont pas déjà été fécondés dans le corps de la femelle? cela serait même d'autant plus probable, que la plupart des espèces de reptiles dont nous parlons sont accouplés plusieurs jours avant la . 
208 LIV. IJ. DE rA REPRODUCTION DES ÊTRES VIVANS.

sortie des œufs. La réponse à celte objection est facile : on pourrait adueltre que ces œufs de reptiles dans lesquels paraît déjà l'embryon ont été fécondés une première fois dans le corps même de la femelle; mais si l'on fait attention que ces embryons, tout visibles qu'ils sont, ne s'accroissent jamais lorsque le mâle ne les a pas arrosés de sperme à leur sortie de la femelle, il faudra bien convenir qu'ils n'ont encore reçu le contact d'aucune semence; car il faut remarquer qu'encore que ces embryons préexistent à la fécondation, cependant il leur faut le contact du fluide prolifique pour s'accroître. Ainsi, qu'ils vivent déjà ou qu'ils soient inanimés, il est sûr que les embryons des grenouilles préexistent dans les ceufs des femelles avant toute intervention du sperme des mâles ; mais il est également certain qu'ils ne s'accroissent jamais sans l'entremise, sans le contact du fluide séminal : tous les faits cités contradictoirement à ce principe sont révocables.

Haller toutefois a beancoup insisté sur un fait propre à établir, non pas que l'embryon se développe sans l'intervention du fluide prolifique, mais qu'il préexiste au contact de ce fluide avec l'œuf. Voici cette observation dont il a déjà été parlé dans un autre endroit de cet ouvrage à propos de la structure de l'œuf des oiseaux. Nous avons dit que le, jaune est revêtu de deux feuillets membraneux, de deux épidermes assez faciles à démontrer à une certaine époque de l'incubation : il est certain que ces deux feuillets du jaune le revêtent dans tous ses points, qu'ils accompagnent son pédicule jusqu'à son union avec le jeune fœtus, et qu'ils s'unissent, le feuillet extérieur avec le péri- 
toine des parois abdominales, et le feuillet intérieur avec le péritoine qui enveloppe l'intestin. Or, demande Haller, est-il possible d'attribuer au hasard cetic union si constamment la même des enveloppes du jaune avec le nouvel être? esi-il raisonnable de croire spontanée une jonction aussi compliquée et dont le but d'utilité est si manifeste? Non, poursuit Haller; il est plus naturel de penser que celte greffe a existé dès l'orimine de l'cuf dans l'ovaire, entre les tuniques da jaune et le germe préexistant de l'embryon; ou plutôt, ce fait seul est la preuve évidente que tout œuf contient dès son commencement les premiers rudimens d'un petit anima!. Ce n'est donc point le fluide séminal qui engendre instantanément l'embryon dans l'œư ; mais son rôle paraît être de lui donner la vie et la faculté de croître : aussi bien la ressemblance des jeunes êtres avec leurs deux parens prouve que tous les deux contribuent en quelque chose à leur production.

Ainsi le principe de l'embryon préexiste à la fécondation, tout invisiblc qu'il est dans l'œuf; mais il naîl de là même de nouvelles et de grandes difficultés: car si tout œuf, même non fécondé, contient le premier germe d'un nouvel être, il faut admettre également que chaque embryon femelle porte en lui les germes inappréciables mais nécessairement réels, de nouveaux œufs, et chacun de ces œufs, les germes d'autant de nouveaux embryons; par conséquent la première femelle de chaque espèce recelait dans son ovaire la suile entière des générations futures : c'est un emboîtement, un cnchâssement de germes propre à effrayer les imaginations les plus calmes et les conI. 
210 LIV. II. DE IA REPRODUGTION DES ËTRES VIVANS.

sciences les plus crédules. Nous traiterons bientòt de celte hypothèse de l'emboitement des germes à l'infini, et cette question même nous obligera d'exprimer avec plus de précision que nous ne le faisons ici ce quil faut entendre par ces germes que nous supposons préexister dans des œufs non encore fécondés par le fluide séminal.

\section{CHAPITPE XXYII.}

Système de Lecuwenhoek ou des Animaicules. Tout vient du Mâle.

Nous avons déjà parlé des animalcules de la semence, et fait pressentir qu'on a profité de leur excessive petitesse et de leur nombre prodigicux pour. expliquer la génération ou la première origine du fœitus. Nous avons vu qu'une seule goulte de sperme en contient des milliers : Leeuwenhoek a supputé que la laite d'un seul poisson renferme un nombre plus grand de ces animalcules qu'il n'y a d'hommes à ha surface du globe, en supposant même les différcns pays aussi peuplés que l'est la plus grande partic de l'Europe.

Ces petits corps mouvans, nous l'avons dit, fixèren! l'attention de beauconp de savans dès qu'unc fois Leeuwenhoek les eut découveris. L’importance qu'on lcur altribuait augmenta beaucoup quand on se fut assuré que la semence seule en contient, et seulement la semence des hommes pubères, capables de se pro-créer. Une fois qu'on eut constaté que ni les femelles ni les nâles, cncore enfans ou déjà très-vicux, ma- 
lades ou très-aflaiblis, n'offrent rien de semblable, et que piusicurs oiscaux n'ont de ces animalcules que dans la saison de leurs amours, alors on n'hésita plus à attribuer l'origine de tous les animaux pourvus d'organes sexuels à ces petits corps mouvans de leur semence; mais on proposa à ce sujet des explications très-diverses.

Les uns ont prérendu que ces animalcules sont autant de jeunes embryons; on a ajouté que ce pelit ver s'accroît peu-à-peu dans l'œuf des ovipares ou dans la matrice des mammifères, et qu'il se complique successivement en subissant des métamorphoses, à la manière des insectes ou de quelques reptiles : on a dit de plus qu'il forme autour de soi ces toiles, ces enveloppes dont Harvey a recherché l'origine dans la matrice des biches, à-peu-près comme le ver-à-soie protège sa larve d'un cocon; mais d'autres personnes ont prétendu que ces animalcules spermatiques ont d'abord la forme exacte de l'animal qui les produit, de sorte que, pour devenir semblables à l'animal parfait, ils n'ont besoin que de croître sans subir de métamorphoses. Nous avons cité les singulières observations de Plantade, de Gaulier, etc., desquelles il résulterait (s'il était permis d'y ajouter quelque confiance) qu'on a vu des fotus d'hommes, d'oiseaux et de quadrupèdes dans le sperme récent des mâles de ces differens êtres, embryons déjà assez formés, malgré leur extrême petitesse, pour offrir l'image très-ressemblante des animaux d'où ils émanent ou qu'ils reproduisent. Les auteurs dont nous parlons l'éprouvent quelque embarras que pour assigner un gîte précis à ces folus en miniature. Or, pour ce quif 
213 LIV. II. DE LA REPRODUCTION DES EेTRES VIVANS.

est des vrais ovipares, il faut bien qu'ils admettent qu'un animalcule se niche dans chacun des œufs déjà sortis ou encore adhérens de la femelle; mais quant aux mammifères, les uns conjecturent qu'un ou plusieurs animalcules se fixent à la matrice, et qu'ils s'y entourent de membranes, comme nous l'avons dit plus haut. La plupart ont préféré l'explication suivante: On suppose qu'un des innoimbrables animalcules du sperme, après avoir traversé la matrice et parcouru l'une de ses trompes, va se ficher dans l'une des vésicules de l'ovaire correspondant, et qu'il ne sintroduit dans celte vésicule qu'au moyen d'une petice ouverture à soupape, dont la valvule se ferme pour ne plus s'ouvrir aussitôt que l'animalcule est entré. D'autres personnes (car nous ne nous soucions pas d'attacher des noms célèbres à des hypothèses qui choquent aussi manifestement le bon sens), d'autres auteurs, disons-nous, ont expliqué cela d'une autre manière : ils ont dit qu'il se fait une adherence, une sorte de greffe entre l'animalcule et le petit cuf, aussi bien qu'une anastomose réciproque entre leurs vaisseanx. Us ont cru expliquer par cette supposition comment le nouvel être ressemble à sa mère comme à son père, quoique ce dernier, selon eux, en fournisse entièrement les premiers rudimens. Enfin, d'autres physiciens ont prétendu que l'animalcule introduit dans l'une des vésicules de l'ovaire a seulement pour but, pour usage de former la moelle épinière du nouvel animal. Cette dernière opinion a été professée tout dernièrement encore par deux hommes d'un grand mérite. J'observe que, de quelque manière que l'on explique la formation des foelus 
CHAY. XXVII. SYSTEMT DE LEEUWSYIOZK.

par les animalcules de la semence, cette hypothèse n'est pas de nature à résister à un examen un peu sérieux. Voici, au réste, les principales objections dont elle est susceptible.

Il est bien vrai que la semence des animaux présente, daus l'âge de la fécondité, de petits corps mobiles qui semblent encore animés; mais comme ces corpuscules perdent bientôt leurs mouvemens, si l'ón admet que ceux des animalcules qui s'introduisent dans des vésicules de l'ovaire ont seuls la propriété de conserver la vie, il faut convenir que la cause de cette particularité étant inconnue, on ne fait ainsi que reculer la difficuité d'un degré: on est toujours forcé de sedemander, ou comment le nouvel être acquiert la vie, ou comment il la conserve, si c'est un animalcule déjà vivant. D'ailleurs est-il naturel que de tant de milliers d'animalcules accumulés dans quelques gouttes de semence, il s'en tronve précisément un ou plusieurs qui jouissent seuls de la faculté de s'accroître? Cela est-il probable? Je sais bien qu'on cite le nombre immense dé certaines graines parmi lesquelles il n'en est qu'un très-petit nombre qui se développent; mais existe-il une vraie similitude entre ces deux exemples? N'est-il pas évident que la germination de ces graines dépend de mille canses diverses à la réunion desquelles on peut donner le nom de hasard, tant elle est fortuite? mais la même espèce d'animal produisant toujours le même nombre de petits, n'est-il pas démontré par cela mème qu'une précision aussi constante dans l'œuvre ne saurait dépendre d'agens aussi multipliés que le sont les animalcules spermatiques? J'ajoute encore que ces corps 
214 LIV. II. DE LA REPRODUGTION DES ÊTRES VIVANS. mobiles sont si ressemblans à ceux quion obtient de certaines infusions, qu'il est difficile d'admettre que les uns soient autrement vivans que ne le sont les autres; et si l'on veut soutenir que ces animalcules se forment spontanément, ne faudra-t-il pas convenir que la formation spontanée du fotus serait tout aussi concevable?

Si l'on avait fait attention que non-seulement les animalcules ne sont pas proportionnés pour le nombre aux foetus produits à-la-fois par chaque espèce, mais qu'ils ne sont pas proporlionnés davantage au volume de ces animaux, de petits animaux en ayant de plus gros que d'autres animaux beaucoup plus volumineux; si l'on avait fait attention que l'on ne trouve jamais d'animalcules dans l'œuf fécondé des viseaux, même lorsque la fécondation de l'œuf pondu date de dix-huit à vingl jours, il est sûr qu'on se fût épargné lant de soins et d'efforts pour faire prévaloir durant près d'un demi-siècle cette théorie singulière, due tout entière à l'admirable invention el à l'abus du microscope. Il est naturel de penser que l'habitude de contempler des corps si exigus a été pour beaucoup dans celle ferveur si générale $\epsilon$ si persévérante pour un système aussi inconséquent qu'improbable.

Cependant Leeuwenhoek élait si convaincu que les corpuscules mouvans du sperme sont de vrais animaux servant à la formation d'autres animaux plus parfaits, qu'il allait jusqu'à admettre qu'ils ont des sexes et engendrent ensemble. Il croyait avoir remarqué deux variétés d'organisation parmi cux, et il ne doutait nullement que les uns ne fussent des mâles et les autres des femelles; il croyait aussi en avoir re- 
CIIAP. XXVII. SYSTHUE DE LEEUWFTHOKK.

marqué de plus petits après ces prétendus accouplemens, et cette succession de générations lui servait à expliquer comment il avait pu trouver de ces petits corps vivans six à sept jours encore après l'émission de la semence, car ces corpuscules ne conservent guère de mouvement au-delà de quelques heures. Mais remarquez que cette observation des sexes, de l'accouplement et de la reproduction des animalcules, détruirait de fond en comble, si clle était avérée, les hypothèses de Iceuwenhoek, de Boerhaave et d'Andry. Effectivement, si ces petits corps s'engendrent entr'eux à la manière des animaux eux-mêmes, il est probable qu'ils sont analogues à ces derniers sous plusieurs autres rapports; or ces animaux ne s'accouplent et n'engendrent que lorsqu'ils sont accrus, lorsque leur organisation est parfaite; loule métamorphose est désormais impossible, la chose est certaine, pour des animaux en état de s'accoupler: comment donc concoit-on que des animalcules assez paraits pour se procréer, puissent éprouver subséquemment d'assez grands accroissemens, des métamorphoses assez considérables, pour donner naissance à des êtres qui sont des millions de fois plus gros qu'eux-mêmes !

Cependant, la preuve, a-t-on dit, que la génération est l'œuvre des animalcules, c'est qu'on trouve toujours de ces corpuscules mouvans dans l'ovaire des. femelles fécondées des mammifères. Je n'examine pas si celte obscrvation a autant d'exactitude et de constance qu'on le prétend; je veux seulement montrer qu'elle ne prouverait rien pour la chose dont il s'agit : car si l'on admet que le sperme parvient jusqu'i 
210 LIV. H. DE LA REPRDUCTON HAS İTRES VIVMT.

l'covaire pour en féconder les résiculeš, il est sûr qu'on doit trouver dans cet ovaire les animalcules que le fluide prolifique contient toujours et en si grand nombre. La présence des animalcules dans les ovaires ne prouverait donc qu'une chose, je venx dire que ces corpuscules indiqueraient seulement quelle voie suit la semence et jusqu'ox́a elle s’introduit.

Je répète done que l'hypothèse de Leeuwenhoek n'est pas soutenable; et s'il élait besoin d'une preuve positive pour en établir la fausseté, on n'aurait qu'à se rappeler l'expérience suivante que nous avons déja citéc : Spallanzani prit du sperme de reptiles dont il uvait soigneusement détruit lons les corpuscules mouvans, et cependant les oufs qu'il arrosa de celte liqueur vinrent à bien.

\section{CHAPITRE XXIX.}

Syslème de Buffon : Molécules organiques, Moule intérieur.

Egal Coucours des Sexes.

A l'époque où M. de Buffon publiait son bel outvrage sur l'Histoire naturclle, le système des animalcules et celui des aufs se partageaient les opinions des physiologistes. Les découvertes de Leeuwenhoek servant de base à l'un de ces systèmes, les observattions de Graaf et d'flifarvey motivant assez puissamment l'autre, Buffon employa tous ses soins et son grand talent à combattre ces trois auteurs; après quoi il se mit lui-même à construire un système nouveau, 

n'ayant rien d'analogue avec les opinions alors reçues; je veux parler de sa fameuse hypothèse des molécules organiques, dont voici les principaux fondemens.

Bufion commença par reprendre en sous-cuvre les expériences microscopiques de Leeuwenhoek et de Hartsoeker sur les animalcules spermatiques : il observa d'abord des corps mouvans dans la semence des mâles adultes et dans les corps jaunes de l'ovaire des femelles; il mit ensuite infuser dans des liquides des organes de divers animaux, des portions de plantes ou des plantes entières, et il trouva partoul des globules mouvans; partout, dans les humeurs même et dans tous les liquides. Alors Buffon confondit tous ces corps mouvans d'une apparence animée, ou plutôt il assimila ces corpuscules des liquides simples et des infusions aux animalcules de la semence; il admit, non pas que tous ces globules mouvans sont des animaux véritables, ainsi que Leeuwenhoek l'admettait des corps mouvans de la semence, mais que ces corpuscules des êtres vivans sont etix-mêmes animés, sans ctre pour cela de vrais animaux. Alors Bufion (ou plutôt Needham) supposa qu'il existe dans la nature une immensité de globules mouvans comme ceux qu'il apercevait dans ses expériences, que ces globules composent tantôt des animaux, tantôt des plantes; que cette matière passe ainsi de l'un de ces corps à l'autre sans s'altérer, sans éprouver de changeuens notables; el celle matière vivante el active qu'il voyait se mouvoir, Buffon la désigna sons le nom de molécules organiques.

Ces molécules, selon Buffon, composent le chyle 
218 LIV. II. DE LA TEPRODUCTION DES ETIES VIVANS.

et les alimens dout le chyle provient; clles sont employées à former tous les organes, à les nourrir el à les accroître. Si ces molécules sont plus ahondantes qu'il ne faut dans certaines paries d'un corps organisé, elles s'y accumulent dans un lieu quelconque, et elles y donnent lieu à des productions spontanćes, à des animaux parasites, à des vers, à des insectes. Souvent, ajoute Buffon, elles se réunissent et s'oreyanisent ainsi dans la nature, en dehors même des corps vivans, et c'est de la sorte qu'elles composent de vrais corps organisés sans le secours d'une généralion sexuclle. Aussi, suivant Buffon, y a-t-il aulant de corps vivans formés spontanément par la rencontre fortuite des molécules organiques, quil y rn a d'engendrés par l'assortiment et le concours des sexes.

Tant qu'un corps vivant continue de s'accrô̂tre, dit le même auteur, toutes ses molécules organiques sont employées à sa nourriture et à son développement; il ne s'en accumule aucune spécialeneul dans nul organe, il ne s'en dissipe point à l'exléricur. Mais lorsqu'au contraire les corps vivans sont tolalement accrus, qu'ils sont jeunes, pleins de force el de vie, ajors ces molécules, devenues trop abondanles pour les besoins ordinaires d'un corps parachevé, s'auassent daus les lesticules el les vésicules séninales des animanx niâles, dans les ovaires des femelles, dans les anthères et le réceptacle des plantes; et il en résulte le pollen des fleurs, le sperme des animaux mâles, les corps jaunes de l'ovaire, des mammilère's femelles, el la cicatricule des oufs des femelles ovipares ( car pour l'ouf lui-mêne, Buflon le regarde 
CHAP. XXIX. SYSTELE DE BUFFON.

comme une vraic matrice) : (clles sont, suivant notre célìbre naturaliste, les vraies scurees de la génération des êtres vivans.

Comme ees molécules organiques, toujonrs aclives et tonjours vivantes, circulent également lans loutes les parties de chaque corps, tous les organes et loutes les humeurs en sont imprégnés, et atssitôt qu'il y a excédent, chaque humeur et chaque organe renvoient de la même sorte des molécules organiques vers le réservoir commun où elles se rassemblent. Par conséquent, dit Buffon, il y a dans la semence du mâle un peu des molécules organiques de tout le corps de l'animal, et l'on conçit que le nouvel être, né de cette semence, doit ressembler à son père. Tigalement, le corps jaune de l'ovaire des femelles étant composé des molécules organiques de chaque organe de la femelle, offre en extrait le corps entier de celle femelle; et par conséquent le nouvel être, né de la combinaison du corps jaune de la femelle et de la semence du mâle, doit ressembler à-la-fois à ses deux auteurs. Les molécules similaires du mâle et de la femelle se réunissent et se combinent ensemble; les molécules venues de l'œil du père, pour citer un exemple, se combinent avec les molécules semblables, provenant de l'œil de la mère, et ainsi de tous les organes.

Si l'on demande à Buffon comment ces molécules organiques, extraites de tous les organes des deux parens, se rassemblent en un tout aussi parfait que l'est chacun des deux êtres d'où el!es proviennent, Buffon répond que cela se fait en vertu d'un moule intérieur; autrement, clles se rassemblent el s'orga- 
2 LIV. 11. DE LA SEPRODUCTON DFS ATRES VIVAXA.

nisent par la raison qu'elles s'organisent et se rassemblent, car les faits physiques généraux n’ont pas d'autre raison pour nous que leur existence et leur réalité même.

Voilà une idée abrégée, mais suffisante, du célèbre système de Buffon sur la gěnération des êtres : système combattu, contredit par les savans de tout un demi-siècle, par la raison que les contemporains de Buffon attachèrent à cette hypothèse originale une importance que Bulfon lui-mème était loin de lui donner. Cependant, pour être juste envers cet houme si éminent, il eût fallu tenir compte des considérations suivantes.

Buflon, lorsqu'il conçut le plan de son immortel ouvrage, dut réfléchir avant toute chose sur les grandes lois de la vie, principalement sur la Reproduction des êtres vivans, et il tut obligé de consulter tous les ouvrages remarquables qui avaient paru jusqualors sur cet acte si important et si mystérieux. Or, que trouva-t-il dans ces ouvrages? souvent nul accord dans les faits, rien d'exact et de satisfaisant dans les théories. Buffon vil bien que lui-même ne pouvait créer un système parfait avec les faits alors connus : d'ailleurs, il ne pouvait ni prévoir ni devancer les Iravaux entrepris depuis lui, par Haller, par Spallanzani, par Dutrochet, etc. Il se résigna donc à faire le recensement de toutes les richesses de la science; i) récapitula presque toujours avec imparlialité les découvertes d'Aristote, d'Harvey, de Graaf, de Malpighi, de Vallisneri, de Lceuwenhoek, de Duverney, et de son propre associé Needham : et lorsqu'une fois il eut disposé tous ses matériaux, Bufion s'iperçut plis. 
rque jamais qu'il fallait à tant de faits épars un lien commun pour l'unité de son œuvre, une idée dominante pour le soulagement des esprits. Il faut ajouter que chaque siècle a ses exigences et ses besoins, et que tout grand homme qu'était Buffon, il fut dominé par l'ascendant du sien : nécessité déplorable, mais universelle. L'époque où Buffon écrivait était éminemment littéraire : le public de son temps ne quittait les écrivains admirés du siècle précédent, que pour des philosophes tels que Voltaire, Montesquieu et Rousseau, les auteurs florissans d'alors. Ce n'était déjà plus la même simplicité, le même abandon, mais plus de profondeur dans la pensée rachetait ces précieux avantages; et à mesure que le langage perdait de sa pureté, la nation devenait plus réfléchie. Il n'est pas inutile pour notre objet présent, d'observer que le XVIII siècle ofirit en France trois périodes fort remarquables, trois caraclères d'esprit très-différens : le dégoût de la licence produisit insensiblement une tendance manifeste à la réflexion et à la philosophie, et vers la fin du siècle cet esprit philosophique engendra l'amour des sciences exactes et leúrs prodiges. C'est dans la seconde de ces périodes que Bufion écrivait; j’ajoute que lni seul, parmi les auteurs ses contemporains, n’a jamais sacrifić au mauvais goût et au dévergondage de la période qui avait précédé, et que c'est être injuste envers lui que de refuser à ses ouvrages d'avoir puissamment hâté la dernière de ces périodes, qui s'est prolongée jusqu'à nos jours.

Cependant, il faut convenir qu'on ne trouve point anx sciences, dans tous les écrits de Buffon, cette physionomic réguliere qu'elles ont prise dans nos 
222 JiV. II. DL LA REPRODUCTION DES LTTRS VIVANS.

temps modernes : l'esprit public n'avait encore ni ce dédain des futilités et des ornemens, ni cette tendance sérieuse vers le vrai, vers l'utile, qu'on lui voit anjourd'hui. La science, à cette époque, ne pouvait se montrer, sinon sans parure, du moins sans résultats coordonnés et sans ensemble : il élait de mode alors d'in roduire dans tous' les genres d'écrits celte unité de vues et d'iniérêt dont on se dispense aujourd'hui souvent même au thétre. II résultait de là pour les savans la nécessité de remplacer par des conjectures les vérités ignorées de leur temps; de sorte que les mêmes causes qui produisaient la supériorité et la perfection des auires ouvrages, ont déterminé les défauts de ceux de Buffon. Toutefois, il est vrai de dire que tout en cédant à la force des circonstances, cet écrivain resta homme de génie jusqu'en ses erreurs. Au lieu de s'attacher au joug comman, hypothèses pour hypothèses, il résolut de remplacer des théories surannées et reconnues pour imparfaites, par des conjectures du moins originales et plus vraisemblables; et d'ailleurs il ne donna son Système des Molécules organiques que comme il avait donné sa Théorie de la Terre, c'est-à-dire moins pour une chose parfaite que comme une conjecture ayant le mérite d'être partout conséquente avec elle-même. Buffón ne cachait point à seslecteurs, pas plus qu'il ne se le dissimulait à lui-même, que ce n'était là qu'une pure hypothèse : un auteur se fait bien rarement illusion à ce sujet, et Buffon devait s'y tromper moins qu'un autre en sa qualité d'hommc supérieur. Aiu reste, on verra par l'Exposé suivan! des principales objections dont cette Théorie de Buffon 
est susceptible, s'il ćlait possible que lui-même pût s'en diissimuler la faiblesse el l'imperfection.

On peut d'abord demander quelles sont les preuves irrécusables de l'existence des molécules organiques, et s'il est bien vrai qu'elles aient l'usage que Buffon leur a assigné. La raison qu'il donne pour démontrer que ce ne sont point des animalcules, est de nature à faire douter que ce soient même des globules mouvans et animés, comme il le prétend; car, par cela même qu'il les a trouvés dans tous les liquides simples et dans les infusions des corps organisés privés de la vie, on peut penser que ce sont là des molécules matérielles qui n'ont rien de plus dans les corps vivans que dans ceux qui ont cessé de vivre; et il faut convenir qu'il y a loin de pareilles molécules au foetus dont la génération est la source; qu'en un mot l'hypothèse de Buffon, fût-elle même fondée, avancerait bien peu le problème de la reproduction des êtres. D'aillcurs, a-t-on vu ces molécules se détacher de chaque organe, les a-t-on vues se rassembler dans les testicules pour en composer le sperme? Loin de là, on sait que la semence émane du sang comme les autres humeurs, que si quelque fluide des grands animaux contient un extrait el les nouveaux principes de tous les organes, cela doil être le sang, puisqu'il est la source commune et le réceptacle des autres fluides et des organes; el, si l'on admettait que le fœutus émané de la semence ressemble à son père par la raison que cette semence provient du sang, et que ce sang renferme un peu de tout ce qu'il y a dans le corps, on voit bien qu'il faudrait admettre la même propriété de reproduction et de ressemblance pour 
224 LIV. II. DE LA REPRODUCTION DES ÊTRES VIVANS. chacune des autres humeurs, puisqu'elles ont une origine toute pareille.

On peut aussi objecter à Buffon que s'il est vrai, comme il semble en être convaincu, que les semences des deux sexes ne donnent la vie à un nouvel être que parce qu'elles réunissent l'une el l'autre un extrait du corps des deux individus, on ne conçoit pas pourquoi chaque sexe isolé ne produit pas un être semblable à lui. Si les choses, en effet, étaient comme il le conçoit, on ne roit pas pourquoi le mâle ne produirait pas un mâle sans le concours de la femelle, ni pourquoi cette femelle n'engendrerait pas d'autres êtres de son sexe sans le concours du mâle. Mais une autre difficulté bien plus grande est celle-ci : comment peut-il se faire que les molécules des deux sexes, unies par ordre d'organes, ne produisent jamais d'hermaphrodites par leur mélange? Comme Buffon a prévu ces deux dernières objections, nous devons dire comment il a cherché à les détruire; et nous saisissons cette circonstance pour rewarquer combien Buffon possède à fond l'art d'écrire, puisque, même dans un sujet aussi obscur, son style ne perd jamais rien de sa clarté, de son élégante précision, de sa correction si parfaite ni de son harmonic.

- Tant que les molécules organiques sont seules de leur espèce, comme clles le sont dans la liqueur séminale de chaque individu, leur action ne produit. aucun effet parce qu'elle est sans réaction; ces molécules sont en mouvement continuel les unes à l'égard des aulres, et il n'y a ricn qui puisse fixer leur activité, puisqu'clles sont toutes également animées, ćgalement actives; ainsi il ne se pout faire aucune 
rẻunion de ces molécules qui soit sêmblable à l'animal, ni dans l'une, ni dans l'autre des liqueurs séminales des deux sexes, parce qu'il n'y a, ni.dans l'une ni dans l'autre, aucune partie dissemblable, aucune partie qui puisse servir d'appui ou de base à l'action de ces molécules en mouvement; mais lorsque ces liqueurs sont mêlées, alors il y a des parties dissemblables, et ces parties sont les molécules qui proviennent des parties sexuelles, ce sont celles-là qui servent de base et de point d'appui aux autres molécules, et qui en fixent l'activité; ces parties étant les seules qui soient différentes des autres, il n'y a qu'elles seules qui puissent avoir un effet différent, réagir contre les autres et arrêter leur mouvement.

- Dans cette supposition les molécules organiques qui, dans le mélange des liqueurs séminales des deux individus, représentent les parties sexuelles du mâle, seront les seules 'qui pourront servir de base ou de point d'appui aux molécules organiques qui proviennent de toules les parties du corps de la femelle; et de même les molécules organiques qui, daus ce mélange, représentent les parties sexuelles de la femelle, seront les seules qui serviront de point d'appui aux molécules organiques qui proviennent de toutes les parties du corps du mâle, et cela, parce que ce sont les seules qui soient en effet différentes des auires. De là on pourrait conclure que l'enfant mâle est formé des molécules organiques de la mère pour le reste du corps, et qu'au contraire la femelle ne tire de sa mère que le sexe, et qu'elle prend tout le reste de son père : les garçons devraient donc, à l'exception des parties du sexe, ressembler davantage I. 
226 LIY. II. DE LA REPRODUCTION DES ÊTRES VIVANS.

à leur mère qu'à leur père, et les filles plus au père qu’à la mère; cette conséquence, qui suit nécessairement de notre supposition, n'est peut-être pas assez conforme à l'expérience.

" En considérant sous ce point de vue la génération par les sexes, nous en conclurons que ce doit être la manière de reproduction la plus ordinaire, comme elle l'est en effet. Les individus dont l'organisation est la plus complète, comme celle des animaux dont le corps fait un tout qui ne peut être ni séparé ni divisé, donit toutes les puissances se rapportent à un seul point et se combinent exactement, ne pourront se reproduire que par cette voie, parce qu'ils ne contiennent en effet que des parties qui sont toutes semblables entre elles, dont la réunion ne peut se faire qu'au moyen de quelques autres parties différentes, fournies par un autre individu; ceux dont l'organisation est moins parfaite, comme l'est celle des végétaux dont le corps fait un tout qui peut être divisé et séparé sans être détruit, pourront se reproduire par d'autres voies, $1^{\circ}$. parce qu'ils contiennent des parties dissemblables; $2^{\circ}$. parce que ces êtres n'ayant pas une forme aussi déterminée et aussi fixe que celle de l'animal, les parties peuvent suppléer les unes aux autres et se changer selon les circonstances, comme l'on voit les racines devenir des branches et pousser des feuilles lorsqu'on les expose à l'air, ce qui fait que la position et l'établissement du local des molécules qui doivent former le petit individu se peuvent faire de plusieurs manières.

"Il en sera de même des animaux dont l'organisation ne fait pas un tout bien déterminé, commie les. 
CHAP. XXIX. SYSTÈME DE ELFFON.

polypes d'eau douce, et les autres qui peuvent se reproduire par division; ces êtres organisés sont moins un seul animal que plusieurs corps organisés semblables, réunis sous une enveloppe commune, comme les arbres sont aussi composés de petits arbres semblables, qui sont leurs branches et leurs bourgeons. Les pucerons qui engendrent seuls, contiennent aussi des parties dissemblables, puisqu'après avoir produit d'autres pucerons, ils se changent en mouches qui ne produisent rien. Les limaçons se communiquent mutuellement ces parties dissemblables, et ensuite ils produisent tous les deux; ainsi dans toutes les manières communes dont la génération s'opère, nous vôyons que la réunion des molécules organiques qui doivent former la nouvelle production, ne peut se faire que par le moyen de quelques autres parties différentes qui servent de point d'appui à ces molécules, et qui par leur réunion soient capables de fixer le mouvement de ces molécules actives.

\Si l'on donne à l'idée du mot sexe toute l'étendue que nous lui supposons ici; on pourra dire que les sexes se trouvent partout dans la nature; car alors le sexe ne sera que la partie qui doit fournir les molécules organiques différentes des autres, et qui doivent servir de point d'appui pour leur réunion. Mais c'est assez raisonner, ajoute Buffon, sur une question que je pouvais me dispenser de mettre en avant, que je pouvais aussi résoudre tout d'un coup, en disant que Dieu ayant créé lés sexes, il est nécessaire que les animaux se reproduisent par leur moyen. En effet, nous ne sommes pas fails pour rendre raison du pourquoi des choses : nous ne sommes pas en état d'ex- 


\section{LIV. IT. DL LA REPRODCCTION DLS ÊTHES VIVANS.}

pliquer pourquoi la uature emploie presque toujours les sexes pour la reproduction des animaux; nous ne saurons jamais, je crois, pourquoi ces sexes existent, et nous devons nous contenter de raisonner sur ce qui est, sur les choses telles qu'elles sont, puisque nous ne pouvons remonter au-delà qu'en faisảnt des suppositions qui s'éloignent peut-être autant de la vérité, que nous nous éloignons nous-mêmes de la sphère où nous devons nous contenir, et à laquelle se borne la petite élendue de nos connaissances.

Que de réflexions fait naître ce passage de Buffon! que d’idées! comme elles s'enchaînent! et après cela , comme l'auteur de ce bel édifice le détruit d'un souffle! Nous admirons d'abord le physicien accomnplissant son devoir d'interprétateur de la nature; mais bientôt le philosophe vient nous humilier en s'humiliant lui-même par l'aveu sincère de son ignorance. Quelle lecon pour les savans, quel préservatif contre la tentation des systèmes!

Ce qu'on a coulume de dire d'un premier mensonge obligeant à de nouveaux mensonges, nous le voyons se réaliser ici pour les hypothèses : Buffon n'a pas sitôt supposé qu'il se détache ou reflue de chaque partie des corps organisés vivans des molécules conservant l'empreínte de ces parties diverses, qu'il se voit entraîné, pour n'être pas inconséquent, à beaucoup d'autres suppositions. Appréciant de lui-même la plupart des objections dont son système est susceptible, Buffon se hâte de les prévenir par ses réponses, et chaque nouvelle preuve qu'il allègue à l'appui de sa théorie confirme et souvent fortifie les premiers doutes loin de.les détruire. Lui demande- 
t-on par quelle raison ses globules mourans el animés ne s'organisent pas isolément dans chaque iudiviàu? C'est, répond-il, parce qu'ils sont trop similaires, et que ne se faisant point mutuellement obstacle, ils se meuvent sans relâche, ce qui les empêche de se rapprocher et de s'unir, car le mouvement nuit à l'attraction; au lieu que, dans le mélange des semences des deux individus, les globules provenant des parties sexuelles se font mutuellement ćquilibre, et les globules sexuels de l'un des individus deviennent ainsila première base de tout l'édifice; en même temps qu'ils déterminent le sexe du nouvel être. Mais qu'arrive-t-il pour les êtres qui n'ont point de sexes? comment se reproduisent les polypes, et les plantes naissant de boutures? car puisque les molécules sont ici toutes similaires, comment, restant toujours açitées des mêmes mouvemens, peuvent-elles s'unir et s'organiser? Ensuite, pour les êtres qui ont des sexes, pourquoi l'un des individus fournit-il seul les globules Gestinés aux parties sexuelles? que deviennent-les globules sexuels de célui des deux individus qui ne fournit rien pour le sexe du nouvel être? comment, si les globules mouvans des dcux semences sont composés des molécules organiques formant l'excédent des organes des deux parens, comment, dis-je, peuvent-elles conserver l'image ressemblante de ces organes, puisqu'elles n'ont pu en pénétrer la trame? Comment.... mais, nous l'avons vu, Buffon consiruit d'abord un système que le plus grand nombre des faits évidens rend vraisemblable, et une fois ses principes posés, il explique la réalité par àes firlions, et rélorque cbaque argument par autant de conjectures nourelle.. 
230

LIV. II. DE LA REPRODUCTION DES ETTRES VITANS.

S'il rencontre un exemple formellement opposé à son système, comme celui des pucerons engendrant sans. accouplement quoiqu'ayant des sexes, $*$ Buffon explique ce cas exceptionnel par l'hypothèse même que ce seul cas bien interprété renverserait. Assailli de tous côtés par des faits inflexibles, Buffon, interrogeant sa conscience, finit pár partager lui-même les doutes qu'il voulait dissiper; et ce retour soudain d'un sage détruit l'œuvre de son génie.

Ainsi, nous voyons le système de Buffon perdre toute sa vraisemblance, à ne le considérer uniquement que comme une suite de raisonnemens et d'opinions, et tout en admettant comme réels les faits mêmes que Buffon suppose; mais, que serait-ce donc, si nous examinions arec toute la sévérité d'un crilique ces faits dọnt il s'autorise? Nous avons vu que cę système repose tout entier sur l'existence et le mélange des semences du mâle et de la femelle, et il est manifeste que cette dernière n'a pas de semence. Buffon suppose que la source du fluide séminal de la femelle est dans le corps jaune de son ovaire, et cependant ce corps jaune, loin de préexister à la conception, résulte tout simplement de la rupture d'une des vésicules de l'ovaire; par cơnséquent, alors même que la femelle aurait une sorte de semence, l'origine n'en pourrait être attribuée au corps jaune. Mais, je répète que les femelles n'ont point de semence : l'espèce d'éjaculation qu'elles semblent éprouver dans le coït a sans doute inspiré cette erreur, si universelle parmi le peuple et les philosophes, que les femelles répandent un fluide prolifique comme les mâles; ínais personne n'a vu cette prétendue semence. D'ailleurs, 
d'où proviendrait-elle? Puisq̉u'on la suppose analogue au sperme du mâle, il faudrait, ainsi que chez le mâle, qu'elle fụ̂t sécrétée dans une espèce de testicule : conséquemment, ce n'est que de l'ovaire qu'elle pourrait émaner. Or, les ovaires ne laissent rien transpirer de leur substance; ils sont entièrement formés de vésicules sans conduits excréteurs et sans accès. De toutes parts adhérentes au tissu de l'ovaire, ce n'est qu'en se rompant iu'elles produisent quelque chose, et nous avọns vu que cette sorte de rupture n'a lieu que dans les cas de conception. Si donc la semence qu'on attribue aux femelles provenait de l'ovaire, on trouverait au moins une vésicule rompue par chaque copulation; or, nous savons, par ce qu'on voit dans l'espèce humaine, combien cela est contraire à la réalité. Les ovaires ne produisent donc point de semence. On objecterait vainement que les trompes, qủe l'utérus ou le vagin peuvent produire une sorte de semence; car il ne flue jamais de ces organes qu'uné sorte de mucus qui n'a rien d'analogue avec le sperme. Et, d'ailleurs, où serait la source de ce fluide séminal dans les femelles des ovipares, elles dont l'œuf est déjà tout formé dans leurs ovaires à l'époque où le sperme du mâle le féconde? où serait-elle dans les grenouilles, dans les salamandrẹs, et dans cęux des poissons qui engendrent sans accouplement, puisque lés mâles de ces espèces ne fécondent les œufs qu'après 'qu'ils sont sortis du corps des femelles? Comment admettrait-on un mélange de semence, là où il n'y a point de vrai coït?

Sans l'illustre nom de son auteur, ce serait sans doute déjà trop d'objections contre un système si 


\section{I.IV. H. DE L. REPROOUGTION CLS ETRES PIVANS.}

fragile; cependant nous ne devons point passer sous silence la plus puissante des difficultés. D'ailleurs, ne s'est-on pas aperçu que tout en retraçant les erreurs d'un grand homme, nous écrivons doublement l'histoire de la nature, puisque nous montrons à-lafois l'ignorance des hommes, les mystères de cette nature, cl l'impuissance même du génie à concevoir ces myslères. Mais j’ai parlé d'une dernière objection au système de Buffon et à plusieurs autres systèmes, et je vais essayer de la présenter ici dans toute sa simplicité, et, s'il m'est possible, dans toute sa force.

On dit que le foetus résulte des semences des deux individus, que chacune de ces deux semences est composée de globules mouvans et animés, et que ces globules sont de véritables molécules organiques, provenant de l'excédent des organes des deux sexes, et formant l'extrait complet de toutes les parties de chacun de ces deux corps, et l'on dit qu'ellès en conservent l'image. On ajoute que ces molécules forment en petit le nouvel être, absolument comme d'autres molécules semblables composent en grand le corps des deux individus d'où nâit l'embryon. II suit de là que l'être engendré doit être l'image parfaite de ses auteurs, et c'est même dans le but d'expliquer les ressemblances des jeunes animaux avec leurs parens, qu'on a inventé celte supposition vraisemblable. On corrobore ce système en ajoutant que les enfans héritent de leurs auteurs pour les infirmités, pour certains signes, et pour les irrégularités ou l'excès de quelques organes, tout comme ils en héritent pour une structure plus exacte et normale. Il est évident que, dans lesprit d'une pareille 
CUAP. XXIX. SYSTLHE DE BUFFON.

hypothèse, non sculement le nouvel être doit offrir l'empreinte mitigée de tous les organes des deux parens; mais que, par plus forle raison, il doit être formé des mêmes organes que ses aitteurs, et n'en doit posséder aucun qu'ils n'aient eux-mêmes. Or, indépendamment des organes sexuels, qui ne ressemblent qu'aux mêmes parties de l'un des deux parens, nous he voyons pas que cette ressemblance soit aussi exacte que ce système le ferait supposer. Par exemple, l'homme et la femme adultes n'ont plus de thymus, et cependant le foelus a cet organe très-développé, très-manifeste; il présente des vaisseaux ombilicaux très-spacieux, un canal artériel allant de l'artère pulmonaire à l'aorte, et une ouverture très-visible à la cloison des orelllettes du cœur, et néanmoins ses parens n'ont plus que les vestiges presque inappréciables de ces dispositions natives. Enfin, on ne voit pas qu'un animal privé d'un membre, d'un testicule, ou de toute autre partie non indispensable à la vie, qu'un homme privé de cristallins par une opération de cataracte, qu'une femme à qui les mamelles ou le col utérin ont été amputés, on n'observe pas que des individus ainsi mutilés donnent jamais naissance à des êtres d'une structure moins parfaite que si aucun organe ne leur eût manqué : en d'autres mots, les mutilations des êtres vivans ne se transmettent point des parens à leur progéniture.

Que doit-on conclure de toutes ces choses? C'est qu'il existe un type primordial pour chaque espèce des corps organisés, c'est que, la structure acquise, les défauts contraclés par les pareus ne peuvent que modifier légèrement ce type criginel, ce patron indé- 
234 LIV. II. DE LA REPRODCCIION DES ÀTRES VIVANS. pendant, jusqu'à un certain degré, des êtres qui lui donnent l'existence ou la manifestation; c'est qu'en outre le mode de formation du fotus est un mystère qui nous est impénétrable. Si jamais quelqu'un conservait l'espérance d'une découverte aussi admirable que celle de la première cause de la reproduction des êtres, nous l'invitons à lire Buffon et Haller pour se dispenser d'une entreprise n'ayant ni de succès possible, ni de but raisonnable. Si néanmoins il persistait toujours dans le même sentiment de confiance en son génie, je l'en avertis encore, qu'il redoute les saillies d'une imagination qui ne saurait que le trahir! Pour moi, j'avoue qu'après avoir long-temps médité le système de Buffon sur cette matière, système si remarquable, si ingénieux, si mûrement pensé, si merveilleusement lié en toutes ses parties, et au premier abord si vraisemblable; je confesse qu'après cette longue étude, et toutes les recherches qu'elle exige, j'en ai conçu une défiance de moi-même, un scepticisme, un dédain des systèmes hypothétiques, une prédilection décidée et un goût exclusif pour l'observation pure et raisonnée, enfin, une sorte de découragement d'esprit que je n'avais jamais autant éprouvé. 


\section{CHAPITRE XXX.}

Conclusion de ce Livre.

Nous l'avons vu, aucun être vivant n'est produit spontanément : il est vrai que la reproduction de ces êtres n'est pas toujours le résultat du concours des sexes, mais elle suppöse constamment une souchemère, une parenté, une espèce d'œuf pour origine ou comme berceau. Nous avons exposé combien les phénomènes de la génération diffèrent pour les êtres ayant des sexes; mais au milieu de cette diversité d'actes, nous avons vu du moins qu'il existe dans tous un principe commun qui est l'œuf, ét dans tous un concours nécessaire des deux sexes : c'est constamment de la femelle que nous avons vu provenir cet œuf, mais nous savons qu'il n'est jamais fécond sans l'intervention de la semence du mâle; de sorte que nous n'avons pu partager l'opinion des auteurs qui ont supposé que le fotus provenait exclusivement de l'un des sexes. Nous aurions eu plus de propension à adopter d'autres opinions qui admettent, pour la procréation d'un nouvel être, l'égal concours des deux individus de sexes différens; mais comme, malgré la réalité de ce concours, tout ce que nous avons dit jusqu'à présent nous en montre le mode sans en indiquer l'essence, nous avons dû n'envisager ces théories qu'uniquement à cause de leur vraisemblance et de leur probabilité. Hippocrate, l'inter- 
2.56 H.V. II. DE LA IEPRODUCTION DES ÊTLES VIVANS.

prète des opinions des anciens, pense que le nouvel être résulte de l'union des semences; et nous rejetons cette hypothèse par la raison que les femelles n'ont point de semence. Aristote prétend que la femelle fournit la matière, la trame inanimée du nouvel être; il ajoute que la liqueur prolifique du mâle communique la vie et la'forme à ce principe inerte ou matériel; mais nous rejetons encore ce système d'un grand homme, parce qu'il est clair que cette matière préexistante dans la femelle, et cette forme ajoutée par le mâle, sont choses purement hypothétiques. Nous rejetons pareillement le système de la contagion séminale d'Harvey; nous le rejetons par des motifs encore plus puissans, mais surtoul parce que nous connaissons l'origine de l'œuf des mammifères, origine ignorée d'Harvey, et parce que la semence dont cet homme célèbre niait l'accès dans la matrice, a été trouvée dans cet organe par plusieurs anatomistes postérieurs à Harvey. Enfin, Buffon expliqua cette production d'un être nouveau par l'attraction mutuelle de ce qu'il nomme les molécules organiques des semences des deux sexes; mais, outre que les femelles n'ont point de semence, nous avons démontré combien de raisons rendent cette belle hypothèse invraisemblable.

Après avoir ainsi rejeté avec justice ces différens systèmes d'hommes admirés pour la puissance de leur génie, nous aurions pu commettre une faute impardonnable et la plus grave des inconséquences, c'eût élé de substituer nous-même un nouveau système à toutes ces théories que nous avions combattues et délaissćes. Mais cette faute si grave, nous ne l'avons 
point commise : arrivé au terme de l'évidence, nous nous sommes gardé de le franchir. Après avoir fait l'histoire des faits les plus certains, nous nous bornons à porter nos regards sur la longue route que nous venons de parcourir; et c'est cette vue générale que l'on verra consignée ici. Point de productions spontanées: tout être vivant a des liens de parenté avec ce qui a vécu. Tout embryon provient 'd'une sorted'cuf, cet cuf vient de la femelle, et dans les espèces qui ont des sexes, c'est la semence du male qui le féconde. Mais quelle est la part de la femelle, quelle est celle du mâle dans cet acte admirable? voilà ce que nous reconnaissons ignorer.

Cependant il nous reste plusieurs questions à examiner. Est-il quelque nouveau moyen de s'assurer si le principe de l'embryon préexiste dans les femelles? ou bien, sil se forme au moment de l'union des sexes, est-ce seulement pièce à pièce, et, dans ce cas, quelles sont les parties qui se forment les premières? Cette production de l'embryon est-elle, au contraire, simultanée pour tous les organes, et alors quelles sont les parties d'abord apparentes? enfin, quelles sont les lois de la Formation, de l'Évolution, ou du Développement des corps organisés? quels sont les plus âgés de leurs organes? quels sont les progrès, le terme et les irrégularités de leur accroissement?... C'est ce dont nous allons traiter dans le livre suivant. 


\section{LIVRE TROISILUTE.}

\section{De l'Accroissement des Gorps vivans;}

De l'Origine, de la première Apparition et de l'Age'comparé de leurs principaux Organes; des Métamorphoses et des Monstruosités.

\section{CHAPITRE PREMIER.}

Délails et Considérations sur l'Origine et les Progrès du Poulet dans l'OEuf.

Nous allons exposer rapidement dans ce chapitre selon quels progrès se manifestent les différentes parties de l'embryon des oiseaux dans un œuf fécond sjumis à l'incubation. Nous parleróns des parties accessoires du nouvel être aussi bien que de ses organes essentiels; et si nous commençons par le poulet, c'est parce qu'il a été observé, dès sa première origine, avec un soin, avec une exactitude qu'il est impossible d'appliquer à aucune autre espèce d'animal.

Tout le monde sait que le jaune d'un œuf, même infécond, porle une tache blanche et arrondie à la surface du plus léger de ses deux pôles : c'est là ce qu'on nomme la cicatricule. Nous avons dit que Parisanus avait cru à tort que cette tache était formée par la semence du mâle, opinion d'après laquelle cette zône blanche serait un indice assuré de la fécondation de l'œuf; et nous avons ajouté qu'Harvey avait détruit 
CHAP. 7. VIE ET PROGRES DU POULET DANS L'EEUF. 259 ce préjugé. Cependant il est vrai de dire que cette cicatricule du vitellus est plus épaisse et plus large dans un œuf qui a reçu l'influence du fluide séminal, qu'elle ne l'est dans un autre : mais c'est principalement l'incubation qui agrandit cette cicatricule dans toutes ses dimensions. Si nous parlons avant tout de cette tache du jaune, c'est à cause de son importance : c'est là, en effet, que se manifestent les premiers vestiges du jeune être. Au-dessous d'elle, on voit paraître, dès les premiers temps de l'incubation, un petit sac nommé follicule du jaune: c'est le premier indice de l'embryon, c'est la première marque de l'organisation commencante. Ce follicule ou bulle est manifeste dès le commencement de l'incubation; Malpighi l'a même observé dans des œufs féconds qui n'avaient pas encore été couvés. Ce petit corps est d'une teinte blanche; on ne sait pas très-précisément si c'est là le sac ébauché de l'amnios, et si l'embryon y est dèslors renfermé.

La membrane amnios, dont nous avons déjà parlé en décrivant la structure de l'œuf, est apparente vers la douzième heure de l'incubation; elle est adossée à la cicatricule et lui adhère.

On a nommé halons, une sorte de cercles concentriques les uns aux autres, lesquels se forment et grandissent dans l'œuf durant les premières heures de l'incubation : on les observe dès la septième heure, et ils prennent ensuite un grand accroissement depuis cette époque jusqu'à la quarantième heure. La chaleur ordinaire les fait également grandir. On ne sait pas ce que deviennent ces halons; bientôt 
24́ LIV. HII. DE L'ACCROISSEMIENT DES CORTS VIVAXS.

on les perd de vue : quelques personnes ont pensé que ce pouvait être l'origine obscure des vaisseaux.

L'embryon lui-même est visible au microscope dès la douzième heure de l'incubation. Malpighi l'a distingué dès la sixième heure, quelquefois même il l'a vu avant que l'incubation eùt commencé ; mais nous devons dire qu'en général les obervations de Malpighi ont devancé de plusieurs heures celles des autres observateurs, ce qui semble dî̀ et à la puissance de ses microscopes, et au climat plus chaud en Italie qu'en France, qu'en Angleterre et en Allemagne. Nous ferons les mêmes remarques pour les embryons des reptiles et les métamorphoses des insectes. Toutefois, nous l'avons déja dit, Malpighi lui-même n'a jamais apercu aucun vestige d'embryon dans des œufs non fécondés.

On a d'abord observé (1), vers la douzième heure, une tête dépassant supérieurement le follicule du jaune, et à cette époque, cependant, ce follicule avait plus de volume que l'embryon entier. Mais, à partir de cette douzième heure jusqu'à la vingtquatrième, l'accroissement du jeune être est d'une rapidité extrême; il est plus que doublé dans ce court période d'une demi-journée. A trente-une heures, la tête du poulet paraît fendue : Haller dit que cela tient à la transparence des parties intermédiaires; mais nous verrons à quelle loi générale ce fait appartient. Comme dans ces premiers temps de la

(1) Voyez Harvey, Malpighi, Haller, Maitre-Jean, etc., te. 


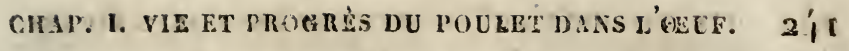
vie du poulet l'amnios a plus d'étendue que l'embryon n'a de volume; celui-ci se tient dans une grande rectitude, son cou n'est point courbé. A quarántè heures, la tête du poulet prend l'apparence d'un trèfle, eflet dû aux partiès déjà cartilagineuses des principaux os dui crâne. De quarante à quarante-hurit heures, la tête prent la forme d'une massue, à-peuprès comme les globulès mouvans de la semence; elle est tournée vers le petit bout de l'ouf et incinée vers le côté droit de l'embryon. L'accroissemen't qui avait été si rapide depuis la douzième beure jusqu'à la vingt-quatrième, êt même jusqu'à la quarrarrtième, seimblè alors tout-à coup se ralentir: il y a plus, l'embryon semble s'amincir à son iniliéu vers la cinquantième heure; et l'on devinera la cause de ce phénomène, si l’on se rappelle ce que noưs aróns dit du sac de l'allantoïde, qui commence alors á sortir du poulet pour aller se répandre au-déhors de lui. Environ à la cinquantième heure, les mouvemens du cœur deviennent visibles; c'est vers la soixantième que les courbures du tronc commencent à se dessiner; alors aussi la veine jugulaire devient manifeste. Les ailes apparaissent vers la soixante-dixième heure, le foie à la quatre-vingt-seizièrne, c'est-à-dire vers la fin du quatrième jour. Le cerveaú est encore totalement fluide à la fin du cinquième jovir: A cent vingt-quatre heures, à-peu-près;, apparaissent les rudimens des intestins, le rectum, le cœcum, eto. Vers la cent trentième heure, le petit animal se meúl, par conséquent ses muscles sont formés, et des nertis en travèrsent le tissu, comme du sang l'arrose. Iies poumons sont visibles ầ la cent trente-huitièmè heuré, I. 
242 LIV. III. DE L'A CCROISSEMENT DES CORPS VIVANS.

les reins à la cent quarante-deuxième; alors aussi les intestins sont achevés, ou, si l'on veut, toul-à-fait évidens : car ce changement si léger dans les termes exprime deux théories formellement opposées l'une à l'autre. A la cent soixante-huitième heure, ou septième jour révolu, le cerveau devient à moitié solide ou comme muqueux. Les côles sont visibles au huitième jour : à cette même époque (la cent quatrevingt-sixième heure), la tête forme environ la moitié de l'embryon; elle est égale au reste du corps. Mais bientôt les parties inférieures du jeune animal prennent de l'accroissement. Au neuvième jour, on voit paraître le sternum; au dixième, la vésicule biliaire: c'est à cetle épóque que les plumes commencent à poindre. Les yeux sont excessivement grands le onzième jour, et l'on peut les distinguer dès le quatrième. Les poumöns ne sont entièrement couverts, la poitrine n'est ferniée qu'au douzième jour : l'embryon alors est long d'environ deux pouces. La ráte n'est visible qué, le quatorzième jour : alors les poumons sont de toutes parts adhérens aux parois du thorax, qui; comme noús l'avons dit, est maintenant achevé depuis deux jours. Le poulet semble chercher à respirer le quinzième jour : il avait ouvert le bec dès le huitième. A seize jours, l'animal a environ trois pouces; à dix-huit jours, il a trois pouces et demi. Le dix-neuvième jouŕ, il commence à piauler, bien que la coquille soit toujours intacte; mais nous savons qu'il existe de l'air dans l'intérieur de l'œuf. A vingt jours, le poulet est de partout en contact avec ses meinbranes et la coque de l'œuf. Enfin, l'éclosion se fait le vingt-unième jour. L'animal a alors au moins 
CHAP. I. VIE ET PROGRÉS DU POLLET DAYS L'OEUF. 2.55 quatre pouces, et il grandit ordinairement à-peu-près d'un pouce dans la quinzaine suivante.

On a supposé que l'accroissement du poulet était cent fois plus rapide le premier jour que le vingtunième jour; mais cette crue du jeune animal est encore bien plus lente après l'éclosion qu'elle ne l'avait été les derniers jours de l'incubation, puisque, n'ayant que trois pouces environ le seizième jour, il en avait quatre le vingt-unième, et qu'il n'a augmenté que d'un pouce quatorze jours après sa naissance; c'est-à-dire le trente-cinquième jour de son existence entière. Nous verrons que ces progrès graduellement ralentis de la crue sont un des caractères communs à tous les corps organisés, à l'homme, aux animaux, et même aux plantes. C'est moins l'œuvre totale qui coûte à la nature, que sa conception et son achèvement.

Dans cette chronologie du poulet, nous n'avons fait qu'indiquer les organes à-peu-près dans l'ordre où ils se manifestent; mais, dans le but d'enseigner plus précisément les changemens qu'ils éprouvent et leurs progrès, nous allons reprendre, un à un, chacun des principaux organes, et muntrer comment ils naissent, à quelle heure et sous quelle forme ils se manifestent, enfin dans quel ordre et quelles proportions ils s'accroissent.

Cœur. Haller a vu distinctement le cœur, encore incomplet, baltre dès la fin du deuxième jour : il était blanc ou transparent, avait la figure d'un fer à cheval à convexité tour néè vers la tête, était trèsrapproché de celle-ci, et toujours entouré de membranes dès sa première apparition. Il n'est engagé dans la poitrine que lorsque les parois en sont ache- 


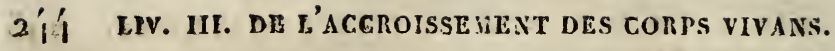
víes, ce qui arrive vers la cent quarante-deuxième heure. A quarante-neuf heures, on distingue deux vésicules palpitantes qui s'envoient l'une à l'autre un sang coloré. L'une de ces vésicules est formée par le ventricule gauche, l'autre présente le commencement de l'aorte, et voilà justement ce qui donne à l'ensemble de cesparties l'apparence d'une flèche colorée en rouge. Ce n'est ordinairement qu'à la cinquantième heure qu'on commence à apercevoir les trois points sautillans d'A ristote; ce sont trois vésicules rouges qui ne cessent de palpiter, et qui sont formées par l'origine dilatée de l'aorte, par le ventricule gauche qui alors existe seul, et par une seule oreillette. Les battemens de l'oreillette précèdent les battemens des deux autres cavités; mais il est vrai de dirc qu'il faut une vue bien perçante, bien attentive, pour voir le sang rouge passer de l'oreillette dans le ventricule , encore bien que les parois de l'ouverture intermédiaire soient incolores. Toutefois, on peut s'assurer que le ventricule et l'oreillelte: pâlissent au moment de leur contraction.

C'est dans le haut de la veine cave-inférieure, continualion de la veine: ombilicale, que se forment les oreillettes du cour, lesquelles commencent par ne faire qu'une seule cavité; mais vers la fin du quatrième jour, on voit apparaître les premières traces de la séparation des deux oreillettes : la gauche est d'abord la plus grande, elle déborde l'autré postéricurement, et bientôt ces deux cavités se prononcent et sisolent de plus en plus. Toutefois, la gauche reste la plus grande ordinairement jusqu'au vinglième. jour. 
CIIAP. 1. VIE ET PROGRÉS DE POULET DINS L'OEUF. 245

Le ventricule du cœur est unique durant les quatre premiers jours de l'incubation ; il est blanc, il est incolore et transparent, mais pourtant déjà musculeux loi'squ'il commence à paraître. Il devient pointu dès la soixante-sixième heure: sa forme générale est celle d'un rein. Vers la cent quarante-quatrième heure, c'est-à-dire au sixième jour révolu, on aperçoit les rudimens d'un deuxième ventricule; c'est d'abord une sorte de tubérosité cachée presque entièrement par l'origine de l'artère aorte. Cette petite masse est de forme ovale; elle est placée en travers, au-dessus de l'autre ventricule, et beaucoup plus courte que lui. Rien ne change pour le premier ventricule déjà formé; le nouveau se place à sa droile, demeure toujours plus court, plus faible que lui, et ne parlicipe nullement à la formation de la pointe du cœur. En un mot, cette dernière cavité du cour est ce qu'on nomme le ventricule droit: Malpighi a erré en disant le contraire. Lorsque le cour du poulet est ainsi composé, alors il paraît contenir deux gouttelettes dé sang, isolées l'une de l'autre par une liggne blanche ou incolore.

Le cœur du poulet est formé dès sa première apparition par une autre partie dont je n'ai pas encore farlé, et à laquelle Haller donnait le nom de canat auriculaire. On ne connaît pas bien l'usage de cette partie accessoire, qui n'a d'ailleurs qu'une existence temporaire. EHle disparaît en effet vers le sixième jour, ou plutôt elle se confond avec le reste du cœur, à l'endroit même où ses différentes cavités s'unissent. Cette sorte de canal reste incolore jusqu'à sa disparition. Mais pourquoi se raccourcit-il à mesure que le resle 
246 Liv. III. DE L'ACCROIBSEMENT DES CORPS VIVANS.

du cœur prend de l'accroissement? Serait-il un instrument, un moyen d'union entre les oreillettes et les ventricules? Les accolerait-il intimement l'un à l'autre comme un étau, en se resserrant et se concentrant? Enfin, pourquoi reste-t-il blanc, alors même que les cavités du cœur sont rouges? Toujours est-il que le creur du poulet a, dès la fin du sixième jour, toute la perfection dont il est susceptible.

Aorte. On voit l'artèrc aorte aussi tôt que le premier ventricule, sans qu'on sache bien si elle lui préexiste. Haller réprimąnde doucement Malpighi pour avoir regardé l'origine dilatée de l'aorte comme étant le ventricule gauche. Au - dessous du bulbe d'origine de celte grosse arlère on aperçoit les racines bientôt unies et concentrées de l'aorte dorsale : ce bulbe lui-même disparaît totalement vers la fin du sixième jour. Alors, dit Haller, l'aorte paraît divisée en trois branches. On ne voit pas à cette heure de battemens dans les trois divisions de l'aorte; mais les pulsations sont manifestes dans les artères ombilicales, et ce pouls est très-rapide dans un fœetus resté intact et bien vivant. L'artère pulmonaire, qui est àpeu-près du même volume que l'aorte, se divise en deux branches, envoyant l'une et l'autre une grosse division au poumon correspondant; mais ces deux branches de l'artère pulmonaire fournissent chacune un rameau très-volumineux à chacun des deux troncs de l'aorte dorsale, et l'on distingue ces deux divisions artérielles d'après leur cours, c'est-à-dire en canal artériel droit, et canal artériel gauche. Ce dernier vaisseau est analogue au canal artériel des quadrupèdes èl de l'homme, l'autre est particulier aux oi- 
CHAP. I. VIE ET PROGRÈS DU POULET DAXS L'UEVI. 247 seaux, et il est le premier à s'oblitérer; il commence déjà à-s'épaissir et à se fẹrmer par le bout supérieur dès le premier jour de l'éclosion, et il n'en reste plus aucun vestige quarante jours après la naissance du poulet. L'oblitération du canal artériel gauche suit de près celle de l'autre canal.

Nous avon's dit que dès le sixième jour la structure du cœur est aussi parfaite qu'elle le sera jamais. Dès lors, les quatre carités sont formées el distinctes, le canal auriculaire qui occupait lintervalle des deux oreillettes, ce canal, qui peul-être est le premier rudiment du cœur, disparaît en se confondant avec le reste de l'organe un peu avant la cent cinquantième heure; alors aussi les deux grosses artères qui naissent des veptricules sont très-évidentes, et c'est à la même époque que le coeur devient perpendiculaire; mais en vertu de quelle affinité tant de parties s'unissent-elles? quelle est l'intelligence qui produit avec une telle constance un aggrégat aussi bien coor-। donné? quelle est la puissance qui rend cette succession de parties si régulière, et le jeu de ce merveilleux assemblage si concordant? C'est là ce qu'on ignore, et précisément voilà le motif, mais aussi l'écueil de tant de systèmes différens. Mais revenons aux organes et à leur première apparition.

Poumors. Nous avons dit qu'on apercevait les poumons vers la cent trente-huitième heure; ils ont alors une longueur d'environ une ligne, et leur transparence est la cause qui empêche de les distinguer plus tôt. Haller a plusieurs fois augmenté leur consistance el leur capacité en projetant sur eux un peu de vinaigre. Le développement ultérieur de ces organes 
24 LIV. III. DE L'ACGROISSEMHNT DES CORPS VIVANS.

est extrêmement rapide; ils rougissent en même temps qu'ils s'accroîssent. Nous avons dit à quelle époque les parois solides et charnues de la poitrine les enveloppent, et à quelle autre heure ils adhèrent à ces parois. Il est remarquable que le poumon du poulet se précipite toujours au fond de l'eau, alors même que le petit animal a déjà piaulé dans sa coque; mais il surnage constamment dans un poulet éclos, qui a respiré l'air libre.

Fork. Le foie est visible à la fin du quatrième jour, c'est-à-dire deux jours après le ventricule gauche du cœur, et plus de quarånte heures avant la première apparition des poumons. Ses lobes ne sont bien dessinćs que vers le sixième jour : l'estomac est embrassé par eux, et la pointe du cœur, à l'époque dont nous parlons, est reçue dans leur intervalle. Cet organe est d'un beau jaune le dix-neuvième jour, mais il est quelquefois vert deux jours auparavant. La vésicule biliaire esi bien apparente vers le huitième jour. Tout le temps qu'elle reste blanche ou transparente, la bile n'est point amère; elle verdit le dixième jour, et quatre jours plus tard elle prend de l'amertume.

Estomag et Organes migestifs. L'estomac date àpeu-près de la même heure que le poumon; je veux dire qu'on en voit les premières ébauches vers la cent trente-huitième heure. Au dixième jour, environ, on trouve pour la première fois, dans la cavilé de l'estomac et celle de l'œsophage, un caillé blanc, ordinairement mêlé de bile. Quelques personnes ont pensé, entr'autres Haller, que ce pouvait être un résidu des eaux de l'amnios que le poulet, suppose-t-on, aurait avalées; et l'on ajoute qu'il est fort possible 
CIAP. I. VIE ET PROGRÈS DU POULET DANS L'UEUF. 249 que celte amnios soustraite soit remplacée par l'albumen de l'œuf, lequel effectivement diminue, quelle qu'en soit la cause. Le conduit digestif, ainsi que nous l'avons dit, commence à paraître vers le cinquième jour. Nơus savons déjà quelles sont ses connivences avec le pédicule du jaune de l'œuf, et cominent le péritoine se continue doublement avec les tuniques de ce vitellus : Haller va jusqu’à prétendre que ce prolongement $\mathrm{du} \mathrm{j}$ aune contient des valvules, absolument comme l'intestin auquel il s'unit. Le conduit digestif entier ne contient, jusqu'à l'éclosion de l'animal, que des glaires filantes, ou quelquefois aussi des grumeaux verts : la matière, comme calcaire, que nous avons indiquée dans l'œesophage et dans l'estomac, n'occupe l'intestin qu'après l'éclosion du poulet. La vessie existe d'abord isolée de l'intestin; en insufflant l'allantoïde, on voit cette vessie se gonfler tout près du rectum; mais elle finit par se confondre avec ce dernier organe pour former le cloaque, triple cavité formant le terme commun des organes génitaux, urinaires et digestifs.

Moelle ḱpiatèn (1). Malpighi en a découvert łes premières traces dès la quinzième heure de l'incubation : Serres ne les a pu apercevoir qu'au bout de vingt heures. Cetle moelle était alors composée de deux cordons extrêmement déliés, divisés dans toute lcur étendue; mais dès la trente-sixième heure, ces deux cordons étaient partout réunis, excepté dans la région du sacrup. Il n'y a aucun renflement visible jusqu'ạ septième jour; mais alors, on aperçoit le renflement inférieur, et, le jour suivant, le renflement su-

(1) Voyez 'Tiedemann, Pander, et surtout Scrres. 
périeur. Ces petites tubérosités de la moelle épinière correspondent aux membres de l'animal, et'leur paraissent destinées; mais ces membres les devancent de quelques heures. On observe que c'est le renflement inférieur qui est le plus gros jusqu'à l'époque de la naissance, et qu'il reste, jusque-là, divisé en deux parlies. Il résulte de ce que nous venons de dire, que la moelle épinière existe manifestement plus de vingt heures avant que les mouvemens du cœur ne soient apparens. Nous voyons aussi, par l'époque où cetle moellé est visible, et surtout par sa bifurcation originaire, combien sont vaines les hypothèses de ceux qui font provenir cette moelle d'un des animalcules de la semence, et qui ensuite font naître le cour de la moells épinière, et du cœur tous les autres organes.

Le Cerveau. De la trentième à la trente-sixième heure, on voit paraître les trois vésicules cérébrales, premiers rudimens des trois divisions principales et originaires du cerveau. La vésicule antérieure correspond aux lobes antérieurs, ou cerveau proprement dit; la plus apparente et la première formée de ces vếsicules représente les lobes postérieurs ou opliques (tubercules quadrijumaux); enfin, la troisième vésicule est l'origine de la moelle allongée : le cervelet se montre plus tard.

Vers la quarantième heure, la tête est volumineuse comparativement à la masse du corps entier: cela dépend de l'augmentation des vésicules cérébrales, toutes remplies alors d'un liquide incolore. Le quatrième jour, la tête grossit beaucoup; elle forme à elie seule le tiers de l'embryon. C'est de ce moment que date la séparation médiane des vésicules cérébrales, car, jusque-là, elles composaient une 
CHAP. I. VIE ET PROGRÈS DU POLLET DANS L'OUY. 25 I masse informe partout continue. Jusqu'au septième jour, la vésicule des lobes optiques est beaucoup plus volumineuse que celle des lobes antérieurs; puis elles deviennent presque égales du seplième au huilième jour; mais, à partir du dixième, les lobes antérieurs l'emportent définitivement paur toujours, et de plus en plus, sur les lobes optiques on quadrijumeaux.

Le cervelet ne paraît que du cinquième au sixième jour; il semble provenir des parties latérales de la moelle allongée, et est d'abord tout simplement composé de deux lames minces, séparées l'une de l'autre par un assez grand intervalle, et recouvertes à cette prenière époque par les lobes optiques, alors trèsvolumineux : ces derniers, en effet, composent à eux seuls, le sixième jour, la moitié de la masse cúrébrale, c'est-à-dire plus de la quarantième partie de la tolalité de l'embryon.

Le neuvième jour, les lobes optiques se sillonnent à leur surface, et ils se doublent ou plutôt se divisent. Ils ne formaient jusquà celte heure que deux éminences, maintenant ils en forment quatre, et, pour la première fois, ils méritent le surnom de tubercules quadrijumeaux; mais les deux éminences anlérieures ont seules beaucoup de volume; les postérieures sont excessivement petites en comparairaison des autres.

Bientôt toutes les parties du cerveau se réunissent vers leur milieu, et le raphé de séparation disparaît. Cette jonction médiane des parties latérales a lieu vers le dixième jour pour le cervelet. Au quatorzième jour, les feuillets ou lames de ce dernier organe se 
252 LIV. III. DB L'ACGROISSLMENT DES CORPS vivANS. multiplient : mais les changemens les plus remarquables du cerveau du poulet, c'est la concentration de toutes ses parties, et l'espèce de bascule qu'éprouvent, en se rapprochant l'un de l'autre, le cervelet et le cerveau proprement dit. Cette révolution singulière, qui intervertit tous les rapports jusque-là existans entre les organes cérébraux, a lieu du quinzième au dix-neuvième jour de l'incubation, et voici de quelle manière. Le cervelet se porte en avant et un peu en haut, en même temps les lobes optiques s'écarlent et se dépriment pour leur faire place; le cerveau, de son côté, se porte en haut et un peu en arrière, de manière à se rapprocher du cervelet; et comme, en outre, ces deux organes prennent du volume, tandis que les lobes optiques restent àpeu-près stationnaires, il en résulte que ces derniers lobes, qui dans les premières heures de l'incubation étaient placés au sommet et au centre de la masse cérébrale, sont finalement surmontés et recouverts par le cervelet et les lobes antérieurs, et qu'ils ne laissent plus voir latéralement que la portion la plus excentrique de leurs lobes que ne peut recouvrir le cerveau. Enfin ce changement est si remarquable, qu'on pourrait croire que les lobes optiques sont nouvellement sur-ajoutés, tant ils ressemblent peu à ce qu'on les voyait les premiers jours de leur production. On ne trouve guère de glande pinéale que le vingtième jour.

La consistance du cerveau éprouve aussi beaucoup de changemens : toute la masse en reste fluide ordinairement jusqu'au huitième ou neuvième jour; elle devient comme gélatineuse le douzième : jusque-là le cerveau surnage dans l'eau et finit par s'y dis- 
CILAP. 1. VIE ET PROGRÈS DU MULLET DANS L'EEUF. 253 soudre. Mais, vers le quinzième jour, sa consistance augmente, il se solidifie peu à peu, et alors il ne surnage ni ne se dissout plus. Quant à la coloration de sa sibstance, c'est surtout vers le douzième jour qu'elle se prononce pour ne plus changer : c'est alors que le cerveau et le cervelet deviennent grisâtres à leur surface. La blancheur extérieure des lobes optiques est sourent déjà manifeste un ou deux jours plus tôt (dixième jour ).

Enfin, le poids absolu ct proportionnel de l'encéphale varie aussi beaucoup : très-considérable vers le quatrième jour, comparativement à celui du reste du corps, il forme, le septième jour, la vingtième partie - du poids total de l'embryon, la quinzième parlie le neuviëme jour, la trente-unième le vingtième jour, et sculcment la quarante-sixième partie lors de l'éclosion du poulet.

Nerfs. Le premier nerf visible est l'oplique, on l'aperçoit du quatrième au cinquième jour : c'est àpeu-près l'époque où l'œil lui-même est déjà fort apparent. Après ce premier nerf on aperçoit successivement la troisième paire, vers le septième jour de l'incubation; la quatrième et la sixième päre, le huitième jour; la cinquième paire ou trifacial, le dixième; la septième et la huilième, c'est-à-dire le facial et l'auditif, vers le onzième ou douzième jour, etc. Ainsi les nerfs de l'œil sont formés les premiers, avant même ceux de l'orcille et de la face.

OEı. Les yeux restent long-temps d'une blancheur parfaite : ils ne deviennent apparens que Inrsque le noir de la choroide se forme et se rend lui-même évident, , ct cela n'arrive presque jamais avant la lin 
254 LIV. III. DE L'ACCROISSESLNT DES CUUPS VIVANS. du quatrième jour. Dès leur première apparition les yeux sont d'une grandeur disproportionnée, qu'on me permette ce mot, avec le reste du petit animal : ils forment à-peu-près la vingtième partie du poulet entier vers le septième jour, ce qui doit paraître étonnant. Il est vrai que huit jours après ils n'en forment plus que la trente-huitième partie, Haller l'assure; et à partir de ce moment ils restent à-peu-près stationnaires, tandis que le reste du corps prend de grands accroissemens. Au reste, l'œil du poulet doit principalement son grand volume au corps vitré, car le cristallin est toujours très-petit. La rétine est apparente le septième jour, à cause de l'augmentation du vernis noir qui revêt la choroïde subjacente : alors aussi apparaissent distinctement les vaisseaux ciliaires, et poúr la même raison : la zône ciliaire est déjà parfaite versle huitième jour. Quantà la membrane pupillaire, il paraît qu'il n'en existe point dans l'embryon des oiseaux; mais nous la trouverons dans les foetus des mamınifères. On peut aussi remarquer que les fibres circulaires et longitudinales de l'iris ne sont pas aussi discernables dans les oiseaux que dans les jeunes vivipares. Mais c'en est assez sur les organes essentiels du poulet, nous allons parler maintenant de seș parties accessoires, ou plutôt de ses dépendances, ainsi que de ses actes ou fonctions.

Membranes. On sait que la membrane de l'amnios est visible avant loute autre partie; on croit même que le petit follicule que Malpighi et Haller ant aperçu au dessous de la cicatricule est le premier indice de ce sac membraneux. Le développement de l'amnios est toujours concordant avec celui 
CHAP. I. VIR ET PROGKÈS DU POULET DANS L'OEUF. 255 de l'embryon, et son origine est contemporaine à ce dernier. Quant aux pellicules du vitellus, nous avons vu comment ils sont successivement rompus, et tout porte à croire qu'ils sont antérieurs à l'incubation : Haller et Bonnet ont pensé que la connexion de ces pellicules avec le péritoine préexistait à la fécondation même. Mais il en est autrement de l'allantoide, ainsi que des membranes chorion et moyenne de l'œuf : ces parties sont le produit de l'incubation. L'allantoïde est une production de la vessie de l'embryon; nous arons vu qu'elle șort du ventre du poulet vers'le quatrième jour, et que ce n'est que successivement et au bout de neuf à dix jours qu'elle environne tout l'œuf et qu'elle en revêt partout la coquille. C'est donc là une production certainement secondaire; je dis même chose des membranes, moyenne et chorion, qui ne sont que les feuillets isolés de l'allantoïde; je dis même chose aussi du fluide blanchâtre qui est contenu dans cette poche et qu'on a quelquefois confondu avec le blanc de l'veuf. Ainsi donc voilà plusieurs parties qui résultent à coup sûr de l'incubation et des premiers accroissements du poulet, bien loin de leur être antérieures.

Vaisseadx sanguins. Haller a vu dans l'ueuf, de la trente-sixième à la quarante-huitième heure de l'incubation, et Malpighi dès la douzième, un segment de cercle tacheté de points de couleur de rouille, c'est-à-dire d'un rouge obscur et rembruni : c'est là l'ébauche d'un réseau vasculaire. Ces premiers vaisseaux sont apparens à la surface du jaune, au gros bout de l'œuf, au voisinage de la cicatricule, et là où nous avons dit qu'il s'est formé un réservoir 
256 L.v. UI. DE I.'ACROISAFMYAT DFS CORPS VIVANS. d'air par le retrait des parties fluides de l'œuf: c'est à ce premier lacis de vaisseaux qu'on a donné le nom de figure veineuse: on n'aperçoit alors nul autre vaisseau dans toute la masse de l'œuf, et comme ceux dont nous venons de parler se bornent au vitellus et à se's tuniques, nous pouvons en conclure que ces premiers vaisseaux communiquent avec les misentériques, an nroyen du canal du jaune, soit qu'ils proviennent de ces mésentériques, ou qu'au contraire ils leur préexistent : il est du moins évident qu'ils ne sont ni l'origine directe, ni une dépendance des vaisseaux, ombilicaux. Et en effet, nous avons dit que ces dènniers vaisseaux accompagnent partout l'allantoïde et ses déployemens progressifs autour de l'ueuf, nous avons dit qu'ils ne sortent du ventre de l'embryon pour pénétrér dans la masse fluide de l'œuf, qu'au moment où l'allan par conséquent ces vaisseaux ne deviennent visibles que vers le quatrième ou cinquième jour, même on ne les peut voir d'abord que dans une fort petite étendue, et ce n'est que verśle neúvième ou dixième jour que tont l'œuf est entouré du superbe réseau formé par leurs ramifications, puisque ce n'est qu'à ce moment que le développement de l'allaritoïde est entièrement opéré. Or c'est en effet là ce qu'on observe. Il est clair qu'on ne peut plus apercevoir la figure veineuse du vitellus dès qu'une fois l'allantoïde a achevé d'environner l'œuf dans tous les sens; il est certain que le beaú réseau vasculaire qu'on voit alors, provient exclusivement des vaisseaux ombilicaux. Haller avait bien observé que l'injection sanguine de l'œuf est progressive et non pas simultanée; mais comme il 
GMAP. I. VIE ET PROGRES DU POUTE DANS X'OEUF. 25 j iguorait la loi .insi que la cause de ce progrès des vaisseaux, la description qu'il donne de cette espèce de phénomène est pleine d'obscurité. Haller avait bien vu que cette injection de l'ouf est parfaite vers le neuvième jour; et comme le cour est alors bien conformé depuis trois jours, comme aussi il voyait que la veine ombilicale n'avait de pulsations apparentes que vers ce même neuvième jour, ce judicieux physiologiste concluait de toutes ces choses que le cœur étai l'unique promoteur de tous ces changemens : il ignorait combien y participait le développement graduel de la membrane allantoïde; mais cette partic de la science est aussi évidente aujourd'hui que l'est la circulation du sang.

Fluides et humeurs. Nous ne reviendrons pas ici sur ce que nous avons dit du vitellus et de l'albumen de l'œuf, sur l'humeur de l'amnios et de l'allantoïde ( $V$ oy. chap. XII du liv. II ); nous devons seulement rappeler que l'allantö̈de est déjà remplie d'un fluide abondant qui la fait franchir l'ombilic de l'embryon, au moins trois jours ayant que les reins ne soient visibles. Voilà l'ordre à-peu-près dans lequel les humeurs du poulet se succèdent : le sang et ses premiers vaisseaux sont visibles au bout de moins de deux jours; peu après, l'humeur amnios est déjà appréciable; celle de l'allantoïde est abondante dès le quatrième jour, trois jours avant les reins; la bile ne s'amasse manifestement dans sa vésicule que vers le dixième jour; et le foie, qui la sécrète, est déjà apparent dès le quatrième. Ainsi, la présence du sang et le développenent des vaisseaux sanguins précède toutes les humeurs de l'embryon, comme le

I. 
cneur qui meut ce sang précède les autres organes. Ces organes ensuite précèdent leurs humeurs respectives; il n'y a que le liquide de l'allantoïde à quil'on ne peut découvrir de source apparente au moment de son origine; car, si cette humeur vient des reins, il faut donc que leur transparence les rende long-temps invisibles; mais est-il sûr qu'elle provienne des reins? Ici même se présente une question nouvelle, et c'est la plus embarrassante : toutes les humeurs venant du sang, aussi bi€n que les organes, le sang lui-même d'où provient-il? sont-ce les élémens de l'œuf qui en fournissent les matériaux? est-ce l'air amassé vers le gros bout de la coquille, et pénétrant à travers les porosités de cette coquille, qui rougit et renouvelle le sang? ou bien ce fluide vital est-il spontanément formé de toutes pièces? Enfin, l'embryon une fois accru, l'ouf ayant toujours le même volume, conserve-t-il exactement le même poids; en d'autres mots, les organes du nouvel être sont-ils seulement formés des matériaux préexistans dans l'œuf? Je ne sache pas qu'aucun physiologiste ait encore abordé cette question, et voici comment je la traite.

Premier principe. Le problème qui nous occupe actuellement est complexe; il suppose la solution préalable de plusieurs questions, et, d'abord, n'y at-il dans l'embryon du poulet que ce qui existait déjà dans l'œuf? Autrement, l'œuf conserve-t-il le même poirls vers le terme de l'incubation? On a pesé un œuf fécondé avant qu'il ne fût incubé; le poids en élait de dix gros. On a pesé comparativement ce même œuf après vingt jours d'incubation, au moment où le poulet allait bientôt éclore, et alors l'øuf 
CHAP. I. VIE TT PROGRÉS dU POLLET DANS L'EeUF. 259 entier pesait treize gros, et le poulet seul plus de cinq gros, e'est-à-dirè près de la moitié du poids total. Il suit de là que l'œuf a augmenté de trois gros duránt l'incubation. Or, comme l'embryon n'a de communication qu'avec l'œuf, au sęin duquel il se forme et s'accroît, on peut demander d'où provient celte augmentalion de poids et de matière. Il est bien vrai que l'air pénètre daus l'œuf à travers les porosités de la coque, il est vrai aussi que ce fluide remplit dès le commencement de l'incubation le vide qui se forme vers le gros bout de la coquille; on peut admeltre en conséquence que l'air absorbé par l'embryon a pu participer à cette augmentation du poids de l'œuf; mais comment croire que l'air absorbé ait pu à lui seul accroître la masse de l'œuf de trois gros dans le court espace de vingt-un jours? Bien qu'on n'ait entrepris aucune expérience, quon n'ait pas encore mesuré avec exactitude la quantité d'air que l'œuf absorbe ; malgré cette omission, disons-nous, il faut avouer qu'il paraît peu vraisemblable que lá quantité d'air consommé soit aussi énorme : par conséquent on pourrait croire. qu'il se produit quelque principe nouveau, et d'une manière lentement spontanée, pour l'organisation du jeune oiseau. Cependant, si l'on réfléchit que nous ne voyons rien se former dans l'univers qui n'ait ses élémens tout créés dans les choses préexistantes à son origine; si l’on rélléchit que ces ćlémens constitutifs de tous les corps sont dans des proportions constamment les mêmes, et que c'est à cette slabilité des élémens que tient l'harmonie perpétuelle et la durée de toutes choses; on en conclura qu'il 
260 LIV. III. DE L'ACCROISSEMENT DEs Corps vivans. ne se produit rien de nouveau dans l'œuf pour l'ac. croissement de l'embryon, et que cette augmentalion provient de l'air absorbé ou d'autres principes ignorés, mais réellement antérieurs au nouvel être. Il ne se forme donc aucune matière nouvelle dans l'œuf, et la masse ne s'en accroît qu'aux dépens de ce qu'il absorbe autour de lui. Mais d'où viennent les organes et les humeurs du jeune embryon? lequel est le premier formé des organes? lequel précède, ou du cœur ou du sang? C'est par des faits exacts, par des observations attentives, qu'il convient de résoudre de pareilles questions. Or, voici ce qu'on a bien vu et constaté : Haller a vu le cœur battre seulement vers quarante et quelques heures; d'autres observateurs ont aperçu les premiers rudimens de la moelle épinière avant la trentième heure de l'incubation; et plusieurs ont vu les premières apparences de vaisseaux, dans ce qu'on nomme figure veineuse, avant la vingtième heure, et Malpighi avant même la dix-neuvième. Il résulterait de là que la moclle épinière précède le cœur, mais que le-sang devance tout le reste. Quant au premier aspect des organes, ils sont tous primitivement à l'état fluide, ce n'est qu'insensiblement qu'ils se solidifient; et ce n'est pas une des choses les moins étonnantes de la formation du poulet, qu'une aussi grande diversité d'organes procèdent tous d'un fluide d'une apparence identique. Mais, si les parties solides de l'embryon ont un fluide commun et similaire pour première origine, il faut remarquer que les humeurs spéciales à leur tour proviennent des organes, et conséquemment leur succèdent, bien loin de les précéder : le foic 
CHAP. I. VIE LT PROGRiS DU POULET DANS L'OeUF. 261 précède la bile; les reins, les urines, etc.; et comme le sang lui-même précède toutes les parties, fluides ou solides, et qu'il paraît les former, on peut demander quelle en est la première source.

Origine du sang. Ce fluide, ainsi que nous l'avons dit, est le premier indice de la formation du nouve! être; il est la première chose apparente, et c'est par lui que tout le reste semble être formé : ce qu'est le sang pour un corps vivant accru, il l'est également pour l'origine, pour la première ébauche de chacun de ses organes; mais lui-même, d'où vient-il? Cette question paraît peu embarrassante pour l'embryou des vivipares; car, puisque le jeune être tient à sal mère, on trouve tout naturel d'admettre que le sang vienne d'elle à lui; on ne réfléchit pas que l'union des deux êtres, que l'adhérence de l'œuf avec la matrice, suppose une vie égale des deux parts, un concours de vaisseaux entre l'œuf et celle matrice; ainsi, la difficulté est donc la même pour les vivipares et pour les ovipares, et ce que nous allons dire ici pour ces deruiers êtres, aura des conséquences relativement. aux mammifères eux-mêmes.

Il faut se rappeler ce qu'étail l'œuf à sa première origine dans l'ovaire, et long-temps mêrne après sa première apparition sous la forme d'une vésicule bien distincte. Nous savons que celte vésicule tenait à l'ovaire dans la plus grande partie de son étendue, elle ávait les mêmes membranes, les mêmes vaisseaux que l'ovaire. Je parle des vaisseaux; car il est évident que tout organe participant à la vie de l'ensemble est toujours pourvu de vaisseaux, et cela est vrai de l'ovile des oiseaux plus que d'aucun autre ovule, puis- 
2032 LW. III. DE L'ACEROISABHENT DLS GORPS VIVANS.

qu'il acquiert un grand accroissement dans l'intéricur de l'animal, avant même d'avoir rompu ses adhérences avec la totalité de l'ovaire. Or, qu'arrivet-il lorsque cotte rupture a lieu? Il arrive que les vạisseaux nourriciers de l'ueuf se déchirent en même temps que son pédicule membraneux; par conséquent une extrémité de ces vaisseaux demeure dans l'ovaire, tandis que l'autre extrémité reste attachée et ramifiée dans l'œuf même. Le jaune de l'œuf a beau se revêtir ensuite des glaires de l'oviducte, qui en forment le blanc, et d'une coquille de plus en plus solide, on voit bien que les vaisseaux du vitellus continuent d'y rester, quoiqu'invisibles. Or, ce vitellus ou jaune a deux tuniques; je veux parler de la membrane propre de l'ovule primitif, et de la pellicule surajoutée du péritoine de la mère, et ces deux membranes contiennent, aussi bien que la cicatricule du vitellus, des ramifications des vaisseaux en question. Maintenant, lorsque l'ouff est soumis à l'incubation, la chaleur en dilate toutes les parties, les vaisseaux comme le reste, et il en résulte qu'au bout de quelque temps la surface du vitellus paraît injectée de sang et comme formée de vaisseaux. D'après cette simple, mais fidèle interprétation des faits, il est évident que les premièrs vaisseaux visibles dans l'œuf incubé ne sont qu'une dépendance de ceux de la mère, et que c'est encore le sang de cette mère qu'on voit circuler dans l'œuf les premiers jours de l'incubation. Il en est de même apparemment des vaisśeaux de la cicatricule et de l'origine de ceux de l'embryon. Ainsi donc, la première source des vaisseaux de l'œuf et de l'embryon cst dans l'ovaire même de l'oiseau femelle. 
CHAP. I. VIE ET PROGRES DL POLLET DANS L OELF. 2.53

Respiration. Ces premières goultelettes de sang, venant de la mère, s'accroissent bientôt, et par la portion d'air que les membranes du juune absorbent, et par les parties fluides et nutritives de l'œuf qui passent successivement dans les vaisseaux. Ainsi donc, il y a déjà respiration pour ce pelit être renfermé dans l'œuf, comme il y en aura plustard, lorsque le poulet sera éclos; mais ce ne sont pas les mêmes organes qui opèrent celte respiration à toutes les époques. lespremiers jours de l'incubation, l'air n'est encore alssorbé que par la partie des pellicules du vitellus qui sont voisines du vide situé au gros bout de la cocquille; et, à cause de cela, c'est en ce lieu que les premic:s vaisseaux sont rouges et apparens : mais plus tard, lorsque l'allantoïde esı déployéc, la respiration n'est plus opérée que par les vaisseaux ramifiés à la surface du feuillet extérieur de l'allantoide, je veux dire le chorion. Comme alors la surface du vitellus est de toutes parts séparée de la coquille, elle n'a plus avec l'air aucun contact possible, et elle reste en conséquence tout-à-fait étrangère à la respiration du jeune être ; et cela arrive à-peu-près du huitième au dixième jour. ( oy. Chap. XIII du liv. précédent.) Enfin, sur les derniers temps de l'incubation, le petit animal respire un peu d'air par ses propres poumons; il en respire, puisqu'il piaule; et cela ne peut avoir lieu que quand toutes les membranes divisant l'œuf en compartimens sont rompues. Ainsi, l'embryon du poulet respire, successivement par les membranes du jaune, par le feuillet extérieur de l'allantoide, et finalement aussi par le poumon, lequel, après l'éclosion, est l'organe respiratoire de toutc la vie. L'air vient donc au poulet, $1^{\circ}$. par 
26 LIV. HI. DE LACCROISSEHENT LRS CORP VIVANS.

le réservoir qui est au gros bout de la coquille; $2^{\circ}$. par les porosités naturelles de cette coquille. Il resterait à préciser quelle est la partie de l'air absorbée, et quelle quantité l'œuf en consomme durant toute l'incubation.

Colonation. Les couleurs de l'embryon sont successives, aussi bien que l'apparition de ses divers or-. ganes. La première ébauche du nouvel être a d'abord. la couleur du vitellus, au seịn duquel elle apparaît; ensuite, vers la quarantième heure, on voit de premiers vaisseaux couleur de rouille; à soixante-douze. heures environ, ces vaisseaux sont d'un beau rouge. Le noir de la choroïde se prononce vers le quatrième jour; le vert de la bile vers le dixième; après quoi cette bile devient bleuâtre à l'époque de l'éclosion. Ainsi; les différentes couleurs de l'embryon se succèdent à-peu-près dans cet ordre : le jaune, le rouge sale, le rosé, le noir, le vert, et le bleu. La bile est verte quatre jours avant d'être amère. Il faudrait rechercher avec quelles autres circonstances ces premiers changemens coïncident. Haller a tenté le problème sans le résoudre.

Mouvenfrss. On a vu battre le cœur du poulet dès quarante-huit heures d'incubation, c'est-à-dire près d'un jour après l'apparition de la moelle épinière; mais ce n'est qu'au bout de neuf jours qu'on a pu. voir des battemens dans la veine ombilicale. Ces pulsations sont très-rapides, très-fréquentes : on en a compté jusque par-delà cent quarante dans une minute. On remarque aussi qu'elles persistent longtemps encore après que la vie du jeune être s'est. très-aflaiblie : on les voit persévé rer durant quelques 
CHAP. I. VIS ET PROGRES DU POURET DANS L'EEUF. 26. minutes dans l'embryon d'un œuf qu'on a laissé plusieurs heures plongé dans l'eau froide. Il résulte de cette ténacité de Ja vie dans l'embryon des oiseaux, que les oufs peuvent être long-temps abandonnés des couveuses sans que cela préjudicie beaucoup aux jeunes animaux qui en doivent naître. Dans le poulet éclos, les cavités du cœur se contractent dans le même ordre que chez les mammifères : le ventricule. gauche cesse le premier d'agir et de palpiter, ensuite le ventricule droit, puis l'oreillette gauche, et c'est l'oreillette droite qui se meut la dernière. Haller a obsęrvé que, tant que le poulet est dans l'ouf, le ventricule droit se meut plus long-temps que l'oreillette; et cette différence est due à ce que la respiration n'existant pas encore, les poumons ne font aucun obstacle à la circulation alors établie. L'air, la chaleur, l'insufflation, raniment surtout les monvemens d'un cœur affaibli. Lorsque les quatre cavités du cœur se sont complétées et affrontées, alors clles battent deux par deux. On 'ne oit plus dès-lors les ventricules pâlir à chaque systole. On convient qu'on voit quelquefois, lorsque le jeune poulet est très-affaibli, les oreillettes, et les ventricules se contracter en même temps; mais alors aucun des comyartimens ne se vide. La circulation aussi semble quelquefois se faire à rebours, au moins pour deux cavités. Haller assure qu'il a vu la veine cave se contracter dans un poulet éclos; mais il n'a jamais va de mouvemens péristaltiques dans l'intestin ni dans l'es-. tomac de l'embryon renfermé dans l'œuf. Le poulet remue aussi le bec plusieurs jours avant l'incubation, soit pour avaler des eaux de l'amnios, soit pour as-. 
266 LIV. III. DE L'ACCROISSRMUTT DES GORPS VIVANS.

pirer un peu de l'air du réservoir et pour piauler, soit enfin pour déchirer les membranes et briser la coquille qui le tiennent emprisonné. Je dis qu'il respire, et cela est certain, puisqu'on l'entend piauler avant l'ouverture de l'ouf; mais il ne prend jamais assez d'air pour que scs poumons surnagent: cela n'arrive qu’après l'éclosion. Nouvelle analogie avec le fotus des mammifíres.

Nuthition. Le jaunc de l'ouf est la principalc source où le poulet puise sa nourriture; et nous avons vu par quelle voie directe ce jaune communique avec l'intestin de l'embryon. Une chose semble contredire l'usage que nous assignons au vitellus, c'est que cette partie fluide de l'œuf, au lieu de diminuer à mesure que le poulet prend de l'accroissement, loin de là semble augmenter de volume : mais il faut remarquer que le blanc ou albumen passe peu-à-peu dans ce vitellus pour réparer les déperditions qu'il éprouve, et l'on dit que ce passage a lieu par des vaisseaux que Haller a surnommés blancs, précisément parce qu'ils sont imperceptibles. Toujours est-il que l'albumen a complètement disparu à l'époque de l'éclosion du poulet; si l'on a quelquefois pensé le contraire, cela venait de l'erreur où l'on se laissait aller en prenant pour de l'albumen le fluide aqueux et souvent grumeleux qui est renfermé dans la cavité de l'allantoïle, une fois qu'elle est développée, c'est-à-dire après le dixième jour de l'incubation. Le poulet puise aussi. beaucoup dans le sang qui circule dans l'œuf et dans l'air de l'atmosphère ; on objecterait vainement à la proposition que j'énonce que le sang lui-même provient du poulet, el voici pourquoi : d'aliord, 
CHAY. I. VIE ET PROGRÈS DU POZLET DAYS L'OSLF. $2 \mathrm{CH}^{7}$ nous venons de voir ci-dessus que la première origine des vaisseaux de l'œuf émane de l'ovaire de la femelle; nous savons de plus que la masse lotale de l'œuf et de son embryon augmente de piusieurs gros pendant la durée de l'incubation; or, comine l'œuf ne pe:t s'accroìtre qu'aux dépens des tluides qui sont autour de lui, c'est priucipalement de l'air que vient cette angmentation totale, et l'air n'est employé qu'à faire du sang : ainsi, les rudimens de vaisseaux venus de l'ovaire de la mère, l'air ambiant qui se combine à ce sang pour en accrô̂tre la masse, le jaune qui se répand dans l'intestin et qui, une fois absorbé, va circuler dans les vaisseaux sanguins; rien de tout cela n'appartient en propre à l'embryon, et telle est la raison qui nous a fảit dire que le poulet s'accroît par le vitellus, par le sang, et nous devons ajouter par l'air, en conséquence de ce qui précède. Au reste, les bases une fois posées, rien ne parait plus naturel que ce que nous venons de dire : il est évident que ce poulet ne se forme pas de lui-même, tout le nouvel être est l'ouvrage de la nutrition, rien ne préexiste à son exercice; si ce n'est un germe prinitif, un type originel, dont l'arrangement ne parait point accessible à l'investigation des hommes.

\section{CHAPITRE II.}

Accroissement progressif des Reptiles et des Poissons.

Ne voulant pas nous exposer à des répétitions, nous the ferons mention, à l'occasion des ruptiles et des 
2?8 LIV. HI. DE L'ACCHOSSEMET DLS CORPS VIVANS.

poissons, que de ceux des phénomènes de l'accroissement qui leur sont particuliers. Nous ne parlerons. donc ni des progrès des organes, qui s'accroissent lans ces animaux comme nou's les avons vus s'accroître dans l'embryon des oiseaux; ni des progrès. du squelette, à cause de l'analogie que nous indiquerons plus loin entre tous les animaux vertébrés. Quant aux parties accessoires de l'œaf, nous savons déjà que la plupart de cess animaux n'ont ni d'allantoïde, ni de véritable cordon ombilical. ( $/$ oyez le Chap. XIII du livre précédent. ) Ils ont seulement une sorte de vitellus communiquant avec l'intestin, un sac rempli d'amnios, et c'est au sein de ce fluide que les embryons nagent, c'est là aussi que ceux d'entr'eux qui ont des branchies respirent : à l'entour de cette première cavité en est une deuxième, et celle dernière est remplie d'une sorte de mucus ou de glaires servant à la nutrition des jeunes animaux, à-peu-près comme l'albumen à l'égard des oiseaux. Il est évident que nous n'entendons parler dans ce moment que des poissons, et des reptiles à métamorphoses, ou batraciens; car les autres reptiles ont des œufs organisés à peu de chose près comme celui de la poule et des autres volatiles.

Examinons d'abord quelques-uns des changemens de l'embryon des reptiles batraciens durant les métamorphoses qu'il éprouve.

L'œuf de ce genre d'animaux est composé de deux. portions de sphère, l'une noire, l'autre blanche; en même temps il devient ovale, de rond qu'il était. On. convient assez généralement que la portion noire de cet cuf est composée des rudimens encore indiscer- 
nables du jeune animal : toutefois cet embryon n'est bien évident ( je parle surtout de celui de l'espèce grenouille; que vers le cinquième ou le sixième jour. Il paraît alors sous la forme de têtard : il est composé d'une grosse tête arrondie ou plutòt ovoïde, et d'une queue assez allongée. Ce jeune animal finit par sortir de l'œuf en rompant les membranes qui le retiennent ou l'enveloppent. La bouche de ce têtard est placée en dessous, vers le milieu de la grosse tête, ce qui oblige l'animal à se renverser sur le dos toutes les fois qu'il a besoin de prendre ou de rejeter quelque chose par la bouche. Quinze jours environ après la sortie de l'embryon, on voit paraître ses deux yeux vers le milieu de la tête; en même temps les pattes de derrière commencent à se montrer. Vers le trentième jour, les pattes de devant naissent à leur tour, et alors celles de derrière sont déjà achevées. Les branchies des têtards datent des premiers temps de son existence, et elles se développent de plus en plus dans la mesure de tout le corps. Enfin, au bout d'environ quatre-vingt-dix jours, le têtard se dépouille de sa peau, de ses branchies, etc., et l'on voit alors de vraies grenouilles à la place de ces premiers êtres si mal proportionnés et si difformes. La queue seule persiste encore quelque temps, à cause de sa solidité; mais bientôt elle disparaît entièrement.

On ne sait pas encore très-bien quels changemens éprouve le système vasculaire du têtard au moment de sa métamorphose (1); il y a même plusieurs autres

(1) L'Institut de France a mis trois années de suite celle question au concours et toujours sans résultat. 
9-0 LIF. III. DE L'ACCROISSTMTKT DIS CORPS VIVANS.

points d'orgyanogrénésie qui ne sont pas non plus parfaitement éclaircis; mais voilà ce qui arrive pour le système nerveux.

D'abord, nous devons dire que les premiers linéamens de ce système sont assez difficiles à apercevoir à raison du fond rembruni de l'œuf lui-mềme, car on sait que la substance de la moelle épinière est d'une teinte à-peu-près semblable. Cependant, vers le dixième jour on aperçoit la vésicule des tubercules quadrijumeaux : ce n'est qu'au bout d'une quinzaine de jours qu'on commence à voir les premiers rudimens de la moelle épinière et du cerveau proprement dit. Une chose remarquable, c'est que, contrairement à cette manifestation tardive de la moelle épinière, on voit se mouvoir les têtards dès le cinquième ou sixième jour de leur existence dans l'œuf. Or, il fant bien que dans un animal de l'ordre des verlébrés, il y ait quelque organe nerveux qui préside à ces mouveimens; et en effet, on a trouvé avant toute apparition de la moelle, les nerfs latéraux qu'on suppose émaner d'elle; et ce qui est fort curieux, ces rerfs avaient déjà des ganglions à celle de leurs extrémités qui avoisine le canal vertébral (1). Cela dut faire douter de l'origine centrale qu'on attribuait à ces nerfs, cela dut faire réfléchir sur le mode suivant lequel se développent les organes; et nous verrons qu'effectivement ce fait d'organisation se lie à une loi générale absolument ignorée des anciens anatomistes.

Les tubercules quadrijumeaux sont donc les pre-

(1) Voyez le bel ourrage sur l'Anatomie comparée du Cerveau Paris, Gabon. 
mières parties apparentes du système nerveux des reptiles batraciens : celte partie cóstégalement la plus évidente dans les premiers temps du poulet; on peut même remarquer qu'il y a analogie sous ce rapport entre le poulet de quarante heures d'incubation et le têiard de douze à quatorze jours. Ce développement des lobes optiques est d'ailleurs dans un accord assez parfait avec la prompte apparition des yeux des embryons de ces classes d'animaux. On remarque aussi que les cordons originairement divisés de la woelle épinière commencent à se réunir vers le dixhuilième jour de la vie du têtard. Vers la même époque, les tubercules quadrijumeaux offrent une rainure à leur centre, ce qui les rend dignes alors senlement de ce nom de quadrijumeaux; car, avant et après cctle époque, ces éminences sont doubles, mais non quadruples. Quant au cervelet, ses premiers rudimens n'apparaissent que vers le vingt-quatrième jour sous la forme de deur lames latérales aplaties. J'observe, en passant, que la formation tardive de cet organe semblerait annoncer qu'il n'exerce pas d'action bien importante relativement à la vie ellemême. Ces deux lames du cervelel restent séparées durant plisieurs jours, ensuite elles se réunissent sur la ligne mx́diane.

Plus tard, vers le soixanle-dixiome jour, la portion de moelle épinière renfermée dans la queue diminue, puis disparaît; celte atrophie s'arrête au renflement inférieur de la moelle épinière, lequel par cela même devient plus gros, à raison de la plus grande quanlité de sang dont il est imprégné. C'est vers le trentième jour que les différentes parties du 
cerveau ont la structure èt l'ensemble qu'elles auront toute la vie, mais elles n'ont pas encore tout leur accroissement : le système nervenx du têtard offre à-peu-près l'équivalent de ce qu'on voit dans les poulets de sept jours d'incubation. Il est remarquable que le cervelet ne fasse presque aucun progrès depuis le vingt-huitième jusqu'au cinquante-cinquième jour. Il demeure au reste toujours très-petit; seulement il éprouve, à partir de cette dernière époque, un léger prolongement pointu en árrière. Il ne faut done pas s'étonner de l'erreur que quelques personnes ont commise, de croiı: que les reptiles batraciens étaient absolument dépourvus de cervelet; tous ces reptiles ont cet organe, mais la plupart l'ont d'un volume extrêmement exigu.

A l'égard des poissons, nous avons dit, en parlant de leur mode de reproduction (Chap. IX du livre 1I), à peu-près tout ce que l'on sait sur l'accroissement progressif de leurs organes. Nous allons ajouter ici quelques délails touchant leur système nerveux; nous parlerons plus loin de leur squelette.

La masse cérébrale des poissons déjà accrus offre des formes et un volume analogues à ce qu'on voit dans les embryons très-jeunes des reptiles, des oiseaux et des mammifères : ce qui n'est qu'une ébauche imparfaite dans les êtres de ces dernières classes, forme l'état normal dans les poissons; l'âge adulte chez eux est l'enfance des autres. Leur cervelet est d'une petitesse excessive; il reste en outre toujours divisé en deux parties dans certains poissons de l'ordre des cartilagineux : leurs lobes opliques sont placés à la surface du cerveau, comme dans l'embryon des 
oiseaux, etc.; mais, en outre, ils ne sont qu'au nombre de deux; de plus, ils sont creux et resient toujours tels, encore comme dansles embryons des autres classes. Et la preuve que malgréla différence de leur aspect et de leur volume dans les diverses classes d'animaux, la preuve, dis-je, que ce sont des organes de même nature, c'est l'insertion des nerf's qui la fournit. On retrouve aussi, dans le cerveau des poissons, l'analogue des lobes antérieurs, mais beaucoup moins volumineux que dans les individus parfaits des autres classes des vertébrés. D’ailleurs on en voit provenir le nerf olfactif, ce qui détruit toute incertitude dans la détermination de ces organes.

Outre le cervelet; outre les tubercules quadrijumeaux, qui ne sont ici que bijumeaux dans tous les temps; enfin, outre les lobes cérébraux, d'où l'on voit sortir les nerfs olfactifs, il y a de plus dans le cervelet des poissons une quatrième paire de lobes, que M. Serres, entr'autres anatomistes, regarde comme l'équival ent des corps optiques; c'est-à-dire, qu'aulieu d'être enfoncés dansla substance des lobescérébraux, comme chez les mammifères, ces corps sont détachés, isolés du reste, et forment des lobes indépendans. On fonde cette détermination presque uniquement d'après la situation de la glande pinéale : il devait en effet paraître fort extraordinaire que les lobes destinés à l'olfaction eussent un volume si énorme, précisément chez des êtres qui vivent dans un milieu où les odeurs ne sont pas transmissibles. J'ajoute, toutefois, que de forts habiles anatomistes u'ont pu trouver la glande pinéale dans beaucoup de poissons, ce qui doit nuire à l'impor- 
274 LIV. III. DE L'ACCROISSEMENT DES CORPS VIVANS.

tance qu'on lui accorde comme organe régulateur: cela soit dit, au reste, sans aucune idée de défaveur relativement à l'ouvrage de $\mathbf{M}$. Serres, qui est à mes yeux, aussi bien que l'ouvrage de M. Geoffroy St.Hilaire, l'un des traités les plus estimables de l'époque où nous vivons.

\section{CHAPITRE III.}

Accroissemens progressifs de l'Embryon de l'Homme et des Mammifères.

Il ne faut pas s'attendre à trouver, sur l'accroissement des mammifères, autant d'exactitude et de précision que nous en avons mis en faisant l'histoire de l'embryon des oiseaux : tant de détails seraient ici mensongers. Il n'est pas possible d'observer heure par heure, ni même jour par jour, les progrès de la gestation des vivipares, comme on le fait pour l'incubation des ovipares; outre que les faits de ce genre, comparés d'un mammifère à l'autre, n'ont pas des circonstances entièrement semblables, comme ils en ont pour la classe des oiseaux. D'ailleurs, quel a été le mammifère le plus observé sous ce rapport? Il est certain que c'estl'homme; et précisément son incontinence ordinaire, les raisons morales de décence et de pudeur, qui lui prescrivent des réticences ou des mensonges touchant les actes par lesquels il se procrée, cette noble retenue de l'homme et ce respect de lui-même, qui le portent à garder un profond 
CHAP. III. IMBRYON DE L'HOHIE, ETC.

inystère sur ses voluptés; ce sont là les motifs qui empêchent presque toujours d'assigner une époque précise à la fécondation dans notre espèce, et de là vient l'incertitude des observations dont l'accroissement progressif du fotus a été l'objet. Souvent done on s'est trompé d'époque; et d'ailleurs, l'influence du climat, la saison de l'année, l'âge, l'état si changeant de la santé, les maladies, les passions, toutes ces choses et beaucoup d'autres exercent un grand empire sur l'accroissement du nouvel être.

Convaincu donc de la réalité de toutes ces causes d'erreur, nous ne ferons d'abord aucun système; nous omettrons les observations contradictoires de beaucoup d'auteurs; nous choisirons parmi elles, pour les joindre à ce que nous avons vu nous-mêmes, les faits les mieux avérés; et, sans d'abord nous inquiéter de leur enchainement ou de leur théorie commune, peut-être verrons-nous plus tard vers quels principes ils conduisent ( 1 ).

Nous disons que l'époque précise de la première apparition du fotus n'est pas très-bien connue. Haller n'a pu trouver d'embryon dans l'ovule de la brebis avant le dix-neuvième jour; Harvey n'a rien vu de plus précoce dans les biches; mais Home a constaté les premiers rudimens d'un embryon dans un œuf humain de huit jours. Il est vrai que notre espèce est celle où les observations de cette nature ont le moins de précision : il est sûr, d'ailleurs, que les préjugés ou les systèmes dont chaque auteur est préoccupé, exercent, même à

(1) Voyez Iarvey, Haller, Wolff, Bichat, Meckel, Pander, Chaus. sier, Ticdemann, Béclard, Serres, Okeń, Baudelocque, cte. 
2-6 Liv. III. DE L'ACGroissenient DES CORPS vivaNs. son insu, beaucoup d'influence sur les faits qu'il observe et qu'il raconte. Sans donc attacher trop d'importance à ce qui concerne les premiers temps de l'embryon des mammifères, voici les documens qui paraissent les plus avérés. Je répète que nous parlerons principalement du fotus humain dans l'ensemble de ce chapitre.

A sa première apparition dans l'espèce d'œuf qui le renferme, l'embryon n'offre aucun organe, aucune partie distincte. La petite masse qu'on aperçoit pour la première fois vers le vingtième jour, paraît homogène en toutes ses parties. C'est comme un ver à l'état muqueux, sans aucune ouverture visible, ayant trois à quatre lignes d'étendue, et privé de mouvement. On ne peut pas encore juger si ce petit embryon tient à l'œuf, s'il correspond particulièrement à un point précis de ses membranes, ou si cette masse informe et presque imperceptible naît tout simplement au sein de l'amnios, sans connexion avec les enveloppes de ce liquide. Toujours est-il qu'il n'y a rien encore d'appréciable, rien qui indique une tête, des yeux ou des nembres. A ce premier âge, tout est blanc, tout est fluide, tout paraît homogène et non organisé; et dès que les organes paraissent, tout est d'abord symétrique. Haller a trouvé l'œuf de la brebis adhérent à la matrice dès le vingt-denxième jour de la gestation.

L'homme est, de tous les animaux, celui qui a les progrès les plus rapides dans ses premiers commencemens. L'embryon de trente jours a la grosseur d'une fourmi ; il est long d'environ six lignes, il pèse une vingtaine de grains. La tête, qui était d'abord 
représentée par une simple saillie séparée du reste par une sorte d'échancrure, devient alors évidente. Il n'y avait d'abord aucun vestige de membres; mais alors apparaissent les bourgeons d'origine des supérieurs; les autres viennent plus tard. Les yeux sont représentés par deux points noirs, au-devant desquels on voit les premiers vestiges des paupières, alors transparentes. Les oreilles ne sont encore que deux pores déliés mais évidens, sans accompagnement mucilagineux d'aucune espéce. La bouche n'offre alors qu'une étroite ouverture béante, ouverture horizontale et sans lèvres. On ne voit pas encore de placenta; mais déjà la vésicule ombilicale et de très-petits vaisseaux omphalo-mésentériques, déjà l'aorte, et le canal artériel allant de l'artère pulmonaire à l'aorte, sont évidens; aussi bien que le canal originaire du cour, et l'œsophage. On remarque, dès cetle époque, un point d'ossification à la clavicule et à la mâchoire inférieure, parties destinées à entrer en action simullanément et dans un but pareil. Les côtes existent, mais à l'état cartilagineux. Le cerveau et la moelle épinière n'apparaissent encore que sous la forme d'un liquide grisâtre; et pourtant les nerfs latéraux du tronc et de la tête sont déjà appréciables. Le contact de quelques gouttes d'alcohol avec le fluide de la moelle épinière, y rend dès-lors évidente la.substance médullaire dont se composeront plus tard ses cordons latéraux, mais seulement à la surface du liquide.

A quarante jours, l'œuf humain offre à-peu-près le même volume que celui de la poule, ct alors le petit eubryon a la grosseur d'une mouche à miel : c'est de 


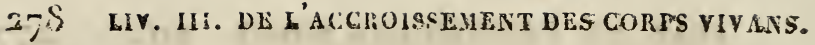

même alors que le placenta commence à devenir visible. On dit que les embryons femelles sont plus. lents à s'accroître, et que les accouchemens tardifs sont ordinairement pour les enfans de ce sexe. Aristote observe à ce sujet que c'est le contraire après la naissance; c'est-à-dire que les filles se développent plus rapidement que les garçons, grandissent et vieillissent plus vite. Du quarantiène au soixantième jour, on aperçoit les divers compartimens des membres, le bras, l'avant-bras et la main ; les choses sont pareilles. pour les autres membres : alors commencent à s'ossifier la plupart des carlilages devant plus tard composer des os. A cette époque le cordon ombilical a beaucoup de volume; il égale le fœtus, si même il ne le surpasse; el dès que ce cordon est visible, une portion de l'e xabryon courbé en devant, et conformé comme une sorte de queue, le dépasse inférieurement.

Au deuxième mois et durant son cours, la longueur de l'embryon est au moins de denx pouces; les oreilles et le nez sont fermés par des membranes. La tête est alors très-grosse à proportion du reste $\mathrm{d} u$ corps, elle forme à elle seule presque moitié de tout l'embryon : mais la face est pour bien peu de chose dans ce volume. Le tronc est courbé en devant à ses. deux extrémités, et le menton appuie sur la poitrine. Jusqu'à la fin du deuxième mois le cau très-gros ne se distingue pas du reste; cette sorte d'isthme est aussi.large que les deux régions qu'elle unit; et cette circonstance fait ressembler l'embryon de cet âge au corps accompli et permanent des poissons. A la même époque, les membres inférieurs dépassent sensiblement l'espèce de queuc formée par le coccix ; les lé- 
vres apparaissent, il y a des alvéoles évidentes aux mâchoires, du méconium blạchâtre dans l'estomac, et l'on voit déjà une espèce de peau recouvrir tout le corps; mais cette pcau n'a pas encore de fibres manifestes. Les membres supérieurs sont alors très-rapprochés de la tête; les autres sont à l'extrémité du tronc, et cela donne à l'embryon une assez grande ressemblance avec ce qu'on voit dans les phoques. La main et le pied sont appréciables environ une semaine avant les bras et les cuisses. Les doigts ne deviennent bien distincts que lorsque le reste du membre est formé: car jusques-là ils restent liés entr'eux par des membranes qui n'en forment qu'une masse unique, et ce n'est qu'après le deuxième mois que ces liens membraneux disparaissent, en commençant par l'extrémité des doigts. Les membres supérieurs, nés les premiers, restent long-temps les plus longs; ce n'est guère qu'a quatre mois et demi de grestation que les membres deviennent égaux, encore faut-il comprendre la longueur du pied dans cette évaluation de l'étendue totale. An troisième mois, vers la onzième somaine, les paupières sont closes; et comme elles sont opaques, elles cachent les yeux absolument; de serte que l'oil de l'embryon est beaucoup plus facileà voir vers le deuxième mois qu'au troisième. Alors les parties cartilagineuses dont se compose la conque de l'oreille commencent à paraître : celte origine date même quelquefois du mois précédent ; mais l'achèvement de la conque n'est parfait que dans le quatrième. Le fotus à cette époque a près de six pouces; la tête est fort saillante, la membrane pupillaire est déjà bien formée, facile.à trouver, et la matic̀re cé- 


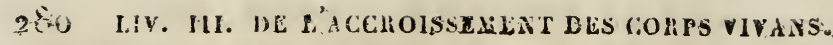

rébrale n'est plus entièrement fluide. Le placenta est très-bien formé, mais la vésicule ombilicale n'existe. déjà plus; il n'y a encore, dans le cours du troisième mois, ni duvet à la peau, ni ongles aux doigts, ni sinus dans les os de la face, ni occlusion des lèvres. Le fœtus alors a son point médian bien audessus de l'ombilic; mais à mesure qu'il avance en âge et qu'il s'accroît, la moitié de l'étendue de tout son corps se rapproche de plus en plus de l'insertion du cordon; de sorte que l'ombilic, qui était tout près de la partie inférieure du foetus dansles premiers mois, indique le milieu de ce corps dans un foetus à terme. Les organes génitaux externes paraissent déjà vers la quinzième semaine.

Le quatrième mois, les bourses sont vides, mais déjà évidentes; le clitoris et le pénis, selon le sexe, sont manifestes : le clitoris est quelcquefois tellement saillant, que cela peut donner lieu à des méprises touchant le sexe du foetus. Dans le cours de ce mois, la vulve devicnt évidente; les lèvres de la bouche, plus accrues, s'unissent; les fontanelles sont très-larges; le foic a in volume proportionnellement excessif, et les reins sont composés de quinze à dix-huit lobes distincts. On remarque que le fæetus prend subitement plus de volume à l'époque où la vésicule ombilicale disparaît, probablement par la même raison que le ventre de l'oiseau s'amincit le jour où l'allantoide en sort.

Au cinquième mois, les cheveux et les ongles apparaissent, le sternum commence à s'ossifier, le méconium gagne l'intestin grêle, le colon prend des. bosselures; et les testicules sont placés au-dessoụs, 
CHAP. IIJ. EABRYON DE L'HOHME, ETC.

mais près des reins. Dans le cours du sixième mois, fa longueur du fotus est d'environ douze pouces ; c'est. seulement alors que la peau prend un aspect fibreux, qu'elle devient rosée et se recouvre d'une sorte de duvet, et que les ongles sont assez solides pour devenir appréciables. La bile est encore séreuse, incolore, insipide, c'est-á-dire qu'elle n'a aucune des qualités qui la caractérisent plus tard. Le méconium parvient à cette époque jusqu'au cœcum, et les reins ont poụ la première fois autour d'eux ce qu'on nomme leur substance corticale. Le mois suivant, vers sa fin, les paupières deviennent libres; la membrane pupillaireg se déchire et laisse ains la prunelle de l'œil ouverte ; les testicules descendent peu-à-peu vers les bourses: c'est aussi pour la première fois qu'on trouve des valyules conniventes dans lès petits intestins. A huit mois, la peau commence à se recouvrir d'un enduit comme suiffeux; le cerveau, jusqu'alors lisse à sa surface, offre enfin des sillons et des éminences; les testicules occupent le scrotum.

A neuf mois, terme de la gestation, le fotus a ordinairement dix-huit pouces de long, et il pèse environ six livres : ses fontanelles sont rétrécies, son ombilic est piacé vers la moitié de sa longueur totale, et les cheveux sont longs d'environ un pouce. A cette époque, le tron de botal existe encore, les vaisseaux ombilicaux et le canai artériel sont librement perméables; le thymus est voluinineux; le fòie, alors très-gros, a son lobe gauche presque égal au lobe droit : la bile est amère, et les capsules surrénales sont très-évidentes. C'est à ces différens caractères qu'on juge si le foetus est venu à terme et depuis. 
282 LIV. HI. DE L'ACGROISSEHENT DES COLPS VIVANS.

quand il est né : la pesanteur spécifique de ses poumons témoigne s'il a respiré.

Nous avons évité de donner les mesures précises du foetus à ses 'différens âges, par la raison qu'elles sont sujettes à.varier, surtout pour les premiers mois. Quant à la dernière moitié de la gestation, voici la règle assez exacte qu'on a découverte : le foetus de quatre mois et demi a presque toujours neuf pouces de long; ensuite il augmente à-peu-près d'un pouce par chaque quinzaine, de deux pouces par mois; ce qui fait précisément la longueur totale de dix-huit pouces qu'ont la plupart des enfans nés à terine.

Chacun des organes, pris isolément, a de même ses progrès, ses accroissemens successifs, ses âges, ses révolutions; nous devons aussi exposer l'histoire rapide de ces différens changemens : mais nous ne nous arrêtons à ces détails minutieux que dans le but d'y puiser quelques principes, quelques lois générales. Nous passerons tout ce qui n'est qu'accessoire et sans conséquences.

Le tissu cèllulaire, dont l'embryon semble d'abord entièrement formé, n'est dans l'origine qu'une sorte de gelée; mais peu-à-peu il acquiert de la consistance. Il ne renferme point de graisse du tout pendant la première moitié de la gestation; ce n'est que vers l'âge de cinq mois qu'il commence à s'en accumuler sous la peau; et il n'en existe encore nulle autre part à l'époque de la naissance. Le tissu fibreux commence par être cellnlaire; il en est ainsi des autres tissus à l'époque de leur première origine. Il $n^{2} y$ a point d'exception pour les cartilages eux-mênes.

Les os ne sont d'abord que des cartilages. Ceux-ci 
ont une substance homogène, sans cavité ni vaisseaux visibles; ils sont d'ailleurs demi-transparens : mais à l'époque de leur transformation, ils se pénètrent peuà-peu de vaisseaux progressivement plus colorés, passant du blanc au jaune, du jaune au rouge; et dès-lors le cartilage perd sa transparence, il devient opaque, des sels terreux se déposent dans ses mailles, principalement du phosphate de chaux; enfin, ce n'est plus un cartilage, c'est une matière osseuse. Les os eux-mêmes, une fois dépouillés de leur substance terreuse, se changent en une espèce de cartilage que l'ébullition réduit à l'état de gélatine.

Nous avons dit que la peau, durant les premiers mois, ressemble à un enduit visqueux; elle reste mince, incolore et transparente jusqu'au cinquième mois : alors elle devient rosée surtout à la face, à la paume des mains et à la plante des pieds; peu-à-peu sa couleur devient plus foncée, sa consistance et son épaisseur plus grandes. Mais du huitième au neuvième mois, elle pâlit sensiblement, et elle ne reste colorée qu'au niveau des plis qu'offre sa surface. Les ongles ne paraissent que vers le cinquième mois, et ils n'ont beaucoup de consistance que verș la fin du sixième : c'est alors aussi que la peau se couvre de duvet et que les cheveux commencent à pousser. Un mois après, on voit paraître le vernis graisseux dont la peau du fuetus reste partout couverte. On sait aussi que les vaisseaux sanguins précèdent les glandes, que celles-ci sont d'abord composées de pelotons séparés, et que les muscles ne prennent leur couleur propre et leur caractère fibrcux que vers le milieu de la gestation : toutefois, ils sc contractent avant ce temps-là. Mais 
2S4 Lir. HI. DE L ACEROISSEMENT DES CORPS VIVANS.

parlons avec plus d'étendue des révolutions qu'éprouvent les organes essentiels du fotus.

Canal digestif. Les intestins sont d'abord ouverts dans toute leur paroi antérieure : insensiblement les parlies se resserrea , les bords correspondans se rapprochent par une puissance inconnue, et l'intestin. devient un canal partout continu. Tant qu'elle existe, la vésicule ombilicale tient à l'inlestin. Ce qu'on a dit les différentes portions isolées dont le conduit digestif serait originairement formé est loin d'ètre certain; seulement, il est digne de remarque que l'intestin se trouve d'abord entrainé vers la base du cordon ombilical, vraisemblablement par la vésicule du même. nom, qui lui est adhérente et qui s'élève alors vers. la cavité commune des membranes fotales.

L'intestin est d'autant plus court à proportion de tout le corps que le foetus est plus jeune; et c'est en outre l'intestin grêle qui est le moins développé. Ise. conduit intestinal n'a guère, dans l'origine, qu'une longueur égale à tout le corps. C'est vers le sixième mois que le gros et le petit intestin ont entr'eux les rapports qu'ils conserveront toujours; mais ce n'est: qu'à l'époque de la naissance que la masse intestinale et le corps entier sont dans des rapports nécessaires et constans pour toute la vie. L'intestin est proportionnellement plus large chez l'embryon, il est. de plus égal partout dans le premier âge; ce n'est que vers les derniers mois de la gestation que le gros intestin mérite son nom, par son ampleur accrue : les bosselures paraissent dès le cinquième mois, et les valvules conniventes le septième. La valvule du cocum est visible dès le troisième mois, et le pylore à quatre 
CHAP. III. EMBRYON DE L'HOMME, ETĆ.

mois et demi. L'estomac a d'abord une position verticale; ensuite il prend peu-à-peu la situation transversale qu'on lui voit chez l'adulte : le cœecum et le grand épiploon sont à-peu-près contemporains; je veux dire, qu'ils datent l'un et l'autre environ du deuxième mois.

Coedr et Vaissa aux sanguins. Les veines sont apparentes avant le cour et avant les artères : celle chose est vraie des oiseaux comme des mammifères. On aperçoit les veines du chorion à une époque où les artères sont encore invisibles. En ce qui louche la première origine des vaisseaux de l'œuf et de l'embryon, je ne répéterai pas ici ce que j'ai dit en parlan' de l'œuf des oiseaux : la première source de ces vaisseaux est dans l'ovaire de la mère; ce sont les vaisseaux ramifiés dans les pellicules de l'ovule qui fournissent le premier sang, ainsi que l'origine des vaisseaux de l'œuf et vraisemblablement aussi ceux de l'embryon. Quant aux nouveaux vaisseaux qui naissent des autres, dans les membranes, dans les tissus secondaires, on a remarqué qu'ils offrent trois différentes périodes de développement : d'abord, vésicules isolées, ils paraissent ensuite sous la forme de canaux creusés dans la substance organisée, et finalement ces-cavités acquièrent des parois distinctes, et forment de vrais vaisseaux comme ceux qui proviennent de l'ovaire. Voici, au reste, de quelle manière il faut concevoir le développement successif des vaisseaux : les fines et d'abord imperceptibles ramifications des membranes de l'ovule (détaché de l'ovaire) se dilatent et s'agrandissent par l’influence du fluide séminal, puissance inconnue dans son essence, mais évidente 
par ses effets; ces petits vaisseaux, émanés de l'ovaire, deviennent un moyen d'union enire l'ovule détaché et les parois contiguës de la matrice qui le renferme. Alors, le nouveau sang venu de la mère pénètre du tissu de l'utérus dans les membranes dú petit œuf; de là naissent, et la veine ombilicale, qui communique avec la veine-cave et par elle avec le cour, et les veines omphalo-mésentériques qui vont aboutir à la veine-porte. Toutefois, il faut observer que la veineporte est visible avant les veines-caves, et que le premier de ces vaisseaux existe seul à l'époque où le cœur commence à paraître. Il est fort vraisemblable que les fines ramifications provenant de l'ovaire de la mère frayent les premières traces, et sont l'origine primitive des vaisseaux de l'embrycn. Ensuite, c'est le cour qui donne le mouvement au fluide sanguin dont ces différens vaisseaux sont remplis.

Le Cœur de l'homme et des mammifères présente les révolutions que nous avons décrites pour celui des oiseaux : il paraît qu'à leur origine les deux ventricules communiquent ensemble, comme on voit communiquer les deux oreillettes jusqu’à la naissance; mais la séparation définitive des ventricules est plus hâtive que celle des oreillettes. Le volume du cœur est proportionnellement plus considérable dans l'embryon très-jeune : il remplit d'abord toute la poitrine du nouvel être. Dans le premier âge, le ventricule gauche existe seul; plus tard, lorsque le ventricule droit est formé, le gauche le surpasse en volume; alors aussi les oreillettes sont plus développées que les ventricules; mais vers le terme de la gestation, les ventricules l'emportent sur les orcil- 
CHAP. III. EMBRYON DE I'IIOHME, ETC.

leltes; les vontricules ersuite peu-à-pcu s'égalisent, et même le droit surpasse le gauche dès le septième mois de la gestation. L'aorte est le seul gros tronc artériel visible dans l'embryon; elle existe seule jusqu'à la septième semaine, et c'est alors que l'artère pulmonaire apparaît pour la première fois ; cette artère, alors dépourvue de branches, communique avec l'aorte au moyen d'un canal artériel unique. Les branches que l'artère pulmonaire envoie aux poumons ne sont apparentês qu'au deuxième mois révolu, et même chacune de ses branches, à l'époque de la naissance, ne fait qu'égaler le volume du canal artériel.

Poumons. On ne voit paraître les poumons que vers la sixième semaine; ils n'occupent alors que le bas de la poitrine, au-dessous du cœur, lequel leur est bien supérieur pour le volume. Ils sont blancs, ils sont aplatis, très-rapprochés l'un de l'autre, et leur surface est unie. Bientôt on les voit se diviser en lobes; ces lobes eux-mêmes sont granuleux, et la masse entière en paraît pleine et solide. Ils deviennent rosés vers le quatrième mois; et c'est encore l'aspect qu'ils ont à l'époque de la naissance.

Grandes. Le Foie, si volumineux dans le foetus, devient apparent dès la deuxième semaine : au bout de deux autres semaines il occupe tout l'abdomen, dont il fait même proéminer les parois encore peu résistantes. Il forme alors à lui seul près de la moitié du poids total du fœtus, tandis qu'à la naissance il n'en fait plus qu'à-peu-près le vinglième; cette diminution du foie commence vers le cent vingtième jour de la gestation. Ses deux lobes, le droit et le gauche, sont 
$2 S 8$ LIV. III. DE L'ACGROISSEMENT DES CORPS VIVANS.

alors presque égaux. Comme les intestins sont trèspeitits à cet âge, la face énorme du foie descend vers les parois de l'abdomen, au lieu de s'adosser au diaphragme comme elle le fait plus tard. A l'époque de la naissance, le foie descend encore jusqu'à l'ounbilic : mais il remonte ensuite peu-à-peu, et loin de continuer de s'accroître, on remarque qüil diminue pendant la première année de l'existence de l'enfant; et cette diminution porte principalement sur le lobe gauche. Cette glande reste presquè à l'état de fluide pendant le premier mois, et ce n'est guère qu'au cinquième qu'elle devient consistante. Sa vésicule apparaît dans le cours du quatrième, mais elle ne se remplit de bile que du septième au huitième mois.

La Rate n'est distincte que vers la fin du deuxième mois. La Thyroïde, alors proportionnellement plus grosse qu'elle ne l'est chez. l'adulte, est aussi plus molle et plus sanguine. Le Thymus n'est visible que dans le cours du quatrième mois; il s'accroît ensuite beaucoup jusqu'à la naissance. Après cela, on le voit croître encore durant les deux premières années; et c'est d'ordinaire vers douze ans qu'il disparaît totalement après avoir graduellement diminué. Quant à sa fonction, on l'ignore : peut-être sert-il de refuge au sang à une époque où le poumon, encore sans usage, ne s'en laisse que difficilement pénétrer. Les Mamelles sont très-appréciables dans le fotus à terme : elles contiennent alors un fluide comme laiteux. Les Capsules surrénales sont déjà distinctes dans le fatus de deux mois : elles augmentent jusqu'à la naissance, et après cela elles diminuent insensible- 
CHAP. III. EMBRYON DE L'HOMME, ETC. $\quad 289$ ment jusqu'à l'atrophie. Elles sont aussi volumineuses que les reins vers le troisième et le quatrième mois de la gestation.

Les Reins ont d'abord une forme irrégulière; de nombreux lobes très-distincts les composent, et le nombre de ces lobes diminue graduellement, à mesure que le fotus avance en âge : alors la surface des reins devient plus unie, leur substance plus serrée, plus compacte. C'est toujours en vèrtu de cette attraction dont nous avons cité tant d'autres effets, que s'opère cé rapprochement de parties originairement distinctes; mais ce n'est qu'à environ six mois queles lobes réunis des reins se recouvrent d'une substance rougeâtre dite corticale. Nous devons ajouter que les lobes des reins ne sont pas tellement réunis à l'époque de la naissance, qu'on n'en puisse encore distinguer de quinze à seize dans chacun de ces organes. La Vessie se confond encore avec l'ouraque vers la quatrième semaine; sa forme est alors fort allongée. L'Ouraque lui-même est très-visible dans le cordon, et on le voit se prolonger assez loin dans son intérieur; il communique etse confond même avec l'allantoïde dans les mamimifères; mais comıne cette dernière poche n'existe pas dans l'homme, on ne sait ni quelle est sa terminaison, ni quels sont ses usages. Ce conduit est si étroit à l'époque de la naissance, que quelques personnes ont prétendu qu'il était alors toujours oblitéré ; mais le contraire a été prouvé par des expériences exactes. J'ajoute que son canal est d'autant plus manifeste que le fœtus est plus jeune : la présence de l'ouraque chez l'homme est le seul motif qu'on puisse alléguer à l'appui de la supI. 
290 LIV. III. DE L'ACCROISSEMENT DES CORPS VIVANS. position qu'il y a originairement une allantoïde dans l'œuf humain.

Organes génitaux. Rien d'appréciable à ce sujet dans le premier âge de l'embryon, en dedans ni en dehors. Les organes internes se forment les premiers; les autres commencent par une petite proéminence divisée, fendue vers son milieu : c'est là l'origine de la vulve ou du scrotum, et l'un des obstacles à la distinction des sexes dans les très-jeunes embryons: Le petit tubercule qui indique le commencement du clitoris ou du pénis se montre vers le même temps, environ le quarante-cinquième jour. Le sexe du jeune être ne se prononce bien que vers trois mois et demi. Chaque testicule est d'abord placé, au moins les cinq premiers mois de la gestation, derrière le péritoine, au-dessous du rein et au-devant du psoas. C'est vers la fin du septième mois que les testicules descendent dans les bourses, et voici de quelle manière : le testicule, encore placé dans l'abdomen; tient en arrière et en bas à la partie supérieure d'une sorte de ligament à moitié composé de fibres musculeuses contractiles el de fibres celluleuses élastiques. Ce ligament, qui s'attache au testicule et qui de plus adhère au péritoine, a son extrémité inférieure fixée au pubis et aux attaches des muscles abdominaux : or, lorsque ce petit corps ligamenteux vient à se rac courcir, c'est-à-dire vers le septième mois, il attire du côté de son bout inférieur, et par conséquent vers les bourses, à travers l'anneau inguinal, le testicule et la portion adhérente du péritoine du voisinage; il entraîne ces parties pour ainsi dire à la remorque, et le résultat de cette 
CHAP. III. EUBRYON DE L'HOMHE, ETC. 291 - Iraction exercée par le ligament conducteur des testicules est de placer ces organes dans les bourses et de donner au scrotum lui-même trois enveloppes nouvelles : je veux dire la portion du péritoine entraînée, d'où naît la tunique vaginale; la partie musculeuse du ligament conducteur, source du crémaster et du dartos, résultant de l'épanouissement de ce muscle crémaster; et enfin la partie fibreuse de ce même ligament, d'où provient la tunique blanche ou albuginée des bourses. Toutefois, cette descente graduelle des testicules ne s'achève quelquefois qu'après la naissance; et l'oblitération de la tunique vaginale provenant du péritoine ne tarde pas à s'effectuer. Cependant la chose est plus lente dans les pays froids et humides, comme la Hollande; et cela même devient, dans de pareilles contrées, une cause fréquente de hernies congéniales.

Les ovaires des embryons femelles sont placés comme les testicules des mâles au-dessous des reins, et sont de même un peu isolés de la matrice; mais des ligamens composés d'un' tissu élastique finissent par les rapprocher de cet organe, dổnt ils surpassent d'abord le volume. Le foetus humain a le col de l'utérus très-gros à proportion du reste: il y a originairement deux cornes à la matrice, mais ces prolongemens sont entièrement disparus à l'époque de la naissance. Les organes génitaux femelles sont d'abord placés trèshaut dans le ventre; mais la rétraction du ligament rond les attire dans le bassin, et ce ligament entrâne avec lui dans l'anneau inguinal une petite portion du péritoine, à la manière de ce que nous avons vu pour le corps ligamenteux conducteur. 
292 LIV. III. DE L'ACGRoIssliment des CORPS VIVANS. des testicules. Nous devons dire que des anatomistes d'un grand mérite ont pensé que les organes génitaux internes proviennent originairement de l'allantoïde, comme ils admettent que l'intestin provient de la vésicule ombilicale : mais quelle importance peut-on attacher à cette opinion, lorsqu'on sait que l'allantoïde elle-même ne peut être vue dans l'œuf humain?

Système nerveux. Le Cerveau et la moelle épinière sont d'abord à l'état fluide : c'est, au reste , une disposition commune à tous les organes, mais plus évidente pour ceux dont nous parlons. Un embryon de mam mifère, âgé de quinze jours, offre déjà des yeux manifestes, un œsophage considérable, déjà aussi le cana! unique formant l'ébauche du cœur, et cependant on ne voit encore qu'un fluide limpide dans le crâne et la gouttière d'origine de l'épine du dos, parties alors membraneuses. A vingt-un jours, quelque chose d'organisé apparaît déjà dans le fluide, mais sans forme arrêtée ni distincte. Alors pourtant les côtes sont déjà cartilagineuses, et les nerfs du tronc et de la têté sont déjà visibles. Voilà bien la preuve que l'hypothèse qui fait provenir, qui fait nâitre ces nerfs du cerveau et de la moelle épinière, n'a aucune basé réelle.

Vers trente' et quelques jours, en même temps que le cordon ombilical est bien distinct, on aperçoit trois vésicules à la tête, sans aucune trace de division médiane; il n'y a également qu'un seul cordon à la moelle épinière : cet état des organes du jeune mammifère correspond à-peu-près à ce qu'on voit dans le poulet de trois jours d'incubation. On conçoit, au reste, que les progrès de l'organisation doivent être 
CHAP. WI. EMBRYON DE L'HOMME, ETE.

plus rapides dans les espèces d'animaux dont la gestation est moins prolongée : l'embryon du lapin est aussi avancé le huitième jour que celui de l'homme à trente jours. $\Lambda$ cette époque les nerfs ne s'unissent pas encore avec leurs centres, je vetix dire qu'ils sont encore isolés de la moclle épinière et. de l'encéphale. Environ le trente-sixième jour, les vésicules cérébrales se partagent en deux, les trois en font six; les antérieures correspondent aux hémisphères du cerveau, ce sont les plus grosses; les postérieures forment l'origine de la moelle allongée; et les plus petites, situées entre les deux autres, représentent les commencemens des tubercules quadrijumeaux. Le cervelet ne paraît pas encore.

Ainsi le système nerveux commence par l'état fluide : on voit se développer, dans le liquide grisâtre d'origine, de petits points opaques et solides, première origine des organes nerveux; c'est absolument comme les points solides et calcaires pour le système osseur. Nous savons aussi que les nerfs existent avant que les centres nerveux ne soient devenus solides et apparens; c'est la preuve que les organes latéraux ne proviennent point des parties centrales, puisque celles-ci paraissent les dernières : c'est une nouvelle analogie du système nerveux avec les pièces du squelette, lesquelles restent cartilagineuses à leur partie moyenne, long-temps après que les parties latérales ont commencé à s'ossifier. Dans leur premier état d'imperfection, de mollesse et de fluidité, ces différens organes paraissent uniques et formés toat d'une venue, sans indice d'une séparation médiane; mais dès que la solidifieation des tissus commence, c'est sur les bords, e'est 
29. LIV. HI. DE L'ACCROISSE MENT DLS COHPS VIVANS. aux parties latérales qu'on en voit les premières manifestations. On dirait une solution saline, laissant déposer ses premiers cristaux sur les parois les plus excentriques du vase qui la renferme; on dirait un fleuve, jetant son limon sur ses rives; enfin, on dirait un continent submergé, dont la retraite graduelle des eaux ne laisse d'abord apercevoir que les confins.

La Moelle épinière, après n'avoir paru formée que d'une partie simple et médiane, est donc ensuite composée de deux cordons latéraux, qui plus tard s'accolen l'un à l'autre et se réunissent. L'embryon humain de deux mois a la moelle de l'épine ouverte en arrière à sa partie supérieure seulement ; mais cette disposilion est temporaire et de courte durée, tandis qu'elle persévère toule la vie chez les reptiles batraciens (les grenouilles, les crapauds, les salamandres). Vers le $50^{\circ}$ jour, la moelle épinière se termine en pointe au coccix. Il faut remarquer que tous les mammifères et l'homme lui-même ont originairement une queue coecigienne; mais ceux des animaux où cet appendice ne persiste pas, le perdent précisément à l'époque où la moelle remonte dans son canal, ce qui commence pour l'embryon humain dans le deuxième mois de la gestation. Cette moelle, avons-nous dit, allait d'abord jusqu'au coccix, mais elle remonte peuà-peu jusqu'au niveau des premières vertèbres lombaires. Avant cette ascension de la moelle épinière dans son canal, les nerfs formant faisceau naissent des côtés de la moelle; mais alors ils la terminent et la dépassent. Ce que nous disons ici est vrai des chauvesouris, des reptiles et des singes sans queue, tout aussi bien que pour l'homme: au contraire, les ani- 
CHAP. III. EMBRYON DE L'HONMr, ETC.

maux dont la queue persiste toute la vie, n'éprouvent pascette ascension de la moelle de l'épine et n'ont point ce faisceau nerveux terminal qu'on appelle queue de cheval. Les nerfs de la moelle épinière ne lui sont partout adhérens et continus que vers la fin du deuxième mois; les cervicaux sont les derniers̀ à se réunir. I.oblitération du canal médian de la moelle ne s'opère ordinairement que dans le cours du sixième mois, et cela même résulte du rapprochement et de l'augmentation graduelle de ses cordons latéraux. La moelle épinière des mammifères a deux renflemens comme celle des oiseaux; et ces renflemens ont également toutes sortes de rapports et de coincidence avec les membres supérieurs et inférieurs.

Le Cervelet n'apparaît que dans le cours du deuxième mois; à son origine il n'est formé que de deux lames. isolées, placées alors entre les tubercules quadrijumcaux et la moelle allongée : ce n'est qu’à cinq mois que les sillons et les proéminences du cervelet apparaissent pour la première fois. On a remarqué que le cervelet s'accroît peu durant le huitième mois, tandis qu'il prend beaucoup d'accroissement dans le cours du septième et du neuvième. Il se pourrait bien que ce fût là une des causes qui rendent le foetus humain plus viable à sept mois qu'au huitième. Le cervelet est à nu à la superficie du cerveau jusqu'au sixième mois de la gestation; mais plus tard les lobes du cerveau le recouvrent. Vers le nouvième mois tout est dans les mêmes proportions que dans l'adulte: les organes cérébraux ont fait alors une sorte de bascule analogue à ce que nous avons décrit touchant les oiseaux.

Les Tubercules quadrijumeaux sont originairement 
creux dans les mammifères; mais cette disposition est temporaire dans cette classe d'animaux, tandis qu'elle est persévérante dans les autres classes de vertébrés, dans les oiseaux, les reptiles et les poissons : cette cavité des tubercules quadrijumeaux disparaît vers le sixième mois dans le folus humain. Ces mêmes tubercules étaient d'abord bijumeaux et situés superficiellement, vers le quatrième et le cinquième mois de la gestation; mais à partir du sixième mois ils s'unissent en un seul corps, s'emplissent, se solidifient, deviennent quadruples par les sillons de leur surface, et le cervelet finit vers cette époque par les recouvrir. C'est encore ä-peu-près ce que nous avons vu dans les oiseaux, mais à un âgre différent.

Les ventricules du cerveau sont d'abord proportionnellement plus larges qu'ils ne le sont dans l'âge adulte : cette dispositiou vient de ce que la substance cérébrale, plus accrue, empiète de plus en plus sur la cavité creusée dans les hémisphères. Cela même aurait dû détromper jadis de la thćorie hypothétique des esprits vitaux. Le développement des scissures et des lobes du cerveau est toujours proportionnel à la masse du noyau central. Les circonvolutions de l'encéphale ne sont manifestes à l'extérieur que vers le cinquième mois de la gestation du fotus humain ; mais elles apparaissent à l'intérieur dès le troisième mois. Quant au corps calleux, il n'est jamais réuni.dans l'homme avant le troisième mois; et lorsqu'il ne s'unit pas, c'est alors comme dans les oiseaux. Il faut se rappeler que les diverses phases d'accroissement de l'embryon deviennent quelquefois l'état permanent de certains fotus monstrucux; et comme cha- 
CHAP. III. EMBRYON DE L'HOMME, ETC. ! 297 que âge de l'embryon des mammilères offre l'équivalent de l'état normal d'une des classes inférieures, mais surtout des oiseaux, des reptiles ou des poissons, il en résulte que l'organe arrêté dans ses progrès, ressemble au même organe permanent'd'une de ces classes. Ainsi, lorsque le cervelet ne se développe pas après le troisième mois de la gestation, alors il reste fort exigu, comme celui des reptiles. Si le corps calleux du mammifère ne s'unit pas vers le troisième mois, il reste disloqué ou inappréciable comme chez les oiseaux : également les tubercules quadrijumeaux du mammifère sont semblables à celui de l'oiseau, lorsqu'ils cessent de croître après le cinquième mois, c'est-à-dire, alors qu'ils sont creux, et formés de deux seules éminences.

Le cerveau n'a pas, à l'époque de la naissance, absolument les mêmes proportions qu'il aura le reste de la vie : par exemple, le cervelet s'accroît depuis l'âge de deux mois, époque de sa première apparition, jusqu'à l'âge de quarante ans: après cela il décline. Au temps de son apogée, le diamètre longitudinal l'emporle d'environ moitié sur te transversal. Or, il est clair que puisque le crâne est de toutes parts rempli par l'encéphale, une de ses parties ne saurait prendre de l'accroissement sans que certaines parties ne diminuent simultanément et dans la même proportion.

Organes des sens. Les paupières sont d'abord intimement adhérentes; elles sont collées au globe de l'œil : cette disposition persévère jusqu'au septième mois. La sclérolique est si mince, si transparente dans ce premier âge, qu'on voit clairement la choroide a 
298 LIV. III. DE L'ACCROISSEMENT DES CORYS VIVANS.

travers son tissu. La cornée, dans l'origine, est opaque, molle et très-épaisse ; elle ne s'amincit que vers le sixième mois; et c'est alors qu'elle devient transparente. La chambre antérieure n'existe pas d'abord, de sorte que la cornée n'est séparée du cristallin que par la membrane pupillaire, laquelle se montre distinctement à trois mois et disparaît à sept. L'humeur aqueuse n'existe donc primitivement qu'audelà de la membrane pupillaire, entr'elle et le cristallin; mais dès que celte pellicule est rompue par la rétraction de ses anses vasculaires, alors l'humeur aqueuse remplit la chambre antérieure de l'ceil, dont l'espace est agrandi par l'amincissement de la cornée. L'humeur vitrée est fluide et rougeâtre dans les premiers temps; elle prend ensuite un peu de consistance et surtout de la limpidité. Le cristallin est d'abord tout fluide, ensuite il devient peu-à-peu consistant; sa forme est dès-lor's sensiblement lenticulaire, c'est-à-dire très-convenable à la réfraction de la lumière à l'époque de la naissance. Nous parlerons ailleurs des progrès et des changemens subséquens.

Quant à l'Oreille, nous avons dit quels changemens elle éprouve dans le cours de la gestation. D'abord composée d'un simple pertuis presque imperceptible, ses parties membraneuses et cartilagineuses se développent peu-à-peu. C'est vers trois mois que le labyrinthe commence à s'ossifier : les diverses parties du rocher croissent et s'endurcissent peu-à-peu, laissant entre les pièces osseuses dont elles sont formées des hiatus et des scissures destinées à clivers usages; el ce qu'il y a de plus admirable dans l'arrangement et les progrès de toutes ces parties, 
CHAP. III. EMBRYON DE L'HOMJE, ETC.

c'est que toutes s'adaptent avec une telle précision, qu'aucun des nerfs, qu'aucun des vaisseaux dont elles sont traversées n'en éprouve jamais ni compression ni contrainte. Les oșselets du tympan s'ossifient de trois à quatre mois envirun.

Le $\mathrm{Nez}$ offre à l'extérieur les changemens que nous avons énoncés. Les progrès des parties intérieures ont beaucoup de lenteur : les lames criblées de l'ethmoide, servant de passage aux innombrables filets du nerf olfactif, ces lames ne sont point encore ossifiées à l'époque de la naissance. Alors non plus il n'existe pas e ncore de sinus.

Nous savons que la Bouche ne se ferme que vers trois mois; et cela est dû au développement des tèrres, qui ne datent que d'alors. Les lèvres ellesmêmes offrent, dans le premier âge de l'embryon, des particularités qui rendent compte des maladies ou des difformités dont elles sont quelquefois le siége dans l'enfance : l'inférieure est échancrée assez largement à sa partie moyenne; et la supérieure, au lieu d'une, présente vers son bord libre deux échancrures analogues mais latérales, que sépare l'une de l'autre un lobe mitoyen. De là au bec de lièvre il n'y a qu'un pas. Quant à la mâchoire inférieure, nous avons dit combien l'ossification commençante en est précoce.

Les Dents ont déjà leurs premiers germes visibles: dès avant le deuxième mois de la g estation. Ce sont alors comme de petites vésicules membraneuses et d'une ténuité excessive : elles tiennent cependant déjà à des filets de nerfs et à des vaisseaux distincts. A quelque temps de là, on aperçoit une petite bulle. 
Jon LIV. HIT, DE L'ACGROISSEMENT DES CORPS VIVANS.

membraneuse, forméc de deux lames, et servant d'enveloppe à une sorte de petit corps apparemment composé de nerfs et de vaisseaux. Toutes ces choses augmentent peu-à-peu, et l'endurcissement commence vers le troisic̀me mois. Il faut dire aussi que ce petit sac, où se rendent des vaisseaux et des nerfs, tient par une de ses extrémités à la gencive de l'alvéole qui la renferme. Voici maintenant dans quel ordre ont lieu les progrès d'ossification pour les différentes dents; nous ajoutons que les premières à s'ossifier

- sont de même les premières à sortir; et cette règle, une fois posée, va nous éviter des répétitions. La première dent incisive, à commencer comme on le fait ordinairement par la ligne médiane, est la première à s'ossifier; ensuite, et à des intervalles égaux pour toutes les dents, c'est la deuxième incisire qui s'ossifie, puis la première molaire, la canine, et la deuxième molaire. Cette dernière dent s'ossifie ordinairement vers le sixième mois. Nous venons de citer cinq dents différentes, prises d'un seul côté; il n'est pas besoin d'ajouter que la chose est pareille pour celles du côté opposé de la même mâchoire : cet ordre est également semblable pour l'ossification et l'évulsion des dents correspondantes de la mâchoire supérieure (car nous parlions de l'inférieure). Toutefois nous devons dire que celles de la mâchoire inférieure précèdent presque toujours les dents analogues et correspondantes de l'autre mâchoire. Nous ferions aussi justement la même remarque pour les dents de deuxième formation, ou de sept ans. Yoilà donc dějà vingt des premières dents dont nous savons l'ordre de succession. Ajoutons à ce qui pré- 
CHAP. III. EMBRYON DE I'HOMHE, F'TC.

tède que la solidification commence pour chacune par le sommet de sa couronne; et que cette ossification est simple, à base unique pour les incisives et les canines, tandis que, pour les molaires, il y a autant de centres osseux primitifs que ces dents ont de racines. C'est lorsque cette portion osseuse des dents est achevée, que l'émail vient peu-à-peu en revêtir la couronne, c'est-à-dire toute la partie qui doit se trouver exposée à l'air après l'évulsion. A l'époque de la naissance, ces vingt dents ne sont encore ni tout-à-fait achevées ni sorties, du moins cela est fort rare. La couronne des incisives est dès-lors complète, mais celle des canines et des molaires n'est encore qu'ébauchée.

SQueletre osseux. L'ossification ne paraît pas commencer avant la sixième semaine. On peut citer dans l'ordre suivant les premières pièces ossifiées du squelette : la clavicule, la mâchoire inférieure et la supérieure, ensuite le fémur, l'humérus, le tibia, les os de l'avant-bras, le péroné, etc. Toutes ces ossifications commençantes se succèdent à quelques jours d'intervalle. Il faut ajouter que ce que noús disons ici de l'ostéogénésie de l'homme est vrai, à de légères variations près, du squelette de toutes les classes d'animaux vertébrés comme du sien. Ainsi donc, quoique nous ne devions citer que l'homme dans ce paragraphe traitant des progrès de l'ossification, nous y avons en vue tous les animaux à squelette.

Environ quinze jours après la clavicule, on voit s'ossifier la colonne vertébrale : ce sont les apophyses des vertèbres qui commencent à s'endurcir; après cela vient le corps ou partic épaisse des vertèbres; mais 
J03 LIV. III. DE L'ACCROISSEMENT DES COnPs VIVANS.

toutes ne s'ossifient pas à-la-fois : ce cont les cervicales qui commencent, et ensuite celles qui viennent après progressivement du haut jusqu'en bas. Celles du sacrum sont encore cartilagineuses le quatrième mois. Cependant ce que nous venons de dire pour les progrès de l'ossification des vertèbres n'est vrai que pour leurs apophyses; car le corps des deux premières cervicales est encore cartilagineux à quatre mois et demi. L'anneau de chaque vertèbre ne s'achève que par la rencontre des points osseux de son corps avec les points osseux de ses apophyses : cette réunion's'effectue d'abord dans les vertèbres dorsales. Il faut ajouter que le corps des vertèbres n'a pas un point unique d'ossification, mais toujours deux points latéraux promptement confondus.

Les còtes commencent à s'ossifier environ quinze jours après la clavicule et quinze jours avant les vertèbres; mais le sternum, plus tardif, est encore tout cartilagineux à quatre mois et demi; à six mois, trois de ses cinq parties osseuses sont déjà ébauchées, èt toutes les cinq le sont vers l'époque révolue de la naissance. Ces cinq portions osseuses du sternum commencent quelquefois par neuf points d'ossification.

La tête est fort compliquée dans son accroissement. Ordinairement l'occipital commence à s'ossifier quelques jours avant la colonne vertébrale ; c'est l'occipital proprement dit qui débute; après cela viennent les condyles de cet os, à l'époque à-peuprès où les vertèbres s'ossifient; puis l'apophyse basilaire : en lout huit points d'ossification pour loccipital, dont quatre pour la partie supérieure, lesquels sont encore distincts à la naissance. Les 
CHAP. HII. EMBKYON DE L'HOMNE, ETG. $\overline{\text { JO5 }}$ points osseux du sphénoïde sont encore plus nom. breux, à raison de la multiplicité de ses apophyses. Ces différentes parties se réunissent vers le huitième mois de la gestation. Le vomer se développe peu de jours après l'occipital ; et le frontal, les pariétaux et la porlion écailleuse du temporal commencent également à s'ossifier peu après l'occipital, quinze jours environ après la clavicule ; mais ne fixons pas de terme absolu, à cause des variations que cela éprouve selon les individus. Le reste des os de la face sont presque tous contemporains de ceux dont nous venons de parler; l'os incisif n'est visible qu'alors, encore n'est-il que peu de temps distinct, à raison de sa prompte soudure avec l'os maxillaire supérieur. La mâchoire inférieure est le premier ossifié des os de la face ; et cependant il est encore formé de deux portions distinctes vers le terme de la gestation. L'hyoïde, l'apophyse styloide et les cartilages du larynx ne s'ossifient jamais qu'après la naissance.

Quant aux os des membres, la clavicule est le premier à s'ossifier; l'omoplate ne vient guère que douze jours après : son premier point osseux est placé à la racine de l'apophyse acromion; l'apophyse coracoïde ne s'ossifie qu'après la naissance. Nous avons dit que l'humérus s'endurcit et s'ossifie un peu après le fémur; à la naissance, ce dernier os présente un point osseux très-petit à son extrémité inférieure; il est le premier des os longs à présenter une épiphyse osseuse. Le péroné s'ossifie un peu après les os de l'avant-bras, et le tibia au même temps que le fémur. Les os du carpe sont entièrement cartilagineux à l'époque de la naissance, mais l'astragale et surtout le 
504 LIV. III. DE L'ACCROISSEMENT DES CORPS VIVANS. calcanéum sont déjà en partie osseux à quatre mois et demi. Les os du métacarpe, du métatarse et des phalanges, commencent à s'ossifier peu de temps après le péroné. Mais c'est déjà trop de détails sans intérêt : nous exposerons plus tard quelques-unes des lois de l'ossification du squelette.

Fluides et humeurs de l'embryon. Nous ne devons pas parler de l'amnios des mammifères, il est trop analogue à l'humeur du même nom que nous arons vue dans les oiseaux; seulement nous remarquons que la nature de ce liquide n'a pas toujcurs été bien appréciée, par la raison que voici : les chimistes ont presque tous confondu, dans leurs analyses, le fluide de l'amnios avec le fluide de l'allantoïde, et il est résulté de là qu'ils ont admis dans le premier des principes qui n'existaient que dans l'autre; mais un jeune chimiste de beaucoup de mérite, M. Lassaigne, a signalé cette inexactitude en l'évitant lui-même. Au reste, ce que nous disons ici ne concerne que les mammifères, car l'œuf humain n'a pas d'allantoïde. Quant au fluide de la vésicule ombilicale, il a beaucoúp d'analogie avec lè vitellus de l'œuf des oiseaux; on sait d'ailleurs qu'il n'en reste bientôt plus de traces dans l'œuf humain, mais la quantité en est énorme dans quelques mammifères. J'ajoute que ces différens liquides sont produits par les membranes qui les renferment. Il y a encore l'humeur sébacée dont la peau est enduite vers les derniers temps de la gestation : quelques personnes ont pensé que ce pouvait être un dépôt des eaux de l'amnios déjà partiellement absorbées; mais i) paraît plus vraisemblable que ce fluide soit dù à une sécrétion particulière des petites glandès que le 
CHAP. HI. ESBRYox DF L'HOMBr, ETC. 505 tissu de la peau renferme. Je dirai même chose du méconium, lequel occupe successivement toutes les parlies du canal digestif : il ne résulte évidemment, ni des eaux de l'amnios résorbées, ni de la bile qui flue de bonne heure dans l'intestin ; c'est une sécrétion particulière à ce canal. Je dis que le méconium est une sécrétion locale, car on trouve également de ce liquide au-dessus et au-dessous des oblitérations accidentelles du conduit digestif. Il est sûr, en effet, que le méconium qui se trouve au-dessus d'une oblitération originaire du pylore ne saurait provenir de la bile, et que celui qui se trouve au-dessous ne peut provenir des eaux de l'amnios. C'est donc une production spéciale, et particulière au fœtus. Mais c'en est assez sur ce sujet; parlons maintenant des Fonclions.

Nutrition. Il est intéressant de rechercher d'où l'embryon tire les matériaux qui servent à le nourrir et à l'accroître; or les opinions ne sont pas unanimes à ce sujet. Toutefois personne ne met en doute que le sang de la veine ombilicale ne soit ici de la plus grande importance. Il est certain que l'origine de ce vaisseau date des premiers jours de l'existence du fotus; il est certain que le cordon ombilical a des communications plus ou moins directes avec les vaisseaux de la mère, et qu'à cause de cela il apporte de la mère au fœtus des alimens tout préparés et facilement assimilables; enfin l'on ne peut douter que les artères ombilicales ne reportent dans le placenta un sang fort différent de celui qui circule vers le fotus par la veine. De pareils faits sont probans, et personne ne les nie. Mais on a dit que la nutrition du foetus avait 
306 LIV. III. DE L'acicroissemtent DEs CORPS viVANS.

d'autres sources que le sang de la mère, d'autres voies que le placenta et le cordon ombilical. On a beaucoup attribué, tántôt à l'eau de l'amnios, tantôt à la vésicule ombilicale : il est sûr que cette dernière dojit servir à l'accroissement de l'embryon, puisqu'on la voit peu-à-peu disparaître à mesure que le foetus prend du volume; il est probable aussi que l'eau de l'amnios s'introduit quelquefois dans le conduit digestif du foetus, surlout lorsque celui-ci se trouve dańs une position extraordinaire, je veux dire la tête en haut; mais comme on a vu des embryons s'accroître quoiqu'ayant les ouvertures oblitérées jusqu’à ta naissance, on doit en conclure que la nutrition ne peut avoir constamment et uniquement une source pareille. Quelques personnes ont aussi pensé qu'une partie des eaux de l'amnios se trouvait absorbée par la peau du foetus, chose aussi difficile à prouver qu'i infirmer. La vésicule ombilicale et les vaisseaux ombilicaux, telles sont apparemment les principales sources de la nutrition du foelus depuis ses commencemens jusquà sa mise au jour.

Respiratron. Il est évident que l'embryon des oiseaux ćprouve unc sorte de respiration dans l'œuf; mais cela n'est pas aussi manifeste pour le fœtus des mammifères. Ici l'air ne peut être absorbé ni par les pellicules d'un vitellus, ni par les feuillets déployés de l'allantoide; il ne peut pas davantage s'introduire directement dans les poumons. Ce qu'on a dit des cris du foetus dans la matrice, au sein de l'amnios, est justement récusé par tous les physiciens judicieux. Cependant il faut bien que le sang du fotus soit renouvelé, il faut ơu'il soit imprégné d'air et d'alimens 
CHAP. ILI. EMBRYOW DE L'HOMME, ETC.

nouveaux; et tout porte à croire que l'embryon respire comme il se nourrit. Mais il y a presque autan $t$ d'opinions différentes que d'auteurs, touchant le modé de la respiration du foetus; tant il est vrai que lout n'est que dissentiment hors du témoignage des sens et hors des voies de la nature. On prétend, par exemple, que le sang de la mère est une sorte d'atmosphère où le sang du fotus puise l'air indispensable à sa propre confection; on prétend qu'il y a dans les membranes foetales des espèces de vaisseaux qui sont occupés à décomposer l'eau de l'amnios pour en extraire de l'air respirable; d'autres personnes, persuadées que le sang de l'embryon continue toujours de communiquer avec le sang de la mère, admettent tout simplement que la respiration pulmonaire de celte dernière suffit aux deux êtres; enfin il est des auteurs qui, considérant l'amalogie apparente du sang veineux et de l'artériel dans le foetus, concluent de cette similitude originaire de deux fluides devenus plus tard si différens, qu'il n'y a aucune respiration dans l'embryon des mammiféres. Le fait est que les deux sortes de sang sont analogucs pour la couleur, que celui des artères est rembruni comme celui des veines. MM. Baër et Rathke àyant signalé dans ces derniers temps des espèces de branchies dans les embryons des animaux vertéliés, notamment dans l'homme et les mammifères, on cn a conclu que vraisemblablement ces organes avaient te même office qu'ils ont toute la vie dans les poissons et les autres animaux aquatiques; et que, l'embryon se trouvant baigné de liquides, sa respiration apparemment s'exerce d'abord comme celle des poissons. Il y a encore beaucoup à faire à ce sujet : à force 
308 LIV. IIY. DE L'ACCROISSEMENT DES CORPS viVANS.

d'observer assidûment les faits, on finira par rendre aux conjectures le discrédit qu'elles méritent.

Circulation. Nous şavons déjà, par ce que nous avons dit du cœur et des vaisseaux du fœtus, en quoi sa circulation est. différente de celle des animaux adultes : ces particularités sont d'ailleurs à peu de chose près pareilles pour les oiseaux et les mammifères. Au reste, ce qu'on à dit du premier passage du sang veineux, venu du cordon ombilical, à travers le trou de botal, sans se mêler à la colonne de sang que la veine cave supérieure verse dans l'oreillette droite, celte assertion, disons-nous, est beaucoup trop absolue pour n'être pas un peu exagérée. On peut voir dans notre $P$ hysiologie médicale les détails relatifs à la Circulation du sang dans le fotus : ce que nous y avons dit de l'homme, s'applique avec de bien légères varialions à tous les mammifères.

Origine de la vie. Les jeunes animaux ne jouissent d'une vie indépendante et pleinement individuelle qu'au moment de leur naissance, alors qu'ils ont rompu toute union avec les organes maternels. Cependant il est sûr que le jeune être est doué d'une sorte de vie dès ses premiers commencemens : car, comment s'accroîtrait-il, comment deviendrait-il adhérent, comment ses divers organes prendraientils graduellement une apparence de plus en plus manifeste? La vie fœtale date donc de l'époque même de l’imprégnation spermatique du germe ou ovule maternel. Toutefois on ne peut juger de la vie que par des manifestations évidentes, je veux dire par les mouvemens du cœur ou des muscles: or, ces phénomènes indiquant la vie, n'ont rien de fort précis 
CHAP. III. EMBRYON DI L'HOMIIE, ETC.

quant à leur origine. Le cœur du poulet a des palpitations évidentes dès la quarante-huitième heure; mais celui des jeunes mammifères ne se meut pas ostensiblement avant le quatorzième jour pour les uns, et le trentième pour les autres. Il est d'ailleurs probable que le cœeur se mouvait déjà avant l'époque où l'on peut l'apercevoir; car l'extrême petitesse et la transparence qui le rendent d'abord invisible, ne sont pas des circonstances propres à l'empêcher d'agir et de palpiter plus tôt. " C'est la semence du mâle, disait "Haller, qui anime, qui donne la vie au foetus; et ce " foctus est vivant, quand son cœur a du mouvement." Or, comme ce physiologiste admet que le cœur préexiste tout formé dans le foetus, de même que le fơtus préexiste dans l'œuf, il suit de là que la vie du foetus daterait, suivant lui, du moment mêrne de la fécondation. Haller doutait si peu de la réalité du fait, qu'il allait jusqu'à dire : a tout est encore blanc, tout " encore invisible dans l'embryon, que néánmoins le " cœur bat et agit déjà. "Malheureusement les assertions les plus formelles ne sont pas toujours les plus certaines.

A l'égard des mouvemens musculaires, on dit qu'il en existe dès le quarantième jour ou même plus tôt pour les embryons mâles, et un peu plus tard pour les foetus de l'autre sexe : c'était au moins l'opinion des anciens, et il faut convenir que les faits acquis par les modernes ne sont pas assez concluans pour autoriser à contredire. nos vieux maîtres. Ces premiers mouvemens, je le répète, sont bien difficiles à distinguer, et l'on doit penser quils sont souvent illusoires dans l'espèce humainc; car, à l'é- 
310 LIV. IIL. DE L'ACGROISSEMENT DES CORPS VIVANS. poque dont nous parlons, les muscles de l'embryon ne sont pas encore discernables; et d'ailleurs, les pièces du squelette n'élant point formées, les mouvemens, s’il en existe réellement, ne sauraient être que vermiculaires. Les grands mouvemens, en effet, supposant des leviers, il n'en peut exister chez les jeunes mammifères que dans le milieu de la gestation. Ils ne sont bien sensibles dans le foetus humain que du quatrième all cinquième mois; à cause d'eux, la vie de l'embryon paraît alors très-manifeste, et d'autant plus, que ces mouvemens persévèrent quelque temps encore après l'expuision et la mort du jeune fœtus. Et comme ces mouvemens qui indiquent prescue sûrement la vie, sont aussi les indices de la volonté en des êlres plus parfaits et plus accrus, à cause de cela on a quelquefois assigné la conscience el à la volonté, ces nobles manifestations de l'âme (et à l'âme elle-même), une origine contemporaine à ces mouvemens spontanés de l'embryon : mais nous avons montré, dans notre autre Physiologic, que les mouremens musculaires; bien loin de désigner incontestablement le règne de la volonté, ne sont même pas toujours de sûrs indices de la vie, puisqu'ils persévèrent encore après sa complète exlinction; et de là nous concluons que nous ne savons rien de précis touchant l'origine sensible de la vie, et absolument rien sur l'origine de l'âme. Les Romains punissaient de mort quiconque avait criminellement procuré l'expulsion d'un folus déjà formé et animé, ce sont les termes de la loi ; et ils fixaient à quarante jours l'époque de l'animation du foetus, ce qui concorde assez bren avec les premiers mouvemens manifestes. Celte. 
CHAP. IV. PREMIÈR ORIGINE DES ORGANES. 3H: rigueur des lois était donc juste; mais il. faut dire qu'elle l'eût été pour les premiers jours de la grossesse tout aussi bien que pour le quarantieme. En effer, si l'on met.de côté les chances d'anéantissemerit ou d'expulsion prématurée du fotus, il est évident que le germe une fois fécondé, une fois conçu, possède en soi toutes les conditions de son développement futur; c'est un être parfaitement existant dès les premier's jours, et il ne lui manque que du temps pour se parachever. Sa destruction alors est donc aussi con-

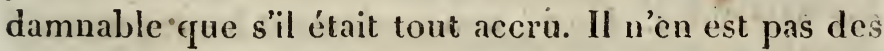
ouvres de la nature comme des ouvrages des hommes: la nalure n'ébauche rien qui n'ait d'abord en soi les élémens de sa perfection; sés intentions sont déjet presque réalisées aussitôt qu'elle commenec à les ma: nifester.

\section{CHAPITLE IV.}

Sur la première Origine des Organes et leur première Aprarition. -

La formation en est-elle simultance ou successive, ou bien est-elle préexistante à la fécondation?

De ce que les différens organes n’apparaissent pas. tous simultanément dans l'embryon qui commence, serait-il raisonnable de conclure que leurs élémens communs ne sont pas contemporains? Serait-il viai que les organes se forment pièce à pièce, de mêmu qu'ils apparaissent un à un? ou bien sont-ils criginaiz rement en petit, sous la forme de germes, tout 
312 LiV. III. DE L'ACCROISSEMENT DES CORPS YIVANS.

ce qu'ils deviendront un jour lorsqu'ils seront parachevés?

Il est certain que les organes n'apparaissent pas tous en même temps; pas tous, dès que l'embryon devient visible. Il est certain que la plupart des organes ont des âges différens, du moins quant à leur première apparition; certain quils ne sont pas tels dès leurs premiers commencemens, quills le deviennent à l'époque de leur perfection finale : les chapitres précédens renferment des faits propres à motiver ces assertions. Ainsi, non-seulement les organes ne sont pas tous contemporains, mais il existe une époque où l'on n'aperçoit rien de visible au sein de l'ovule où l'embryon doit apparaître; mais, en outre, une fois manifestes, les organes changent de forme, de consistance et de contexture. Il ne serait donc pas exact de dire qu'ils se développent ou qu'ils s'accroissent; car il est sûr qu'ils apparaissent successivement dans l'ovule fécondé, où l'on suppose un germe primitif; et après s'être ainsi manifestés, ils se transforment ou se modifient graduellement; de telle sorte même, qu'il est souvent difficile de trouver dans la structure et la forme d'un organe parachevé, quelque preuve de son identité avec le même organe observé dès sa première apparition.

Et qu'on ne croie pas que les plantes dérogent à cette règle reconnue vraie pour le animaux ! ce seraik une erreur. Il est bien vrai que la graine, détachée de son réceptacle, offre en petit les parties essentielles du végétal qui en doit naître $:$ mais cette graine mûrie sur sa tige n'est pas l'équivalent de l'embryon commençánt des animaux; elle représente bien plutôt 
GHAP. IV. PREMIÉRB ORIGINE DES ORGANES. 315 l'état du fotus au moment où, sorti de sa coquille, ou détaché de sa mère, il va exister d'une vie indépendante et individuelle. Mais si l'on remonte à l'origine de cette graine, on trouve un instant où, la fécondation étant opérée, tout est fluide et homogène au sein de sa primitive enveloppe; un moment où rien d'organisé n'apparaît encore à son centre : et c'est là précisément ce qu'on observe pour l'ovule nouvellement détaché et nouvellement incubé des animaux. Il n'y a donc rien d'évident, rien d'organisé , aucun germe apparent et dont les parties soient discernables, dans les premiers instans de la conception; et cela. est également vrai pour les plantes et pour les animaux : la distinclion qu'on a voulu établir à ce sujet est vaine et mensongère.

Voilà pour l'apparence. Maintenant, examinons la question des germes sous le rapport de la nature intime des choses, selon les besoins de l'esprit et les Jumières de la seule raison.

Il est donc vrai qu'il n'y a rien d'évident dans l'ovule vérétal ou animal qui n'est' que fécondé. Cependant ( et sans nous autoriser ici des observations de Malpighi, qui assure avoir vu de premières traces d'organisation dảns un œuf non couvé; ni des observations de Spallanzani, qui admet de pareilles manifestations dans des plantes et même dans des reptiles, avant loute fécondation des ovules ), cependant, dis-je, si l'on fait attention que les êtres vivans de la même famille portent en toutes leurs parties des traits de frappante ressemblance avec les autres êtres de la même espèce, surtout avec leurs auteurs immédiats; si l'on réféchit sur l'ortre admirable et constant 
31/. LIV. III. DE L'ACCROISSEMENT DES CORPS VIVANS.

qui règne dans l'arrangement de leurs organes, et: dans la forme même de chaque organe; si l'on envisage que la structure des êtres de même espèce a la régularité, la constance et toute la perfection qu'un. moule identique aurait pu lui imprimer, on concevra qu'un arrangement où règne si constamment tant d'harmonie et tant d'ensemble ne saurait être l'œuvre spontanée du hasard; on concevra que toutes ces créations individuelles seraient peu d'accord avec les autres phénomènes de la nature; et dès-lors il semblera raisonnable de penser qu'un pareil renouvellement d'organisations façonnées pour la vie, a sa première cause dans la vie de l'êtrè d'où elles proviennent, et des élémens prédisposés dans l'ovule maternel d'après un type primordial et indélébile. Or, c'est à ce type identique pour les êtres de la même espèce, c'est à ces élémens nécessaires des êtres procréés, qu'il faut altacher le nom et l'idée de Germe.

Mais ce germe, qu'est-il? a-t-il quelque chose de matériel? est-ce l'îmage abrégée, mais encore fluide et transparente, mais encore invisibte parce qu'clle est fluide, des organes plus tard apparens? Est-il vrai, par exemple, que les os existent primitivement et en réalité avec leurs formes, mais à l'état fluide, comme il est vrai qu'ils apparaissent d'abord avec l'aspect de cartilages? A cela, nous répendons que, toutes les fois qu'il s'agit de questions de physique, d'objets matériels, les limites des sens, selon nous, doivent servir de limites à la raison. Toutefois cssaierons-nous d'exposer, dans le chapitre suivant, les opinions les plus répandues à ce sujet. 


\section{CIIAPITRE V.}

Ge qu'on entend par Germes. Diverses opinions sur leur Nature, leur Source, leur Préexistence et leur Emboitement iudéfini.

Le mot de Germe est presque toujours employé pour désigner l'image abrégée ou l'ébauche imparfaite d'un être non encore accru; ou plutôt, l'ensemble des élémens primitifs devant servir à sa formation.

On conçoit aisément que tout être vivant, considéré comme une đuvre ayant des progrès successifs, a toujours aussi des commencemens peu manifesies; on conçoit même que les premiers linéamens en soient tout-à-fait invisibles : mais toujours faut-il à tout être vivant un premier principe, des élémens originaires; et voilà justement l'idée qu'il faut attacher à ce mot de germe. C'est dans le même sens qa'un illustre écrivain a dit, voulant proposer aux productions du génie un parfait modèle dans les óeuvres de la nature: " Elle prépare en silence les germes de ses producn tions; elle ébauche, par un acte unique, la forme " primitive de tout être vivant; elle la développe, " elle la perfectionne par un mouvement continu et "dans un temps prescrit : l'ouvrage étonne! mais „ c'est l'empreinte divine dont il porte les traits qui " doit nous frapper. " $\mathrm{Or}$, cette forme originaire de tout êire vivant, cette ébauche primitive conservant les traits persévérans d'une divine empreinte, je dis 
316 LrV. IIV. DE L'AGCROISSRMENT DES GORPS YIVANS.

que toutes ces expressions de Buffon rendent trèshien l'idée de germes préexistans, à laquelle cet auteur s'est néanmoins toujours montré si opposé.

On a beaucoup varié sur la source même de ces germes primitifs des êtres vivans. Les uns les ont considérés comme résultante de la fécondation séminale; d'autres ont supposé qu'ils lui préexistaient. Parmi ceux qui ont pensé que les germes provenaient de la fécondation et lui étaient contemporains, les. anciens auteurs ont émis le principe qu'ils élaient dus à l'union intime des liqueurs simultanément émanẹes des deux individus. Buffon, Needham, et aussi Maupertuis, attribuaient le même résultat à la rencontre et à la combinaison des molécules organiques provenant des deux sexes. D'autres personnes ont admis que les animalcules du mâle se greffaient et s'anastomosaient avec l'ovule des femelles, et que de là résultait la ressemblance des nouveaux. êtres avec leurs deux parens. Voilà pour la premic̀re opinion, selon laquelle le foetus, loin de préexister à la fécondation, en serait au contraire le résultat ou le produit nécessaire.

Selon d'autres opinions, avons-nous dit, les germes préexistent à la fécondation : mais émanent-ils du mâle? proviennent-ils de la femelle? Les sentimens sont partagés sur ce point, d'après les différentes idées qu'on se forme de la puissance respective des deux sexes. Ceux, par exemple, qui ont tout attribué au mâle, ceux qui regardent les animalcules du sperme comme l'élément essentiel des êtres procréés, les auteurs dont nous parlons ont placé dans ces animalcules eux-mêmes le siége des germes réputés préexis- 
tans; mais d'autres, et de plus nombreux, en ont supposé la source commune et exclusive dans l'ovaire, dans les vésicules, ou espèce d'œufs des femelles.

Il est même des auteurs qui ont pensé que ces germes primitifs se trouvaient répandus dans toutes les parties de chaque être vivant : ils ont fondé cette opinion sur la propriété qu'ont beaucoup de ces êtres de reproduire spontanément des parties séparées de leur ensemble, et cet ensemble lui-mênie par quelques-unes de ses parties. Enfin un savant, plus audacieux que les autres, a supposé que ces germes élaient épars dans la nature, que tout est germe dans chaque corps vivant ou mort, dans chaque molécule inerte ou animée; qu'en un mot chaque. portion de matière a la propriété, non-seulement de participer de la vie, de la fomenter, de l'entretenir en la stimulant, ou en lui fournissant de nouveaux matériaux par les transformations dont elle est susceptible; mais que même elle pouvait la commencer, la produire, c'est-à-dire engendrer, quoique inerte, de nouveaux cọps vivans. Nous avons déjà réfuté cette vieille idée d'Aristote et des anciens auteurs, idée rajeunie dans l'autre siècle par un physicien systématique; nous l'avons, dis-je, combattue, et, ce me semble, renversée au chapitre des Productions vivantes et Spontanées. Il ne nous reste donc quà examiner si les nouveaux êtres résultent tout simplement du juste concours des deux sexes, ou si l'un d'eux en contient plus particulièrement ce que nous noinmons les premiers germes. Or, pour ce qui est de la première opinion, qui place l'origine 
318 LIV. III. DE L'ACCROISSEXIENT des CORPS VIVANS.

des germes dans l'union simultanée des deux semences ou dans la combinaison des molécules organiques provenant des deux sexes, nous savons à quoi nous en tenir à ce sujet, depuis que nous avons démontré dans le Livre II que la femelle n'a pas de semence. (Voy. chap. xxix.)

Nous avons aussi exposé ( chap. xviII et xxvin du Livre II) combien d'exagérations on a commises au sujet des prétendus animalcules spermatiques; et d'ailleurs nous avons prouvé, aux chapitres indiqués, que la semence dépouillée de tous ses animalcules apparens n'en jouit pas moins de la faculté de féconder les ovules des femelles. Une seule question nous reste donc à examiner, à éclaircir; il nous reste à rechercher s'il existe réellement quelque chose d'organisé dans l'ovule non encore fécondé de la femelle, et si, contenant ainsi le germe originaire de nouveaux êtres, cette femelle concourt plus que le mâle à la trame primitive des embryons engendrés.

Nous savons par avarce que, dans tout vivipare, de même que dans tout ovipare, le nouvel être apparaît d'abord au sein d'un ovule qui s'est détaché de l'ovaire de la femelle; nous avons vu qu'il ne provient rien de cet ovule sans l'advention de la semence, sans l'entremise du mâle; mais nous savons que cette semence n'a d'action que sur l'ovule. Or comme ce dernier est entouré, dès sa première apparition, de plusieurs membranes ténues qui semblent une ébauche des membrancs futures de lembryon, et comme c'est au cenire de cet ovule qu'apparaît l'embryon lui-même, lout nous porte à penser que ce corps contient originairement, sinon le foctus tout formé, 
CIIAP. V. PREZXISTENGE DES GERMES.

sinon tous ses organes entièrement arrangés, au moins les premiers élémens de cet embryon et de ses organes. D'ailleurs, les premiers linéamens du nouvel être sont déjà indiqués par une tache blanche dans l'œuf non encore fécondé des oiseaux, et ces premières traces d'organisation sont bien plus évidentes encore dans l'ouf de quelques reptiles. Or, pour admettre la préesistence de ce germe dans tout ovule, est-il nécessaire qu’il y soit visible? Ne savons-nous pas que chaque organe commencè par être fluide, et que tout fluide parfaitement transparent est par cela même invisible? Et une preuve que les premiers linéamens de l'embryon ne sont d'abord indiscernables que parce qu'ils sont primitivement fluides et transparens, c'est que les organes qui se manifestent d'abord ont dès cette première apparition un volume assez grand, si grand même, qu'on est porté à penser qu'avant d'être apparens ils existaient dans un autre état, et qu'au lieu de s'être formés peu-à-peu et spontanément, ils n'ont fait que subir une sorte de métamorphose. Un autre motif pour croire que tout embryon a ses linéamens renfermés primitivement dans l'ovule de la femelle, est la constance de chacun de ses organes, la régularité de ses formes, et l'identité de sa structure chez tous les êtres de la nuême espèce. On peut encore citer à l'appui de cetle même opinion le fait sur lequel Haller a eu raison d'insister, je veux dire l'union si constante et la continuité si merveilleuse du péritoine du jeune oiseau avec les tuniques du vitellus, ( oy. chap. xir et xvin du Livre II.) D'autres personnes ont aussi alléguć, en faveur du même sentiment, la génération successive de plusieurs Monocles, 
320 LIV. III. DE L'ACCROISSEMENT DES CORPS VIVANS.

de plusieurs Pucerons femelles vierges; mais nous avons exprimé ailleurs les raisons qui nous font récuser cette observation comme suspecte, ou du moins comme encore mal interprétée jusqu’à prẻsent.

Mais si les germes, bien qu'invisibles, sont préexistans dans l'ovule des femelles, on se demande s'il ne faut pas que ces premiers germes en renferment de nouveaux, ou plutôt si tous les individus de la même espèce ne devaient pas être contenus dans les ovules de la première femelle de cette espèce : c'est même ainși quel'on conçoit l'E mboîtement des germes; et nous sommes forcés de convenir que l'admission préalable de la préexisterice des germes entraîne irrésistiblement à sa suite leur emboîtement indéfini.

Il faut dire qu'il paraît d'abord fort extraordinaire d'admettre que tous lés germes nés et à naître se trouvassent origninairement renfermés dans les ovules des promiers êtres de chaque espèce, et qu'ils y fussent emboîtés dans de premiers germes eux-mêmes invisibles : mais voici comınent la chose nous paraît plus vraisemblable et plus admissible.

Chaque germe, bien qu'inappréciable, contient, avons-nous dit, tous les élémens des organes du nouvel être; mais il ne les renferme. qu'à l'état latent, à l'ćtat rudimentaire, à l'état d'élémens primitifs et non encore caractérisés et manifestes. Il n'existe encore là, sous la forme d'un fluide transparent dont les parties sont indiscernables, que les principes à l'aide desquels tout le nouvel être doit être ultérieurement constitué et organisé. Or, puisque les principes de tous les organes sont dans ce fluide incolore, lcs linćamens des ovaires s'y trouvent également, de 
CHAP. Y. PRÉEXISTENCE DES GERMES.

même que les élémens des autres organes; et comme ces oraires contiennent de leur côté de nouveaux ovules, et ces ovules, à leur tour, les élémens préformés d'embryons à venir, on voit bien que tous ces germes renferment tour-à-tour et simultanément les linéamens, les premiers principes des êtres qui doivent en provenir successivement, puisque chaque gérme contient tout ce qui doit servir à constituer un nouvel être, les linéamens des ovaires tout comme ceux des autres organes. Énfin, chaque ovule contient un germe ; chaque germe est la réunion des élémens d'un nouvel être; les ovaires se trouvent représentés dans cet ensemble comme tout le reste; et l'on sait que tout ovaire renferme plusieurs ovules propres à répéter les linéamens de nouveaux embryons complets, et par conséquent de nouveaux ovaires, de nouveaux ovules, et d'autres germes. Voilà comme je comprends le système de la préexistence et de l'emboîtement successif et indéfini des germes: il suffit, pour le concevoir, d'admettre l'existence d'un premier germe, renfermant tous les principes nécessaires à la formation et à l'arangement parfait d'un seul embryon; le surplus du système découle nécessairement de ce premier principe comme d'une pente naturelle.

On s'est toutefois, mais bien inutilement, occupé de chercher des preuves matérielìes à cet emboîtement successif des giermes préformés : on a cité les productions sans accouplement de plusieurs générations de Monocles et de Pucerons ; Spallanzani a allégué, dans un sens pareil, les végétaux, qui, selon lui, produisent des graines sans fécondation préalable. On s'est de même autorisé de ces bulbes végéI. 
322 LIV. IH. DE L'ACGROISSEMENT DES CORPS VIVANS. tales, renfermant ostensiblement à leur centre les bourgeons devant servir à plusieurs pousses successives; on a cité l'émboîtement manifeste des Volvoces, les grappes florales que présente le cœur des Palmiers pour plusieurs années successives, enfin, on a cité les cas assez rares, mais pourtant réels, de fœtus d'animaux renfermant dans leur intérieur le germe avorté d'un autre fœtus. Littre même a été jusqu'à arguer en faveur de l'emboîtement des germes, de quelques débris de fœtus qu'il avait trouvés dans l'ovaire d'une femme; comme si cela n'avait pas dû être l'effet d'une grossesse extra-utérine.

Ce n'est pas que la plupart de ces preuves ne nous semblent fort récusables; mais la théorie de la préexistence indéfinie des germes n'est pas moins la seule bonne, la seule soutenable. Sans elle, rien ne s'explique d'une manière satisfaisante : il faudrait attribuer un ordre constant au hasard, une succession d'êtres réguliers et ressemblans à autant de créations partielles, créations effectuées par des êtres différens et dans des circonstances dissemblables : aussi voyonsnous le plus grand nombre des philosophes et des grands naturalistes (1) donner le choix à celte théorie sur toutes les autres.

Toutefois, les anatomistes principalement ont opposé beaucoup d'objections à ce système : on a d'abord demandé s'il était possible de concevoir cette infinité de corps emboîtés les uns dans les autres depuis la création jusqu'à l'extinction finale des es-

(1) Haller, Ch. Bonnet, Spallanzani, Cuvier, Decandolle, Leibuilz, etc. 
pèces, et l'on a fait des calculs effrayans à ce sujet. Mais il est manifeste qu'on a eu le tort de transformer en élémens matériels, tous les germes prédisposés pour la vie dans chaque espèce vivante : on a pris pour de de petits corps déjà tout réalisés, ce qu'il ne fallait prendre que pour une aptitude à les engendrer; on a vu de petites masses toutes formées où il n'aurait fallu admettre qu'une puissance à les reproduire. Qui donc a jamais vu cette infirité de germes emboîtés, et depuis quand calcule-t-on le volume et la forme d'objets purement virtuels ou hypothétiques?

On a dit aussi que la ressemblance des enfans avec leurs pères était la preuve que tout l'être ne provenait pas de la femelle. Mais de ce que tout être nouvellement produit aurait sa source primitive dans les ovules de cette femelle, s'ensuit-il donc que le fluide séminal du mâle ne doive exercer sur lui aucune action? N'avons-nous pas vu qu'Aristote allait jusqu'à admettre que la femelle fournissait la Matière, mais que la Forme venait du mâle? On a objecté que l'existence de plusieurs variétés dans la même espèce devait détruire toute idée de préexistence des germes. Comment, a-t-on dit, comment concevoir qu'un être préformé dès la création première puisse subir des modifications dans sa forme et dans sa masse? Mais dès-lors qu'on admet forcément que le mâle peut bien modifier ce germe préformé, comment ne pas admettre aussi que le mâle, une fois modifié par tout ce qui l'environne et l'influence, ne puisse à son tour imprimer aux êtres qu'il féconde les traits de ses propres 'modifications? D'ailleurs, l'être né et déjà accru subit bien des changemens, pourquoi donc 
324 Lif. III. DI: L'ACCROISSEMENT DIS CORPS VIVANS.

le germe non fécondé, le germe encore inerte n'en subirait-il pas? Ce que je dis ici des variétés est également vrai, peut également se dire des métis et des mulets, résultant du croisement des races.

Buffon disait : dans la supposition de la préexistence indéfinie des germes, une grancle difficulté vient de l'inégalité de leur enclavement. En effet, l'emboîtement successif ne peut exister que pour les germes femelles, car lout germe mâle ne contient qu'un mâle, puisque tout germe émane de la femelle. Mais cette objection de Buffon ne serait tout au plus qu'une difficulté pour l'esprit, et seulement selon l'idée qu'il se formait lui-même de ce système de la préexistence; mais ce n'est point un obstacle pour la nature. Bien plus, cette difficulté que Buffon fait naître de l'unité des germes mâles et de la multiplicité des germes femelles, atténuait la première objection qu'il fondait sur la multiplicité effrayante des germes emboîtés.

Une autre objection bien plus importante, infiniment plus sérieuse que celles qui précèdent (car nous ne voulons en cacher aucune), est l'apparition successive des organes, leurs changemens de formes, les complications de plusieurs et la simplification du plus grand nombre. Car, dit-on, si les organes apparaissent successivement, s'ils changent, s'ils se compliquent ou se simplifient, tous n'ont donc pas une origine contemporaine, les élémens n'en étaient donc pas prẻformés, et ce qu'on dit de la préexistence des germes n'est donc qu'un vain système! Et, comme preuve à l'appui de l'argument, on cite le cœur des. oiseaux et des mammifères, qui n'a d'abord qu'une oreillette et qu'un ventricule, et qui acquiert pro- 
CHAP. V. PRÉEXISTKACE DES GERMLS.

gressivement les parties qui lui manquaient à sa première apparition. Mais comment se fait-il que l'organe parlequel Aristote, Harvey, Haller et Ch. Bonnet expliquaient l'animation du germe entier et la première manifestation de l'existence, soit précisément celui qui est le plus notoirement incomplet à la première apparition du foetus? Comment pouvaient-ils puiser une preuve à l'appui de leurs idées, là même où s'offre le motif de la plus puissante objection contre elles? C'est qu'Haller et Bonnet admettaient que le cœur et les autres organes sont d'abord à l'état fluide et indiscernable, et qu'alors qu'il n'en paraît qu'une partie, rela vient de ce que les autres parties ne sont encore que fluides et invisibles, quoique néanmoins déjà trèsréelles. Convaincus donc de cette préexistence du cœur et des autres organes déjà parfaits, mais à l'état fluide, dans un germe invisible, ces grands hommes disaient: l'action de la semence du'mâle s'exerce sur un ou plusieurs ovules de la femelle, sur les germes invisibles qu'ils renferment; non pas indifféremment sur toutes les parties de ces germes, mais seulement sur le cœur encore inanimé de ces germes; alors ce cœur entre en action, le fluide d'abord incolore, mais bicntôt coloré, qu'il renferme, va bientôt serpenter dans tous les organes et les animer tous ; et c'est de ce premier ressort mis en jeu par le contact du fluide séminal, que résulteni l'animation, l'accroissement et la solidification progressive de l'embryon d'abord fluide, d'abord invisible et inanimé, du germe préexistant. Bonnet pensait en outre .que le sperme n'agit sur le germe pour animer le coeur, et par lui tous les organes, qu’à la manière de l'électricité ; il en- 
326 Liv. III. DE L'ACCROISSEMENT DES CORPS vivaxs.

gagea même son ami Spallanzani à tenter des expériences à ce sujet, et Spallanzani épronva que les pressentimens de Bonnet n'avaient rien de réel : l'électricité substituée à la semence ne féconde rien; elle ne fait que hâter l'accroissement des germes fécondés. Mais revenons à l'objection des anatomistes.

Il est donc certain, disent-ils, que le cour est imparfait à sa première apparition, que ce n'est que successivement qu'il s'achève, et que supposer fluides les parties d'abord invisibles n'est qu'une pure supposition, autorisée, il est vrai, par le système de la préexistence des germes, mais non de nature à fortifier ce système. Il est pareillement avéré qưe la plupart des organes sont d'abord divisés, morcelés, que les matériaux en sont primitivement plus nombreux qu'ils ne le paraissent dans les organes parachevés; que les os sont d'abord cartilagineux, et qu'ils ne s'achèvent que par des points osseux détachés, isolés; que les dents sont originairement cachées sous forme de germes dans les gencives. Mais il faut observer que ces différens faits sont plus favorables à la préexistence des germes qu'ils ne lui sont contraires. Nous ne voyons, en effet, dans ces différens phénomènes, que des progrès, des changemens, des transformations, des perfectionnemens successifs, et non des formations nouvelles. Enfin, le fait allégué comme objection, que les membranes chorion et moyenne de l'œuf des oiseaux n'existent qu'au bout de quelques jours d'incubation, et que par conséquent elles ne préexistent point à la fécondation; ce fait, disons-nous, ne contrarie nullement l'hypothèse de la préexistence des germes; car les membranes dont il s'agit résultent du 
déploiement successif de l'allantoïde, de l'allantoïde qui est elle-même un prolongement de la vessie, et ce n'est là qu'un phénomène d'accroissement et d'élongation.

Au reste, nous devons dire que les objections que nous venons de passer en revue, s'appliquent bien plutôt à l'hypothèse de Haller et de Ch. Bonnet qu'à toute autre théorie des différens auteurs; j'ajoute même que ces objections n'attaquent que bien faiblement celle que nous avons exposée vers le milieu de ce chapitre. Mais il faut néanmoins se souvenir que ce n'est qu'une Hypothèse.

\section{CHAPITRE VI.}

Principales Lois selon lesquelles se développent les Organes des Animaux.

Tout est originairement fluide dans l'ovule où se développe l'embryon; ce n'est que peu-à-peu et par degrés que les organes apparaissent et se solidifient. Or, cette solidification n'est pas simultanée pour toutes les parties. Il en faut dire autant des couleurs : elles ont de niême leurs progrès et leur succession. La couleur du sang n'a pas d'abord cette vivacité qu'on lui connaît dans les animaux adultes, mais elle est la première à se manifester; ce n'est que plus tard qu'apparaît la couleur verdâtre de la bile, plus tard que la choroide se noircit. Le cerveau et les reins ont d'abord universellement une couleur homogène : les 
deux teintes naturelles à ces organes ne sont pas originaires.

Les organes les plus homogènes et les plus concentrés dans les animaux adultes, sont fractionnés, composés de lobes ou de points séparés à leur première origine dans la fœlus. Les os qui ont le plus dè continuité dans les animaux parfaits, sont formés, chez l'embryon, de points osseux plus ou moins multipliés et que séparent des cartilages, lesquels sont insensiblement envahis par la matière osseuse; et c'est seulement alors que l'os devient partout similaire. Les reins (je parle principalement de l'embryon humain), les reins et le foie sont d'abord composés de parties détachées, de lobes séparés les uns des autres, et qui emploient à se réunir un temps plus ou moins long.

Les organes des animaux supérieurs affectent une. symétrie d'autant plus parfaite qu'ils sont plus rapprochés du moment de leur origine. Cela vient surtout de ce qu'ils procèdent (au moins le plus grand nombre) de la circonférence au centre, et non pas du centre à la circonférence, ainsi que le croyaient nos pères. Les nerfs sont visibles avant les centres nerveux auxquels ils tiennent attachés; les parties latérales du cerveau et de la moelle épinière sont d'abord isolées, et ce n'est que postérieurement que se forme la partie médiane de ces organes par la réunion de leurs parties latẻrales. Il en est de mème des os : leur solidification commence toujours parallèlement sur chaque moitié latérale; même les os impairs ont des points d'ossification doubles et symétriques avant de sc concentror en un point cen- 
tral. Egalement, la matrice est d’abork bilide, la glande thyroïde aussi; partout l'on voit se rúaliser cette loi de développement excentrique et de symétrie : on assure même que les vaisseaux sanguins suivent la même règle dans leur développement, c'està-dire que les petits vaisseaux de la circonférence précèdent les gros vaisseaux du centre.

Si l'on en croyait le témoignage des sens, tous les organes ne seraient pas contemporains : il y a des temps différens, la chose est certaine, pour la manifestation de chacun d'eux. La moelle épinière est l'un des premiers à se montrer; on voit le cour avant les poumons, le foie avant la rate, le cerveau avant les reins et l'estomac, les vaisseaux sanguins avant les os. Mais est-il sûr que cette appàrence successive des organes soit l'indice irrécusable d'une origine difürente? A-t-on prouvé que les organes les derniers visibles ne se soient formés quaprès les autres? Ne serait-ce pas là Je simple effet de la transparence des tissus ou des fluides originares? Enfin, les organes, tout successifs qu'ils sont quant à leur première apparition, ne sont-ils pas tous simultanés pour l'origine, le même germe n'en contient-il pas à-la-fois tous les élémens? Toujours est-il quils ne sont pas tous apparens aux mêmes heures, de même qu'ils sont loin d'avoir primitivement la forme et la disposition qu'on leur voit dans des animaux adultes. D'ailleurs, tous ne vivent, tous ne subsistent pas durant le même laps de temps; lous n'ont pas la même durée. Sans parler de ceux qui se confondent ou se transforment; sans parler du canal auriculaire, qui disparaît dans le reste du corur à l'époque où celui-ci se 
parachève; sans parler du trou de botal, du canal ou des canaux artériels, des vaisseaux ombilicaux et omphalo-mésentériques qui s'oblitèrent et s'effacent, il y a les dents qui se remplacent successivement après leur première et lente apparition; il y a le thymus qui s'atrophie jusqu'à s'anéantir, et les capsules surrénales qui diminuent aussi d'une manière sensible. Enfin, il est vrai de dire que, parmi les organes dont le rôle n'est que subalterne pour l'accomplissement de la vie, il en est plusieurs qui disparaissent avant le terme de l'existence, soit que ces parties ne fussent destinées qu’à un usage temporaire, soit qu'ils n'eussent, même dès l'origine, absolument aucun usage à remplir.

Nous avons dit que les organes commencent tous par un état de fluidité parfaite, et que ce n'est que par degrés insensibles qu'ils prennent la consistance qui leur est naturelle. Il faut ajouter que cette sorte de révolution dans la structure est plus lente à s'achever que les changemens dans la configuration : un os a déjà sa forme indiquée dans la trame cartilagineuse qui n'en est que le premier commencement; les différentes parties dú cerveau sont déjà dessin̨ées au moment où plusieurs d'entre elles sont encore liuides ou creuses à leur centre, et avant que les deux couleurs, regardées comme indice de deux différentes substances, se soient encore manifestées. Enfin, la texture n'est pas aussi promptement terminée que la conformation et l'arrangement extérieurs.

Disons aussi que les organes ne sont pas à tous les âges dans les mêmes proportions pour le volume : Les orgarses principaus sont évidemment d'autant plus 
prédominans qu'on s'éloigne moins des premiers temps de leur formation. Cela est vrai pour le foie, pour le cœur, pour le cerveau; cela est également vrai pour les yeux et pour les nerfs des folus. Sans doute ces organes n'ont pas encore le volume qu'ils doivent avoir lorsque la crue sera parachevée; mais ils prédominent alors sur le reste, et leur développement subséquent est moins marqué qu'en beaucoup d'autres organes. Il se pourrait même que le foctus humain de huit mois dût à une condition de cette nature l'inviabilité qu'on dit être plus formelle pour cet âge que pour des fotus plus jeunes d'un mois. Il existe d'autres organes dont la cruẹ se ralentit ou qui même s'attrophient.: nous en avons parlé. Il est aussi des tissus ou même des espèces d'organes dont l'origine ou l'accroissement excessif sont l'effet de maladies. Les parties les plus précoces et les plus vivantes sont en général celles qui sont les plus rapprochées de la tête.

On a cru trouver des analogies importantes, non seulement entre les différens animaux (surtout les vertébrés), mais encore entre les animaux des différentes classes et les âges de l'homme et des mammifìres les plus semblables à l'homme. Cette idée, encore toute jeune, a reçu tant de développemens, et jouit d'une si-grande importance aujourd'hui, que nous nous trouvons porté à lui consacrer un chapitre à part. Mais nous allons commencer par montrer les analogies des animaux supérieurs entr'eux. 


\section{CHAPITRE VII.}

Analogies de composition des Animaux rcrtébrés.

Si l'on se contentait d'énoncer que tous les animaux vertébrés sont analogues entr'eux, on pourrait croire qu'il s'agit là d'un paradoxe exprimé en termes trop vagues pour mériter réfutation. On pourrait demander en quoi un serpent ressemble à un mainmifère quadrupède, et quelle sorte d'analogie on peut trouver entre une grenouille et un oiseau. Si l'on ajoutait que ces différens animaux, tout dissemblables qu'ils parais:ent, sont néanuroins composés des mêmes élémens, des mêmes tissus; quỉils jouissent de propriétés pareilles ou du moins fort analogues; on pourrait encore repousser celte idée comme vaine et superlue : cette analogie d'instrumens paraîlrait naturelle en des corps jouissant tous égaleinent de la vie: Telle est, en eflet, l'idée qu'on se fórma d'abord de l'Analogisme, lorsqu'un naturaliste du premłer ordre en promulgua les lois et en déduisit les conséquences. On rejeta ses vues sans examen, et l'on traita de chimère une pensée pleine de profondeur et de vérite. Chacun combaltit et rejeta cette idée, uniquement d'après le sens qu'il $y$ attachait personnellement. On ne daigna même pas s"informer ce que voulait exprimer l'auteur original; et ce fut la faute du mol analogie. La signification de ce terme était trop bien arrêtée dans le langage commun, pour qu'on pût 
CHAP. VII. ANALOGIES DES ANMULX VRTTERRES. $5 \overline{5}$ penser qu'il exprimât celtc fois une idéc nouvelle : aux choses neuves il faut des mots nouveaux.

On doit donc entendre ici par ce mot d'analogie, que les organes des animaux vertébrés sont composés des mêmes matériaus constitutifs, et jusqu'à un certain point du même nombre de pièces pour chaque organe similaire. Cela ne veut pas dire que ces animaux aient tous rigoureusement le même nombre d'organes ou de compartimens d'organes: non, car il en est beaucoup qui manquent toul-à-fait de certaines parlies qu'on retrouve très-développées dans d'autres espèces. 11 est sûr que les Boas, privés de membres, ne sauraient ressembler, sous ce rapport, aux mammifères pourvus de quatre membres, ni aux poissons pourvus de nageoires; mais dans des organes analogues, on retrouve des matériaux, des pièces constitulives analogues. Nous n'avons même pas besoin de parler des organes intérieurs, tels que les arlères, les viscères, les muscles, etc. : c'est une chose connue même du vulgaire, cue les animaux supérieurs de l'apparence mêne la plus dissemblable sont analogues par les organes intéricurs, par les entrailles. Nous n'avons qu'à parcourir tous les organes des animaux vertébrés, pour nous assurer qu'il existe en beaucoup de points de leur structure des analogies inconlestables. Cependant nous devons dire que, pour mieux découvrir en eux ces parlies analogues, il est convenable d'étudier par choix les jeunes animaux, les embryons de préférence aux animaux adultes; car chez ces derniers, les caractères distinctifs des genres el des espèces finissent par dégruiser, sous d'apparentes différences, tout ce que la trame essentielle et primitive contient 
3.34 LIV. III. DE L'ACCrOISSEMENT DES CORIS VIVANS. d'identique on de similaire. Mais citons des exemples.

Rien ne paraît plus dissemblable au premier abord que l'enveloppe extéricure des animaux vertébrés : le moyen de voir des analogies entre des écailles, des plumes et une peau nue ou gluante! le moyen de trouver quelque similitude en tre la cuirasse des Tatous et la peau glissante et délicate d'une Anguille! Cependant, si l'on remonte jusqu'aux premiers âges des animaux, on trouve chez tous une membrane mince et molle, une peau simple et dénudée; et lorsqu'on suit les progrès subséquens de cette enveloppe, on est porté à voir, dans ses différens prolongemens, des productions analogues à ce même épiderme qui garnit constamment la surface de chaque animal. Qu'importe que l'extérieur soit velu, écailleux, emplumé ou cuirassé ! nous ne voyons dans toutes ces choses que des changemens dans le développement ou la configuration; mais ce sont toujours des productions de l'épiderme.

Parcourons le squelette, et ces analogies nous paraî ront encore plus évidentes. Nous voyons chez tous les animaux supérieurs une colonne centrale d'os empilés, nommés vertèbres; chez tous, des apophyses ou éminences naissent de ces vertèbres, et chez la plupart, ces apophyses se prolongent assez au-devant du corps pour former des côtes et constituer les parois d'une cavité recélant le cœur et des poumons. Toutes ces choses paraissent fort diversifiées chez les différentes espèces d'animaux accrus et parachevés; mais si l'on remonte jusqu'à l'origine, jusqu'à ce moment où l'ossification commence, alors on s'apercoit que les premiers élémens constitutifs sont sem- 
CHAP. VII. ANALOGIES DES ANIMAUX VERTÉBRÉS. 555 blables, que les points d'ossification sont les mêmes. Ceci est encore plus évident pour la tête des arimaux. Assurément il paraît d'abord difficile de penser que la lête d'un crocodille, d'un oiseau, soit composée des mêmes élémens, précisément des mêmes pièces que celle de l'homme ou d'un mammifère: si même on compare les os de ces différentes têtes provenant d'animaux adultes, on est forcé de convenir qu'on trouve entr'elles beaucoup plus de différences que de similitudes; elles semblent différer par les divers fragmens, presque autant que par la forme généralc et par l'ensemble. Mais si l'on prend ces têles osseuses à l'époque où leurs matériaux commencent à s'ossifier, on se convainc alors qu'il y a parité presque entière pour le nombre de pièces dont elles se composent originairement. D'où vient donc, direz - vous, qu'après tant de ressemblance entre les matériaux, il survient de si notables contrastes dans l'ensemble de l'œuvre? pourquoi tant d'analogie dans les élémens produit-elle finalement des dissemblances si notoires dans l'édifice total une fois qu'il est accompli? Ici la question se complique : les pièces essentielles sont d'abord en nombre pareil, cela est vrai; mais toutes n'ont ni la même configuration ni le même volume; telle partie, excessivement réduite dans une espèce, prend un rolume extrême dans telle autre; et cette partie si accrue dans certains animaux, fait souvent comme avorter d'autres parties qui l'avoisinent. Il y a des têtes où le vomer et les os du nez ont presque autant de volume que l'os du front; mais ce ne sont pas moins pour cela le coronal, les naseanx et le vomer. Une autre cause qui diver- 
siiie, dans la suite, des organisations identiquement les mêmes quant aux élémens primitifs, c'est que ces élémens, c'est que ces fragmens divers restent isolés les uns des autres dans cerlaines espèces, tandis qu'il en est d'autres où la plupart de ces pièces primitivement isolées se groupent et se réunissent ; et ces diverses dispositions se réalisent surtout dans ceite boite osseuse servant de réceptacle au cerveau et aux sens. 'Il fallait bien que l'enveloppe solide se modifiât à la convenance des organes essentiels qu'elle renferme et qu'elle protège.

Ce n'est pas, au reste, le seul exemple où les pièces du squelelte soicnt modifiées par les organes fondamentaux dans la dépendance desquels elles se trouvent : dans les poissons, par exemple, nous voyons les os de la poitrine suivre dans leur déplacement les organes respiratoires, et se grouper comme cux aux environs de la tête. L'air ne pouvant aller chercher le sang et les branchies dans des animaux séjournant dans l'eau, il fallail bien que le sang et les branchies se rapprochassent de l'eau renfermant un peu d'air', qu'elles se plaçassent dans le voisinage des mâchoires qui expriment l'air de cetle eau qu'elles compriment; et puisque les branchies devaient se déplacer, il fallait bien qu'elles fussent accompagnées des os qui les soutiennent, et des muscles qui les font agir. Tout s'enchaîne et se nécessite dans les organisations vivantes comme dans nos institulions sociales.

Ces analogies, si évidentes pour le système osseux, ont de même été constatées pour les organes nerreux. Mais roici ce qu'il est essentiel d'observer. Les organcs des animaux rertébrés sont analogues quant 
CIIAP. VIII. PARALLÈLE DES AGES ET DES ESPÈCES. 350 à leurs élémens constitutifs, ils sont analogues à une certaine époque; mais cette époque n'est pas la même pour toutes les classes : les jeunes mammifères ressemblent à l'embryon de l'homme moins accru qu'eux; mais ils ressemblent en même temps aux jeunes oiseaux plus accrus, et aux reptiles et poissons encore plus accrus ou même déjà parachevés. Ainsi les classes de vertébrés ne sont analogues qu'à des âges très-différens pour chaque classe : les poissons et les reptiles ne ressemblent qu'à des oiseaux et à des mammifères plus jeunes qu'eux; et comme ces derniers êtres continuent de croître et de se compliquer à une période où les reptiles et les poissons demeurent slationnaires, il en résulte que des structures qui semblaient d'abord fort similaires, finissent par devenir extrêmement différentes et presque sans analogie notable. Ceci nous conduit à traiter du Parallèle des âges avec les différentes classes d'animaux, et à examiner la théorie des Monstruosités les plus ordinaires.

\section{CHAPITRE VIII.}

Échelonnement des Organisations animales.

(Les premiers âges de l'homme correspondent successivement aux diflërentes classes des animaux vertébrés : aux poissons d'abord, puis aux reptiles, aux oiseaux et anx mammifères (1). )

Nous venons d'établir que les différentes classes des animaux supérieurs, malgré leurs dissemblances

(1) Voyez Geoffroy-Saint-Hilaire, Autenrieth, F. Meckel, Tiedemann, Bainville, Serres, Oken, Goüthe, etc.

I. 
3.38 IIV. III. DE L'ACCROISSEMENT DES CORPS VIVANS. apparentes, peuvent être ramenées à un type commun, à une base à-peu-prês identique pour tous ces êtres. L'objet de ce chapitre-ci est de montrer que chaque animal supérieur subit des révolutions analogues à ce qu'on observe dans toute la sćrie des animaux qui lui sont inférieurs; autrement, un seul animal vertébré présente dans ses évolutions successives, depuis sa première origine jusqu'à son achèvement parfait, tout ce que les diverses classes placées plus bas ont de différences permanentes. Il suit de là qu'on pourrait faire une véritable anatomie comparée (quant aux choses principales) en suivant avec assiduité l'accroissement d'un même embryon.

Il suffit de parcourir, en les résumant, les détails où nous sommes entré touchant l'accroissement des animaux supérieurs, pour motiver les principes que nous venons de poser.

Par sa mollesse, par sa parfaite dénudation autant que par sa simplicité, la peau de l'embryon humain ressemble à la peau durable des méduses, des polypes, et de quelques reptiles sans écailles. L'ouverture antérieure et médiane qu'offrent temporairement les parois du ventre de ce même fotus encore trèsjeune, le fait ressembler, sous ce rapport, à quelques mollusques de l'ordre des huîtres, dont le manteau reste divisé durant toute la vie. Dans le premier âge aussi, les muscles sont décolorés, mous, gélatineux, et ils sont privés de tendons, comme dans les animaux les plus inférieurs, comme dans les vers, par exemple. Les os du fotus humain sont presque arrondis, comme dans les animaux moins élevés, mais adultes. Le même os qui, plus tard, ne doit former qu'un tout unique, 
GHAP. MII. PARATLLE DES ACRS ET DES ESPICES. 359 est presque toujours divisé, dans le premier âge de l'homme, en autant de points d'ossification que le même os offre de pièces séparées chez les mammifères et les oiseaux, mais surtout chez les reptiles et les poissons adultes. Cette disposition, cette correspondance de l'état temporaire des os de l'homme avee l'état permanent des mêmes os dans les autres vertébrés, est surtout manifeste dans l'occipital et le sphénoïde, dans le maxillaire supérieur et le temporal, dans plusieurs os de la face et dans le sternum : le sternum - par exemple, a presque toujours neuf pièces dans les premiers âges du fœtus humain, et il en a de même neuf, toute la vie, chez les tortues. L'os maxillaire supérieur est d'abord composé de cinf pièces dans l'embryon de l'homme, et le même os du crocodile conserve persévéramment ces cinq pièces isolées. Nous pourrions citer beaucoup d'autres exemples de ces parallélismes des âges et des classes, exemples également puisés dans les détails du squelelle. C'est même en vertu de cette loi que les os des animaux inférieurs sónt, en général, plus nombreux que ceux des animaux plus élevés qu'eux, et que le squelelte animal présente d'autant plus de pièces osseuses isolées qu'on se rapproche davantagé des premiers temps de l'ossification. Enfin, il y presque autant de différence entre le squelette im parfait du fotus humain et le squelette de l'homme adulte, qu'entre. le squelette d'un reptile adulte et celui d'un mammifère à l'état de fotus.

Nous verrons constamment de pareilles similitudes entre l'état permanent des aninaux inférieurs et les états transitoires de l'embryon des êtres plus élevés. 
3 亿̧O LIV. HI. DE L'ACCROISSENENT DES CORPS VIVINS. Le cueur du foetus humain, par exemple, est d'abord formé d'une cavité unique; ensuite il se complique jusqu'à avoir quatre cavités différentes, qui même, après avoir momentanément communiqué toutes ensemble, ne tardent pas à s'isoler.l'une de l'autre; de sorte que les deux cavités du côté gauche finissent par n'avoir plus de communication directe avẹc les cavités droiteś. Cette esquisse des progrès du cœur chez l'homme, chez les mammifères et les oiseaux, indique une nouvelle analogie entre l'embryon humain trèsjeune et ?’encore privé d'un cœur apparent, et les Vers qui. n'ont jamais de cœur; puis, lorsque le cœur de l'embryon a déjà un ventricule, il ressemble à celui des Araignées 'et des crustacés : après cela, ce cœur a deux cavités comme celui des poissons et des reptiles batraciens. Enfin, lorsqu'il a trois cavités (les deux oreillettes n'en formant qu'une), il ressemble au cœur dés Tortues et des Serpens; et tant que la cloison de sés oreillettes reste percée de ce qu'on nomme le trou de botal, le cœur du fotus humain offre une analogie frappante avec une disposition permanente chez les Phoques.

En poursuivant cette comparaison des progrès du fotus avec l'état permanent des animaux adultes d'un ordre inférieur, nous voyons le sang veineux de l'embryon humain communiquer primitivement avec le sang artériel, disposition naturelle dans tous les animaux inférieurs à partir des oiseaux : le conduit digestif du fotus est d'abord simple et court, sans cœecum distinct, sans estomac appréciable, comme dans les animaux de bas étage. Le foie est originairement composé de petits compartimens, comme 
CHAP. VIII. PARALELE dES AGES LT DLS ESPECES. Jíl on le voit toute la vie dans les crustacés; plus tard, il ressemble à celui des mollusques, alors qu'il est formé de lobes lâchement unis : ce même foie, si volumineux dans le fotus, est alors analogue au foie des animaux adultes des classes inférieures; et il ressemble surtout à celui des invertébrés; lorsqu'à son origine il manque encore de vésicule biliaire. La rate et le thymus, toujours absens en tout animal sans vertèbres ( et même ce dernier n'existe pas dans les poissons ), ces organes ne se développent que trìstard dans l'embryon de l'homme et des mammifères. Même remarque à l'égard de l'os sternum : il manque en beåcoup de reptiles et dans tous les poissons, et précisément sa venue est d'une extrême lenteur dans l'embryon des grands animaux. En général, les organes dont manquent les animaux inférieurs; sont les plus lents à se montrer dans le foetus humain. Au contraire, la plupart des organes qui n'existent que temporairement dans le fotus humain, sont des premiers à paraître : ainsi les branchies, dans notre espèce, ne sont visibles que dans les temps les plus rapprochés de la conceplion; l'espèce de queue que présente l'embryon de l'homme au quarantième jour, n'existe déjà plus vers le cinquantième.

Les reins des foetus des mammifères sont très-volumineux, comme ils le sont toujours dans les poissons; ils sont d'abord lobés et à surface inégale dans le folus humain, à-peu:près comme on les voit naturellement chez les poissons, chez les oiseaux, chez plusieurs reptiles et mammifères: I,es capsules surrénales sont d'abord très-grosses daus l'embryon humain, disposition analogrue à ce qui existc dans lés 


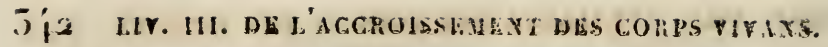

Siuges et dans plusieurs rongeurs adultes. II parait aussi qu'il existe d'abord un cloaque dans l'embryon de l'homme et des mammifères, comme il en exisłe toute la vie dans les animaux ovipares, et dans les Monotrêmes de M. Geoffroy-Saint-Hilaire.

Nous voyons de pareilles analogies dans les instrumens de la respiration, et dans la manière dont celle fonction s'opère : les oiseaux commencent par respirer au moyen des feuillets membraneux de l'allantoïde, comme les Polypes par la peau; le foetus de l'bomme a d'abord des branchies, comme les poissons : les reptiles batraciens, avant d'avoir des poumons aptes à agir, respirent par des branchies, comme les crustacés; les oiseaux respirent par de simples membranes avant de respirer par des poumons; et l'homme reçoit du placenta un sang tout prêt respiré, tant que ses poumons ne peuvent donner accès à l'air de l'atmosphère. Il est inême des animaux (quelques reptiles à métamorphoses) qui offrent successivement ces divers modes de respiration, et qui ressemblent ainsi tour-à-tour aux différentés classes d'animaux, excepté aux insectes (qui respirent par des trachées): ces reptiles respirent donc d'abord par la peau nue, comme les polypes; puis, par des branchies extérieures, comme les crustacés et les annélides; après cela, par des branchies intérieures, comme les poissons; et enfin par des poumons, comme les animaux de leur classe et de celles au-dessus.

La thyroïde et la prostate du fœtus humain sont originairement divisées en lobes isolés, comme ils demeurent toujours dans les mammifèrcs; la matrice, le clitoris et le pénis de ce méme embryon comınen- 


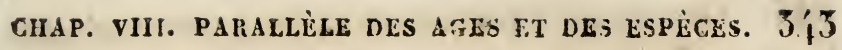
cent par être fendus en deux parties latérales, par ètre bifurqués; disposition persévérante dans plusieurs mammifères, en particulier dans la classe des rongeurs. L'embryon manque d'abord des parties génitales externes, et les animaux inférieurs n'en ont jamais. Le pénis est originairement imperforé, et seulement sillonné, comme dans ceux des mollusques, des reptiles et des oiseaux qui ont cet organe. Lestesticules sont d'abord renfermes dans le ventre, comme chez tous les animaux, à partir des mammifères. Enfin, il est une épóque, il est un âge, où tous les fotus humains paraissent femelles, à cause de la division.des organes extérieurs, et un autre âge où tous paraissent hermaphrodites, à cause de ces fissures externes, coïncidant avec une saillie excessive des organes : et cette disposition équivoque, mais temporaire, est précisément analogue à ce qu'on voit persévérer chez les mollusques et chez quelques poissons.

Mais ces analogies des états transitoires du fœtus avec l'organisation permanente d'animaux plus inférieurs parvenus à l'âge de perfection, ne sont nulle part plus manifestes que dans les détails des organes nerveux. Ainsi l'embryon de l'homme, celui que nous choisissons presque toujours pour terme de nos comparaisons, ce fœtus a d'abord les tubercules quadrijumeaux pareils à ceux des animaux parfaits des reptiles et des poissons : ces organes, chez lui, sont originairement creux, lobulaires, seulement doubles et non quadruples, et de plus ils sont d'abord placés à la superficie de l'encéphale; enfin, ils ressemblent aux mêmes organes des reptiles et des poissons accrus. 


\section{LIV. III. DE L'ACCROISSEMENT DES CORPS VIVANS̈:}

Les animaux mammifères sont les seuls où ces tubercules deviennent quadrijumeaux, les seuls où ils se solidifient par l'oblitération de leur cavité centrale: nous avons déjà parlé de cette particularité. Outre cette première analogie quant au système nerveux, l'embryon humain en offre plusieurs autres avec les animaux parfaitement accrus des classes inférieures : par exemple, les hémisphères du cerveau de l'embryon ont d'abord peu de volume, et ils sont comme roulés, ainsi que chez leś poissons parachevés. Le cervelet est lent à paraître et d'abord très-petit dans l'embryon, semblable en cela à celui des animaux ovipares et surtout à celui des reptiles. Le corps calleux du fotus humain est d'abord divisé; de sorłe qu'on le croirait absent, comme dans les oiseaux de tout âge.

La moelle épinière de l'embryon de l'homme présente une cavité centrale, et cette cavité est toujours permanente dans les animaux parfaits des classes inférieures aux mammifères; el même ses cordons latéraux sunt originairement assez isolés pour donner à l'organe entier l'aspect qu'il conserve toujours dans les animaux articulés. Outre cela, la moelle de l'embryon humain occupe primitivement toute la longueur du canal vertébral, comme chez les autres animaux; et ce n'est qu'à trois mois qu'elle remonie jusqu'aux lombes. Enfin (et nous parlons du systèıne nerveux) l'embryon de l'homme a beaucoup d'analogies, dans ses métamorphoses successives, avec des dispositions permanentes dans. les autres classes de vertébrés : analogies de couleur, de consistance, de yolume, de compartimens de plus en plus nombreux, ana- 
GHAP. VIII. PARALLÈle des AGES ÉT DEs esPìces. 345 logies de scissures, de circonvolutions, et même de facultés.

Quant aux organes des - sens, ils offrent des analogies de même ordre : la bouche du fœetus humain est d'abord sans lèvres, comme dans les animaux vertébrés des classes inférieures; son palais est d'abord divisé, et la bouche à cause de cela communique directement avec les fosses nasales, tout comme dans les reptiles et les oiseaux; la langue est primitivement petite, ainsi que dans les poissons; le nez et l'oreille, dans l'origine, n'ont rien de saillant à l'extérieur; autre ressemblance avec les cétacés et les grands animaux ovipares. L'œil enfin paraît d'abord sans paupière, ainsi qu'il l'est toujours dans les insectes, dans les crustacés, dans les mollusques, les poissons et quelques reptiles.

Enfin, la forme générale de l'embryon humain ne présente pas moins d'analogies avec l'état parfait d'autres animaux : la tête est d'abord assez peu indiquée, pour donner au corps du fœtus l'apparence d'un animal invertébré ; l'absence originaire des membres lui donne l'aspect d'un reptile ou d'un poisson; et le prolongement caudal, dont nous avons déjâ indiqué l'existence pássagère , lui donne momentanément un trait de ressemblance avec toute sorte de quadrupède.

Conclusion. L'embryon des animaux supéricurs présente, dans le cours de son accroissement, la plupart des particularités caractéristiques et permanentes de toules les classes d'animaux : il offre en lui, dans ses différens progrès; le modìle passager de presqac 
tous les genres d'organisations; les commencemens de l'homme sont comme l'image réduite, mais ressemblante, de tout la Règne animal.

Néanmoins (et pour éviter toute exagération), nous devons convenir que les ressemblances que nous avons remarquées, soit entre différens animaux considérés dans leur état de perfection, soit entre un animal supérieur observé dans ses différens âges, dans tous ses progrès, et d'autres animaux d'espèces diverses et inférieures; nous devons convenir, dis-je, que ces analogies sont loin d'établir entre tous ces êtres des similitudes parfaites et générales. Chaque animal conserve toujours, à tout âge, des caractères particuliers à son espèce; et trop de différences existent constamment entre ceux même qui nous semblent les plus ressemblans et de plus près rapprochés, pour que nous puisșions en conclure, ni que tous se doivent ranger suivant une échelle régulièrement graduée, partout unique et partout continue; ni que tous possèdent une trame commune, une base visiblement identique, le même nombre d'organes essentiels, et des organes de la même nature chez tous; ni qu'enfin tous aient pu provenir, par des complications et des métamorphoses graduelles, d'une souche commune, d'un type unique, binaire, ou même ternaire. Nous attestons donc que ces prétendues similitudes sont toujours ou vagues ou partielles, et qu'ellés nous paraissent insuffisantes pour motiver, soit la chaîne uni verselle de $\mathrm{Ch}$. Bonnet, soit la descendance et la filiation successive de Demaillet ou de M. de La Marck, soit enfin l'admission de l'identité organique des au- 
CHAP. VII. PARALLEL DES MGES ET DES ESPECBS. Ji teurs allemands ou français. Si les animaux se re:semblent universellement, nous l'avons déjà dit daus nos prolégomènes, ce n'est que par les phénomènes de l'existence; mais lorsqu'on descend jusqu'aux instrumens producteurs de ces phénomènes, on est surpris de ne plus trouver, au lieu de similitudes annoncées parfaites, que des disparates souvent choquans. Tel animal qui semblerait placé au-dessus d'un autre animal par quelques-uns de ses organes, lui est souvent manifestement inférieur par d'autres endroits de sa struclure : deux animaux entièrement ressemblans, quant à une sorte d'organes, sont quelquefois si dissemblables par le reste de leur conformation, qu'il est impossible de penser à les réunir; enfin, il est des organes qui manquent absolument dans des classes entières d'animaux, ou, ce qui est peutêtre encore plus frappant, qui ont dans deux classes d'animaux apparemment voisines, des dispositions entièrement discordantes. Bien plus, il est certain qu'il n'existe pas un seul organe, non seulement qui ue diffère d'un genre, d'une famille à l'autre, mais que l'on puisse relrouver universellement dans toules les familles, dans tous les genres d'animaux. Nous verrons les preuves de ce que nous disons ici à mesuré que nous avancerons dans l'étude des fonctions de la vie.

D’où vient donc tant de détails sur l'analogie, soit des espèces entr'elles, soit des âges avec ces espèces, et finalement quelles conclusions en tirer? le voici : c'est que les animaux vertébrés sont construits sur un modèle manifestement analogue; qu'ils offrent lous des affuilés évidentes et pour les phénomènes 
5:18 LIV. III. DE L'ACGroIssement des Corits vivans.

et pour les organes essentiels : encore (même pour eux) sommes-nous loin de conclure que la trame en soit parfaitement identique.

\section{CHAPITRE IX.}

Comment la Théorie des Monstruosités dérive des Lois de l'Accroi:sement.

On a pu prévoir par ce qui précède que beaucoup d'anomalies, beaucoup de difformités sourent monstrueuses, résultent d'un arrêt d'accroissement dans un ou plusieurs organes. Et comme l'animal incomplètement développé dans une partie, continue de croître pour le reste du corps, il résulte de là une disproportion entre les organes, qui peut aller jusqu'au disparate le plus choquant. Une autre conséquence du fait dont nous parlons, est la similitude que conservent avec persévérance des parties imparfaites et des organes comme avortés, avec les mêmes organes réguliers du même animal à une époque ąntérieure de son existence : en vain les organes seront-ils tous contemporains; si plusieurs d'entr'eux demeurent statiounaires pendant que les autres cheminent, il y aura toujours disparité dans la forme, dans le développeinent, dans le volume : c'est vainement qu'ils auraient tous la mệme origine; ils n'auront plus tous le même âge, tous n'ayant pas eu les mêmes progrès. Qu'importe enfin que-tous aient eu simultanément le même point de départ, si plusieurs d'entr'eux restent loin du but commun, el si plusicurs s'arrêtent 
CHAP. IX. THÉORIE DES MONSTRLOSITÉs.

absulument à différentes distances dans la carrière? Telle est l’idée qu'il faut avoir de la plupart des monstruosités.

Les preuves de ce que nous venons de dire sont aussi nombreuses qu'elles sont évidentes. Qu'est-ce, en effet, que l'absence des poils ou des dents; qu'est la perforation de la cloisun des oreillettes ou des ventricules du cœur; qu'est la conservation du canal artériel, la mollesse', la fluidité, ou la non réunion de l'encéphale ou de la moelle épinière, l'absence du corps calleux, l'excessive petitesse du cervelet, la vacuité permanente des tubercules quadrijumeaux; qu'est la mollesse des os, la persistance des points osseux et l'isolement persévérant des épiphyses; d'où viennent les os réputés surnuméraires, les divisions médianes des vertèbres, la conservation permanente des fontanelles ou des sutures ordinairement temporaires, le spina-bifida, la non réunion des pubis, la présence d'une sorte de queue dans des fœtus humains à terme; comment interpréter la division permanente du palais et de son voile charnu, la persévérance de l'os incisif, le bec de lièvre congénial, l'absence du cœecum, l'énormité du foie; l'absence de la rate ou d'autres organes, la division lobée des reins chez l'homme adulte, la persistance du thymus dans un âge avancé, l'imperfection des organes sexuels et leur ambiguité la plus ordinaire; comment enfin se rendre compte de l'existence du cloaque dans quelques mammifères, de l'excessive grandeur des yeux, du collement des paupières, de la fluidité et de l'opacité lactescente du cristallin, de l'occlusion persévé- 
50 LIV. III. DB L'ACCROISSEMTNT DES CORPS VIVANS.

rante de la pupille, de l'extrême petitesse du nez, de l'occlusion de la bouche, de l'exiguité de la face, et de l'absence des sinus maxillaires: quelle est, dis-je, la cause commune de ces anomalies, si ce n'est un défaut d'accroissement dans les parties qui en sont le siége? A la vérité, nous ignorons pourquoi certains organes cessent ainsi de s'accroître, pourquoi ils demeurent imparfaits; mais comme nous les avons vus passer par les mêmes degrés d'imperfection, et présenter de pareilles ébauches, en étudiant les progrès successifs de l'embryon, nous en concluons qu'ils se sont arrêtés dans leur crue alors que tous les autres continuaient d'aller leur train ordinaire. On peut même observer que plusieurs parties restent parfois dans un développement imparfait chez quelques individus débiles de l'espèce humaine : ainsi l'on vait de très-grands yeux bleus s'associer à des cheveux blonds comme ceux d'un jeune enfant, à un nez d'une petilesse extrême, à.des poils rares, à une barbe étiolée, à des membres petits et d'une forme gracieuse, à des os imparfaitement solidifiés, disposés méme à se déformer; et même, la plupart des difformités congéniales dont nous venons de tracer le tableau abrégé, coincident souvent avec de pareils caractères extérieurs.

Remarquons aussi que ce qui est difformité pour un animal est souvent une disposition naturelle et constaute dans un autre; de sorte que les monstruosités dans une classe d'êtres ont des analogies irrécusables dans l'organisation régulière d'autres aniınaux, aussi bien que dans les progrès naturels des em- 
CHAP. IX. THÉORIE DES HONSTRUOSITÉS.

bryons de mêıne espèce que l'être monstrueux : mais pour donner à ce principe toute l'évidence dont il est susceptible, citons des exemples.

Il est clair que le défaut de poils, chez un mammifère, est analogue à ce qu'ón voil dans les classes les plus inférieures, où la peau est nue. Si la peau est écailleuse, cela rapproche le mammifère des poissons et des reptiles ophidiens. La non réunion des pubis, anomale chez l'homme, est naturelle, est régulière dans les oișeaux et plusieurs autres ovipares. Les mammifères et l'homme ont quelquefois le palais divisé, comme les oiseaux, comme les poissons et plusieurs reptiles : je dis même chose de l'absence anomale des dents chez l'homme et les mammifères. Le développement monstrueux du foie a lieu naturellement dans les oiseaux, les poissons, quelques reptiles et céţacés. L'absence anomale de la vésicule biliaire est un trait d'analogie entre l'homme et les solipèdes, et beaucoup d'oiseaux et de poissons. L'absence d'une trompe ou d'un ovaire est anomale dans les mammifères; mais elle est constante chez les oiseaux et plusicurs mollusques. La bifurcation de la matrice, disposition monstrueuse dans l'espèce humaine, est régulièré et permanente en beaucoup de mammifères, de reptiles et de poissons. Enfin, n'avoir qu'un testicule, ou les avoir tous les deux retenus hors des bourses, dans l'abdomen; manquer de pénis, ou l'avoir imperforé, seulcment sillonné à sa surface; avoir un cloaque, conserver la membrane pupillaire après la naissance, ou offrir une pupille plus ou moins allongée ou déformée; manquer de langue ou l'avoir bifurquée; n'avoir que des membres comme avortés 
352 LIV. HI. DE L'ACCROISSEMENT DES Corirs VIVANS.

ou nuls : toutes ces, particularités d'organisation, monstrucuses dans l'homme, sont naturelles et constantes en d'autres espèces. On peut même dire que les monstres doubles sont analogues aux animaux composés des classes les plus inférieures, en cela, qu'ils s'unissent l'un à l'autre, non seulement par la peau, mais aussi, mais en même temps par le conduit digestif et par les vaisseaux.

Cependant, si ces difformités résultant de l'absence ou de l'imperfection des organes, trouvent leur explication dans le mode d'accroissement des animaux; si elles ont des analogies irrécusables dans les premières ébauches de leurs embryons respectifs, aussi bien que dans l'organisation permanente d'animaux plus inférieurs, nous devons dire 'qu'il est impossible de rattacher à la même loi les monstruosités par excès ou multiplication d'organes. Et d'aillenrs, quand même toutes les anomalies sembleraient résulter d'un défant d'accroissement, en connaîtrions-nous mieux la vraic nature et la cause précise? Savons-nous ce qui s'est opposé au parfait développement de telle partie, devenue monstrueuse à force d'être irrégulière et discordante? Savons-nous si la cause de celte difformité est primitivement inhérente au germe, à l'ovule de la femelle, ou à la semence du mâle : savons-nous si elle résulte du mode de fécondation; ou si, lui étant étrangère, elle lui préexiste ou lui succède?

Toutefois, doit-on remarquer au sujet des monsIruosités :

$1^{\circ}$. Qu'elles ne dépassent jamais de certaines limites: les difformités ont des règles stables comme les disposilions normales. Par exemple, le cour ne reste 
CHAP. IX. THÉORIE DES MONSTHUOSITÉs. jamais perforé à ses cloisons que selon un mode toujours analogue; les doigts surnuméraires sont tous semblablement disposés, etc.

$2^{\circ}$. Qu'elles conservent une sorte de symétric, au milieu même des irrégularités les plus choquantes.

$5^{\circ}$. Que l'absence ou l'amoindrissement excessif d'un organe coincide souvent avec l'extrême développement d'un autre organe.

$4^{\circ}$. Que les anomalies et les monsłruosités sont fréquemment héréditaires; ce qui autoriserait à penser qu'elles ont leur cause dans la disposition primitive des germes.

$5^{\circ}$. Qu'elles affectent les femelles plus souvent que les mâles, précisément parce que les femelles ont un degré d'organisation moins avancé.

$6^{\circ}$. Qu'elles ont plus de prédilection pour le côté gauche du corps que pour le côté droit, et par une raison semblable, le côté gauche étant toujours plus faible et plus imparfait.

$7^{\circ}$. Qu'un organe absent, déformé ou monstrueux, a nécessairement d'extrêmes influences sur toute la structure de l'animal imparfait; influences qui ne se bornent point aux formes et aux connexions, mais qui s'étendent même, en vertu des lois de soliảarité et de coexistence (1), à toute l'économie des orgares.

$8^{\circ}$. Que certaines difformités marchent ensemble; par exemple, l'absence du cerveau et l'absence des capsules surrénales; l'existence de doigts surnuméraires et la division persévérante de la voûte palatine; la perforation de la cloison inter-ventriculaire du

(1) Voyez notre rhysiologie Médicalc. 
55. LIV. III. DE L'ACGROISSLUENT DES CORPS VIVANS. cour, et la division médiane et permanente del'utérus et du vagin; la pelitesse excessive des poumons et l'énormité du foie. Ajontons que ces dispositions coexistantes dans les monstres, coexistent aussi, mais naturellement, dans plusieurs classes d'animaux.

$9^{\circ}$. Que les monstruosités extérieures consistent presque toujours en additions, en excès; tandis que les monstruosités internes sont ordinairement des soustractions, des disparitions plus ou moins complètes. Rappelons à ce sujet, comme source de ces particularités, que les parties extérieures sont doubles, symétriques et originairement divisées.

! $0^{\circ}$. Qu'un organe monstrueux, soit en plus, soit en moins, est rarement composé d'autres élémens, ou de moins d'élémens primitifs et fondamentaus, Tue l'organe régulier.

$11^{\circ}$. Que si beaucoup de monstruosités semblent résulter de la rupture originaire d'ovules fécondés simultanément ou à la suite l'un de l'autre, que si beaucoup de difformités et de dispositions bizarres paraissent tenir à des adhérences entre des organes et au moyen de tissus et de vaisscaux similaires; si des brides, si des compressions ou des blessures peuvent donner lieu à la plupart des monstruosités dont les observateurs sont le plus frappés, il n'est pas moins certain que beaucoup d'autres ne doivent paraître inexplicables, et ne proviennent de causes assurément inconnues; ne fussent que les inversions complètes des viscères de droite à gauche et de gauche à droite, ne fût-ce surtout que l'existence d'organes surnuméraires en des animaux ne manquant d'ailleurs d'aucune partie. 
CHAP. IX. THÉORIE DES MIONSTRUOOSITÉs. $\quad 355$

$12^{\circ}$. Que quand même la plupart des monstruosités sembleraient résulter de causes mécaniques agissant sur les organes à diverses époques de leur accroissement, il n'en faudrait pas moins convenir que' plusieurs paraissent absolument originaires, et antérieures même à la conception.

13․ Que les organes les plus diversifiés dans la série animale, sont les plus disposés à la monstruosité dans les êtres supérieurs.

14. Que la coloration des parties difformes et anomales n'est jamais pareille à la coloration des mêmes parties régulières.

I5․ Qu'un organe est d'autant plus exposé aux dif-. formités, que les révolutions qu'il subit naturellement sont plus nombreuses et plus compliquées.

$16^{\circ}$. Que les monstruosités diverses sont particulières, et jusqu'à un certain point constantes, dans tels organes et dans telles espèces d'animaux.

$17^{\circ}$. Que les parties ordinairement le moins symétriques et les plus inconstanles dans leur conformation, sont de même les plus disposées à devenir monstrueuses.

18. Qu'il est presque inoui qu'un monstre doublé ait, en outre de cette duplicité, des organes surnuméraires.

$19^{\circ}$. Qu'à la vérité, la même femelle produit souvent plusieurs fœtus offrant tous des monstruosités pareilles; mais que quelquefois aussi l'un de ces fœetus offre en plus le même organe qu'un foetus précédent avait en moins:

20. Qu'ún monstre double paraît résulter de cette: même loi, en vertu de laquelle les deux moitiés pri- 
356 LIV. III. DE L'ACCROISSEMENT DES CORPS VIVANS.

mitivement isolées d'un animal vertébré, se réunissent finalement pour former un être unique.

$21^{\circ}$. Qu'il n'est pas logique ( outre que cette hypothèse n'éclaire nullement le problème), qu'il n'est point raisonnable d'attribuer les monstruosités des organes à des modifications originaires des artères : car, s'il est vrai que le sang est l'élément indispensable de tout organe, s'il est vrai que le calibre des vaisseaux est toujours proportionné au volume de ces organes, comme à la nature, à la multiplicité et à l'énergie de leurs fonctions; s'il est démontré qu'un organe diminue lorsque ses vaisseaux se rétrécissent par une cause quelconque, il n'est pas moins avéré que les vaisseaux s'affaissent et s'oblitèrent à mesure que leurs organes respectifs s'atrophient; et qu'au contraire ils se dilatent et grossissent dans la même proportion que les organes dans le tissu desquels ils se répandent. D'après cela, comment prononcer si l'absence d'un organe ou si son excès d'accroissement vient de ce que ses artères sont plus ou moins amples; ou si les artères ne doivent, au contraire, les modifications de leur calibre qu'à l'état particulier de l'organe aựuel elles sont destinées? Comment distinguer la cause d'avec l'effet, en deux phénomènes "constamment simultanés et coexistans? D'ailleurs, fùt-il prouvé que toute irrégularité des organes provieut réellement d'une différence originaire des artères, saurait - on mieux la cause de cette différence, et le principe des monstruosités serait-il par-là révélé ?

$22^{\circ}$. Qu'erifin, les monstres ont toujours quelquesuns de leurs organes au-dessous de leur âge, et par conséquent au-dessous de leur classe : jamais au-. 
CHAP. IX. THÉORIE DES MONSTRUOSITÉS.

dessus. Un oiseau ou un mammifère monstrueux a souvent des organes analogues à ceux d'un reptile ou d'un poisson; mais jamais un o iseau n'a d'organes de mammifères; jamais un poisson, jamais un reptile n'en ont d'oiseau. Cette règle est générale et constante.

\section{CHAPITRE X:}

Lolllermaphrodisme accidentel des $\Lambda$ nimaux. - Reurarques sur les Organes sexuels et leurs Anomalies.

On pourrait regarder le sexe mâle comme un degrí d'organisation plus avancé que le sexe femelle : quelques personnes ont même été jusqu'à affirmer que les organes génitaux mâleš résultaient du développement ultérieur d'organes originairement femelles. Toujours est-il qu'il est une époque où tout embryon des classes supérieures, quel que soit son sexe, paraît formé sur un patron femelle : bien plus, alors que les différences sexuelles se sont nettement prononcées, les foetus mâles offrent encore de notables analogies avec les fotus de l'autre sexe : les testicules sont encore contenus dans l'abdomen, et la verge a l'urèthre encore perforé en dessous, etc. Et dans l'enfance même, ce n'est qu'avec une grande lenteur que les mâles prennent les caractères décidés de leur sexe; ils sont mâles depuis long-temps par les parties génitales, qu'ils restent encore femelles par le reste de la structure. Les jeunes garcons conservent de longues 
358 LIV. III. DE L'ACCROISSEMENT DES CORPS VIVANS. années le menton lisse, le larynx étroit, la voix argentine et les formes arrondies des jeunes filles; les petits oiseaux de tout sexe ont d'abord le plumage de leurs mères, et muent en même temps qu'elles. Il en est ainsi de tous les caractères extérieurs et distinctifs du sexe mâle : la crinière du Lion, les crêtes, les ergots ou les divers ornemens des oiseaux mâles, les ramures des Cerfs, les cornes des ruminans, les vives couleurs ou la puissante énergie qui sont l'apanage des mâles de quelques espèces, tous ces caractères sont lents à se prononcer.

Les diverses anomalies des organes sexuels peuvent être rattachées sans trop d'efforts au type normal, aux dispositions régulières : on peut leur trouver à toutes, de quelque sorte qu'elles soient, dies analogies évidentes, soit dans les accroissemens progressifs de l'embryon, soit dans les animaux achevés des classes inférieures, à l'être qui offre la difformité ou l'anomalie. Admettons d'abord que les organes génitaux des deux sexes, formés sur le même patron, n'offrent originairement aucune différence notable: il est clair que des organes toujours pareillement perforés et bifurqués, auront chez les deux sexes le caractère des organes femelles. Ensuite les organes mâles devenant plus saillans à une époque où la division médiane n'a pas cessé, les embryons des deux sexes auront tous à cet âge l'apparence d'hermaphrodites : enfin, un plus grand développement donnera aux organes mâles leurs caractères distinctifs, et alors toule confusion deviendra impossible entre les individus des deux sexes. Mais supposons que les organes mâles cessent de croître avant leur entier dévelop- 
CUAP. X. IIERHAPHRODISHE ACCIDENTEL.

pement; il est manifeste que selon le degré où ils se scront arrêtés, les animaux conserveront le caractère ou d'hermaphrodites ou de femelles, encore qu'ils aient des testicules dans l'intérieur de l'abdomen. Supposons maintenant que ce soient les organes femelles qui restent inachevés ou qui avortent, alors les animaux seront neutres, ils ne parîitront d'aucun sexe; et cependant ils conserveront la plupart des caractères des femelles, quoiqu'avec de moindres développemens. Ainsi, les mâles seront des femelles en plus, comme les neutres des femelles en moins. Or, la partie de cette proposition qui concerne les neutres, paraît démontrée par ce qu'on observe dans. les insectes hyménoptères, particulièrement dans le genre Abeille. Cette famille d'insectes a des mâles assez nombreux, peu de femelles, et le reste des laborieuses républiques qu'elles composent est formé d'abeilles neutres, n'ayant d'organes appréciables d'aucun sexe. Rien ne prouverait donc encore que ces êtres informes appartiennent plutôt à un sexe qu'à l'autre; mais voici les expériences qui l’ont appris. On a essayé de donner à ces animaux incomplets le développement qu'ont les autres insectes nés des mêmes larves et des mêmes parens qu'eux; on les a tenus renfermés comme se renferment d'elles-mêmes les abeilles-mères; une ample et convenable nourriture leur a été abandonnée ; et l'on s'est aperçu que dans des conditions aussi favorables, elles acquéraient des organes sexuels. On pense bien, d'après la ressemblance qu'ont ces mouches neutres avec les vraies femelles, qu'elles deviennent des femelles lorsque leur crue est accomplie ; c'est, en effet, ce dont on s'est assuré : jamais 
360 LIV. HI. DE L'ACGROISSEMENT DES CORPS VIVANS.

on n'a vu provenir de mâles, des larves d'où l'on savait que naîtraient naturellement des abeilles neutres; jamais on n'a vu de jeunes abeilles neutres se transformer en abeilles mâles. Ces remarques sont également vraies des neutres d'autres espèces, parmi les Fourmis et parmi les Termites, etc.

Cet accroissement artificiel des organes sexuels des insectes neutres prouve, il est vrai, que leur slérilité et leur imperfection génitale dépendraient de l'avortement des organes, il prouve que ces organes élaient femelles; mais il faut aussi convenir, et avec impartialité, que le même fail est la preuve irrécusable que, tout ressemblans qu'ils soient, les organes propres à chaque sexe ont aussi leurs élémens spéciaux, qui ne se transforment jamais.

On a donc eu tort de croire que tous les hermaphrodiles par anomalie n'étaient que des individus monstrueux du sexe femelle : c'est à tort, ai-je dit, qu'on l'a cru; car il est prouvé que beaucoup d'animaux mâles paraissent hermaphrodites par la seule raison que les organes sexuels se sont arrêtés dans leur développement. Ces organes, dans les cas dont nous parlons, présentent de si grandes analogies avec les organes femelles, qu'il est souvent impossible de décider, à la première vue, quel est réellement le sexe de l'être ainsi conformé : en même témps aussi les autres organes du corps présentent quelquefois des caractères trop ambigus pour ne pas accroître l'indécision. Il y a donc dans ce cas ressemblance et confusion des caractères distincts des sexes. Mais d'autres fois l'hermaphrodisme consiste dans l'absence d'un caractère sexuel. Enfin, il est une autre sorte 
CIIAP. X. HERMIPHRODISUE ACCIDENTEL. $\mathbf{3 6}$ d'hermaphrodisme : celui-là consiste dans la présence d'organes sexuels superflus, sur-ajoutés à un corps bien conformé en toutes ses parties, et formant contraste avec elles. Il y a donc trois variétés principales d'hermaphrodisme anomal ou irrégulier : l'hermaphrodisme par arrêt du développement, donnant lieu à la confusion de caractères encore mal dessinés; l'hermaphrodisme par absence de quelque caractère ( par absence des testicules, du vagin, de la matrice, par exemple ); enfin, l'hermaphrodisme avec addition et superfluité d'organes ambigus et contrastans. Nous allons entrer dans quelques détails touchant ces difformités sexuelles, presque toujours congéniales; et nous parlerons principalement de l'influence qu'elles ont sur toute la structure des corps où elles se rencontrent.

Nous venons de dire que les difformités des organes génitaux ont la plus grande influence sur les autres organes du corps; qu'ils en modifient l'aspect et souvent la structure, souvent aussi l'accroissement, et jusqu'aux fonctions. Il est rare que toute la structure du corps soit dans un contraste parfait avec les organes sexuels; je veux dire qu'il est peu ordinairé que des organes de femelles, par exemple, se trouvent associés à un corps paraissant mâle par toute son économie. Cela pourtant n'est pas sans exemple : les tribunaux français ont eu à prononcer tout récemment sur un cas de cette espèce; et il faut convenir que cette association d'organes sexuels contrastant avec l'aspect du corps, forme le genre d'hermaphrodisme le plus insidieux. Mais presque toujours le corps d'un vrai hermaphrodite porte universellement l'cmpreinte 
362 IV. III. DE L'AGCROISSEMENT DES CORPS VIVANS.

ou de la réunion superflue d'organes génitaux des deux sexes, ou de l'imperfection, de l'avortement ou de l'absence des organes d'un sexe : il y a, par exemple, du mâle et de la femelle, dans toute la structure d'un animal dont le sexe est double ou ambigu. Et même, tant est puissante l'influence des parties génitales sur le reste des organes, tant est grand le pouvoir qu'on a raison de leur accorder, qu'ordinairement on conjecture qu'ils sont imparfaits, déformés, ou débiles, dans un animal n'offrant que les traits incertains de son sexe. On augure peu favorablement des facultés viriles d'un homme dont les hanches sont larges, dont la barbe est étiolée et la poitrine étroite, dont les formes sont gracieusement arrondies, et dont la voix est douce et faible. Également, on conserve des incertitudes sur la bonne conformation de toute femme dont la voix a le timbre viril, qui a les hanches étroites, les extrémités volumineuses, et le menton velu. Le mutisme et le défaut de crêle chez les cơs, l'inaptitude à couver chez les poules, sont presque toujours de sûrs indices d'impuissance chez l'un, de stérilité chez l'autre.

L'espèce d'hermaphrodisme qui consiste dans le mélange ambigu d'organes génitaux des deux sexes, a fréquemment son siége d'un seul côté du corps, rarement des deux côtés. Notons bien qu'on observe tout le contraire pour l'hermaphrodisme résultant d'un arrêt dans le développement, et comme d'une sorte d'avortement des organes; celui - là est toujours égal des deux côtés, toujours symétrique. On conçoit qu'il ne peut pas être autrement disposé, puisqu'il est la conséquence de la division primitive 
et accidentellement persévérante d'organes qui auraient dû se réunir sur la ligne médiane du corps. Or, le premier genre, l'hermaphrodisme complexe, celui qui est unilatéral ou croisé, enfin l'hermaphrodisme véritable (avec organes associés des deux sexes) est plus rare que l'hermaphrodisme simple et symétrique, résultant d'un défaut d'accroissement des organes. Toutefois on en cite de nombreux exemples, surtout pour les poissons, pour des iasectes et des crustacés, très-peu pour les mammifères, encore moins pour les oiseaux, et nul pour les reptiles. On trouve souvent dans quelques poissons, particulièrement dans la Carpe, dans le Brochet et le Merlan, un testicule d'un côté du corps, et de l'autre côté un ovaire. On a de même trouvé, dans une poule, un testicule à droite et un ovaire du côté opposé. Morand a décrit un cas très-remarquable d'hermaphrodisme chez l'homme : d'un côté du corps on rencontra un testicule avec son conduit déférent; de l'autre côté il y avait un ovaire et une trompe; entre ces organes contrastans on trouva une matrice fort bien caractérisée et répondant à l'axe du corps. Mais presque toujours l'hermaphrodisme de l'homme est apparent plutôt que réel : ainsi voit-on des enfans qui n'ont qu'un testicule dans les bourses, et dont le pénis, arrêté dans son développement et percé en dessous, offre l'apparence trompeuse d'un clitoris. C'est là l'espèce d'hermaphrodisme que nous nommons. simple, par arrêt dans l'accroissement, sans mélange, sans confusion des organes des deux sexes. Quant au véritable hermaphrodisme, celui qui est unilatéral ou croisć, on a observé que les organes femelles se ma- 
56 ' LIV. III. DE L'ACChOISSEMENT DES CorPS VIYANS. nifestent plutôt à gauche, les organes mâles occupant le coté drơit. Cela paraît d'accord avec ce qu'on sait des sexes et des deux moitiés latérales du corps : il est naturel que le côté droit, comme le plus fort et le mieux organisé, soit dévolu de préférence au sexe le plus énergique. Toutefois, cette disposition est loin d'être constante.

Les organes constituant l'hermaphrodisme par leur difformité ou par leur association vicieuse varient selon l'espèce d'hermaphrodisme. Ainsi, dans l'hermaphrodisme simple, on par arrêt dans l'accroissement, presque toujours la cause d'indécision vient, tantôt du pénis, qui est imperforé, tantôt de la matrice, qui est divisée; d'autres fois, ce sont les bourses, qui sont fendues de manière à ressembler aux lèvres d'une vulve; d'autres fois, le clitoris, à qui une saillie excessive donne l'apparence d'un pénis imparfait. L'hermaphrodisme par absence résulte ordinairement ou de ce que les testicules sont arrêtés dans leur descente, ou de ce que le pénis est d'une petitesse excessive, ou de ce que la matrice ou le vagin sont absens ou imperforés, etc. Enfin, l'hermaphrodisme complexe, le véritable hermaphrodisme, a rarement son siége dans les parties extérieures de la génération : il consiste plutôt dans l'association d'un testicule et d'un ovaire, d'une trompe et d'un conduit déférent, d'une matrice jointe à quelque organe du sexe mâle. A raison de l'inaccès des organes monstrueusement associés qui le constituent, ce dernier genre d'hermaphrodisme serait donc de tous le moins apparent, le plus incertain, de même qu'il est de lous le plus rare, s'il ne déterminait pas dans le reste de 
CHAP. X. HERHAPIRODISHE AGGIDLNTEL.

l'économic quelques changemens propres à le manifester. Mais comme les organes génitaux ont une puissante action sur la structure entière du corps, il est sûr que l'espèce d'hermaphrodisme dont nous parlons a des effets d'autant plus marqués sur toutes les parties, qu'il dépend lui-même de la difformité des organes les plus influens, des organes intérieurs, ceux par qui sont imprimés les traits visibles et caractéristiques des sexes. Aussi est-ce presque toujours par l'aspect général des animaux, par leurs caractères extéricurs et leurs instincts, qu'on juge d'un hermaphrodisme qu'on n'aurait pu reconnaître pendant la vie, à cause de la situation profonde des organes où il a sa source.

Autre remarque importante. L'hermaphrodisme par absence d'organes et l'hermaphrodisme par arrêt dansleur accroissement, exercent aussi des influences notables sur toute la structure d'un animal; mais comme ces hermaphrodismes affectent des organes uniques et placés selon l'axe du corps, comme ils affectent également les deux moitiés latérales de ce corps, l'influence à cause de cela en est universelle pour tous les organes, et semblable pour chaque organe habile à l'éprouver, à la ressentir. Il n'en est pas de même de l'hermaphrodisme véritable, né de la réunion anomale d'organes sexuels non similaires : cette dernière espèce rendant le même animal mâle d'un côté, et femelle de l'autre côté, on conçoit qu'un pareil. croisement dans les organes génitaux doit exercer une influence croisée ou plutôt alterne sur la structure de l'animal. Il en est effectivement de ces phénomènes ì-peu-près coinme des effets de la 
566 LIV. IiI. DE L'ACCROISSEMENT DES CORPS VIVANS. compression et des altérations du cerveau. C'est même uniquement par ces altérations locales, alternatives ou diversement variẻes, qu'on a coutume de juger, à l'extérieur des animaux, de leur hermaphrodisme vrai; et voici quelques-unes des remarques pleines d'intérêt qu'on a faites à ce sujet.

On voit souvent des poissons offrir le plus parfait contraste dans la coloration de leurs deux moitiés latérales : la même disposition est exı̂rêmement rare dans les oiseaux, mais très-fréquente dans quelques genres d'insectes, principalement parmi certains $\mathrm{Pa}$ pillons. Dans les cas dont nous parlons, l'animal est tout femelle d'un côté, par la couleur, par la forme, par différens traits de la structure; et de l'autre côté, il est tout mâlc. Mais ce croisement de caractères sexuels et de couleurs contrastantes ne se fait pas toujours d'un côté à l'autre; quelquefois il a lieu d'avant en arrière, de haut en bas, ou bien il alterne deux fois de droite à gauche. Ainsi, dans les papillons, entr'autres dans le Leparis dispar, tantôt les antennes, la poitrine et les ailes antérieures ont les caractères d'un sexe, et les ailes postérieures aussi bien que l'abdomen, les caractères de l'autre sexe. Tantôt l'antenne et les deux ailes d'un côté sont mâles, et les mêmes parties du côté opposé sont femelles. Choses semblables ou analogues se rencontrent chez d'autres animaux plus élevés dans l'échelle des êtres : un Daim, plus femelle que mâle, n'avait de bois qu'au côté gauche du front; une Femme, réputée hermaphrodite, n'avait de barbe qu'au côté droit de la figure. On cite des hermaphrodites d'espèce humaine qui, présentant tous les traits du sexe 
par le haut du corps et par la face, étaient du reste mâles à partir du bassin, lequel était fort rétréci, les cuisses étant velues et carrées; mais l'observateur qui rapporte ce fait ne dit pas en quoi les parties génitales différaient des formes normales. Cela même, it faut le remarque:, est une cause d'erreur, et une cause puissaute; car de ce que l'hermaphrodisme véritable et à source cachée se décèle par des changemens évidens qui rejaillissent sur la structure de tout le corps, et qui se manifestent surtout à sa surface, de là résultent de grands changemens: dès que ces associations de caractères ambigus et contrastans apparaissent, on se hâte d'en conclure que l'être ainsi fait est probablement un véritable hermaphrodite; et cependant on devrait convenir qu'on s'en est rarement assuré, et que la constante précision de ces caractères extérieurs est loin d'être indubitable. Par exemple, il est certain qu'on a trouvé une des mamelles très-développée dans un homme qui était entièrement mâle par le reste de la structure, sans en excepter les parties sexuelles. Mais c'est en particulier pour ceux des insectes dont l'extérieur semble déceler l'hermaphrodisme, qu'on s'est rarement assuré si la disposition des parties génitales concordait par son ambiguité avec l'apparence ambiguë des surfaces. Toutefois, un naturaliste italien, Scopoli, dont l'autorité, il est vrai, est d'une importance assez mince (1), ce

(1) Scopoli prit un jour une trachée-artère d'oiseau pour une espèce d'animal inconnue, et il l'envoya, comme nouveauté, à la Société royale de Londres, où l'on découvrit aussitôt l'erreur. Cela valut à Scopoli les railleries des savans d'Italie et des sarcasıes imprimés do Spallanzaui ; mais terrible fut sa vengeance. 
naturaliste a rapporté l'observation suivante comne lui étant personnelle. Un Papillon du genre phalène ( $p h$. pini), mâle d'un côté et femelle de l'autre côté (quant à la coloration et aux formes extérieures), réunissait des organes génitaux des deux sexes. Cet an:mal s'étant accouplé avec lui-même par la projection du pénis en avant, vers une sorte de vulve, on remarqua que les œufs provenus de cet accouplement extraordinaire donnèrent naissance à des phalènes femelles qui furent fécondes à leur tour. On voit bien que cette observation prouverait que l'hermaphrodisme génital concorde avec l'hermaphrodisme signalé par les surfaces; il prouverait que certains hermaphrodites peuvent engendrer avec eux-mêmes sans intervention d'un autre individu; il prouverait, enfin, qu'il peut naître des animaux réguliers el uniformes d'un hermaphrodite, et que peut-être même ce sont des femelles qui en proviennent toujours. Mais rappelons-nous que c'est Scopoli qui rapporte ce fait; ajoutons cependant qu'un naturaliste irréprochable a cité un phénomène tout pareil, observé dans un Homard aussi hermaphrodite.

Toutefois, la preuve que l'hermaphrodisme apparent aux surfaces du corps, ou se manifestant par les habitudes, n'a pas toujours sa cause dans les parties génitales, c'est que ces changemens ostensibles ne surviennent quelquefois que très-avant dans le cours de la vie, après une existence déjà longue et constamment calme et sans accidens ni souffrances. Ainsi, il n'est pas rare de voir de vieilles femelles d'oiseaux, devenues infécondes par l'âge, revêtir peu-d̀-peu le plumage des mâles de leur espèce, emprunter leurs 
CHAP. X. HERMAPHRODISME ACCIDENTEL.

crêtes, leurs ergots; imiter leur voix et leurs chants, et prendre jusqu’à leurs instincts distinctifs. Des changemens analogues ne sont pas sans exemples même dans l'espèce humaine. Ajoutons que ce faux hermaphrodisme n'atteint que les surfaces, et qu'il n'arrive d'ordinaire qu'à cette époque de l'existence où les organes génitaux, d'ailleurs bien conformés, demeurent sans usage et sans énergie.

Plus les organes génitaux sont simples, plus ils sont ressemblans dans les deux sexes, et plus les animaux où cette disposition s'observe sont disposés à l'hermaphrodisme : c'est le cas où se trouvent les poissons. Quant à la cause de cette difformité, et ici j'entends surtout parler de l'hermaphrodisme complexe, ou avec alliance d'organes sexuels hétérogènes, cette cause est, comme de raison, inconnue. On a prétendu, il est vrai, que cette sorte de monstruosité était l'effet de l'entregreffement de deux sexes différens. Mais alors, comment concevoir que les organes génitaux soient les seuls qui éprouvent de ces associations vicieuses et contrastantes? D'où vient ce choix, cette prédilection pour des parties occupant si peu d'espace? A ce sujet on a fait du moins une remarque intéressante, c'est que lorsque les Vaches font deux veaux jumeaux et de sexe différent, on observe presque toujours que le veau femelle offre quelques caractères d'hermaphrodisme : comme si la nature, plus long-temps et plus occupée du mâle et de ses organes caractéristiques, moins prompts ঐ s'achever, avait étendu jusqu'à la femelle les derniers efforts d'une puissance trop persévérante pour l'un des sexes. 
3-0 LIV. IIr. DE L'ACCROISSEMENT DES CORPS VIVANS.

Ayons soin d'observer que nous n'avons eu en vue, dans ce chapitre, que le seul hermaphrodisme anomal ou irrégulier, et nullement l'hermaphrodisme naturel et ordinaire en quelques espèces, parmi les Mollusques êt les Vers, parmi les Radiaires, etc. Ces auimaux, naturellement hermaphrodiles dans tous les cas, diffèrent des hermaphrodites accidentels, en ce qu'ils sont habiles à se féconder d'euxmêmes, sans l'advention d'un autre individu possédant à la fois les organes des deux sexes et toutes les conditions indispensables à une fécondation parfaite; ce qu'on ne voit jamais dans les hermaphrodites irréguliers, à l'exception peut-être du Papillonphalène de Scopoli et du Homard hermaphrodite de Nichols, que nous avons cités comme phénomènes. Disons aussi que l'hermaphrodisme anomal ne va jamais jusqu'à l'Androgynisme, comme l'hermaphrodisme nalurel : je veux dire qu'un hermaphrodite anomal ne possède jamais des organes assez parfaits, assez distincts et assez complets des deux sexes. pour pouvoir saccoupler doublement avec un animal pareil à lui, exerçant alors simultanément tous les deux, l'un envers l'autre, la double fonction de mâle et de femelle. Non; l'hermaphrodisme accidentel et anomal ne va jamais jusqu'à l'androgynisme: 


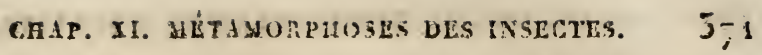

\section{CHAPITRE XI.}

Digression sur la Génération et les Métamorphoses des Insectes.

Disons d'abord quelques mots de la reproduction des insectes, sujet que nous avons volontairement omis au livre précédent, dans le dessein d'y revenir plus à propos et sans répétition à l'occasion de l'Accroissement et des Métamorphoses de ces animaux.

Jusqu’à Rédi, jusqu’à Swammerdam et Malpighi , on erra beaucoup sur le mode de reproduction des insectes : on se persuadait que la génération en était spontanće, et absolument étrangere à un concours des sexes. Mais les auteurs dont je viens de dire les noms détruisirent cette erreur, et mirent à la place des faits précis. On voyait apparaître des vers dans des substances animales disposées à la putréfaction ou déjà putréfiées, et l'on attribuait cette sorte de vers à la putréfaction même. En effet, le moyen de voir quelque similitude de famille entre ces êtres -imparfaits et les insectes ! le moyen d'apercevoir entr'eux quelque caractère de parenté, quelque indice de filiation! On ne savait pas encore les transformations subies par ces animaux; mais dès qu'on eut connaissance de ces métamorphoses, l'histoire entière de la génération des insectes ne tarda pas à se débrouiller.

Rédi prouva que les vers de la viande sont le produit des mouches qui voltigent à l'entour et qui s'en 
372 LIV. III, DE L'ACGROISSEMENT DES CORPS VIVANS.

nourrissent. Leeuwenhoek s'assura que les vers du fromage, espèce de Mittes, ont des sexes, et qu'ils s'accouplent et se reproduisent en pondant une sorte d'œufs d'où naissent de nouvelles mittes. D'autres observateurs acquirent la certitude que les vers qu'on rencontre dans des feuilles, dans des fruits, dans du bois, etc., proviennent d'autres insectes qui ont déposé là leurs œufs, bientôt transformés en larves ou vers temporaires; que ces vers donnent naissance à d'autres insectes parfaits, semblables à ceux d'où les œufs sont provenus; et que les petites: proéminences végétales qui leur servent d'asile, sont le produit des piqûres de ces insectes au moment de la ponte. Pareille chose a été prouvée, quoique plus difficilement, pour les insectes et quelques prétendus vers parasites des animaux; on s'est convaincu que tous proviennent d'un concours sexuel entre insectes de la même espèce, et qu'aucun ne se reproduit spontanément. Enfin, on a vu que la putréfaction des animaux morts, que les maladies des animaux vivans, favorisent la multiplication de certains insectes, paraissant d'abord sous la forme insidieuse de larves, et que ce sont là des circonstances favorables, mais non des causes réelles de leur reproduction.

Il en est donc de la génération des insectes comme de la génération dúplus grand nombre des animaux dont nous avons exposé l'histoire sous ce rapport: tous ont des sexes séparés, hors quelques cas exceptionnels d'hermaphrodisme ou d'un accroissement: avorté; tous s'accouplent, mais diversement; toute femelle a des œufs, qu'un mâle d'espèce pareille féconde au moyen d'une sorte de liqueur séminale. 
CHAP. XI. MÉTAMORPLOSES DES INSECTES.

Mais les femelles d'insectes ne pondent pas toutes des œufs; plusieurs mettent au jour des petits vivans, l'éclosion ayant eu lieu au-dedans du corps : voilà même pourquoi quelques inséctes sont regardés comme vivipares ou ovo-vivipares. Il faut remarquer que les insectes ne sont aptes à se reproduire qu'après avoir subi leurs métamorphoses, c'est-à-dire dans leur état d'achèvement parfait. Ainsi, tous ceux qui doivent avoir des ailes, ne se reproduisent jamais tant que les ailes ne sont pas achevées : et même ceux des insectes qui n'ont point d'ailes, n'engendrent qu'après' leur dernière mue, ou dernière transformation.

Tout ce qui regarde l'amour et l'accouplement des' insectes diffère pour chaque espèce : ainsi, il est bien vrai que, chez la plupart, c'est le mâle qui recherche et agace la femelle; toutefois dans les espèces où les sexes sont inégalement répartis, dans les Abeilles, par exemple, où l'on ne trouve qu'une femelle pour des centaines de mâles, dans cette famille si intéresSante d'insectes, c'est la femelle qui recherche les mâles, elle qui les incite à̀ l'accouplement : chef d'un' sérail, elle prend l'initiative d'un sultan. Presque tous les insectes ont les organes génitaux placés vers l'extrémité du tronc; et comme ces animaux légers s'accouplent presque toujours au milieu de l'air, en volant, beaucoup de mâles ont des espèces de crochets dont ils se servent pour saisir et pour retenir leurs femelles. Il résulte quelquefois de ce mode d'accouplement d'assez vives douleurs pour les femelles, et cela même les rend craintives et fugitives. devant le mâle attaché à les poursuivre. Cela n'est nụlle part plus remarquable que dans l'espèce élé. 
37́́ 'IV. III. DE L'ACCROISSEMTYT DES CORPS PIVAKS.

gante des Demoiselles, dont l'organisation est d'ailleurs si digne d'exciter la curiosité du naturaliste. La femelle de ce genre d'insectes a les organes génitaux situés à l'extrémité d'un corps très-allongé; et comme le mâle a les siens vers le milieu du corps, à-peu-près sur les limites communes du ventre et du corselet, on conçoit combien le concours nécessaire d'organes si étrangement disposés devait rendre bizarre et compliqué l'accouplement de ces insecles. Voici toutefois comme il s'effectue : le mâle saisit sa femclle au cou, au moyen de deux crochets dont l'extrémité de son corps est garnie; après beaucoup de mouvemens et de résistances, la femelle rapproche sa queue, où nous avons dit que se trouvent ses parties génitales, elle la rapproche du ventre $d u$ mâle, et c'est dans cette double et singulière jonction que la fécondation des œufs est consommée. Beaucoup d'insectes s'unissent pour l'accouplement comme les animaux des autres classes; mais il en est qui se mettent ventre a ventre, à-peu-près comme les hérissons; d'aulres; côté à côté, par exemple les sauterelles; quelquues papillons prennent les positions les plus bizarres.

Beaucoup d'insectes, vivant peu de jours ou peu d'heures, s'envolent aussitôt qu'ils ont des ailes, et s'accouplent en l'air dès leur premier vol. Les Ephémères et les Cousins sont particulièrèment dans ce cas, et leur accouplement est aussi court qu'il est prompt. D'autres insectes, parmi lesquels il faut citer les Scarabées et les Papillons, demeurent plus longtemps unis: on remarque même que plusieurs d'entre eux montrent la plus grande indifférence à ce qui les excite ou les entoure tant que dure la copulation, ce 
CHAP. XI. MÉTAMORPHOSES DES IYSEGTES.

qui leur donne un trait d'analogie avec quelques Reptiles, qu'on tue plus aisément qu'on ne les sépare. On assure que dans les Ephémères la femelle est placée sur le mâle.

Il n'y a de constant hermaphrodisme dans aucune espèce d'insectes; toutefois on en roit plusieurs présenter quelques individus réunissant les organes, des deux sexes; on a fait cette observation parmi certains papillons : probablement aussi il y a des saisons de l'année où beaucoup de Pucerons sont hermaphrodites; je fonde cette opinion sur les faits suivans. On a observé que les pucerons sont ovipares en automne, et vivipares au printemps : dans la première saison, la distinclion des mâles et des femelles est manifeste, et chaque ponte d'œufs féconds est précédée d'un accouplement. En été et au printemps, la chose est différente : alors on ne trouve pas de mâles, ou du moins ne les saurait-on distinguer des femelles on femelles prétendues. Alors aussi chacune de ces femelles, même lorsqu'elle a été réduite au plus parfait isolement, accouche d'autres pucerons dont l'apparence est également celle des femelles; et ces lignées d'insectes nés successivement les uns des autres, sont tous produits sans le concours des mâles, sans union sexuelle. Or, comment concevoir que de jeunes pucerons, femelles encore vierges, ;produisent, dès qu'ils sortent de leurs œufs, d'autres pucerons femelles engendrant comme elles sans aucun accouplement, et.cela pendant sept, neuf, douze générations successives, s'il faut en croire Bonnet? Non, la chose ne me semble pas croyable : si ces pucerons paraissent femelles, c'est qu'ils sont probablement hermaphro- 
376 LIV. III. DE L'AGGROISSEMENT DES CORPS VIVANS.

dites; et c'est par la même raison qu'ils se reproluisent sans l'accession des mâles, du moins pendant la belle saison.

Ordinairement les insectes pondent leurs œufs tous à-la-fois ou à diverses reprises, promptes ou lentes, près des lieux ou dans les corps même où chaque larve trouvera, dès sa mise au jour, de quoi exister et se nourrir : c'est ainsi qu'on trouve des œufs d'insectes dans des feuilles, dans des fruits, du bois, des dépouilles ou des substances animales, ou même dans le corps de certains animaux. De Geer a remarqué que même les œufs semblaient se nour-. rir : il s'aperçut que des œufs de Mouches-à-soie, fixés 'dans les pétioles d'une feuille verte et vivante, se ridèrent et se desséchèrent bientôt, dès que cette feuille fut arrachée. Il est des insectes, les Cochenilles par exemple, qui semblent couver leurs œufs, qui les abritent et les protègent, même jusqu'à la mort. Mais nulle autre classe d'animaux ne prodigue plus de soins à leur progéniture que les insectes vivant en sociétés, en petites républiques : ces animaux consacrent une industrie admirable et tous les instans d'une prodigieuse activité à donner un gîte à leurs œufs, à préparer de la nourriture aux larves qui en naîtront, et une abondante subsistance à la mère commune de ces grandes familles. Les individus neutres ou mulets qui existent parmi ces espèces sociables, n'ont de sexe d'aucune espèce, et se bornent à prodiguer des soins aux petits des insectes fécondés, leurs pareils sous d'autres rapports.

Les OEufs des insectes sont presque toujours fécondés dans le corps même des femelles; par consé- 
quent le rôle du mâle est fini à l'époque de la ponte, mais ce ne sont pas des insectes parfaits qui naissent immédiatement de ces œufs; l'achèvement de ces animaux n'a lieu qu'après plusieurs transformations successives (1). Ils passent d'abord presque tous par l'état de Larves, puis par l'état de Nymphes; et finalement, des Insectes achevés naissent de ces dernières; en tout, quatre états, quatre espèces de métamorphoses.

Nous avons dit que l'œuf éclot quelquefois dans le corps de la mère; il n'y a dès-lors, sur quatre, que trois transformations apparentes, la première s'étant faite, loin des yeux, dans le corps même de la femelle. Il est même des insectes qui produisent immédiatement des petits parfaits, au moins dans certaines saisons, et sous l'influence d'une température élevée : nous avons vu que les Pucerons en particulier sont dans ce cas. Les Hippobosques ne subissent ostensiblement qu'une métamorphose; ils n'apparaissent à l'extéricur que sous la forme de nymphe: les autres métamorphoses ont eu lieu au dedans de la femelle. C'est à l'état de Larve, sa première forme, que l'insecte prend presque entièrement tout son volume, tout son accroissement : voilà même la raison pourquoi cette larve éprouve plusieurs mues successives, la même enveloppe ne pouvant long-temps suffire à un corps progressivement accru. L'insecie ne grandit plus aussitôt qu'il est insecte parfait, ê sorti de ses dernières langes.

(1) Consullez Rédi, Swammerdàm, Malpighi, Goddaërt, Leeuwęhoek, Vallisncri, Réaumur, Fabricius, Latreille, clc. 
3-8 LIV. IH. DE L'ACCROISSEMENT DES CORPS VIVANS.

La Nymphe est un état intermédiaire à la larve et.à linsecte parfait; comme la larve est un degré entre l'ouf et la nyuphe. Dans cet état, l’insecte est déjà volumineux et ses différens organes déjà distincts : c'est déjà l'insecte parfait, mais dont les différentes parties, quoique discernables, sont encore emmaillotées et ne grandissent presque plus. La nymphe differe de la larve principalement par le volume plus accru des organes, et par les rudimens déjà très -ảpparens des ailes. Beaucoup d'insectes, surtout parmi les Diptères, n’ont que des mélamorphoses imparfaites; je reux dire qu'ils ressemblent infiniment, dans leurs divers álats, à ce qu'est la larve primitive et véritable, à l'exception que le volune du corps est plus grand et que les ailes sont déjà ébauchées. Au reste, l'extérieur est le même, les organes sont, non aussi manifestes ni aussi accrus, mais aussi nombreux; et les mœurs comme la nourriture sont pareilles. La plupart des insectes sans ailes, ou Aptères, n’ont qu'une métamorphose, ou bien leurs métamorphoses sont presqu'insensibles; plusieurs même n'en ont d'aucune espêce.

Nous ne rappellerons pas ici ce que nous avons dit ailleurs des métamorphoses de quelques Reptiles, et nous ne ferons que faiblement mention des transfor. mations faussement aitribuées à d'autres espèces. Une chose étounante, c'est que long-temps même avant de connaître les métamorphoses véritables des insectes, on croyait à d'autres transformalions purement fabuleuses. On prenait encore les larves et les nymphes des mêmes insectes pour des animaux d'espèces particulières, dans un temps où l'on croyait que les Anguilles provenaient des Écrevisses, que les Anatif 
CRAP. XI. MÉTAMORPHOSES DES INSECTES. $\quad$ 5;9 engendraient des Canards, et que l'Ếpervier se métamorphosait en Coucou (et cela apparemment parce que l'épervier disparaît dans la même saison où revient le coucou). Même en 1780 , ce qu'on a peine à comprendre, un $\mathbf{1 1}$. de la Faille lut à l'Académie des Sciences de Paris, et inséra mêrne dans les Mémoires de cette illustre compagnie, une dissertation dans le but de prouver que les oiseaux de mer, qu'on nomme Macreuses, ne proviennent pas des Huîtres, mais que seulement ces oiseaux composent leurs nids avec des écailles de divers mollusques.

Nous devons ajouter en terminant ce chapitre sur les métamorphoses des insectes, que ces métamorphoses ne sont pas en réalité ce qu'elles paraissent. On jugerait en effet fort mal des révolutions qu'éprouvent les organes de ces animaux, sil'on se bornait à observer les changemens de leur surface, leurs mues, leurs déguisemens successifs, leurs brusques transitions d'une forme, d'une couleur à l'autre. En pénétrant plus avant, la peau une fois enlevée, on voit, absolument comme dans les autres animaux, des organes qui se développent, qui s'accroissent, qui ont en un mot des progrès, bien plutòt qu'ils ne se transforment. 


\section{CHAPITRE XII.}

De la Graine, de la Germination, et de l'Accroissement des Végétaux.

Nous n'avons guères parlé que de la fécondation des plantes dans le chapitre où nous avons traité de leur reproduction sexuelle, et nous n'avons rien dit de la graine, qui est le terme de cette fonction et qui renferme les linéamens d'un nouveau végétal : il nous reste par conséquent à en faire l'histoire. I! serait impossible de comprendre les phénomènes de la germination, si l'on ignorait l'organisation des semences et quel rôle jouent chacune de leurs parties. Ce que nous avons fait pour les ovules des animaux, nous devons le tenter également pour l'œuf végétal: la chose a le même but, la même utilité. Mais, afin d'abréger tant de détails, nous allons présenter, sous la forme de.tableau, les différens organes dont le fruit se compose, ainsi que nous l'avons fait précédemment pour l'œuf des oiseaux en particulier. L'essentiel est que ce tableau soit court, clair et simple. Nous regrettons d'être forcé d'employer beaucoup de mots techniques, n'ayant aucun cours dans le langage commun; mais c'est une nécessité à laquelle il faut se résigner. 


\section{Analyse de l'OEuf végètal (1).}

Fruit : On donne ce nom à l'ensemble des produits de la fécondation d'un végétal. Le fruit comprend les graines, leurs enveloppes, et souvent quelques-unes des parties persistantes de la fleur à laquelle il succède et dont il provient.

Péricarpe : enveloppe générale des graines supportées par le même calice. Le péricarpe communique à-la-fois avec le pistil de la fleur, lequel a charrié le pollen fécondant, et avec les vaisseaux séveux de la plante, par qui le fruit est nourriet accru. On le divise en trois compartimens ou trois couches, sourent peu distinctes en réalité :

L'Epicarpe : épiderme ou sur-peau du péricarpe.

L'Endocarpe : qui est la peau ou membrane interne du fruit. Ce feuillet aroisine les graines et leur forme des loges distinctes : c'est la partic ligneuse des noix, par exemple.

Le Mésocarpe : Ge sont toutes les parties vasculeuses comprises entre l'épicarpe et l'endocarpe. Lorsque cette partie intermédiaire est charnue, on lui donne le nom de Sarcocarpe.

Placenta ou Trophosperme : espèce de bourrelet vasculeux au mojen duquel la graine s'attache au-dedans du péricarpe.

Cordon ombilical, Funicule ou Podosperme : moyen d'union, lien vasculeux de la graine avec le placenta. C'est par le cordon ombilical que la graine communique avec les vaisseaux nourriciers de la plante.

Graine ou Semence : ovule fécondé, œuf végétal, contenant le rudiment d'une nouvelle plante. Elle comprend l'embryon lui-même, ou germe fécondé, avec ses annexes ou enveloppes immédiates, et ses organes nourriciers. On a remarqué que les plus grosses graines, dans les plantes dioiques, produisent ordinairement les mâles, les pieds à étamines, tandis que les petites graines engendrent des femelles,

Spermoderme : peau de la graine. On divise ordinairement le spermoderme en plusieurs couches (de même que pour le péricarpe) auxquelles on donne les noms

(a) Voyez Gortner, C. Richard, Jussieu, Mirbel, Decandolle, Corréa, Rob. Brown, ete, 
De Test : C'est la pellicule la plus extérieure : elle est ordinairement hygroscopique, et attire vers la graino l'eau nécessaire à la germination ;

De Mésoderme ou Sarcoderme: c'est la partie vasculeuse ou charnue qui est sous-jacente au Test : elle est très-distincte dans les baies:

D'Endoplèvre : C'est la membrane interne et presque toujours imperméable du spermoderme : elle est immédiatement contiguë à l'amande.

Ces différentes tuniques de la graine sont perforées vers le sommet ou mamelon de l'amandso, ainsi que l'a prouvé M. Rob. Brown; et l'on conjecture avec vraisemblance que c'est par là que le pollen des étamines, conduit par le pistil, vient féconder les ovules de la fleur.

Ombilic, Hile ou Cicatricule : La parlie de la graine où s'attache le cordon ombilical. C'est ordinairement une sorte de cica. trice.

Amande : On donne ce nom à tout ce que contient le spermoderme. C'est le noyau du fruit; autrement l'embryon lui-même. avec les parties qui lui sont inséparablement unies.

Albumen ou Périsperme : Substance non vasculeuse et comme inerte, ordinairement blanchâtre, qui entoure ou avoisine l'em. bryon, et qui sert à le nourrir durant la germination. C'est le résidu épaissi de l'amnios. L'existence de l'albumen n'esı pas constante dans toutes les graines.

Chorion : C'est la massc pulpeuse qui composait exclusivement les ovules avant l'advention du pollen, avant la fécondatiou. Spallanzani s'y est mépris. (Voy. Cuap. V, Liv. Il.)

Amnios : liqueur au milieu de laquelle nageait l'embryon, et dont la solidification donne lieu à l'albumen. Il n'existe point d'amnios dans les ovules non fécondés \& ce liquide est con temporain de l'embryon.

Vitellus : admis par quelques auteurs, mais sans aucun motif. C'est ce que nous nommons chorion qu'on aura pris pour le vitellus.

Chalazes: On doit nommer ainsi les deux ligamens qui tiennent 'l'embryon altaché aux deux extrémités de l'amande : l'un au sommet ou mamelon (là où les tuniques sont perforées). et c'est par là que paraît pénétrer le fluide fécondateur : l'autre, à la base de l'amande, du côté de l'ombilic, et 
CHAP. XI1. ACCROISSEMENT DES VÉGÉTAUX. 383

c'est la vraie, chalaze ou sorte d'ombilic interne. Celte dernière chalaze parait contenir les vaisseaux ramifiés du cordon ombilical; vaisseaux qui servent d'abord à l'accroissement de l'embryon, el, plus tard, à la germination ou développement.

Embryon : jeune plante en miniature, partie essentielle de la graine: n'apparaissant jarnais avant la fécondation. L'embryon se compose des parties suivantes :

Radicule : C'est l'origine de la jeune racine; elle est ordinairement dirigée du côlé de la vraie chalaze et correspond à l'ombilio de la graine;

Plumule, ou pelite Tige : Cette partie est située plus intéricurement que la radicule, aussi n'apparaît-elle qu’après l'évulsion de cetle deruière ;

Collet : C'est la partie intermédiaire à la radicule et à la plumule : elle tient de l'un et de l'autre. On l'a considérée coinme le cœur du végélal, comme le nœud de la vie. La radicule tend toujours au centre de la terre, la plumule s'élève constamment vers le ciel; le collet ne manifeste aucune de ces lendances ;

Cotylédóns : feuilles scéminales; premières feuilles apparentes dans la germination de la graine, et visibles même avant la germination. Cumme ces corps serrent à nourrir la jeune plante, on les a appelés mamelles végétales. Toule graine do plantes ayant des feuilles, présente constamment des co. tylédons. Cependant on assure que le Lecythis fait exception à celle règle générale.

Vaisseaux : On les admet et on les distingue bien plus pour les fonctions quo on leur suppose que pour les avoir vus réellement isolés. Il y a d'abord les vaisseaux pistillaires ou polliniques, par qui s'effeclue le passage du pollen dans l'ovule: ceux-là président à la fécondalion de la graine; ils sont silués vers le mamelon ou le commet de l'amande. Il y a, de plus, les vaisseaux séveux, provenant du cordon ombilical et communiquant avec la plante. Ces derniers aboutissent à la chalaze principale et servent à la nutrition et à l'accroissement de la graine et de l'embryon qu'elle renferme. Nous verrons quel emploi ont c.s deruiers vaisseaux dans la germination. 
384 LIV. III. DE L'ACCROISSEMENT DES CORPS VIVANS.

11 est aisé de voir combien la graine végétale a d'analogie avec l'œuf fécond et déjà incubé des animaux : il y a dans tous les deux un embryon, des chalazes, un placenta, un cordon ombilical, une cicatricule, un amnios, des membranes, des vaisseaux nourriciers. Les cotylédons de la graine sont l'équivalent du vitellus des oiseaux ou de la vésicule ombilicale des mammifères; l'albumen ou périsperme des graines est l'analogue du blanc d'œuf des oiseaux ou de l'allantoïde des vivipares, etc. : enfin la similitude est frappante.

Phénomènes de la germination. A présent que nous connaissons toutes les parties dont l'œuf végétal se compose, nous devons étudier commentl'embryon s'y développe et comment il en sort. Nous allons donc décrire rapidement les principaux phénomènes et les progrès de la germination des graines ( 1 ).

La jeune plante est déjà toute formée, déjà dessinée en miniature dans la graine fécondée et mûrie; mais elle y est comme dans un état d'assoupissement et d'inertie: la germination est pour elle le signal du réveil et le commencement d'une vie active. Placée dans une terre imbibée d'eau, la graine s'en imprègne; elle se gonfle, ses enveloppes se rompent; et bientôt la jeune racine d'abord, et plus tard la jeune tige, sortent par deux points souvent opposés de la graine, ou plutôt avec une tendance, une direction opposée, puisque la racine s'enfonce dans le sol, tandis que la tige se prolonge à la surface et s'en éloigne. Les cotélydons,

(1) Voyez Ledermuller, Hales, Duhamel, Senebier, Th. de Saussure, Mirbel, etc. 


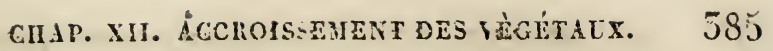
A'abord gonflés, sorlent de terre et deviennent de premières feuilles, ou d'autres fois restent étiolés sous le sol, continuant d'adhérer à la graine. On a fait des observations suivies sur les progrès de la germination pour diverses semences; voici, par exemple, ce qu'on a observé pour le Seigle : dès la première heure le grain de seigle placé sous la terre était gonflé; dès la deuxième heure onvit les premiers filets, les filamens déliés de la radicule; au bout de vingt-quatre heures, toutes les parties de l'embryon apparaissaient hors de la graine; mais les premières feuilles sont encore enveloppées; le quatrième jour, quelques plantes déjà sortent de terre, on voit même alors les feuilles rouges, les vaisseaux séveux, un fin duvèt, des poils tendres; cinquième jour, feuilles déjà longues d'un pouce et déjà vertes; les secondes feuilles paraissent le sixième jour. Ces expériences ont été faites au printemps, par une douce température; le sol était humide et meuble. Mais les graines sont loin de germer toutes avec cette rapidité : il en est pour qui ce premier développement dure une ou plusieurs années. Dès-à-présent nous devons dire quelques mots des agens extérieurs et des premières conditions de la germination. Toute semence, pour germer, a besoin d'air, de chaleur et d'humidité. Les autres choses n'ont qu'une importance secondaire.

Chaleur. La germination n'a jamais lieu dans une température au-dessous de zéro, et elle est promplement arrêtée dans une atmosphère à $40^{\circ} \mathrm{et}$ au-dessus; les jeunes organes sont aussitôt clétruits qu'apparus, et les graines restent improductives. La température I. 
LIV. III. DE L'ACCROISSEMENT DES CORPS VIVANS.

la plus propice est de $15 \grave{d} 20^{\circ}$; voilà pourquoi l'ensemencement des terres ne se fait jamais lors des grandes chaleurs dans les régions méridionales : outre qu'on combine les semailles de manière à ce que les chaleurs de l'été servent à la maturité des graines. Si la difficulté des labours oblige à ensemencer dans les temps froids, alors la germination ne s'effectue de même qu'au printemps, au retour de la chaleur et des beaux jours. Disons âussi que la germination elle-même a pour effet constant de développer un peu de chaleur dans les semences : car la vie et la chaleur sont inséparables.

Eav. Le sol, outre le soutien qu'il donne aux plantes, outre l'abri qu'il prête à leurs racines, n'a guère d'influence sur la germination qu'en raison de l'humidité qui le pénètre. Une graine placée sur une éponge imbibée d'eau, germe aussi bien qu'au sein de la terre : on en a même fait germer dans de l'eau distillée, et dans l'éloignement de toute substance gazeuse. Mais alors la jeune plante avorte bientôt, ou du moins ne produit jamais de graines. L'eau seule, sans air et sans le secours du sol, paraîtrait donc suffire à la simple germination. Ordinairement le test de la graine est doué d'une propriété hygroseopique; il attire vers la semence l'eau répandue autour d'elle. Ensuite l'humidité est absorbée, ou par toute la surface du test, ou sculement par la cicatricule de la graine; mais comme la tunique la plus intérieure est difficilement perméable, quelle que soit la partic par où l'eau est entrée, cette eau ne pénètre jamais dans l'intérieur de la graine que par l'ombilic, et jamais dans l'embryon que par la chalaze : parce 


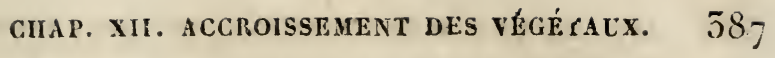
qu'en effet les vaisseaux qui l'absorbent sont tous dirigés dans ce sens. On vérifie aisément cette direction des liquides absorbés par les semences, en teignant l'eau dont on fait usage, avec diverses substances colorées qui la rendent visible dans les vaisseaux absorbans.

Arr. Tous les gaz ne conviennent pas indifféremment à la germination: on s'est: assuré que des graines ne germent ni dans le gaz azote pur, ni dans l'hydrogène, ni dans un air, quelle qu'en soit la nature, qui ne contiendrait pas d'oxigène. Il faut à l'air qui entoure les graines en germination, au moins un huitième d'uxigène, el pas au-delà d'un quart. En plus grande quantité, il activerait beaucoup la pousse de la jeune plante, mais cette crue hâtive serait bientôt suivie de la mort: Il faut aussi observer que peu importe à quel autre gaz l'oxigène est combiné, pourvu qu'il soit dans la proportion que nous avons indiquée.

Ainsi, il faut de l'air, il faut de l'oxigène pour toute germination de semence: nul graine ne peut germer dans le vide. Les semences introduites trop profondément dans le sol pour communiquer avec l'atmosphère, se conservent sans germer. On voit quelquefois, à cause de cela, une térre remuée dans sa profondeur, au bout d'un siècle, donner naissance à des plantes nouvelles, fort différentes de celles qui croissent tout à l'entour. Or, il est probable que ces plantes proviennent de graines enfoncées dans le sol et éloignées de l'air depuis long-temps. Il est vraisemblable aussi que les semences ne germent dans de l'eau distillée qu'à cause de la portion d'air qui s'y 
388 LIV. III. DE L'AGGROISSEMENT DES CORPS VIVANS.

trouve mêlée : car il est certain que les graines submergées pourrissent; et si quelques semences de plantes aquatiques parviennent à germer dans l'eau, cela vient presque toujours de ce que la chaleur développéé en elles par le premier travail de la germination, les rend plus légères, et les élève à la surface du liquide, où elles jouissent du contact de l'air. Disons néanmoins qu'il existe une espèce d'Icodendrum qui germe et végète dans l'air libre sans le concours d'aucune humidité, sans arrosemens.

Divers excitans. L'éłectricité paraît favoriser la germination. Les temps d'orage font promptement germer les semences. Le chlore, et ceux des oxides métalliques auxquels le gaz oxigène est peu adhérent, par exemple l'oxide de manganèse, hâtent visiblement la germination des graines. M. de Humboldt a fait, à cě́t égard, des expériences intéressantes. Cet ingénieux physicien a fait germer, au moyen du chlore, des graines incapables de germer dans les circonstances communes. Cies différens moyens ont un effet d'autant plus puissant, qu'indépendamment de l'oxigène qu'ils fournissent, ils augmentent en même temps la température. On voit, par ce que nous venons đe dire des circonstances favorables ou nécessaires à la germination des graines, de quelles influences il faut préserver celles qu'on veut empêcher de germer. Mais c'en'est assez sur cet objet ; examinons maintenant quel rôle jouent, dans l'acte de la germination, les différentes parties de la graine.

- Enveloppls séminales. La plus extérieure des membranes séminales, le test, comme hygroscopique, sert utilement à la germination; la plus internc, l'endo- 


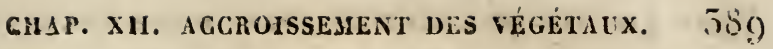
plèvre, comme imperméable, fait que l'humidité qui a transsudé à travers le test, aflue toute entière vers l'ombilic de la graine, où des vaisseaux l'absorbent; elle concourt manifestement aussi à la longue conservation des semences, en empêchan que l'humidité dont elles sont pénétrées ne se dissipc dans l'atmosphère. Toujours est-il que ces membranes ont úne influence assez grande sur la germination, puisque des graines dénudées, ou ne germent point, ou ne germent qu'imparfaitement. Il est probable qu'elles empêchent le trop prompl gônflement des cotylédons en modérant l'afflux des liquides; il est probable aussi qu'elles favorisent, par cette imprégnation de la graine qu'elles ralentissent; aussi bien que par la pression qu'elles exercent sur l'embryon et sur l'albumen, qu'ellés favorisent ainsi, disons-nous, la dissolution et l'émulsion des sucs, sans cela insolubles et réfractaires, de l'albumen et des colylédons. Elles conservent d'ailleurs et concentrent dans l'embryon la chaleur développée dans la semence par le premier travail vital. Elles attirent, elles prolègent, elles compriment, isolent et vêlissent. Mais le gonflement des cotylédons donne à ces derniers la pro. priété de nourrir la jeune plante.

Eubryor. Il est toujours situé dans les membranes dont nous venons de parler. Il tient aux deux extrémités de la graine par deux ligamens ou chalazes: celui de ces ligamens qui l'atlache au sommet de la semence, lui a apporté le principe fécondant du pollen; l'autre ligament, ou la vraie chalaze, situé vers ou tout-à-fait vis-à-vis l'ombilic de la graine, est composé de vaisseaux où circulent les fluides absorbés 
390 LIV. III. DE L'ACCROISSFMENT DES CORPS VIVANS.

servant à le nourrir et à l'accroître. Il paraît certain que la surface de l'embryon commence par absorber l'amnios qui l'environne, et que là même est une des sources où la jeune plante puise sa première nourriture. Quelquefois même la plantule absorbe tout cet amnios, et dans ce cas la graine est sans albumen, et totalement composée par l'embryon; mais alors, par compensation, les cotylédons, plus gros, subviennent au défaut d'albumen. Quant à la radicule, comme elle est toujours dirigée vers l'extérieur de la

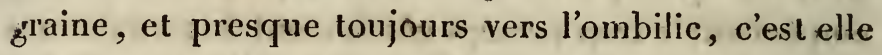
qui absorbe d'abord les fluides qui ont transsudé à travers le test ou à travers la cicatricule, et ces fluides, elle les transmet au reste de l'embryon. La plumule ou jeune tige, plus intérieure, plus centrale, n'absorbe rien d'elle-même, mais elle s'accrôit aux dépens des fluides transmis par la radicule, aux dépens aussi de la substance de l'albumen, et des cotylédons, ou seulement de ces cotylédons, lorsque l'albumen manque absolument; et lorsqu'une fois les membranes séminales sont rompues, la jeune racine, toujours dirigée vers le centre de la terre, puise dans le sol les fluides nécessaires à l'accroissement du jeune végétal.

Cotylédons. Ce sont les premières feuilles de la plante; et la preuve que ce sont des feuilles, c'est qu'ils verdissent à la lumière, qu'ils ont les mêmes vaisseaux, les mêmes glandes ou les mêmes mouvemens que les feuilles véritables; qu'en outre les plantes sans feuilles, comme la Cuscute, n'ont point de cotylédons, et que la position en est entièrement semblable à celle des premières feuilles radicales; de 
CHAP. XiI. ACCROISSEMENT DES VÉgétaUX. 391 sorte qu'on peut juger des cotylédons par les premières feuilles de la lige, comme de ces feuilles par les cotylédons. En un mot, les cotylédons sont les feuilles de la jeune plante, comme la plumule en est la tige, comme la radicule en est la racine. Mais quels sont leurs usages? de deux sortes, selon que les cotylédons sont charnus ou seulement foliacés. Ces derniers, toujours prolongés au-delà du sol, verdissent à la lumière comme les autres feuilles; et comme en outre ils unt des pores à la manière des feuilles véritables, ils absorbent l'air, ils en séparent le carbone pour se l'approprier; et c'est activement qu'ils servent à la nutrition de la nouvelle plante. Les cotylédons charnus, au contraire, n'ont point de pores, n'absorbent point l'air, ne fixent point le carbone, n'élaborent pas de sève; mais ils nourrissent le jeune végétal aux dépens du mucilage ou de la fécule qui compose leur substance, et par cela même qu'ils n'ont point d'action sur l'air, ils restent souvent souterrains, au-dessous de la radicule déjà prolongée, voisins de la graine, ou continuant même d'en faire partie : cette dernière disposition est surtout commune dans les plantes monocotylédones. Une chose démontre combien les cotylédons ont d'influence sur l'accroissement de la jeune plante, c'est qu'on fait mourir celle-ci, on en fait avorter la grermination, aussitôt qu'on en sépare les cotylédons, surtout s'ils sont charnus; au contraire, la germination continue, si l'on divise la graine el l'embryon de manière à ce que chaque portion de la plantule ait sa part des cotylédons. L'embryon végétal se passe plus impunćment de lạ plumule, ou même de la radicule, que de 
3 g2 LIF.' III..DE L'ACCROYSSEMENT DES CORPS VIVhXYS. ses cotylédons; et ce n'est pas sans raison qu'on a donné à ces derniers le nom de mamelles végétales.

Cependantil fautdire que les plantes cryptogames, que tous les végétaux privés de vaisscaux, et même ceux des végétaux vasculeux qui n'ont pas de feuilles, toutes ces plantes, dis-je, et aussi le Lecythis (encore qu'il ait des fecilles), sont dépourvues, à ce qu'on croit, de cotylédons; et néanmoins elles ont une espèce de germination et elles s'accroissent. Quel autre organe leur tient donc lieu de cotylédons? et d'où tirent-elles leur première nourriture? nous n'en savons rien. Il est même probable qu'on range parmi ics acotylédones beaucoup de plantes qu'on se verra forcé d'en ôter dans la suite, après un examen plus attentif; de la même manière qu'on avait entassé jarmi les cryptogames beaucoup de végétaux dans lesquels on a reconnu des organes reproducteurs incontestables.

Les cotylédons commencent donc par se gonfler, une fois que les liquides absorbés par la radicule ont pénétré jusqu'à eux, et bientôt feur volume s'accroît assez pour rompre les enveloppes séminales : il faut que cette force d'expansion des embryons soit bien puissante, puisqu'elle suffit pour déterminer l'ouverture de noyaux impénétrables à nos instrumens. Toutefois, et après s'être ainsi gonflés, les cotylédons se vident peu-à-peu et se flétrissent. Voici une expêrience assez curieuse qu'on a faite à ce sujet : elle prouve combien est important le rôle des cotylédons durant la germination des graines. " On a pris des Haricots muirs et sees, pesant en masse cent soixantedouze grains; à cux seuls, les-cotylédons formaient 


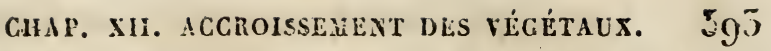
les ${ }_{1}^{13} \mathrm{du}$ poids total, c'est-d̀-dire, cent soixante grains. Une fois gonflés, ces mêmes cotylédons pesaient trois cent six grains; mais après leur flétrissure, la germination étant effectuée, ils se réduisirent tellement qu'ils ne pesaient plus que vingt-neuf grains. Ils avaient donc fourni à la jeune planle deux cent soixante-dixsept grains de matière, dont cent trente-un de leur propre substance; et les cent quarante-six autres grains provenaient des liquides que leur avait communiqués la radicule.

Albumen. Nous avons dit que c'est l'amnios épaissi, concrété; par conséquent il n'existe d'albumen que dans les semences dont l'embryon n'a pas absorbé tout l'amnios. Les graines dont les cotylédons sont charnus, mais principalement celles dont l'embryon a deux cotylédons, sont sujettes à manquer d'albumen; et alors la graine est entièrement formée par l'embryon. Ce mode d'organisation est plus rare parmi les plantes monocotylédones, et, comme l'albumen est la partie essentiellement nourrissante des semences, il ne faut pas s'étonner si les différens peuples vont puiser leur nourriture principalement dans les graines des plantes monocotylédones. L'albumen sert à la germination de la même manière que les cotylédons charnus : composé d'une substance huileuse ou amylacée, l'humidité dont le pénètre la radicule le ramallit peu-à-peu et le réduit presque à l'état d'émulsion. L'albumen lui-même est inerte; il ne prend aucune part active à la végétation; ·c'est uniquement un réservoir de nourriture, destinć à l'embryon qüil avoisine. C'est comue le blanc des œuifs d'oiseaux et 
Jg ́́ LiY. III. DE L'AGCROISSEMENT DES CORPS VIVANS.

les glaires des œufs de poissons et de reptiles batraciens : il disparaît peu-à-peu par les progrès de la germination. Un embryon végétal, séparé de son albuunen ou périsperme, et mis en terre, s'y conserve sans germer; de la même manière que le germe d'un œuf d'oiseau, alors même qu'il est fécondé, ne prend aucun accroissement dans l'ovaire tant que l'albumen ou blanc de l'œuf nes'y est pas joint durant son passage à travers l'oviducte. Ensuite, la radicule est déjà en état de suffire seule à l'alimentation du jeune végétal, à l'époque où disparaissent l'albumen de la graine et la substance des cotylédons. Ce n'est même qu'alors que la jeune racine commence à s'acquitter manifestement de ses fonctions; mais bientôt elle est secondée par l'action absorbante et carbonisante des feuilles nouvellement nées.

I $^{\text {rs }}$ Vaisseaux. Il est manifeste que les vaisseaux chargés, lors de la germination, d'absorber les liquides ct de les transmettre à la plantule, sont une émanation, une dépendance de ceux qui faisaient communiquer la graine avec la plante-mère. Or, la communication si constante et toujours si parfaite de ces vaisseaux du cordon ombilical avec les vaisseaux de la radicule, anncnce qu'il y avait eu préméditation pour une œuvre si bien accomplie, préexistence d'élémens pour des parties si merveilleusement assorties et concordantes. Nous voyons ici la répétition de ce que nous avons observé pour l'ovule des animaux : je veux dire que les vaisseaux de là graine, parfaitement abauchés avec ceux de l'èmbryon, émanent de la plante-mère, tout comme les premiers vaisseaux visi- 


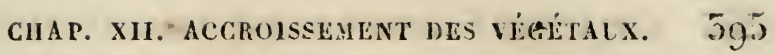
bles dans l'ocuí proviennent des vaisscaux rompas de l'ovaire maternel.

Fluides et matériaux nutritifs. L'espèce de mucilage dont l'ovule végétal est totalement formé avant la fécondation, finil bientòt par disparaître dès que l'embryon se manifeste. En même temps, et pour la première fois, on voit apparaître l'amnios, fluide aqueux, analogue à ce qu'on voit dans les ovules d'animaux, et qui paraît servir de premier aliment au petit embryon caché dans la graine et dont ce fluide baigne toute la surface. Après ce premier développcment, et lorsque la germination s'effectue, la plantule tire sa nourriture de plusicurs souroes: $a^{\circ}$. de l'albumen ou amnios concrété, qui l'avoisine; $2^{\circ}$. de la substance succulente des colylédons charnus, lesquels sont peu-à-peu ramollis et rendus solubles par l'absorption de l'oxygène de l'air et le dégagement d'une portion de leur carbone; $5^{\circ}$. desfluides aqueux absorbés par les membranes séminales, et transmis, par la cicatricule, au rudiment de la jeune racine; $4^{\circ}$. de l'oxygène de l'air, gaz qui a pour usage d'extraire, en se combinant avec lui, la portion surabondante de carbone contenu dans la graine qui germe; de sorte que celte graine exbale de ce gaz acide carbonique, a-peu-près l'équivalent de ce qu'elle absorbe en oxygène, absolument comme pour la respiration les animaux; $5^{\circ}$. Jes parties déjà vertes de la plantule, les cotylédons, par èxemple, s’ils sont minces, s'sils sont pourvus de pores ou stomates, en un mot, les cotylédons réellement foliacés, au licu d'oxigène, absorbent du gaz acide carbonique, fixent le carbone dans la jeune plante, et le combinant aux fluides pompés par 
ग56 LIV. III. DE L'ACCROISSEMENT DSS COPPS VIVANS.

la radicule, en composent une première sève. II faut observer que la lumière est nécessaire à la fixation du carbone dans les plantes.

Direction de la jeune plante. Dès son premier développement la radicule se dirige vers le centre de la terre, et la jeune tige, au contraire, dans un sens diamétralement opposé. On aurait beau changer, contrarier cette direction naturelle des.végétaux; ils y reviennent toujours et irrésistiblement malgré les obstacles. On a essayé de tourner une plante bout pour bout dans un tube; on avait placé la tige en bas et la racine en haut; on avait eu soin, en outre, d'abreuver celle-ci des sucs qu'elle a coutume de puiser dans la terre: mais la plante s'est retournée d'ellemême; elle briserait plutôt ses entraves que de changer sa pente. On a aussi placé une graine en germination au centre d'une boule sphérique qu'on tournait sans relâche: elle se trouvait de la sorte toujours ćloignée du centre de la terre, ou plutôt le globe dans l'axe duquel on l'avait mise lui tenait lieu de globe tcrrestre; et le peu de racines qu'elle produisit se tortilla autour d'elle précisément selon l'axe dè sa sphère artificielle. Cependant on est parvenu, sinon à changer, du moins à modérer celte tendance centripète de la racine, en plaçant une couche de terre très-sèche sous une autre couche de terre constamment imbibée d'eau : alors la racine descend toujours en se tortillant, mais elle s'enfonce beaucoup moins qu'à l'ordinaire. C'est que, dans ce cas, l'avidité que la racine a pour l'eau contrebalance un peu sa propension à s'enfoncè, à descendre. Toutefois, c'est la 
CHAP. XIl. ACGroissmMeNT dEs vÉgétaux. 597 preuve que le besoin d'humidité n'est pas la cause unique de cette tendance centripète.

Il paraîtrait que les racines sont influencées par le support auquel elles s'attachent, beaucoup plus que par une influence planétaire; car les plantes parasites dérogent à cette propension centripète, si universelle pour les végétaux attachés à la terre. Le Gui, par exemple, pousse indifféremment dans toutes les directions; ses racines s'implantent du côté du zénith tout aussi bien que du côté contraire : il n'a de point central que dans l'arbre où il tient attaché et qui le nourrit.

ACGroIsSEMENT PROGRESSIF des végÉtAux. Nous avons montré comment la plumule se dégage du sein de la graine, et comment elle sort de terre pour former la tige : il n'y a par conséquent, dans les plantes, qu'une partie qui demeure stablement à sa première place, c'est le collet ou noud vital. Cette partie est intermédiaire aux fibres descendantes de la racine et aux fibres ascendantes de la tige. A mesure que cetle tige s'élève, elle se couvre de feuilles; chacun des bourgeons placés dans l'angle rentrant de ces dernières, donne lieu à des branches, à des rameaux; ces bourgeons s'accroissent absolument comme l'embryon primitif: et même on a considéré chacun d'eux comine autant de germes ou d'embryons, auxquels on a supposé jusqu’à des racines engainées dans le corps ligneux de la tige principale. La tige elle-même est composée d'une moelle centrale, d'une portion dure et ligneuse, d'aubier, de liber et d'une écorce. Cies différentes parties ont d'abord peu de consistance dans la jeune tige qui commence à croître: la moelle 
398 LIV. IIT. DE L'AGCro ISSEMENT DES CORPS VIVANS.

est d'abord abondante, le corps ligneux est encore à demi lluide, et l'écorce a peu d'épaisseur. Ce n'est qu'au bout d'une année que la couche ligneuse se dessine : et c'est le signal du dépérissement et de la prochaine destruction des plantes qui ne sont qu'annuelles. Ce durcissement du tissu végétal, en entravant le conrs de la sève, favorise l'épanouissement des fieurs et la maturité des fruits; de sorte que la propagation de l'espèce est favorisée par les, poêmes causes qui abrègent la durée de la vie. Voilà pour les végétaux qui ne durent qu'une année : mais, dans ceux qui vivent plus longtemps on voit une nouvelle couche ligneuse se former tous les ans. Que celle nouvelle couche résulte d'une transformation du liber, ou de l'organisation progressive de l'humeur végétale qu'on appelle cambium, toujours est-il que chaque couche annuelle entoure dans tous les sens les autres couches formées avant elle, et qu'elle n'en est séparée que par des zônes celluleuses que remplit un suc séveux, zônes qui même s'effacent peu-à-peu à mesure que les premières couches solidifiées se pressent, en s'épaississant, les unes contre les autres. Ainsi l'on peut juger de l'accroissement des végétaux à deux cotélydons par le nombre des couches ligneuses et concentriques dont leur tronc est formé : et comme les plus extérieures de ces couches sont les plus jeunes, à cause de cela on a donné aux plantes dicotylédones le nom d'Exogènes : nous verrons pourquoi les monocotylédones ont reçu celui d'Endogènes.

Mais si le nombre des zônes ligneuses peut faire apprécier l'âge d'une plante, il faul observer cependant que ce calcul n'est exact que pour la portion 
coupée de ce végétal; car chaque nouvelle couche se solidifiant chaque année, chacune d'elles en conséquence ne s'étend point de l'un à l'autre bout du végétal. L'époque où la couche ligneuse se durcit est le terme de l'accroissement pour l'année entière : l'année suivante, la tige se prolonge; et la première couche ligneuse de cette production nouvelle se continue avec la nouvelle couche ligneuse du rameau de l'année précédente. De sorte que l'on peut juger, par la série des décroissemens des couches ligneuses, à quelle hauteur s'est prolongée la pousse de chaque année. On juge de l'âge total d'un arbre, par le nombre des zônes ligneuses de cette portion du tronc qui touche à la terre; et de l'âge particulier de chaque prolongement du rameau, par le nombre de ses propres couches. Lorsqu'il se développe une branche sur les côtés de la tige principale, cette branche se revêt chaque année; et de plus, toutes les couches ligneuses du tronc qui sont postérieures à la naissance de cette branche, en recourrent exactement la base adhérente; de sorteque son origine se trouve de plus en plus enfoncée dans le tronc principal. C'est de là que proviennent les nœuḍs du bois, dont l'extrême solidité résulte d'une nutrition plus active, et aussi de ce que la base de la branche, progressivement accrue, a tassé les unes contre les autres, en les repoussant, ces couches ligneuses qui lui forment une sorte de virole.

Si la portion endurcie de la tige ne croît plus dèslors en longueur, il n'en est pas de même pour la tige encore jeune et non encore ligneuse. Lorsqu'on fait des marques à égales distances suivant la Jongueur 
4CO LIV. III. DE L'ACGROISSEMENT DES COMPS vivaNs.

d'une tige nouvelle, on voit que ces marques demeurant toujours à égales distances, se sont néanmoins sensiblement écartées les unes des autres. On a la preuve naturelle de cette même élongation dans la disposition des feuilles sur les tiges : car elles y étaient d'abord comme groupées sur des points trèspeu distans entr'eux; et bientôt on les voit s'isoler, s'éloigner les unes des autres et s'éparpiller.

Quant à l'accroissement en épaisseur, il s'opère toujours, ainsi que nous l'avons dit, vers la surface, pour ce qui est des couches ligneuses; c'est-à-dire, que les plus centrales sont les premières formées: toujours en dedans, au contraire, pour ce qui regarde l'écorce, c'tst-à-dire que la nouvelle couche corticale se forme au dessous de l'ancienne écorce, qui se gerce et meurt, étant devenue trop étroite pour recouvrir le corps ligneux plus accru ; à-peu-près comme on voit muer les Crustacés et les larves d'Insectes à mesure que le corps de ces animaux s'accroît. Nous traiterons ailleurs des sources mêmes et de la formation de l'écorce et du corps ligneux; mais nous devons insister davantage sur le mode de développement et les progrès de chacune des parties dont les tiges sont distinctement formées (1).

Moelle centrade. Ce tissu celluleux occupe le centre des végétaux dicotylédons dans toute leurétendue; mais tout continu qu'il paraît depuis le sommet d'un arbre jusqu'à sa base, il est réellement composé d'autant de parties distinctes qu'il y a de pousses succes-

(1) Voyez Malpighi, Grew, Hales, Duhanel, Knight. Mirbel, Du Petit.Thouars, Dutrochet, Decandolle. 
CHAP. XII. ACGROISSEMENT DES VÉGÉTAUX. 401 sives dans le même végétal. Au lieu de se renfler au niveau des branches latérales, comme la moelle épinière des animaux au niveau des membres, la moelle végétale se rétrécit ou s'interrompt vis-à-vis les endroits d'où naissent des rameaux. Elle se creuse dans les tiges herbacées à mesure qu'elles croissent en épaisseur; elle s'endurcit et se dessèche dans les vieux arbres, mais sans disparaître absolument. Toutefois, si l'on transplante une branche peu volumineuse d'un vieux arbre, on concoit que les branches nées de cette bouture n'auront qu'une moelle peu appréciable; car le volume de la moelle est ordinairement proportionné à la grosseur des branches, comme sa consistance à leur jeunesse. Elle n'est molle et succulente que dans le premier âge des plantes; et il paraît certain qu'elle donne une première nourriture à la jeune tige, de même que les cotylédons, ou le périsperme de la graine, nourrissent d'abord tout l'embryon lorsqu îl commence à végéter.

Corches ligneuszs. On nomme ainsi les zônes endurcies qui composent la substance des arbres, et qui s'étendent depuis la moelle centrale jusqu'à l'écorce. Elles sont de deux sortes : les plus âgées, situées au cœur du végétal, composent le bois parfait, tandis que les plus jeunes, les extérieures, portent le nom d'aubier (à cause de leur blancheur), ou de bois imparfait. Cette différence entre les deux sortes de bois est très-marquée dans les bois très-durs : ainsi l'ébène, qui est d'un noir si prononcé dès qu'il est endurci, est d'abord blanchâtre à l'état d'aubier. Les arbres qui croissent dans des lieux humides ont quelque efois des couches d'aubier très-nombreuses. Souvent aussi les I. 2.6 
402 LIV. III. DE L'ACCROISSTMENT DES CORPS TIVANS.

couches d'aubier sont plus nombreuses d'un des côtés d'un arbre, celles de l'autre côté s'étant plus rapidement transformées en bois parfait. Du côté des moins nombreuses s'en trouvent aussi de plus épaisses, et cela dépend de, ce que les racines, plus grosses et mieux nourries de ce côté, donnent plus de volume aux couches quil leur correspondent, en même temps qu'elles les transforment plus vite en bois parfait.

Les mêmes causes qui multiplient les couches d'aubier sont celles qui les rendent plus minces, la mauvaise terre, de petites racines, en un mot le défaut d'une nouriture assez ahondante. Comme l'aubier est moins solide que le bois, moins compacte, moins durable, plus atlaquable par l'humidité et les insectes, on a proposé d'écorcer totalement les arbres un an avant de les abattre; par ce moyen il ne peut se former de nouvel aubier, et la conche précédente de ce bois imparfait a le temps de se transformer en bois parfait, en bois solide. La dureté dübois dépend beaucoup moins du tissu ligneux lui-même que de la consistance des sucs déposés dans ses cellules, dans ses mailles; or les sucs extravasés dans l'aubier sont plus abondans et presque fluides. On transforme du bois en aubier à-peu-près comme on ohange en cartilages les os les plus endurcis, je veux dire en dissolvant la malière qui s'est déposée dans le tissu propre; à l'aide de l'acide nitrique, par exemple.

Nous avons vu que chaque végétal à plusieurs cotylédons acquiert chaque année une nouvelle couche ligneuse; mais cette couche s'est-elle formée tout-àla-fois et 'tout d'une venue, ou est-elle composée d'autant de couches partielles qu'elle met de jours, do 
chap. xII. ACCROISSEMENT DES vî́GÉtAuX. 403 semaines ou de mois à se former et à s'endurcir? Duhamel a admis des formations partielles et successives, et il cite des expériences à l'appui de son opinion. $O$ n a remarqué que la couche d'une année se confondait. quelquefois avec celle d'une autre année, et c'est ainsi qu'on explique pourquni des ormes de cent ans, abattus aux Champs-Élysées de Paris, ont pu n'ofrir que quatre-vingt-cruatorze couches. On a aussi prétendu qu'ily avait parfois deux couches ligrneuses pour la même année. Mais les couches de chaque annće n'ont pas toutes la même grosseur : cela est subordonné aux saisons, à la tempéralure, et surlout à l'âge : c'est de vingt à trente ans que le tronc des chênes, par exemple, grossit davantage; les couches de celte époque ont beaucoup plus d'épaisseur que celles de dix ans ou de soixante.

Ainsi les couches ligneuses se recouvrent l'une l'autre et s'accolent à mesure qu'elles se succèdent; ei comme elles sont déjà endurcies et dejjà engaînées au bout d'une année, il en résulte qu'elles ne peuvent plus alors prendre aucun accroissement, si ce n'est, encore quolque temps, en refoulant peu-à-peu ct faisant disparaître le lissu cellulaire interposé entr'elles. II suit de là que ces couches n'éprouvent plas sensiblement, après la premiëre année, ni progrès, ni changemens de volume ou de forme; de sorte que si l'une d'elles a élé ou gelée ou entanéc, sculptéc ou couverte de chiffres et d'inscriptions, si des corps étrangers lui adbèrent et la trauspercent, ces marques, ces corps étrangers, ces lésions, fûl-ce même après un siècle, se reirouveront fidèleuent conservés dans celle même couche et à leur daie précise. C'est 
40年 LIV. HII. DE L'AGCROISSEMENT DES CORPS VIVANS. ainsi qu'on peut calculer, en arlditionnant les couches ligneuses superposées à une gélivure, à l'hiver de quelle année correspond cette dernière. C'est à ces enclavemens successifs qu'il faut attribuer ces corps organisés, fruits, graines de plantes, dépouilles d'animaux, découverts au centre de vieux arbres, et que certaines personnes ont attribués faussement à des productions spontanées. Un clou enfoncé dans la dernière couche ligneuse d'un arbre, se retrouvera, vingt années après, vingt couches plus profondément : quoique fiché d'abord à la superficie, et demeurant sans déplácement, sans attraction ni percussion d'aueune sorte, il aura cheminé vers le cœur de l'arbre. Cependant il est resté immobile, mais tout a changé autour de lui. Demandez pourquoi les racines du Gui paraissent si profondes, pourquoi on les retrouve jusque dans les couches centrales; pourquoi les branches paraissent s'enfoncer progressivement dans leurs troncs, et comment se forment les nodosités ligneuses : c'est par la même cause dont nous venons. de citer d'autres effets et d'expliquer l'action. C'est aussi par la même raison que toute compression longtemps persévérante d'un tronc ligneux y produit des. excavations de plus en plus profondes.

Éconce. Fibreuse à l'intérieur, celluleuse en dehors, l'écorce a beauçoup d'analogie avec les couches ligneuses, quant à la superposition de ses lames, mais elle se développe en sens inverse. J'ajoute qu'elle est traversée, comme le bois, par des rayons médullaires qu'on a supposés être une émanation de la moelle centrale.

H se forme chaque année une couche d'écorce, 
CHAP. XII. ACGROISSEMENT DES VËGÉTAUX. 405 comme une conche de bois; mais la dernière écorce, au lieu de s'appliquer en dehors de la précédente, à la manière des couches ligneuses, se formant au contraire en dedans de la vieille écorce, il suit de là que la jeune couche corticale se trouve voisine de la jeune couche ligneuse, et que, l'année suivante, elles se trouvent séparées l'une de l'antre par deux nouvelles couches des deux sortes. La nouvelle écorce, appélée liber, est d'abord interne; mais au bout d'une année elle est poussée vers l'extérieur; au contraire de la nouvelle couche de bois, ou de l'aubier, lequel tend à devenir central, elle tend, elle, à la surface. Il est probable que la source commune de ces productions contiguës, mais opposées, se trouve au lieu de leur contiguité; et l'on croit que c'est le cambium dont nous parlerons ailleurs.

Ainsi, il se forme chaque année une couche corticale aussi bien qu'une couche ligneuse : mais il y a cette différence entr'elles, que les couches. ligneuses se superposent, et persévèrent en se durcissąnt, tandis que la vieille couche d'écorce se desquamme ou meurt chaque année; et nous devons observer que l'addition des couches de bois rendait indispensable ce continuel renouvellement de l'écorce et sa destruction : car la même enveloppe corticale ne saurait contenir un tronc augmenté chaque année d'une nouvelle couche ligneuse. Ce qui paraît d'abord singulier, c'est que ce soit la plus petite écorce qui recouvre la plus grande; mais ce qui rétablit les proportions, ce sont les gercures de l'écorce la plus vieille et la plus extérieure. Ajoutons que la destruction annuelle de l'écorce est déterminée par la circonstance mêmè qui la nécessite, 
406 LIV. III. DE L'a Genolsskment dis cors vivans.

je veux dire par l'accroissement progressif du corps ligneux; et voilà comment. L'addilion d'une nouvelle couche de bois aux couches précédentes cause la distension de l'écorce, son amincissement, ses gercures, surtout la compression de ses vaisseaux, et bientôt l'écorce ancienne meurt et se dessèche par défaut de nourrilure. Mais remarquons que, puisque la renovation de l'écorce est nécessitéc par l'accroissement du corps ligneux, il faut nécessairement aussi que la formalion de la nouvelle écorce oa du liber soit postéricure à l'achèvement parfait de la nouvelle conche ligneuse; car si la formation de la nouvelle écorce et du nouveau bois, si la production du liber et de l'aubier était simultanée, on voit bien que le liber serait rompu et çétruit par compression avant que d'être entièrement achevé. Non, il ne paraît pas probable que ces deux corps se forment à-la-fois dans. fa même saison, pas probable qu'ils puisent en même temps des matériaux à la même source; mais la produclion en est successive, et vraisemblablement la nouvelle écorce est formée du résidu des matériuux composant le bois nouveau.

Puisque la couche corticale tend tonjours vers le dehors des végétaux, les corps étrangers dont on la traverse, les inscriptions qu'on y grave, ne disparaissent point vers l'intérieur, comme nous l'avons dit de ce qu'on grave, de ce qu'on enfonce dans le corps ligncux. Seulement, comme l'écorce est toujonrs distendue, les empreintes qu'elle présente sont progressivement agrandies suivant l'épaisseur; des corps étrangers fichés à la même hauteur dans son tissu, so trouvent, au boul d'un certain temps, plus éloignés. 
CIAP. XII. ACGROISSEJENT DES VÉGÉTACX.

l'un de l'autre qu'ils n'étaient originairement, etc. C'est par le degré d'élargissement de lettres inscrites sur le tronc monstrueux des Baobabs, qu'Adanson. supputa que ces arbres étonnans devaient avoir cinq à six mille ans d'existence. A force de s'élargir, les inscriptions el les sculptures gravées sur l'écorce finissent par se défigurer et par devenir indéchifrables; mais comme presque toujours le bois s'est trouvé endoinmagé en même temps que l'écorce superposée. on peut espérer, en fouillant plus avant dans un trone d'arbre, de retrouver intacts et de grandeur primitive les caractères déjà presque méconnaissables de l'écorce, Supposons des inscriptions datant d'un demisiècle, je dis qu'on peut retrouver dans la cinquantième couche ligneuse, en allant de l'extérieur vers. le canal médullaire, l'inscription des caractères originaires dont l'écorce ne porte plus que des traces obscurcies.

Exvelopperelduleuse. Elle est située à l'extérieur des autres couches corticales : elle est pour ainsi dire la moelle de l'écorce, et elle est analogue à celle-ci par sa structure non moins que par son organisation. En cffet, elle succède de dedans en dehors au liber et à l'écorce proprement dite, tout comme la moelle. centrale succède, de dehors en dedans, à l'aubier et aux couches ligneuses; or, nous savons que l'ordre des couches est en sens contraire dans le bois et dans l'écorce. Eependant la position de l'enveloppe celluleuse au dehors du végétal la fait différer de la moello. véritable, $I^{\circ}$. parce qu'au lieu d'être concentrée dans un canal, elle forme une zône autour des antres parties; et $2^{\circ}$. parce que son contact arce l'air luiperat 
408 LIV. III. DE L' $\Lambda$ CCGROISSEMENT DEs CORPS VIVANS.

d'agir sur lui, d'absorber, de fixer du carbone et de verdir. Celte enveloppe est excessivement mince dans le Platane ; très-épaisse, au contraire, dans le Chêneliège, dont on la sépare artificiellement pour les besoins de l'homme, une ou deux années avant sa desquammation naturelle. Elle partage les distensions, les gercures des couches corticales, et sa chute est périodique dans plusieurs sortes d'arbres; mais il faut avouer que son mode de reproduction n'a pas été convenablement expliqué jusqu’à présent.

Épiderme. C'est la pellicule placée à la surface de. l'enveloppe celluleuse dont nous venons de parler: elle paraìt tout-à-fait distincte de cette enveloppe, seulement elle lui adhère et la revêt. On a plus ou moins de difficulté à l'en séparer. Si l'on fait attention à la manière dont les arbres s'accroissent ct dont l'écorce se renouvelle en se fendillant et se desséchant, on comprendra que l'épiderme doit être dilacéré chaque année, et qu'il n'est bien distinct, avec les propriétés qui le caractérisent, que dans les jeunes troncs et les branches nouvelles, ou bien encore dans les intervalles des gerçures dis vieilles couches. Il ne faut pas prendre pour un seul épiderme cette masse informe, cette couche épaisse et inégale dont le tronc des vieux arbres est couvert; ce sont là des débris amoncelés et comme le cadavre de plusieurs écorces successives. Il y a des plantes qui paraissent avoir plusieurs épidermes superposés : le bouleau est dans co, cas; aussi est-ce l'un des arbres de nos climals qui résiste le mieux au froid el qui redoute moins les régions glaciales.

Racines. Les racines des plantes Exogènes croissent 
CHAP. Xil. ACcroissEnent des végétaux. 409 en épaisseur absolument de la mème manière que les tiges; elles forment en conséquence, par leur rencontre avec ces dernières, deux espèces de cônes dont les bases s'adossent à ce point intermédiaire qu'on nomme le collet. Mais dans les plantes Endogènes ou Monocolylédones, au lieu de deux cônes, ce sont deux cylindres. Les racines ne croissent que par leurs extrémités; le corps même de la racine n'éprouve pas d'élongation totale comme nous l'avons dit pour les jeunes tiges : des marques placées à égales distances sur les racines encore tendres n'éprouvent jamais d'écartement sensible, et si on coupe ces racines, elles ne s'allongent plus. D'ailleurs elles diffèrent des tiges, en ce qu'elles n'ont ni trachées ni stomates ou pores, ni moelle centrale : toutefois elles ont comme elles des rayons médullaires, ce qui prouve que ces rayons ne sont pas nécessairement une émanation de la moelle dans les tiges. Du reste, elles ont, : comme ces dernières, une enveloppe celluleuse, une écorce, un liber, des couches successives, d'âges et de dureté différente; car leur àccroissement a lieu par zônes annuelles, comme pour les tiges. lilles sont pourtant très-différentes des tiges : clles ne verdissent jamais, lors même qu'elles seraient exposées à l'air; elles n'absorbent jamais de carbone, et quoi qu'on ait pu dire, jamais elles ne se transforment réellement en tiges, ni jamais les tiges en racines. Dans l'expérience de Duhamel, du retournement d'un arbre, on voit des racines naître des tiges, et des tiges provenir des racines; mais les unes ni les autres ne se transforment; et même on voit périr, dans cette expérience, et les jeunes racines et les nouvelles pousses 


\section{10 LIV. III. DE L'ACCROISSEMENT DES CORPS TTVANS.}

de la tige. Nous avons vu que les branches des arbres dépendent des racines dans ce sens, que les plus grosses branches sont toujours du côté des racines les plus volumineuses, parce que ces dernières fournissent de ce côté une nourriture plus abondante. Par la même raison, les couches dubois sont plus rapidement parfaites, plus dures, plus épaisses, etl'aubier moins persévérant du côté des plus grosses racines. On a aussi observé que les arbres situés sur ie penchant d'une montagne ont des branches parallèles aux racines; c'est-à-dire qu'elles sont courtes et verticales du côté de la cîme, et longues et pendantes à cause. de leur poids plus grand du côté de la vallée; parce que les racines n'éprouvent, en ce dernier sens, aucun obstacle à s'accroître, aucune difficulté à descendre et à se nourrir dans le sol.

Il suffit pour que les racines poussent des tiges ousurgeons, qu'elles soient en contact avec l'air : et pour que des racines naissent des tiges, il faut que celles-ci soient placées près d'un sọ hunide ou même qu'elles y pénètrent. Les tiges noueuses, et celles que beaucoup de fluides pénètrent, les plantes grasses ouaqueuses, sont celles d'où proviennent plus aisément des racines; et celles-ci naissent surtout vers les nouds et les articulations. Il est peu de parties vertes dans les végétaux qui ne puissent donner naissance à des racines : celles-ci naissent d'espèces de petites glandes ou Lenticules que l'écorce commune contient dans son épaisseur. Ces dernières racines sont nommées adventives. L'usage des racines est de fixer les plantes dans le sol et de les nourrir. On juge de leur âge comme nous avons dit qu'on juge de l'âge des tige 
CIAAP. XII. ACCROISSEMENT DES VÉGÉTAUX. 411 exogènes, par le nombre des couches ligneuses concentriques.

Feurles. Ordinairement avant de se développer les feuilles sont roulées, plićes ou diversement contournćes dans leur bourgeon : mais leur mode d'èpanouissement a beaucoup de constance et de régularité pour celles de la même espèce. On peut observer, quant à leur disposition, que jamais deux feuilles parallèles ne se recouvrent immédiatement; mais que la troisième est ordinairement placée vis-à-vis de la première, et la quatrième en face de la deuxième; que les plantes dicolylédones ou Exogènes ont constamment leurs fiuilles primordiales opposées, tandis que les plantes Endogènes les ont alternes. Chaque année ordinairement les feuilles articulées lombent d'elles-mêmes, cn se désarticulant; celles qui sont continuss avec la lige meurent sans tomber, sans se détacher. Les feuilles qui absorbent et qui exhalent beaucoup, sont les plus promptes à se faner ét à périr; érralement, colles qui ont un bouton dans leur aisselle sont plus tôt tombées que les antres.

Fleurs. Eiles se développent, se déplissent, se déroulent et s'épanouissent à la manière des feuilles : ordinairement elles terminent les tiges ou leurs rameaux, ou naissent dans l'aisselle des fenilles ou des rameaux. Les difiérentes partics qui composent les Fleurs sont presque tonjours alternatives : c'est-à-dire, que les divisions de la Corolle répondent à l'intervalle des divisions du calice; que les Étamines sont situées vis-à-vis ces dernières, et en consérquence dans l'intervalle des Pétales; et enfin que les Pistils sont pa- 
412 LIV. III. DE L'ACGROISSEMENT DES CORPS VIYANS.

rallèles aux pétales et qu'elles alternent avec les étamines. Cette disposition est rarement transgressée.

Nous ne donnerons pas d'autres détails sur les fleurs: Il en a été fait mention dans une autre partie de cet ouvrage. ( oy. chap. V du livre 11.)

Nous n'avons eu en vue, dans ce chapitre, que ce qui concerne l'accroissement et l'organisation des végétaux Dicotylédones ou Exogènes : nous ferons quelques remarques rapides, dans le chapitre qui va suivre, sur les végétaux à un cotylédon, ou Endogènes. Ces derniers sont en effet trop différens des. autres pour n'en être pas séparés.

\section{CHAPITRE XIII.}

Remarques sur l'Accroissement des Planles Monocolylédones ou Endogènes.

Les plantes qui naissent avec un seul cotylédon se ressemblent, en outre, par d'autres caractères (i), mais surtout par leur mode d'accroissement. D'abord elles sont Endogènes, c'est-à-dire que ce sont leurs parties excentriques qui sont les premières formées, et que c'est à leur centre qu'elles produisent des couches nouvelles : voilà déjà deux caractères qui les diflérencient formellement des plantes à deux Cotylédons ou Exogènes. Outre cela, elles ne sont pas.

(1) Voyez D'Aubenton, Desfontaines, Mirbel, Decandolle, Richard, Du Pelit-Thouars, Dutrochet, Lestiboudois, ctc. 
CHAP. XIII. REMARQUES SUR IES MONOCOTYLÉDONES. 413 formées de deux parties distinctes comme ces dernières; elles n'ont pas comme elles un bois nettement séparé d'une écorce, elles ne sont pas formées de deux parties s'accroissant en sens contraire; et si elles ressemblent à l'une de ces deux parties composant le tronc des dicotylédones, c'est uniquement à l'écorce, puisqu'elles s'accroissent en dedans comme celle-ci. Elles n'offrent donc qu'une seule masse uniforme ex sensiblement homogène; et de plus, elles n'ont ni de moelle centrale, ni de rayons médullaires.

Si l'on coupe la tige d'un palmier, par exemple, " on voit qu'elle n'est composée que dé fibres éparses, entremêlées d'un tissu cellulaire qui les unit les unes aux autres. On remarque anssi que les fibres de la circonférence sont serrées les unes contre les autres, d'une consistance très-ferme, et évidemment plus âgées que les fibres intérieures. Ces dernières, an contraire, sont écartées, sont molles, d'une nature plus herbacée, et entourées d'un tissu cellulaire lâche et féculent. Chaque fibre est un faiseeau mélangé de trachées et de vaisseaux divers, entremêlés en outre d'un tissu cellulaire allongé, et entourés d'un tissu cellulaire à mailles arrondies. La différence de consistance entre le centre et la circonférence du tronc est toujours sensible, et quelquefois très-remarquable. If est des palmiers dont la partie extéricure est tellement dure, que la hache ne peut l'entamer; tandis que le centre est un tissu lâche et spongieux, qui s'altère par l'humidité. La circonférence des palmiers, quant à la consistance et à l'âge, représente donc le bois de nos arbres; tandis que le centre est comme une sorte d'aubier. Toutefois il faut remarquer que ces deux 


\section{$41 /$ LIV. III. DE L'ACCROISSEJENT DES CORPS VIVANS.}

organes sont placés dans un sens inverse de ce que nous avons l'habitude de voir dans les exogènes. C'est de cet aubier central que naissent les feuilles et les Oleurs; c'est en un mot, c'est toujours par le centre que s'effeclue le développement de toutes les parlies des palmiers. Les jeunes feuilles des pousses annuelles des Dicotylédones ou Exogènes naissent, il est vrai, semblablement en dedans des feuilles plus anciennes, ou à l'intérieur des bourgreons; mais si, sous ce rapport, il y a ressemblance entre les deux grandes classes de végétaux, elles n'en diffèrent pas moins en cela, que tout le reste du développement du tronc se fait par l'addition de nouvelles couches ligncuses et en dehors des premières; tandis que, dans les Endogènes ou Monocutylédones, l'accroissement s'opère par l'interposilion de nouvelles fibres, et seulement vers le centre du tronc."

On a comparé l'évolution ou développement des Palmiers au déploiement successif des cylindres emboîtés d'une lunette d'approche. Dès son origine, en effet, le palmier pousse une première rangée de feuilles qui lui forment comme un couronnement. Chaque annéc suivante, on voit naître à l'extrémité de la tige une nouvelle rangée ou touffe de feuilles, et ces feuilles elles-mêmes sont la terminaison et comme l'épanouissement d'une nouvelle couche qui s'est formée à l'intérieur de l'arbre, en dedans de la couche de l'année précédente. Il résulte de là que le palmier se compose de couches concentriques les unes aux autres, mais non distinctes entr'elles; et ces couches se forment et se succèdent à l'inverse des oouches ligneuses des plantes dicotylédones ou Exo- 
CAAP. XIII. REMARQUES SOR LES MONOCOTYLEDONES. 415 gènes : les couches les plus internes sont les dernières formées. Et comme les couches les plus extérieures, de tontes les premières formées, sont trop dures, lors du développement des couches subséquentes, trop solides, pour céder à la pression que ces dernières exercent sur elles, à cause de cela les plantes monocotylédones ou Endogènes ne font de progrès qu'en haıteur et nullement en épaisseur : bien plus, le développement des couches à l'intérieur produisant toujours chaque année des expansions semblables à l'extrémité de la vieille tige, il en résulte que les tiges des plantes monocotylédones sont sensiblement de la même grosseur dans toute leur étendue, sensiblement cylindriques. Car nous avons dit que les couches extérieures ne peuvent s'agrandir ni se dilater.

Pour juger de l'âge des Palmiers ou des autres monocolylédones vivaces, il suffirait de savoir le nombre des couches ajoutées intérieurement et chaque année l'une à l'autre; mais puisque ces couches ne sont pas distinctes, nullement séparées, il faut recourir à un autre moyen. Or, 'nous trouvons unc base plus sûre pour un semblable calcul, dans ces anneaux de feuilles qui couronnen! annuellement ce genre de plantes. Si les feuilles tombent, il reste au moins des cicatrices indiquant leur présence et résultant de leur chute ou destruction. La difficulté est que dans la suite des temps ces cicatrices même-finissent par s'effacer, et alors plus de moyens précis pour s'assurer de l'âge de ces végétaux : il ne reste tout au plus que l'appréciation de la longueur totale de la tige, composée de fractions a-peu-près égales pour chaque année, et par la com- 
\$16 LIV. IIr. DE L'ACCROISSEMENT DES CORPS VIVANS. paraison de la longueur totale avec la mesure d'une année, on peut juger quel nombre d'années il a fallu pour le développement du tout ensemble.

Il résulte de ce mode de développement des plantes monocotylédones plusieurs particularités notables. Par exemple, comme ces végétaux ne croissent sensiblement qu'en hauteur, on conçoit qu'il suffit qu'une seule pousse annuelle soit entravée, ralentie par n’importe quelle cause, pour déterminer un étranglement manifeste dans la tige: on a vu des plantes de la famille dont nous parlons, présenter des étranglemens sensibles par le simple effet d'une longue traversée sur mer par un temps inopportun. La même cause ne peut produire d'effets semblables sur la tige des exogènes ou dicotylédones; car comme elles croissent par couches concentriques superposées les unes sur les autres, il est clair que la maigreur, que l'amoindrissement de l'une d'elles doit porter sur tous les points de la tige également, puisque cette nouvelle couche dépérie enveloppe toutes les parties alors existantes du végétal. S'agit-il, au contraire, des effets de compressions exercées sur ces tiges? ces compressions, on en voit la raison, produiront alternalivement des dépressions et des bourrelets sur les plantes exogènes ou dicotylédones (puisqu'elles s'accroissent à l'extérieur ); tandis qu'elles n'auront aucun effet, aucun résultat apparent sur des plantes endogènes, dont la croissance se lait par le centre. Une Viorne, en conséquence, produit des empreintes sur un jeune Ormeau qu'elle enserre, et ne laisse aucune trace au contraire sur la tige d'un Palmier. Ce sont là des effets différens d'une cause scmblable. 
Chap. xiv. Monsthiosités vigktales.

Ce que nous venons de dire des palmiers est également vrai, à de faibles modifications près, de toutes les plantes à un seul cotylédon ou endogènes : toutes diffèrent des exogènes, en ce qu'elles croissent en dedans, en ce qu'elles n'ont point d'écorce, point de moelle centrale isolée, point de couches annuelles appréciables, nul progrès pour l'épaisseur après les premières années, mais seulement un accroissement en hauteur par des pousses terminales. Autrefois, avant qu'on eût nettement différencié les végétaux endogènes des exogènes, on ne pouvait dire rien de général sur les tiges et leur accroissement, sans être arrêté à tout instant par des exceptions embarrassantes; aujourd'hui que ces généralités sont plus restreintes, elle sont du moins d'une grande exactitude.

La nature est si variée dans ses productions, si diversifiée dans ses phénomènes, si féconde en causes secondaires, que pour découvrir la vérité dans ses ceuvres, il faut ordinairement descendre jusqu'aux faits individuels. Les généralités ne sont souvent que de superbes mensonges.

\section{CHAPITRE XIV.}

Irrégularites, Anomalics réelles ou seulement apparentes des Végétzux. - Soudures. - Arortemens. - Mítamorphoses.

Lẹs Anomalies et les Difformités sont encore plus fréquentes pour les plantes que pour les 'animaux. Beaucoup sont purement accidentelles, et causées, I. 
41 $18^{\circ}$ LIV. HI. DE L'ACGROISSEMENT DES CORPS VIVANS.

soit par descompressions, d'où naissent de profondes dépressions dans les liges exogènes; soit par des froids Irop-vifs et trop prolongés, ce qui engendre des gélivures concentriques pour les plantes exogènes, et des étranglemrens insolites pour les endogènes; soit par des piqûres d'insectes, d'où résultent rles végétations irrégulières, des proéminences difformes. La moelle centrale peut aussi se trouver déjetée d'un côté de la tige et loin de son axe, par l'effet de l'épaisseur plus grande des couches ligneuses du côté opposé; et cela arrive toutes les fois que les racines trouvent dans un sens, plus que dans les autres, de la facilité à s'étendre, à croître et à se nourrir. Il suffit quelquefois, ou de couper les bourgeons floraux, ou de détruire ceux des boutons à bois qui sont prédisposés à prendre de l'accroissement, pour déterminer la crue d'autres parties qui, sans cela, fussent demeurées stationnaires: et même celte opération si simple peut changer l'aspect et la physionomie de lout un végétal, au point de le rendre méconnaissable à distance.

Mais il est vrai de dire que la plupart des difformités sont natives, ou du moins originairement prédisposées dans quelques espèces. Les causes en sont diverses: tantôt ces anomalies tiennent à un avortement d'organes, tantôt à une soudure, à une adhérence, ou bien à une sorte de métamorphose de certaines parties. Nous allons citer des exemples de chacune de ces espèces d'irrégularités.

Quant aux Avortemens de beaucoup d'organes, c'est une chose assez commune dans les plantes; il est impossible d'en nier l'existence. Ainsi la première 
CHAP. XIV. MONSTRUOSITÉS VÉGÉTALES.

Heur de la Rue a seule dix ćtamines (et c'est à cause de cela que Linné a rangé cette plante dans la Décandrie), mais les autres fleurs n'en ont que huit: les deux autres arortent constamment. L.cs lieurs tétradynames de beaucoup de crucifères deviennent quelquefois simplement Tétrandres, par l'avorlement des deux pelites étamines ordinairement sur-ajoutées aux quatre grandes. Benucoup d'autres plantes manquent souvent ainsi de plusieurs des étamines composant le nombre total naturel à leur espèce. On voit pareillement manquer, chez cerlaius végélaux, des pétales, des pistils dans la fleur, des graiaes dans l'ovaire, un cotylédon dans l'embryon, elc. Le même arrêt dans l'accroissement, le même défaut d'organisation se remarque dans les auires pariies de la plante : c'est ainsi que beaucoup de feuilies se transforment en simples vrilles; que de jeunes rameaux, manquant re nouriture, se transforment en épines; et si quelques plantes, ont la siugularité de n'avoir d'épines que dans une culure plus perfectionnée et plus favorable. cela dépend de ce qu'une nourriture trop abondante a déterminé la production de rameaux supplémentaires qu'il n'est pas dans la nature diu végétal de développer.

Les cxemples de Soudures sont aussi fort nombreux; et même ces adhérences sont si constantes dans certaines familles de plantes, qu'on pourrait aisément se méprendre en les confondant avec des dispositions normaḷes et un état naturel. Il est assez fréquent de voir les deux cotylédons de quelques graines de dicoIylédones tellement unis, qu'on croirait qu'il n'existe réellement qu'un seul cotylédon: cela est vrai en 
420 LIV. III. DE L'ACCROISSEMENT DES CORPS VIVINS.

particulier du Cycas. Deux graines se soudent aussi quelquefois pour n'en former qu'une, et cette double graine renferme alors deux cotylédons, il est vrai souvent imparfaits. Les étamines s'unissent de même, tantôt par leurs anthères (dans les fleurs composées ou Syngénèses); tantôt par les filets, dans les plantes de la Monadelphie, de la Polyadelphie, etc. celles du Barnasia sont soudées à-la-fois par les anthères et par les filets. La même chose se remarque pour les pistils et pour les ovaires. Deux feuilles, deux fleurs, deux branches, deux troncs, deux racines souvent se greffent ensemble, de manière à ne plus former qu'un corps unique après leur soudure.

J'en dis autant des Transformations ou Métamorphoses; les exemples en sont nombreux. Sans parler de la racine et de la tige, qui (quoi qu'on en ait dit) ne se transforment jamais l'une ou l'autre, on voit de jeunes rameaux se changer en épines, ainsi que nous l'avons exposé,par une sorte d'avortement; et cesépines redeviennent rameaux foliacés, lorsque le sol où vit la plante est plus riche, moins ingral. Il est de même habituel que les feuilles du calice des composées se chaugent en aigrettes sèches; que les étamines, et parfois aussi les pistils, dans les fleurs doubles; se transforment en pétales; une chose plus rare, c'est la transformation des pétales en étamines. Enfin, les feuilles se changent quelquefois en vrilles, les pétioles ou même les tiges en feuilles : il n'y a pas jusqu'au spermoderme, ou peau de la semence, à qui l'on n'ait vu subir de ces dernières transformations (1).

(1) M. Du Petit-Thouars.-Consultez aussi, pour tout ce chapitre, Goëthe, Autenrieth, Decandol!e, Currea, Cassini, Rob. Brown, elc. 
Comme ces métamorphoses, ces avortemens et soudures d'organes sont d'une grande constance dans certaines espèces, il est résulté de là qu'on a souvent pris de pareilles anomalies pour l'état naturel; et qu'au contraire, l'état primitif et de nature a passé pour une irrégularité, pour une anomalie. Ainsi on a vn des fleurs présenter plus d'étamines qu'elles n'en ont d'habitude; d'autres, dont les étamines sont ordinairement soudées, les avoir isolées; on a vu des fleurs qui n'avaient habituellement que des pétales nombreux, offrir tout-à-coup plus d'étamines et moins de pétales, vu des aigrettes changées en feuilles de calice, des pétales redevenus pistils alans quelques anémones, des épines transformées en vrais rameaux, etc.; et l'on a pris toutes ces choses pour des difformités, pour des anomalies, lorsqu'au contraire il n'aurait fallu y voir qu'un relour à l'état primitif et normal.

Cependant nous avons plusieurs moyens de nous assurer que ces développemens extraordinaires d'organes sonht l'état de nature. Indépendamment de ce que la symćtrie des organes paraît visiblement altérée, nous voyons, par exemple, certains Géraniums n'avoir que cinq ou sept étamines, tandis que la plupart des plantes de ce genre en ont dix; et c'est un, mpotif de croire quil y a dans ce cas avortement. Outre cela, on retrouve presque toujours quelques rudimens des organes avortés, nouveau motif. Maintenant si la nême fleur, qui n'avait que sept étamines, vient à en offrir dix, n'est-il pas naturel de penser que ce dernier cas est la disposition régulière de cétte fleur? On voit une rose avec des pétales nombrẹx, et peu 
ou point d'étamines; est-ce là l'état de nature? on transplante la tige où tenait cette fleur dans un sol moins fertile et d'une culture plus négligée, et alors on voit diminuer le nombre des pétates, et se multiplier lẹs étamines dans la même proportion : est-ce là une anomalie? est - ce là une irrégularité? n'est-il pas évident, au contraire, que les pétales multipliés de la fleur double n'étaient que des étamines, jo ne dis pas avortées, mais transformées? C'est cle la même manière qu'on voit parfois se transformer en étamines, des cornets de fleurs d'Ancolie; que les Anémones dont la culture avait changé les pistils en pélales, reprennent ces pistils, lorsqu'on les abandonne sans culture. Mais voici un exemple plus décisif. Je suppose qu'on trouve six glands au lieu d'un dans une capsule de Chene, n'est-il pas vrai qu'on croira à une monstruosité ? ce ne serait pourtant là qu'une disposition normale et régulière; car il est sûr que le jeune fruit du chêne se compose originairement de trois loges contenant deux grains chacune; et si le gland est ordinairement unique, cela n'est dì qu'a l'avortement des cinq autres semences qui lui furent contemporaines : il en est de même du fruit du marronier, mais je ne finirais pas si je voulais citer seuflement la centième partie des faits de ce genre.

Redisons done que l'habitude des dispositions les plus irrégulières fait regarder souvent comme anomalie un retour à la régularité native; je veux dire à la restilution d'organes habituellement avortés. Il est clair que, dans toute espèce où les monstruosités sont fréquentes, on est porté à regarder comme monstres, les êtres les plus réguliers : et c'est précisément. 
ee qui arrive pour beaucoup de plantes. Il est facile de s'habituer à prendre pour des tous uniques, mais seulement divisés, des organes réellement composés de parties distinctes. Ainsi on dit que le calice, que la corole se divisent, au lieu qu'il faudrait dire que ces organes sont composés de pièces entr'elles adhérentes et soudées, comme on a raison de le dire des étamines et des pistils unis.

Il faudrait aussi changer le langage, ou du moins les idées, pour ce qui regarde ies avortemens de divers organes. Ainsi, certains fruits n'ont qu'une loge cloisonnée, que parce que plusieurs fruits se sont soudés pour n'en former qu'un; certaines fleurs ne sont stériles, que parce que les étamines ou les pistils ont avorté : peut-ètre mème beaucoup de plantes ne sont-elles dioiqques ou monö̈ques, c'est-a-dire a fleurs diversement unisexuelles, qu'à raison d'm avortement des pistils daus certaines plantes ou dans une partie des fleurs, ou à cause d'un semblable avortement des étamines dans les autres. Et ce qui at:torise encore celte opinion relativement aux dioïques, c'est qu'il est peu de fleurs de celte nature qui ne présentent au moins parfois la réunion d'organes ınâles et d'organes femelles; et voilà même la source des erreurs que commit Spallanzani au sujet des. graines du chanvre. (Voyez chap. V, liv. II.).

Remarquons à ce sujet qu'il paraît aussi naturel: aux plantes d'être hermaphrodites, je veux dire de réunir les organes des deux sexes dans les mêmes fleurs, qu'il esi naturel aux animaux supérieurs d'être unisexucls. Et même tout porte à penser que les. plantes ne deviennent uniscxuelles, qu'en vertu des. 
424 LIV. III. DE L'AGCROISSEMENT DES CORPS VIVANS.

mêmes causes qui font paraître les animaux vertébrús hermaphrodites, c'est-à-dire par un arrêt dans l'accroissement, par une sorte d'avortement des organes reproducteurs.

Il est encore plusieurs observations à faire à l'égard des anomalies et des monstruosités des plantes; voici les principales :

$1^{\circ}$. Les organes des végétaux sont d'autant moins variables, d'autant moins exposés à se déformer, à devenir irréguliers, qu'ils sont moins nombreux : leur grand nombre les expose davantage à des compressions, et à cause de cela à des avortemens, à des soudures. Les fleurs en épi, Jes pédoncules multiflores, les fleurs composées, sont les plus enclins à des anomalies, à des avorlemens, et à des irrégularités diverses.

$2^{\circ}$. En général, les premiers organes développés sont les plus réguliers : la plante jouit alors de toute son énergie. Il est rare que les premières fleurs éprouvent des avortemens; elles offrent presque toujours le caractère normal de l'espèce et de la famille : nous en avons cité un exemple pour la Rue. Il en est de même pour tous les autres organes: les feuilles primordiales sont, à cause de cela, toujours plus significatives. Ainsi toute plante dont les premières feuilles sont alternes, est monocolylédone : une disposition semblable serait monstrueuse dans les dicotylédones ou Exogènes.

$3^{\circ}$. Les fleurs terminales sont les plus régulières, parce qu'elles sont tes plus libres, et qu'elles sont d'ailleurs dans le sens direct des vaisseaux : la liberté et l'isolement favorisent la régularité de structure. 
$4^{\circ}$. Il existe pour chaque organe des plantes une sorte de symétrie qui peut indiquer les anomalies qu'elle éprouve : il y a pour chaque famille de régétaux un certain arrangement, un certain nombre arrêté d'organes, qui en font découvir les transgressions. Ainsi les pétales, les sépales, les étamines, les pistils et les ovaires sont toujours dans des proportions relatives : le nombre des uns est tantôt pareil, tantòt double, tantôt multiple des autres. Outre cela les divisions du calice sont ordinairement parallèles à l'attache des étamines, les étamines alternent souvent avec les pétales et les pistils, et ces dernicrs, par conséquent, sont ordinairement parallèles aux pétales.

$5^{\circ}$. Les plantes dicotylédones ont une sorte de prédilection pour les nombres quatre et cinq, et leurs multiples : cinq ou quatre pétales; huit, cinq, dix, douze, vingt étamines ; quatre, cinq ou huit pistils, etc., sont, pour ces plantes, des proportions assez habituelles. Le nombre trois et ses multiples est surtout familier aux plantes monocotylédones ou endogènes. Il naît de là un nouveau moyen de décoụ-, vrir des irrégularités, des soudures, des avortemens d'organes, un moyen de constater des anomalies.

$6^{\circ}$. Ce qui serait régulier pour les plantes dicotylédones, est souvent irrégulier et monstrueux pour les monocotylédones.

$7^{\circ}$. L'avortement d'un des organes floraux entraine presque toujours à sa suite l'avortement d'autres organes, de sorte que les fleurs conservent leurs proportions et la plus parfaite symétrie au sein même des plus grandes irrógularités. C'est ainsi, par exemple, 
426 hIV. III. DE L'AGCroISSHMENT DES CoRPS VIVAIS.

qu'on retrouve sur une même tige des fleurs dont le. calice a quatre divisions, la corolle quatre pétales, à huit'étamires et quatre pistils et ovaires; et d'autres fleurs à cinq pistils, dix élamines, cinq pétales et cinq divisions au calice. La symétrie est par là conservée.

$S^{\circ}$. Souvent une plante imparfaite au moment de son épanouissement, était parfaite un peu auparavant. C'est absolument comme pour les animaux : les anomalies proviennent presque tonjours de ce que les différentes parties n'ent pas fait parallèlement des progrès, de ce que plusieurs sont restées stationnaires à des âges différens.

$9^{\circ}$. On prend souvent pour un état régulier, dans les plantes, une monstruosité habituelle, et l'on regarde, au contraire, comme anomalie, une simple restitution de l'état régulier et primitif. Ce qu'on appelle Pélorie dans plusieurs fleurs, n'est point une monstruosité; e'est tout simplement la crue achevée, le développement régnlarisé d'étamines habituellemont arortées.

- $10^{\circ}$. Il est commun que deux organes ne se fondent. entre eus qu'en conséquence de ce qu'une autre partie ne s'est pas accrue; il est de même ordinaire qu'une partie n'avorte que parce que d'autres parties abreuvées des mèmes sucs se sont rapidement accrues. Ainsi, les bourgeons médians de certains arbres avortent par suite de l'ćlongation rapide des bourgeons latéraux; mais si ces derniers sont détruits ou $\mathrm{cmpe-}$ chés, alors le bourgeon central se développe. Il est bien vrai que, dans ce balancement des organes voisins, l'extrême développement de l'un dépend sou- 
CIIAP. XIF. MONSTRUOSITÊS VÉGÉTAGES.

vent de l'avortement d'un autre, mais la règle opposée est infiniment plus ordinaire.

$1:^{\circ}$. Ce que nous venons de dire sapplique aux métamorphoses. Il est difficile de dire, par exemple, si les bractées de l'Hortensia ne 's'accroissent et ne se teignent des plus belles couleurs que parce que ses fleurs véritables avortent, ou si l'avortement de ces dernières n'est dû qu'à l'excessif développement des autres. Le phénomène des fleurs doubles provient bien plutôt d'une métamorphose que d'un avoriement; car il n’a jamais lieu que dans les circonstances. les plus propices au rapide accroissement des végétaux.

$12^{\circ}$. Lorsque deux organes ou deux parties se fondent pour n'en former qu'une, il arrive alors presque toujours qu'il y a en même temps surcroît et diminution d'organes : deux fleurs ou deux graines soudées ont plus de parties qu'il n'en faudrait pour une seule, et moins que les deux ensemble. C'est ainsi que deux semences unies de dicotylédones, n'offrent que trois cotylédons, au lieu.de quatre, dans les deux embryons soudés qu'elles renferment(1). Les monstres doubles d'animaux présentent des caractères absolument analogues.

$13^{\circ}$. Les organes floraux conligus sont les plus enclins à se métamorphoser les uns dans les aulres; ainsi le calice se change quelquefois en pétales colorés, les pétales deviennent étamines, les étamines

(1) Observation de M. Decandolle fils, Fequel se moulre dejà digue de porter un nom qu'ont pour toujours illustré les tiavaus de son père. 
4 28 LIV. III. DE L'ACGROISSEMENT DES CORPS VIVANS. pistils ou même ovaires, ou de même en sens inverse.

14. Il est certain qu on a vu des étamines se changer tout à-fait ou partiellement en ovaires, c'est-àdire contenir des ovules avec ou sans pollen (1). On a vu pareillement des pistils se changer en étamines et porter des espèces d'anthères remplis de pollen. Les organes floraux peuvent donc se métamorphoser réciproquement les uns dans les autres; tous peuvent de même se transformer en pétales; il n'y a pas jusqu'aux divisions du calice, jusqu'aux bractées, et qui plus est jusqu'aux feuilles de la tige, qui ne puissent ressembler aux pétales et en revêtir les brillantes couleurs. Il n'est pas, en outre, un seul de ces organes reproducteurs des plantes, pas même les semences, qu'on n'ait vu parfois se transformer en feuilles. De toutes ces observations on conclut que ces organes sont tous de même nature, tous ressemblans aux feuilles; qu'enfin tout végétal ne se compose que de trois organes différemment configurés, savoir : la racine, la tige et les feuilles.

\section{CHAPITRE XV.}

Circonstances indispensables au premier Accroissement des corps virans. - Incubation. - Gestation. - Germination. - Avortement singulier des Didelphes.

Chaque être vivant a sa première origine dans un autre être scmblablè lui : beaucoup même prennent

(1) M. Du I'etit-Thouars. 
lcurs premiers accroissemens précisément dans le lieu ou du moins dans l'être où ils ont leur première source, tt ils ne commencent à vivre d'une existence indépendante qu'au moment où ils quittent le sein maternel. Mais il est d'autres êtres très-nombreux qui se développent, loin de teur première origine, dans un ovule, séparé du corps vivant qui l'a produit, et au sein duquel le nouvel être trouve, en même temps qu'un abri, tout ce qui peut servir à le nourrir et à l'accroître : nous pouvons citer des exemples de ces différens modes d'accroissement. D'abord, les véritables Vivipares produisent des petits vivans, et la première crue de ces jeunes animaux s'effectue dans la matrice de leur mère. Quant aux animaux Ovipares, ils ne sortent ordinairement de l'œuf où ils prennent naissance, qu'un certain temps àprès que cet œuf est lui-même détaché de la femelle qui l'a produit. D'autres ovipares, il est vrai, éclosent au-dedans de leur mère, et on les appelle à cause de cela Ovo-vivipares. Enfin, les Plantes, déjà formées en miniature dans les graines encore adhérentes au réceptacle dé la plante-mère, ne se développent d'une manière évidente qu'après la chute de ces graines dans un sol ou sur des corps favorablement disposés. Il est des végétaux qui donnent naissance, sans fleurs visibles, sans véritables graines, à des Bulbes contcnant les linéamens de plantes nouvelles : il est de même bourgeons, des Gemmes, sortes d'oufs imparfaits, étrangers à toute espèce de fécondation; et cesbourgeons, détachés de leur souche commune après y 
\30 LIV. IIr. DE L'AGCROISSEMENT DES CORPS vIVANS.

avoir pris un notable accroissement, vont ensuitc former de nouveaux animaux.

Mainlenant, outre la circonstance de provenir ious d'êtres semblables à eux et d'avoir primitivement adhéré à leur propre substance, outre cetle autre circonstance de naîtré tous d'une sorte de bourgeon ou d'un ovule au sein duquel le germe du nouvel être est d'abord invisible, tous les corps vivans ont en commun cette autre parlicularité, que le premier accroissement ne s'en effectue qu'à la condition, ou qu'ils adhèrent à leur mère, ou qu'ils en éprouvent le voisinage, qu'ils en reçoivent une bienfaisante chaleur, ou du moins une chaleur étrangère leur tenant lieu de celte chaleur maternelle et vivifiante. Toujours est-il que tous les corps vivans trouvent dans l'ovule qui leur sert de premier berceau, la première nourriture nécessaire à leur premier accroissement; et que tous ont également besoin d'une chaleur étrangère, agissant sur eux jusqu'à ce qu'ils jouissent d'une existence individuclle entière, jusqu'à ce qu'ils effectuent une sorte de respiration, en agissant pour le décomposer, sur l'air libre ou emprisonné qui les entoure.

Ainsi donc, tous les êtres vivans éprouvent le besoin d'une sorte d'Incubation. Le jeune Polype ne se détache de sa souche originaire qu'après qu'il est déjà assez formé pour suffire scul à ses propres besoins. Cependant il faut remarquer que les polypes nés durant l'hiver ou dans l'automne se détachent assez vite de la base commune pour se développer isolément, tandis que ceux de l'été demeurent plus long- 
iemps aggrégés. Celles des plantes qui se reproduisent par des bulbes ou des espéces de bourgeons, ressemblent beaucoup aux polypes en ce que nous venons de dire; les bulbes ne se détachent de la plaute-mère qu'après leur avoir longy-temps adhéré. et seulement alors 'qu'ils peuvent s'enraciner et s'accroître. La graine encore renferméc dans l'ovaire où elle a été fécondée, contient déja l'embryon visible d'une nouvelle plante : elle subit là une sorte d'incubation; et comme elle reçoit sa part des vaisseaux ramifiés dans le tissa de la plante-mère, et d'ailleurs comme ces vaisscaux sont immédiatement continus aux siens, à cause de cela elle ressemble beaucoup micux à ce qu'on observe pour les jeunes vivipares qu'à ce qui a lieu pour les ovipares. Il est même des graines qui germent avant de s'ètre détachées de la plante mère : les fruils du Manglier en sont un exemple. Une graine, quelle qu'elle soit, étant déposée, loin dujour, dans un sol humide et assez léger pour permettre l'accès de l'air, l'embryon déjà formé qu'elle recèle continue de s'accroître. La radicule s'implante dans la terre, où ses nombreuses ramifications puisent des sucs nourriciers; la plumule se prolonge en tige ordinairement hors du sol ; les cotylédons, ou premières feuilles séminales, tantôt restent au-dessous de la plumule et tantôt et plus souvent la surmonient, et, sortis de terre ou se trouvant cachés par le sol, ils finissent par se flétrir, leur substance s'épuisant peu-à-peu par la nourriture quiils fournissent à la plante nouvelle : ensuite on voit successivement paraîlre des fenilles, des bourgeons, des fleurs; et de ces fleurs naissent de nouvelles graines, renfermant 
452 LIV. III. DE L'ACÇOISSEMENT DES CORPS VIVANS.

les embryons d'autres plantes. Ainsi la graine, tant qu'elle reste attachée à son réceptacle, est l'image assez parfaite de l'ovile des vivipares; mais une fois insérée dans le sol, elle éprouve une sorte d'incubation à la manière des œufs des ovipares.

Tous les êtres vivans offrent la plus parfaite similitude en ce que nous venons de dire. Les Crustacés portent leurs ceufs, jusqu'à ce qu'ils éclosent, sous l'extrémité évasée de leur queue; beaucoup de Mollusques gardent les leurs à l'intérieur de leur corps jusqu'à ce que des petits en naissent : ils sont par conséquent ovo-vivipares. On voit des Araignées porter leurs œufs patiemment dans leurs mains et les échâuffer jusqu'à parfaite éclosion. Quelques Insectes, quoique se reproduisant tous par des oufs, mettent au jour des petits vivans; d'autres accouchent de larves, ou de nymphes déjà deux fois transformées. Il en est d'autres qui déposent leurs oufs dans des feuilles, dans des fruits ou des corps ligneux, dans le conduit digestif ou dans les narines d'autres animaux, dans des peaux ou des vêtemens, dans des immondices ou des chairs en putréfaction; et ils éprouvent, dans ces diverses circonstances, une chaleur favorable à leur développement et aux progrès de leurs métamorphoses. On voit même des insectes qui cowvent réellement leurs œufs : la Cochenille, par exemple, couvre les siens de son propre corps façonné en bouclier; et elle meurt en les protégeant, et les échautfant d'un reste de chaleur vitale.

Beaucoup de Vers engendrent dans le corps d'autres animaux. Les Poissons, ou sont ovo-vivipares, ou déposent leurs oufs dans des plages et sclon des 
Cinap. Xv. DE L'hicubation, etc.

expositions favorables à l'éclosion de leurs petits. Les mères, en général, leur donnent peu de soins, et n'exercent d'incubation d'aucune espèce : les œufs une fois déposés, elles les abandonnent. Toutefois, il est plusieurs espèces qui tiennent leur frai renfermé dans une sorte de poche située derrière l'anus, ou appendue à la peau du ventre. Les Reptiles, presque tous, déposent leurs 'oufs à-peu-près comme les poissons; seulement la longueur de l'accouchement, dans quelques espèces, détermine des effets équivalensà un commencement d'incubation. D'autres même prennent de leur progéniture des soins tout particuliers : ainsi, le Pipa femelle reçoit ses œufs, des mains du mâle, qui aide à l'accouchement, dans une soite de cavités ou de cellules creusées dans la peau de son dos ; et c'est là qu'ils éclosent par l'eḷet d'une véritable incubation.

La plupart des Oiseaux couvent eux-mêmes leurs propres œufs, ou d'autres pour eux. On a dit que quelques oiseaux des pays équatoriaux n'étaient pas soumis à ce long assujettissement, la chaleur naturelle au climat poúvant suffire à l'éclosion de leurs œufs : on disait chose pareille de l'autruche; on assurait qu'il ne couvait jamais; mais Adanson s'est assuré, à l'instigation de Réaumur, que cet oiseau couve au Sénégal, au moins pendant la fraîcheur dés nuits. Cette incubation naturelle des oiseaux peut être remplacée artificiellement par la chaleur des fumiers, du soleil, ou des fours. Ces divers moyens, que nous ont d'abord enseignés les Égyptiens, ont été imités dans les divers états d'Europe. Reaumur a donné d'inté1. 
234́ LIV. III. DE L'ACCROISSEMENT DES CORPS VIVANS. ressans détails et de bons préceptes au sujet des incubations artificielles. On peut même faire éclore des œufs en les exposant d'une manière persévérante à l'influence de la chaleur humaine : on assure que l'impératrice Livie eut recours à de semblables prátiques par superstition plutôt que par amusement ou curjosité. J'ai dit que l'oiseau d'une espèce peut couver les œufs d'une autre espèce, sans dommage pour les jeunes embryons, la chaleur des oiseaux étant àpeu-près la miême pour tous. Le Coucou, par exemple, dépose ses œufs dans le nid d'autres oiseaux qui les couvent pour lui. Une chose étonne à ce sujet, c'est que les oiseaux ne produisent jamais au jour de petits vivans: je dis que la chose paraît étonnante, parce que beaucoup d'entr'eux conservent leurs œufs tout fécondés par les mâles à l'intérieur du corps, tout autant de temps qu'il en faut pour les faire éclore par l'incubation. On sait qu'un Coq, dans une seule copulation, féconde quelquefois de quinze à vingt œufs, dont les derniers ne sont pondus qu'au. bout de vingt à trente jours; or, il ne faut que vingtun jours d'incubation extérieure pour en déterminer l'éclosion. Comment donc des œufs fécondés dans le même instant, et pondus à de si longs intervalles, ont-ils tous également besoin de la même durée d'incubation? La chose paraît assez difficile à expliquer : voici toutefois quelle en paraît être la cause. Les ovules de l'oiseau ne sont pas encore assez parfaits, tant qu'ils restent attachés à l'ovaire, pour servir à l'accroissement du jeune oiseau; et ce n'est que durant le trajet que suit l'œuf dans les oviductes qu'il 
CIAP. xv. DE L'INGUbation, etc.

revêt toutes ses parties indispensables, qu'il se complète. Jusque-là il manquait d'albumen, fluide nécessaire à l'alimentation de l'embryon.

A l'égard des animaux vivipares ou Mammifères, ils produisent tous, comme leur nom l'indique, ils mettent au jour immédiatement des petits vivans, fnetus d'abord continus à la substance de leur mère, existant de son propre sang, et renfermés, outre cela, dans les enveloppesंde l'ovule primitif, graduellement accru, au sein duquel ils nagent dans les eaux de l'amnios. Au terme de la gestation ces foetus se séparent de leur mère, et ce n'est qu'au moment de leur sortie de l'utérus maternel que commence leur individualité, c'est-à-dire leur respiration.

Quelques animaux continuent cette incubation à l'égard de leur progéniture, quelque temps encore après l'accouchement : beaucoup d'oiseaux continuent de couver leurs petits après l'éclosion; les mammifères exercent de même une sorte d'incubation temporaire par le fait de l'allaitement. Il est des cétacés qui portent leurs petits nouvellement nés dans leurs bras; et même quelques animaux avalent leurs jeunes nourrissons et les gardent quelques instans dans leur bouche, soit pour les préserver d'un danger imụinent, soit pour les réchauffer dans l'élat de souffrance et de maladie.

La grande famille des animaux Didelphes ou Marsupiaux présente, sous ce rapport, les plus curieux phénomènes. Il paraît que ces animaux ont une matrice dépourvue de col et de rétrécissement, et que de là vient qu'ils avortent. Que cette cause soit réelle, qu'elle soit la seule ou qu'il y en ait d'autres, toujours 
456 LIV. III. DE L'ACCROISSEMENT DES CORPS VIVANS. est-il que les animaux de cette classe, les sarigues, les kanguroos, les dasyures, les péramèles, les phascolômes, les koala, mettent bas leurs portées avant l'époque où les fœtus seraient assez accrus et assez forts pour vivre isolés, pour se nourrir d'eux-mêmes et respirer. Afin d'obvier aux effets naturels de cette sorte d'avortement, les petits embryon's encore informes sont transposés, on ne sait par quelles voies ni quels moyens, de l'utérus oùils ont commencé d'exister, dans la poche mammaire que la plupart des animaux de cette famille ont sous le ventre. Ils se fixent par la bouche aux nombreuses tétines alors gonflées que protège la bourse abdominale; ils leur adhèrent inséparablement, et même leur bouche semble ne plus faire qu'un même tout continu avec les mamelons : c'est à ce point, que le sang de la mamelle paraît passer dans le corps du jeune animal qui s'y trouve attaché , ou que du moins les vaisseaux sanguins, des mamelons paraissent s'anastomoser avec les_vaisseaux „des lèvres des embryons. J'ai dit qu'on ne savait quelle voie suivent ces petits êtres informes pourjparvenir jusqu'aux tétines, jusqu'à la bourse ventrale. Il est cependant probable qu'ils sortent par la vulve, et que la mère les transporte après cela, avec une circonspection et une tendresse infinie, dans la poche protectrice où sont contenues et abritées les mamelles. Toutefois, quelques personnes ont assuré que la peau du ventre et ses parois entières se fendaient pour livrer un passage direct de l'utérus dans la bourse mammaire. Toujours reste-t-il un grand nombre de points fort incertains touchant l'histoire de ces animaux singuliers; mais nous espérons fer- 
CHAP. XV. DE L'INCUBATION, ETC.

mement que les recherches de MM. Quoy et Gaimard, maintenant à la Nouvelle Hollande ( patrie des kanguroos et des phascolômes ), dissiperont bientôt la plupart de nos incertitudes.

On ignore si les petits embryons fixés aux tétines de leurs mères en tirent du lait ou du sang; si ces tétines leur tiennent lieu de placenta ou de vraies mamelles. Et même on n'a pu encore s'assurer si les traces du cordon ombilical étaient évidentes dans les jeunes Didelphes : il est du moins certain qu'à l'époque où ces embryons se fixent aux tétines de leur mère, l'ombilic est dès-lors véritablement transporté à la bouche, qui en tient lieu. On remarque que la bourse abdominale est fermée dans les premiers temps, et qu'elle ne s'ouvre qu'au moment où la respiration devient indispensable. Quelques personnes ont pensé que ces animanx n'habitaient en aucun temps l'utérus, qu'ils naissaient immédiatement aux tétines, et qu'ils n'avaient jamais ni vrai placenta ni ombilic. Mais cette opinion a peu de probabilités.

Les différens genres de la famille des Didelphes n'ont pas tous de poche sous le ventre : ceux de ces animaux qui en sont dépourvus, ont du moins des plis qui en occupent la place; et ces espèces-là s'emparent des nids délaissés des oiseaux pour y incuber leurs petits. 


\section{CHAPITRE XVI.}

Naissance des Corps vivans. Durée variable de la Gestation, de l'fncubation, efc.

La nouvelle Plante sort de sa graine ordinairement après quelques jours de dépôt dans le sól où on l'a semée : la durée de cette évolution varie beaucoup selon l'espèce de graine, selon l'hưmidité ou l'épaisseur de la terre dont elle est recouverte. Entre le Seigle, qui ne met que quelques henres à germer, et le Rosier ou le Cornouiller, à qui il faut des années', il est des degrés intermédiaires presque infinis. En général, la Germination est plus rapide à l'ombre qu'au soleil, dans un terrain léger que dans une terre grasse et lourde; plus rapide pour des graines nouvelles et tendres que pour celles qui seraient vieilles et endurcies. La présence d'un air chargé de beaucoup d'oxygène est d'ailleurs une condition favorable à la promptitude de la germination. Nous avons dit qu'il est des graines qui germent avant même d'être détachées de leur ovaire, de leur réceptacle : l'embryon du Manglier est si prompt à sortir, qu'on le voit rompre ses cnveloppes avant même que le fruit se soit séparé de l'arbre qui l'a produit; et même la petite plante finit par se séparer de la graine avant la chute de cette dernière; et sa radicule, comme la partie la plus pesante de cet embryon végétal, étant la première à toucher le sol, se cramponne dans la terre et s'y en- 
CHAP. XVI. NAISSANCE DES INIMAUX, ETC.

racine. La manière dont la plantule sort du fruit et rompt ses enveloppes, varie extrêmement selon le genre de graine : il faut même avouer que cela est souvent fort irrégulier, et peu susceptible d'être ramené à des formes ou des lois précises. On ne sait point encore, par exemple, comment ni par quelles forces s'ourrent les noyaux ligneux dont beaucoup de semences sont entourées.

La durée de l'Incubation des œufs d'Insectes n'est pas non plus la même pour toutes les espèces. Nous savons que c'est sous la forme de larves que les jeunes insectes sortent d'abord de leurs ovules, dont le volume accru de leur corps a rompu l'enveloppe. Ensuite, le jeune insecte prenant beaucoup de volume sous sa première forme dé larve, mue à cause de cela à plusieurs reprises. Il est des insectes, surtout parmi les Scarabées, dont les larves ne se transforment qu'au bout de plusieurs années. Beaucoup de Mollusques éclosent au-dedans de l'animal femelle ou hermaphrodite, et plusieurs, dès en naissant, portent déjà des rudimens de coquilles. Les Ćrustacés, les Arachnides, sortent, sous la forme accomplie d'animaux , des oufs contenant leurs germes; et c'est finalement par les mouvemens de leurs pattes et de leur tête qu'ils rompent les entraves qui les y retenaient. Les Poissons et les Reptiles en agissent de la même manière : c'est aux mouvemens de leur queue quils doivent presque toujours leur expulsion de leurs ovules respectifs, dont ils brisent la coquille ou déchirent les membranes. Toutefois cette opération est assez difficile en ceux de ces animaux dont les œufs ont une coquille dure, épaisse et calcaire. La chose 
440 LIV. III. DE L'ACCROISSEMENT DES CORPS VIVANS. devenait encore plus difficultueuse chez les poissons cartilagincux, à raison de l'enveloppe coriace dont leurs oufs sont pourvus. Mais la nature a obvié à cet obstacle en séparant tout prêt, du reste de la coquille, le segment formant l'une de ses extrémités; et d'après cette disposition le petit poisson Chondroptérigien n'a plus à rompre, pour éclore, qu'une membrane simple et assez friable. La plupart des poissons naissent dix à vingt jours après la ponte des œufs. Une remarque assez vraie, c'est qu'il sort généralement des foetus plus accrus, plus parfaits, des ocufs fécondés hors du corps des femelles.

Mais la dur'ée de l'incubation est très-variable, surtout dans la nombreuse classe des oiseaux. La Poule couve ordinairement vingt-un jours; le Serin, quinze à dix-huit, selon la variété ; le Canard, vingt-cinq ; les Cygnes, de quarante à quarante-cinq jours; le Paon trente, le.Pigeon quatorze, et l'Oiseau-Mouche douze jours. On remarque que les jeunes oiseaux sont d'autant plus forts à l'époque de l'éclosion, qu'ils ont subi une incubation plus longue. Non-seulement le terme de l'incubation varie d'une espèce à l'autre ; mais il est même variable pour les individus de la même espèce, et qui plus est de la même couvée. Il est rare que tous les œufs incubés simultanément éclosent à la même heure; les naissances sont ordinairement successives. On a vu des œufs de poules commencer d'éclore même dès le treizième jour (M. d'Arcet), et continuer par intervalles inégaux, mais de jour en jour et d'œuf en ouf, jusqu'au vingt-unième jour. Parmi les causes qui accélèrent la naissance des oiseaux, il n'en est pas dont la puissance soit plus ma- 
CHAP. XVI. NAISSANCE DES ANIMAUX, ETC. 㣟 nifeste que la chaleur du climat et l'abondance de l'électricité répandue dans l'air : il est sûr au moins que les progrès de l'incubation sont plus rapides dans les pays méridionaux et dans les temps d'orage, et cependant les œuís de toutes les espèces d'oiseaux éclosent à la même température; et quelques degrés de chaleur de plus, daus les incubations artificielles, ne produisent pas toujours plus de célérité dans l'éclosion.

La manière dont le Poulet sort de sa prison est vraiment curieuse. D'abord, c'est-à-dire après les premiers jours, et toujours ensuite, tant qu'il est renfermé dans sa coquille, le jeune animal est ramassé en boule, la tête placée sous l'aile droile, et la partie antérieure du corps tournée vers le gros bout de la coquille. C'est dans cette position, la tête placée sous l'aile, le bec dirigé du côté du dos et vers le côté droit, que le poulet prélude à l'ouverture et au brisement de sa coquille. Il frappe successivement de nombreux coups de bec de gauche à droite, et toujours en tournant, en pivotant sur lui-même; de sorte qu'il finit par détacher, après l'avoir circonscrit, un segment de couronne à la grosse extrémité de la coquille, èt ce qui est fort singulier, c'est que cette pirouette du poulet s'effectue toujours de droite à gauche, la tête continuant toujours de rester sous l'aile droite.

Cependant cette opération est quelquefois si lente, si languissamment accomplie, que le poulet peut suc'comber dans de vains efforts, s'il n'est assez tôt secouru et secondé. Alors que la couronne ou segment de coquille est délachéc du reste, lo poulet fait effort 
443. LIV. III. DE L'ACGROISSTMENT DES CORPS VIVANS. pour le renverser, et il parvient à ce résultat en arcboutant ses pieds contre le bout opposé de cette coquille : dès-lors il a ủne issue libre pour son expulsion. C'est alors aussi, et pour la première fois, qu'il redresse le cou, et qu'il retire sa tête de dessous l'aile. Quelquefois il arrive que l'air entre dans la coquille avant l'achèvement de son ouverture; alors le vitellus épaissi peut agglutiner les plumes du jeune. oiseau, et le retenir là invariablement collé : cette adhérence a souvent lieu avant la eassure de la coquille, et alors elle met obstacle à la rotation du jeune oiseau dins sa sphère.

Quant aux petits des Vivipares, leur expulsion de la matrice s'effectue sans action de leur part, sans participation d'aucune sorte. Leur mise au jour paraît due principaleınent au retour sur lui-même de l'utérus. long-temps et de plus en plus distendu, distendu par l'embryon toujours plus volumineux, en même temps. que par les eaux de l'amnios qui l'environnent. L'évacuation de ces eaux précède la sortie du foetus, et le décollement da placenta ou des cotylédons, unis aux débris des membranes fœlales, ne vient qu'ensuite chez les vivipares : de même, dans la plupart des animaux, à l'exception peut-être des seuls Pucerons, c'est la tête qui sort la première. Ordinairement le bassin est assez large pour livrer passage au fœtus; toutefois cette disposition n'est pas générale : dans la Taupe, par exemple, cette cavité osseuse est si étroite, que la matrice s'ouvre et que l'accouchement s'effectue en dehors et par-devant le bassin. Nous avons dit que les Didelphes avortent naturellement et toujours. 
CHAP. XVI. NAISSANCE DES ANIMACX, ETC. 445

La durée de la Gestation n'est pas la même pour les mammifères d'espèce différente : elle varie même pour les individus de la même espèce, par des influencès qu'on n'a pas encore pu suffisamment éclaircir et préciser. Toutefois, voici ce qu'on sait de plus exact sur la durée ordinaire de la gestation dans les animaux les plus connus :

La Brebis, la Gazelle et la Chèvre portent 5 mois;

La Vache et la femelle du Morse, 9 mois;

Le Singe, égalemeut 9 mois;

La Jument et l'Anesse , 11 mois;

L'Éléphant et le Chaneau, 10 mois;

La Truie et la Laie, 4 mois;

La Biche et la femelle de l'Élan, 8 mois ;

Le Chien, le Loup et le Renard, 62 jours ;

Le Chat et la Fouine, 56 jours;

Le Lièvre et le Lapin, 30 jours;

Le Cochon d'inde, 21 jours, durée de l'incubation du poulet.

Nous avons dit que le terme de la gestation est sujet à varier encore plus peut-ètre que celui de l'incubation des oiseaux, lequel pourtant est loin d'être invariable; et à ce sujet nous devons prévenir d'une exagération qui nous est échappée en traçant une esquisse rapide de la Génération de l'Homme, page 184 de ce volume. Voici, au reste, des remarques et des expériences qu'on a faites à ce sujet (1) :

Sur 577 Vaches, 21 ont vélé avant 9 mois; et 12 seulement, juste le $270^{\mathrm{e}}$ jour. Pour le surplus, 544

(1) Voycz un Mémoire intéressant de M. Tessier parmi ceux de l'Institut de France, année 1817 . 
44 LIV. III. DE L'ACGROISSEMENT DES CORPS VIVANS.

ont mis bas depuis ce $270^{\circ}$ jour jusqu'au $299^{\circ}$; et 10 , du $299^{\circ}$ au $321^{\mathrm{e}}$. La plus hâtive a vêlé le $240^{\circ}$, et la plus tardive le $321^{\mathrm{e}}$ jour.

Les Jumens ont pouliné depuis le $330^{\circ}$ jour jusqu'au $419^{\circ}$; les Brebis ont mis bas du $145^{\circ}$ au $356^{\circ}$; les Chiennes, du $58^{\circ}$ au $65^{\circ}$; la Truie, depuis le $112^{\circ}$ jusqu'au $124^{\circ}$; et le Lapin, du $27^{\circ}$ au $35^{\mathrm{e}}$ jour, etc.

On s'est de plus assuré que, ni l'âge ou la constitulion des femelles ou des mâles, ni le régime alimentaire, ni la race d'animaux, le sexe des foetus ni leur volume, la saison de l'année ni les différentes phases lunaires, ne produisaient ces irrégularités de la gestation. On ne conçoit pas davantage les causes de ces mêmes irrégularilés dans l'espèce humaine; on sait seulement que les causes d'incertitude de diverse nature y sont extrêmement multipliées : de sorte que la latitude accordée par nos lois pour les probabilités des naissances légitimes, est sagement établie sur la connaissance et la juste appréciation des lois de la nature.

\section{CHAPITRE XVII.}

Résumé du Livre III.

Nous avons décrit avec détails lés commencemens et les progrès de l'embryon des Oiseaux et des Mammifères, nommément pour celui de l'Homme; nous avous ígalement énoucé ce qu'on sait de plus ccrtain touchant l'évolution des Poissons et des hep- 
tiles; nous avons suivi l'apparition de chacun des organes principaux et les révolutions qưils éprouvent. Nous avons vu qu'ils se forment de la circonférence au centre, ou plutôt que c'est ainsi qu'ils apparaissent : car leur arrangement tcujours parfait, la constance de leurs formes et de leurs connexions, et surtout la ressemblance si exacte des nouveaux êtres avec leurs auteurs, sont de puissans motifs pour croire que l'origine de tous les organes est contemporaine, encore qu'ils ne se manifestent qu'à des temps différens. Ces mêmes raisons et plusieurs autres que nous n'avons point tues, nous ont pareillement fait penser que chaque nouvel être préexiste dans l'ovule maternel au sein duquel la fécondation séminale le fait apparaître, et nous avons dit de quelle manière l'emboîtement successif des êtres de la même espèce nous semble probable. Nous avons ensuite exposé les principales lois du développement des orga nes dans les animaux supéricurs, dit quelles analogies s'observent dans l'organisation de ces êtres, et quels rapports existent entre les différens âges.des animaux supérieurs et les classes d'animaux déjà parachevés placés au-dessous d'eux. Toutefois n'avons-nous pas caché les restriclions qu'on est forcé de faire en établissant de pareilles similitudes.

Nous avons aussi dit quelque chose de l'accroissement des Animaux inférieurs, des métamorphoses des Insectes, et nous n'avons trouvé là rien de contradictoire avec ce que nous avions conclu touchant les animaux des classes plus éleveés.

L'accroissement des plantes nous a ensuite occupé, el nous avons trouvé à leur sujet de grandes analogies 
446 hiv. 1 iI. DE L'ACGroissement des Corips vivans.

avec ce que nous avions exposé pour les animaux : partout même connexion des nouveaux êtres avec l'être producteur, mêmes commencemens imperceptibles, même nécessité d'un fluide fécondant, mêmes progrès des oryanes, progrès s'effecluant chez tous sous l'influence d'une sorte d'incubation. Il n'est pas jusqu'aux irrégularités de structure, jusqu'aux anomalies paraissant les plus monstrueuses, où nous n'ayons retrouvé l'empire des lois selon lesquelles a. lieu l'accroissement normal, le développement ordinaire; et nous avons fait ces remarques pour les plantes tout aussi bien que pour les animaux : nous avons vu que les monstruosités chez tous sont presque toujours le résultat d'un arrêt dans la crue de quelques-uns de leurs organes, l'effet de quelque compression, d'adhérences, de soudures, d'avortemens ou de transformations.

Enfin nous avons conduit chaque être jusqu'à son parfait isolement de sa souche originaire, jusqu'à sa mise au jour, et nous avons dit le terme ordinaire - et les phénomènes de la naissance pour la plupart des êtres. Souvent mème nous les avons suivis pardelà leur naissance : nous avons agi de la sorte, en particulier pour les végétaux; et c'était chose nécessaire, puisque ces êtres continuent de croître longtemps même après avoir commencé à dépérir. Nous traiterons ailleurs des modifications qu'introduisent dans l'organisation des êtres, et dans les progrès de leur accroissement, les différentes circonstances de la vie, le sexe, l'hérédité; nous dirons quelles variétés résultent de la bâtardise, de l'influence des climats, du régime alimentaire; les changemens périodiques 
CHAP. XVII. RÉSUMÉ DU LIVRE III.

produits par les saisons, par l'hivernation, par l'amour, par la mue, etc. Nous n'avons guère envisagé, dans ce livre-ci, que les révolutions naturelles des êtres vivans dans leurs premiers âges, et les irrégularités qu'ils éprouvent quelquefois par des causes inhérentes à leur propre nature.

Nous allons rechercher, dans le livre suivant, comment les êtres vivans subviennent à leurs besoins d'alimentation, comment ils se Nourrissent. 


\title{
HIVRE QUATRIÈME.
}

\author{
De la Nutrition.
}

\section{CHAPITRE PREMIER.}

Objet de ce Livre.

Nous n'avons pas besoin de dire que nous traitons de la Nutrition des êtres vivans, car si la vie ne subsiste qu'au moyen de la nutrition, il n'est pas moins vrai que la nutrition suppose toujours la vie. Les corps inertes se décomposent, se délitent, se combinent ou s'agglomèrent diversement; mais les corps doués de la vie sont les seuls qui se nourrissent en assimilant à leur propre substance, par des actes visibles et une puissance cachée, des molécules de corps étrangers.

Étudier la nutrition dans tous les corps vivans, en observer les différens modes, en comparer les voies, les matériaux, les moyens, est une des grandes difficultés de la Physiologie, une de ses parties les plus complexes. Il faut examiner, dans un pareil sujet, d'abord les Alimens dont les êtres vivans font usage, ensuite les Organes qui préparent ces alimens, qui les modifient, les altèrent, ou qui simplement les absorbent: il est aussi nécessaire d'examiner la nature dés 
changemens que subissent les substances alimentaires, combien d'agents y concourent, quels phénomènes en résultent, quel est le produit définitif des alimens digérés, comment ce principe est réparti dans les vaisseaux, distribué par eux dans lés différens organes; et rechercher, s'il est possible, par quelle puissance et selon quel mode ces organes se l'assimilent.

Nous remarquerons d'abord que la nutrition des Végétaux n'est pas aussi compliquéc que la nutrition des Animaux. Les plantes commencent par absorber les substances dont elles se doivent nourrir; sans doute aussi elles attirent à elles ces substancés, mais elles n'ont ni de sens pour les discerner, ni de mouvemens pour les prendre par choix ou préférence, ni de réservoir central où les in troduire, ni d'organes compliqués servant à les digérer. Elles absorbent simplement différens fluides, ces fluides circulent dans des vaisseaux où ils s'élaborent, où ils se décomposent; l'air vient s'y mèler par une sorte de respiration, et de toutes ces combinaisons résulte une sève parfaite qui se répand dans toutes les parties du végétal et qui le nourrit. Mais les choses sont plus compliquées dans les animaux : ces derniers êtres usent ordinairement d'alimens solides; doués de sentiment, ils les sentent, les désirent et les choisissent; pourvus d'organes moteurs, ils les saisissent et souvent aussi les atténuent, les divisent; différens fluides imprègnent ces alimens dans la cavité centrale où ils s'amassent, et c'est également dans ce réservoir que s'opèrent les changemens collectivement exprimés par le mot de digestion.

Après cela, la partie essentiellement nutritive des alimens se trouve séparée des molécules inutiles fors I. 
mant résidu; ce résidu est rejeté hors du corps comme cxcrément, tandis que le principe nutritif, ou chyle, est absorbé par des vaisseaux, mêlé à l'air dans des espèces de poumons, réparti dans tous les organes à l'aide de conduits vasculaires, dans lesquels il a presque toujours les qualités de ce qu'on nomme sang. C'est ensuite dans ce fluide circulant que les organes puisent les principes dont ils ont besoin pour s'accroître, ou pour réparer les pertes qu'ils ne cessent d'éprouver. Nous traiterons aussi la question de savoir si les corps vivans se décomposent et se recomposent réellement et à de certains périodes.

\section{CHAPITRE 11.}

De la Nutrition dans les commencemens de la vie.

Nous ne pouvons que réunir ici ce que nous avons dit en plusieurs endroits du livre précédent sur la nutrition de divers embryons.

Ainsi, l'Embryon végétal, apparu au sein d'un ovule fécondé par du pollen, se nourrit d'abord aux dépens de l'amnios qui l'entoure, et, ensuite, au moyen des fluides en circulation dans les vaisseaux que la plante-mère fournit à la jeune graine. Après cela, pendant la germination, l'humidité du sol s'introduit par l'ombilic jusqu'à la plantule; les cotylédons et l'albumen s'en imprègnent et se gonflent, et toutes ces parties, se ramollissant et devenant émulsives, fournissent aux premiers accroissemens de la 


\section{CnA1. 11. NUTRITIOY DES FOETUS.}

plante nouvelle. Pendant cela, la jeune tige s'élève dans l'air, la radicule s'enfonce de plus en plus dans le sol; et ces deux organes puisent dans leurs milieux respectifs les matériaux nécessaires à la nutrition du nouveau Végétal. Quant aux plantes qui proviennent de Bulbes ou d'Oignons, les bourgeons par lesquels elles commencent, s'accroissent aux dépens de lasubstance même de ces bulbes, qui ne sont, à vrai dire, qu'un réservoir de nourriture.

Les gemmes formant l'origine de nouveaux Polypes, communiquent long-temps avec le polype principal, et se nourrissent, comme lui, des alimens introduits et digérés dans sa cavité centrale; et lorsqu'ils viennent à s'isoler de cette souche-mère, ils sont en état de digérer individuellement à leur tour.

Tous les animaux qui proviennent d'OEufs se nourrissent, tant qu'ils y sont contenus, des différens fluides composant l'ovule. L'albumen dè l'œuf paraît être la première substance utilisée pour la nourriture de l'embryon. On sait, par exemple, que rien ne se développe dans un œuf fécondé tant que l'albumen en est absent : on sait de plus que cet albumen disparaît entièrement dans les œufs d'Oiseaux, plusieurs jours avant l'éclosion, et que l'autre fluide qu'on a quelquefois pris pour de l'albumen, appartient à la cavité de l'allantoide. Vers le terme de l'éciosion, et peu après qu'elle est opérée, c'est le jaune ou vitellus qui pourvoit aux besoins du jeune animal. On sait que ce jaune rentre peu-à-peu dans Ie ventre du foetus près d'éclore, el qu'il finit par se vider entièrement dans l'intestin, et par disparaître. L'espèce de glaires gluantes dont les oufs de Poissons et de Reptiles sont 
entonrés, est aussi de la plus grande nécessité anx fơtus qui doivent naître de ces œufs : Spallanzani s'est: plusieurs fois assuré que ceux qu'on en a privés demeurent stériles. II paraît également que l'amuios sert à la nourriture des foetus des Ovipares, puisque ce fluide finit par disparaître entièrement åvant l'éclosion de beaucoup de ces animaux.

Quant aux Insectes, indépendamment des substances nutritives dont leurs œufs sont composés, ces animaux ont l'admirable prévoyance de faire leur ponte au milieu ou dans le voisinage d'alimens tout préparés pour les premiers besoins de leur progéniture. Il est certain d'ailleurs que ces êtres ont besoin d'alimens différens dans les diverses transformations qu'ils subissent. Nous en parlerons plus loin.

On a acquis la certilude qu'il est des wufs qui grossissent sans s'être rompus. Or, celte augmentation du volume des œufs ne peut avoir lieu qu’à l'aide des gaz, de l'humidité ou des alimens quelconques qu'ils out absorbés par leur surface. Nous avons déjà dit que de Geer a vu se flétrir des œufs d'insectes encaissés dans des feuilles vertes, une fois que celles-ci furent détachées de leur support.

Enfin, l'embryon des Mammifères a plusieurs sonrces de nutrition : si l'ainnios de l'ovule finit par n'avoir aucun usage à cet égard, il est probable qu'il n'en est pas ainsi pour l'embryon commençant; néanmoins la chose est toin d'être prouvée. Ia vésicule ombilicale, analogue au vitellus des œufs d'oiseaux, a certainement pour usage de nourrir les jeunes fotus : sd diminution progressive pendant la gestation et ses connexions avec l'intestin sont de puissantes raisons 
pour l'admettre. Mais la source principale où les foctus de Vivipares puisent des alimens, est le placenta ; c'est là que les ramifications de la veine onbilicale pompent le sang tout préparé de la mère, pour le transporter dans les organes du fotus. Il est permis de récuser les observations citées par quelques auteurs, où des foetus de 'mammifères sont supposés avoir pu se nourrir et s'accroître nonobstant l'absence du cordon ombilical. A l'égard de la gélatine de Warthon, espèce de mucus dont le cordon ombilical est imprégné, il est difficile de croire qu'elle ait une grande part dans l'alimentation du foetus.

Quelque chose qu'on sache sur la nutrition dos embryons, il reste toujours une difficulté extrême en ce qui regarde l'origine de l'aclion nutritive, quant à ses moyens et à ses premiers instrumens. En effet, tant que l'embryon n'a encore aucun organe apparent, comment concevoir qu'il se puisse nourrir? quelle voie alors peut-on assigner à la nourriture, et que! est l'instrument qui sert à l'absorber, à la préparer el la répartir? comment concevoir la fonction même la plus simple dans un être dénué d'organes? L'admission de germes préexistars dans les ovules détruit, il est vrai, une parlie de celte dificulté, puisqu'elie permet d'admettre des organes déjà ébauchés là oùles sens n'en découvrent aucune trace. Et cependant, comment concevoir une action quelconque à des organes encore fluides? ou comment admettre des progrès d'accroissement et de solidificalion sans l'action nutritive? Sans doute on peut répondre à cela par de. vaines subtilités; mais de raisous solides, de raisons certaines, je dois dire que je n'en sais, aueune. 


\section{CHAPITRE III.}

Des Alimens et de la Nutrition des Plantes.

Comme les Plantes sont dépourvues de mouvement pour aller chercher leurs alimens, pour choisir leur. nourriture, il fallait bien qu'elles se nourrissent de substances fluides circulant autour d'elles et s'y renouvelant sans cesse. Or la plupart plongeanț constamment, par l'une de leurs extrémités dans l'air, et par l'autre dans un sol humide, elles trouvent ainsi dans ces deux milieux les matériaux nécessaires à leur alimentation. Les racines, ou plutôt la seule extrémité des racines, absorbent l'humidité du sol avec une puissance dont nous chercherons ailleurs à évaluer le degré. Celte absorption peut être considérable; des plantes plongées dans des vases remplis d'eau en ont absorbé des quantités énormes : Hales et Senebier ont fait à ce sujet d'intéressantes expériences. $\mathrm{On}$ observe que les tiges pourvues de feuilles absorbent beaucoup plus que celles qui en sont dénuées : mais comme c'est par les feuilles que se dissipe la plus grande partie des fluides absorbés, les tiges sans feuilles profitengt plus que les autres de cette absorption.

Je disais que c'est l'extrémité des racines qui absorbe : la chose est prouvéc. Une racine dont le che"velu a été coupé et qui n'a plus qu'un tronc mutilé, n'absorbe plus assez pour les besoins de la plante, et alors la nutrition languit ou cesse. On sait aussi qu'il 
sulfit de plonger dans l'eau l'extrémité des racines pour maintenir intacte l'absorption; tandis que le corps même de la racine ne produit sous ce rapport que des résultats, ou nuls, ou insuffisans. Senebier a cité des faits de ce genre qui ne laissent aucune prise au doute et à l'incertitude.

Les plantes absorlsent donc l'humidité du sol par l'extrémité de leurs racines, mais elles n'absorbent pas ordinairement cette eau seule et débarrassée des substances qu'elle dissout ou tient suspendues. Elles la prennent sáturée de sels divers, de gaz ou de certaines substances colorées. Seulement il est vrai de dire qu'elles absorbent d'autant plus des liquides qui leur sont accessibles, que ces liquides sont plus purs et moins saturés de substances étrangères. Plus l'eau est chargée, ou de débris de végétaux, ou de gaz acide carbonique, de substances salines ou de molécules colorantes, moins' est grande la quantité que les racines en absorbent. On peut voir les expériences de Duhamel et de plusieurs autres à cet égard. Toutefois c'est à ces substances disşoutes dans l'eau, que les plantes doivent la plupart de leurs alimens et des diverses matières dont elles se composent. M. Th. de Saussure a prouvé qu'elles ne forment de toutes pièces aucun des principes qu'on retrouve dans leur analyse. Le sol oú elles croissent, et l'air qui les environne, fournissent tous les élémens de leur composition.

C'est pour cela que la végétation et les propriétés des plantes varient suivant chaque pays, d'après la nature du sol : pour cela que la nature des végétaux doit être assortie à la composition des terres : pour cela que les planics salurées de soude ne croissent que sur 
les côtes marines, et près des murs ou dans des terrains mêlés de décombrrs, les plantes chargées de nitre. D'autres çonséquences relatives à la culture découlent des mêmes faits; par exemple, puisque les racines n'absorbent d'alimens que par leur extrémité, on conçait qu'à mesure qu'elles poussent, elles rencontrent de nouvelle terre contenant les principes dont le végétal a besoin ; elles abandonnent ainsi successivement la partie du sol qu'elles ont épuisée de ceux de ses prineipes que la nutrition des plantes rend nécessaires. On conçait par là comment les plantes de même nature se nuisent par leur trop prochain voisinage, tandis que des plantes différentes, ayant des racines contrairement dirigées, peuvent croître l'une près de l'autre sans se nuire mutuellement. Si donc on faisait succéder dans le même sol des plantes de la même espèce, on voit quill serait déraisonnable d'espérer des récoltes abondantes, si le sol n'avait préalablement été remué, et rennuvelé par des engrais: și l'on veut ensemencer sans relâche les mêmies terres sans faire alterner les cultures, il faut les engraisser excessivement ; mais si l'on veut épargner les engrais, il faut faire alterner les espèces des plantes cultivées aux mêmes lieux.

On voit bien où les végétaux puisent les matériaux de leur nutrition, mais on ne sait rien sur les altérations qu'éprouvent ces principes : la chimie, nonobstant les incroyables progrès qu'elle a faits dans ces derniers temps, la chimie est encore inhabile à expliquer de pareils mystères. Quelle foi peut-on accorder à l'explication d'un ordre de phénomènes dont on ne connait que les termes extrèmes? on sait de 
quels alimens les plantes se nourrissent, on sait les principes chimiques dont elles-mêmes se composent, on connaît aussi leurs produits; mais que sait-on des préparatifs, des changemens intermédiaires, et comment bâtir là dessus des systèmes? Toutefois ces difficultés n'ont point arrêté Senebier et surtout Th. de Saussure, et voici l'explication qu'ils donnent de la nutrition des plantes: * Les substances absorbées deQ viennent les parties intégrantes des végétaux; elles n. se combinent avec eux en nature, ou leur fournis- sent leurs élémens pour cette combinaison qui forme - la nourriture propre à les développer. L'eau intro- duit dans les plantes l'acide carbonique qu'elle a dis- sous; celte eau acidulée dissout à son tour la terre - calcaire et quelques atomes de silice, surtout si \ cette dernière est combinée à quelques parties de - potasse. La lumière décompose dans la plante l'a- cide carbonique, et en précipite le carbone dans - son parenchyme; la terre calcaire et la siliccuse se - précipitent de même par l'évaporation de l'eau et - par la décomposition de l'eau et de l'acide carbo"nique. Ces deux élémens, en s'unissant avec l'oxy- gène, avec l'hydrogène et le carbone, fournissent " l'ćlément des gommes, celui des résines, des huiles, * des acides, qui rempliront les mailles du réseau - primordial constituant les parties da germe; l'union n des builes, des acides, etc., forment à leur tour - des sucs propres, en se combinant diversement. \#(1) Mais nous n'avons eneore parlé que des alimens véritables que les végétaux puisent dạns le sol ạ

(1) Voyez Scncbier, 
moyen de leurs racines 3 il est incontestable pourtant qu'une partie importante de leur nourriture leur est fournie par l'air qui les entoure et qu'ils absorbent. Toutefois nous devons prévenir que ce sont exclusivement certaines parties des plantes qui absorbent une certaine partie de l'air : les seules parties vertes des végétaux absorbent le gaz acide carbonique, sans cesse introduit dans l'atmosphère et par la combustion et par la respiration des animaux. Les plantes gardent pour. elles et s'assimilent le carbone de ce gaz acide carbonique, tandis qu'elles rejettent la plus grande partie de l'oxygène qui s'y trouvait combiné : et il résulte de. là que le tissu solide des végélaux est en partie formé. par une substance primitivement à l'état gazeux.

On s'est assuré de cette absorption du gaz carbonique par les végétaux, et de cette fixation du carbone. dans leur tissu ; on s'en est assuré par des expériences irrécusables. On a mis des plantes dans un air mêlé de gaz acide carbonique, on a ensuite analysé cet air; et l'on a trouvé qu'il avait perdu du gaz acide carbonique : qu'au contraire, il avait acquis de l'oxygène, et que le tissu du végétal avait augmenté à-peu-près dans la proportion du carbone disparu par absorption. Il suffit même de placer des plantes dans une eau courante, pour s'assurer qu'elles décomposent une parlic de l'air : on les voit dans ce cas dégager des bulles. d'air, alors même qu'on les aurait préalablement soumises à l'action de la pompe preumatique. Cet air que les plantes dégagent sous les eaux, est le produit de. la décomposition qu'elles ont fait subir à la portion de gaz acide carbonique dissous dans le liquide qui. les submerge; et la preuve que la chose arrive ainsi ${ }_{2}$ 
CHAP. IV. NUTRITION DES ANIMATX INFÉRIEURS. $\quad 459$ c'est qu'il ne s'effectue aucun dégagement analogue dans les plantes qu'on a plongées dans de l'eau privée d'air, soit par la distillation, soit par l'ébullition. L'air dégagé est de l'oxygène pur, dont les plantes ont séparé le carbone pour se l'approprier.

L'action de la lumière est nécessaire à cette décomposition de l'air par les plantes; elles absorbent de l'oxygène au lieu de carbone dans l'obscurité. Et comme leur couleur verte est due principalement à la fixation de ce carbone, les plantes très-ombragées restent pâles et étiolées. Néanmoins la chose n'est pas sans exception : on voit des végétaux très-verts, loin du jour, dans des mines profondes; la plupart des embryons des différentes graines sont d'une belle couleur verle, quoique recouverts par d'épais tégumens qui les rendent inaccessibles à la lumière du jour. Tout cela prouve donc que le carbone peut se fixer dans les plantes sans le concours pourtant utile de la lumière.

Nous reviendrons avec plus de détails sur ces différens faits, en traitant de la Respiration des végétaux.

\section{CIIAPITRE IV.}

Des Alimens et de la Nutrition des Animaux inférieurs.

Nous allons essayer d'exposer dans ce chapitre ce qu'on sait de plus certain touchant la nutrition des Animaux Invertébrés. Nous parlerons des alimens dont ils font usage, des organes qui reçoivent et qụi pré- 
parent la nourriture, et aussi, autant que cela est pos» sible, des altérations qu'éprouvent les alimens avant de devenir assimilables aux organes qu'ils nourrissent.

Polypes. Tout ce qu'on sait sur la nutrition des. Polypes est dû au célèbre Tremb!ey. Après avoir découvert ces animaux en 1740, il étudia, les années, suivantes, les fonctions de ces êtres singuliers, qu'il prenait d'abord pour des plantes, et que Réaumur lui avait aidé à distinguer d'elles, en leur donnant, le premier, le nom de Polypes. Ce fut en 1744 que Trembley publia, dans un second Mémoire, ses découvertes sur la nutrition de ces animanx; et les faits contenus dans ce travail font admirer la patience et l'exactitude scrupuleuse de ce grand observaleur, qui a trouvé l'immortalité en traçant l'histoire de l'être apparemment le plus imparfait de la nature. J'analyse les faits qu'il raconte.

Trembley avait fait ses premières découvertes sur les Polypes verts; mais il lui fut impossible de découvriv comment ils se nourrissaient. 'Toutefois, après qu'il se fut persuadé (à câuse de leurs mouvemens) que c'étaient des animaux, il soupçonna que l'ouverture qui se fait remarquer à leur partie antérieure leur tenait lieu de bouche: mais, comme il ne rencontra depuis aucun autre polype de cette espèce, il ne put vérifier ses soupçons à leur sujet. Cependant il découvrit, tout en cherchant vainement les premiers, d'autres polypes rouges et plus grands; il expérimenta sur eux, it les trouva doués des mệmes propriétés que lui avaient montrées les premiers, et de plus il vit comment ils se nourrissaient. Des Mille-pieds se trouvant daus l'eau où nageaient çes polypes, Trembley 
CHAP. IV. NUTRITION DES INIMAUX INFÉRIEURS. 畐I s'aperçut bientot que ces animaux saisissaient les millepieds, qu'ils les enlacaient de leurs longs tentacules, et que finalement ils les introduisaient dans leur corps. 11 doutait d'abord de ce qu'il voyait; mais en y regardant de plus près, il vit le mille-pieds dans l'intérieur du polype; il l'y vit remuer, l'y vit mourir, et il l'y aperçut ensuite déjà en partie digéré. Plus de doute alors que les polypes ne fussent des animaux voraces, eux à qui l'on refusait auparavant jusqu'à la पqualité d'animaux. Trembiey vit par-là que les tentacules des polypes leur servaient de bras pour saisir leur proie, aussi bien que de pieds pour mouvoir leur corps entier; il se convainquit aussi que l'ouverture centrale leur servait de bouche, et qu'ils avaientà l'intéricur du corps une cavité leur tenant lieu d'intestin.

Une chose singulière, c'est qu'en quelque endroit que le mille-pieds touche aux bras d'un polype, il en est précisément saisi, et que quelque mouvement qu'il fasse ensuite pour se débarrasser, le tentacule a beau être très-faible, très-ténu, il ne saurait jamais ni le rompre nile faire céder. Souvent l'insecte entraîne le tentacule en divers sens, de même qu'un poisson entraîne la ligne où il tient altaché, mais sans pouvoir le rompre: C'est qu'il y a là plus qu'une force physique : il y a contraction d'un petit membre vivant. Dès que le polype a englouti sa proie, son corps se gonfle et se raccourcit; en même temps il devient immobile, et semble dans une sorte d'engourdissement et de stupeur. Tous ces effets ont la durée de la digestion : ils cessent avec elle.

Les Mille-pieds ne composent pas uniquement la 
nourriture des polypes; ces derniers dévorent aussi d'autres insectes, et surtout des Pucerons. Pour prendre ces animaux dont il se nourrit, le polype étend ses bras et les dispose en filet, en réseau, àpeu-près comme l'araignée dispose les fils de sa toile ; et les insectes tombent aisément dans ces embûches: Ainsi que l'observe 'Trembley, le polype ne peut se nourrir de ces animaux qu'à raison de l'excessive ex́tensibilité de son corps et des espèces de lèvres̀ qui circonscrivent sa bouche; car ces insectes, ces pucerons, ces mille-pieds, sont aussi gros ou même plus gros que sa propre tête, et ce n'est qu'en se dilatant beaucoup que cette bouche peut leur livrer passage. Un polype peut renfermer dans sa cavité, à la file les uns des autres, jusqu'à une douzaine de pucerons, et alors il est rempli partout, et son corps présente autant de renflemens qu'il contient d'insectes. Après cela, on le voit diminuer et s'amincir à mesure que la digestion s'effectue, et à commencer par la tête.

Lorsque les pucerons viennent à manquer, les polypes peuvent se nourrir de différens Vers, et ils les avalent repliés sur eux-mêmes, puisque ces vers sont presque toujours plus longs que les polypes. Mais la chose la plus surprenante est de voir ces petits animaux informes, qui ont à peine trois lignes de longueur et moins d'une demi-ligne d'épaisseur, avaler jusqu'à des Gardons et autres petits poissons, longs d'au moins quatre lignes. Toutefois ils trouvent moyen de les saisir, de les retenir, de s'en emparer à l'aide de leurs bras ou tentacules, fortement contractés à cet effet: ils parviennent même presque toujours, à les introduire dans leur cavité centrale; et cela tient 
CHAP. IV. NUTRITION DES ANIMAUX INFÉRIEURS. 463 leur peau tellement distendue, qu'elle devient alors assez transparente pour laisser voir le poisson à travers son tissu, presqu'aussi distinctement que s'il était à nu. Il est certain cependant que ce poisson perd la vic au bout d'environ un quart-d'heure, qu'ensuite il est ramolli et en partie sucé et digéré ; et lorsque le polype vient à le rendre, quelque temps après, par la même ouverture qui a servi à l'introduire, ce poisson est alors tellement défiguré qu'on a peine à le reconnaître.

Nous voyons jusqu'où va la voracité des polypes: on s'est assuré qu'ils peuvent prendre un volume d'alimens trois ou quatre fois plus considérable que leur propre corps. Il faut ajouter qu'il est peu de substances animales qui ne leur puissent servir d'alimens; Trembley les a plusieurs fois nourris avec des débris d'animaux, et même avec de la viande de boucherie finement hachée. Ils digèrent également toutes ces substances; mais les végétaux leur sont impropres : ils les rejettent sans les avoir altérés, et même les infusions les font périr.

Ces animaux singuliers semblent avoir quelques sens pour distinguer ce qui peut les nourrir, et une volonté pour s'en emparer : il est sûr au moins qu'ils laissent indifféremment s'échapper les vers ou insectes qui viennent s'embarrasser dans leurs tentacules, alors qu'ils n'ont plus besoin de nourriture. Au contraire, lorsqu'ils ont faim, ils saisissent avec un empressement extrême les petits animaux qui leur sont accessibles; souvent même on voit deux polypes saisir ì-la-fois, par ses deux extrémités, le même Ver, le même Mille-pieds, l'avaler chacun de leur côté; et, 
si l'un d'eux ne lâche prise, celui de ces animaux quii a le plus de force ou de grosseur, parvient sonvent a engloulir dans son petit corps et le Ver qüil convoite, et l'autre Polype qui lui disputait sa proie. A cette occasion il faut remarquer une particularité nouvelle : ces mêmes polypes qui tuent si rapidement et qui digèrent les animaux vivans qu'ils ont une fois avalés, n'ont aucune action sur les animaux de leur sorte; ils les rendent intacts et vivans comme ils étaient en entrant dans leur corps. Mème il leur arrive souvent, tant leur voracité est extıême, d'àvaler leurs propres bras avec la proie qu'ils doivent à leur action, et ces bras sortent de leur corps comme ils y étaient entrés. Trembley s'est assuré par tous les moyens possibles, que les polypes ne se peuvent servir d'alimens à eux-mêmes, et qu'à l'instar de plusieurs autres animaux, quelque affamés qu'ils soient, ils ne sè mangent jamais les uns les autres.

Trembley a aussi observé que le froid qui engourdit les polypes, leur ôte l'appélit et le mouvement précisément dans une saison où disparaissent les animaux dont ils font leur nourriture habituelle. Leur appélit et leurs mouvemens rènaissent avec le retour de la chaleur et des insectes dont ils vivent; et on les voit alternativement croître et décroître selon qu'ils reçoivent beaucoup ou peu de nourriture.

Les polypes digèrent plus rapidement en été qu'en touteautre saison : leur digestion alors est ordinairement achevée en douze heures; leur corps est vide, et leurs excrémens sont déjà rejetés au bout de ce temps. Encore que ces animaux mangent beaucoup moins dans les saisons froides, il leur faut toutefois plus de 
Cilap. IV. NUTRITION DES ANIMAt; inférteurs. 465 temps pour digérer. Mais, ntême dans les saisons chaudes, ils peuvent rester trois ou quatre mois privés d'alimeus sans mourir : Trembley l'a expérimenté. I.e même investigateur s'est aussi assuré que les excrémens des polypes ne sont jamais rejetés que par la bouche, autrement, par l'ouverture antérieure, quoiqu'il y ait une sorte d'ouverture terminale au bout opposé. Cette dernière semblerait n'avoir pour unique usage que de servir à inouvoir el à cramponner les polypes en faisant l'office de ventouse.

Mais quelles altérations subissent les substancrs servant de nourriture aux Polypes? Comment sen opère la digestion? Sil faut encore en croire Trembley, et personne à notre avis n'est plus digne d'une entière confiance; selon Trembley, donc, les Vers sont ramollis et comme déchirés à leur sortie du corps des polypes : mais les insectes ne sont qu'un peu macérés et changés de couleur; les Pucerons, de rouges qu'ils étaient lors de leur introduction, sont pâles et incolores à leur sortie. Or, comme la couleur rouge qu'ils avaient, dépendait des matières renfermées dans l'intestin de ces insectes, il est permis de penser que les polypes ont absorbé ces matières, destinées à nourrir les pucerons, et déjà digérẻes par eux, pour s'en nourrir eux-mêmes.

La partie fluide que les polypes ont séparée de leurs alimens, circule à plusieurs reprises dans toute l'étendue de la cavité du polype, tantôt de bas en haut, tantôt en sens contraire ; et même elle passe durant ces flux et reflux, de la principale cavité dı corps dans chaque petite cavité dont les tentacules sont creusés selon leur axe. Car il faut observer que

I.

30 
chaque bras on tentacule des polypes est limage exacte da corps lui-même. Trembley est parvenu à décourrir les petits trous qui font communiquer chaque cavité des bras avec la cavité principale. Les polypes ont donc, pour airsi dire, autant d'estomacs accessoires que de tentacules.

La couleur des polypes doit beaucoup à la quantité et à l'espèce de nourriture dont ces êtres font uisage : plus ils mangent, plus leur couleur devient foncée; le jeûne tes décolore peu-i-peu. Nous disons anssi, et Trembley s'est assuré đu fait, que les polypes prennent la couleur des alimens dont ils se nourrissent. Les pucerons, dont ils sucent le suc rouge intestinal, les font devenir rouges; les limaces et surtout les tétards de Grenouilles les rendent noires; ils deviennent cramoisis lorsqu'on les nourrit d'Araignées rouges; et verts, lorsqu'on leur donne des Pucerons verts, etc. Mais celte couleur n'est pas durable, errcore qu'elle imprègne le tissu même des polypes : an bout de vingt à trente jours d'uin jeûne absolu, ils deviennent incolores. On aurait tort d'inférer de là qu'ils ont besoin de ce temps pour se recomposer; car ne mangeant rien, comment se recomposeraientils?

La voie que suit la nourriture pour pénétrêr la substance des polypes est fort peu connue. On n'a pu trouver de vaisseaux dans ces êtres; on sait seulement que les grains nombreux dont leur peau est comme criblée, sont les premiersà'se colorer; mais on ne sait ni par quel intermédiaire ils reçoivent cette couleur, ni par quels canaux ils la transmettent aux autres parties.

Jl est remarquable que les polypes se nourrissant 
CIAP. IV. NUTRITION DES ANIMAUX InfÉrIEURs. 467 à-peu-près indistinctement de toute substance animale, sont eux-mêmes impropres à servir d'alimens à̀ aucun autre animal.

Vers. La bouche des Vers est petite, circulaire et terminale. Leur canal aliment:ire est simple et sans périloine appréciable : il est de plus toutà-fait adhérent au reste du corps, de sorte qu'il semble une cavité creusée dans le parenchyme même de l'animal. Il règne souvent selon toute la longueur du corps, quelquefois aussi il est incomplet, fort restreint; il est même des vers, appelés à cause de cela parenchymateux, où l'on ne découvre absolument aucun organe digestif, nulle trace d'intestin. C'est ainsi que le caractère regardé comme lè plus sûrement indicatif de l'Animal, n'existe même pas universellement et avec certitude dans tous les animaux: Les vers n'ont ni dents, ni foie, ni pancréas, du moins n'en a-t-on encore pu découvrir. Il y a, dans quelques vers, un ou plusieurs cœcums: L'anus est terminal et parallèle à l'axe du corps, c'est-à-dire médian.

Beaucoup de vers semblent puiser leur nourriture uniquement dans la terre : ils y trouvent sans doute des débris de corps organisés, et ils les séparent des substances minérales et inorganiques qui les enveloppent. Les Vers aquatiques pompent le fluide dans lequel ils vivent, et ils y trouvent apparemment quelques molécules alimentaires, par exemple des débris de mollusques, d'insectes, de végétaux, etc. Quant aux Vers parasites, ils se nourrissent aux dépens des corps leur servant d'asile, ou au moyen des substances introduites dans ces êtres pour leur propre alinientation. 
Les Ténias, par exemple, ne présentent aucun organe propre à exercer une digestion, nul réservoir pour contenir des alimens; ils trouvent leur nourriture toute préparée dans le corps des animaux où ils habitent. lls ont tout simplement, sur leurs parties latérales, des pores ou suçoirs, et c'est par-là qu'ils absorbent leurs alimens. C'est comme les végétaux parasites, qui n'ont pas de racine, une fois qu'ils sont cramponnés à leurs supports. La Cuscute n'a une sorte de petite racine qu'à l'époque de sa naissance; mais bientôt cette racine imparfaitc, devenue inutile, disparait entièrement : il en est de la plupart des vers intestinaux comme des Ténias. Il est d'autres Vers parasites, conme les Ligules, qui même n'ont pas de pores ou suçoirs, et qui absorbent par la surface de leur corps à la manière des Graines en germination.

Il est remarquable que presque chaque espèce d'animal a son espèce de Vers parasites; et même il y a quasi une espèce particulière pour le parenchyme de chaque organe principal. Le ver du foie n'est pas celui du rein ou du poumon, de même que celui des Oiseaux ne ressemble pas à celui du Chien ou du Porc. Ce sont ces vers développés dans la substance des organes, dont on ne connaît, ni préci sément l'origine et le mode de propagation, ni les moyens de nourriture et les instrumens digestifs; car ce sont ceux-là en qui l'on ne peut découvrir de conduits alimentaires.

En général, les Vers intestinaux s'accommodent bien de la nourriture dont l'animal où ils vivent fait habituellement usage. Cependant les substances sucrées, le lait, les fruits, les crudités de toute sorte leur conviennent mieux que des'alimens plus subs- 
CHAP. IV. NETRITION DES ANIMAUX INFÉRIEURS. 460 tantiels; le jeûne des animaux les fait eux-mêmes. pâtir, et sert ainsi, par les souffrances qu'ils causent alor's, à signaler leur existence. Je me souviens d'un malade qu'on traitait pour une inflammation de l'estomac : on le saigna par les sangsues, on le fit jeûner avec rigueur, et loin de diminuer, ses souffrances augmentaient. Bientôt le caractère des coliques, l'état irrégulier de la pupille, de brusques contractions. musculaires, le calme du cœur et le défaut de fièvre, désignèrent la présence des vers : on fit manger le malade, les douleurs et les autres symptômes diminuèrent: on lui donna des vermifuges, et les vers furent expulsés, et tout rentra dans l'ordre.

Nous avons dit ce qui convientaux Vers: il faut dire aussi ce qui les contrarie ou leur fait mal. Or, parmi ces dernières substances, aucune n'a plus d'action que les amers, les racines de fougère et surtout de grenadier, l'écorce de kina ou de chêne, les lichens, le pelit chêne, la mousse de Corse, etc. Les substances désagréablement aromatiques, la tanaisie, le semen-contra; l'huile simple aussi, mais surtout l'huile animale de Dippel, l'huile de térébenthine, etc.; toutes ces substances tuent presqu'immanquablement les vers intestinaux, ou du moins rendent leur expulsion plus. facile, par l'espèce d'étourdissement et de faiblesse qu'elles leur occasionent. Il y a aussi des moyens méeaniques pour expulser les vers : je veux parler des purgatifs très-forts, lesquels font lâcher prise aux vers el les font sortir du tube alimentaire, par les fortes. sccousses qu'ils impriment aux parois du canal digeslif. Quant aux vers de l'intérieur des organes solides, il n'est aucun moyen de les attaquer ou de les faire- 
mourir. On sait seulement que leur multiplication est d'autant plus grande, que la santé des animaux est elle-même plus faible et plus altérée : tout ce qui favorise les forces et le bon état de la vie leur est done nuisible; ils ne prospèrent jamaịs plus que dans l'état de maladie.

Il est şûr que les vers ne se nourrissent et ne se multiplient qu'au détriment des animaux qui leur.donnent asile : leur présence dans l'ințestin de l'homme ou des animaux produit parfois une maigreur excessive, et des symptômes de véritable consomption. Je me souviens d'un jeune malade qui toussait sans cesse, qui maigrissait à vue d'œil, et qu'on croyait phthisique. Je lui donnai du Jichen, presqu'autant par déférence pour des préventions de famille, que par conviction touchant le genre de la maladie, que par confiance dans le remède : toujours est - il que le lichen, qui peut-être en̂t eu de mauvais effets si le malade eût été réellement poitrinaire, lui rendit au contraire des forces, du calme et de l'embonpoint, fit cesser la toux et revenir la santé ; mais en voici la raison : l'amertume du remède détermina l'expulsion de vers nombreux. C'était là le mal, et on l'avait méconnu. Au reste, ce n'est pas la première fois 'qu'un malade a dû la fin de ses souffrances et sa guérison parfaite à une erreur de son médecin.

Insectes. It y a des Insectes qui ne se nourrissent que de substances animales ou végétales, il en est qui vivent indifiéremment des mnes et des autres. II ch est qui font leur nourriture de substances mortes ou déjà décomposées ou altérées; et d'antres qui ne mangent que des corps jouisssant de la vie. On conçoit que 
CHAP, IV. NUTRITION DES ANMAUX INGÉRIERS. 47 de pareilles différences dans les mœurs en doivent iutroduire dans la structure. On voit aussi quelques-uns de ces animaux qui se nourrissent d'excrémens ou de terreaux formés des débris de différens corps vivans; mais aucun ne fait sa pâture, ainsi qu'on l'a insiuué par erreur ou par système, de corps inertes ou de substances minérales.

Nous ạvons déjà dit que les insectes pondent leurs aufs près ou dans des substances propres à servir de nourriture à leurs larves ou leurs chenilles: on en voit même qui, comme les Papillons, se nourrissent du suc des fleurs, et dont les nymphes vivent da!ns des plantes qui ne conviennent qu'à elles et non ì l'insecte parfait. De sorte que l'animal se trouve dirigé dans le choix du lieu de sa ponte, par un anlre: instinct que celui qui préside à sa propre alimentation. Pareillement, les Cousins, tout aériens qüils sont, déposent leurs œufsà la surface des eaux, parce qu'en effet leurs larves sont aquatiques. Il en est do même de plusieurs autres.

Beaucoup d'insectes vivant en société, et commo en républiques, on t'habitude d'amasser des alinens dans la saison propice à leur récolte, pour les saisons. de l'année où cette moisson ne pourrait se faire. Cela. est vrai surtout des insectes qui vivent du suc des teurs, car on voit bien que les fleurs n'ont qu'um. durée assez courle. Les Abeilles, par exemple, récoltent du miel durant la belle saison pour les autres: lemps de l'annće ou les plantes se fanent ou meurent; inais cette prévoyance de leur part a particulicrement pour objet l'alimentation de leur progéniture. Un a dit aussi que les Fourmis trawaillaient l'ćté fous 
l'hiver, et elles ont paru à cause de cela un modèle salutairement proposable aux paresseux; mais, s'il est vrai que ces animaux travaillent sans relâche dans les beaux jours de l'année, il ne l'est pas moins que c'est pour leurs larves bien plus que pour eux-mêmes qu'ils font tant et de si abondantes récoltes; car il est indubitable que l'engourdissement où les jette le froid de l'hiver, les délivre alors de tout besoin de nourriture. Certains insectes, certaines larves au moins, vivent constamment des mêmes substances : on voit des chenilles ne se nourrir que desfeuilles d'une seule espèce d'arbre et mourir à leur défaut. Les Vers-à-soie se nourrissent exclusivement des feuilles de Mûrier. linfin il y a presqu'une espèce de chenilles par espèce d'arbres ou d'herbes. Même remarque à l'égard des Chenilles carnassières : la larve des Mouches à viande ne saurait vivre de substances végétales; et même il y a des chenilles qui ne sanraient s'accommoder que d'une sorte de viande. Disons cependant qu'il en est qui souffrent plus de diversité dans leur nourriture. On en voit, par exemple, qui tout en se nourrissant do substances végétales, leur préfèrent parfois les débris dépecés de leurs semblables. Également, pour l'état parfait, certains insectes se nourrissent indifféremment de diverses substances : la Guêpe, par exemple, se jette tour-à-tour sur des fruits, sur des alimens sucrés, sur des sucs de viande, sur des insectes, sur des cadavres même : le miel aussi leur convient infiniment. Les Mouches à deux ailes, connues par l'importunité de leur vol et leurs titillations agaçantes, les mouches ont des goûts presqu'aussi variés : tout lẹur est bon, et on les voit passer brusquement de la sub- 
CHAP. IV. NUTRITION DES ANIMAEX INFÉRLERS. $\{73$ stance la plus délétère sur les mets les plus savoureux, que leur contact peut ainsi imprégner de poisons.

Beaucoup d'insecles changent de nourriture en passant de l'état de larves à l'état d'animaux parfaits; plusieurs sont sarcophages dans un âge, et phytophages dans l'autre. Les chenilles se nourrissent de feuilles ordinairement, et les Papillons qui en proviennent ne sucent guère que le suc épuré des fleurs : les Mouches préfèrent à tout le reste les choses sucrées, tandis qu'à l'état de larve il leur faut des substances animales inortes et déjà corrompues. II faut aussi remarruer que les insectes carnassiers, si voraces dans les oxcasions propices, peuvent se passer d'alimens un temps beaucoup plus long que les insectes herbivores : ceux-ci mangent sans relâche, ou du moins tout le jour pour les uns, toute la nuit pour d'autres.

Une remarque pleine d'intérêt, c'est qu'il est des insectes qui font leur nourriture, et presqu'uniquement leur habitation, d'une certaine espèce de plante. On pourrait même en classer beaucoup d'après l'espèce de végétal leur servant de pâture et d'asile. Un de mes anciens condisciples et mon ami, M. Havet, que tous les savans de Paris ont connu, et dont plusieurs ont déploré la mort prémalurée, ce jeune botaniste à qui tant de connaissances étaient familières, et qui savait tout abréger, tout simplifier, tout parer, tout embellir par les charmes d'un esprit derenu trop rare dans un siècle qu'envahissent insensiblement les froids calculs d'unc politique ambilicuse, M. Havet, avant d'aller s'ensevelir clans les marais meurtriers de Madagascar, sans profit pour les sciences qu'il aurail si bien servies à Paris même, 
avec quelques encouragemens, inspiré par une idée de Bernardin de Saint-Pierre, son auteur favori, avait entrepris, dès l'année 1817 , un joli cours, mis à la portée des gens dı monde, et où il divisait les. Insectes d'après le genre de Plantes servant à leur habitation et à leur nourriture. Cet essai d'un homme d'esprit eut un succès; remarquable. Il s'agissait là beaucoup moins d'un cours, que d'aimables conférences, où les réflexions de l'auditoire venaient, non contredire, mais parfois redresser les vues rapides et souvent un peu hardies du nouveau professeur. On voyait assister à ce cours ce que Paris renfermait de. plus distingué dạns le culte mixte des lettres et des sciences : M. B. de Mirbel, qu'il est inutile de désigner autrement que par son nom ou par l'indication de ses ouvrages; feu M. Thory, qui a eu le bonheur d'associer d'inappréciables descriptions de roses aux figures sans pareilles de Redouté; madame A. Tastu, si chère à la poésie ; madame $\mathbf{E}$. Voyart, traducteur d'Auguste La Fontaine, et auteur de plusieurs compositions originales; M. A. Thiébaut de Berneaud, le traducteur de. Théophraste, commenté par lui et par M. G. Cuvier; M. F. Lallemand, professeur de Montpellier, et si connu par ses Lettres sur l'Encéphale, et vingt autres. Je dois ajouter que M. Havet faisait ce cours en commun avec M. V. Audouin.

Les chenillès qui rongent les feuilles ont deux mâchoires latérales, agissant et se fermant comme des ciseaux. Beaucoup d'insectes, les Cigales, les Pucerons, les Punaises, se nourrissen! surtout en pompant, au moyen d'une trompe contraclile, le suc des plantes ou ịls se reposent ou restent attachés. Les 
GHAP. IV. NUTRITION DES ANIMAUX INFÉliEURS. 4-5 Pucerons particulièrement s'emplissent le eanal digestif de la liqueur sucrée des jeunes pousses des végétaux. C'est à̀ ce suc qu'il faut attribuer la couleur rougeâtre de leurs entrailles; et nous avons vu que. le même liquide rougit la substance des Polypes quị se sont nourris de pucerons. Comme ce fluide a une. saveur miellée, même lors de son expulsion du corps des pucerons, cela fait que les Fourmis, friandes de tout ce qui est sucré, s'attachent à la poursuite de ces petits animaux. Les Cigales à l'état de larves ou de nymphes, pómpent aussi la sève des plantes où elles sont fixées : mais ce suc étant trop abondant pour leur simple nourriture, est ensuite rendu par. l'intestin sous la forme de bulles aériennes, et c'est dans ce liquide assez ressemblant à de la salive agitée et mêlée d'air, que l'on trouvę les petiles cigales avant leur complet développement. Elles finisșent après cẹla par riepomper peu-à-peu ce liquide séveux et nourricier, de sorte qu'il leur sert à-la-fois d'aliment et d'abri. Les Cochenilles demeurant constamment fixées aux mêmes endroits, sont réduites à sucer la partie des végétaux où elles s'attachent. Mais à l'égard des insectes dont les œufs et les larves ont pour asile des fruits, des feuilles et des excroissances en forme de noix de galles, etc., ceux-kà sont alimentés dans leurs premiers états par la substance même des végétaux qui les recèlent et les abritent. II y a une espèce de Chenille qui vit ęt se transforme dans une masse absolument résineuse; je veux parler d'une chenille qui se trouve darss une galle ou proéminenco du Pin. Cet animal pent être plonģé, sans mourir, mềe dans l'huile de tẹrébeuthine", si nuibible a la plum 
part des insectes. Les Abeilles se nourrissent de cetle substance sucrée qu'elles pompent au sein des fleurs, et dont elles forment leur miel. Beaucoup d'autres insectes imitent ces derniers, si ce n'est pour leur admirable industrie, du moins pour la nourriture dont ils font usage.

La plıpart des fruits charnus, des fruits à noyau et des différentes graines, recèlent assez souvent des larves ou des chenilles de différens insectes; mais ce sont toujours les mêmes espèces pour chaque sorte de graines ou de fruits. Tantôt les insectes imparfaits se bornent à ronger la partie charnue et succulente des fruits; tantôt is n'en attaquent que les pepins ou, les noyaux, et ce qui paraît d'abord singulier, c'est qu'on ne retrouve pas constamment les traces de l'ouverture par où les germes de ces animaux ont dû être introduits. Comme ils proviennent presque toujours d'œufs assez petits pour pouvoir passer par les trous les plus étroits, la simple piqûre qui a pu leur frayer une voic facile s'est ensuite effacée, sinon fermée, par l’accroisscment du fruit qui les renferme : celi assurément en a imposé quelquefois, en faisant croire à des productions spontanées. On peut voir la preuve et des exemples de ce que nous disons ici dans la plupart des fruits verreux.

Reaumur a décrit avec complaisance el avec un vrai talent ciobservation, la manière dont les Charançons et les Calandres rongent les semences de graminées, le Froment et surtout l'Orğe. Les œufs de ces insectes sont introduits par les femelles dans ces semences. encore jeunes, de sorte que, ainsi que nous le disions à l’instant même, on ne parvient pas toujours à 
CIAP. IV. NUTRITION DES ANIMAUX INFERIEURS. 4;7 découvrir l’ouverture qui leur a livré passage. Ces animaux restent là sous leur état de larves et dechenilles; ils détru isent toule la partie nutritive des graines pour s'alimenter, ils exercent là toutes leurs fonctions; chaque semence est pour cux un petit monde lout-àfait séparé du grand, et lorsqu'enfin l'insecte prend sa forme dernière et parfaite, il parvient à sortir de sa prison en soulevant une petile barrière facile à briser : c'est une espèce d'éclosion analogue à celle des Oiseaux et de quelques Poissons. Un fait rapporté par Réaumur et qui mérite d'être connu, c'est que les semences de divers Gramens renfermant de Irès-jeunes chenilles, contiennent beaucoup plus d'excrémens que d'autres semences, où l'on trouve des chenilles prêtes à se transformer en insectes parfaits; de sorte qu'il semblerait résulter de là que ces animaux, d'abord trop avides et peu prévoyans, sont finalement réduits à se nourrir des débris et des résidus de leurs premiers alimens. Ce que nous venons de lire ne s'applique qu'aux Calandres, dont une espèce cause encore de plus grands dégâts que les autres, puisqu'elle a la nuisible propriété de faire adhérer entr'eux, à l'aide d'un enduit, plusieurs semences qu'elle corrode successivement. Mais le Charançon produit surtout de grands dommages; car après avoir rongé sourdement l'intérieur des grains de blé ou d'urge, lorsqu'il est à l'état de larve et de chenille, il conlinue ses dégâts sous la forme d'insecte parfait. I.es fumigations de soufre et de tabac sont les moyens dont on a retiré le plus d'avantages pour la destruction de ces dangereux animaux, qui affament l'houme en détériorant sa plus utile nourriture. 
Il y a des larves d'insectes qui sê nichent dans les racines des plantes, qui les rongent, et qui par là font dépérir tout le végétal; d'autres, placées dans la terre, se nourrissent des débris des corps organisés qui se trouvent mêlés au sol; il en est enfin qui vivent de substances animales putréfiées, ou même d'excrémens. Les Dermestes se fourrent dans les substances animales même desséchées; ils sont le fléau le plus redoutable des cabinets d'histoire naturelle : la seule huile de térébenthine parvient quelquefois à les faire mourir. Ils attaquent les peaux, les cuirs, les reliures de livres, les fourrures, les vêtemens de tissu de laine ou de coton; ils en absorbent touté la substance animale, et finissent par les perforer, par les détruire.

D'autres larves d'insectes se nourrissent avant que de se transformer, de la substance niême d'autres animaux vivans, leur servant de berceau et d'asile; on en a vu plusieurs fois dans différentes parties du corps humain. Les OEstres se développent et se nourrissent dans le euir du dos des Bœufs et des Cerf's; lieu vù les femelles de cette espèce déposent les œufs d'où les petits éclosent. Les Hippobosques ont pour premier refuge l'intestin des chevaux; même on les a vus quelquefois s'introduire jusqu'à l'estomac, c'est donc dans la cavité digestive des animaux qu'ils vivent en parasites.

Le Mouton loge aussi dans ses sinus frontaux la larve d'une espèce d'Olistre, qui se nourrit là, dans la membrane pituitaire, du sang qui la pénètre et des mucosités qui la lubréfient. Si les Hippobosques causent souvent de grandes agitations aux Chevaux, si 
CIIAP. IV. NUTRIOLN DES ANIMAUX INFÉRIEUR.

les OEstres des Boufs donnent parfois à ces animaux beaucoup de souffrances, les OEstres des Moutons aussi deviennent quelquefois pour eux la cause déterminante de mouvemens irréguliers, de sauts bondissans, de vertiges; peut-être mềme sont-ils capables de produire seuls tous les symptômes du mal singulier connu sous le nom de Tournis. Les Taons n'attaquent que les chevaux et les bêtes à cornes.

L'homme a aussi ses animaux parasites̀ : sans parler de ceux qui se fixent à la surface de son corps, qui ne pénètrent jamais au-delà de cette surface, et qui, se nourrissant surtout de son sang et de ses humeurs, se multiplient priucipalement par la misère, la débauche on la malpropreté; sans parler, dis-je, de ces espèces si connues, nous devons rappeler le petit insecte de la Gale, espèce de Ciron ou d'Acarus, lequel paraît être la câuse déterminante des pustules et du prurit incommode qui signalent la maladie degoûtante que nous venons de nommer. Linné croyait également que la Dyssenterie était causée par un insecte analogue à celui de la gale, et cela lui servait à expliquer pourquoi cette maladie devient quelquefois contagieuse aussi bien que l'autre. Chaque animal paraît donc avoir, sinon son espèce, du moins sa variété d'insectes parasites : la Puce n'attaque guère que l'Homme et le Chien. Mais il est d'autres insectes qui, sans ètre précisément parasites, n'ont pas moins d'incommodités pour les animaux qu'ils piquent, qu'ils titillent, d'où ils tirent du sang et qu'ils tourmentent, ou la nuit seulement, ou le jour et la nuit. Les Mouches et les Cousins, et principalement dans les pays du nord pour ces derniers animaux, sont le per- 
pétuel tourment de l'homme ct d'autres espèces, en particulier dans certaines saisons. Les Punaises domestiques pompent le sang de l'homme pendant la nuit. Les Cousins s'altaquent surtout et presque sans relâche aux Hommes et aux lièvres : de Geer assure même que ces insectes vont jusqu'à faire périr (il parle de ce qui arrive en Laponie) les premières. portées du Lièvre. On croit avoir remarqué que les femelles seules se nourrissent du sang de l'homme ou d'autres animaux, et que les mâles, au lieu de faire de cuisantes piqûres, comme elles, se bornent apparemment à pomper les sucs miellés des fleurs. Il n'y a pas jusqu'aux Insectes eux-mêmes qui n'aient leurs Insectes parasites; plusieurs même, principalement du genre des Ichneumons, se nourrissent et se développent dans le propre corps des chenilles de plusieurs insectes, et ne croissent qu'en détruisant et dévorant la substance de ces chenilles. On a remarqué l'espèce d'économie et de prévoyance que ces insectes mettent dans leurs déprédations ; par exemple ils ménagent tellement la substance des chenilles leur scrvant et d'asile et de pâture, qu'ils en conservent juste jusqu'au moment de leur transformation finale et de leur sortie : et ce qui doit paraître encore plus singulier, c'est qu'il se niche des larves d'un petit Ichneumon jusque dans le corps des Pucerons, et même dans des œufs de Papillons. En voilà bien asssez pour montrer qu'il n'est pas de si petit animal qui ne puisse servir de refuge et de proie à d'autres animaux plus petits; mais quel est le dernier terme de cet enclavement, et de celte réciprocité de secours et de destruction? 


\section{CHAP. IV. NUThITION DES ATIHAUX INFÉRIEURS. 481}

Les insectes une fois accrus et transformés doivent la nourriture qui leur est nécessaire, soit à la force, soit à la ruse, usant pour l'obtenir des armes et de lindustrieux instinct qui leur sont nécessaires. Beaucoup portent la voracité jusqu'à s'entre-dévorer, après des luttes meurtrières. Les Araignées, les Mouches et les Guêpes sont dans ce cas. On sait aussi par quels moyens admirables par leur complication et leur ordonnance, l'Araignée parvient à s'emparer des insectes qui font sa nourriture accoutumée. Non seulcment cet animal saisit et immole à-ses besoins les Mouches qui s'embarrassent dans ses réseaux, mais Pélisson a prouvé, par ce quill raconte des récréations de sa longue et dure captivité, qu'il est possible d'attirer les araignées, promptes à s'apprivoiser, jusqu'aux insectes tenus loin de leurs toiles, et qu'on saisit en leur intention et pour leur usage. Les ruses ingénicuses de la Fourmi-lion sont connues, et ce n'est point ici le lieu de les rappeler.

Il n'est pas d'insectes qui, plus que les Pucerons, soient aussi avidement recherchés comme proie favorite par d'autres insectes: ils doivent tant d'ennemis et tant de dangers à leur petitésse, à la fragilité de leur texture, à leur propre gloutonnerie; qui fait que leur corps est pour ainsi dire un réservoir de nourriture; enfin, ils le doivent à l'extrême facilité de leur accès, aussi bien quà la saveur miellée des sucs dont ils se remplissent. Au reste, ce n'est pas toujours pour eux-mêmes que tant d'insectes se montrent si voraces; c'est souvent pour emmagasiner pour leurs larves qu'ils commettent tant de rapines: 
d'autres fois même ils portent des provisions à leurs chenilles ou à leurs larves, et leur donnent pour ainsi dire la becquée à la manière des oiseaux.

Enfin, on observe la plus grande diversité dans les alimens dont les insectes font usage : on ne conçoit guère, par exemple, la bizarre préférence qu'une espèce de Teigne affecte pour la cire des ruches d'Abeilles, trouvant précisément près d'elle, et:à sa disposition, un miel savoureux qu'elle dédaigne. Comment d'ailleurs cette cire peut-elle être dissonte? A quelle modification doit-elle d'être transformée en aliment? Il est remarquable aussi que certains insectes paraissent changer de nourriture : la Mitte du chocolat, par exemple, n'a pas toujours pu se nourrir de cette substance, qui est d'invention moderne, à moins cependant qu'elle n'ait été importée avec le fruit même du Cacao. On pourrait élever de pareils doutes au sujet de beaucoup d'autres insectes destructeurs des alimens de l'homme.

Organes et áctes digestifs des insegtes. Ici, comme partout, les Organes digestifs sont en rapport avec l'espèce d'alimens, et les préparations qu'ils doivent subir: Ainsi les Insectes Suceurs ont une simple Trompe contractile pour prendre les alimens, des organes très-simples pour les préparer, des membres peu compliqués et mal disposés pour l'aggression, des puissances musculaires trop faibles pour d'heureux combats. Ceux de ces animaux qui se nourrissent des substances végétales ont surtout des Lèvres très-prononcées, une espèce de Langue, des Mâchoires : le derrière de leur tête s'élargit beaucoup 
CIAP. IV. NUTRITION DES ANIMAUX INFÉRIEURS. 483 dans le but prémédité par la nature, d'offrir aux puissances musculaires de larges surfaces pour attaches. En ce qui touche le conduit digestif lui-même, on a voulu y retrouver les divers compartimens qui le composent manifestement chez l'homme et les grands animaux : on l'a donc divisé dans les insectes, comme dans ces derniers êtres, en Pharynx, OEsophage, Estomac, Intestins petits et gros, etc. On s'est du moins assuré (et le fait est certain) que ce conduit a plus de longueur chez les insectes herbivores que chez les carnassiers : il n'a guère que la longueur du corps entier dans ceux-ci, tandis que son étendue est double ou triple chez les autres.

Le conduit digestif des insectes présente en outre plusieurs organes accessoires, sur l'usage et la destination desquels les anatomistes sont divisés d'opinion. L'un de ces organes est un vrai Gésier; il est placé à la suite de l'estomac, entre cet organe et le Duodénum; deux valvules situées à ses deux extrémités le séparent au moins par moment de l'intestin et de l'estomac. On ne trouve cet organe que dans les insectes gloutons, herbivores ou carnassiers, mais il existe principalement dans les herbivores. C'est d'abord au sujet de ce gésier qu'il y a eu dissidence entre divers anatomistes : plusieurs ont cru voir en cet organe l'analogue de l'un des quatre estomacs des grands animaux ruminans; et comme plusieurs insectes herbivores, les Sauterelles entrautres, rejettent souvent par la bouche une matière brune provenant de l'estomac, on a cru que ces animaux ruminaient; mais cette opinion n'a aucun motif so- 
lide (1). Il est bien vrai que plusieurs insectes de la famille des Orthoptères ont la singulière faculté de rejeter par la bouche, à volonté et comme moyen de défense, les sucs biiiaires versés dans l'estomac ou dans l'intestin; mais de Rumination véritable, ces animaux n'en excrcent aucunement. Il n'y a chez eux qu'un canal unique pour les alimens; ils n'ont point, comme les ruminans, de prolongement supplémentaire à l'œsophage faisant communiquer le gésier (regardé à tort comme l'analogue du bonnet des ruminans) avecla bouche. Ce qu'on arait pris pour des estomacs supplémentaires ou pour des cocums, ne sont tout simplement que des vaisseaux particuliers, tenant lieu du foie et engendrant une sorte de bile.

Ces vaisseaux et glandes biliaires sont de la plus singulière structure : ce n'est que par les fluides qui en proviennent qu'ils ressemblent au foie. Ils n'ont absolument rien de la texture des glandes. Mais on a eu tort, je le répète, de les regarder comme des dépendances de l'intestin, car ils ne contiennent point ordinairement d'alimens. On a eu tort aussi.de les prendre pour des vaisseanx chylifères, car ils contiennent des sucs dans l'état de jeûne toutaussi bien qu'après des repas copieux. On remarque que les animaux voraces ont seuls deux ordres de vaisseaux biliaires: les supérieurs, s'ouvrant dans l'estomac, dans le gésier, ou tout près de ces organes, dans le duodénum; les autres, les vaisseaux biliaires infé-

(1) Voyez Swammerdam, Malpighi, Leeuwenhoek, Valisneri, Léaumur, Lyounet, de Geer, Fabricius, Latreille, Marcel de Serres, G. Curier, Strauss, Audouin, M. Edwards, etc. 
CHAP. IV. NUTRITION DES ANIMAUX INTERIEURS. 485 rieurs, aboutissent dans le duodénùm ou dans la suite du petit intestin.

Le conduit alimentaire des insectes offre plusieurs valvules formant intersection. Quelquefois il $\mathbf{y}$ a une de ces valvules entre l'estomac et l'osophage, quand, par exemple, les vaisseaux biliaires s'ouvren t dans l'estomac. Il en existe toujours une à chaque exlrémité du gésier, quand cet organe ne manque pas; et une autre, à-l'extrémité du petit intestin, comme dans les grands animaux. Et lorsqu'il n'y a pas de gésier, l'estomac est séparé du duodénum par une valvule épaisse, garnie de fibres musculaires, représentant une sorte de pylore. Les insectes suceurs, se nourrissant de fluides, ont l'intestin beaucoup moins compliqué que les autres familles:- à peine y distingue-t-on des valvules.

Les insectes digèrent leurs alimens à la manière des grands animaux : leur nourriture a le même cours, subit des altérations analogues. C'est surtout le contact des fluides biliaires qui opère de grands chan-. gemens; c'est du moins après la mixture de ces fluides avec les alimens qu'on voit ces derniers changer de nature, et qu'une soirte de chyle s'en séparc. La régurgitation de cette bile jusqu'à la bouche, dans plusieurs espèces, paraît leur tenir lieu-de salive. Mais on ne sait nullement par quels vaisseaux ni par quel moteur cette nourriture essentielle est ensuite rípartie entre les organes; nous verrons, en effet, que ces animaux n'ont point de cœur véritable, ni leur fluide central de mouvement sensible. On sait seulement que leur intestin est entouré de toutes. parls par des vaisscaux aćriens ou trachées; à l'aide 
desquels il s'opère une espèce de respiration sans déplacement manifeste du fluide nutritif. Au reste, il sera fait mention ailleurs et de la Circulation et de la Respiration de ces animaux.

Crustacés. Les Crabes, les Ecrevisses, etc., se nourrissent en général de substances animales, et par préférence même de celles qui sont presque putréfiées. Plusieurs crustacés sont parasites et sucent à ce titre les fluides nourriciers des animaux dans l'intérieur desquels ils se fixent ou sur lesquels ils se cramponnent.

La bouche de ces animaux est fort compliquée: elle est formée, à la manière de celle de beaucoup d'insectes, de divers compartimens qui la rendent propre à broyer. Plusieurs ont l'estomac renflé, toujours dilaté et tenu constamment étendu par des muscles attachés à ses parties latérales. L'estomac des Ecrevisses est situé vers le haut du corps, près de la tête; il est pourvu de plusieurs paires de dẹts pyloriques, dont plusieurs sont supportées par des espèces d'arrêtes en crochet : les autres dents's, situées dans le voisinage du pylore, sont aplaties et propres à broyer la nourriture. Une particularité remarquable, ce sont ces petites concrétions blanches et calcaires qu'on trouve dans l'estomac de tous les crustacés à longue queue, vers l'époque de la mue : ces petites pierres, nommées faussement yeux d'écrevisses, ne' sont pas plus des yeux qu'elles ne sont propres aux écrevisses; tous les crustacés à test solide en présentent de semblables. L'intestin des crustacés est assez égal. Ceux de ces animaux qui ont dix pieds ont une valvule au milieu du canal digestif, et près de là (comme dans les animaux vertébrés) un appendice cœcal assez pro- 
CIIAP. IV. NUTRITION DES ANIMAUX INFÉRIEURS.

longé. L'anus est inférieur et il termine le corps; le foie est volumineux, assez ressemblant au cerveau, et composé de tubes grêles et nombreux, éparpillés dans tout le corps : c'est ce qu'on nomme farce. Il s'étend, tant il est considérable, jusqu'à la queue des Pagures. On ne lui a pas trouvé de conduits biliaires distincts dans tous les Crustacés, mais il en a de menifestes dans les Décapodes. C'est une espèce de canal cholédoque qui s'ouvre entre l'estomac et l'intestin. Les crustacés n'ont, à ce qu'il paraît, ni pancréas ni péritoine.

Mollusques. La plupart des Mollusques ont une sorte de bouche et des lèvres; plusieurs même ont des espèces de dents cornées que l'on nomme mâchoires à cause de leur largeur. II en est aussi beaucoup dans la bouche desquels on aperçoit une petite éminence charnue que l'on prend pour une langue: ce mamelon charnu se meut ordinairement plutôt en arrière qu'en tout autre sens, mais il est presque toujours adhérent dans tous ses points, quelquefois même on le voit se continuer sous la forme d'une spirale fixée tout le long de l'œsophage jusqu'à l'estomac. D'autres mollusques ont une sorte de trompe, et dans ces deux cas, qu'il y ait prolongement de la langue en spirale, ou présence d'une trompe, alors il n'y a de dents d'aucune espèce. On n'observe non plus ni dents ni glandes salivaires dans les mollusques acéphales; mais les céphalopodes ont des glandes salivaires.

L'œsophage est ordinairement très-long; mais son ampleur varie. Quelquefois il forme une dilatation en forme de jabot. L'estomac est tantôt simple, et tantôt à plusieurs loges dans d'autres mollusques. 
Celui des mollusques acéphales est creusé presqu'indistinctement dans le foie, lequel l'entoure de toutes parts; et la bile passe directement, sans détours ni longs circuits, du foie dans l'estomac. Une chose singulière ce sont ces stylets cristallins, espèce de petites végétations salines et transparentes, que l'on rencontre dans les conduits biliaires de cette classe d'animaux. Mais l'estomac n'est pas entouré par le foie dans les mollusques à tête. On remarque d'ailleurs qu'il est plus gros dans ceux qui vivent de plantes que dans ceux qui se nourrissent d'animaux, de coquillages. La bile est versée dans l'estomac chez plusieurs cspèces: l'intestin des mollusques a des circonvolutions variables. L'anus est diversement disposé dans plusieurs classes; il est percé tantôt en devant, tantôt en arrière, souvent sur les côtés, et c'est le plus ordinairement à droite : mais il se termine toujours à la partie postérieure du manteau dans les mollusques acéphales.

Les Mollusques dont la tête est garnie de tentacules, les Poulpes, les Calmars, saisissent leurs proies avec ces appendices : ceux-ci vivent ou de plantes ou d'autres animaux à la chasse desquels on les voit courir. Mais les Acéphales, ne pouvant discerner ni saisir Jeurs aliments, n'ayant d'organes ni pour la salive ni pour la préhension des alimens, paraissent se nourrir exclusivement avec des substances fluides. Beaucoup de mollusques ont la faculté de rester un temps fort long sans nourriture. Nous savons au reste fort peu de chose touchant la digestion et les fonctions nutritives de cette classe d'êtres (1).

(1) Voycz Poli, D. de Montfort, G. Cuvier, Lamarck, Pérom, Blainvilie, etc., et différens Voyageurs. 
CIAP. จ. NUTRIT:ON DES ANIMAUX sulÉrietrs. 489

\section{CIIAPITRE V.}

Parlicularités sur la Nutrilion des $\Lambda$ nimaux supéricurs ou Vertébrés.

Les faits abondent tellement au sujet de la Nutrition des animaux vertébrés, que nous croyons devoir nous frayer une route au milieu de cette foule de choses curieuses, et choisir sur notre passage ce que nous rencontrerons de plus intéressant.

Manufères. Parmi les animaux vivipares ou à mamelles, on remarque la plus grande diversité pour la nourriture. Il en est qui ne se nourrissent que de chair ou de substances animales; d'autres, au contraire, ne se repaissent que d'herbes on de productions végétạles. Il en est aussi dont la nourriture est mixte, puisée à-la-fois ou indifféremment dans les deux règnes. On exprime d'ordinaire par les noms simples de carnivores, d'herhivores et d'omnivores, ou par ceux de sarcophages, de phytophages, et de polyphages, ces propensions natives de certains animaux pour une sorte d'aliment plutôt que pour une autre.

Ces premières différences des animaux, quant à la nourriture, supposent ou entraînent d'autres différences quant aux organes. Un animal carnivore a plus de dents qu'un herbivore, et ces dents sont plus inégales, plus propres à déchirer, plus tranchantes; il a des mâchoires plus dégagées, plus puissantes, mues par des muscles plus gros et plus vigoureux; son estowac est moins vaste, el les parois en sont plus 
minces; ses intestins sont plus courts, et partant, son ventre moins volumineux, ses formes plus grêles. Les membres aussi sont disposés autrement que dans les herbivores, l'instinct de voracité ayant besoin d'instrumens déchirans et agiles, propres à le satisfaire. Enfin, il est peu d'organes sur qui ne réagisse, sur qui ne s'imprime et ne se fasse sentir, et par qui ne se manifeste, pour des yeux exercés, l'espèce d'alimens dont un animal vivipare fait usage : cela rejaillit jusque sur son caractère, sur ses instincts et ses mœurs. Mais ce n'est point ici le lieu d'entrer dans de plus grands détails à ce sujet.

Beaucoup d'animaux carnivores ont besoin de chairs vivantes, ce quiles oblige à des combats, à des agressions perpétuelles et au carnage. D’autres préfèrent à ces curées meurtrières et difficiles, des chairs mortes ou déjà putréfiées : le Lion tue toû̃ ce qu'il mange, mais la Hyène tire sa nourriture du fond des charniers ou des tombeaux. Il est aussi quelques carnivores qui se bornent à sucer le sang des animaux qu'ils massacrent; quelques espèces de Martes et de Chauve-Souris sont dans ce cas, nommément les Putois et les Vampires. Les Sarigues se nourrissent presque uniquement d'cufs d'oiseaux. Les Fourmilliers, dénués de dents, se nourrissent de fourmis et d'autres insectes, qu'ils engluent au moyen de leur langue, favorablement disposée à cet effet.

Les animaux herbivores ont, ainsi que nous l'avons dit, des mâchoires moins puissantes, mues par des muscles plus faibles, armées de dents plus propres à Lroyer qu'à mordre ou réchirè, des membres peu disposés à l'agression; mais, en revanche, leur 
CHAP. V. NUTRITION DES ANIMAUX SUPĹRIEURS. $49^{1}$ estomac est plus spacieux, il a des parois plus épaisses et plus musculeuses, et quelquefois il est multiple ou complexe; leurs intestins sont plus longs, plus gros; leurs formes plus massives.

En général, les animaux qui Ruminent, c'est-à-dire ceux dont les alimens refluent vers la bouche par l'œsophage, pour être broyés de nouveau après avoir déjà séjourné dans les estomacs, ceux-là ont presque tous des cornes ou des bois au front, et manquent de dents incisives à la mâchoire d'en haut. Tous, en outre, ont quatre estomacs, ou un estomac divisé en quatre cavités. Voici, au réste, quelle est la disposition de ces estomacs. Le premier de tous est la panse, ou l'herbier; celui-ci est très-grand et il occupe presque entièrement le côté gauche de l'abdomen; le deuxième estomac, ou bonnet, la plus pelite des quatre cavités, est placé à droite et en devant de la panse; plus à droite encore, et tout-à-fait en arrière du foie, est le troisième estomac ou feuillet, lequel communique par une ouverture peu spacieuse, avec le quatrième estomac ou caillette. Ce dernier est l'analogue de ce qu'on voit chez les animaux qui n'ont qu'un estomac simple, et il communique avec le duodénum par une sorte de pylore. La séparation des deux premiers estomacs est peu sensible; mais les autres sont séparés l'un de l'autre par des rétrécissemens assez marqués pour ne permettre aucune confusion. L'cesophage s'insère dans la portion droite de la panse, et, de plus, une espèce de goutlière de prolongement le fait communiquer avec le bonnet et le feuillet.

Lorsque les herbes viennent d'être mâchées et pour la première fois avalées, elles sont introduites dans. 
la panse, de celle-ci dans le bonnet; et ce n'ese qu'après avoir déjà subi l'action de ces organes, s'être imprégnées des sucs qui y sont sécrétés, et s'y être ramollies, qu'elles remontent par l'œsophage dans la bouche, afin de subir là une nouvelle trituration plus parfaite que la première; et, celte deuxième fois, elles sont déposées immédiatement dans le bonnet, sans avoir de nouveau séjourné dans la panse. Les ruminans tout jeunes qui se nourrissent du lait de leur mère, n'ont point encore de rumination, et le liquide dont ils s'abreuvent passe directement dans les derniers estomacs, tout comme nous venons de voir que la chose arrive pour les alimens déjà ruminés des animaux adultes. Mais c'en est assez à ce sujet:

Plusieurs Cétacés ont un estomac presque aussi compliqué que les ruminans : le Dauphin et le Marsouin, par exemple, ont pour estomac quatre cavités. placées à la. file les unes des autres; il existe de plus entre les trois premières poches une sorte de canal court, formant un passage étroit à l'aide duquel la communication s'établit de l'une à l'autre. Toutefois ces animaux ne ruminent point.

Beaucoup de Rongeurs ont l'estomac divisé comme en plusieurs cavités par des étranglemens §̀ quelques: uns paraissent avoir deux estomacs, mais cette dernière disposition est surtont bien marquée dans les Kanguroos, particulièrement dans le Kanguroo-rat. Les herbivores qui ne ruminent pas ont d'ordinaire l'œsophage inséré vers le milieu de l'estomac, co dernier organe disposé de manière à prolonger le séjour des alimens du côté de la rate, c'est-à-dire à gauche, et l'orifice du pylore fort ćtroit. Remar- 
CHAP. v. NUTRITION DES ANIMAUX SUPÉRIEURS. $49^{3}$ quons aussi que les rongeurs ont ordinairement deux dents incisives, isolées des autres dents, à chaque mâchoire, et que leurs jambes postérieures, presque toujours plus longues que les antérieures, les prédisposent à sauter.

Les organes digestifs de l'Homme et des Singes tiennent à-la-fois de ce que nous avons dit exister chez les herbivores et chez les carnivores. L'homme a toutes les espèces de dents : des dents tranchantes et déchirantes, comme les carnivores, et des dents molaires ou broyantes sans inégalités sensibles, comme les herbivores. Sa mâchoire inférieure se meut dans tous les sens : horizontalement comme dans les animaux se nourrissant d'herbes, et perpendiculairement comme chez les carnassiers. Son estomac est simple, mais assez vaste et à parois moyennes. Le reste des organes tient le milieu entre les deux classes de mammifères dont nous avons parlé.

L'Ours et le Blaireau, qui paraissent surtout organisés pour être carnivores, se nourrissent toutèfois presqu'indifféremment de toutes sortes d'alimens tirés des deux règnes des corps organisés. Mais rien n'est plus rare que de voir un herbivore se nourrir de choses animales, ou un carnivore se repaître de végétaux : cela ne se rencontre guère que parmi les animaux que l'homme a su s'assujettir et rendre ses compagnons et ses imitateurs. Ainsi, le Chien affamé mange du pain et quelquefois même des végétaux. On a vu des Chats, privés d'alimens, dévorer, pour assouvir leur faim, jusqu'à des tissus de lin. Les Rats aussi, quoique organisés en tout comme les herbivores, mangent souvent des substances animales. On a 
observé que des chairs déposées dans l'estomac du Cheval n'y subissent aucune altération: mais on a vu des Chèvres ne manger que des substances animales, et elles digéraient ces substances.

A l'égard des boissons, les animaux carnivores en éprouvent moins le besoin que les herbivores. Mar-. corelle a prouvé qu'à conditions égales, on se passe plus facilement de liquides avec des alimens gras. Toutefois le Chameau est un des animaux qui reste, sans en soulfrir, le plus de temps sans boire.

La manière dont boivent les mammifères varie beaucoup: l'homme avale les liquides tout comme les solides; mais il boit aussi par succion. Les animaux carnivores lappent, et, à cause de cela, on pourrait (ainsi que je l'ai expérimenté) les faire mourir de soif ou de rage en leur tenant la trachée-artère ouverte à l'extérieur, cela leur ôtant la faculté d'aspirer les liquides. L'Ours mord l'eau comme un fruit ou tout autre aliment; il ne lappe ni ne suce. La plupart des herbivores boivent par succion, et pour les faire périr par la soif il suffirait de paralyser leur langue. On a dit que l'homme était le seul animal qui bût sans soif.

Oiseaux. Les Oiseaux aussi ont une nourriture très-diversifiée; les uns se-nourrissent de graines, et c'est le plus grand nombre; d'autres préfèrent les insectes, quelques-uns ne dévorent que des poissons; il en est qui se massacrent les uns les autres et qui font leur proie d'autres oiseaux ; plusieurs vivent du suc des fleurs; enfin, il y a des animaux de cette classe qui font leur nourriture de cadavres.

Nous devons répéter, à l'occasion des oiseaux, ce. que nous avons dit des mammifères : la conformation 
cilap. v. Nutrition des animaux supÉrieurs. 495 de leurs organes est toujours assortie au genre d'alimens dont ils font usage. Le bec des oiseaux carnassiers est toujours plus fort, plus recourbé, mieux disposé pour le combat. Leurs pattes ont plus de puissance; les ongles en sont plus aigus , plus redoutables. Leurs ailes sont plus longues, leur sternum a plus de saillie, et leur vol plus d'étendue : ceux des oiseaux qui se nourrissent d'insectes ont surtout des ailes très-longues, et leurs pieds sont courts. Les oiseaux pêcheurs ont le cou long, le bec aussi est très-prolongé, el leurs pattes méritent pour la plupart d'être comparées à des échasses. Ces animaux sont, en outre, organisés de manière à leur permettre de rester de longues heures debout sans fatigue, dispposition nécessaire, ainsi que la patience, au succès de leurs entreprises et au maintien de leur existence. Leurs pattes sont presque toujours palmées, et tout leur corps disposé à surnager sans de grands efforts. Les oiseaux vivant d'insectes ont le bec effilé, le vol léger, des formes élégantes, et ils sont presque continuellement au milieu des airs. Ceux qui vivent de graines sont moins légers, moins disposés pour le vol; ils sont plus terrestres qu'aériens. Leurs pieds ont plus de solidité que de puissance; leurs ongles et leur bec sont ordinairement obtus : mais ils ont un jabot souvent très-prononcé, et un gésier très-épais. Leurs ailes ont peu d'étendue.

On trouve trois poches distinctes dans la cavité digestive des oiseaux; les deux premières ne sont que des dilatations de l'œsophage, l'autre est le véritable estomac. Le jabot est la première de ces cavités : placé au bas du cou, c'est là que les alimens 
avalés s'accumulent d'abord et font leur premier s'jour. Cette poche est membraneuse, et composée de trois tuniques, ainsi que le reste du conduit digestif. La deuxième cavité, ou le ventricule succenturié, espèce d'estomac accessoire, est placé entre le jabot et le gésier. Les parois de ce deuxième sac contiennent des glandes nombreuses. Le troisième estomac, l'estomac par excellence, est nommé gésier. Celuici a des parois beaucoup plus épaisses que les deux autres, il est aussi infiniment plus musculeux; il est tapissé à l'intérieur par une couche coriace et comme cornée, qui paraît inerte, et dont la résistance est extrême. Ces poches digestives prćsentent de grandes difiérences dans les diverses familles d'oiseaux, selon surtout les substances dont ils se nourrissent. Le jabot est beaucoup plus prononcé dans les granivores qu'en aucune autre famille; et cependant l'Autruche manque totalement de jabot. Les oiseaux piscivores ou ichtyophages n'ont point de jabot non plus; mais leur estomac accessoire est plus vasie que chez le commun des oiseaux. En général, l'estomac succenturié a un volume très-considérable dans les oiseaux manquant de jabot. Ce sont les granivores qui ont le gésier le plus épais, le plus puissant : les carnivores l'ont presque tous très-mince: Le Héron, comme piscivore, n'a point de jabot, et ses deux autres estomacs n'en font qu'un.

Le Coucou, selon la. remarque d'Hérissant, présente une disposition toute particulière quant à son estomac. Tous les oiseaux, en effet, onit l'estomac placé près de l'échine, au-dessus des intestins, tandis que le Coucou l'a placé tout près de la peau du ventre. 
CHAP. v. NUTRITION DES ANIMAUX SUPÉRIEURS. 497 Nous devons dire que quelques anatomistes ont cru voir dans cette disposition tout-à-fait insignifiante la cause pour laquelle le coucou abandonne ses œufs et ne les couve jamais.

Il nous serait difficile d'énumérer sans omission toutes les particularités intéressantes que présente la classe des oiseaux sous le seul rapport des organes digestifs et des habitudes de nutrition. Par exemple, les Granivores ont constamment des cailloux, des graviers ou d'antres corps solides et à surface inégale dans leur gésier, et rien n'est plus malaisé que de dégarnir entièrement l'estomac de ces corps résistans, qui paraissent destinę́s à seconder l'action du gésier : il n'y a de rendus avec les excrémens que ceux de ces corps étrangers.dont la surface est lisse sans nulle inégalité. Les morceaux de cuivre qu'avalent les Autruches finissent par empoisonner ces animaux, par le vert-de-gris quise forme dans les dépressions du métal. Les Oiseaux de proie nocturnes avalent indistinctement toutes les parties des oiseaux leur servant de pature, tout, os, plumes, viande, etc. Mais ils rejettent ensuite, ronlées en masse, toutes les substances réfractaires à l'action de l'estomac. Les Pélicans conservent des alimens pour plusieurs jours dans le réservoir placé sous le bec, et les Cormorans brisent les pattes des animaux qu'ils ont pris et qu'ils réservent pour des temps plus éloignés.

Beaucoup d'Oiseaux granivores digèrent très-difficilement, mais enfin digèrent les substances animales, les vers, les insectes, les débris d'animaux introduits dans leur estomac : mais les oiseaux carnassiers ne peuvent digérer les graines qu'on leur fait avaler; des

I.

32 
graines de plantesícéréales sont restées absolument intactes pendant des jours entiers dans l'estomac dess oiseaux de proie.

Il est des oiseaux qui boivent par une vraie déglutition à tête redressée; mais il en est d'autres, les Pigeons, par exemple, qui boivent par aspiration: On ne peut pas dire que ce soit par succion, car la langue des oiseaux gallinacés et des pigeons, loin d'être charnue, est presque entièrement osseuse. II serait curieux de s'assurer de ce qu'il arriverait à ces animaux après qu'on leur aurait ouvert la trachée.

Reptiles. Presque tous les Reptiles ont un estomac dépourvu de cul-de-sac, un estomac très-allongé et de forme ovale. Les parois en sont minces et les fibres musculeuses peu marquées.

L'estomac des Tortues va en se rétrécissant depuis le cardia jusqu'au pylore, lequel est sans valvule. Celui des Crocodiles présente un grand cul-de-sac à parois fort épaisses, et une autre petite poche séparée près de l'œsophage. Les Serpens ont l'estomac configuré en forme de boyau, et pas beaucoup plus gros que l'intestin lui-même. L'estomac des Grenouilles et des autres Batraciens, d'abord assez dilaté près de l'œsophage, se rétrécit ensuite peu-à-peu en approchant du pylore, et il forme en outre une courbure assez marquée. Du reste, il y a pour les reptiles et les poissons, aussi bien que pour les mammifères et les oiseaux, une exacte concordance entre l'organisation et la nourriture : c'est à ce point, qu'on peut assez sûrement juger de l'une par l'autre.

Les Tortues se nourrissent à-la-fois d'herbes, de poissons, de mollusques : elles brisent jusqu'à des 
CHAP. v. NUTRITION DES ANIMAUX SUPÉrieURS. coquillages, dans le but de dévorer les animaux qu'ils renferment. Les Batraciens, et entre autres les Grenouilles, sont herbivores à l'état de Têtards, et carnivores à l'état parfait : aussi ces animaux ont-ils des intestins proportionnellement plus spacieux et plus longs dans leur premier état qu'après leur première métamorphose. On remarque précisément le contraire dans les insectes nommés Hydrophiles, dont les larves sont carnivores.

Les Crocodiles font une grande dépense de substances animales: la largeur de leur gueule, qu'accroît encore la manière dont s'articulent et se meuvent simultanément leurs mâchoires, permet à ces animaux d'engloutir des proies énormes. Leur appétit est si insatiable, leur gloutonnerie si effrayante, qu'il est permis d'attribuer au désir de détruire des animaux aussi nuisibles par leurs déprédations, les solennels honneurs que l'Égypte superstitieuse rendait autrefois à leurs cadavres.

Les Serpens et tous les Ophidiens sont omnivores: les chairs d'animaux, les nufs d'oiseaux, les larves d'insectes ou du moins de quelques insectes, le miel, le sang de plusieurs animaux, le vin, les fruits, tout leur plaît, tout leur est bon. Les Couleurres aiment surtout les Limacons et les Grenouilles : on dit qu'ils sucent le sang des animaux : cela veut dire qu'ils enfoncent leurs dents, souvent venimeuses, dans les chairs, et qu'ils avalent le sang des blessures qu'ils produisent ainsi; car ces animaux n'exercent pas de vraie succion comme font les Sangsues, etc. On assure que les Serpens s'enivrent de vin; Aristote va jusqu'à affirmer qu'on parvient sûrement à prendre des 
vipères en mettant près des haies qu'elles habitent des vases remplis de cette liqueur.

On sait que la plupart des Serpens avalent souventdes animaux entiers sans division préalable : les gros serpens nommés Boas engloutissent ainsi, tant leur gueule a d'étendue, tant leur tube digestif est dilatable, jusqu'à des quadrupèdes vivipares d'un volume bien supérieur au volume de leur propre corps. Et comme la digestion des Serpens est d'une lenteur extrême, il résulte de là que l'animal saisi par le serpent a le temps de se putréfier dans celles de ses parties qui restent exposées à l'air, pendant que les parties introduites dans le conduit digestif se ramollissent et sont digérées. Il résulterait encore de cette: particularité que les serpens périraient asphyxiés par privation d'air, si l'extrémité de leur trachée-artère ne venait s'ouvrir assez près de l'orifice de la bouche pour n'être point obstruée par l'énorme-proie engloutie par l'animal. J'ai fait cette remarque il y a quelques années sur un Orvet : ce petit reptile venait d'avaler une grenouille beaucoup plus grosse que lui; une porlion de la grenouille était déjà entrée dins. l'œsophage ; l'autre portion, et c'était la plus considérable, remplissait la bouche de l'orvet ou sortait au dehors. Je me demandais comment l'animal pouvait, ainsi rempli, continuer de respirer; j'examinai sa bouche, ses mâchoires, et je vis très-distinctement l'orifice de la trachée-artère tout près du bord de la. mâchoire inférieure; de sorte que chaque fois que l'orvet éprouvait le besoin de respirer, il lui sưfisait d'augmenter un peu l'écartement de ses mâchoires: l'air alors pouvait entrer par l'ouverture découverte 
CHAP. V. NUTRITION DES ANLMLX SUPERIEUR. Jol de la trachée. Mème chose arrive pour les aulres serpens.

Poissons. Obligés par leur genre de respiration $t$ par la configuration de leur corps et de leurs membres à séjourner constamment dans les eaux, les Poissons ne se nourrissent que de substances aquatiques. Je sais bien qu'Aristote a assuré qu'il existail un poisson qui venait à terre pour se nourrir; mais c'est là une des mille assertions de cet auteur dont il nous est permis de douter, nonobstant nos respects pour sa haute raison. On sait que les poissons font leur nourriture des algues, des plantes qui croissent dans la vase du fond des eaux; que la plupart dévorent leur propre frai au temps des amours, et même que plusieurs s'entre-détruisent pour se nourrir. Il est certain qu'ils mangent aussi d'autres animaux, des insectes, des vers, des mollusques, etc. : on connaît la voracité des Requins et le danger de leurs approches. Il y a pour les poissons, comme pour les autres animaux, des carnivores et de vrais herbivores: il y en a aussi d'omnivores. On voit des Carpes et d'autres éspèces manger jusqu'à du pain. La plupart aiment beaucoup les Vers et les préfèrent à tout le reste : aussi se sert-on de ces animaux pour appât. On sait que les poissons recherchent avec avidité les substances odorantes ou parfumées; l'ambre, le musc, la coque du Levant, les attirent, et l'on fait un grand usage de plusieurs substances analogues dans l'art de la pêche. La viande pourric aussi est un puissant appât pour plusieurs poissons, en particulier pour les Anguilles.

Au demeurant, pour la nutrition comms pour to 
leur histoire, il reste beaucoup de choses obscures au sujet des Poissons. Ils vivent habituellement si loin de nos yeux, et sont si peu susceptibles de résister quelques instans au contact de l'air libre, que nous ne pouvons guères les étudier qu'à distance, et jamais entièrement isolés du liquide leur servant d'élément indispensable. Nous ne savons point, par exemple, coument peuvent vivre, des semaines entières, les poissons renfermés dans des bocaux où l'on ne fait pénétrer absolument aucun vestige de matière nutritive, animale ou végétale. La, nutrition des Poissons dorés, que l'on a tout simplement pourvus d'eau, me semble un des problèmes de la physiologie le plus difficile à résoudre. Est-ce que les particules organiques imperceptibles, suspendues dans l'eau, suffisent à leur alimentation? Est-ce qu'ils décomposent l'eau pour se nourrir de ses élémens? ou bien la lenteur de leurs fonctions leur permettrait-elle de vivre pendant des mois entiers sans autre ressource que l'air absorbé par les ouies pour la respiration?

L'estomac des poissons se continue souvent sans limites sensibles avec l'œsophage ; sa séparation d'avec l'intestia n'est pas toujours beaucoup mieux tracée. La forme de l'estomac est celle d'une cloche allongée vers le lieu de son attache. Il est toujours simple, n'a jamais plus d'un cul-de-sac, et la saillie de celui-ci varie selon que le poisson est carnivore ou herbivore. L'intestin est variable quant à sa longueur et à sa configuration. Plusieurs poissons ont le rectum séparé des autres gros intestins par une valvule; beaucoup ont des appendices pyloriques nombreux, espèces de cœcums qui ont frappé l'attention de Spallanzani, 
CHAP. Vi. MÉcanishe dE La digestion. 503 et dont l'usage est ignoré. L’intestin de l'Esturgeon présente dans une partie de sa longueur une spirale fort remarquable, et cette spirale est formée par la membrane muqueuse. Quel en est l'usage?

Nous ne devons point quitter ce sujet sans relever l'erreur d'Aristote, qui prétend que le Scare rumine. Assurément Aristote aura confondu avec la vraie ru. mirfation les mouvemens que tout poisson ne cesse d'exécuter avec sa bouche et ses opercules pour attirer l'eau dans ses branchies et pour l'en chasser.

\section{CHAPITRE VI.}

Mécanisme de la Digestion, principalement dans les Animaux verlébrés. - Expériences et Théories à ce sujet.

Nourriture des Animaux. Nous avons vu que tout animal ne peut se nourrir qu'au moyen de substances provenant elles-mêmes de corps qui ont eu vie; la vie ne s'entretient que parla destruction des corps vivans. C'est pour avoir cru trop légèrement à de fausses apparences, que quelques personnes ont admis en de certains animaux la faculté de se nourrir de corps inertes. Cette opinion est erronée. La terre jaune que des Loups affamés mangent parfois avec rage, ne sert qu'à tromper une faim dévorante; les Mollusques ne digèrent pas davantage les débris des roches ou des vieux bois qu'ils perforent ou détruisent; les Poissons ne vivent point de la vase inerte du fond des mers, ni les Vers, de la terre qu'ils introduisent dans leur 
corps : tout au plus en séparent-ils quelques débris de corps origanisés qui se trouvent mêlés avec ces substances inorganiques. Les Oiseaux ne digèrent nullement non plus les substances minérales qui sont parfois violemment brisées ou pulvérisées pảr leur gésier. Si l'on a cru à de pareilles choses, c'est pour les avoir trop légèrement examinées.

La nourriture des animaux est, au reste, trèsdiverse. On remarque assez généralement que les êtres les plus simples n'ont besoin que d'alimens peu composés. Il existe une concordance assez parfaite entre la complication des organes et l'ordre d'alimens dont les animaux font usage. Ensuite, peu importe pour notre objet présent qu'un animal se nourrisse de chair vivante, comme le Lion on l'Aigle; de cadavres, comme la Hyène, les Corbeaux ou les Vautours; de poissons, comme les Luutres ou les Oiseaux échassiers; de racines, comme le Porc ou le Sanglier; de fourmis, comme les Pics, ou de simples herbes, comme les Mammifères rongeurs ou ruminans : peu nous importe quils soient omnivores comme l'Homme, les Singes et l'Ours. Nous n'avons qu'un but dans ce chapitre, c'est d'étudier au moyen de quels instrumens et selon quel unode les animaux digèrent.

Organes essentiels servant a ha digestion. Les alimens d'abord doivent être saisis, soit par des membres agiles, des palpes ou des tentacules, qui.les portent à la bouche; soit immédiatement par la bouche, à l'aide de lèvres, de dents ou d'un bec; d'autres fois ils sont attirés à l'aide d'une espèce d'aspiration, compe dans la Sangsue, ou englués par la langue, comme dans les Pics et les Fourmilliers. Une fois in- 
CHAP. VI. MÉGANISME DE LA DIGESTION. 505 Iroduits dans la bouche, ils sont soumis à l'action de :ombreux organes chargés de les diviser, de les imiber, de les goûter, de les déglutir, le les faire heminer, de les attérer, en un mot, de les digérer, d'en extraire une sorte de liquide particulier qu'on nomme chyle (c'est l'aliment par excellence), et finalęment d'en expulser le résidu ou l'excrément.

La plupart des grands animaux ont les deux mâchoires munies de dents ayant pour usage de diviser les alimens; un bec corné et fort résistant remplit la même destination que les dents dans les Oiseaux, les Monotrêmès et les Toriues. La langue, qu'elle soit molle ou solide, sert à réunir les alimens dispersés dans la bouche; de plus elle apprécie leur saveur, et l'impression qu'elle en éprouve, transmise au cerveau par les nerfs, rejaillit ensuite du cerveau vers les autres organes digestifs, pour les disposer, pour les exciter à l'action qui leur est propre. Les glandes sécrètent des sucs dont le bol alimentaire s'imprègne; la langue se gonfle, se raccourcit et fait la bascule; le voile du palais s'élève vers les fosses nasales pour en fermer l'accès; le pharynx se contracte sur le bol alimentaire et le transmet bientôt à l'ossophage; la glotte se rétrécit et l'épiglotte la recouvre et la protège ; ce qui empêche l'introduction de tout fragment alimentaire dans le larynx. L'wesophage transmet à l'estomac les alimens qu'il recoit du pharynx. Restent encore les principaux organes de la digestion : l'estomac, qui les reçoit et les modifie durant le séjour plus ou moins long qu'ils font dans sa cavitć; les intestins, où ils se mêlent à diverses humeurs; c'est pendant leur séjour et leur trajet dans ces der- 
niers organes, que les alimens se séparent en deux parties, je veux dire ên excrémens que rejette audehors ce dernier intestin, et en chyle, fluide nourricier qui, une fois absorbé, chemine dans des vaisseaux particuliers qui le mêlent au sang.

Humeurs. Plusieurs Humeurs, sécrétées par des glandes spéciales, par des follicules ou des membranes, concourent à produire les altérations que subissent les alimens dans le trajet du tube digestif. Nous parlerons d'abord de la salive, fluide fourni par des glandes placées en beaucoup d'animaux près des mâchoires, mais n'existant point chez d'autres, particulièrement dans les oiseaux, chez lesquels ce fluide est pour ainsi dire remplacé par l'humeur abondante et visqueuse que fournissent les follicules nombreux de l'estomac succenturié, lequel est intermédiaire, ainsi que nous l'avons vu, au jabot et au gésier. Outre la sạlive, qui se mêtle aux alimens pendant leur mastication et leur trituration, et qui dans l'état de jeûne et de vacuité de l'estomac afflue dans la cavité de ce viscère, il y a d'autres humeurs formées ou versées dans l'intérieur du tube digestif, savoir : $1^{\circ}$. le mucus de la bouche, celui du gosier, du pharynx, de l'œsophage, de l'estomac et des intestins; $2^{\circ}$. le fluide perspiratoire qu'exhalent à la surface de la muqueuse digestive les extrémités des vaisseaux artériels; $3^{\circ}$. l'humeur folliculaire que forment toutes les cryptes muqueuses placées dans l'épaisseur de la même membrane; $4^{\circ}$. la bile, humeur formée par le foie, et que le conduit cholédoque verse dans la cavité du duodénum ou premier intestin; $5^{\circ}$. l'humeur pancréatique, espèce de salive abdominale, dont le pancréas est la source, et 
GHAP. VI. MÉCANISME DE LA DIGESTION. 507 qu'un conduit excréteur particulier verse aussi dans le duodénum, près de l'endroit où vient aboutir le conduit cholédoque.

Ce qu'on nomme suc gastrique n'est point une humeur spéciale ou simple, ainsi qu'on pourrait le croire et que certaines personnes l'ont admis : ce liquide, dont la quantité est parfois considérablè, est tout uniment un composé, un mélange de salive, de mucus, du fluide perspiratoire et de l'humeur folliculaire des premières voies digestives. C'est un liquide peu homogène, contenant des flocons, d'une apparence louche, couvert de mousse, souvent salé, quelquefois acide, et dont quelques personnes et certains animaux fournissent des quantités énormes, alors que l'estomac est à jeûn. Nous reviêndrons sur les qualités et les propriétés de ce liquide. Le suc intestinal est encore plus composé que le précédent; car aux résidus des sucs gastriques qui ont traversé le pylore il se joint du mucus et d'autres fluides fournis par la muqueuse des intestins, et de plus de la bile et du fluide pancréatique, quelquefois aussi des bribes d'alimens et du chyle, et c'est justement à ce mélange de tant de choses qu'on donne le nom de suc intestinal. Il se forme en outre différens gaz dans la cavité intestinale aux différentes périodes de la digestion.

ChangeMens ÉPRouvés PAR LES ALIMENS dANS L'EstoMAC. Comment pourrions-nous dire quelque chose de général touchant les premiers préparatifs de la digestion, puisque ces premiers phénomènes diffèrent dans les divers animaux? nous savons que la préhension des alimens varie beancoup de classes à classes et souvent d'espèce à espèce : l'insalivation, 
il y a des animaux nombreux qui n'ont pas de salive; la gustation, la langue de beaucoup d'animaux est si solide, si complètement osseuse, qu'il est difficile d'admettre qu'un pareil organe perçoive quelque peu distinclement les qualités sapides des alimens; la mastication, les oiseaux granivores surtout n'en exercent aucune; beaucoup d'autres animaux comme privés de dents, ne peuvent non plus diviser les substances dont ils se nourrissent; il y a aussi beaucoup de différence entre les vrais carnivores, qui déchirent et avalent les chairs sans les mâcher, et les herbivores ruminans, qui mâchent à deux reprises différentes les. mêmes herbes. Nous devons donc nous borner ici à suivre les changemens qu'éprouvent les alimens une fois qu'ils sont parvenus dans la cavité de l'estomac.

Quelle que soit l'espèce d'alimeits, et en quelque. animal que cé soit, ordinairement il se passe une ou plusieurs heures avant qu'on puisse observer des: changemens notables dans ${ }^{\circ}$ la masse alimentaire accumulée dans l'estomac. Après cela les alimens se ramollissent, s'altèrent, changent de couleur et souvent de saveur; à l'exception des graines qui sont recouvertes d'un épiderme inattaquable, l'altération commence par la surface des substances alimentaires, et il faut remarquer que les qualités du chyme diffèrent extrêmement selon l'espèce d'alimens d'où il résulte: les herbes ramollies et deux fois triturées des ruminans donnent un autre produit stomacal ou chymeux que des chairs ou que des graines de céréales. Nous devons dire aussi que la digestion des substances animales est plus prompte que celle des alimens. founis par des végétaux. Les animaux carnivores di- 
Cirar. vi. MÉGanisme de la digestion. 509 gèrent plus vile que les herbivores, et l'Homme et les Singes, qui sont omnirores, ont plus tòt digéré des viand $€ s$ que des légumes ou des fruits. Il arrive même assez fréquemment que des fragmens de végétaux parcourent tout le canal digestif sans avoir perdu leurs qualités naturelles et distinctives, sans s'êlre aucunement altérées; ce qui est fort rare pour les substances animales.

C'est à leur surface, avons-nous dit, que les alimens amasșés daris l'estomac commencent à se ramollir et à s'altérer; nous avons ajouté que les substances recouvertes d'un épiderme faisaient seules exception. On remarque aussi que la digestion est d'abord manifeste pour les alimens placés à la superficie de la masse totale : les substances qui touchent aux parois de l'estomac sont déjà ramollies et d'une odeur aigre, que celles du centre n'ont encore perdu aucune de leurs qualités primitives. 11 est fort notable aussi que ce soit dans le voisinage du pylore que. la digestion commence : c'est constamment dans la portion pylorique de l'estomac que l'on trouve le premier chyme. D'où cela vient-il? est-ce que les premiers alimens digérés dans toutes les parties de l'estomac affluent vers ce lieu? ou ne serait-ce qu'en cet endroit, et à raison des mouvemens qui s'y exécutent, ou des lluides qui s'y forment, que le premier travail peut s'accomplir?

Les alimens ramollis et diggérés par l'estomac, autrement le chyme, forment une masse à-peu-près homogène, de couleur variable pour les divers animaux, ordinairement grisâtre dans notre espèce et dans beaucoup d'autres, d'une odeur et d'une sa- 
veur aigres, et, à cause de cette acidité, rougissant le papier de tournesol. Souvent il se forme, il se dégage différens gaz dans l'estomac durant la digestion, mais principalement lorsque les animaux sont malades ou affaiblis : c'est le plus ordinairement un mélange d'azote, d'oxygène, d'hydrogène et de gaz acide carbonique. Nous en parlerons en faisant l'histoire des fluides et des humeurs.

Pour le plus grand nombre des animaux, c'est l'estomac, et uniquement l'estomac $\{$ qui opère le premier travail de la digestion ou la formation du chyme; et même les intestins n'achèvent lè grand ourrage de la formation du chyle qu'autant que l'estomac a exactement accompli ce premier préparatif. Cependant la chose semble se passer différemment dans quelques animaux; je veux dire qu'il en est quelques-uns où les intestins et l'estomac paraissent avoir des limites et des destinations moins précises. Le Cheval, par exemple, qui n'a qu'un estomac fort étroit et qui néanmoins mange sans discontinuer durant des heures entières, le cheval n'aurait pu renfermer dans son estomac si restreint, jusqu'à leur parfaite chymification, tous les alimens qu'il consomme. Qu'est-il donc arrivé? c'est que le pylore de cet animal reste toujours béant, et que les alimens passent sans obstacle de l'estomac dans l'intestin avant d'avoir été complètement chymifiés; de sorte que les intestins complètent l'action par trop inachevée de l'estomac, sans que cette confusion de fonctions préjudicie à la digestion.

La durée de la chymification varie beaucoup d'un animal à l'autre : les Mammifères et Oiseaux carnivores n'ont besoin que de quelques heures pour ac- 
CHap. VI. MÉcanisue de LA digestion. 511 complir cette fonction, tandis que les Serpens et la plupart des Reptiles emploient des jours entiers et jusquu'à des semaines à la parachever. Nous verrons à quelles conditions paraît tenir cette différence. Le même animal met souvent des temps très-inégaux à digérer ses alimens; sa digestion est prompte ou lente selon que sa santé esi: plus ou moins parfaite, selon que les alimens sont peu ou trop abondans; que leur division est plus ou moins grande, et aussi selon la nature propre de ces alimens. Tel animal ne saurait digérer ou digère péniblement tel aliment qu'un autre animal chymifie en peu d'heures et sans en souffrir.

Conditions de LA dïgestion ET PHÉNOMÈNES LOCAUX QUi L'ACcompaginent. A mesure que les alimens remplissent l'estomac, leur volume distend les parois de l'abdomen et produit la compression plus considérable de tous les viscères renfermés dans cette cavité : cela même fait affluer plus de sang veineux vers le foie par la veine-porte, et détermine une sécrétion plus abondante du fluide biliaire. L'estomac des mammifères est baloté à-la-fois par plusieurs mouvemens : et par les pulsations artérielles, et par les mouvemens alternatifs du diaphragme, et par les oscillations de l'extrémité inférieure de l'œsophage, lequel ne discontinue. guère de se contracter durant l'inspiration et de se relâcher pendant l'expiration. En outre l'estomac lui-même, ainsi que le reste du tube digestif, a des contractions sensibles, s'exercant d'ordinaire de haut en bas, de l'œsophage vers le duodénum, et se manifestant surtout vers la petite extrémité de l'estomac, là où les alimens commencent à se chymifier. Dès que le cbyme est formé, ce sont ces mêmes os- 
cillations de la portion pylorique de l'estomac qui font franchir le pylore aux alimens ainsi altérés. Le pylore, naturellement fermé chez la plupart des animaux, ue s'ourre jamais que sous l'influence des contractions dont nous parlons. Ajoutons que les alimens sont soumis à l'action des sucs accumulés dans l'estomac ou sécrétés à sa surface, et entourés d'organes imprégnés d'une chaleur égale qui est toujours à-peu-près de $32^{\circ}$ Réaumur.

Ces différens phénomènes varient un peu pour quelques animaux : par exemple, les Oiseaux gallinacés ont un gésier qui est susceptible de contractions non pas très-évidentes (encore que Réaumur et Spallanzani les aient vues distinctement), mais à coup sûr plus puissantes qu'en aucun autre estomac. Le Cheval, non seulement a le cardia fermé, ce qui s'oppose au vomissement; non seulement le pylore toujours béant, ce qui permet le passage continuel des alimens, de l'estomac dans le duodénum; mais en outre, les contractions de l'estomac dans cette espèce sont plus manifestes vers la portion splénique que dans la pylorique.

NÉcessité des nerfa et des vaisseaux pour la digesTION. Il y a besoin de nerfs pour la digestion : nerfs servant à donner le sentiment de la faim ; nerfs animant les muscles qui servent à la préhension des alimens, à leur mastication, à leur déglutition, etc. ; nerfs présidant à la digestion elle-même, ce sont les nerfs de la dixième paire ou pneumo-gastriques.

On a fait bcaucoup d'expériences an sujet de ces derniers nerfs, et ces expériences ont souvent conduit à des résultats contradictoires : les uns ont dit que 
CHAP. V1. MÉCANISHE DE LA DIGESTION. 513 leur section, ligature ou destruction, empêchait la digestion stomacale; d'autres ont assuré que ces nerfs envoyant des filets à-la-fois au larynx, aux poumons et au cœur, leur section ne produisait la mort ou n'arrêtait le travail digestif qu'en raison de l'oppression, de l'asphyxie, ou du ralentissement de la circu-

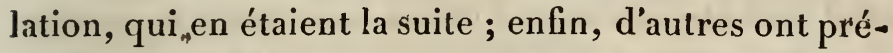
tendu qu'en coupant ces nerfs au bas de l'œsophage, la digestion n'était plus par-là empêchée, mais seulêment ralentie et rendue plus imparfaite, et ce dernier résultat a été vérifié à plusieurs reprises et tout récemment encore. Il est sûr que des Chevaux sur qui la section des nerfs pneumo-gastriques a été pratiquée tout près du diaphragme, ont continué d'avoir faim, de manger, et même de digérer. La même opération ne produit pas d'efrets fort sensibles sur les Oiseaux. M. W. Philipp a émis l'opinion singulière qu'on pouvait remplacer l'influence de ces nerfs détruits, par un couránt galvanique appliqué à leurs tronçons; mais ce résultat est loin d'être incontestable, outre que l'auteur qui l'atteste convient lui-même de son inconstance.

A l'égard des vaisseaux sanguins, ils sont indispensables à la digestion par vingt raisons différentes: d'abord ils communiquent la chaleur aux organes, donnent le mouvement aux muscles, fournissent les sucs servant à la digestion, et le reste.

LES PRINGIPAUX ORganes CONCOURENT a LA Digistion. Puisque les vaisseaux sanguins sont nécessaires à la préparation digestive des alimens, il est clair que le cœur, par qui le sang est mu, que les poumons ou les branchies, par qui ce fluide est renouvelé et I. 
parachevé, que le cerveau et la moelle épinière, si nécessaires à l'aclion du cueur et des organes respiratoires, que tous ces organes ont une action au moins médiate sur la digestion des alimens. Le cerveau et la moelle épinière agissent d'ailleurs plus immédiatement dans le même but, par l'entremise des neı:fs, pour quelques sensations et certains mouvemens qui ont des relations avec la digestion : ainsi, la faiu ne pourrait être sentie sans cervean; le tube digestif cesserait. enfin de se mouvoir s'il était privé de ses n.erfs, et les nerfs n'ont de puissance qu'autant qu'ils s'unissent ou au cerveau ou à la moelle épinière. Nous ne finirions point, si nous voulions suivre par combien de voies les principaux organes d'un animal vertíbré se trouvent liés à l'action de l'estomac et à l'accomplissement de la digestion. Les remarques précédentes nous paraissent suffisantes.

Hypotuises ad suJet de la digestion. - Trituration. Ce qu'avaient expérimenté les physiciens de l'Académie del Cimento et beaucoup d'autres savans, an sujet de l'estomac des oiseaux gallinacés, la force ćlonnante de cet estomac, les corps brisés ou pulvérisés par lui, toutes ces observations firent penser que la digestion résultait principalement d'une sorte de Trituration. Mais on n'avait pas réfléchi que les autres espèces d'animaux sont loin d'avoir un estomac aussi énergique que les Poules et les autres oiseaux de basse-cour; on oublia d'observer que la digestion ne consiste pas seulement dans la division et le ramollissement des alimens, mais qu'en outre ceux-ci changent de nature, qu'ils se décolorent et s'acidifient. J'ajoute que l'estomac de beaucoup d'aniznaux 
CHAP. VI. İं́CANISHE DE LA DIGESTION. 515 sc contracte si faiblement, qu'à peine y peut-on découvrir des mouvemens; et même, les pressions qu'il exerce sur les substances contenues dans sa cavité sont si faibles, qu'il n'en résulte aucun mal pour les vers délicats et fragiles que l'on rencontre souvent dans cet organe en beaucoup d'espèces d'animaux, notamment dans les Salamandres.

Fermentation. La digestion ne consiste pas davantage en une simple Fermentalion. Il est viai qu'il se produit souvent quelques gaz dans un estomac rempli d'alimens, et que le chyme est légèrement acide; mais tout cela ne ressemble point à ce qui se passe dans des substances en fermentation dans ua vase inerte; il n'y a point de mouvement général et instantané, il n'y a point non plus de tuméfaction subite dans la masse alimentaire, point de production rapide de gaz abondans: l'altération des alimens est lente et successive. D'ailleurs la chymification est telle, qu'il ne se produit jamais rien d'analogue en des alimens plongés dans de l'eau pure et mis en fermentation dans des vases inorganiques, exposés eux-mêmes à une température élevée. Bien plus, ii n'y a jamais de véritable fermentation dans les alimens plongés, hors de l'estomac, dans des vases remplis de suc gastrique récent; à plus forte raison n'en doit-il nullement survenir dans l'estomac, où les alimens se trouvent sous la puissance de la vie. Mais il faut convenir que la salive seule ne s'oppose point à la fermentation dans des vases inertes. Les gaz rendus par la bouche durant la di gestion résultent ordinairement de la vaporisation de l'air introduit dans l'estomac avec les alimens, et son expulsion provient tout simplement de l'expansion 
que lui fait éprouver la chaleur vitale. Si quelquefois il se montre quelques signes de fermentation pendant la digestion des personnes très-affaiblies ou malades, on voit bien qu'il n'y a rien à conclure de là quant à l'état ordinaire, et dans ce cas même l'exception alléguée appuie la règle.

Putréfaction. De ce que les animaux carnivores ont la plupart l'haleine puante, de ce qu'il se manifeste quelquefois une odeur putride dans l'estomac de l'homme lui-même, on a conclu que la digestion stomacale n'était qu'une sorte de Putréfaction. Mais ce phénomène n'a lieu que dans les cas où la santé est altérée, encore la chose est-elle fort rare même alors. Il faut d'ailleurs observer : $1^{\circ}$. qu'il faut au moins dix à douze heures pour que la putréfaction s'établisse dans des substances animales, et que la digestion se fait en quatre ou six heures dans les oiseaux ou mammifères carnivores. $2^{\circ}$. Spallanzani mit un morceau de viande dans une petite fiole remplie d'eau, et le tout fut ensuite introduit dans l'estomac d'une corneille; l'estomac d'une autre Corneille reçut à nu un semblable morceau de viande pareille; or, il arriva que la viande de l'estomac fut digérée au bout de trois heures, et que la viande de la bouteille ne commença à se putréfier qu'après la neuvième heure. $3^{\circ}$. Les Reptiles, dans l'estomac desquels les alimens sont si lents à s'altérér, ne présentent pas davantage de putréfaction. $4^{\circ}$. Le suc gastrique empêche la putréfaction, bien loin de la produire; on l'a conseillé contre des ulcères, on l'a employé pour déterger les plaies de mauvais aspect. $5^{\circ}$. On a vu des animaux entiers que n'avaient encore engloutis qu'imparfaite- 
GHAP. Vi. MÉcanisMe de la Digistion. 517 ment des Serpens, commencer à se putréfier en dehors, tandis que la partie contenue dans l'estomac n'offrait aucun caractère de putréfaction. $6^{\circ}$. ' a viande même putréfiée reprend les caractères de la viande fraîche dans l'estomac, ou même dans le suc gastrique récent. $7^{\circ}$. Beaucoup d'animaux, les Corbéaux, des Insectes, des Vers, les Hiboux, les Vautours, la Hyène, le Chacal, se nourrissent de chairs pourries et de cadavres, mais ces substances perdent leur putridité et leur puanteur dans l'estomac qui les digère : il en fut de même pour un Pigeon que Spallanzani rendit carnivore en l'aframant, et qu'il habitua même à ne se nourrir que de chairs déjà putréfiées; ces chairs redevenaient fraîches et inodores dans son estomac.

Action de l'air. Varignon, l'ami de Fontenelle et de l'abbé de Saint-Pierre, pensait que la première division des alimens était l'effet du dégagement de l'air introduit dans l'estomac et dilaté par la chaleur du corps. Un chimiste moderne a été plus loin, en soutenant que cet air se décompose, et qu'un de ses principes constituans est l'agent du ramollissement et de la dissolution de la masse alimentaire : opinion qu'on réfute assez en se bornant à l'exposer.

Dissolution. Spallanzani crut que la digestion consistait tout simplement en une Dissolution des alimens par le suc gastrique. Il fonda cette opinion sur de nombreuses expériences, entr'autres sur ce que beaucoup d'animaux carnivores digèrent jusqu'à des os, el sur ce que des coquilles et des coraux introduits dans l'estomac d'oiseaux granivores perdent une partie de leur substance; il crut voir de l'analogie 
entre l'action du suc gastrique sur ces coquilles, et l'action du vinaigre sur des corps calcaires analogues. Enfin la digestion n'était pour lui qu'une véritable dissolution. Mais il faut observer : $1^{\circ}$. que le suc gastrique n'agit sur les semences et sur les herbes, dans les Oiseaux gallinacés et dans les Mammifères ruminans, qu'autant que ces substances ont été préalablement divisées et triturées; $2^{\circ}$. que la chymification n'est pas une véritable dissolution, puisqu'il reste définitivement une masse solide, équivalente à la masse des alimens employés à sa confection. C'est un changement, une altération dont la nature est peu connue, et à quoil'on ne produit rien de parfaitement analogue par les différens procédés chimiques. Mais on jugera mieux ce qu'il en fiaut penser par ce que nous allons rapporter des expériences entreprises au sujet de la digestion.

Boërhaave a cru que la digestion résultait à-la-fois de toutes les actions dont nous venons à l'instant de montrer l'insuffisance; mais il est convenu de respecter éternellement le nom de Boërhaave, sans jamais ajouter d'importance à ses hypothèses physiologiques: dieu merci le règne en est passé!

\section{CHAPITRE VII.}

Expériences touchant la Digestion. - Action de l'Estomac et du Suc gastrique.

L'académic de Florence si célèbre sous le noin del cimento, Rédi, Magalotti, Reaumur, Vallisneri et Spallanzani, ont fait, au sujet de la digestion, d'in- 
CIIAP. VII. EXPÉRIENCES SUR LA DIGESTION. 519 téressantes expériences, bien préférables aux conjectures les plus ingénieuses. Nous nous proposons d'en exposer les principaux résultats dans ce chapitre.

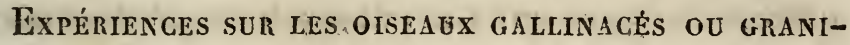
vores. Le gésier ou véritable estomac des Oiseaux granivores est doué d'une force étonnante; il brise des corps d'une grande solidité; il émousse des instrumens pointus ou acérés. Reaumur avait introduit dans l'estomac d'un de ces animaux six boules de verre remplies d'orge, ces boules furent brisées sans qu'il resiât de fragmens visibles lorsqu'il examina les parties. On calcula, par comparaison, que la force employée pour produire un tel effet avait dû équivaloir à près de douze livres. Le même gésier aplatit ou brise des tubes de fer blanc, et jusqu'à des lubes de fer ou de cuivre d'nne épaisseur médiocre; et l'on a stippulé qu'il avait fallu pour cela une force équivalente à 8 o et jusqu'à 555 livres. C'est de la sorte que l'estomac des Poules et des Oies, etc. , brise des noix, des noiseites, qu'il use des tubes de plomb, des médailles, du verre, des pièces de monnaies, ainsi que Borelli, Duverney, Fontenelle, Reaumur, en citent des exemples. Un dindon a divisé fort menu de la sorle jusqu'à vingt-cinq noix entières qu'on avait intioduites dans son tube digestif. Des perles poussées dans l'estomac des oiseaux gallinacés n'ont point été brisées, mais elles sunt devenues plus belles, plus polies, plus éclatantes. Spallanzani avait introduit dans l'estomac d'un de ces animaux, une balle de plomb traversée par douze aiguilles fort piquantes; ces aigruilles furent toutes brisées sans que le gésicr parût blessé ou déchiré; il en fut de même d'une, autre. 
balle de plomb qui étaịt débordée par douze pointes de lancettes neuves et acérées, et même plusieurs de ces fragmens d'aiguilles et de lancettes disparurent entièrement sans que l'on pût savoir ce qu'elles étaient devenues : peut-être avaient-elles été pulvérisées. II avait suffi de seize à trente-six heures pour obtenir de pareils effets. Un grenat à douze facettes, ou dodécaèdre, avait presqu'entièrement perdu tous ses angles, était presque devenu lisse et sphéroïde, après un mois de séjour dans l'estomac d'un Pigeon. J'ajoute que le gésier commence à exercer son action si énergique sur les corps qu'il renferme, ordinairement au bout de deux heures, et en quelques heures tout est fini.

Je répète que le gésier brise les corps les plus blessans, les plus aigus, sans en éprouver de plaies ni de contusions visibles, sans en être traversé : cependant Spallanzani note qu'ayant introduit quelques épingles dans le conduit digestif d'une Poule, il en trouva deux qui s'étaient implantées comme dans une pelotte, dans le gésier de cet animal.

L'énergie du gésier des Oiseaux granivores est telle, que plusieurs physiciens avaient attribué à cette seule action la digestion de ces animaux, commettant ainsi le tort de faire abstraction totale des sucs gastriques, sans lesquels cette fonction ne pourrait s'opérer, même dans les gallinacés. Spallanzani a mieux apprécié les choses que ne l'avaient fait Reaumur et ses autres devanciers; il a parfaitement vu que l'action du suc gastrique servait à la digestion de ces oiseaux comme à celle des autres animaux; il s'est assuré, en outre, que ces liquides n'avaient d'action 
CHAP. VII. EXPÉRIEYCES SUR IA DIGESTION. 521 sur les graines, sur le pain dont on nourrit ces oiseaux, qu'autant que ces substances avaient été préalablement divisées, soit artificiellement, soit par le gésier lui-même. Il s'est servi, à cet effet, de tubes perforés et résistans, qu'il remplissait de graines et dans lesquels les sucs gastriques trouvaient facilement accès : si les graines occupant ces tubes étaient divisées, la digestion s'en opérait au bout de quelques heures aussi bien que si elles eussent été à nu dans l'estomac: mais elles ne subissaient aucune altération lorsqu'elles s'y trouvaient entières et sans broiement préalable.

La trituration opérée par le gésier est done nécessaire à la digestion des graines, dont se nourrissent lés oiseaux gallinacés. Personne ne nie ce fait aujourd'hui, mais plusieurs physiciens ont attribué cette trituration, non à l'action immédiate du gésier, mais au contact des graviers, souvent fort nombreux, qu'on rencontre daus l'estomaci des oiseaux dont nous parlons. On fortifie cette opinion en disant que ces graviers et cailloux doivent avoir un usage; et quel autre usage peuvent-iis avoir, ajoute-t-on, si ce n'est de briser les alimens qui les heurtent? Spallanzani a examiné cette question avec beaucoup plus de soin qu'elle ne méritait. Il a vu qu'on trouvait constamment de ces graviers dans les oiseaux granivores, qu'on en trouvait quelquefois jusqu'à deux cents dans le même animal, et que le volume en était proportionnel au volume des oiseaux; que les oiseaux retenus, élevés et nourris par la main de l'homme, avaient moins de ces graviers que les oiseaux abandonnés à 'eux-mêmes, mais qu'ils en conservaient toujours 
quelques-uns jusqu'à la mort; de plus, il s'est assuré que les oiseaux tout jeunes ont déjà des cailloux dans le gésier, leurs parens en mêlant toujours dans les premières becquées d'alimens qu'ils leur donnent, et le même physicien n'est parvenu à éloigner tout caillou du gésier que dans des oiseaux, dans des Pigeons qu'il avait fait éclore et qu'il avait nourris saus le secours et loin de leur mère. Il a viı après cela, que ces oiseaux privés de graviers, digéraient tout aussi bien que ceux qui en étaient amplement approvisionnés.

C'est donc l'action musculaire du gésier qui opère les effets étonnans qu'on attribuait faussement à des corps étrangers, c'est par ses mouvemens propres qu'il broye les graines, qu'il triture les alimens et les rend perméables aux sucs qu'il contient en abondance et auxquels il est assez ordinaire que la bile se mêle, ce qui est cause de la saveur amère 'qu'on leur trouve ainsi qu'aux alimens qu'ils ont pénétrés. J'ajoute que Reaumur et Spallanzani ont vu remuer le gésier mis à nu, et qu'ils ont même aperçu ces mouvemens à rravers les parois dia ventre restées intactes. Il faut aussi noter que les Oiseaux granivores digèrent lentement les viandes, surtout si elles sont crues et non divisées, beaucoup plus lentement que les graines : ils les digèrent moins rapidement que les Hérons, les Corneilles et les autres oiseaux carnassiers. Cependant leur suc gastrique est abondant : Spallanzani a obtenu d'un Pigeon, dans le jabot duquel il avait introduit une éponge, une once de ce liquide en douze heures, et jusquà sept onces en dix heures chez un Coq d'Inde. 
CHAP. VII. EXPERIENCES SCR LI DIGESTION. $52 . \bar{~}$

Nous devons observer que les graines ne passent. point subitement et à-la-fois du jabot, où elles se ramollissent et se gonfient, dans le gésier. qui les triture et les digère; la progression en est lente, à-peuprès comme on le voit dans cette partie de nos monlins d'où la graine passe peu-à-peu sous la meule qui doit l'écraser.

Expériences sur les oiseatx carnivores. La digestion de ces animaux est beaucoup plus prompte que celle des oiseaux gallinacés, et elle peut s'effectuer dans des tubes résistans et percés de trous favorisant l'accès du suc gastrique; presque aussi promptement que lorsque les alimens sont à nu dans l'estomac. La digestion s'opère donc dans ces animaux presque exclusivement par l'action du suc, gastrique, aidé de la chaleur vitale; toutefois, des tubes fermés, n'ayant aucune communication avec la cavilé digestive, de pareils tubes remplis de viande et de suc gastrique récent, introduits dans l'estomac des oiseaux en question, ont offert la viande qu'ils renfermaient presque sans aucune altération après plusieurs heures.

Un poisson et une grenouille ayant été donnés à un Héron sans division préalable et sans envcloppe intermédiaire, au bout de vingt-quatre heures le poisson était entièrement digéré, et la grenouille n'était que ramollie. Ordinairement les Corneill es ont achevé leur digestion au bout seulement de trois heures. Or, ces oiseaux n'ont point; comme les gallinacés, un gẹsier très-énergique par qui les alimens puissent être fortement pressés et triturés; la digestion, chez eux, je le répète, est donc presque entièrement effectuée par l'action des sucs de l'estomac et de l'œsophage. 
-sur les substances alimentaires. Toutefois on se tromperait beaucoup si l'on croyait que l'estomac de ces oiseaux est incapable de mouvemens : la plupart des oiseaux carnassiers vomissent; ils vomissent les parties peu susceptibles d'être digérées, les plumes, les poils, les os, etc.; or, le vomissement, dans ces êtres, est principalement accompli par l'aclion propre de l'estomac, puisqu'ils n'ont point de vrai diaphragme propre à servir d'arc-boutant durant les efforts de ce genre.

L'expérience des tubes percés est aussi efficace dans les Chouettes, dans les.Ducs, dans les Milans, les Aigles, les Vautours, les Faucons, etc., que dans les Hérons et les Corneilles. La digestion des substances remplissant des conduits accessibles au suc gastrique, s'opère constamment et en peu d'heures, surtout dans les Faucons, dont la puissance digestive est extrême. Les Faucons digèrent júsqu'à des cuirs non tannés, et même la portion osseuse des dents. La plupart de ces oiseaux carnassiers ne peuvent digérer, quoi qu'on fasse pour les y porter et les y rendre propres, ni les graines de céréales, ni le pain, ni des plantes, enfin, rien de végétal (en exceptant toutefois les Corneilles). Cependant Spallanzani est venu à bout d'habituer un Aigle à manger du pain; et bien plus', ce même aigle, très-affamé, digérait ce pain sans le vomir. Cela n'est pas, au reste, plus étonnant que de voir le même expérimentateur habituer un Pigeon à manger de la viande et même des chairs déjà putréfiées. Mais nous devons dire que Reaumur ni Spallanzani n'ont pu faire digérer de substances végétales ni au Milan, ni aux Ducs, ni aux 
CHAP. VII. EXPÉRIENCES SUR LA DIGESTION. 525

Faucons. Cela vient, quant aux graines entières, de ce que ces animaux n'ont point un gésier assez énergique pour faire éprouver à ces semences la trituration qui est nécessaire à l'action subséquente des sucs gastriques.

Haller, d'après un anglais nommé Cheyne, assure que les Corneilles ne se peuvent manger les unes les autres, ou que du moins la chair de l'une n'est point digérée dans une autre : ipsa cornix cornicis carnem ingestam non potest coquere.... Mais Haller fut induit en erreur; les corneillès peuvent digérer la chair de leurs pareils : même chose est vraie du Loup, du Chien et de plusieurs autres animaux, à l'égard desquels on a eu le tort de la nier. Parmi les animaux carnivores, il n'y a guère que les Polypes quí ne soient bons à servir d'alimens ni à d'autres animaux ni à eux-mêmés. Observons cependant que les carnivores par excellence ont une chair trop animalisée, trop coriace, trop peu digestive, trop disposée à la putréfaction, en un mot, trop dégoûtante, pour que de nouveaux animaux puissent habituellement s'en nourrir; mais elle n'est pas plus impropre à être digérée par les êtres de la même espèce qu'elle ne l'est pour d'autres espèces; et les carnivores se nourrissent de toute chair dans les cas extrêmes.

Faits relatifs a la nourrature et a la nigestion DE L'AIGLE. L'Aigle en liberté comme en esclavage se nourrit d'animaux vivans; les oiseaux sont sa proie préférée, mais à leur défaut toute chair lui est bonne, surtout s'il peut la déchirer après avoir lutté pour l'obtenir. Si l'aigle est captif, ses plumes se hérissent et son regard devient plus féroce à la vue d'un animal 
vivant, abandonné à ses entreprises et livré à sa voracité. Alors il déploie ses ailes, vole doucement autour de sa proie convoitée, et bientôt se précipite sur le dos de l'animal qu'on lui sacrifie. Une serre fixée sur sa tête, afin d'en éviter les morsures, l'autre serre enfoncée profondément dans les flancs jusqu'aux entrailles, il assiste ainsi aux tourmens de sa victime, et n'emploie son bec pour la déchirer, quaprès que la vie s'est lentement éteinte dans les souffances. L'aigle fait à la peau une déchirure d'abord trèséroite, mais il l'agrandit bientôt, dès qu'il parvient à découvrir la chair saignante, qu'il dévore avec avidité et sans relâche jusquà ce qu'il en soit entièrement rassasié. Quelque cruel que soit l'aigle, l'homme n'a rien à redouter de ses atteintes.

Quand l'aigle peut choisir ses alimens, il dédaigne la peau, comme trop coriace, les os, comme trop durs et blessans, le canal intestinal, comme peu digestible et dégoûlant par les matières qu'il renferme. Un repas par jour lui suffit, et dans ce seul repas l'aigle consomme environ trente onces de viande. Son piemier estomac est très-vaste, el c'est dans sa cavité que s'accumulent d'abord les alimens, après quoi ils pénètrent dans le deuxième et véritable estomac, qui nous semble être l'équivalent du gésier des Oiseaux granivores.

Une particularité qu'on remarque sur l'aigle, c'est qu'aux premicrs morceanx de chair qu'il avale, il sort de ses narines deux petits ruisseaux de liqueur qui descendent jusqu'à l'extrémité du bec, où ils forment goutte; et ce liquide qui continue de couler pendant toute la durée des repas de cet oiseau, entre 
CHAP. vil. EXPURENCES SER LA DIGESTION. 527 presque toujours dans l'intérieur de la bouche et se mêle aux alimens. Spallanzani, qui a surtout bien observé ce phénomène, assure que ce fluide est d'un bleu clair, que son goût est salé, et sa transparence aussi grande que celle de l'eau de source. On peut penser que cette liqueur provient de la glande lacrymale, et qu'elle remplit ici lc même office que fait ailleurs la salive : nous avons eu soin de dire que les oiseaux n’ont ni salive, ni glandes salivaires.

L'Aigle boit, si on lui présente des-liquides abonslans, et pourvu que les vases qui les renferment en soient à-peu-près remplis. Dans le cas contraire, il ne se sert dédaigrieusement des liquides qu'on lui présente que pour baigner son bec et arroser ses plumes. Tous les autres oiseaux de proie boivent également, encore qu'on ait prétendu le contraire. Ce-pendant il est vrai de dire quon est parvenu à nourrir un Duc durant huit mois entiers sans boisson; mais nous devons ajouter que cet animal mourut alors, et qu'il éiait très-maigre. Le Lion boit également. Toutefois il faut convenir que les animaux carnivores dont la digestion. est plus rapide, ont moins besoin de boissons que les herbivores; encore trouve-t-on parmi ceux-ci le Chameau et le Dromadaire, qui peuvent rester plusieurs jours entiers sans boire.

L'aigle ne mange jamais de lui-même ni pain ni graines; si on en introduit de force dans son estomac, il rejette ces substances par le vomissement. Néanmoins Spailanzani est parvenu, non pas à faire manger du pain à l'aigle qu'il retenait captif et qu'il avait affamè à cet effet, ses efforts furent vains sous ce rapport; mais il lui fit digérer, sans qu'il survîul de 
vomissement, sans qu'il restât de résidu visible, jusqu'à six onces à-la-fois de pain introduit de force; et Spallanzani voulant s'assurer si les parois de l'estomac concouraient à cette digestion du pain par leur action compressive et triturante, fit usage de ses tubes perforés; il les remplit de pain, même de fromage, et ces différentes substances se trouvaient digérées au bout de vingt-quatre heures. Les graines écrasées et préalablement moulues, se digéraient aussi dans ces tubes; mais elles restaient sans altération et tout-àfait intactes, lorsqu'on les introduisait entières et seulement ramollies, soit dans les tubes, soit à nu dans l'estomac. Ainsi le gésier de l'aigle est incapable d'exercer de trituration.

Bien plus, le même Spallanzani s'est assuré que ce n'est point dans le premier estomac de l'aigle, dans l'estomac succenturié, que se digèrent les viandes et les autres alimens dont il fait sa nourriture; cet organe ne fait que ramollir ces substances, et c'est dans l'autre estomac que s'effectue la préparation digestive: de sorte que le premier estomac de l'aigle n'a pas plus d'action sur les alimens que le jabot des oiseaux granivores n'en a sur les graines.

A raison de la digestion, l'aigle digère plús tôt la cervelle que le foie, plus vite le foie que la chair musculaire, mieux les muscles du corps que la substance du cœur, et les tendons plus lentement que tout le reste, à l'exception des os, que cependant il peut ausși digérer, surtout s'ils sont petits ou concassés, ramollis ou amincis.

La digestion est beaucoup plus énergiquement effectuée et plus rapide dans l'Aigle qu'en aucun autre 
CHAP. VII. EXPÉRIENCES SUR LA DIGESTION. 529 oiseau de proie, plus rapide par conséquent qu'en aucun autre oiseau. Le Faucon même ne digère ni ausși vite 'ni aussi bien que l'Aigle des alimens peu digestibles : cependant l'aigle mange au moins trois fois autant que le faucon; mais ses sucs gastriqties sont plus abondans, plus actifs, et c'est à cela principalement que paraît tenir l'énergie de la digestion. Toutefois ce n'est guères qu'à l'égard des os qu'on peut dire que l'aigle digère plus vite que le faucon et les autres oiseaux de proie; car lorsqu'on donne à ces animaux une petite portion de viande, et la même quantité à chacun, l'aigle ne digère pas la sienne sensiblement plus vite que les autres oiseaux de proie. Mais, ce qu'il faut remarquer, l'Aigle digère trente onces de viande pendant que le Faucon en digère dix onces et la Chouette trois onces. Une autre chose singulière, c'est que le deuxième estomac de l'aigle ne peut contenir qu'environ trois onces de liquide, tandis que le premier estomac en peut recevoir environ trente-huit onces : cela même doit ralentir le passage des alimens d'une de ces cavités dans l'autre, et rendre en conséquence la digestion plus parfaite. La grande capacité de l'estomac succenturié des oiseaux de proie fait aussi qu'ils peuvent rester long-temps sans inanger après s'être repus jusqu'à satiété. Le deuxième estomac de l'aigle représente assez bien la jambe et le pied de l'homme : le pylore occupe la pointe de la partie de l'organe qui répond au pied.

Expériences au suJet de La digestion de l'homme, etc. Si un Homme sain et encore jeune, digérant bien et faisant convenablement toutes ses fonctions, avale le matin à jeun un sac de toile claire, rempli par qua- 
rante à soixante grains de chair de volaille cuile ef mâchée, d'ordinaire cette viande est digérée entièrement au bout de dix-hnit à vingt-quatre heures. Si l'on emploie de la chair crue de bouf ou de veau, au bout de trente heures environ ces viandes sont en partie digérées, surtout la viande de.veau, et ce qu'il en reste dans la bourse de toile est aussi desséché et aussi dur que si on l'avait comprimée. Spallanzani, qui a fait plusieurs expériences pareilles à celle-ci, ne savait à quoi attribuer ce desséchement de la viande rendue sans avoir été digérée; il avait d'ailleurs observé semblable chose dans plusieurs mammifères, et il avait vu que le même effet se réalisait pour le pain comme pour la viande: il se demandait si cela ne dépendait pas de la compression exercée sur les alimens par l'estomac. Mais l'estomac de l'homme et de la plupart des mammifères a peu de force, de faibles fibres musculeuses; on ne lui voit exécuter que des mouvemens peu étendus et souvent même peu manifestes; il ne brise ni les graines, ni les noyaux introduits dans sa cavité, et même il en sort souvent sans qu'ils aient été rompus, des raisins mûrs, des cerises ou d'autres fruits dont le parenchyme mou n'est protégé que par une légère pellicule.

L'estomac de I'Homme n'a donc pas le pouvoir de comprimer les substances qu'il recoit et digire, et ce n'est.point parce 'qu'il les comprime qu'il les digère, ou qu'il dessèche ce qu'il n'a pu digérer. Pour mieux s'assurer du fait, Spallanzani a plusieurs fois avalé des tubes de bois remplis de viande, de pain, etc. ; et il a vu constamment que ces alimens étaient tout aussi bien digérés et digérés presque aussi vite que s’ils 
CIAP. VII. EXPÉRIENCES SUR I.A DIGESTION. 551 eussent été introduits à nu dans l'estomac : outre cela ils n'étaient jamais desséchés. Quelle esł donc la vraie cause de ce desséchement des alimens imparfaitement digérés par l'estomac de l'homme et de plusieurs animaux? cela dépend uniquement de l'absorption qui s'exerce avec énergie dans les intestins, ce qui prive les substances qui les parcourent des sucs dont elles sont pénétrées. Ce desséchement a lieu pour les alimens introduits soit à nu, soit entourés de tissus; mais il n'a jamais lieu pour ceux quoon a renfermés dans des tubes, par la raison que les vaisseaux absorbans ne peuvent agir sur les substances que ces tubes contiennent, et que d'ailleurs les fluides intestinaux et le mucus pénètrent dans ces petits vases a travers les trous dont ils sont criblés. J’ajoute que les alimens ne sont jamais desséchés dans l'estomac et avant d'avoir franchi le pylore, ainsi qu'on peut s'en assurer en retirant ces substances du tube digestif assez tôt pour qu'ils n'aient pu encore passer dans l'intestin.

Utilití de la mastication. Nous avons dit ce qui arrive pour des alimens divisés et triturés par les dents, nous savons combien la digestion en est facile: mais il n'en est pas de même à beaucoup près pour les alimens non divisés. Pour préciser la différence de la digestion dans ces deux cas, Spallanzani a fait l'expérience suivante : il a rempli deux tubes d'égal calibre avec quarante-cinq grains pour chaque tube de chair de pigeon cuite ; mais avec l'attention de mâcher la chair renferınée dans l'un de ces tubes, et de laisser la chair contenue dans l'autre sans mastication ni division, mais entière. Ces tubes avalés en même 
LIV. IV. DI LA NUTRITION.

temps par Spallanzani, sortirent naturellement de l'intestin au bout de dix-neuf heures, et voici quelles différences présenta la viande qu'ils contenaient : celle qui avait été mâchée était réduite de quarantecinq grains à quatre, et il restait encore dix-huit grains de la chair entière de l'autre tube : la différence était donc de quatorze grains, c'est-à-dire près d'un tiers.

On peut faire des observations analogues sur beaucoup d'autres animaux : plusieurs ne digèrent inıparfaitement les substances végétales ou animales que pour les avoir trop incomplètement mâchées ou triturées. C'est même la raison pour laquelle plusieurs rendent encore reconnaissables et presque entières des portions des alimens dont ils font leur nourriture.

Observations ft expériences SUR La digestion des CHIEns, ETG. Les Chiens rendent souvent des portions de chairs qui paraissent à peine altérées tant les fibres en sont bien conservées : seulement ces fibres sont desséchées, dures et privées de sucs. Cela a principalement lieu pour les ligamens, pour les tendons, les intestins, et pour les gros muscles des membres. Boërrhaave avait observé ces phénomènes, et il n'allait à rien moins qu'à en conclure que les chairs ne se chymifient point dans l'estomac du chien, et que toute digestion consiste chez cet animal dans une simple expression des viandes qu'il mange, et dans l'absorption des sucs nourrissans que ces viandes fournissent. Haller cita ces faits avec complaisance et parut disposé à les interpréter comme son maître. Spallanzani examina les choses de plus près : il vit d'abord que les Chiens ne rendent jamais de substances 
CIIAP. VII. EXPÉRIENCES SUR LA DIGESTION. 553 animales, même parmi les moins digestibles, sяns les avoir altérées, amoindries. Il s'aperçut, à la vérité, que des fragmens de chairs sortaient souvent du corps de ces animaux assez bien conservés et toujours très-durs et desséchés. Mais il présuma avec raison que cela tenait à l'extrême gloutonneric de ces êtres, qui mangent beaucoup, qui avalent trop vite et souvent sans mâcher. Il vit de plus, que les alimens séjournent peu dans l'estomac des chiens, trop peu pour subir convenablement et autant qu'il faudrait l'action des sucs digestifs : il résolut en conséquence de prolonger ce séjour des alimens dans l'estomac par un moyen quelconque; et puisque le pylore se montrait trop facile à franchir dans cetle espèce; il joignit aux alimens de petites éponges, dans le but de boucher le pylore par ces corps si facilement dilatables : à l'aide de pareilles précautions, il fit séjourner diverses sortes d'alimens dans l'estomac des Chiens; et les ayant retirés après quatre ou cinq jours, il vit que ces alimens étaient très-bien digérés, et qu'il n'en restait nul résidu. Ces expériences faites ou ì $\mathrm{nu}$, ou avec des bourses de toile ou des tubes, donnèrent des résultats ana!ogrues.

LES DIFFÉRENS ALIMENS SONT DIVERSEMENT DIGESTIBLES. Nous avons eu soin de dire, autant que nous l'avons pu, quels alimens conviennent le mieux à chaque espèce d'animal, nous ne voulons parler ici que de ce qui concerne l'Homme. Il faut remarquer gue la question de digestibilité variable des alimens n'a beaucoup d'intérêt que pour notre espèce : premièrement, parce que chaque animal n'use d'ordinaire que de la nourriture qui lui convient le mieux, et que les 
espèces d'alimens dont il fait usage sont presque (oujours et à cause de cela fort restreintes; taudis que l'homme est omnivore, je veux dire que loute sorte d'aliment lui convient : secondement, parce que, même parmi les alimens qui lui sont le meins favorables ou les plus nuisibles, il n'en est aucun que ses caprices ne lui fassent désirer, que sa perfide industrie ne lui rende agréable; aucun que les vicissitudes de la vie sociale, et quelquefois le plus affreux dénuement, ne lui fassent trouver délicieux ou ne lui rendent nécessaire.

On possède des faits exacts autant qu'intéressans au sujet des alimens qui conviennent le mieux a l'homme; on a plusieurs moyens d'observer quelles. sont les substances qu'il digère plus rapidement ou qui lui sont le plus profitables. Le vomissement est l'un de ces moyens, soit qu'il dépende d'une maladie, soit qu'il résulte de l'emploi d'un émétique, ou qu'it soit volontaire, ainsi que plusieurs hommes ont la faculté de le produire. Nous devons à cet égard des remarques intéressantes à MM. Gosse et de Montègre. On a de même su profiter des fistules, qui parfois permettent de voir à travers les parois abdominales détruites, ce qui se passe dans l'estomac. On a aussi mis à contribution, dans ces derniers temps, les cas assez rares d'anus contre nature: il suffit de consulter ce qu'ont publié à ce sujet MM. Lallemand et Dupuytren.

On a donc observé que les alimens les plus digestibles pour l'homme et pour beaucoup d'animaux sont: la chair de veau, d'agneau, de poulets et de volailles; les cufs de poule frais et à moitić cuits, le 
lait de vache, plusieurs poissons cuits à l'eau, et as-* saisonnés tout simplement de sel et de persil; à l'huile, ou frits, ou avec différens apprêts compliqués, les poissons se digèrent moins bien. Les végétaux faciles à digérer sont: les épinards, le céleri, surtout la racine; les jeunes asperges, les bourgeons de houblon, les placenta d'artichants, la pulpe cuite des fruits à pepins ou à noyaux, surtout si elle est su crée et aromatisée; les semences farineuses des plantes céréales, le blé, le riz, lcs pois, elc.; le pain, le lendemain de sa cuisson, mais surtout le pain salé, et principalement le pain blanc; les navets, les salsifis, les pommes de terre nouvelles; la gomme arabique.

Moins digestibles sont les substances suivantes : la chair de porc et de sanglier, les œufs durs ou différemment apprêtés; les différentes salades crues, les choux, les cardons, les bettes, les oignons, les carottes, le raifort, le pain chaud, les figues, les pâtisseries, les fritures, et les assaisonnemens au vinaigre ou à l'huile : l'estomac n'attaque qu'imparfaitement ces différentes choses, mais la digestion s'en achève dans l'intestin.

Enfin nous citerons parmi les alimens les plus indigestes : les parties tendineuses et cartilagineuses, mais surtout les membranes du bœuf, du porc, du veau, des volailles, de la raie, etc.; les os, alors même qu'ils sont très-divisés ; les substances graisseuses ou huileuses, le blanc d'œuf durci par la chaleur; les champignons, les morilles, les truffes; les semences huileuses, telles que les noix, les amandes, 
pignons, pistaches; les pepins de raisins, de poinmes, etc.; les olives, le cacao; les différentes huiles, les raisins secs, les rafles de raisins frais, l'épiderme des diverses semences ou des fruits, les gousses de pois, les écorces, beaucoup de graines émulsives ou ligneuses, lesquelles subissent si peu l'action de l'estomac, qu'elles germent sans difficulté à la sortie de l'intestin; et c'est même ainsi que beaucoup de plantes se disséminent et se prōpagent d'un pays à l'autre.

Disons aussi qu'il est plusieurs substances dont le mélange avec les alimens facilite la digestion; par exemple : le sel marin, même pour les herbes dont se nourrissent les Ruminans; les épices, le vin, les liqueurs à petites doses, les différens fromages, le sucre, les substances amères, particulièrement le cachou.

On cite au nombre des choses capables de troubler la digestion : l'eau, surtout si elle est chaude et prise en grande quantité peu après avoir mangé, car ce liquide fait sortir les alimens de l'estomac avant qu'ils aient été digérés; les acides et le quina, pris après ${ }^{5}$ le repas; les corps gras, la douce-amère, le kermès, l'émétique et les dirers poisons, à quẻlque petite dose qu'on les prenne; la position assise, les travaux de l'esprit et les affections tristes, retardent aussi la digestion ou la troublent.

Un célèbre chirurgien anglais, A. Cooper, a fait des essais analogues pour l'espèce du Chien, et il a vu que cet animal digère plus aisément le porc que le moutón, le mouton plus rapidement que le veau, et le bœuf moins bien que tout le reste. Il a vu de 
GHAP. VIl. EXPÉRIENGES SUR LA DIGESTION. 5.37 même que le poisson et le fromage étaient fort digestibles, et que la viande bouillie était plus vite digérée que la viande rôtie.

Les os PEUvent-ILS ÊTKE DIGÉrÉs? Les Chiens jeunes, forts et dans un bon état de santé, digèrent les os; et même, ce qui est plus étonnant, Spallanzani leur a vu altérer profondément jusqu'à l'émail des dents. Quoique Boërhaave prétende le contraire, la chose est avérée. Les Faucons, les Aigles, les Corneilles, qui naturellement dédaignent les os ou les rejettent, néanmoins les digèrent, si, après les avoir introduits dans leur estomac, on trouve le moyen de les y faire séjourner : un Faucon peut manger un pigeon entier chaque jour, et les os sont digérés comme le reste de l'animal. Semblablement les Serpens et les Couleuvres digèrent les os; Spallanzani en a fait l'épreuve. Mais il faut dire que les petits os, les os peu solides, sont les seuls qui soient digérés entièrement et en peu de temps; les os les plus durs ont besoin d'avoir été divisés pour être ramollis et.dissous, autrement ils. n'éprouvent qu'un amincissement et une simple perte de substance. Il est remarqủable qu'avant d'être digérés, ils passent à l'état cartilagineux, et ressemblent à de la gélatine endurcie, comme s’ils avaient été soumis à l'action de l'acide nitrique. Je dois ajouter que la digestion de ces corps si durs et si réfractaires ne saurait être attribuée à l'action triturante de l'esto. mac, puisqu'ils ne sont digérés que par ceux des animaux dont l'estomac est le plus mince et le moins énergique : le gésier si.puissant des Gallinacés n’a absolument aucune action sur eux; et les animaux qui digèrent les as, n'ont absolument aucune aclion 
sur les graines entières les plus rendres. La digestion des os est donc uniquement l'ouvrage du snc gastrique, et celui de l'Aigle est de tous le plus actif pour un tel résultat.

Expériences sul la digestion des ruminans. Les. résultats obtenus quant à la digestion des Mammifères ruminans ont beaucoup de rapport avec ce qu'on observe dans les oiseaux Granivores ; ces animaux ne digèrent les herbes et les graines introduites dans leurs estomacs, qu'autant que ces substances ont été préalablement divisées, mâchées, trịturées. C'est vainement que des herbes entières, que des graines solides et intactes ont été introduites, soit à nu, soit enveloppées de toile, ou renfermées dans des tubes perforés, dans leur canal digestif : ces substances r'ont subi aucune digestion; elles ont été humectées, ramollies, et voilà tout. Même chose arrivait lors'ju'on les avait imprégnées de salive.

Au contraire, si on introduit des sacs ou des tubes remplis d'herbes ou de graines mâchées dans l'estomac des ruminans, alors la digestion de ces alimens est achevée, est parfaite au bout de quelques heures. On a fait de semblables expériences pour les Bœufs, pour les Moutons, etc., et elles ont offert dans tous les ruminans des résultats semblables. On en a fait également pour le Cheval, qui cependant ne rumine pas, et les effets ont été pareils.

Expíniences sur L $\Lambda$ digestion des reptiles eT DES poissons. Ces animaux ont la plus grande analogie avec tous ceux dont nous avons déjà parlé quant à la digestion; sculement ils digèrent plus lentement qu'eux : il leur-faut souvent plus de jours pour pa- 
CIAP. VII. ESPIRIENCES SUR LA DIGESTION.

rachever cet acte, qu'il ne faut d'heures aux Mammifères et aux Oiscaux de proie. Au reste, le suc gastrique joue le même rôle ici que nous lui avons vu remplir ailleurs.

Je crois avoir dit qu'on avait trouvé une souris entière dans l'estomac d'une Grenouille : l'animal n'était ni écrasé, ni divisé ; et cependant, sans qu'il présentât aucun caractère de putridité, aucune mauvaise odeur, les chairs en étaient fort macérées, et les os eux-mêmes étaient sensiblement ramollis et déjà amoindris. Tout cela était donc l'ouvrage du suc gastrique; et la preuve qu'il en était ainsi, c'est que des alimens introduits immédiatement dans l'estomac y ont subi une digestion, il est vrại fort lente, mais pourtant parfaite. Les Salamandres présentent une autre preuve du même fait : ces animaux se nourrissent de vers; ces vers, ils les ramollissent, et semblent presque les dissoudre; or, cela ne saurait être l'effet de l'action de leur mince estomac, puisque les salamandres ont presque toujours et naturellement dans l'estomac de petits vers parasites très-délicats, faciles à écraser, qui vivent là saṇs trouble et sans la moindre compression. La plus légère pression exercée sur eux par l'estomac briserait bientôt ces petits vers vivans si fragiles.

Je ne pourrais que répéter ici ce que jai déjà dit, si je voulais donner quelques détails sur la digestion des Serpens, des Couleuvres, des Tortues, des Lézards, etc. Je dois seulement insister de nouveau sur la lenteur extrême de cettefonction en ces animaux : la digestion des Couleuvres, pour cxemple, s'est quelquefois à peine ébauchće au bout de six à huit jours; 
on a trouvé un lézard dans l'une d'elles, lequel an bout de seize jours de macération n'était pas visiblement altéré. Un Serpent garda un poulet durant trois grands mois dans son estomac, et après un temps si long l'animal n'était pas encore entièrement digéré. Remarquons à ce sujet combiển il serait peu raisonnable d'assimiler la digestion à la putréfaction, puisque cette dernière est déjà très-avancée au bout de trois jours.

La digestion s'opère à l'aide aussi du suc gastrique dans les poissons; et elle y est moins lente que dans les reptiles : les Carpes et les Brochets surtout, ont assez de quelques heures pour accomplir la transformation des alimens. Cependant l'estomac de ces animaux est peu capable d'aclion.

La digestion PEUT-ELLE S'Opérer ou S'ÉbaUCHER daNS z'OESOPHAGE? Spallanzani ayant introduit dans l'œsophage d'un Héron une grenouille qui pénétrait en même temps dans l'estomac de cet oiseau, il put s'assurer que la grenouille avait subi dans toute son étendue, au bout de quelques heures, une altération, un ramollissement notable; mais ce ramollissement et ce commencement de digestion était beaucoup moins marqué pour la portion qui avait séjourné dans l'œsophage que pour l'autre partie. Il varia cette expérience, avec des tubes, avec des boulettes que retenaient fixement des fils, et il vit constamment que l'œsophage de ces oiseaux effecluait une sorte de digestion, mais beaucoup moins sensiblement que le véritable estomac. Même expérience fut faite sur d'autres animaux, et elle eut le même résultat sur ụ̂n grand nombre Un morceau de poumon de vache qui 
CHAP. VII. EXPÉRIENCES SUR LA DIGESTION. 541 avait séjourné treize heures dans l'œsophage d'un Oiseau de proie, et seulement dans l'œsophage, perdit plusieurs grains de sa substance dans cette épreuve.

On a trouvé des Brochets et des Carpes qui avaient. avalé des poissons d'une longueur telle, que cette proie occupaît à-la-fois et l'estomac et l'œsophage; or on a remarqué que, dans ce cas, la portion de poisson qui était renfermée dans l'estomac était beaucoup plus digérée que le reste, et que le ramollissement allait ensuite en diminuant de bas en haut, à mesure qu'on remontait du fond de l'estomac vers le haut de l'œsophage. L'œsophage peut donc, jusqu'à un certain point, ébaucher la digestion sans le concours de l'estomac véritable.

Cependant il n'en est plus ainsi si l'on passe des poissons aux Serpens. On a trouvé des Couleuvres dont les premiers compartimens du conduit digestif étaient entièrement remplis, ou par une grenouille, ou par tout autre animal, et l'animal englouti ne paraissait ramolli et digéré 'qu'absolument dans la portion descendue dans l'estomac.

Digestions artipicielles. Plusieurs physiologistes ont tenté, avec des succès variés, d'effectuer des digestions sans le concours de l'estomac, en employant tout simplement des sucs gastriques extraits de différens animaux, et mêlant ensuite ces sucs à divers alimens. Nous allons citer brièvement quelques-uns des résultats obtenus de ces expériences.

Spallanzani, à qui sont dues les principales tentatives de ce genre, introduisit dans un tube de verre des grains de froment bien divisés, et il remplit un autre tube semblable au premier avec de la chair de 
chapon cuite; au préalable, notre physicien avait eu soin de laisser macérer et la chair et les grains dans le jabot d'un coq-d'Inde, voulant ainsi réunir dans son expérience tous les préparatifs nécessaires à son succès. L'expérience de Spallanzani était parfaite, puisqu'elle réalisait toutes les circonstances préliminaires de la digestion, puisqu'elle imitait ce qui se fait naturellement dans les digestions ordinaires, à l'exception de la seule circonstance qu'elle avait pour but de faire apprécier. Ces alimens, déjà macérẻs, furent baignés de sucs gastriques tout récemment extraits du gésier d'un coq-d'Inde, après quoi on ferma exactement les tubes avec de la cire d'Espagne; et afin de rendre l'expérience tout-à-fait à l'abri de reproches et d'objections, Spallanzani plaça ces petits vases sous ses aisselles, et ils $\mathrm{y}$ restèrent sans déplacement durant trois jours. Ces tubes ayant été ouverts au bout de ce temps, on trouva les grains de froment en partie délayés et digérés; la chair était ramollie et devenue bleuâtre, sans la moindre odeur de pourriture ; cette chair, remise dans son tube avec de nouveau suc gastrique, fut replacée sous l'aisselle durant un jour, et au boui de ce temps elle était totalement dissoute. Sans doute ce n'était pas là une digestion véritable, mais peu s'en fallait ; et, quand on ne tiendrait compte que du défaut de putréfaction de la chair, il est sûr que ce fait tout seúl démóntrerait, dans le suc gastrique, une énergie, une puissance incontestable, et telle qu'aucun autre fluide n'en possède de semblable.

Pour mieux faire ressortir les effets dus au suc gastrique, Spallanzani répéta son expérience avec les 
CHAP. vit. EXPÉRENCES ser LA DIGESTION. 545 mêmes précaulions el circonstances, à la difrérence près qu'il substitua de l'eau simple et pure au liquide de l'estomac, et voici ce qu'il eut occasion d'observer : au bout de trois jours de séjour persévérant sons les aisselles, la chair d'un tube paraissait légèrement dissoute à sa surface, mais elle était restée fibreuse, rouge et cohérente à l'intéricur; elle était restée chair, et de plus elle sentait très-mauvais. La fécule des grains occupant l'autre tube était simplement délayée, mais non altérée, et partant fort reconnaissable. Les conséquences àe pareils faits saisissent d'euxmêmes et les yeux et l'esprit. Il faut retenir que ces expériences échouent si le suc gastrique n'est récent.

Ces essais, répétés pour plusieurs animaux, ont donné chez tous des résultats analogues. Cependant on a fait plusieurs remarques qui méritent d'être rapportées $: 1^{\circ}$. Le suc gastrique froid ne produit que des effets peu sensibles, seulement il s'oppose à la putréfaction; $2^{\circ}$. il exerce sa propriété dissolvante et digestive à mesure que la chaleur, soit vitale, soit artificielle, soit solaire, élève sa propre température; $3^{\circ}$. le liquide abondant de l'œsophage des Oiseaux n'a pas , à beaucoup près, la même force dissolvante que celui de l'estomac; $4^{\circ}$. il suffit souvent que le suc gastrique ait été retiré de l'estomac à l'aide d'éponges pour perdre toute son énergie, ainsi que Spallanzani en a fait l'épreuve pour les Corneilles; $5^{\circ}$. le suc gastrique ne. dissout les herbes qu'on y plonge qu'autant qu'on a eu la précaution de les broyer, de les mâcher, et de les imprégner de salive ; $6^{\circ}$. le suc gastrique des Poissons et des Reptiles n'a qu'une action faible et extrêmement lente; $7^{\circ}$. celui de l'Homme, aidé d'une cha- 
leur égale à celle de l'estomac, ramollit et semble di gérer la chair debœuf dans l'espace de trente-six heures; $8^{\circ}$. le suc gastrique d'une espèce agit souvent sur des substances extrêmement variées, et cependant celui d'une espèce n'a pas toujours d'action sur les alimens convenables à une autre espèce; $9^{\circ}$. la graisse n'est nullement altérée par le suc gastrique, pas même lorsqu'elle en subit l'action dans l'intérieur de l'estomac; la bile parvient seule à la dissoudre, aussi n'est-elle digérée que dans les intestins; $10^{\circ}$. le pain, mêlé à du suc gastrique, s’altère peu, il s'acidifie seulement; mais le fluide intestinal finit par dissoudre le pain, et par former, en se mêlant à lui, un liquide homogène: ce mélange dégage ensuite une odeur intestinale. Bien entendu que les fioles dans lesquelles se font de pareilles expériences, sont exposées à une température équivalente à celle du corps de l'animal dont on emploie le suc gastrique.

Quelques personnes ont voulu contester la réalité des digestions artificielles; mais les motifs qu'elles allèguent nous semblent peu importans.

Y A-T-IL ENCORE DIGESTION APRÈS LA MORT? On POUvait penser, d'après les expériences que j'ai rapportées touchant les digestions artificielles, que l'estomac lui-même, en tant que baigné de sucs gastriques, pouvait continuèr de digérer après la mort, et qui plus est se digérer lui-même. Hunter fut le premier qui énonça que le suc gastrique agit sur les parois de l'estomac après la mort, et il attribua à cette sorte de digestion les érosions ou perforations que l'on rencontre parfois à l'estomac des cadavres humains. Spallanzani fixa son attention sur ce phénomène sans par- 
CHAP. VII. EXPÉRENCES SUR LA DJUESTION 5,15 venir à le vérifier; mais il constala que l'estomad digère réellement encore après la mort les substances dont on l'a rempli aux derniers instans de la vie, ou même tôt après sa complèle extinction. Ce judicieux physiologiste avait soin de déposer ses cadavres dans des étuves qui pussent leur conserver la même chàleur qu'aux corps vivans, et au bout de quelques heures il trouvait les alimens sensiblement digérés. Les résultats qu'il obtint furent surtout manifestes sur les Oiseaux; moins marqués, mais pourtant encore appréciables dans les Poissons et les Repliles, derniers animaux dont les digestions sont naturellement. si lentes.

Spallanzani fit de semblables expériences sur des Chiens et des Chats, et les résuitats furent pareils. I! faut remarquer que pour fermer toute voic à l'erreur et à la confusion, on a soin de faire long-temps jeûner, avant de les tuer, les animaux dont les cadavres sont prédestinés à de semblables essais. L.es estomacs morts digèrent. jusqu’à des fragmens d'intestin, et même des lambeaux d'autres estomacs dont on les remplit, et pourtant ils ne paraissent pas subir eux-mêtncs l'action dissolvante du suc gastrique. Il faudrait rechercher si les Hommes qui succombent à des viclences subites, à des accidens ou à des supplices, continuent également de digérer alors que toute vie a cessé. C'est surtout après une mort pareille que Hunter disait avoir rencontré des perforations et des ulcérations à l'estomac des cadavres.

Spallanzani voulut éprouver si l'estomac, détaché des autrés organes aussitôt après la mort, effectuerait aussi bien la digestion, sous des influences extéricures 1. 
cen tout semblables, qu'un estomac conservant sa 'place et toutes ses connexions, et il s'assura que les digestions alors étaient moins parfaites. Il attribuait principalement celte différence à ce que l'estomac, alors séparé de tout vaisseau sanguin, laissait transpirer une moindre quantité de suc gastrique; mais peut-être l'absence de tout nerf était-elle aussi là pour quelque chose.

\section{CHAPITRE VIII.}

Suile du précédent. - Progrès de la Digestion, action des Intestins, ctc. ; formation, absorption el cours du Chyle.

Nous ne nous sommes occupé jusqu'ici que des changemens que subissent les alimens dans l'estomac; nous devons étudier maintenant, mais avec brièveté, les progrès et l'achèvement de la digestion dans le's intestins. Et quant à ces derniers organes, on a coutume de les distinguer, souvent sans beaucoup de motifs, en gros et grêles : on fait ènsuite trois portions fort peu distinctes de ceux-ci, et l'on désigne ces portions arbitrairement délimitées, par les noms inexacts ou insignifians de duodénum, jéjunum et iléum. A l'égard des gros intestius, on est convenu de les faire commencer à parlir de la valvule de Bauhin, lorsque cette valvule existe; et toute l'élendue de l'inteśtin comprise entre cette valvule et l'anus est divisée en trois portions plus précises que celles de l'intestin grêle, et on les désigne par les noms bizarres de cocum, colon, et rectum. Yoilà les organes à l'inté- 
CHAP. VIII. PRogrès ET SUITE dE LA DIgestion. 547 rieur desquels la digestion s'achève. Les intestins grềles sont contournés sur eux-mêmes et garnis de replis ou valvules surnommées conniventes, encore bien qu'elles soient isolées les unes des autres; et cetle double disposition du canal où cheminent les alimens ne pouvant qu'en ralentir le cours, n'est pas indifférente à la perfection du chyle, non plus qu'à sa séparation et à son absorption. Outre cela, les conduits de la bile et du súc pancréalique s'ourrent vers le commencement de l'intestin, qui de plus est parlout arrosé de sucs abondans et de mucus, produits de la sécrétion de sa tunique intérieure. Pour ce qui est des gros intestins, e'est dans leur cavité que se moulent et se durcissent les excrémens; aussi sont-ils dépourvus de valvules conniventes, abreuvés de moins de sucs, et pourvus de fibres musculeuses plus éneigiques. Suivons maintenant les progrès de la digestion, à partir du pylore où nous l'avons laissée.

Marche du chyme. Nous avons dit que le chyme formé lentement à la superficie de la masse alimenLaire que renferme l'estomac, s'amasse près du pylore à mesure qu'il se forme. Or les mêmes contractions, les contractions douces et presque insensibles qui le font arriver là, lui font ensuite franchir, en devenant plus vives et plus étendues, l'ouverture étroite du pylore. Cependant nous devons dire que ces grandes contraclions, nécessaires pour l'expulsion du chyme hors de la cavité de l'estomac, ont coutume de commencer vers le milieu du duodénum, que de là elles se propagent au pylore et de proche en proche à toute la périphérie de l'estomac; mais ce mouvement de bas en haut (pendant la durée duquel quelques per- 
sonnes éprouvent un si grand malaise) se convertit tout-à-coup en un mouvement opposé; et c'est à l'aide de celte sorte de reflux que le chyme traverse enfin le pylore, entr'ouvert à cet effet et par la même cause. Ce mouvement se répète ensuite et autant de fois que l'exige la quantité de chyme nouvellement formé. C'est de celtẹ manière, successivement et comme par secousses, que l'intestin se remplit peu-à-peu des alimens chymifiés par l'estomac. J'ajoute que le cours du chyme est ensuite fort lent dans toute l'étendue de l'intestin grêle; lente aussi est la marche des excrémens; faibles sont les mouveunens de l'intestin, hors les cas de maladie ou de passion.

Changemens du chyme. Action de la bile. La plénitude de l'intestin grêle favorise l'écoulement de la bile et du suc pancréatique; outre que son acidité excite la sécrétion de ces humeurs, aussi bien que des sucs intestinaux et du mucus. Tous ces fluides nouveaux, mêlés au chyme, en changent déjà la nature : ce chyme perd bientôt et presqu'entièrement son acidité, ce qui en arrête l'espèce de fermentation sourdement commençante; de grisâtre qu'il était il devient jaunâtre; et sa saveur a de l'amertume. Celte amertume existe en beaucoup d'animaux dès l'estomac; ćela a lieu particulièrement dans les oiseaux; par la raison qu'en ces derniers êtres la bile a coutume de pénétrer dans l'estomac par le pylore. Si les alimens contenaient de la graisse ou des matières huileuses, ces substances nullement altérées par l'estomac, vont l'être dans l'intestin : la bile agissant sur elles, les dissout et en compose une sorte de savon tui-même soluble. 
GHap. vil. progrès et suite de La Digestion. 5/9

A l'exception des matières huilcuses et graisseuses, et à l'exception des herbes, l'intestin laisse passer sans les altérer, les substances que l'estomac n'aurait pas préalablement digérées. Les mêmes alimens produisent un chyme semblable dans des animaux d'espèce pareille, et les changemens que le chyme éprouve ensuite se ressemblent également. Remarquons ici que le chyme provenant de substances végétales n'est pas semblable au chyme qu'ont produit des matières animales : celui-ci est plus épais et plus visqueux, est rougeåtre et ne caille pas le lait; l'autre est presque fluide, jaunâlre, et il caille le lait. Le chyme fourni par les régétaux est moins riche en matière nourrissante, et il ne contient pas de substance albumineuse comme le chyme résultant des viandes. Il se dégage pendant la digestion intestinale, et selon le stade où elle est parvenue, différens gaz dont la nature varie suivant l'espèce d'animal, suivant les alimens dont il a fait usage, suivant son âge et son état de santé, et surtout suivant la partie de l'intestin où l'on a puisé ces gaz. Nous avons dit que nous reviendrions ailleurs sur cet objet.

Quelque temps après que le chyme est descendu dans l'intestin grêle, et après qu'il a subi l'action de la bile, il se divise en deux parties: une qui est fluide et qu'on nomme chyle, c'est la partie qui sert à nourrir l'animal; et l'autre qui est plus solide, plus grossière, moins homogène; c'est le résidu de la nourriture, et ce que l'animal rejette de son corps sous.le nom d'excrèmens.

Cette séparation du chyle, et même sa formation, paraît due surtout à !'accession de la bile; du nioins 
est-il certain que la digestion est toujours imparfaite, et le chyle nul ou peu abondant, lorsque la bile n'a pu se mêler au chyme préparé par l'estomac. M.Brodie, l'un des plus savans physiologistes de l'Europe, assure qu'il a constamment empêché la formation du chyle dans les animaux dont il avait lié le conduit cholédoque, ou canal de la bile. Nous croyons vrais tous les résultats qu'il raconte; néanmoins un autre physiologiste fort habile aussi en a obtenu de différens.

'Le chyle se forme ordinairement deux ou quatre heures après que le chyme a passé de l'estomac dans le duodénum. Mais cela est moins prompt dans les. Poissons, et beaucoup plus lent encore chez les. Reptiles.

Quelques personnes ont assuré qu'elles avaient trouvé du chyle bien formé dans les vaisseaux blancs qui partent de l'estomac, et elles ont dit en conséquence que l'estomac formait du chyle; mais il est probable qu'on n'a vu de pareilles choses qu'en des. animaux dans l'estomac desquels la bile se mêle fréquemment aux sucs gastriques. Il paraît que le Chien est dans ce cas; mais il faut se garder d'étendre cela à tous les ànimaux.

LEs INTESTINS DIGÈRENT-ILS DES ALINENS NoN CHYMIFIÉs? On éprouverait de l'embarras à résoudre celte question à priari; 'car il existe des faits à l'aide desquels on pourrait soutenir tour-à-tour le pour et le contre. Et d'abord, beaucoup d'observations prouvent que l'estomac ne fait subir aucune altération sensible à de certains alimens, si l'eslomac ne les a préalablement modifiés, digérés, chymifiés. D'autre part, les alimens éprouvent de l'altération en quelque 
CIAP. VIII. PROGRÈS ET SUITE DF LA DIGESTION. 551 point du corps qu'on les introduise : les bribes de pain ou de viandes qui s'arrêtent dans le gosier, au voisinage des amygdales, s'altèrent visiblement et se ramollissent; un morceau de lard placé et retenu. dans la bouche, a paru s'y être ramolli; il avait aussi. changé de couleur. II n'y a pas jusqu'aux cataplasmes. de fécule appliqués sur la peau, qui ne subissent une altération très-différente d'une simple fermentation. Il est donc certain qu'on ne peut rien conclure de. ces différens faits, puịsqu'ils semblent se contredire. Mais recourons à l'expérience.

On a introduit des viandes cuites et des chairs crues dans l'in testin de.plusieurs chiens; on en a même altaché au haut de l'intestin grệle afin d'en empêcher la descente trop rapide, et l'on a vu que ces matières. avaient éprouvé un ramollissement sensible, et même qu'elles avaient diminué de volume. Il faut ajouter que ces chairs avaient contracté là une odeur extrêmement fétide, et que rien n'assure qu'elles fussent susceptibles, dans l'état où elles se trouvaient réduites, de fournir une sorte de chyle ou quelquechose d'alimentaire à l'animal. Cela ne ressemble. guère à une vraie digestion; et quant au ramollissement superficiel et à l'absorption légère des chairs. ainsi introduites dans l'intestin, il n'est aucune partic du corps qui ne soit susceptible d'opérer quelque chose de semblable. Concluons donc de ces faits que nu!le digestion bonne, complète et efficace, n'est possible sans le concours de l'estomac. S'il en était autrement, on pourrait nourrir par l'intestin les malades dont l'estomac ne saurait plus ou rien recevoir, 
ou rien digérer de ce qu'il reçoit : et de pareilles. tentatives n'ont eu jusqu'à ce jour aucun succès.

Formation et REJET des Excréuens. Les excrémens, séparés du chyle qui les surnage et dont l'absorption s'opère dans le haut de d'intestin, perdent peu-à-peu, à mesure qu'ils descendent vers les.gros intestins, la fluidité qu'ils avaient dans le milieu de l'intestin grêle. Le mucus des gros intestins en favorise la marche vers l'anus; mais les loges que présentent ces conduits de distance en distance, en prolongent le séjour et en accroissent la consistance. C'est par l'action des fibres musculeuses des intestins que les excrémens sont peu-à-peu poussés vers l'anus, et c'est par les muscles abdominaux quils sont finalement rejetés hors du corps. Cette expulsion résulte d'un mécanisme assez compliqué où la glotte, au moins chez les mammifères, joue un rôle inportant. Le rejet des matières fécales est beaucoup plus facile chez les animaux ovipares et dans l'Ornithorrhynque; et cette diférence résulte de ce que ces animaux ayant un cloaque, leurs urines s'amassent dans ce lieu aussi bien que les excrémens, qu'elies délayent.

Les excrémens diffèrent pour chaque espèce d'animal ; mais la plus grande diférence s'observe surtout entre les carnivores et les herbivores. Le même animal, s'il est omnivore, a des excrémens irès-différens, suivant qu'il use d'alimens végétaus ou d'alimens tirés de l'autre règne. Les excrémens provenant d'une nourriture animale ont la propriété de faire cailler le lait, et il n'existe rien de semblable pour les fécès des alimens végétaux. C'est absolument le 
CHAP. VIII. PROGRìs ET SUITE DE LA DIGESTION. 55.3 contraire de ce que nous avons dit pour le chyme des carnivores et des herbivorés. Bordeu surtout a fait d'intéressantes remarques à ce sujet; la curiosité naturelle à son esprit ingénieux lui a fait surmonter les dégoûts d'une étude si répugnante. Les recherches de Prout ont beaucoup moins d"intérêt, mais plus de précision que celles de Bordeu.

Les animaux qui digèrent des os ont des excrémens particuliers et fort remarquables. On retrouve sonvent dans les malières peu digestibles que l'estomac a laissé passe: sans les altérer, des fibres de muscles desséchés, des lambeaux de membranes, des morceaux d'intestin surtout, des portions de tendons, de ligamens, de cartilages, et des fragmens d'os; on y retrouve principalement des végétaux, des graines entières, à cause de l'épiderme, lequel se montre toujours réfractaire à l'action du suc gasțique; on y trouve des noyaux, etc. Les animaux éjeûnés ou insuffisamment nourris ont des excrémens plus solides. L'état de maladie produit souvent un effet contraire, aussi bien que la glóutonncrie.

Ajoutons que les boissons aussi se digèrent : bien plus, beaucoup de liquides laissent des excrémens dars l'intestin, encore qu'une grande partie en soit absorbée dès l'estomac. D’ailletirs il suflit qu'elles șoient un peu irritantes pour qu'elles excitent la sécrétion de la bile et du mucus, et ces fluides digérés avec les boissons laișsent des résidus comme elles. On est quelquefois étonné de la masse d'excrémens que contient l'intestin d'un homme malade ou d'un animal éjeûné qui ne prend depuis des jours entiers que des liquides. Ajoutons cependant que l'eau, les alcoo- 
liques et d'autres liquides simples, ne fournissent rien d'eux-mêmes ni pour la:nutrition ni-pour les: excrémens.

Mouvenress rétrogradrs. On nomme péristaltiques: les mouvemens à l'aide desquels la, masse alimentaire parcourt lintestin; mais il existe d'antres mouvemens. qui s'effectuent en sens contraire, c'est-à-dire de bas: en haut, et ceux-là ont reçu le nom d'anti-péristaltiques. Ces derniers mouvemens produisent divers. phénomènes, tels: que la Régurgitation, la Rumination, le Vomissement, etc. L'acte par lequel des. Oiseaux et des Insectes partagent avec leur progéniture des alimens déjà digérés pour leur propre estomac, est une sorte de régurgitation due à de semblables mouvemens. J'en dis autant de cette humeur brune et toute bilieuse que rendent les Sauterelles, du suc miellé qui sort tout élaboré du corps des Abeilles, des humeurs noirâtres que beaucoup de Mollusques marins répandent autour 'd'eux afin d'échappèr à leurs ennemis : enfin, toutes les classes d'animaux ont une sorte de vomissement ou de régurgitation. Les Oiseaux de proie vomissent naturellement après chaque repas, dans le but de se débarrasser de toute substance, ou dégoûtante; our réfractaire à l'action de l'estomac. Parmi les mammifères, aucun animal ne vomit plus aisément que le Chat. Ce phénomène s'observe aussi chez les Chiens, chez les Ruminans, chez les Salamandres et les Serpens parmi les reptiles, et quant aux poissons, surtoue chez les Carpes. Mais tous les vertébrés, à l'exception du Cheval (cbez qui la disposilion du cardia met obstacle au retour des alimens vers l'osophage), à celle 
CIIAP. VIII. PROGRès ET SUITE DH LA DIGESTION. 555 exception près, il n'est peut-être pas un animal vertébré qui n'ait la faculté de romir; et nous ne connaissons pas d'exceptions pour les classes inférieures. Il y a plus, les Polypes et les animaux voisins des. polypes, les Radiaires, les Tuniciers, tous les êtres enfin qui n'ont qu'une seule issue, une ouverture unique à l’intestin, tous ces animaux ne rejettent chaque jour le résidu de leurs alimens qu'au moyen d'une espèce de vomissement.

Ce n'est point ici le lieu d'insister sur le mécanisme de ce phénomène, en disant quelles puissances concourent à le produire. On peut voir ce que nous avons dit dans notre Physiologie médicale sur la Théorie des Efforts, et il sera facile dans faire l'application a l'objet présent (1).

Absorption et couks du chyce. Nous savons que le chyle se sépare do la masse alimentaire après qu'elle a séjourné dans la cavilé distendue diu duodénum, et peu de temps après que la bile et le fluide pancréatique ont agi sur elle, on ne sait précisément de quelle manière. Quant aux caractères et aux qualités du chyle, cette substance n'est bien visible et n'a pu être convenablement étudiée que dans les mammifères, et'il nous suffira de dire pour le moment que ce fluide est presque toujours d'un blanc opaque, ce qui lui a valu d'être comparé au lait; que de plus il a l'odeur du sperme, et qu'abandonné à lui-même, et hors.

(2) Voyez, en outre, les Mémoires ex professo de Baryle de Toulouse, de Chirac, de Magendie, de Legallois, d'Isid. Bourdon, de F. Lallemand, de Dupuy, de Porlal, de Pierlagnel, de Tissot de Lyon, de Maingault, de Bouvenol, de Lieutaud; quelques Rapports de MM. Hallér Percy, Chaussier, Béclard, Mérat, G. Cuvicr, llumboldt, etc. 
de ses vaisseaux, il se sépare en deux parties, dont l'une est séreuse et saliae, tandis que l'autre est fibrineuse; qu'enfin il se comporte à cet égard à-peu-près comme le sang. Nous devons ajouter que le chyle déposé dans un vase inerte prend ordinairement une teinte rosée, ce qui paraît dû à l'action de l'oxigène sur lui, et qu'en outre il surnage à sa surface une matière particulière, formant comme une sorte de nuage : on conçoit bien, d'après cela, qu'on ait pu comparer le chyle au lait, et qu'on soit allé jusqu’à regarder celui-ci comme le produit de l'autre. Ce qu'il y a de certain, c'est que rien n'influe sur l'abondance du lait ou du fluide prolifique, autant que la production abondante du chyle. Du reste, la naturé des alimens dont se nourrissent les animaux, introduit de notables différences dans le chyle qui provient de la digestion; le même chyle ne résulte point d'alimens dissemblables : les matières grasses produisent un chyle plus blanc et plus opaque que les substances non graisseuses. Mais jamais le chyle ne prend la teinte des substances colorantes introduites dans l'intestin; il n'en prend aussi que très-difficilement l'odeur.

Une fois sépảré de la manière chymeuse, dont il peut ẹtre regardé coinme une sorte d'extrait, le chyle surnage cette matière, et s'amasse par petits ruisseaux dans les sinus des valvules muqueuses, dont l'intérieur de l'intestin grêle est garni. Il séjourne là quelques instans, et c'est en ce licu qu'il est absorbé par les petits vaisseaux qui le doivent transporter de proche en proche jusque dans la masse du sang. Dire précisément de quelle manière, en vertu de quelle force et par quel mécanisme s'effectue celte absorption du 
Chap. vilt. prokres et SUITE de la digestion. 557 chyle, ne rien laisser à désirer à cet égard, nous serait impossible; nous aimons nieux mésatisfaire la curiosité du lecteur qu'induire son esprit à errer, en exposant comme faits avérés, de pures conjectures. En examinant avec soin, et à l'œil nu, l'intérieur de l'intestin au moment où le chyle est déjà tout formé, on voit, à la surface de la membrane intestinale, de petites éminences ou villosités comme spongieuses, qui paraissent s'ériger et se remplir de liquide : si on comprime ces villosités, il en sort du chyle. On a examiné ces petits monticules au moyen du microscope, et l'on y a déconvert les ramifications extrêmement nombreuses de divers vaisseaux; on a a cru voir en outre, à leur surface, de très-petits pores, comme qui dirait des piqûres d'aiguilles, et l'on a dû penser que ce pouvait être là l'origine de ces vaisseaux blancs, dits lactés, ou chylifères, dans l'intérieur desquels on trouve incontestablement du chyle, là où on les voit serpenter dans l'épaisseur du mésentère: Ajoutons cependant que Spallanzani a observé des pores analogues dans l'intérieur de l'estomac de l'aigle, et qu'il n'a vu dans ces étroits pertuis que l'issue probable des sucs gastriques. Mais que ces orifices qu'on a cru voir à la surface de l'intestin soient réellement l'ouvertụre absorbante des vaisseaux du chyle, ou qu'il en soit autrement, toujours est-il raisonnable d'admettre qu'il doit exister quelque chose d'analogue, et que c'est par de petites bouches de cette nature que le chyle se trouve pompé ou absorbé à la surface de l'intestin. Quelques personnes n'ont vu qu'un pur effet d'imbibition toute physique et toute inerte dans ce phénomène, el elles 
I.IV. IV. DE LA NUTHITION.

ont appuyé leur opinion sur ce que l'absorption du chyle persévère quelques instans encore après la mort.

Quel que soit le mode selon lequel se fait l'absorption du chyle, il est sû̀r qu'on voit ce liquide dans les petits vaisseaux blancs qui parcourent le mésentère, entre les deux feuillets du péritoine dont ce repli membraneux est formé; il est sûr que ces vaisseaux traversent les corps glanduleux qui chez les animaux mammifères sont fort multipliés dans le mésentère, que de plus ils communiquent tous avec le canal thoracique, simple ou double, lequel paraît être leur tronc commun et leur réservoir général. Ce conduit thoracique a lui-même sa terminaison dans la veine sous-clavière gauche, et son embouchure dans ce vaisseau sanguin est garnie d'une valvule membraneuse qui permet au chyle de se mêler au sang, mais qui s'oppose à ce que le sang de la veine s'introduise dans le canal du chyle.

Ainsi le chyle séparé des alimens dans l'intestin, déposé et accumulé dans les sinus des valvules conniventes de la membrane intestinale, pompé on ne sait comment ni par quelle puissance, mais pénétrant incontestablement dans les vaisseaux lymphatiques de l'intestin, traverse les glandes mésentériques, est porté par ses propres vaisseaux dans le conduit thoracique, et c'est par ce canal qu'il est définitivement versé dans le sang. Ce cours du chyle n'est pas seulement une supposition vraisemblable; on s'est assuré de sa réalité par des expériences. Il suffit d'ouvrir le conduit thoracique pour s'assurer que le chyle y circule de bas en haut, ou plutôt de l'intestin vers 
cilap. VIII. Progrìs et SUITE de la digestion. 559 la veine sous-clavière. Il est certain que les muscles abdominaux et tous les organes des efforts ont la plus grande influence sur la rapidité de son cours : on voit le jet de ce liquide augmenter en volume et devenir plus rapide, lorsque l'animal sur qui l'on fait l'expérience crie ou tente quelque efforl à glotle fermée ou rétrécie. La pression mutuelle des organes du ventre les uns sur les autres, influe aussi beaucoup sur le cours du chyle; ce cours est sensiblement ralenti par l'ouverture de l'abdomen. Les mouvemens respiratoires et les pressions causées par le diąphragme ne sont pas non plus choses indifférentes à la rapidité du chyle dans ses. vaisseaux. L'incision du canal thoracique près du lieu où il se termine dans la veine sous-clavière, a laissé couler chez un chien une demi-once de chyle dans l'espace de cinq minutes; ce qui ferait six onces par heure. Au reste, on conçoit que la quantité de ce liquide est subordonnée à la quantité des alimens, à leur nature, et aussi beaucou à leur digestion plus ou moins parfaite (1).

LE CANAL THORACIQUE EST-IL LA SEULE VOIE DU CIIYLE? On voit bien à la vérité tous les vaisseaux chylifères aboutir dans le conduit thoracique; on voit le chyle couler avec une certaine rapidité dans sa caviéé, et il est sûr qu'il aboutit finalement dans la veine sousclavière. Mais tout le chyle suit-il cette voie unique pour s'aller mêler au sang? et n'y a-t-il que les vais-

(1) Voyez Pecquet, Rudbeck, Hewson, Monro, J. Hunter, Mascagni, Duverney, Cruiskshanck, Flandrin, Meckel l'ancien', Dupuy, Dupuytren, Magendie, Fodérà, Leuret et Lassaigne, Fohmann et Gmelin, Tiedemanu, Ségalas, Lauth, Lippi, Rossi de Parme, Аیtommarchi, etc. 
seaux hlancs dits chylifères qui absorbent le chyle?

Le canal thoracique est si élroit, les fluides dont il est rempli ont un cours si lent, que quelques personnes ont pensé que, non seulement la lymphe, non seulement la sérosité et les différens liquides absorbés avaient une voie différente, un autre trajet et d'autres moyens absorbans; mais que même le chyle ne passait peut-être pas tout par les vaisseaux chylifères et leur réservoir commun. D'abord Duverney ne pouvant rencontrer dans les Oiseaux ni vaisseaux chylifères, ni glandes mésentériques, cela lui fit conjecturer que la nourriture dans cette classe d'êtres avait peutêtre d'autres vaisseaux que les lymphaliques pour parvenir au sang: il en vint ensuite jusqu'à douter de l'usage qu'on assigne exclusivement an canal thoracique, même quantaux mammifères. Dans le but done de s'éclairer à ce sujet, Duverney lia sur un Chien les veines sous-clavière et jugulaire gauches, un peu audessous de l'insertion terminale du canal thoracique; et ce qui fortifia ses doutes, c'est que re chien vécut quinze jours après cette opération, laquelle aurait dù le tuer en peu de temps, si le chyle n'avait eu que ce moyen de communication; cependant cet animal n'avait qu'un seul conduit thoracique, ainsi qu'on put s'en assurer par la dissection.

Mêmes expériences ont été répétées depuis Duverney. Quelques personnes ont assuré que la mort arrivait toujours cing à six jours après l'opération précédente chez les Che vaux et Chiens dont les vaisseaux chylifères ne conservaient de communication avec le sang qu'au moyen du canal thoracique lié; tandis que, selon elies, les movens de communication 
CHAP. Vilt. SUite ET PROgRès de la digestion. 561 étaient multiples en ceux qui avaient survécu à la nềme expérience. M. Dupuytren, qui s'est longtemps et très-particulièrement occupé de cet objet, affirme qu'il s’est assuré de la réalité de ce qui précède par l'injection des vaisseaux, et par la dissection attentive qu'il en a faite. Cependant deux habiles expérimentateurs de l'École d'Alfort ont tout récemmentinfirméces résultats: plusieurs fois illeurest arrivé delier le canal thoracique sur des Chiens ou des Chevaux. Ce conduit était unique, l'injection prouvait que les vaisseaux chylifères n'avaient plus de communication avec la veine sous-clavière, et cependant.plusieurs de ces animaux ont survécu des mois entiers à l'opération. Un Chien, entr'autres, a prolongé son existence jusqu'à cinquante-huit jours après l'expérience, et cependant le conduit thoracique de cet animal n'offrit aucune anastomose, aucune bifurcation ni division allant aux vaisseaux sanguins. Les auteurs dont nous parlons ont conclu de leurs expériences, que les veines aussi absorbent le chyle, et ils assurent qu'après avoir lié la veine porte, ils ont distinctement reconnu le eaillot du chyle mêlé au sang de cette veine.

Il faut convenir qu'il est rare qu'un gros animal ne succombe pas tôt après la ligature du canal thoracique, lorsque ce canal est simple tet sans vaisseaux de dérivation. Si done quelques animaux résistent plus long-temps aux graves résultats d'une telle općralion, voici quelles en sont les causes. D'abord il existe quelquefois des vaisseaux de communication et des anastomoses que les injections ne sauraient démontrer, encore que ces canaux accessoires fussent aisé- 
ment perméables aux fluides vivans : car nul analomiste n'a sans doute la prétention d'égaler l'art des injections au cours naturel des fluides pendant la vie. Ensuite beaucoup d'animaux ont la faculté de vivre long-temps sans manger; on cite pour notre espèce et pour beaucoup d'autres, des exemples étonnans d'abstinence. Les Animaux dormeurs, par cxemple, restent des mois entiers sans prendre aucune nourriture, et ils vivent alors de leur propre súbstance. Pourquoi n'en serait -il pas ainsi des animaux qu'on dit avoir survécu à la ligature du conduit thoracique? I. chose nous paraît d'autant plus naturelle, qu'une semblable opération trouble les fonctions, produit la fièvre; et l'on sait que la fièvre ôte tout appétit comme tout moyen de digérer. Mais on ajoute que plusieurs de ces animaux conservaient leur embonpoint et la santé. A cela nous répondons que sans aucun doute le chyle est ordinairement absorbé par les vaisseaux dits chylifères; mais quand ces vaisseaux sont obstrués, est-il défendu de croire que les veines les remplacent? Nous avons cité une expérience à l'appui de cette prévention si naturelle : et d'ailleurs ne sait-on pas en combien d'autres circonstances nombreuses les veines absorbent? ce sont elles, en effet, qui absorbent les liquides simples, les substances odorantes et colorées, les médicamens, les poisons : c'est par leur moyen que ces différentes substances manifestent leur présence dans les urines et le sang, et leur action sur différens organes, avant que le chyle n'en puisse offrir aucune trace. C'est de même par les veines que disparaissent si rapidement de l'intestin et de l'esto- 
CHAP. YIII. SLITE LT PROGRES DE IA DIGESTION. 565 mac des quantités énormes de différens liquides; pourquoi donc leur refuserait-on absolument.la faculté d'absorber le chyle?

Mais un autre fait bicn important, qui finit d'expliquer et de rendre viaisemblables toutes les expériences contradictoires que nous avons citées, c'est qu'il paraît démontré que les vaisseaux blancs communiquent de tous côtés avec les différentes veines : toutefois, commc ces communications ne sont pas égales, ne sont pas constantes chez tous les êtres de la même espèce, là même est l'origine de ces apparentes contradictions qui embarrassaient l'esprit.

Ce que Devient le chyle: QUille EST SA DESTINATION; QUELS EN SONT LES USAGEs. Nous venons de suivre le chyle depuis la cavilé intestinale, où des vaisseaux l'absorbent, jusque dans la veine sous-clavière gauche où il se mêle et se confond avec lc sang. Circulant ensuite avec ce liquide, traversant les organes respiratoires, mis en contact avec l'air, mu par le cœur et réparti dans les vaisseaux artériels qui naissent de l'aorte, que devient-il dans ce long trajet, et quel parti en tirent les divers organes du corps? voilà ce qu'il serait important de savoir. Comme le sang éprouve sans cesse des déperditions pour la formation des humeurs et la nutrition des organes, il faut bien qu'il répare les pertes qu'il fait; or le chyle, à cela près de la couleur, a tant d'analogie avec le sang, et par sa séparation spontanée en plusieurs parties, et par la fibrine qu'il contient, et aussi par l'oxygène qui le colore en rouge, qu'il est naturel de croire que ce fluide provenant des alimens digérés, se change en véritable sang lors de son passage à travers les organes de la res- 
piration, et qu’a partir de ces organes il a perdu tous les caractères qui le distinguaient du sang préexistant. Mais revenons à la nutrition.

\section{CHAPITRE IX.}

Conditions principales de la Nutrition des Animaux. - Choses qui la modifient et la diversifient, elle et la Digestion.

Nous ne pourrons aborder l'obscur mécanisme de la nutrition, et plusieurs grandes questions et conjectures qui s'y rattachent, qu'après avoir envisagé les eonditions favorables ou défavorables à celte fonction importante : c'est le seul moyen d'arriver à quelques résultats certains. Nous allons donc faire une revue rapide de choses qui ont manifestement le plus d'influence sur la nutrition : le malheur est que nous citerons parfois des faits particuliers à une espèce d'animal, et le plus souvent à notre propre espèce.

Borssons'. Au temps où les expériences du médecin Dodart faisaient le plus de bruit (1), un autre membre de l'ancienne Académie des Sciences résolut de les poursuivre en les variant : il les répéta dans le but surtout d'apprécier l'influence des boissons sur la nutrition des organes et l'embonpoint du corps. A cet effet, Marcorelle passa deux mois entiers sans boire ni eau, ni vin, et il perdit pendant cela cinq livres et demie de son poids total (il pesait cent vingt livres). Après quoi s'étant remis à son régime habiluel, mangeant

(1) Voyez nolre Physiologic médicale. 
CHAl. IX. CHOSES QQE LA MODHFIENT.

toujours des mêmes choses, mais reprenant l'usage du vin pur et étendu d'eau, ce lui fut assez de six jours de ce nouveau régime pour récupérer six livres de substance, c'est-à-dire un onzième en sus de cè qu'il avait perdu. I observa en outre qu'aucun aliment autant que les végétaux ne donne le désir et Je besoin de boire. Voilà ce qui prouve l'influence des boissons chez l'homme; mais s'ensuit-il que de boire beaucoup soit chose favorable à l'émbonpoint? Non, assurément; les faits chaque jour observés 'prouvent le contraire. Trop de boissons fatiguent lestomac et nuisent à la digestion des alimens. Le thé, les boissons chaudes, hâtent la digestion, mais c'est en l'entravant: après de pareilles boissons, les alimens traversent le pylore avant d'avoir été suffisamment chymifiés. A l'égard des alcoholiques et de tous les liquides excitans, épicés, salés ou acides; ces fluides favorisent la formation du chyle, en ce sens, qu'ils déterminent un flux abondant des sncs intestinaux, gastriques, pancréatiques et biliaires; mais les boissons alcoholiques nuisent ensuite à la nutrition par l'excitation qu'elles cousent à tous les organes, en activant outre mesure les mouvemens du cour; elles nuisent par le sommeil, qu'elles rendent court ou qu'elles agitent.

Ajoutons encore, au sujet des animaux, qu'il en est qui ne boivent jamais, et ce sont presque lous des Carnivores. Le Chameau aussi peut rester plusieurs jours sans boire, et cette abstinence de liquides ne paraît pas le faire souffrir : il est vrai qu'on trouve dans l'estomac de cet animal des espèces de poches dónt la destination paraît être de retenir des liquides en réserve, en s'en remplissant et s'en imprégnant à la 
manière des éponges. Au reste, la plupart des animaux paraissent engraisser d'autant plus vite qu'ils prennent moins de liquides. Les Chevaux et l'Ane, au rapport d'Aristote, font exception à celte règle, à raison peut-être de l'énorme quantité d'herbes grossières et souvent sèches dont ces animaux se remplissent sans relâche. On a coutume de supprimer peuà-peu les boissons aux Porcs et à plusieurs autres animaux, lorsqu'on veut les engraisser.

Alinuns solines. Il n'est pas besoin de dire que les longs jeûnes et l'abstinence absolụe amaigrissent: mais il faut rappeler que la privation d'alimens n'est pas également ressentie par tous les animaux, ni toujours de la même manière par les animaux d'une même espèce, non plus que par le même animal placé dans des circonstances diverses. La jeunesse, les excès, la fatigue, les veilles excessives, les passions (alors que les paroxysmes en ont cessé), la convalescence des maladies longues, les choses excitantes (après qu'elles ont produit leurs rapides effets), l'air sec et froid, et les climats et saisons où l'on en ressent l'influence, ce sont là autant de causes qui rendent plus grand et plus vivement ressenti le besoin d'alimens solides; et au contraire, la vieillesse, le sommeil prolongé, l'hivernation, le repos parfait, les bains chauds, diminuent ce besoin : la faim abandonne l'oisive opulence pour tourmenter la paurreté.

En général, les animaux carnivores supportent beaucoup mieux l'abstinence que les herbivores. Le Lion, les oiseaux de proie, l'Aigle en particulier, les Serpens, les Araignćes, tous ces animaux restent quekquefois des temps très - longs privés d'alimens, sans. 
CHAP. Ix. CHOSES QUi bA MODHWENT.

paraitre beaucoup en souffrir : ils sont seulement à cause de cela, d'ordinaire, plus maigres que les animaux se nourrissant d'herbes ou de fruits. Dans l'espèce humaine, on a vu des vieillards, surtout des femmes, rester des mois entiers sans prendre d'alimens. On cile un insensé mystique qui; s’imaginant follement être le Christ en personne, resta les quarante jours du carême sans user d'aucun aliment quelconque; il se bornait, sans jamais rien avaler, à promener des liquides dans sa bouche. L'humidité et l'obscurité, unies au repos, affaiblissent les effets de l'abstinence : un Chier qui était dans les circonstances que nous venons de dire, resta près de cinquante jours vivant sans rien prendre. Les hommes à imagination vive, et principalement les fous furieux, ont une faim dévorante, une digestion extrêmement énergique, et ils consomment des quantités énormes d'alimens : il en est de même des idiots. Outre que le bon sens et la sagesse enseignent la tempérance, rien: ne distrait de la faim, après le sommeil qui l'abolit, autant que l'excrcice assidu de la pensée.

Si chaque animal ne prenait d'alimens que tout juste ce dont il a besoin pour exister, la masse des destructions dans les deux règnes serait prodigieusement moins grande, et cela même prolongerait la vie de toute manière. Cornaro, dont on citait l'intempérance durant sa jeunesse, s'assujettit à ne plus prendre chaque jour, à l'âge de quarante ans, que treize: onces de liquides et douze d'alimens solides, aussi simples que ceux d'Iccus; et cette diète sévère et constante lui permit de vivre par-dẹlà cent ans. 11 est à remarquer que les excès de tous les genres fati- 
guent beaucoup plus, causent des maladies et abrègent l'existence, bien plus que les privations. Il est plus aisé, en effet, je parle de notre espèce, de satisfaire aux simples besoins de la vie que de se défendre de les outrepasser : il sto si fréquent de confondre avec l'aiguillon de la faim les perfides saillies de la sensualité ! Disons cependant qu'il faut à chaque animal plus d'alimens que n'en exigent les pertes à réparer et les dépenses journalières de la nutrition; il faut, de plus que cela, un surcroît d'excitans pour stimuler les organes, et ce superflu de nourriture est lui-même nécessaire à l'énergie du corps, à la plénitude de l'existence.

Il est beaucoup d'autres considérationsi importantes au sujet des alimens de l'homme et des maux qui résultent d'un régime mal ordonné; mais ce n'est point ici le lieu de nous arrêter sur de tels sujets, et nous devons dire que c'est dans notre Physiologie médicale qu'il faut chercher des détails sur tout ce qui intéresse la conservation de la santé de l'homme et la prolongation de la vie.

Trmpérature; Saison; Cumat. Il y a discordance quant à l'influence de la chaleur sur la nutrition des. divers animaux. Je veux dire que cette chaleur est utile aux animaux inférieurs: et aux derniers des vertébrés, ceux qu'on désigne sous le nom générique d'animaux à sang froid; mais elle est nuisible à la nutrition comme à la digestion du plus grand nombre đes vertébrés du premier ordre, des oiseaux et des. mammières. Je dis du plus grand nombre, parce qu'il y a quelques différences quant aux Oiseaux qui émigrent et aux Mammifèrčs qui dorment des mois 
GIIAP. IX. CIIOSES QUI LA MODIFIVNT.

entiers. Nous traiterons aillcurs de ces derniers êtres et des particularités qui résultent, pour tous les phénomènes de leur existence, des caractìres dont nous parlons.

Toujours est-il que les animaux de bas étage, depuis les Polypes jusqu'aux Serpens, et à d'antres reptiles qu'il ne faut pas exempter de la règle, digèrent mieux et plus rapidement, prennent plus de nourriture et d'embonpoint, dans les climats, dans les saisons chaudes, que sous des influences contraires. On peut même remarquer que ces animaux sont plus développés et plus multipliés dans les pays chauds qu'ailleurs. Les Couleuvres, entr'autres, digèrent mal au printemps, par la raison qu'alors elles relèvent à peine de l'engourdissement où les a jetées le froid rigoureux de l'hiver. Remarque analogue à l'égard des poịssons.

Mais la chaleur vive est nuisible à la nutrition des vertébrés supérieurs, et par l'amour qu'elle réveille en eux et les excès où elle les conduit, et par les transpirations de la peau qu'ellé rend excessives, et par la faim qu'elle affaiblit précisément alors où le besoin d'alimens est le plus réel pour les organes: nuisible enfin pour la digestion, toujours très-lente et très-difficile en ces animaux dans une température trop chaude. Trop de chaleur, en effet, affaiblit les forces digestives, à raison des sucs gastriques alors moins abondans, et parce qu'en ostre les contractions de l'estomac et des intestins sont beaucoup plus faibles. Aussi, voit-on la plupart des oiseaux et des mammifères maigrir durant les saisons chaudes ct récupórer des chairs et de la graisse dans l'hiver. Quelque- 
fois même on remarque arec étonnement l'excessif embonpoint que prennent tout-à-coup certains oiseaux au milieu de la saison la plus rigoureuse, et alors que la terre est couverte de neige et de frimas. Mais cela provient des causes que nous avons indiquées : de l'énergie accrue de l'estomac, de l'abondance des sucs digestifs, de la transpiration de la peau alors presque nulle, et surtout de ce que la Providence a veillé à ce que l'époque des plus grands frolds fût précisément le temps de la parfaite maturité de quelques fruits d'arbres verts ou autres, dont ces oiseaux se nourrissent. On peut vérifier ce que nous. disons ici à l'égard des Merles de notre pays, se nourrissant, au milieu des neiges, des fruits mûrs et devenus succulẹns du houx et de l'aubépine. Les Ortolans aussi offrent le curieux phénomène d'un embonpoint extrême acquis en quelques heures; mais cela dépend d'autres causes.

Pratiques t́prouvées Quant a la produgtion de L'mabonpoint; mutication, zitc. Outre les circonstances favorables à l'embonpoint, desquelles, nous avons déjád et suffisamment parlé, outre le repos, la tranquillité, le sommeil, une abondante et convenable nourriture, obtenue régulièrement, sans longues recherches et sans efforts, et une dose plutôt petite que grande de boissons; outre l'influence incontestée de l'àge mitoyen et du sexe femelle, on a observé les. bons effets de certaines circonstances et de quelques procédés, el l'on a fait un précepte d'en régulariser l'usage. C'est ainsi qu'après avoir remarqué que les cxcès des sexes amaigrissent beaucoup les mâles à l'époque du rut ou des amours, et s'être assuré que les. 
CII A. IX, CIOSIS QUI LA MODIFIENT.

femelles, comme moins emportćes et moins lascives, éprouvent à un moindre degré l'amaigrissement produit par l'effervescence génitale, on s'est imaginé de pratiquer la castration des animaux mâles, non pas seulement (chez quelques-uns) pour les rendre plus doux, plus susceptibles d'être apprivoisés, plus attentifs à la voix de l'homme et plus dociles à sa volonté; mais dans le but principal de donner plus de volume et d'ampleur à leurs organes, en un mot plus d'énergie et plus de régularité à leur nutrition. Nous voyons chaque jour pratiquer de semblables opérations chez lés animaux destinés à nos festins, et même chez les poissons conservés dans les viviers. Il est sûr que ceux des animaux que l'on a ainsi privés des organes prolifiques, prennent plus de volume et plus d'embonpoint à proportion des désirs et des déperditions souvent excessives dont on les préserve, et de l'énergie vitale qu'on leur ôte. Encore que le besoin des sexes ait moins d'effets chez les femelles que chez les mâles, cependant, comıne la gestation et l'allaitement chez les uns, la ponte et l'incubation chez les autres, ne laissent pas que de les amaigrir quelquefois excessivement, on en est venu à pratiquer la castration chez les deux sexes en certains animaux destinés à flatter la sensualité des riches délicats. Pav exemple, ce procédé est mis en usage pour des Poissons, pour quelques Oiseaux domestiques, et les Truies qui viennent de naître.

A ce sujet faisons une remarque. Nous venons de voir la castration utilisée pour favoriser la nutrition et produire l'embonpoint; ailleurs nous verrons préconiser le même moyen pour apprivoisen cerm 
tains animaux ou sauvages ou trop ardens, pour réprimer les fougueuses saillies d'un caractère autrement indomptable; ailleurs encore, et dans notre propre espèce, nous verrons la castration venir aur secours de la défiance et du despotisme chez les peuples tyrans et tyrannisés de l'Orient; et, plus près de nous, chez un peuple ami qui nous ressemble sans nous imiter, que nous estimons sans l'envier, nous verrons le cruel euneuchisme tourné en habitude, afin de charmer, par des sons plus suaves et plus mélodieux, les ennuis de l'opulence fatiguée de plaisirs. Ainsi; la castration sert tour-à-tour, ou les besoins: de la sensualité et de la gourmandise, ou l'amour du commandement, ou les justes craintes d'une jalousie effrénée touchant des infidélités toutefois pardonnables; elle est tantôt un instrument d'oppression, de polygamie ou d'esclavage, tantôt une sauve-garde contre la coquetterie et linconstance des femmes rendues captives pour la plus grande volupté d'un seul, et tantôt un raffinement du luxe, un criminel caprice de mélomanie, ou un infâme remède contre la satiété la plus déplorable.

Au rang des pratiques favorisant l'embonpoint; Aristote place l'insuffation; il prétend qu'en son pays et de son temps on introduisait avec force de l'air sous la peau des Bœufs afin de les engraisser mieux et plus vite. Mais rien n'agit sur le bon état de la nutrition autant que le brusque passage d'une grande fatigue au repos parfait, de l'agitation à l'indolence, de l'inquiétude à la sécurité, et du jeûne à l'intempérance. Les bestiaux maigres qu'on mène au loin dans de gras pâturages, prennent un embonpoint plus 
CHAP. X. QUESTIONS IT GONJECTURE.

rapide que ceux qui n'ont point bougé de ces lieux faverables : l'on voit ici la double influence et du repos succédant à la fatigue, et de la profusion d'alimens venant après l'abstinence. Il est beaucoup d'animaux que l'on fail ainsi préalablement jeûner plusieurs jours dans le but de les mettre plus vite en chair. L'obscurité aussi, et l'esclavage, sont favorables aux mêmes vues, et ce sont des moyens dont on use habituellement dans nos métairies, pour surcharger d'eubonpoint des oiseaux et quelques quadrupèdes. Afin de rendre pour eux l'obscurité plus profonde, on va quelquefois jusqu'à aveugler les animaux qu'on veut engraisser jusqu'à l'excès : on recourt souvent à de semblables pratiques pour certains oiseaux de basse-cour; et l'on peut observer qu'alors le foie de ces animaux est graisseux. Est-il quelque cruauté que la gourmandise ne fasse commellre!

\section{CHAPITRE $\mathrm{X}$.}

Questions et Doutes sur la Nutrition des Animaux.

On a contume d'énoncer au sujet de la nutrition beaucoup plus de lieux communs que de vrais principes. On dit, par exemple, que les animaux se décomposent et se recomposent sans cesse; que leurs organes puisent dans le sang, pour se les assimiler, les principes réparateurs dont ils ont besoin pour leur nutrition; que les végétaux et les animaux font incessamment entr'cux des échanges mutuels et d'ordinaire assez parfaitement compensís; quil n'y a pas deux 
sortes de matière, l'une morte, l'autre vivante, mais que la même matière, subissant des transformations perpétuelles, est tantôt vivante et tantôt inerte, lour-à-tour animale, végétale, ou inorganique; on ajoute que tout, dans l'animal, provient des alimens dont il se nourrit, puisque les organes puisent dans le sang les élémens servant à les former et à les entretenir, et que le sang se répare avec le chyle, lequel provient lui-même des alimens : on va jusqu’à assigner un terme précis à la rénovation entière des organes. Nous allons examiner successivement ces différentes questions, et p!usieurs autres qui s'y trouvent liées plus ou moins intimement.

LES ORGANES SE RENOUvELLENT-ILs? Un chirurgien de Londres, nommé Belchier, observa le premier que les os d'un Cochon, qui s'était nourri de garance, étaient ronges. Ce fait attira l'attention des physiologistes anglais, qui le firent promptement connaître à toute l'Europe. On refit l'expérience, Duhamel surtout s'altacha à la varier; et comme on obtint constamment le même résultat, on ne craignit pas de conclure que le fait était général : de ce que la garance rougissait les os, de ce qu'ensuite cette coloration disparaissait, on en tira la conséquence qu'apparemment les os se renouvellent. Si les os se renouvellent, les autres organes aussi doivent se recomposer : on se laissa séduire par l'analogie, et l'on admit ce principe comme s'il cût été fondè sur des faits suffisans. Cependant le fait allégué ne me semble pas renfermer la preuve convaincante qu'on a cru y voir; et je trouve les raisons suivantes pour lui refuser l'importance qu'on s'est plu à lui prêter : $1^{\circ}$. Il est prouvé que la garance ne colore d'une manière sensible que 
CIAT. $x$. QLESTIONS ET CONJEC'TURE.

lesos, et non les autres oiganes; et nous trouvons dans les premiers un arrangement tout particulier d'oì peut. provenir la différence des choses observées. $2^{\circ}$. La garance ne rougit pas toute l'étendue, toute l'épaisseur d'un os, elle n'en rougit que la surface : or, comme les os continuent de crôitre en épaisseur, il se peut que la garance ait une telle affinité avec les sels calcaires dont se forme la nouvelle porlion de l'organe, qu'elle y reste attnchée et comme combinée, et qu'ensuite le mouvement de la vie l'en sépare; ne sait-on pas qu'il s'opère constamment, au sein de tous les organes, une absorption, une élimination de toute substance non participante à la vie? 11 en est des effets de la garance comme de toute coloration maladive ou accidentelle des organes; l'absorption enlève aux tissus vivans tout ce qui leur est étranger : mais gardons-nous d'en tirer la conséquence que ces tissus formant trame vivante, éprouvent cux-mêmes une rénovation! $3^{\circ}$. De ce qu'une couleur appliquée à la peau, ou à tout autre tissu, disparaîtra au bout d'un cerlain laps de temps, je me garderai d'en conclure que l'organe ainsi coloré s'est lui-même renouvelé durant le temps quil a mis à se décolorer; il est aisé de voir qu'un tel raisonnement serait forcé. Mais, ce qui est beaucoup plus opposé à la théorie que nous combattons comme fausse et improbable, c'est qu'il est des tachées, des empreintes, des colorations d'organes, qui persistent toute la vie sans jamais disparaître: la teinte nuire produite par la pierre infernale, les figures tracées capricieusement sur la peau de nos soldats, cette sorte de tatouage est indélébile. fo. Les cicatrices non plus ne disparaissent jamais; et 
comment ce fiait, si universellement connu, pourrail-il se concilier avec la rénovation des tissus? 5०. Il est également démontré qu'aucuise partie des organes ne se reproduit; el cependant si un organe pouvait se renouvcler tolalement, comment, par la même raisun, pourrait-il ne pas se reproduire quand il est ou détruit ou mutilé ? Concluons donc que la proposition par laquelle on énonce que les organes se renouvellent est au moins hasardée et ne repose que sur des faits mal interprétés. Alors même qu'il serait prouvé que les os éprouvent une sorte de rénovation, il n'en faudrait rien conclure pour la masse des organes : les os, en effet, ne sont qu'à moitié vivans et organiques; des sels abondans remplissent les mailles de leur tissu, et l'on conçoit que ces sels se renouvellent sans que les tissus eux-mêmes éprou $\rightarrow$ vent cie pareils changemens.

LA RÉvolution NUTRITIVE A - T - ELLE LIEU TOUS LES SEPT ANs? La question de rénovation totale des organes en trois ans, selon les uns, el en sept années, selon les autres, est plus d'à moitié résolue par ce qui précède. Nous avons vu, en effet, que l'on a pris pour des renouvellemens de tissus une simple élimination de molécules étrangères au corps vivant, de molécules ne pouvant prendre part à la vie. Or, cetle Cimination, comme celle de la garance, dont les os sont rougis, ou comme celle du nitrate d'argent, par qui la peau est colorée en noir, ne s'effectue pas dans le même laps de temps pour les différens organes et pour les substances de toute nature; cela dépend de l'âge des aninıaux, du genre du tissu imprégné, et de la maliere imprégnante. Mais il faut oublier pour 
CHAP. X. QUESTIONS ET CONJECTULES.

toujours ce conte tout fabuleux de la rénovation septennale des corps vivans.

Comment LES ORganes 'S'EMPARENT-ILS DE LA NOURRITURe, ET QUE DEVIENT-ELLE? Nous avons suivi le chyle depuis l'intestin où en est la source, jusque dans les vaisseaux sanguins, partout ramifiés, qui le distribuent entre les différens organes, chacun desquels -en reçoit une quantité relative à son volume. Quant à ce que devient cette nourriture ou ce chyle mêlé au sang et devenu sang lui-même; on ne saurait qu'énoncer des conjectures à ce sujet. Il est, au reste, trois différentes manières d'envisager la question; ou plutôt, l'aliment renfermé dans le sang a trois destinations réelles ou probables. Premièrement, ceux qui admettent que même la trame des organes est sans cesse renouvelée, supposent que chacune des parties vivantes extrait du sang, par une sorte de choix ou d'affinité élective, ce qu'il faut à son renouvellement, à sa recomposition. Mais nous avons montré combien de raisons rendent improbable cette rénovation des organes, et cette élection d'élémens propres à les recomposer. Celte première destination des alimens n'est vraie qu'en des corps non encore accrus, qu'en des organes inachevés ; car, une fois accomplis, la trame en reste assurément toujours la même, ainsi que le prouvent les faits que nous avons cités. Secondement, le véritable usage que les organes font de la nourriture est relatif à la formation des humeurs et des fluides divers des corps vivans, et au continuel développement de la chaleur. C'est principalement sous le rapport des humeurs qu'ils produisent, que ces organes exercent sur les principes 
du sang et sur les élémens alimentaires qui s'y trouvent confondus, cette sorte d'affinité élective, cette préférence dont nous parlions à l'instant; c'est par cette action, et dans ce but seulement, que ces organes épuisent peu-à-peu tout ce que le sang contient de principes nutritifs. En troisième lieu, enfin, les organes ont besoin d'un sang nouveau, d'un sang chargé de principes alimentaires, et richement respiré, pour l'entretien de leurs propriétés, pour le jeu de leurs fonctions. C'est un dernier et incontestable usage des principes nutritifs, répandus dans le sang, d'entretenir ainsi une excitation perpétuelle dans toutes nos parties. Il est certain que même les organes dont ne provient aucune humeur appréciable, éprouvent autant que tous les autres le besoin du contact répété, du cours rapide et continuel d'un sang nouveau, d'un sang chargé d'air vital et de chyle, c'està-dire d'un sang constamment renouvelé par la digestion d'alimens convenables, et par la respiration d'un air chargé d'oxigène. 'Tout organe dont l'artère est rétrécie s'amaigrit; il s'atrophie et n'a plus de fonctions, si son artère est totalement supprimée. Peut-être pourrait-on arguer de cette diminution des organes qu'on a privés de vaisseaux accessibles au sang artériel, qu'il est donc vrai qu'ils se décomposent sans cesse, et qu'ils ne se renouvellent qu'au moyen du sang qui les pénètre; mais je réponds à cela, qu'un organe séparé de ses vaisseaux n'est plus dans l'état de vie et de résistance dans lequel le contact du sang a coutume de l'entretenir, et que d'ailleurs l'action absorbante qui s'exerce ordinairement sur ces fluides abreuvant les organes, se tourne, alors 
CHAP. X. QUESTIONS ET CONJEGTURES.

que le sang a cessé d'y pénétrer, sur le tissu même des parties vivantes; ou plutôt, et cette dernière considération est la plus importante, chaque organe, à l'exception des os et des cartilages, est composé presque entièrement de liquides dont la disparition persuade à tort que l'organe même, que sa propre trame solide, a perdu de son volume. Ainsi la nourriture a donc pour destination de maintenir dans les organes la température et l'excitation qui leur sont indispensables, et de fournir les élémens des humeurs qu'ils sécrètent. Les alimens ne servent à la composition de la trame même de nos parties, que dans le premier âge et jusqu'à la crue parfaite des animaux; et voilà pourquoi les jeunes animaux ressentent plus promptement et davantage le besoin de nourriture et les effets de l'abstinence.

Effets compliqués de L'abstinence. L'abstinence ou l'absence de nouveau chyle a pour premier effet de diminuer la masse du sang et les principes alimentaires qui s'y trouvent suspendus. Ensuite, la masse du sang étant diminuée et appauvrie, la température vitale baisse, la quantité des humeurs sécrétées est moindre et elles sont moins parfaites, l'excitation des organes est aussi affaiblie; et par toutes ces causes les fonctions de la vie ne se font plus comme en santé. Le coiar ne bat plus avec la même force, les organes respiratoires ne combinent plus autant d'air avec le sang qui les traverse, cette combinaison est moins parfaite; et cela même accroît encore les premiers efiets de trouble, d'irrégularité et de faiblesse pour le reste des organes et pour leurs fonclions. Si l'on vient à cesser l'abstinence, la nouvelte digestion est 
moins parfaite, et parce qu'il y a moins de sang et un sang d'un cours moins rapide, et moins de chaJeur; et parce qu'il y a moins de sucs salivaires et gastriques, moins de mucus, moins de bile, et que ces humeurs sont moins parfaites; et parce qu'aussi les fibres musculaires de l'estomac et des intestins ont moins d'énergie, etc., etc. La digestion étant plus lente, le chyle moins parfait, moins élaboré, moins abondant, respiré moins complètement, et réparti avec plus de mollesse et de lenteur dans des organes moins aptes à s'en emparer, de toutes ces causes résulte l'amaigrissement du corps, la faiblesse des muscles, l'inaptitude à l'action, un état de langueur, de souffrance, et de décrépitude anticipée.

Toutes les parties du corps éprouvent, chez tous les animaux, les effets d'une nutrition aussi imparfaite; les jeunes plus que les vieux; ceux qui dorment, moins que ceux qui veillent et agissent; ceux du nord plus que ceux du midi, les mâles plus que les femelles; ceux qui sont maigres moins que ceux qui ont de l'embonpoint, les carnivores moins que les herbivores; ceux dont le cœur a quatre cavités, plus que ceux en qui cet organe est moins complexe; les animaux à grande respiration aérienne plus que ceux dont la respiration est plus restreinte ou aquatique. Les cheveux, les poils, plumes ou écailles, sont les premières parties à montrer les effets d'une abstinence prolongée ou d'une mauvaise nourriture; les parties pileuses tombent, blanchissent ou se détériorent. La cornée oculaire aussi finit par se ternir, par s'enflammer, et parfois par s'ulcérer à son centre. Également, les dents perdent leur blancheur éclatante, 
CHAP. X. QUESTIONS ET CONJECTURES.

et souvent jusqu'au poli de leur surface; et ce sont autant d'effets qui persévèrent jusqu'à la fin de la vie.

Y A-T-IL DANS UN CORPS VIVANT QURLQUE PRINCIPE Étranger adX alimens dont il s'est nourri? On de: mande souvent siles animaux forment en eux-mêmes, par le seul pouvoir de la nutrition, des principes totalement étrangers à l'air qu'ils absorbent et aux alimens qu'ils digèrent. La réponse à celte question ne saurait être long-temps indécise. D'abord, à commencer par le sang, la chimie est inhabile à expliquer, et tout-à-fait incapable, par ses procédés ordinaires, d'imiter ce fluide vital cù tous les autres fluides ont leur source commune. En considérant même le sang comme un ensemble combiné pour les besoins de la vie, de tout ce qui provient, et de l'air respiré, et des alimens digérés, on est loin de trouver dans ce liquide les divers élémens dont se composent tous les organes, ou les élémens des humeurs que ces organes sécrètent. On ne trouve dans le sang, ni la gélatine des os toute formée, ni l'acide urique de l'urine tout préparé. Il est vrai que ces principes pourraient bien provenir des choses du dehors, et dissimuler leurs véritables qualités pour former le sang, et reprendre ensuite ces qualités primitives pour composer les organes non encore accrus. Mais toujours serait-il vrai de dire que la nutrition opère des combinaisons telles, dans nos organes et nos humeurs, que les lois de la chimie ne sauraient en rendre comple; en un mot, que le travail nutritif ne résulte point d'un simple dépôt des élémens puisés dans la nourriture. Ce sont les organes eux-mèmes qui assurément amalgament à leur manière et qui peut-être aussi 
modifient les substances dont ils se composent; mais toujours est-il probable que les premiers principes des organes et des humeurs sont contenus dans le sang et proviennent élémentairement des alimens ou de l'air; puisque les animaux carnivores qu'on a soumis à une longue privation de substances aninales ont ces humeurs autrement composées que ceux d'entr'eux qui ont continué de vivre selon leur instinct.

Les physiologistes, admettant presque tous que les organes du corps ne cessent de se décomposer et de se recomposer tant que dure la vie, ne pouvaient se rendre compte comment il se faisait que des animaux nourris long-temps d'alimens non azotés continuaient d'avoir des organes aussi imprégnés d'azote que d'autres animaux soumis à un régime constamment animal ; mais tout étonnement doit cesser à ce sujet, dès que l'on considère que la trame même des organes reste toujours la même.

EsT-IL VRAI QU'IL N'Y AIT QU'UN ALIMENT POUR LA Nutrition D'organes si Diversifićs ? Ceux qui ont dit " qu'il existe plusieurs alimens, mais que néanmoins il n'y a qu'un aliment ", ont cru proclamer là une chose profonde, Jorsqu'ils ne faisaient qu'exprimer prétentieusement une proposition obscure. Il est sûr, en effet, que ce prétendu principe a quelque chose de louche dans quelque sens qu'on l'envisage. Non seulement les alimens diffèrent infiniment entr'eux, mais le chyle qui provient de leur digestion diffère aussi beaucoup selon leur nature: le chyle qui résulte de la digestion de substances animales n'est pas semblable au chyle des végétaux, Les 
produits chimiques des matières nutritives sont de même très-différens : on s'est assuré qu'une. molécule de fibrine contient un tiers plus d'azote qu'une molécule d'albumine. Enfin, veut-on considérer les résultats définitifs de la digestion? Quoi de plus dissemblable qu'un carnivore et un herbivore!

Toutefois, il faut dire que, quel que soit le chyle, quelle que soit la nature des alimens qui l'ont produit, il a toujours pour même résultat de recomposer le sang, de développer de la chaleur, d'exciter les organes et de leur donner de l'énergie, de fournir à la composition des humeurs, et de former primitivement les organes des jeunes animaux. Il est permis de s'étonner qu'un liquide d'une apparence aussi simple que le chyle, puisse suffire seul à la fabrication de tant d'organes différens, de tant d'humeurs distinctes; et cela même qui cause notre surprise, fortifie la persuasion où nous sommes que chaque tissu, chaque organe exerce sur les principes du sang qui l'imprègne, une action, non seulement d'affinité et. d'élection, mais vraisemblablement aussi de combinaison et de transformation : chacune de nos parties est une sorte de laboratoire de chimie vivante, où se forment des produits que la chimie des hommes ne saurait imiler.

Échanges hutuels Des deux règnes. Les végétaux se nourrissent d'air et de liquides; le carbone surtout se fixe durablement dans leur tissu et le solidifie. Les animaux phytophages font leur nourriture de substances végétales, ek fournissent à leur tour des alimens aux animaux carnassiers. Voilà comme les substances alimentaires s'enchaînent et se graduent, depuis les 
fluides gazeux jusqu'aux córps organisés. Les débris des animaux servent ensuite à fomenter de nombreuses? productions végétales, et les végétaux alimentent immédiatement ou médiatement tous les animaux. Il y a des échanges continuels entre les corps organisés des deux règnes; les plantes ne peuvent pas plus se passer des animaux que ceux - ci ne peuvent se passer des autres : la disparition de l'un des deux règnés de corps organisés entraînerait inévitablement la destruction de l'autre règne. Nous reviendrons sur ce commerce nécessaire des animaux et des végétaux en parlant de leur Respiration.

Unité et transformations de la matière. Un végétal ou un animal, à sa première origine, ne doit à sa souche maternelle qu'un peu de fluide renfermé dans des membranes : après cela, ses accroissemens successifs proviennent entièrement, et de l'air qu'íl respire, ct des alimens qu'il absorbe ou qu'il digère. C'est donc la matière générale, répandue dans l'univers, la matière brute, modifiée par l'action vitale , qui compose uniquement la substance des corps organisés. Lorsqu'ensuite les corps vivans ont perdu l'existence et qu'ils se dissocient, les débris de leurs organes, réduits à leurs plus simples élémens, vọnt se confondre ou avec l'atmosphère ou avec le globè terrestre; en un mot, ils redeviennent matière brute. C'est donc toujours la même matière, ainsi que je le disais, qui passe tour-à-tour de l'état inerte à l'état de vie; et les transformations qu'elle subit de la sorte sont dues à cette force de nutrition dont nous venons d'étudier les instrumens et les actes compliqués. Qúant ạ ce principe insaisissable qui anime, qui re- 
CIIAP. X. QUESTIONS ET GONJEGTURES.

prend et quitte tour-à-tour et des millions de fois la même matière depuis le commencement de ces mondes dont nous admirons le merveilleux ensemble et le sublime enchainement, la nature ou l'essence nous en est totalement inconnue; l'origine même de la vie, qui remonte à l'acte mystérieux de la génération, ne saurait en être déterminée d'une manière précise ; et toutes les investigations des hommes pour découvrir le secret de sa reproduction ne saura jamais nous conduire qu'à l'areu d'une entière ignorance.

INFLUENCE DES NERFS SUR LA NUTRITION. II est incontestable que les nerfs sont nécessaires à la nutrition et à la parfaite conservation des organes : un organe dont les nerfs ont été coupés ou comprimés ne tarde pas à dépérir, à s'émacier; quelquefois même il s'effectue des ulcérations dans les parties dont les nerfs ont été détruits. Après avoir coupé sur un Chien le nerf de la cinquième paire, ou trijumeau, on vit la conjonctive s'enflammer, les humeurs de l'œil devenir troubles, la cornée se ternir, et finalement s'ulcérer et se détacher. C'est ainsi qu'on voit des organes s'atrophier par l'unique raison que les nerfs qu'ils reçoivent ont souffert : c'est par une cause semblable, à laquelle se joint aussi l'influence défavorable de l'inaction, que les membres paralysés dent nolablement de leur volume. 


\section{CHAPITRE XI.}

Quelques Remarques supplémentaires sur la Nutrition.

Influenee du sel mapin. Il est bien avéré que le sel de cuisine a d'utiles effets sur la digestion des alimens, qu'il l'accélère; et comme ce condiment n'est jamais employé dans nos mets qu'à doses assez faibles, on a tiré de là de singulières conséquences touchant le mode d'action dont quelques personnes pensaient que la digestion résultait. On a dit : le sel marin n'est anti-septique qu'à grandes doses; à doses plus faibles, loin de l'empêcher, il favorise la putréfaction et l'accélère. Par conséquent, a-t-on ajouté, le sel ne favorise la digestion qu'à raison de ce qu'il est employé à d'assez petites doses dans les alimens, pour en fomenter la putréfaction. Spallanzani n'a pas dédaigné de faire des expériences propres à éclairer cet objet : il a vu que le sel marin à petites doses, comme à doses plus fortes, aidait toujours la digestion, sans jamais déterminer de fermentation putride; et il s'est assuré que les propriétés digestives de ce sel sont dues à ce qu'il sollicite par son contact aveć l'estomac une sécrétion plus abondante de sucs gastriques.

Maladirs. On a souvent remarqué que la digestion languissait en des animaux soumis à divers essais, que quelquefois même il se manifestait chez eux un commencement de fermentation putride. Mais les 
êtres sur qui l'on a fait de pareilles remarques étaient ou très-vieux, ou malades. Spallanzani parle d'un vieux Duc-à-huppe qui offrait des phénomènes fort curieux de cette nature. Mais on conçoit qu'il serait peu convenable de tirer aucune conséquence générale de ces faits exceptionnels.

Rapport du volune des artères avec la nutrition DES ORGANES. On peut remarquer que les artères ont toujours un volume parfaitement concordant avec celui des organes; elles grossissent à proportion de leur développement. Mais il est difficile de dire où est le premier terme de cet accord : impossible de préciser si l'artère se dilate avant que l'organe ne grossisse, ou si le progrès commence par l'organe. C'est donc moins une influence que nous signalons, qu'une relation constante dont nous faisons la remarque.

Alimens trop uniformes sont nuisibles ( 1 . On avait óbservé dès il y a long-temps (malheureusement ces observations n'avaient rien de précis ), on admettait vaguement que la variélé. des alimens était nécessaire à l'entretien de la santé chez les animaux omnivores; qu'une nourriture par trop uniforme pouvait aller jusqu'à compronettre l'existence. On a fait lout récemment des expériences suivies à ce sujet, et l'on s'est assuré que le préjugé populaire était fondé sur des faits réels, et d'accord avec l'observation. Des Chiens que l'on nourrissait exclusivement d'œufs durs et de fromage, se sont peu-à-peu amaigris, ont perdu leurs poils et ont fini par succomber. Un

(1) Voyez les expériences de Dodart, de Marcorelle, de Spallanzaui, de Gosse, de Magendie, d'A. Cooper', elc. 
Ane à qui l'on ne donnait que du riz, tantôt sec, tantôt humide et cuit, n'a résisté que quinze jours à un pareil régime. Il est vrai qu'un Coq a supporté le même aliment toujours semblable, plusieurs mois sans dépérir; mais la règle générale n’en est pas moins rigoureusement exacte, appliquée à ceux des animaux pour qui il est naturel d'user d'alimens de plusieurs sortes. On s'est de plus assuré qu'après avoir été lentement affaiblis par un régime défavorable à raison de sa trop grande uniformité, c'était en vain qu'on redonnait à ces animaux une nourriture saine et variée, en vain qu'on les soutenait par toutes choses bonnes et salubres; ils n'en continuaient pas moins de s'acheminer vers un entier dépérissement. Ils meurent tout comme s'ils n'avaient pas changé d'alimens, et leur mort est aussi prompte. Parmi les observations curieuses qu'on a faites au même sujet, on doit noter la propriété qu'a le pain bis ou de munition de nourrir long-temps le Chien sans le faire dépérir, tandis que le pain blanc ne tarde pas à l'amaigrir. On a aussi remarqué que les Rongeurs vivent plus longtemps en mangeant exclusivement de la chair musculaire, qu'en usant de toute autre nourriture.

NÉCEssité DES ALIMENS AzOTÉS POUR QUELQUes ANImadx. Lorsqu'on nourrit un Chien avec du sucre seul, ou seulement avec de la gomme ou du beurre, substances non azotées, ces animaux ne tardent pas à s'amaigrir, à s'émacier, à dépérir visiblement : leurs poils tombent, leurs cornées souvent s'exulcèrent, et la mort vient bientôt terminer cette lente décomposition d'organes qui ont cessé d'être abreuvés d'alimens azotés. De plus, la bile et l'urine de ces animaux. 
CHAP. XI. REMARQUES SUR LA NUTRITION. 589 'ont les mêmes propriétés et composans qu'on leur trouve dans les vrais herbivores ou ruminans. Mais de ce que des animaux carnassiers comme le chien ont besoin 'd'une nourriture azotée, c'est-à-dire animale, il n'en faut pas conclure qu'il y ait même nécessité pour tous les animaux : l'expérience contredirait à chaque pas une pareille conclusion. Dire que les carnivores ont besoin d'alimens azotés, c'est répéter en d'autres mots ce qu'exprime leur titre distinctif de carnivores. Nous pensons donc qu'on a fait de ce principe des applications beaucoup trop larges et trop exclusives à ce qui regarde le régime de l'homme et ses infirmités. Il est d'ailleurs probable que les substances non azotées, données toujours semblables durant de longues semaines à des chiens, doivent beaucoup de leurs pernicieux effets à cette uniformité de nourriture qu'à l'instant même nous déclarions sì dangereuse.

FIN DU PREMIER VOLUAE. 



\title{
TAB̉E DES MATIÈRES
}

\author{
DU PREMIER VOLUME.
}

DÉDICAGE.

PRÉFACE.

\section{LIVRE PREMIER.}

\section{Des Corps Vivans en général.}

CHAPITRE PREMIER.

Idée des Corps Vivans, et des Rapports qu'ils ont arec toutes choses.

- CHAPITRE II.

Deux classes de Corps organisés : Animaux et Végétaux.

CHAPITRE III.

Êtres ambigus : cause d'erreur et de confusion. - Existe. t-il des êtres intermédiaires aux animaux et aux plantes? 5 CHAPITRE IV.

Conditions de la Vie : Organes indispensables; Unité dans l'action; Concordance et Perfection dans la struclure.

CHAPITRE V.

Dépendance mutuclle des Organes, variable selon les êtreș. $\quad 16$ CHAPITRE VI.

Symétric des Corps Vivans. 


\section{CHAPITRE VII.}

Il y a moins d'Analogie entre les Organes des corps vivans qu'entre les Fonctions de ces organes. . . . . . .

\section{CHAPITRE VIIr.}

Divers Degrés d’Organisation: Complication graduelle des êtres.

CHAPITRE IX.

Chaîne universelle des Êtres.

CHAPITRE $X$.

Lòi de Subordination et de Coexistence : Comment on peut juger de tout un être organisé par une de ses parties.

GHAPITRE XI.

Quels sont les plus importans des Organes Première base de Classification des Êtres vivans. . . . . . . . 38

\section{LIVRE SEGOND}

\section{De la Reproduction des Corps Vivans.}

GHAPITRE PREMIER.

Première Origine des Animaux et des Plantes. . . . . 44 CHAPITRE II.

Idée de la Reproduction des Êtres vivans.

CHAPITRE III.

Existe-t-il des êtres organisés dont la production soit spontanée? . . . . . . . . . . . . . . 49

CHAPITRE IV.

Reproduction sans le concours d'organes sexuels. . . . 59 CHAPITRE V.

Reproduction sexuelle des plantes. 
DES MATIÈRES.

CHAPITRE VI.

Reproduction sexuelle des Vers et des Animaux Radiaires. 84 CHAPITRE VII.

Reproduction sexuelle des Arachnides et des Crustacés. - $\quad 86$ CHAPITRE VIII.

Comment se Reproduisent les Mollusques. . . . . 88 GHAPITRE IX.

Idée générale de la Génération chez les Poissons. . . $\quad 9^{2}$ CHAPITRE $\mathrm{X}$.

De la Génération chez les Reptiles. . . . . . . . $9^{5}$ CHAPITRE XI.

Idée de la Reproduction des Oiseaux. . . . . . . 100 CHAPITRE XII.

De la Composition et de la Structure de l'OEuf des Oiseaux avant et durant lincubation. . . . . . . . . . 103

CHAPITRE XIII.

Comparaison des OEufs de Reptiles et de Poissons avee les précédens. . . . . . . . . . . . . . . 115

\section{CHAPITRE XIV.}

Des Enveloppes fœetales des Mammifères, et de leur analogie avec l'OEuf des Oiseaux. . . . . . . . 122 CHAPITRE XV.

Organes génitaux des femelles. Origine de l'œuf et de l'embryon des Mammifères. . . . . . . . . . 129

CHAPITRE XVI.

Les Êtres organisés engendrent-ils tous par unc sorte d'OEufs? 140 GHAPITRE XVII.

Génération équiroque de l'Ornithorhynque. . . . . . 142 GHAPITRE XVIII.

De la Liqueur Sérninale des mâles et de la Fécondation des femelles. . . . . . . . . . . 144 I. 


\section{CHAPITRE XIX.}

Fécondations artificielles.

GHAPITRE XX.

Remarques d'Aristote sur les Sexes et l'Accouplement des animaux. . . . . . . . . . . . . . 161

CHAPITRE XXI.

Limites des Espèces. Adultérisme. Bâtards. Métis. Mulets. 175 CHAPITRE XXII.

Esquisse d'une Histoire eritique et comparée de la Génération de l'Homnie.

CHAPITRE XXIII.

Principaux Systèmes sur la Génération. $19^{2}$ CHAPITRE XXIV.

Système d'Hippocrate : Mélange dẹs Semences. . . . . 194 GHAPITRE XXV.

Système d'Aristote : Forme et Matière. . . . . . . ${ }^{16}$ CHAPITRE XXVI.

Système d'Harvey : Contagion séminale. . . . . . 198 CHAPITRE XXVII.

Système des OEufs. L'Ėmbryon provient de la Mère. Swammerdam, Spallanzani, etc. . . . . . . . 203

GHAPITRE XXVIII.

Système de Lceuwenhoek ou des Animalcules. Tout vient du Mâle. . . . . . . . . . . . . . . 210 CHAPITRE .XXIX.

Système de Buffon : Molécules organiques, Moule intérieur. Égal Concours des Sexes. . . . . . . ${ }_{216} 6$ GHAPITRE XXX.

Conclusion de ce Livre. . . . . . . . . . 235 


\section{IIVRE TROISI PME.}

\section{De l'Accroissement des Corps vivans;}

De l'Origine, de la première Apparition et de l'Age comparé de leurs principaux Organes; des Mótamorphoses et des Monstruosités.

\section{GHAPITRE PREMIER.}

Détails et Considérations sur l'Origine et les Progrès du

Poulet dans l'OEuf.. . . . . . . . . . . 238

Cnur. . . . . . . . . . . . . . 243

Aorte. . . . . . . . . . . . 246

Poumons. . . . . . . . . . . . . 247

Foie... . . . . . . . . . . $2 / 48$

Estomac et organes digestifs. . . . . . ib.

Moelle épiniere. . . . . . . : . . . 249

Cerveau. . . . . . . . . . . . 250

Nerfs. . . . . . . : . ...... . 255

Olit. . . . . . . . . . . . . ib.

Membranes. . . . . . . . . . . 254

Vaisseaux sanguins. . . . . . . . . . 255

Fluides et humeurs. . . . . . . . . 257

l'remier principe. . . . . . . . . . . $25 \%$

Origine du sang. . . . . . . . . . . $26 \iota$

Respitation. . . . . . . . . . . . . 263

Coloration. . . . . . . . . . . . 264

Mouvemens. . . . . . . . . . ... . ib.

Nutrition. . . . . . . . . . 206

GHAPITTE H.

Accroissement progressif des Reptiles et des Poissons. . . ${ }_{2} 67$

GHAPITRE, III.

Accroissemens progressifs de I'Embryon de l'llomme et

des Mammiferes. . . . . . . . . . . 274

Canal diģestif. . . . . . . . . . . . $2 \& 4$

Cœur et Vaisseaux sanguins. . . . . . . ' 285

P'uutaons. . .......... . . . . 287 


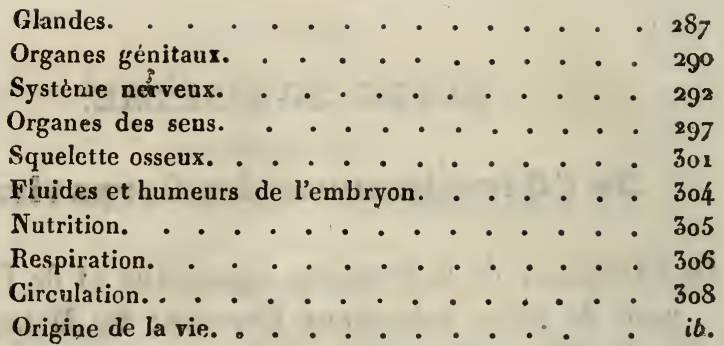

CHAPITRE IV.

Sur la première Origine des Organes et leur première Apparition. - La formation en est-elle simultanée ou successive, ou bien est-elle préexistante à la fécondation?

CHAPITRE V.

Ce qu'on entend par Germes. Direrses opinions sur leur Nature, leur Source, leur Préexistence et leur Emboîtement indéfini.

CHAPITRE VI.

Principales Lois sclon lesquelles se développent les Organes des Animaux.

CHAPITRE VII.

Analogies de composition des Animaux vertébrés.

\section{CHAPITRE VIII.}

Échelonnement des Organisations animales. (Les premiers âges de l'homme correspondent successivement, en quelques points de leur structure aux différentes classes des animaux vertébrés : aux poissons d'abord, puis aux reptiles, aux oiseaux et aux mammifères. ) . . . .

\section{CHAPITRE IX.}

Comment la Théoric des Monstruositès dérive des Lois de l'Accroissement. .

\section{CHAPITRE $\mathrm{X}$.}

De l'Hermaphrodisme accidentel des Animaux. - Remarques sur les Organes sexuels et leurs Anomalies. . . . 


\section{CHAPITRE XI.}

Digression sur la Génération et les Métamorphoses des Insectes. . . . . . . . . . . . . . . . 57 . 31

\section{CHAPITRE XII.}

De la Graine, de la Germination, et de l'Accroissement des Végètaux. . . . . . . . . . . . . . . 380

Analyse de l'OEuf végétal. . . . . . . . 38 ı

Phénomènes de la Germination. . . . . . . 384

Chaleur. . . . . . . . . . . . 385

Eau. . . . . . . . . . . 386

Air. . . . . . . . . . . . 387

Divers excitans. . . . . . . . . . 388

Enveloppes seiminales. . . . . . . . ib.

Embryon. . . . . . . . . . . . . 389

Cotylédons. . . . . . . . . . . 392

Albumen. . . . . . . . . . . 393

Premiers Vaisseaux. . . . : . . . . 394

Fluides et matériaux nutritifs. . . . . . . $39^{5}$

Direction de la jeune plante. . . . . . . . $3 y 6$

Accroissement progressif des végétaux. . . . 397

Moelle centrale. . . . . . . . . . 400

Couches ligneuses. . . . . . . . . . 401

Écorce. . . . . . . . . . . . . . 404

Enveloppe celluleuse. . . . . . . . 407

Épiderme. . . . . . . . . . . . . $40 \mathrm{~s}$

Racines. . . . . . . . . $i b$.

Feuilles, . . . . . . . . . . . 411

Fleurs. . . . . . . . . . . $i$.

CHAPITRE XIII.

Remarques sur l'Accroissement des Plantes Monocotylédones ou Endogènes. . . . . . . . . . . . . 412 CHAPITRE XIV.

Irrégularités, Anomalies réelles on seulement apparentes des Végétaux. - Soudures. - Arortemens. - Métamorphoses. . . . . . . . . . . . 417

\section{CHAPITRE XV.}

Circonstances indispensables au premier Accroissement des corps vivans. - Incubation. - Gestation. - Germination. - Avortement singulier des Didelphes. . . . . 428 


\section{CHAPITRE XVI.}

Naissance des Corps vivans. Nurée variable de la Gestation, de l'Incubation, etc.

CHAPITRE XVII.

liésumé du Livre III.

\section{IIVRE QUATRIEMS.}

\section{De la Nutrition.}

\section{CIIAPITRE PREMIER.}

Oljjet de ce Livre.

CHAPITRE 11.

De la Natrilion dans les commencemens de la vie. . . . 450 CIIAPITRE III.

Des Alinenis et de la Nutrition des Píntes.

$$
\text { CHAPITRE IV. }
$$

Des Alimens et de la Nutrition des Animaux inférieurs. $\quad 459$

$$
\begin{aligned}
& \text { Polypes. } \\
& \text { Vers. . . * * . . . . . } 460 \\
& \text { Insectes. . . . - • . • • • • • } 467 \\
& \text { Organes et actes digestifs des } \\
& \text { Crustacés. } \\
& \text { Mollusques. }
\end{aligned}
$$

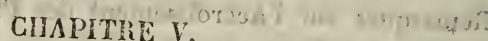

Particularités sur la Nutrilion des Animan supérienrs ou
Vertébrés.

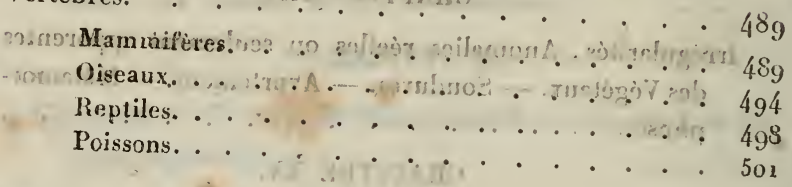

C. CHAPITRE VI.

Mécanisme de la Digestion, principalement dans los Aniina vertébrés. - Expéricnces el Théuries à ce sujet. . 503 
Nourriture des Animaux. . . . . . . . 503

Organes essentiels servant à la digestion. . . . 504

Humeurs. . . . . . . . . . . . 5ofi

Changemens éprouvés par les alimens dans l'estomac. 507

Conditions de la digestion et phénomènes locaux qui

l'accompagnent. . . . . . . . . . . 5II

Nécessité des nerfs et des vaisseaux pour la digestion. 512

Les principaux organes concourent à la digestion. - 513

Hypothèses au sujet de la digestion.-Trituration. . $51 / 4$

Fermentation. . . . . . . . . . 515

Putréfaction. . . . . . . . . . 516

Action de l'air. . . . . . . . . . 517

Dissolution. . . . . . . . . . . ib.

\section{CHAPITRE VII.}

Expériences louchant la Digcstion. - Action de l'Estomac et du Suc gastrique. . . . . . : . . 518

Expériences sur les Oiseaux gallinacés ou granivores. $\quad 519$

Expériences sur les Oiseaux carnivores. . . . . . 525

Faits relatifs à la nourriture et à la digestion de l'Aigle. $\quad 5_{2} 5$

Expériences au sujet de la digestion de l'Homme, etc. $\quad 529$

Utilité de la mastication. . . . . . . . 53 :

Observations et expériences sur la digestion des

Chiens, etc. . . . . . . . . . 522

Les différens alimens sont diversement digestibles. . 553

Les os peuvent-ils être digérés ? . . . . . . 5ï7

Expériences sur la digestion des Ruminans. • . 558

Expériences sur la digestion des Reptiles et des Poissons. . . . . . . . . . . . i ib.

La digestion peut-elle s'opérer ou s'èbaucher dans l'œsophage ? . . . . . . . . . . . 540

Digestions artificielles. . . . . . . . . 541

Y a-t-il encore digestion après la mort? . . . . 544

\section{CHAPITRE VIII.}

Suite du précédent. - Progrès de la Digestion, action des

Intestins , etc.; formation, absorplion et cours du Chyle. 546

Marche du chyme. . . . . . . . . 547

Changement du chyme. Action de la bile. . . 543

Les Intestins digèrent.ils des alimens non chymifiés? 550

Formation et rejet des excrémens. . . . . . 552

Mouvemens rétrngrades. . . . . . . . . 554

Absorption et cours du chyle. . . . . . . 555 
Le canal thorachique est-il la seule voie du chyle? .

Ce que devient le chyle: quelle est sa destination;

quels en sont les usages. . . . . . . 563

CHAPITRE IX.

Conditions principales de la Nutrition des Animaux. Choses qui la modifient et la diversifient, elle et la Digestion.

Boissons. . . . . . . . . . . . ib.

Alimens solides. . . . . . . . . - 566

Température; saison; climat. . . . . . . 563

Pratiques éprouvées quant à la production de l'embonpoint; mutilation, etc. . . . . . 570

GHAPITRE $X$.

Questions et Doutes sur la Nutrition des Animaux. . . 573

Les organes se renouvellent-ils? . . . . . . 574

La révolution nutritive a-t-elle lieu tous les sept ans ? 576

Comment les organes s'emparent-ils de la nourriture et que devient-elle ? . . . . . . . 577

Effets compliqués de l'abstinénce. • . . . . 579

$Y$ a-t il dans un corps vivant quelque principe étranger aux alimens dont il s'est nourri ? . . . . 58

Est.il vrai qu'il n'y ait qu'un aliment pour la nutrition d'organes si diversifiés?. • . . . . . $58_{2}$

Échanges mutuels des deux règnes. . . . . . 583

Unité et Transformations de la matière. . . . 584

Influence des nerfs sur la nutrition. . . . . 585

\section{CHAPITRE XI.}

Quelques Remarques sur la Nutrition. . . . . 585

Influence du sel marin. . . . . . . . . $i b$.

Maladies. . . . . . . . . . . . $5 \& 6$

Kapport du volume des artères avec la nutrition des organes. - . . . . . . . . . . ib.

Alimens trop uniformes sont nuisibles. . . . . 587

Nécessité des alimens azotés pour quelques animaux. $\quad 588$

FIN DE LA TABLE DU PREMIER VOLUME.

Imprimerie de Goefren, rue Mazarine, $n^{\circ}, 23$. 






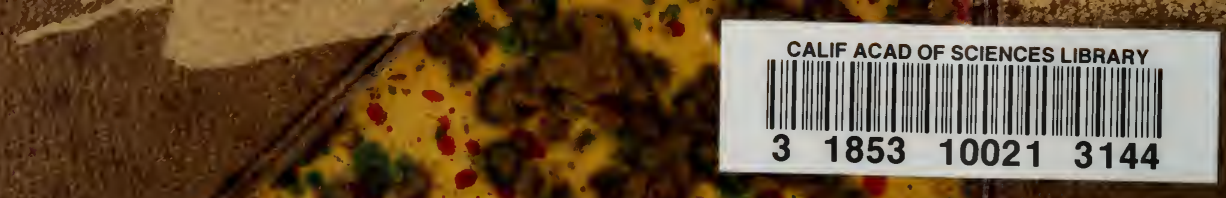

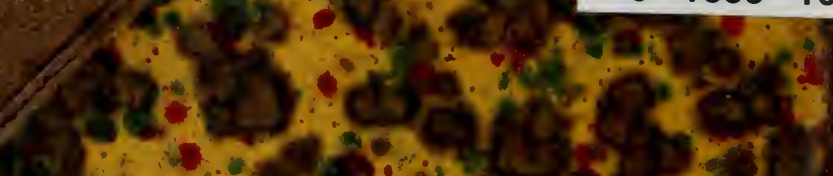
A. Q. P. a.t. 3
4
4

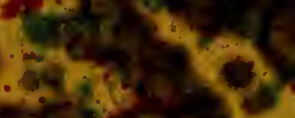

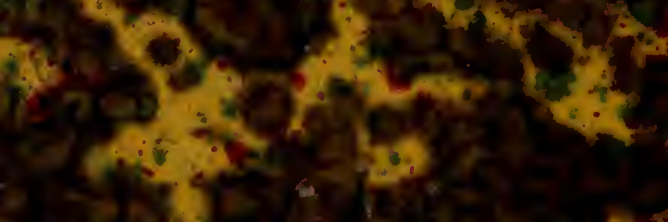<smiles>[CH]1C=C1</smiles>

r on Wh of Non

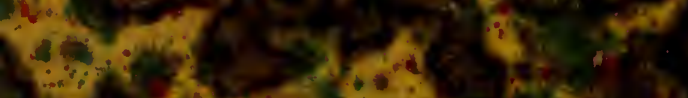

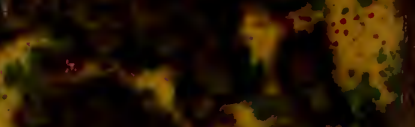

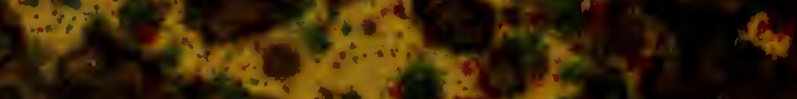

